INEEL/EXT-97-01389

\title{
Vitrified Waste Option Study Report
}

\author{
D. A. Lopez \\ R. R. Kimmitt
}

Published February 1998

Idaho National Engineering and Environmental Laboratory High Level Radioactive Waste (HLW) Programs Department

Lockheed Martin Idaho Technologies Company Idaho Falls, Idaho 83415

Prepared for the

U.S. Department of Energy

Assistant Secretary for Environmental Management

Under DOE Idaho Operations Office

Contract DE-AC07-94ID13223

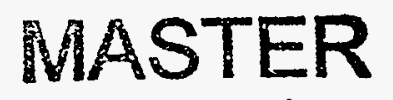




\begin{abstract}
A "Settlement Agreement" between the Department of Energy and the State of Idaho mandates that all radioactive high-level waste (HLW) now stored at the Idaho Chemical Processing Plant (ICPP) will be treated so that it is ready to be moved out of Idaho for disposal by a target date of 2035. This report investigates vitrification treatment of all ICPP calcine, including the existing and future HLW calcine resulting from calcining liquid Sodium-Bearing Waste (SBW). Currently, the SBW is stored in the tank farm at the ICPP. Vitrification of these wastes is an acceptable treatment method for complying with the Settlement Agreement. This method involves vitrifying the calcined waste and casting the vitrified mass into stainless steel canisters that will be ready to be moved out of Idaho for disposal by 2035 . These canisters will be stored at the Idaho National Engineering and Environmental Laboratory (INEEL) until they are sent to a HLW national repository. The operating period for vitrification treatment will be from 2013 through 2032; all HLW will be treated and in storage by the end of 2032 .
\end{abstract}

\title{
DISCLAIMER
}

\footnotetext{
This report was prepared as an account of work sponsored by an agency of the United States Government. Neither the United States Government nor any agency thereof, nor any of their employees, makes any warranty, express or implied, or assumes any legal liability or responsibility for the accuracy, completeness, or usefulness of any information, apparatus, product, or process disclosed, or represents that its use would not infringe privately owned rights. Reference herein to any specific commercial product, process, or service by trade name, trademark, manufacturer, or otherwise does not necessarily constitute or imply its endorsement, recommendation, or favoring by the United States Government or any agency thereof. The views and opinions of authors expressed herein do not necessarily state or reflect those of the United States Government or any agency thereof.
} 


\section{DISCLAIMER}

Portions of this document may be illegible electronic image products. Images are produced from the best available original document. 


\section{DISCLAIMER}

Portions of this document may be illegible electronic image products. Images are produced from the best available original document. 


\section{SUMMARY}

Treatment of HLW at the ICPP at the INEEL is mandated under a "Settlement Agreement" between the Department of Energy (DOE) and the State of Idaho. Among other things, the Settlement Agreement requires that treated HLW be ready to be moved out of Idaho for disposal by a target date of 2035 . For one method of compliance, the INEEL proposes to calcine the existing liquid SBW and add it to the HLW calcine presently stored in the Calcined Solid Storage Facilities (CSSF) at the ICPP. The calcine would then be treated and placed in canisters suitable to transport off site and dispose of in a HLW national repository. This treatment can be accomplished by a number of treatment options; the option studied in this report is called the Non-separations Alternative, Vitrified Waste Option (VWO). Borosilicate glass in welded stainless steel canisters is the waste form currently preferred at the repository. The objective of this report is to provide cost estimates for facilities and operations to vitrify calcined $\mathrm{HLW}$ and place it in interim storage in HLW Glass Canisters (GCs) that are acceptable to ship to, and dispose of at, the repository. This option will not process any waste generated after 2012. The Savannah River Site (SRS) Defense Waste Processing Facility (DWPF) canister was selected to use in this report.

Design bases and criteria, requirements, regulations, and codes and standard studies were conducted and corresponding Engineering Design Files (EDFs) were issued. These studies included requirements of DOE, Environmental Protection Agency (EPA), the State of Idaho, Nuclear Regulatory Commission (NRC), and Department of Transportation (DOT) that were applicable to all Non-Separations Alternatives including the VWO. The operating period for the Vitrification Facility (VF) is from 2013 through 2032, and $5435 \mathrm{~m}^{3}$ of calcine will be processed, resulting in $14,115 \mathrm{GCs}$ of vitrified waste produced and stored in the VWO interim storage facility (ISF). Costs for analytical support, costs to ship the GCs to the repository, and the costs to dispose of the GCs at the repository, are outside the scope of this report.

The major processes involved in the VWO are to (1) obtain calcine from the ICPP CSSF using a Calcine Retrieval and Transport System (CRTS), (2) blend (homogenize) calcine batches received from the CRTS, (3) sample the calcine to determine chemistry, (4) obtain Glass frit from rail deliveries to mix with the calcine, (5) select a glass frit for the calcine chemistry analyzed, (6) mix the calcine and frit in the proper ratio (7) deliver the mix to a joule melter, (8) vitrify the mixture to form borosilicate glass, (9) pour the glass into suitable canisters, (10) weld, leak check, and decontaminate the filled canisters, (11) transport the canisters to an Interim Storage Facility (ISF) and place in interim storage, (12) process the melter offgas, and (13) send solid to a low-level radioactive waste (LLW) to an appropriate disposal facility and send liquid waste to an evaporator facility. All the processes, except 1 and 11, will be accomplished in the VF.

A process chemical engineer first formulated the basic VF processes necessary to successfully vitrify the calcine into an acceptable borosilicate glass and to cast it into appropriate canisters. The process engineer also calculated, 
and documented, qualitative parameters of the processes that would allow treating all calcined waste by the end of 2032. A design team of specialists then implemented that process, and documented the work in this Report. The CRTS, the ISF, and the Utilities Support necessary to support the VF were studied and similar but separate documents were issued for these studies. The VWO consists of the VF, CRTS, ISF, and the Utilities Support. The latter three systems are described briefly in this report and their documents are either included or referenced. The CRTS, ISF, and Utilities Support cost estimates are each included in their respective reports and their cost summaries are combined with the VF costs in Section 4 of this report to arrive at the total VWO costs.

The VF design team compiled and formulated key assumptions for the VF and VWO. To take advantage of work previously completed on non-separations vitrification, the Vitrification Facility design presented in the report Idaho Chemical Processing Plant Waste Immobilization Facility Direct Vitrification Option Feasibility Study Report, by Raytheon Engineers and Contractors, Inc., ${ }^{1}$ was used as a "Baseline Design" for the VWO VF. Changes to the baseline were made as necessary to implement the process engineering study and to address requirements and assumptions different from those in the Raytheon baseline design.

The majority of the main text of this report describes the VWO VF in detail. The facility will be located in the northeast corner of the ICPP. Utilities for the facility are detailed in a separate report. It will be a multistory building that extends from $32 \mathrm{ft}$ below, to $75 \mathrm{ft}$ above grade elevation, and has a floor plan occupying an area measuring $391 \times 178 \mathrm{ft}$. It will be designed to house the equipment and operations for non-separations processing of HLW calcine while providing essential features for safe and efficient operation and maintenance. The VF layout is based on a centrally located process cell complex with limited personell access and heavy concrete walls for shielding. The remotely operated cells will house equipment that presents a high radiation hazard but requires minimal maintenance. The periphery of the facility contains office space, support areas, and nonradioactive operation areas. The facility will have a separate system for processing melter offgas and reclaiming mercury waste. The building will comply with requirements of DOE Order 6430.1A-1325

(Laboratory Facilities including Hot Laboratories). In addition to the melter offgas system, the VF will have separate primary, secondary, and office ventilation zones. Airflow will be from areas of lower contamination to areas of higher contamination where areas of higher potential airborne contamination will be kept at less than ambient pressure.

To facilitate equipment changeout and maintenance, the facility is based on the canyon design approach using hatches in the cell ceilings that can be removed to provide access to cell equipment by a large remotely operated bridge crane. Above the ceiling hatches is a large, open maintenance area that can be used for laydown, maintenance, sizing, packaging, and removal and retrieval of equipment. The equipment can also be moved into a separate decontamination room and subsequently to separate remote and hands on maintenance cells.

The heart of the VF is the vitrification process that includes the melters, the off-gas treatment system, and the scrubber blowdown processing system. 
The Vitrification process receives calcine and glass frit from two different systems. The calcine is pneumatically transferred into two large fluidized bed blender tanks in the VF by two parallel lines from the CRTS. The calcine is then fluidized and homogenized in each tank by separate VF air injection systems. A pneumatic transfer system on each tank delivers the calcine to a calcine weigh hopper that measures and dispenses it into a ribbon blender for mixing with the proper amount of glass frit and delivery to the melter. Each of six different glass frit mixtures is delivered to the building by rail car. Each mixture is placed in a separate silo outside the VF. A series of auger and bucket conveyors transports the frit to six separate indoor tanks, then to a glass frit weigh tank, and finally to the ribbon blender for mixing with the calcine and dispensing into the melter.

The electrically powered melters are designed to operate at about $1,100^{\circ} \mathrm{C}$. The "feed material" fed to the melter is a mixture of calcine and glass forming additives, both in solid form. Unmelted feed material floats on top of the molten glass, forming a "cold cap" that reduces emissions of volatile species. The melters include ports to drain salt, slag, or elemental metal should these phases form during operation. Product glass is gravity fed through a separate port into the storage canisters.

A limited amount of ventilation air is allowed to enter the melter to cool instrument and viewing ports. The air collects volatile gases and fine particulates that are removed in the off-gas treatment system. The contaminants of greatest concern are mercury and radioactive cesium. Four different scrubbing units in series maximize contaminant removal efficiency. Contaminated water from the off-gas treatment system is processed in the vitrification facility to collect and immobilize mercury. This treatment is intended to put the mercury in suitable forms for storage and disposal under existing waste disposal regulations. Further treatment of the scrubber blowdown water is performed at facilities included in the separate utilities study.

The vitrified mass is poured into DWPF type canisters, which are then cooled, capped, and transported through three separate cells: lid welding and leak checking, decontamination, and exterior contamination swipe testing. The filled canisters are then placed in a subgrade tunnel and transferred to the IFS for storage.

The instrumentation and control (I\&C) systems were scaled from 1,687 instruments in the Raytheon baseline design to 1,461 for the VF. The electrical utility is provided by the facilities described in the utilities study. The VF requires connected, demand, and standby power loads of 2,568, 1,959, and $800 \mathrm{kVA}$, respectively. Automatic wet-pipe sprinkler systems in the operating galleries, office areas, and for high efficiency particulate air (HEPA) deluge systems will provide fire protection. The hot cells will be provided with either limited water, or gaseous extinguishing systems. Information regarding the CRTS is provided in EDF-waste treatment system (WTS)-002 (attached in Appendix A) and for the ISF in the Interim Storage Study Report. ${ }^{2}$

Cost estimates were performed on the VF and VWO. The total costs for the VWO are summarized as follows and include costs for the CRTF, the ISF, and the Utility Service: 
- Total Cost (unescalated) is $\$ 2,586,060,000$

- Total Cost (with escalation, management reserve, \& contingency) is $\$ 6,802,205,000$

- $\quad$ Discounted Cost (escalated) is $\$ 1,894,379,000$.

After these official cost estimates were completed, it was recognized that an additional cost will be incurred for the utilities support portion of the VWO option only. The VWO will send offgas scrubber water to be processed in the utilities process equipment waste (PEW) facility. The resulting evaporatorbottoms sludge will be treated and disposed of as mixed LLW, because, by 2013 when the VWO begins operation an INEEL facility may not exist to treat or dispose of this sludge. Therefore, a cursory estimate was made of the total-cost of a new 120, 55-gal drum per yr grouting facility. The cost also includes disposal of the resulting waste in a NRC-licensed LLW disposal facility. This cost was estimated using best engineering practices, but was not subject to the standard cost estimate method, review process, or verification process. The total cost including construction, operations, post operations, escalation, management reserve, contingency, and waste disposal was estimated at $\$ 33,000,000$.

The maturity of the VF technology was evaluated and determined to be high (between the Engineering Development and the Implementation stage). The risk associated with the VF technical key assumptions were evaluated numerically from a possible score of 1 through 9 with 9 representing the highest risk. No risk was rated higher than 4; therefore, the project has no serious risks. Failure modes were listed and discussed in general, but detailed effects analyses were beyond the scope of this report.

The Project Data Sheet (PDS) and its supporting data were completed for the VF and are included. A list of recommended future studies that will be needed to support future design efforts, and that was beyond the scope of this report, is included.

The primary conclusions of this report are that the VF technology is mature and well established as evidenced by ongoing GC production at both the SRS DWPF and at the West Valley Demonstration Project. The GCs produced by the VF will be NRC licensed for ISF storage under 10 CFR 72, and under 10 CFR 71 for transport in a Type B shipping container. The GC transportation package will also meet DOT HLW shipping regulations in 49 CFR 173. The total cost for the VWO is listed above in this Section. 


\section{CONCLUSIONS}

The non-separations alternative VWO consists of the CRTS, the VF, the ISF, and Utilities Support. Designs were based on existing feasibility and conceptual designs for other facilities having similar requirements. This report concentrates on the VF portion of the VWO

The VF in this report will produce approximately 14,000 SRS type DWPF GCs for the non-separations alternative during its 20-yr operating life (from 2013 through 2032). This is equivalent to as many as 35,000 metric tons of HLW GCs. This assumes 24 hour per day, seven days per week operation, with a $50 \%$ process up time. The SRS DWPF canister design will be an acceptable waste form for eventual transportation offsite and storage at the repository. The planned date for all HLW GCs to stored in a road-ready condition, at the ISF, is the end of 2032, which is two years ahead of the 2035 date targeted by DOE and the State of Idaho in the Settlement Agreement. ${ }^{3}$ The VWO VF is designed for dry calcine from the ICPP Calcined Solid Storage Facility (CSSF) only. This is because of the assumption that all SBW will have been calcined and placed in the CSSF before the start of VF operation.

The maturity of the canisterized vitrified production is well established as evidenced by ongoing GC production at both the SRS DWPF and at the West Valley Demonstration Facility. These facilities are both successfully producing and storing acceptable road-ready vitrified product, which will meet the Department of Energy Environmental Management (DOE-EM) and Department of Energy Radioactive Waste (DOE-RW) repository requirements (Waste Acceptance Product Specifications for Vitrified High-Level Waste Forms, ${ }^{4}$ and the Waste Acceptance System Requirements Document ${ }^{5}$ ). The total costs for the VWO are summarized as follows and include costs for the CRTF, the ISF, and the Utility Service:

- Total Cost (unescallated) is $\$ 2,586,060,000$

- Total Cost (with escalation, management reserve, \& contingency) is $\$ 6,802,205,000$

- $\quad$ Discounted Cost (escalated) is $\$ 1,894,379,000$. 


\section{RECOMMENDATIONS}

Communication should be initiated with the NRC, State of Idaho, EPA, repository, and each state and EPA Region through which the waste will be transported for disposal. Future studies are recommended in section 11.2 of this report. 


\section{ACKNOWLEDGEMENTS}

The following team of people made significant contributions of their time and expertise to this study. Their work is reflected throughout this report and its appendices:

\begin{tabular}{|l|l|}
\hline Rick Adams & Schedule \\
\hline Stephanie Austad & $\begin{array}{l}\text { AE Facility design and development of site, plot, and floor plans, sections, and } \\
\text { elevations, Report writing, and Regulatory and Design Requirements. }\end{array}$ \\
\hline $\begin{array}{l}\text { Chris Baim } \\
\text { Ancil Gibbs } \\
\text { Eloise Snell }\end{array}$ & Facility, Drawing and P\&ID Drafting \\
\hline $\begin{array}{l}\text { Ed Baker } \\
\text { Michael Gifford }\end{array}$ & Glass frit retrieval and transfer systems \\
\hline Jila Banaee & Applicable regulations, requirements \\
\hline Ted Bohn & Radiation and shielding calculations \\
Henry Peterson & \\
\hline John Duggan & Electrical Design \\
\hline Sara Gifford & Calcine Retrieval and Transfer System \\
\hline Jeff Hansen & Instrumentation and control \\
\hline Dan James & Construction cost estimate \\
\hline Bob Jamison & Industrial design, Manpower requirements \\
\hline Jack Prendergast & \\
\hline Rod Kimmitt & Process and offgas system design, Information input and development, Project Data \\
\hline Sheets, Risk Analysis, Report writing, overall support in many areas.
\end{tabular}




\section{CONTENTS}

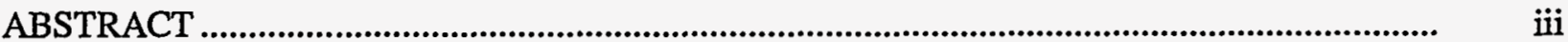

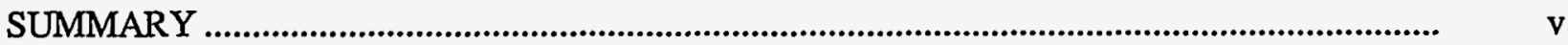

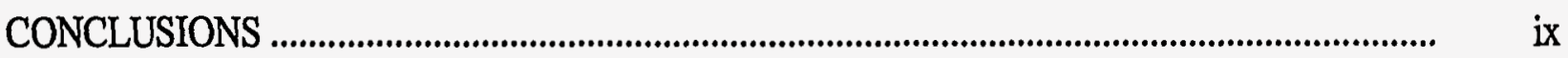

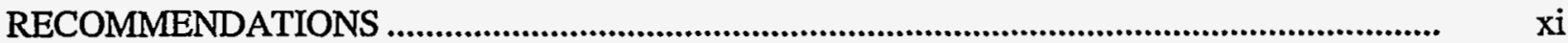

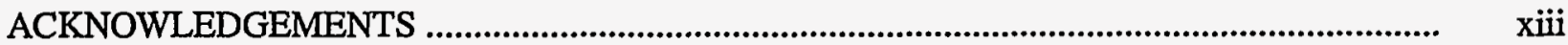

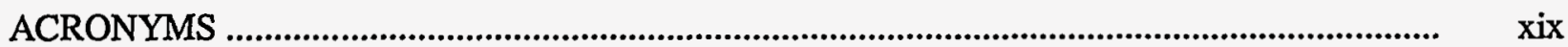

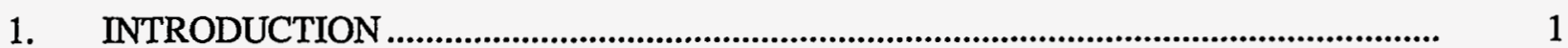

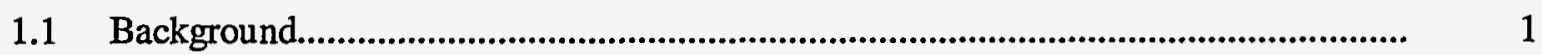

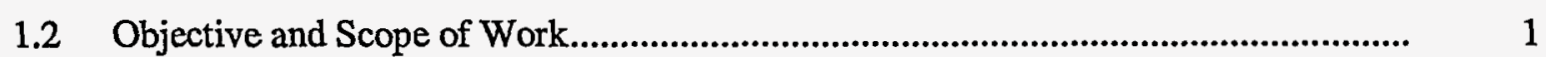

2. DESIGN BASIS, KEY ASSUMPTIONS, AND REQUIREMENTS ............................. 3

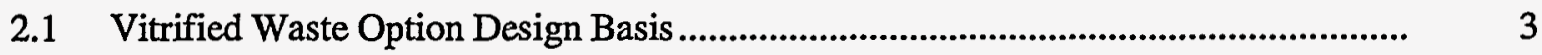

2.1.1 Calcine Retrieval and Transport System........................................................ 3

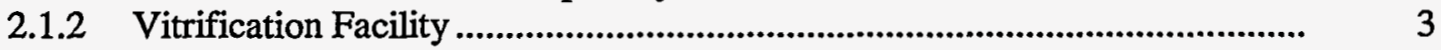

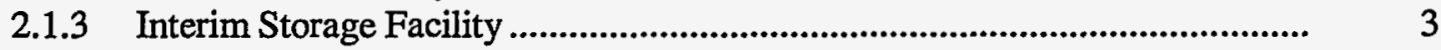

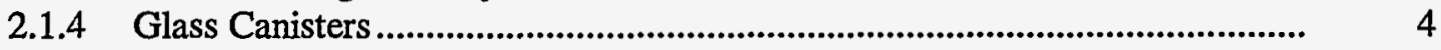

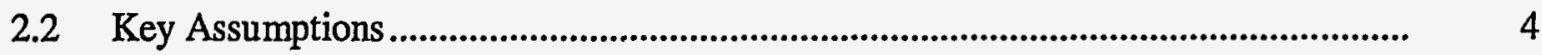

2.2.1 Work Scope Assumptions.................................................................... 5

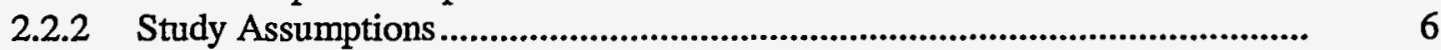

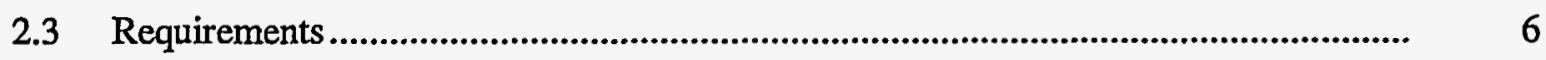

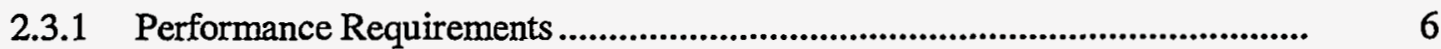

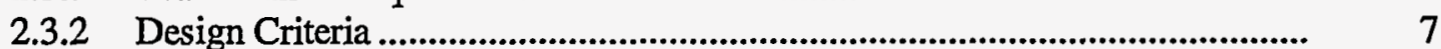

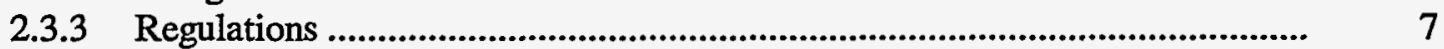

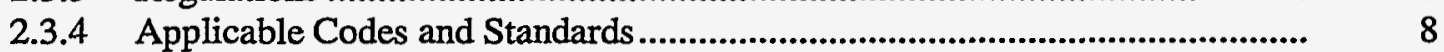

2.3.5 HLW National Repository Waste Acceptance Criteria .................................. 8

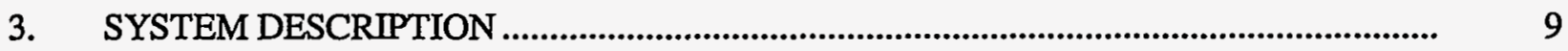

3.1 Calcine Retrieval and Transport System .......................................................... 9

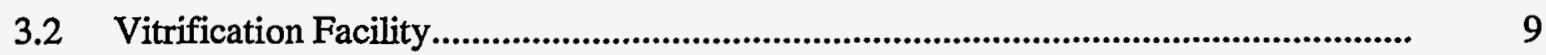

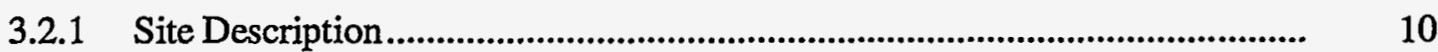

3.2.2 Underground Utilities ........................................................................ 10 


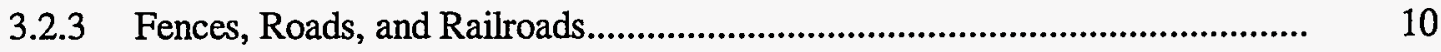

3.2.4 Facility Layout ..................................................................................... 10

3.2.5 Structural Features.............................................................................. 11

3.2.6 Vitrification Facility Processes .......................................................... 12

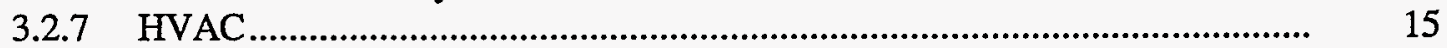

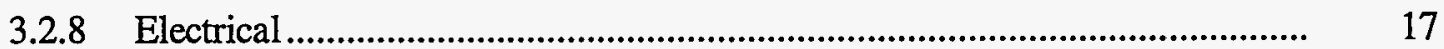

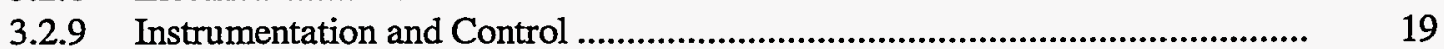

3.2.10 Fire Protection Systems and Equipment ...................................................... 19

3.2.11 Fire Detection and Alarm Systems ............................................................ 21

3.2.12 Utility Control System and Fiber Optic Cable ............................................. 22

3.2.13 Vitrification Facility Staffing ................................................................ 22

3.2.14 Strategic Materials.................................................................................. 22

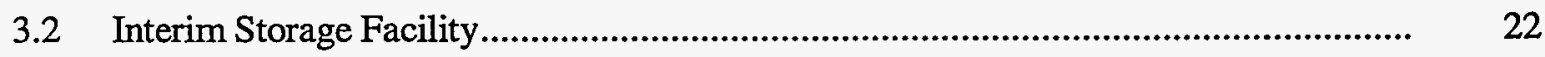

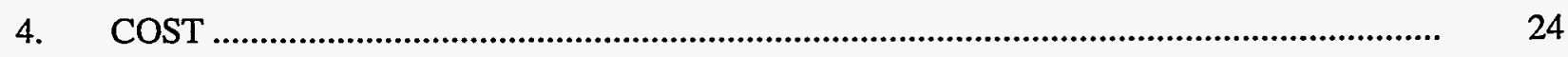

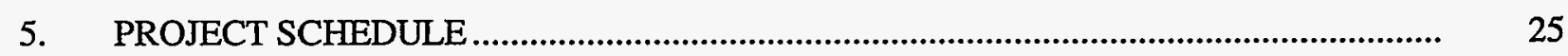

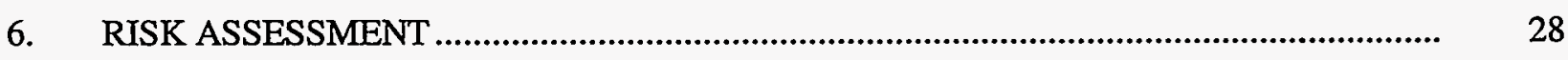

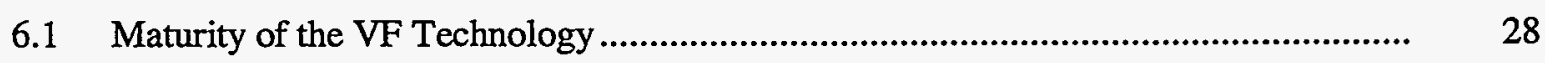

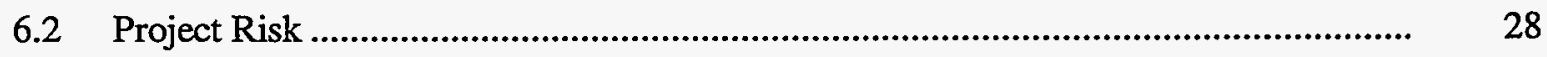

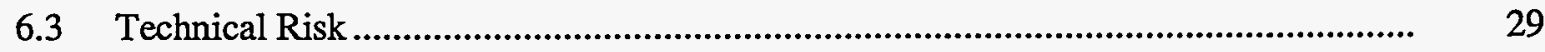

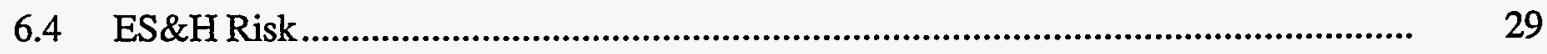

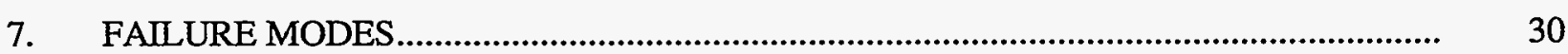

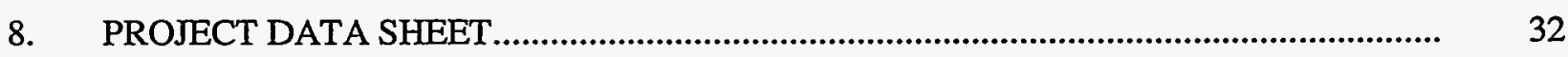

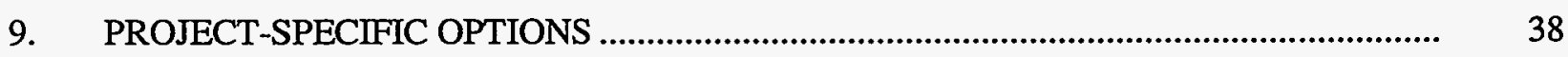

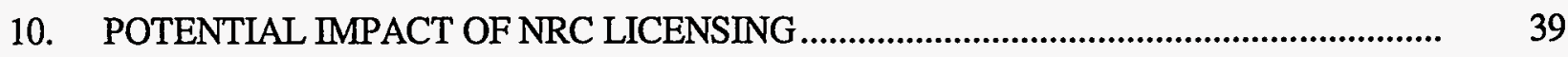

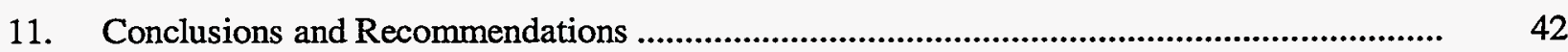

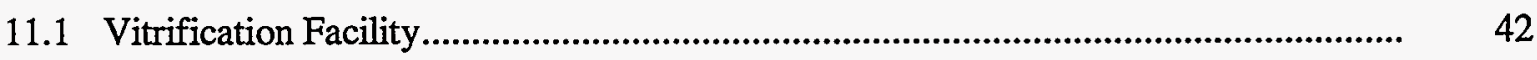

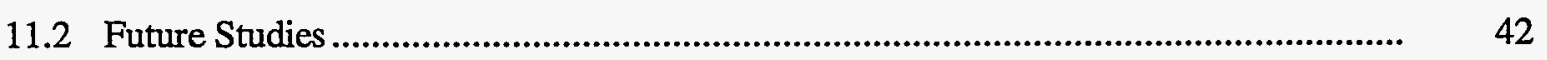

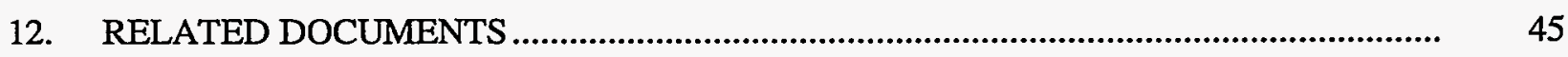

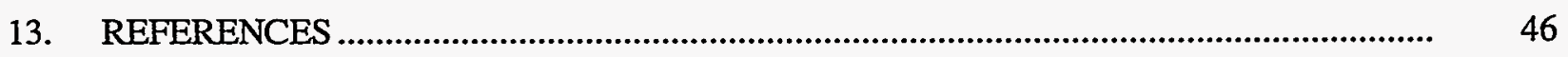

Appendix A-Engineering Design Files

Appendix B-Drawings

xvi 
Appendix C-Key Assumptions

Appendix D—Cell Descriptions

Appendix E-HVAC Requirements

Appendix $\mathrm{F}$-Cost Estimates

Appendix G-Risk Assessment Data Sheets

Appendix H-VF Project Data Sheet Supporting Data

Appendix I-Remote Handling

Appendix J-Conveying Systems

\section{TABLES}

1. Vitrification facility ventilation requirements. .......................................................... 18

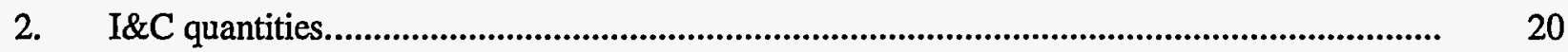

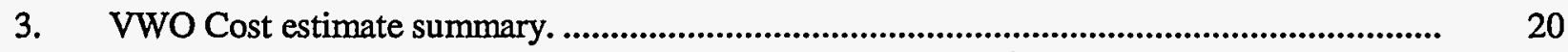

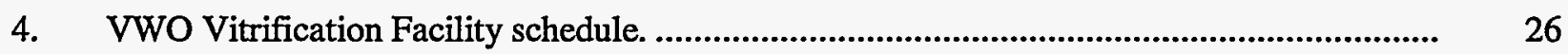

5. Project Data Sheet for non-separations VWO Vitrification Facility................................... 33 


\section{ACRONYMS}

AES Architectural Engineering Standards

AHJ authority having jurisdiction

AHU air handler unit

ASME American Society of Mechanical Engineers

CCTV closed-circuit television

CRTS Calcine Retrieval and Transport System

CSSF Calcined Solid Storage Facilities

DBA design basis accident

D\&D decontamination and decommissioning

DNFSB Defense Nuclear Facilities Safety Board

DOE U.S. Department of Energy

DOE-EM Department of Energy Environmental Management

DOE-ID Department of Energy Idaho Operations Office

DOE-RW Department of Energy Radioactive Waste

DOT Department of Transportation

DWPF Defense Waste Processing Facility

ECA environmentally controlled area

EDF Engineering Design File

EIS environmental impact statement

EPA Environmental Protection Agency

ES\&H Environment, Safety and Health

FPE fire protection engineer

GAC granular activated carbon

GC glass canister 
GFE government-furnished equipment

HAW high-activity waste

HEPA high efficiency particulate air

HLW high-level radioactive waste

HVAC heating, ventilation, and air conditioning

I\&C instrumentation and control

ICPP Idaho Chemical Processing Plant

INEEL Idaho National Engineering and Environmental Laboratory

ISF interim storage facility

ITS intermediate transport station

LAN local area network

LAW low-activity waste

LDR land disposal restriction

LLW low-level radioactive waste

NEPA National Environmental Policy Act of 1969

NRC Nuclear Regulatory Commission

PCS plant control system

PDS Project Data Sheet

PEW process equipment waste

RCRA Resource Conservation and Recovery Act

SBW sodium-bearing waste

SNF spent nuclear fuel

SRS Savannah River Site

TEC total estimated cost

TPC total project cost 


$\begin{array}{ll}\text { TRU } & \text { Transuranic } \\ \text { UCS } & \text { utility control system } \\ \text { VF } & \text { Vitrification Facility } \\ \text { VWO } & \text { Vitrified Waste Option } \\ \text { WAC } & \text { waste acceptance criteria } \\ \text { WAPS } & \text { Waste Acceptance Product Specification } \\ \text { WIF } & \text { Waste Immobilization Facility } \\ \text { WS } & \text { work scope } \\ \text { WTF } & \text { waste treatment facility } \\ \text { WTS } & \text { waste treatment study }\end{array}$




\section{Vitrified Waste Option Study Report}

\section{INTRODUCTION}

Treatment of HLW at the ICPP at the INEEL is mandated under a "Settlement Agreement" between the DOE and the State of Idaho." Among other things, the Settlement Agreement requires that this treated HLW be ready to be moved out of Idaho for disposal by a target date of 2035 .

Proposed HLW treatment includes the "Non-separations Alternative" VWO in which all HLW and SBW will be in dry calcine form in the ICPP CSSF. The VWO includes the CRTS, the VF, and the ISF. In addition, analytical support services will be required, and this portion of the study will be scoped and costs estimated in a separate study to be done in the future. This analytical support will include analysis of glass frit, calcine blends, offgas wastewater, vitrification samples, and other process and waste agents. The CRTS transports the calcine from the CSSF to the VF. The VF mixes the calcine with an appropriate glass frit, vitrifies the mixture, casts it into GCs, and seals and prepares the GCs in a road-ready condition for transfer to the ISF. Transfer to the ISF will occur from 2013 through 2032. This report includes designs for the CRTS (based on modifications to the Fluor Daniel Waste Treatment Facilities Feasibility Study $60 \%$ review package ${ }^{6}$ ), the VF (based on modifications to the Raytheon Direct Vitrification Option Feasibility Study Report, ${ }^{1}$ for handling dry calcine only), and the ISF (based on a modifications to the Fluor Daniel Inc., Waste Treatment Facilities Feasibility Study ${ }^{7}$ ).

\subsection{Background}

Calcination is a treatment process that transforms liquid waste into a more stable granular solid. Past calcining activities at the ICPP produced large amounts of calcine that is now stored in CSSF bins at the ICPP. In addition, SBW is stored in the ICPP tank farm. Various possible HLW treatment alternatives are under consideration; however, the treatment method assumed for this report is vitrification of the HLW under the Non-separations Alternative (also called the Direct Vitrification Alternative). A concept for a VF for the Non-separations Alternative has been developed and is contained in the Raytheon Direct Vitrification Option Feasibility Study Report. ${ }^{1}$ This reference design was used as a baseline for the VF design presented in this report.

\subsection{Objective and Scope of Work}

This report provides information, including the cost estimates for the VF and cost summaries for the entire VWO. The VWO is one of several options being considered to treat ICPP calcined HLW. The VWO consists of the CRTS, the VF, the ISF, and the Utilities Support. This information will be used as input to an environmental impact statement (EIS) that will be used to select the option that will be implemented.

Because the processes and equipment for the CRTS, the ISF, and for the Utilities Support are relatively generic to all of the Non-separations WTF options, they each have separate reports. Their reports are given separately in the CRTS system EDF (EDF-WTS-002 in Appendix A), in the Interim Storage Study Report, ${ }^{2}$ and in and the Utilities and Infrastructure Report. ${ }^{10}$ Although costs and limited discussion of the CRTS, ISF, and Utilities Support are included, this report primarily documents the work associated with the VF. 
Drawing VWO-C-1 in Appendix B (all VF drawings in this report are included in Appendix B) is an ICPP Site Plan showing the location of the CSSF, the VF, and the ISF. The overall VWO process schematic is shown on Drawing VWO-01, and includes several steps: (a), CRTS transport of calcine from the CSSF to the VF, (b) mixing the calcine with the appropriate type and quantity of glass frit, (c) vitrifying the calcine/frit mix in an joule melter and casting it in canisters, (d) treating the melter offgas, and (e) transporting the GCs to the ISF.

Failure modes were noted, project risks were identified and evaluated, and PDS were prepared and summarized. 


\section{DESIGN BASIS, KEY ASSUMPTIONS, AND REQUIREMENTS}

\subsection{Vitrified Waste Option Design Basis}

As discussed above, the VWO consists of the CRTS, the VF, the ISF, and Utilities Support. The design bases for these facilities are discussed in this section.

\subsubsection{Calcine Retrieval and Transport System}

The design basis for the CRTS is given in the Fluor Daniel Waste Treatment Facilities Feasibility Study 60\% review package. ${ }^{6}$ EDF-WTS-002 in Appendix A documents the work done on the CRTS for alternatives including the VWO. The CRTS is generic to most of the waste treatment options studied. EDF-WTS-002 provides all CRTS components and their costs but the VF building contains the following final CRTS equipment: calcine separation cyclones, sintered metal filters, HEPA filters, calcine transport blowers, and transport-air coolers.

\subsubsection{Vitrification Facility}

As indicated, the design for the Direct Vitrification Facility portion of the Waste Immobilization Facility (WIF) presented in the Raytheon Direct Vitrification Option Feasibility Study Report, ${ }^{1}$ is the baseline design used to develop the design presented in this report. The baseline design was changed to incorporate assumptions and requirements of this report. The baseline VF receives SBW waste in liquid form from ICPP storage tanks, and not as a dry calcined material. A basic assumption of this report is that the liquid SBW will be calcined and contained in the CSSF before being transported to the VF, as described in CRTS system EDF-WTS-002 in Appendix A. Because of this assumption, much of the liquid handling equipment (including the three rotary kilns) was eliminated from the baseline design for this report. This virtually eliminates the "process equipment canyon" from the baseline design. In addition, the baseline $\mathrm{GC}$ has been changed from a 2 - $\mathrm{ft}$ in diameter $\times 5$ - $\mathrm{ft}$ long canister to a 2 -ft in diameter $\times 10$-ft long DWPF canister. In this report, the baseline throughput rate of 6.8, 5-ft long GCs per day (See the Raytheon Direct Vitrification Option Feasibility Study Report, ${ }^{1}$ Volume IV, page Appendix F-14, Table 1.3-1), has been changed to an average of 3.9 (and a maximum of 5), 10-ft long DWPF GCs per day.

Costs were estimated for the VF with the required equipment and operations modifications. The three small stir melters that operated simultaneously in the baseline design were also replaced by two large, cold-cap melters (an operating melter and an installed spare). The orientation of the underground loadout tunnel, used to transfer GCs from the VF to the ISF, was changed from the south to the East Side of the facility to accommodate the location of the new ISF (as given in the Interim Storage Study Report ${ }^{2}$ ). Another major change was using carbon dioxide pellet blasting for GC decontamination, instead of the baseline's water/glass-frit blasting decontamination solution. This was done to avoid adding contaminated wet slurry to the waste to be calcined. This slurry would have to be dried and vitrified or otherwise disposed of.

\subsubsection{Interim Storage Facility}

The Interim Storage Study Report, ${ }^{2}$ presents the study for the VWO ISF (as well as storage facilities for the other applicable waste treatment options). The design baseline for the ISF is given in the Fluor Daniel Inc., Waste Treatment Facilities Feasibility Study. ${ }^{7}$ The ISF design will be a basic unit (holding about $900 \mathrm{GCs}$ ) that will be repeated, as necessary, to accommodate the GCs produced by a 
particular waste treatment option. In the case of the VWO, the number of ISF units was increased until they could accommodate a minimum of $14,115 \mathrm{GCs}$.

\subsubsection{Glass Canisters}

The standard waste form required by the Waste Acceptance Product Specifications for Vitrified High-Level Waste Forms, ${ }^{4}$ is borosilicate glass. EDF-DPC-003 contained in the DPC Loading Feasibility Study Report, ${ }^{8}$ includes details on the glass form and the DWPF GCs. Resource Conservation and Recovery Act (RCRA) hazardous wastes are not allowed in the waste form. The DWPF canister meets HLW national repository Waste Acceptance Criteria (WAC) for dimensions. EDF-DPC-001, contained in the DPC Loading Feasibility Study Report, ${ }^{8}$ defines the expected weight values used as a design basis for this report: the heaviest weight will be $2,418 \mathrm{~kg}(5,331 \mathrm{lb}$.) for a $100 \%$ filled DWPF GC. This weight was used to establish VF crane and handling cart specifications. The DWPF GC was used in this report instead of the 5-ft long baseline design canister. A 10-ft instead of 5-ft long GC is preferred because it meets the repository philosophy of co-disposing of 10-ft long spent nuclear fuel (SNF) canisters and 10-ft long GCs in the same co-disposal container.

The glass volume and canister estimate from EDF-VWO-001 in Appendix A establishes 14,115 as the total number of DWPF GCs necessary to vitrify all ICPP calcine. The throughput rate of the facility was established assuming 24 hour per day, seven day per week operation for 20 years, with a total of $50 \%$ combined planned and unplanned downtime. The throughput is based on processing a constant calcine mass flow rate of $4,500 \mathrm{lb}$ per day. The total glass volume (volume of the vitrified calcine and glass frit mixture) can vary daily because different calcine types and chemistries have different densities and may require different ratios of glass frit to calcine. The average daily throughput (based on $4,500 \mathrm{lb}$ of calcine having an average specific gravity of 1.41 and with and average mix ratio of glass frit to calcine of 3:1) will be $3.9 \mathrm{GCs}$. The maximum daily throughput, based on $4,500 \mathrm{lb}$ of calcine per day and the maximum glass frit to calcine ratio, will be 5 GCs.

To demonstrate that the characterization of the final waste form will be road ready and will meet repository requirements of Waste Acceptance Product Specifications for Vitrified High-Level Waste Forms, ${ }^{4}$ the expected final waste form was compared to the requirements of Appendix $\mathrm{C}$ from the Waste Disposal Options Feasibility Study. ${ }^{9}$ The VWO final expected waste form GC was determined to meet all requirements.

Although this report is based on a 10 -ft long DWPF canister, the DOE Hanford Facility has adopted a 4.5 meter (15-ft) long canister to contain immobilized HLW. This longer canister is apparently acceptable for co-disposal at the repository, and therefore should be considered before finalizing the VWO canister size. Consideration of the 15 - $\mathrm{ft}$ canister has been addressed by adding a corresponding future study in Section 11.2. The longer canister will increase the capitol cost of the VF because the head height of the four VF levels, depth of excavation, equipment capacities, etc., would increase. The ISF transport tunnel height, GC handling machine size and capacity, and the ceiling height will also increase. However, the total number of 15-ft long canisters would only equal about two-thirds of the 14,115-10-ft canisters; so, handling, shipping, final disposal operations, and costs would be greatly reduced if the longer canisters were adopted.

\subsection{Key Assumptions}

The following subsections list the key assumptions used throughout this Study. Appendix C offers more detail on these assumptions and their bases. All assumptions used throughout this study fall into one of three categories: 
- Work Scope (WS) assumptions - Those that could affect the feasibility or are fundamental to the approach used and are usually program driven

- $\quad$ Study assumptions (S)- Those that affect the design, cost, or schedule

- $\quad$ Minor assumptions $(M)$ - Those that helped establish a basis for calculations, with no appreciable impact on design or cost

Assumptions listed below include Work Scope and Study assumptions, while Minor assumptions are noted only in EDFs or other pertinent locations where they were needed.

\subsubsection{Work Scope Assumptions}

The following Work Scope (WS) Assumptions formed the framework, i.e. the directed charter, for this Study. Although some of these assumptions are highly subject to change, it is beyond the scope of this study to evaluate the associated risk.

- WS-1 Evaporation and solids stabilization capability will be provided by the PEW facility and future PEW facility upgrades (see the Utilities and Infrastructure Report ${ }^{10}$ ).

- WS-2 The GCs, as scoped, will meet the repository Waste Acceptance Product Specifications (WAPS) for co-disposal with SNF.

- WS-3 The final waste from package - vitrified waste in excess of $85 \%$ full in a sealed 61cm outside diameter $\times 3-\mathrm{m}$ long SRS-DWPF-Type canister - will be licensable under NRC requirements for ISF storage under $10 \mathrm{CFR} 72$, and NRC licensable for transportation in a Type B shipping container under $10 \mathrm{CFR} 71$. The HLW GC transportation package will also be required to meet DOT regulations found in 49 CFR 173.

- WS-4 This option will not process any waste generated after 2012. All SBW will be calcined by this date.

- WS-5 All LLW or mixed LLW produced by the VF will be Class A, B, or C as defined in NRC 10 CFR 61.55.

- WS-6 All of the wastes produced from the treatment and storage facilities will meet the requirements enforced by the Environmental Protection Agency (EPA), the DOE, the U.S. Department of Transportation (DOT), the Nuclear Regulatory Commission (NRC), and other potential target repositories for the disposal. Delisting petitions will be successful.

- WS-7 Delisting in Idaho for storage does not automatically delist the waste in all states, therefore, a delisting petition must be granted for each state or region through which the waste will travel on the way to the disposal facility.

- WS-8 The VF analytical support will be provided by a future facility for which costs are not included in this study. 


\subsubsection{Study Assumptions}

The following Study (S) Assumptions were identified during the study and used to establish a basis for design and cost:

- S-1 The VWO VF will be designed based on the Raytheon Waste immobilization Facility Direct Vitrification option in Volume 4 of the Raytheon Direct Vitrification Option Feasibility Study Report, Reference 2, (Option 21)

- S-2 Six different glass frit compositions will be a sufficient number to accommodate the variability in the calcine chemical composition. Separate storage silos and feed hoppers will be provided for each of these materials.

- $\quad \mathrm{S}-3$ Calcine volume will be $5435 \mathrm{~m}^{3}$ with an average density of $1408 \mathrm{~kg}$ per m .

- S-4 Each canister will be loaded with $0.72 \mathrm{~m}^{3}$ of glass. The number of canisters produced is approximately $14,115\left(10,163 \mathrm{~m}^{3}\right.$ of glass product $)$.

- S-5 For on-Site facilities (INEEL), physical security requirements can be met with typical access controls such as card readers and alarmed doors to the facility using the same requirements and systems as used for SNF.

- S-6 The calcine particle size, and particle size distribution, as delivered to the VF by the CRTS, can be used without further size reduction processing.

- S-7 A shielded probe system can be used in the VF exhaust stack instead of an isokenetic sampling system to monitor the offgas and HEPA-filtered heating, ventilation, and air conditioning (HVAC) exhaust air.

- S-8 Precipitation of mercury as a sulfide salt will meet the definition of amalgamation with sulfur under 40 CFR 268, so that the solids will meet the RCRA Land Disposal Restriction (LDR).

- S-9 No GCs will require recycling due poor glass product contained within them or due to improper welding of lids on full canisters.

\subsection{Requirements}

\subsubsection{Performance Requirements}

Section C. 3 of the Settlement Agreement between DOE and the State of Idaho, ${ }^{3}$ states that "DOE shall treat all high-level waste currently at INEEL so that it is ready to be moved out of Idaho for disposal by a target date of 2035." The VWO process, as proposed in this report, will start producing GCs by 2013 and finish by 2032, which is ahead of the target date. The total number DWPF GCs was estimated at 14,115 , which requires an average throughput rate of $3.9 \mathrm{GCs}$ per operating day for this 20 -year operating life.

The throughput of the Raytheon Direct Vitrification Option Feasibility Study Report ${ }^{1}$ (used as the baseline for this report), is $6.8,2-\mathrm{ft}$ diameter by 5 -ft long GCs per day while the throughput for the VF in 
this report will be 3.9, 2-ft diameter by $10-\mathrm{ft}$ long GCs per day. Each 5 -ft long GC holds about $44 \%$ of the glass volume of a 10-ft long GC. Therefore, 6.8, 5-ft long GCs per day from the baseline design will carry an amount of glass equal to 3.0,10-ft long GCs per day in the VWO. This rate is $0.9 \mathrm{GCs}$ per day below the required amount of glass to produce the design's rate of $3.9 \mathrm{GCs}$ per day. This design deficit in glass production has been eliminated by increasing the rate of calcine delivery from the CSSF, by redesigning the glass frit delivery system, and by replacing the three small stir melters with a single, large-capacity, cold cap melter capable of meeting the required glass production rate.

The baseline design rate for canister handling, filling, cooling, capping, welding, decontaminating, smearing, and transporting to the ISF, is based on a rate of 6.8, 5-ft long GCs per day. The DWPF canisters in this report will be twice the length of the existing Raytheon canister, but this should not affect the rate at which an individual canister can be processed. The required average throughput rate of 3.9, $10-\mathrm{ft}$ long GCs per day for this report is only about only $57 \%$ of the baseline design throughput rate of $6.8 \mathrm{GCs}$ per day. Therefore, the canister handling methodology and equipment (with some lifting capacity increases for the increase canister weight) specified in the baseline design should be adequate for the canister handling throughput rate in the VWO design. Some baseline-designs for special canister processing stations and equipment must be changed because the cell heights in the baseline design will not be sufficient to lift a 10 -ft long canister over a $10-\mathrm{ft}$ tall station. Therefore, the canister stations and airlocks must be redesigned for side access instead of top access. However, because these stations will be specialized pieces of equipment, they can be designed in either manner without a significant cost increase.

\subsubsection{Design Criteria}

Section 3.0 of the regulatory and design requirements in EDF-WTS-004 in Appendix A, provides general design requirements for the HLW treatment alternatives, including non-separations vitrification. The purpose of the document is to delineate the design requirements for the non-separations and transuranic (TRU)-only separations options for the Waste Treatment Facilities (WTF) studies. The document provides a set of high-level requirements to guide the development of the conceptual designs of the facilities and provide a reasonable basis for cost estimating purposes. Process criteria such as the waste form acceptance criteria, treatment standards, and so forth are covered by other sections in this report.

\subsubsection{Regulations}

The regulatory requirements and criteria, in EDF-WTS-003 Appendix A, identify and provide a survey of the existing environmental regulations and standard criteria pertaining to the design, construction, operation, and performance of the proposed waste treatment and storage facilities at the ICPP. The EDF also provides an assessment of the current NRC regulations and their potential applicability to the proposed facilities, if the facilities were to be licensed by the NRC.

The EDF covers all non-separations options including the VWO. The principal sources of requirements for the design, construction, and operations for the VWO are the DOE, the DOE Idaho Operations Office (DOE-ID), the EPA, the Idaho laws and regulations, the National Environmental Policy Act (NEPA), and other local codes and standards. All work is expected to be performed in accordance with the DOE/RW/0333P, "Quality Assurance Requirements and Description."

It is assumed that neither the VWO nor the CRTS will be NRC licensed, but will be designed and constructed under DOE Orders, with maintenance of status-quo interfaces with other regulatory and oversight agencies such as the EPA, State of Idaho, and the Defense Nuclear Facilities Safety Board (DNFSB). These facilities will be designed and built to DOE Orders, including 6430.1A, General Design Criteria, and other DOE codes and standards, as presented in EDF-WTS-003. No current NRC 
regulations exist to license waste treatment facilities, such as the VF. The ISF, however, will be NRC licensed under 10 CFR 72.

The GCs will be NRC licensed for ISF storage under 10 CFR 72, and NRC licensed for transportation in a Type B shipping container under 10 CFR 71. The HLW GC transportation package will also be required to meet DOT regulations found in 49 CFR 173.

\subsubsection{Applicable Codes and Standards}

Codes and standards, applicable to the proposed facility, are discussed in detail in the regulatory requirements for design of waste processing facilities, EDF-WTS-003, and the regulatory and design requirements for waste treatment facilities, EDF-WTS-004, both in Appendix A.

\subsubsection{HLW National Repository Waste Acceptance Criteria}

The key repository waste acceptance criteria related to vitrified HLW storage at the INEEL are summarized in EDF-DPC-003, which is contained in the DPC Loading Feasibility Study Report, ${ }^{8}$ and in the Standard Criteria of Candidate Repositories and Environmental Regulations for the Treatment and Disposal of ICPP Radioactive Mixed Waste. ${ }^{11}$ These criteria were derived from the WAPS. The WAPS was derived from the requirements listed in the Waste Acceptance System Requirements Document. ${ }^{5}$ The Waste Disposal Options Feasibility Study, ${ }^{9}$ also contains applicable WAPS criteria. The standard waste form is borosilicate glass, although provisions exist to qualify other waste forms. The final waste form cannot exhibit the properties of a RCRA hazardous waste. The GCs must meet the specifications listed in the WAPS; the waste form must meet the required physical characteristics, and must be accompanied by the required documentation.

To demonstrate that the characterization of the final vitrified waste form will meet the requirements for repository disposal in the WAPS, ${ }^{4}$ the expected final waste form was compared to the requirements of Appendix C from the Waste Disposal Options Feasibility Study. ${ }^{9}$ The VWO expected final waste form $\mathrm{GC}$ was determined to meet all of those requirements. 


\section{SYSTEM DESCRIPTION}

\subsection{Calcine Retrieval and Transport System}

EDF-WTS-002, in Appendix A, contains the detailed description of the CRTS portion of the VWO (it also contains CRTS descriptions for other waste treatment options). This section is a summary description of the CRTS.

The CRTS retrieves calcine from CSSF bins and places it directly in one of two transportation systems. Each transportation system consists of two closed-loop stages of pneumatic calcine transfer. The first stage pneumatically transfers calcine from the CSSF area to an Intermediate Transport Station (ITS) and the second pneumatically transfers calcine from the ITS to the fluidized bed calcine blending vessels inside the VF. The seven CSSF bins are covered by confinement enclosures that have an associated ventilation, instrumentation, and control building. The calcine retrieval system will remove the calcine from a bin and place it directly in the closed loop pneumatic transport system.

Calcine retrieval will be accomplished pneumatically with a suction nozzle and an air jet. The air jet will fluidize the calcine inside the bin and the suction nozzle will lift it out of the bin. Calcine enters the transport system through a shielded jumper from the retrieval line. A vertical deployment apparatus will keep the retrieval lines near the surface of the bulk calcine. The calcine will be retrieved at 2,700 $\mathrm{kg} / \mathrm{hr}$ from each bin. When both transport systems are operating, calcine will be delivered to the ITS at $5,400 \mathrm{~kg} / \mathrm{hr}$. The ITS delivers calcine to the VF at the same rate.

Throughout calcine processing, retrieval can be switched from one CSSF bin to another as they are emptied or as different calcine mixes are required. For example, the frequent switching between CSSF bins could be used to adjust the mix of calcine types being delivered. The closed-loop pneumatic transfer systems operate at a vacuum and minimize the amount of released transport air by recycling it. Each system consists of the transfer line, a cyclone separator for removing the calcine from the air stream, a sintered metal filter and a HEPA filter to remove solid particulate, a blower for air circulation, and an air chiller to cool the air heated by blower compression. Each transport system will have a duplicate calcine transport line, in case the original line becomes plugged. Each transport system will be accompanied by a return airline, and all lines will be located above grade and bermed to provide shielding. Diverter valves will ensure that calcine can be transported from the CSSF bins to the ITS or to the VF in either line of the transport system. The CRTS cyclone separators, sintered metal filters, HEPA filters, transport blowers, and air chillers for the ITS are located in the VF fluidized bed calcine blender cells. The costs for these components are included in the total costs for the CRTS given in EDF-WTS-002. The total CRTS costs are also presented in Section 4 of this report.

\subsection{Vitrification Facility}

The function of the VF is to receive dry calcine waste from the CSSF, vitrify the calcine, package the vitrified waste into road ready canisters, and transport these GCs to the disposal facility via a transfer tunnel. Mercury-containing waste will be packaged and transported to a mixed LLW disposal facility. To accomplish this the VF will receive glass frit by rail, mix it with calcine, and vitrify the mixture in one of two VF melters. The molten glass will be poured into 2 - $\mathrm{ft}$ diameter $\times 10-\mathrm{ft}$ long DWPF canisters.

Verbal input from SRS DWPF personnel is documented in EDF-VWO-003 in Appendix A. This information was carefully considered in developing the VF design presented in this report. 


\subsubsection{Site Description}

The Vitrification Facility will be located in the northeast corner of the ICPP between the east perimeter fence and Hemlock Street to the west, because of the close proximity to the waste sources. The facility will be sited on an environmentally controlled area (ECA-CPP-26), which it is assumed, will be released for construction.

Existing site soils consist of poorly graded, gravely and sandy alluvial deposits ranging from 35 to $40 \mathrm{ft}$ deep that overlay a 8 - $\mathrm{ft}$ thick clay layer which rests on a massive basalt bedrock formation.

Groundwater is not located above the basalt elevation.

The floor elevation at grade will be higher that the 100-yr flood elevation in accordance with RCRA requirements or the ICPP probable maximum flood elevation. The lowest floor level elevation was chosen to minimize excavation of existing bedrock.

The facility was sited for delivery, service, and emergency vehicle accessibility. Site roads connect to existing streets and have adequate maneuvering area for delivery trucks.

\subsubsection{Underground Utilities}

The Utilities and Infrastructure Report, ${ }^{10}$ is a study that establishes a design for the existing and planned utilities that will be required by the VWO (as well as establishing designs for some of the other HLW waste treatment options). Reference 10 also contains the cost estimates of VWO utilities presented in the Section 4 of this report.

\subsubsection{Fences, Roads, and Railroads}

The Vitrification Facility and ISF will be enclosed by a fence with gates for access roads and railroad crossings. The fence will be a chain-link security fence, typical of that around the perimeter of the ICPP complex. Parking will be provided for approximately 30 site vehicles with head-bolt heaters.

\subsubsection{Facility Layout}

The VF will be a multistory building that extends $32 \mathrm{ft}$ below and $75 \mathrm{ft}$ above grade, and has a footprint occupying an area measuring $391 \mathrm{ft} \times 178 \mathrm{ft}$. The VF design plan and elevation views are shown on Drawings VWO-A-1 through VWO-A-5 in Appendix B. It will be designed to house the equipment and operations for non-separations processing of calcined HLW while providing essential features for safe and efficient operation and maintenance. The VF layout is based on a centrally located process cell complex with heavy concrete walls for shielding, and limited personnel access. EDF-VWO007, Fluidized Bed Blending Tank Cell Shielding Calculations, in Appendix A, contains a calculation of the concrete shielding wall thickness necessary to reduce the maximum calcine radiation source field in the VF to $0.10 \mathrm{mrem} / \mathrm{hr}$ or less. The cells will house equipment that presents a high radiation hazard but requires minimal maintenance. The cells will be enclosed by shielding walls with installed manipulators and shielding windows that facilitate maintenance from the operating corridors that surround these process areas. The periphery of the facility contains office space, support areas, and nonradioactive operation areas.

3.2.4.1 Below Grade Features. The below grade areas of the VF house the 32-ft high empty canister loading and storage bay, the canister filling and capping cell, the decon cell, and a full canister storage/staging area. The canister filling and capping cell, decon cell, and full canister storage/staging 
area contain 3-ft thick, decontaminable shielding walls, ceilings, and floors. The calcine retrieval and transport equipment, and calcine receiving and blending tanks will be located near the north end of the VF and continue from $32 \mathrm{ft} 0 \mathrm{in}$. below to $45 \mathrm{ft} 0$ in. above grade in cells with 4 - $\mathrm{ft}$ thick shielding walls, floors and ceilings. Five stairways and a freight elevator, located near the northeast corner, will provide for personnel egress and equipment loading throughout the building.

3.2.4.2 Above Grade Features. Level $0 \mathrm{ft} 0$ in. contains the vitrification melter cells, scrubber blowdown treatment system, smear cell, weld cell, equipment decon cell, remote maintenance cell, hands-on maintenance room, sulfide and dry sodium storage room, decon solution makeup room, decon solution distribution equipment room, and the equipment loadout area. Six glass frit silos 13-ft in diameter by 20 -ft tall and a $10-\mathrm{ft}$ diameter stack will be located outside at grade level, east of the facility. Administrative areas, including office, control room, restroom/change room space, will be located on the west side of the facility. The HVAC exhaust equipment will be located adjacent to the process cells to facilitate filtering close to the contamination source. Five stairways provide egress, and a freight elevator, a truck loading bay, and an equipment loadout bay provide maneuverability for equipment and raw materials throughout the facility. Airlocks will be provided at the entrance to the personnel corridors between the process cells, at the interface between the office and operating corridor, and directly between the operating corridor and the change rooms. Airlocks will be provided in the loading bays for canister and freight delivery trucks.

The level 21-ft 0 -in. above grade contains the upper portions of the melter, smear, weld, loadout, offgas system, and HVAC exhaust equipment rooms. The building HVAC supply equipment room will be located on this level. Access to the remote maintenance and equipment decon cells below will be provided in the laydown area at the south end of the building.

The level 45 -ft 0 -in. above grade consists primarily of a large, shielded high bay (the maintenance/disassembly cell) that contains a 75-ton overhead bridge crane and hatch covers to all process cells below. The crane can lift, set aside, and replace all removable cell covers. After cell cover removal, the crane can move components to and from the equipment decontamination cell and remote maintenance cell through the cell covers on Level 21. A conveyer system will transport glass frit from six receiving tanks, located in the corridor, to a ribbon blender that serves either melter cell.

\subsubsection{Structural Features}

The process area of this facility has a concrete superstructure extending $45 \mathrm{ft}$ above grade. The cell walls will generally be 3 to 4 -ft thick and support a formed cast-in-place concrete roof. The process cell walls extend to a 4-ft thick foundation 32-ft below finished grade. The operating corridor outside walls will be reinforced concrete and extend to $32-\mathrm{ft}$ below finished grade.

Process cells have 1/4-in. thick stainless steel floors and 1/8-in. thick wall liner plates. Only the lower $2 \mathrm{ft}$ of all cell walls will be lined, except the sample and decon cells, which will be fully lined. The tops of all cells at the $45 \mathrm{ft}$ elevation, as shown in Drawing VWO-A-4 in Appendix B, will be covered by stepped, 4-ft thick, concrete plug-type hatch covers that can be removed by the 75-ton bridge crane to completely expose the equipment below.

The building superstructure containing the office and HVAC supply equipment area consists of an ordinary braced-frame system. Metal panels enclose the roof and walls. Office floors will be 6-in. reinforced concrete slab-on-grade or supported on concrete topped metal decking and structural steel framing where elevated. Grade beams and isolated column spread footings support the structural steel frame of the building. 


\subsubsection{Vitrification Facility Processes}

As described above, the major processes for the VWO will be as follows (See Drawing VWO-01 in Appendix B): (1) Obtain calcine from the ICPP CSSF using the CRTS, (2) Mix calcine and glass frit, (3) Vitrify the mixture, pour it into canisters, and prepare GCs in a road-ready condition, (4) Transport GCs to the ISF, and (5) Process the vitrification offgas. Drawings VWO-02 through VWO-05 and VWO-06 through VWO-10 (in Appendix B) are subtier flow diagrams for the VF derived from the main diagram, Drawing VWO-01. The vitrification process relies heavily on remote handling and conveying systems (details on these features are provided in Appendices I and J).

3.2.6.1 Empty Canister Handling. Drawing VWO-09 (Appendix B) shows the process flow for the empty canisters from the truck airlock loading dock to the canister filling station in the canister filling and capping cell. Empty canisters will be delivered by trucks that enter the truck airlock near the northeast corner of the VF. Each crane that will be used to lift individual empty or full canisters will be equipped with a SRS DWPF Canister Grapple (an existing SRS design). Canisters will be removed from the truck by an empty canister crane and grapple, and placed on the HLW canister transfer cart. The cart will be moved into the elevator at the end of the airlock and lowered to the -32-ft level. The cart will be removed from the elevator and staged at the entrance to the empty canister storage room. The empty canister handling crane and grapple will pick a canister from the HLW canister transfer cart, move it into the empty canister storage room, and place it in the empty canister storage rack. The empty canister handling crane and grapple will lift an empty canister, move it into the empty canister transfer airlock, and place it on the canister shuttle cart in the airlock. The canister will be moved into the canister filling and capping cell on the canister shuttle cart. Once inside the canister filling and capping cell, the empty canister will be lifted off the canister shuttle cart by the filled canister transport crane and grapple, and transferred to the canister lifting mechanism under the melter canister filling weir.

3.2.6.2 Vitrification Process. A detailed process description is given in the vitrification process description (EDF-VWO-002 in Appendix A). The EDF tabulates the material balances and flow rates for process lines shown on Drawings VWO-04, -06, -07, and -08. The vitrification process entails calcine blending, calcine and frit handling and mixing, vitrifying the mixture in a melter, receiving empty canisters, staging and transporting of canisters, pouring the glass from the melter into the canisters, cooling and capping the canisters, welding the GC lid and leak testing the weld, decontaminating and smear-testing the GCs, treating the melter offgas, and transporting the GCs from the VF to the ISF through the interconnecting transfer tunnel. All unit operations will be accomplished by equipment sized to deliver an average of $3.9 \mathrm{GCs}$ per day and a maximum of $5 \mathrm{GCs}$ per day to the ISF.

Drawing VWO-07 in Appendix B shows the three VF calcine handling systems: the Calcine Transfer System, the Calcine Fluidized bed system, and the Vitrification Facility Calcine Transfer System. The calcine transfer system consists of the final pneumatic calcine transfer portion of the CRTS, and is therefore shown in phantom. The blower (ID Fan) moves the air and entrained calcine through the inlet lines to the separation cyclone where the calcine is removed by centrifugal force and drains by gravity into the calcine blending tank. The air exits the top of the cyclone and enters the sintered metal filter where most of the fine particulate is removed. The sintered metal filter will be periodically backflushed to clean the calcine fines from the upstream side. The fines from the backflushing also drain by gravity into the calcine blending tank. The air exits the sintered metal filter and is further cleaned by a two-stage HEPA filter plenum before entering the blower. The air stream exiting the blower has been heated by compression and must have its temperature lowered by a downstream cooler. After exiting the cooler, $90 \%$ of the air is returned to the CRTS intermediate transfer station, and the remaining air is exhausted through the VF exhaust stack. 
The calcine fluidized bed system is used to homogenize a batch of calcine that is delivered to the blending tank from the calcine delivery system. Each blending tank holds $525 \mathrm{ft}^{3}$ of calcine that may be stratified in multiple layers and of three different chemistries. The calcine in the batch must be blended (homogenized) and then analyzed to determine the proper glass frit chemistry to mix with it to produce an acceptable vitrified HLW product. A calcine blending blower forces pressurized air into a plenum at the bottom of the blending tank. The air passes through a perforated plate, exiting at high velocity into the calcine resting on top of the plate. This high velocity air fluidizes and homogenizes the calcine batch in about 30 minutes. The fluidizing air exits the top of the blending vessel and enters a clean up train consisting of the separation cyclone, a sintered metal filter, a HEPA filter, and an exhaust fan. The operation of this clean up train is almost identical to that described above for the calcine transfer system, except that the exhaust air is not cooled, and all the air is exhausted through the building stack.

The vitrification facility calcine transfer system is a pneumatic system used to transport homogenized calcine from the blending vessel to the calcine weigh tank (located in the melter cell), before it is mixed with glass frit and vitrified. The transfer system is identical in operation to the exhaust system just described for the calcine fluidized bed system, except that the cyclone and sintered metal filter drain calcine by gravity to the calcine weigh tank. The calcine blending blower described above is first activated to fluidize the calcine that is then transported to the vitrification facility calcine transfer cyclone through a perforated pipe manifold located in the blending tank. Exhaust from the transfer system is routed to the stack. All blenders, cyclones, sintered metal filters, HEPA filters, fans, and the cooler, will be contained in shielded cells and maintained by remote methods.

Drawing VWO-08 in Appendix B shows the system used to receive glass frit, to transfer it to a ribbon blender for mixing with calcine, and to deliver the mixture to the melter. The glass frit will be mixed with the calcine to produce acceptable borosilicate glass product. EDF-VWO-007, Bulk Material transportation: Glass Frit, in Appendix A, contains proposed glass frit storage and conveyor systems investigated in this study. The glass frit will be delivered to the VF by rail hopper car and offloaded to a subgrade bin. Six different types of glass frit will be used in the VF. Each type of frit will be conveyed from the rail bin to one of six dedicated, 13 -ft-diameter by 20 -ft tall silos located outside on the east side of the VF. Each type of frit will be transferred from its silo to a corresponding receiving tank, 45-ft above grade inside the VF, by one of six dedicated auger/bucket conveyor systems. Depending on the chemical analysis of the calcine in the blending tank, a frit type will be selected and transferred from its corresponding receiving tank at the $45-\mathrm{ft}$ level to the frit weigh tank by a single auger conveyor. All frit handling equipment described will be located in clean areas and will be maintained by hands on methods. The frit will flow through a rotary valve in the bottom of the frit weigh tank, and gravity feed through a pipe that penetrates the melter cell shielding wall. The frit will then flow into a ribbon blender in the melter cell.

A rotary metering valve at the exit of the calcine weigh tank, shown in Drawing VWO-07, will meter calcine and deliver it to the ribbon blender in the melter cell. The ribbon blender supplies a mixture of calcine and glass frit directly to the melter. The glass is discharged from the melter when it overflows from a forehearth weir, and pours into the DWPF canister located directly beneath the weir. The canister will be held in the canister heater (part of the canister lifting mechanism) to prevent formation of void pockets in the glass melt during pouring.

The melters selected in this report were based on the design of the Transportable Vitrification System currently in operation at the DOE East Tennessee Technology Park. They will be refractory-lined vessels that employ joule (electric resistance) heating. Electrodes will be located directly in the melt. Separate electric heaters mounted in the melter lids will be used for startup. Each melter will be connected through a compression seal to the canister in a cell below. A primary melter and an installed spare melter system will be provided with the VF. Each melter will be $13-\mathrm{ft}$ in diameter $\times 23-\mathrm{ft}$ tall, and 
have one weir for glass product discharge and another weir for removal of slag or salt layers that may form during operation. Each melter weighs about 50,000 pounds when empty and about 115,000 pounds when full of glass. The melter will be insulated and heated by three banks of electrodes. Two banks will be located in the molten glass; the third bank will be mounted in the headspace above the liquid. The melter holds approximately 3,000 gal of glass that will be discharged by gravity in a semi-continuous fashion. Each canister will be mounted directly under the product glass discharge weir of the melter. Each of the two melters installed uses a maximum of $950 \mathrm{~kW}$ during operation. Only one melter will be in use at any time. The highest power demand occurs during startup. Three power supplies will be used, one for each of the three banks of electrodes. The lid (headspace) heaters will also be connected to an emergency power supply capable of providing $500 \mathrm{~kW}$. In case of a power outage, the lid heaters will keep the glass in a molten state. The melter offgas will be directed to the vitrification offgas treatment system. Purge gas from the canister filling operation will also be directed to the vitrification offgas treatment system.

3.2.6.3 Full Canister Handling. Drawing VWO-09 (Appendix B) shows the process flow for the filled GCs from the canister filling station in the canister filling and capping cell, to placing the GC on the transfer tunnel canister transport cart in preparation for transport to the ISF. After the canister is filled with glass in the filling station, it will be lowered, removed from the lifting mechanism by the filled canister transport crane and grapple, and transported to the GC cooling station. The GC cools for 24 hours, and a lid will be placed on it by the canister sealing manipulator. It will then be transported to the welding/leak test station via the canister weld handling crane and grapple. The lid will be sealed by the GTAW welding module. The sealed canister will then be lowered, through a hatch in the welding cell floor by the canister weld handling crane and grapple, into the decontamination cell. The canister decontamination handling crane and grapple will lift the GC and place it in the decontamination spray chamber. The crane and grapple also raise, lower, and rotate the GC in the spray chamber for complete coverage by the spray nozzles. The decontamination process uses solid carbon dioxide pellets under high velocity to remove oxide and contamination from the GCs. Approximately $100 \mathrm{scfm}$ of sublimated carbon dioxide vapor will be removed by the HVAC exhaust system. The oxide coating may form on the GC from exposure to the cell atmosphere while being heated and maintained at high temperatures during the canister pouring operation. This canister decontamination handling crane and grapple then place the GC below the smear cell hatch located in the decontamination cell ceiling. The hatch will be opened and the smeared canister loadout crane and grapple will raise the GC into the smear cell, and place it into the smearing station. After the GC is monitored for residual contamination by a smear monitor, the smeared canister loadout crane and grapple will either return the GC to the decontamination cell or lower it through a hatch in the floor into the transfer tunnel and place it on the canister transport cart, which will transfer it to the ISF.

3.2.6.4 Offgas System. The main offgas treatment system components, in the melter cell, will be directly coupled to the melter with offgas routing distances kept as short as possible. For standby redundancy, the offgas trains for both melters can be coupled and interconnected as required. Following removal of the cell covers, all components, including HEPA filters, will be remotely exchangeable by means of the master-slave manipulators or the $\mathrm{PaR},{ }^{\circledR}$ and the maintenance/disassembly cell bridge crane. Offgas components will be jumper connected and modular.

A wet scrubber system will remove contaminants from the offgas. The offgas temperature will vary from 400 to $1,000^{\circ} \mathrm{C}$, so a quench vessel will be used. A venturi scrubber will remove gross particulates, and a packed bed scrubber will remove volatile contaminants and fumes. A granular activated carbon (GAC) vessel will remove trace amounts of mercury. The offgas system will also include a demister and electric heaters upstream of the GAC bed to reduce relative humidity, and HEPA 
filters to reduce radioactive particulates to acceptable levels in the offgas emission air stream. A vacuum is maintained on the melter and offgas equipment by an induced-draft fan.

The calcine contains mercury oxide $(\mathrm{HgO})$ at concentrations up to 3\%. This compound will decompose in the melt; therefore, the scrubber solution can become heavily laden with mercury. Based on experience with the DWPF melter, a fraction of the mercury is likely to be captured in the off-gas scrubber solution in ionic form with the majority of the metal in elemental form. Material balance calculations support the assumption that $90 \%$ of the mercury is present in the off-gas system as the metal element.

Two processes are provided to remove mercury from the scrubber blowdown water. Elemental mercury is separated by gravity, washed with demineralized water, and amalgamated with copper. The washing step removes the majority of residual radionuclides, allowing the amalgam to be stored and disposed of as LLW. Amalgamation will take place in 1-gal containers, which will be overpacked in 30gal drums for transport and storage. Most operations involved in amalgamation are performed directly by the operators. These steps include filling the 1-gal containers with mercury and copper; sealing the lids; placing the containers on the jar mill; removing the containers from the jar mill; and, placing the containers into the overpack drums. The amalgam meets the treatment requirements of 40 CFR 268.40 for radioactive elemental mercury.

Dissolved (ionic) mercury is precipitated as insoluble mercury sulfide by blending the scrubber blowdown water with a sodium sulfide solution. This process is performed after the elemental mercury has been removed. The water thus treated is sent to an existing process waste evaporator. It is assumed that precipitation of mercury as a sulfide salt, will meet the definition of amalgamation with sulfur under 40 CFR 268. If this is the case, the solids will meet the RCRA LDR.

Mercury is also expected to be present in the GAC bed in the off-gas treatment system. Spent carbon will likely be sent to a new retorting facility identified in the current version of the INEEL Site Treatment Plan. The elemental mercury condensed from the retort would have to be amalgamated to meet LDR requirements.

\subsubsection{HVAC}

In addition to the offgas system, the VF will be required to have two ventliation confinement zones per DOE Order 6430.1A. This section will deal with the two confinement zones, and the nonconfinement area. A ventilation confinement system will be provided, which, in conjunction with the physical barriers, maintains a continuous airflow pattern from areas of low potential contamination to areas of high potential contamination. The objectives of the confinement systems are to prevent the spread of radioactive and other hazardous materials to occupied areas; and to minimize the release of radioactive and other hazardous materials in facility effluents. The primary confinement consists of the process hot cells and hot maintenance areas, which will be exhausted through two stages of HEPA filters. The primary confinement boundary will be comprised of hot cell walls, welded stainless steel ductwork and HVAC equipment designed to maintain its structural integrity during and after operational and natural-phenomena design basis accidents (DBAs). The secondary confinement boundary consists of the operating corridors and other building structures that surround the primary confinement. The secondary confinement boundary contains all ventilation system equipment such as HEPA filter units and exhaust fans. The non-confinement boundary consists of offices, control rooms and support areas outside the secondary confinement boundary. The non-confinement zones do not require unique ventilation systems and will be maintained at a slight positive pressure with respect to ambient. HEPA filters will remove contaminated particulates, but no carbon absorber beds will be provided in the primary filter trains, because semivolatile fission products and iodine will be removed by the offgas system. 
Drawing HV-1 (Appendix B) depicts the air flow diagram of the HVAC system for the VF, and the HVAC requirements are contained in Appendix E. Up to three air handling units (AHU) will supply $158,000 \mathrm{cfm}$ of conditioned air to the operating corridor at levels $+45 \mathrm{ft},+21 \mathrm{ft}, 0 \mathrm{ft} 0 \mathrm{in},-16 \mathrm{ft}$ and $-32 \mathrm{ft}$. Air from the operating corridors will be cascaded into the hot cells via AHUs, each consisting of a supply blower and a single stage testable HEPA filter. The cascade air supply units with air flow rates less than $11,000 \mathrm{cfm}$ will have $100 \%$ redundant filter sections, and units with air flow rates greater than or equal to $11,000 \mathrm{cfm}$ will have $25 \%$ redundant filters sections. Air from the hot cells will be exhausted to the stack through two stages of testable HEPA filter units and exhaust fans. HEPA filters and exhaust fans will have $100 \%$ redundancy for filter sections with less than $11,000 \mathrm{cfm}$ air flow, $50 \%$ redundancy for filter sections with air flow between 11,000 and $31,600 \mathrm{cfm}$, and $25 \%$ redundancy for filters sections with air flow of greater than or equal $31,600 \mathrm{cfm}$.

The HEPA filter units for the secondary confinement zone will be located in the exhaust filter room. This room will be provided with $11,400 \mathrm{cfm}$ of conditioned air via a single-zone AHU. Air from the exhaust filter will be exhausted to the stack through single stages of testable HEPA filters and an exhaust fan. HEPA filters and exhaust fans will have $50 \%$ redundancy. The control room will be provided with an independent HVAC system. Air from the room will be recirculated. Supply AHUs will have $100 \%$ redundancy.

The supply AHUs used to deliver air to various spaces in the facility will be housed in an HVAC equipment room at level $0 \mathrm{ft} 0 \mathrm{in}$. Two single-zone AHUs will provide conditioned air to this room to offset internal heat gains. Air from the room will be recirculated. Administrative offices will be provided with an independent HVAC system. Air from these rooms will be recirculated.

The facility will be provided with an independent chilled water system consisting of central chillers and pumps, delivering chilled water to various cooling coils. This system removes built-up heat from process equipment because cooling will not be required for personnel comfort in the operating corridor. The facility will obtain steam for comfort heating from an ICPP central steam supply facility (see the Utilities and Infrastructure Report). ${ }^{10}$ The HVAC system will be controlled by a central electronic system located within the facility.

Redundancy will ensure proper ventilation confinement during HEPA filter changeout or fan maintenance. Exhaust ductwork will be located in areas that will not be normally occupied. HEPA filter housings will have the capability to be leak tested and tested for filter efficiency in place. Single stage HEPA filtration will be provided at the hot cell intakes to prevent possible contamination from momentary back flow to the occupied areas. HEPA filters units will be designed per the American Society of Mechanical Engineers (ASME), N509, Nuclear Power Plant Air-Cleaning Units and Components, and tested per ASME N510, Testing of Nuclear Air Treatment Systems. Confinement boundaries will be sealed to maintain isolation when pressure differentials fall below normal conditions. Exhaust systems for the primary and secondary confinements will be round stainless steel welded joint ductwork designed and installed in accordance with applicable Sheet Metal and Air Conditioning Contractors National Association, Uniform Mechanical Code, and American Conference of Governmental Industrial Hygienists standards.

Confinement zones will be supplied by once through ventilation. All the airflow from these zones will be HEPA filtered and discharged to the exhaust stack, with no air recirculation. Each HEPA filter unit includes a stainless steel plenum housing, a deluge system, demister, prefilter, two stages of sidebagout HEPA filters, DOP test sections and ports, and an exhaust fan. The exhaust fans have integral adjustable flow control. The supply and exhaust fans for the hot cells can be powered from the INEEL site standby power grid (see the Utilities and Infrastructure Report). ${ }^{10}$ This allows the ventilation confinement to be maintained in the hot cells during a loss of off-Site power condition. 
Automatic local stand-alone controllers will be provided with the HVAC equipment. Graphic displays mimicking the HVAC system will be available in the control room for monitoring and for remote manual override control. The HVAC system will have local operator stations. However, the control room operator will have supervisory control capability to start and stop the HVAC system and to change setpoints. Alarms and out-of-tolerance conditions will be annunciated in the control room. It is assumed that a shielded probe system can be used in the VF exhaust stack to monitor the discharge from the ventilation system and offgas exhaust.

This facility will be designed with the following ventilation parameters:

- Eight air changes per hour for primary confinement

- Four air changes per hour for secondary confinement

- One cfm per square foot for administrative areas

- Two cfm per square foot for the control room

- One stage of testable HEPA filters for hot cell inlet

- Two stages of testable HEPA filters for hot cell exhaust

- One stage of testable HEPA filters for secondary confinement exhaust

- Once through ventilation for primary and secondary confinement zones

- $\quad$ Room pressures maintained in accordance with Table 1.

It is assumed that areas with large in-cell heat loads, which exceed normal nuclear ventilation capability, will have additional fan coil cooling units installed. These units will recirculate the air for cooling purposes only and will have no filtering capabilities. An example of this would be auxiliary room cooling for removing heat from canister cooling station in the canister filling and capping cell.

\subsubsection{Electrical}

The VF electrical requirements were established and details are contained in EDF-VWO-005 (Appendix A). The facility power requirements are estimated at:

- $\quad$ Connected load $2,568 \mathrm{kVA}$

- $\quad$ Demand load $1,959 \mathrm{kVA}$

- $\quad$ Standby power $800 \mathrm{kVA}$.

Normal power should be available from the existing $13.8 \mathrm{kV}$ electrical distribution center. Standby power will be supplied as indicated in the Utilities and Infrastructure Report. ${ }^{10}$ 
Table 1. Vitrification facility ventilation requirements.

\begin{tabular}{|c|c|c|c|c|c|}
\hline Number & Room & $\begin{array}{c}\text { Room } \\
\text { Volume }\left(\mathrm{ft}^{3}\right) \\
\mathrm{X} 1000 \\
\end{array}$ & $\begin{array}{c}\text { Required Air } \\
\text { Changes per } \\
\text { Hour }\end{array}$ & $\begin{array}{c}\text { Static pressure } \\
\text { Required } \\
\text { (TWG) }\end{array}$ & $\begin{array}{c}\text { Ventilation } \\
\text { Required } \\
\text { (cfm) } \times 1000\end{array}$ \\
\hline 1 & Operating Floor (45-ft) & 1,175 & 4 & -0.25 & 78.3 \\
\hline 2 & Crane maintenance & 48.5 & 8 & -0.75 & 6.4 \\
\hline 3 & Operating Floor (21-ft) & 371 & 4 & -0.25 & 24.7 \\
\hline 4 & Blend Room & 152 & 8 & -0.75 & 20.2 \\
\hline 5 & Next to Blend Room (21-ft) & 21 & 8 & -0.75 & 2.8 \\
\hline 6 & Melter Room 1 & 59 & 8 & -0.75 & 7.8 \\
\hline 7 & Melter Room 2 & 59 & 8 & -0.75 & 7.8 \\
\hline 8 & HVAC Supply Equip. Room & 149 & 4 & -0.25 & 9.9 \\
\hline 9 & Electrical Room & 37 & 4 & +0.1 & 2.4 \\
\hline 10 & Welding Cubical & 74 & 8 & -0.75 & 9.8 \\
\hline 11 & Smear Cubical & 63 & 8 & -0.75 & 8.4 \\
\hline 12 & Decontamination Cell & 47 & 8 & -0.75 & 6.2 \\
\hline 13 & Loading Cell & 23 & 8 & -0.75 & 3.0 \\
\hline 14 & Load-out Cell & 29 & 8 & -0.75 & 3.8 \\
\hline 15 & Scrubber Blowdown Cell & 49 & 8 & -0.75 & 6.5 \\
\hline 16 & Scrubber Cell & 21 & 8 & -0.75 & 2.8 \\
\hline 17 & Dry Storage Cell & 21 & 8 & -0.75 & 2.8 \\
\hline 18 & HVAC Exhaust Equip. Rm. & 86 & 4 & -0.25 & 5.7 \\
\hline 19 & Electrical Room & 12 & 4 & +0.1 & 0.8 \\
\hline 20 & Operating Floor $(0-\mathrm{ft})$ & 318 & 4 & -0.25 & 21.2 \\
\hline 21 & Offices & 64 & NA & +0.1 & 0.5 \\
\hline 22 & Truck Airlock & 14 & 4 & -0.25 & .93 \\
\hline 23 & Truck Airlock & 13 & 4 & -0.25 & .86 \\
\hline 24 & HVAC Exhaust Rm (0-ft) & 86 & 4 & -0.25 & 5.7 \\
\hline 25 & Empty Canister Stor. Rm. & 104 & 4 & -0.25 & 6.9 \\
\hline 27 & Full Canister Storage Cell & 52 & 8 & -0.75 & 6.9 \\
\hline 28 & Canister Filling \& Capping Cell & 140 & 8 & -0.75 & 18.6 \\
\hline 29 & Operating Floor $(-32-\mathrm{ft})$ & 507 & 4 & -0.25 & 33.8 \\
\hline 30 & $\begin{array}{l}\text { Blend Rm HVAC (-32-ft- 18- } \\
\text { in.) }\end{array}$ & 50 & 8 & -0.75 & 6.6 \\
\hline 31 & Transfer Tunnel & 70 & 8 & -0.75 & 9.3 \\
\hline
\end{tabular}




\subsubsection{Instrumentation and Control}

The Raytheon Direct Vitrification Option Feasibility Study Report ${ }^{1}$ baseline design was used for this I\&C estimate, for I\&C system requirements, and for subsequent material and installation costs. Differences between the baseline design and the design presented in this report were used to ratio the number of instruments from the baseline design. The following assumptions allowed estimation of the instrument types and quantities required for the VWO design (as with the baseline facility and process cells, the HVAC I\&C cost estimate is included in the HVAC estimate).

- The process I\&C measurements decrease by approximately $10 \%$ as a result of deleting the slurry mix, evaporation, and storage of the liquid feed

- VF process I\&C measurements decrease by approximately $5 \%$ due to reducing melter trains (including melting cell) from 3 to 2 (because of the large number of instrument measurements required for each melter train)

- A shielded probe system instead of an a isokenetic sampling system will be used in the VF exhaust stack to monitor stack effluents

- The electrical estimate includes telephones, facility public address systems, fire alarm systems, local control stations, and lighting protection systems consistent with the baseline

- The process I\&C system downstream of the melters will be the same as the baseline design (for example: filling, cooling, capping, smearing, welding, decontaminating, and associated canister transfer and handling equipment); therefore, the estimate is identical to the baseline estimates for these areas

- I\&C for the offgas treatment system design in this report is the same in the baseline design

- The canister filling monitoring I\&C cost for each melter system will be the same as in baseline design (a government-funded equipment (GFE) cost of $\$ 2$ million); therefore, the VF cost for two melter systems will be $\$ 4$ million

- The GC leak check system I\&C, located in the welding cell, will cost the same as the baseline design (a GFE cost of $\$ 1$ million).

Table 2 lists I\&C system estimates for both the baseline Vitrification Facility I\&C, and the VWO VF I\&C, based on the above assumptions.

\subsubsection{Fire Protection Systems and Equipment}

Both DOE-ID Architectural Engineering Standard (AES) 1530 and DOE 5480.7A call for automatic fire suppression to be provided in all new construction; thus, fire suppression will be required in all areas, including the hot cells and interim storage areas. DOE-ID AES 1530 provides for this requirement to be waived, if the variance is approved by the cognizant fire protection engineer (FPE), and if concurrence is obtained from the DOE-ID authority having jurisdiction (AHJ).

In general, all areas of the VF require some form of automatic fire suppression. With the exceptions noted below, automatic wet pipe sprinkler systems will be used. All "cold" areas (such as offices and corridors) will be provided with automatic wet pipe suppression systems. Automatic water 
Table 2. I\&C quantities.

\begin{tabular}{lcc}
\hline \multicolumn{1}{c}{ Description } & VWO \\
Alpha Continuous Air Monitors & $\begin{array}{c}\text { Baseline Quantity } \\
\text { (Ref Only) }\end{array}$ & $\begin{array}{c}\text { VF } \\
\text { Quantity }\end{array}$ \\
\hline Beta Continuous Air Monitors & 20 & 19 \\
Remote area Monitors & 20 & 19 \\
Frisker & 16 & 15 \\
Personnel Contamination Monitor & 26 & 24 \\
Air Sample Probe & 8 & 8 \\
Plant Control System Hardware & 56 & 52 \\
Plant Control System Software & 9 & 7 \\
Entrance Warning Signs & 9 & 7 \\
Local Area Warning & 56 & 56 \\
Data Management System Hardware & 32 & 32 \\
Data Management System Software & 9 & 7 \\
Closed-circuit television (CCTV) & 9 & 7 \\
System in Control Room & 1 & 298 \\
Instrument Bulks Allowance & 350 & 298 \\
Control and Safety Valves & 350 & 298 \\
Electronic Instruments & 350 & 2 \\
Pneumatic Instruments & & 298 \\
\hline
\end{tabular}

deluge suppression systems will be provided upstream of HEPA filters in all final filter plenums that have a leading face area exceeding $16 \mathrm{ft}^{2}$. Manual fire extinguishers will be located throughout the facility.

Historically, some hot cells have been constructed and operated without automatic suppression or detection systems. However, based on the nature of the hazards and the cost of equipment within the VF hot cells, it is unlikely that automatic suppression can be omitted in the hot cells. If a detailed analysis of the cells is performed during later design phases, and the potential for fire is found to be very low, omission of suppression systems will be considered. All suppression systems have disadvantages, which must be considered in hot cell applications, including:

- Potential to spread contamination via air/gas flow or water

- Difficulty and cost of cleanup after a discharge

- Difficulties involved in maintaining confinement (negative pressure) during a fire incident and discharge of the suppression system. 
Hot cells in the process area which need to be safe, or where the costs of cleanup of a water discharge will be prohibitive, will be evaluated/identified during later phases of design. These cells will be provided with either limited water or gaseous extinguishing systems; the choice will be made considering both the technical merits and the costs of the systems for the specific cells involved. The system currently recommended is a limited water sprinkler system. This recommendation was based on technical advantages (such as least impact on overall design and on probable lowest cost for the system).

\subsubsection{Fire Detection and Alarm Systems}

Automatic detection systems are a required part of redundant fire protection systems, as defined by DOE 5480.7A, and will be provided throughout the VF facility. DOE 6430.1A requires redundant and automatic detection systems to process confinement systems. The need for automatic detection systems elsewhere will be determined by the cognizant FPE, with concurrence by the DOE AHJ. The alarm and detection system will be compatible with the existing on-Site alarm and detection system, and will be arranged to automatically notify the CFA fire department of all alarm conditions at the VF.

With the exception of the Interim Storage Areas, automatic and manual detection will be provided in all areas of the VF, including the various hot cells. Alarms will sound locally (at the protected building) at a facility main fire alarm control panel. In all "cold" areas, such as administrative and office areas, and operating corridors, smoke detection will be provided. Areas such as equipment rooms, where the ambient conditions may not be suitable for smoke detection, will be provided with rate of rise thermal detection systems.

Smoke detection will be provided in HVAC ducts as required by the Uniform Building Code and related Codes, and by National Fire Protection Association Standards. Thermal detection will be provided upstream of final HEPA filters, as required by DOE Orders, and the DOE Fire Protection Resource Manual.

Thermal detectors have been used successfully in hot cells, and are currently recommended for this facility because

- Thermal detectors can be arranged to be tested remotely (testing is not a concern)

- It may be possible to arrange the detector installation so that failed detectors can be replaced from outside the hot cell; such a design is "standard" on glovebox enclosures at some facilities

As an alternative to standard thermal detection in hot cells, an "incipient" fire detection system, such as a "VESDA" system will be considered because:

- This is an air sampling system, which can be arranged to sample air at various levels and locations throughout the hot cells; therefore, products of combustion are more likely to be detected at an early stage.

- The air sampled by the system is potentially contaminated; therefore it must be returned to the cell, or exhausted through another HEPA filter. AHU components of this system will also potentially be contaminated.

- Maintenance of such a system could be a significant problem in areas that are highly radioactive. 


\subsubsection{Utility Control System and Fiber Optic Cable}

The existing Utility Control System (UCS) fiber optic cable loop at ICPP consists of six dedicated fibers in a 36-fiber, fiber optic cable. Three loops of fiber optic cable encircle the ICPP site and control and monitor the UCS, the fire alarm system, the voice paging and public address system, the criticality alarms, and local area network (LAN) systems. To connect the VF into these systems one of the loops must have all 36 fibers cut and the loop expanded to include VF. All above systems must be tested to ensure proper functioning before reactivation.

The UCS controls the main and tie breakers of all Load Centers at ICPP, while the Plant Control System (PCS) controls the main and tie breakers on the downstream motor control center and power centers. In addition, the PCS controls the starting and stopping of all loads in the facility/building. The UCS and PCS combined allow load shedding of unimportant loads from the electrical system, thus limiting and controlling the standby load requirements at ICPP.

VF and ISF will be located directly over the top of an existing ductbank that extends from the coal fired steam generation plant into the fuel processing restoration facility area (north-south running ductbank). The ductbank and the fiber optic cable will be rerouted around the east side of the ISF. The fiber optic loop will occur in an existing manhole. New fiber optic cable and ductbank will be routed to the VF from this location. Rerouting of existing fiber optic cable or ductbank is not required in this option.

\subsubsection{Vitrification Facility Staffing}

EDF-VWO-004 (Appendix A) documents a VF staffing study that indicates 124 operational, maintenance, and supporting staff will be required for the VF.

\subsubsection{Strategic Materials}

The strategic and critical materials list from the Stockpile Report to the Congress, ${ }^{12}$ was reviewed with respect to materials and processes to be included in the VF. It was determined that no materials in that list will be used in the VF.

\subsection{Interim Storage Facility}

The Interim Storage Study Report, ${ }^{2}$ establishes the design of the ISF that is required as part of the VWO (as well as establishing designs for some other HLW WTF options). The report also contains the cost estimates of the VWO ISF presented in Section 4 of this report. This section is a brief summary of the VWO ISF.

Drawing VWO-C-1 in Appendix B shows the positions of the VF and ISF at ICPP. The ISF is designed to receive, handle, and store approximately 14,000 GCs produced at the VF from 2013 through 2032. The ISF is based on the storage facility presented in the Fluor Daniel Inc., Waste Treatment Facilities Feasibility Study Report. ${ }^{7}$ It will be a metal building, or a series of connected buildings with a shielding floor at grade level, and a 40-ft below-grade area under the shielding floor. This subgrade area holds approximately 5,048, round, 37-ft long (approximate), vertical steel tubes. These tubes span from the below grade room floor to the shielding floor above, and can each accept and store three DWPF GCs produced in the VF. The three DWPF GCs will be stacked vertically in each tube. Each tube has a removable shield plug at its upper end in the shielding floor. The plugs shield the above-grade building area and allow access to the tubes to insert and remove the GCs. The GCs will transfer thermal energy to 
the tubes, which must be cooled to maintain safe temperatures (accomplished by natural crossflow convection over the tube exterior surfaces). This horizontal convection across the tubes will be passively induced by exhausting the cooling air through a vertical chimney space formed between two parallel walls at one side of the ISF building. An air inlet on the opposite side of the building will supply passive inlet cooling air. This system provides failure proof passive cooling of the GCs for the storage life of the ISF.

The primary operation performed in the ISF is placing, and eventually removing, GCs to and from the storage tubes. To accomplish this, a GC is first transferred from the VF to the ISF on the canister transport cart in the interconnecting below-grade tunnel. An ISF canister handling machine lifts the GC from the cart into its shielded cavity. The machine then aligns itself with one of the storage tubes, removes the shield plug from the top of the tube, lowers the GC into the tube, and replaces the plug. Once they are inside the sealed tubes, the GCs are considered to be in interim storage. 


\section{4. $\cos T$}

Table 3 presents the summary of the cost estimates for the CRTS, the VWO, the ISF, and the Utilities Support. In addition, Table 3 includes a summation of the costs of all of these individual facilities, which represent the total costs of the VWO. Appendix F presents the VF detailed costs estimates, cash flow curves, and project schedule. The estimate in Appendix F was based on modifications to the baseline design in the Raytheon Direct Vitrification Option Feasibility Study Report. ${ }^{1}$

EDF-WTS-002 in Appendix A is the source of the costs of the CRTS, developed for the VWO and included in Table 3. The Interim Storage Study Report ${ }^{2}$ is the source of the costs of the IFS, developed for the VWO and included in Table 3. The Utilities and Infrastructure Report. ${ }^{10}$ is the source of the costs of the Utilities Support function, developed for the VWO and included in Table 3.

The Total Project Cost (TPC) in Table 3 is the sum of the Total Estimated Cost (TEC) for design and construction plus Other Project Cost (OPC). The OPC includes development, pre-design, and postconstruction activities. As indicated above an additional cursory cost of $\$ 33,000,000$ was estimated for a grout facility, and LLW disposal of the PEW facility evaporator-bottoms. This cost is an addition to the costs listed in Table 3.

Table 3. VWO Cost estimate summary.

\begin{tabular}{|c|c|c|c|c|c|}
\hline Cost Item & $\begin{array}{c}\text { CRTS } \\
(\mathrm{k} \$)\end{array}$ & $\begin{array}{l}\text { VWO } \\
(\mathrm{k} \$)\end{array}$ & $\begin{array}{l}\text { ISF } \\
(k \$)\end{array}$ & $\begin{array}{c}\text { Utilities } \\
(\mathrm{k} \$)\end{array}$ & $\begin{array}{c}\text { Totals } \\
(\mathrm{k} \$)\end{array}$ \\
\hline OPC (unescalated) & 21,267 & 137,644 & 16,228 & 1,341 & 176,480 \\
\hline OPC Escalation & 9,358 & 11,912 & 4,153 & 266 & 25,689 \\
\hline OPC Mgmt Reserve & 0 & 0 & 0 & 0 & 0 \\
\hline OPC Contingency & 10,475 & 46,444 & 5,118 & 393 & 62,430 \\
\hline Total OPC & 41,100 & 196,000 & 25,500 & 2,000 & 264,599 \\
\hline TEC (unescalated) & 127,031 & 327,157 & 382,783 & 9,856 & 846,827 \\
\hline TEC Escalation & 53,841 & 89,835 & 138,310 & 3,563 & 285,549 \\
\hline TEC Mgmt Reserve & 13,788 & 28,939 & 40,065 & 938 & 83,730 \\
\hline TEC Contingency & 51,611 & 154,069 & 65,043 & 2,943 & 273,666 \\
\hline Total TEC & 246,271 & 600,000 & 626,200 & 17,300 & $1,489,772$ \\
\hline TPC (unescalated) & 148,298 & 464,801 & 399,011 & 11,197 & $1,023,307$ \\
\hline TPC Escalation & 63,199 & 101,747 & 142,463 & 3,829 & 311,238 \\
\hline TPC Mgmt Reserve & 13,788 & 28,939 & 40,065 & 938 & 83,730 \\
\hline TPC Contingency & 62,086 & 200,513 & 70,161 & 3,336 & 336,096 \\
\hline Total TPC & 287,371 & 796,000 & 651,700 & 19,300 & $1,754,371$ \\
\hline Operations (unescalated) & 72,781 & 857,074 & 149,756 & 58 & $1,079,669$ \\
\hline Operations Escalation & 71,923 & 777,226 & 172,524 & 67 & $1,021,740$ \\
\hline Operations Contingency & 43,411 & 490,290 & 96,684 & 38 & 630,423 \\
\hline Total Operations & 188,115 & $2,124,590$ & 418,964 & 163 & $2,731,832$ \\
\hline Post Operations (unescalated) & 21,960 & 354,600 & 106,263 & 260 & 483,083 \\
\hline Post Operations Escalation & 37,071 & 600,677 & 666,956 & 565 & $1,305,269$ \\
\hline Post Operations Contingency & 8,855 & 286,583 & 231,966 & 247 & 527,651 \\
\hline Total Post Operations & 67,886 & $1,241,860$ & $1,005,184$ & 1,072 & $2,316,003$ \\
\hline Total Cost (unescalated) & 243,039 & $1,676,476$ & 655,030 & 11,515 & $2,586,060$ \\
\hline $\begin{array}{l}\text { Total Cost (w/escalation, mgt. } \\
\text { Reserve, \& contingency) }\end{array}$ & 543,371 & $4,162,451$ & $2,075,848$ & 20,535 & $6,802,205$ \\
\hline Discounted Cost (escalated) & 196,876 & $1,261,578$ & 426,040 & 9,885 & $1,894,379$ \\
\hline
\end{tabular}




\section{PROJECT SCHEDULE}

The design, construction, and operation project schedule, which is included in the cost estimates in Appendix F, is shown below in Table 4. The entire schedule spans from start of conceptual design and project management in June 2110, until the end of D\&D in December 2038. The four-year construction schedule spans from November 2007 until November 2011. Testing lasts $2.5 \mathrm{yr}$, from June 2010 until startup in January 2013. The operation period is from 2013 through 2032, and D\&D is from 2033 through 2038. 
Table 4. VWO Vitrification Facility Schedule.

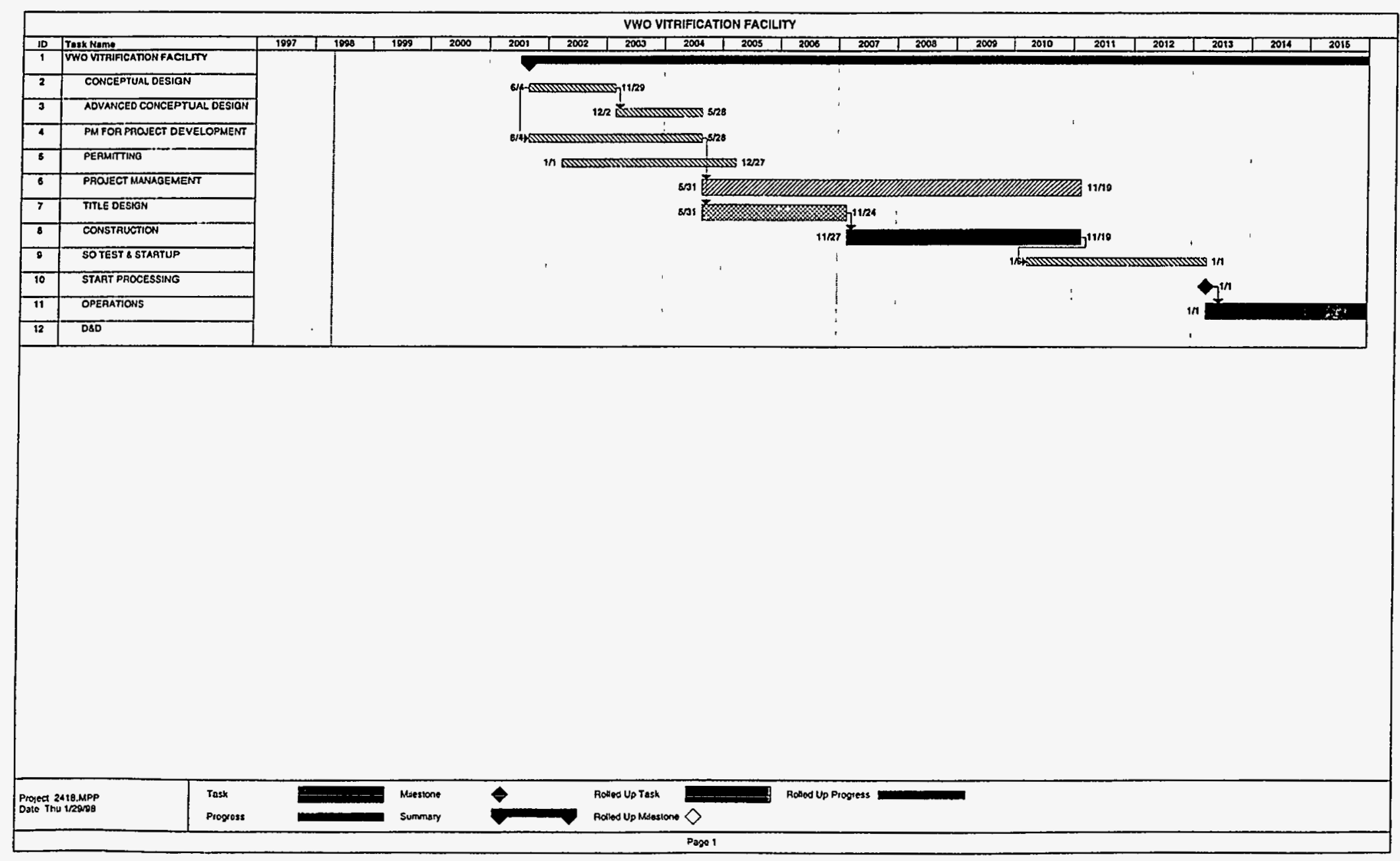




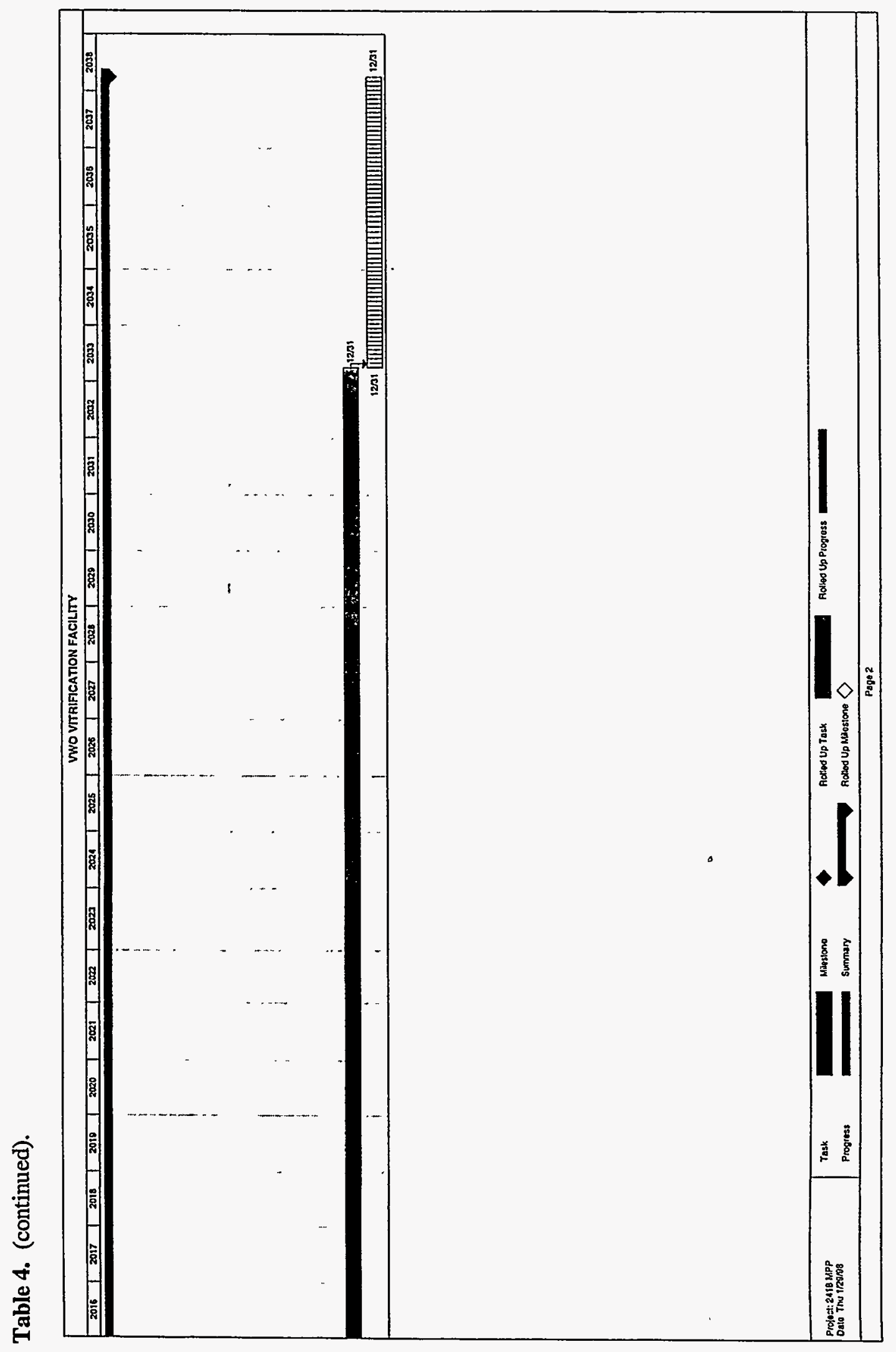




\section{RISK ASSESSMENT}

Schedule and cost risks identified for the VF in this report are categorized according to the source of the risk. The risks were derived by postulating that the key study assumptions from Section 2.2 were incorrect.

The work scope (WS) assumptions provide the framework for this report. Some of them are highly subject to change and would have a significant impact on the results of this report. However, the programmatic risks from any incorrect WS assumption are beyond the scope of this report.

The study (S) assumptions are those which can have a significant impact on the results of the report and which are within the scope of the report. They derive from design studies and technical decisions made during the design process. Risk assessments are performed on these assumptions.

The highest risk is rated at "4" (out of "9"). Environmental, Safety, and Health (ES\&H) risks were not identified for this project. Appendix $G$ includes data sheets for all identified risks with an explanation of the Risk Rating calculation method. On the forms in Appendix G, risks are identified as related to project management, technical problems, or ESH issues. This project was assessed as having only project and technical risks. These are discussed in Sections 6.1 and 6.2 below.

\subsection{Project Risk}

P.1 It may not be possible to fill all canisters with $0.72 \mathrm{~m}^{3}$ of product glass. Risk $=4$ (Probability $=2$, Impact $=2$ ).

P.2 Canisters may not meet EPA/NRC/DOT requirements for transportation and disposal at the repository. Risk $=3$ (Probability $=1$, Impact $=3$ ).

P.3 Physical security requirements may not be met with the typical controls used at ICPP (card readers, alarmed doors, etc.). Risk $=2$ (Probability $=1$, Impact $=2$ ).

P.4 The VF exhaust stack shielded probe system may not be an acceptable substitute for an isokenetic sampling system. Risk $=1$ (Probability $=1$, Impact $=1$ ).

P.5 The amount of calcine to be processed may differ significantly from current estimates. Risk $=1$ (Probability $=1$, Impact $=1$ ).

P.6 Precipitation of mercury sulfide (in scrubber blowdown) with sulfide salt may not meet the LDR requirement for amalgamation of mercury. This would require addition of process equipment to the proposed facility. Risk $=2$ (Probability $=1$, Impact $=2$ ).

\subsection{Technical Risk}

T.1 The six frit compositions is assumed to be a sufficient number for blending with calcine might not be able to meet the product performance requirements with all possible calcine mixtures. Risk = 1 (Probability $=1$, Impact $=1)$.

T.2 Production of acceptable glass may require grinding of calcine to reduce its particle size range before addition to the melter. Risk $=3$ (Probability $=1$, Impact $=3$ ). 


\subsection{Maturity of the VF Technology}

Guidance to determine the maturity of the VF technology is found in the Interim Guidance-Office of Science and Technology Technical Decision Process, DOE Standard Operating Procedure. ${ }^{13}$ The maturity is classified by stages 1 through 7, titled (1) Basic Research, (2) Applied Research, (3) Exploratory Development, (4) Advanced Development, (5) Engineering Development, (6) Demonstration, and (7) Implementation. Requirements for each stage dealing with minimum goals, objectives, measures of effectiveness, actions, and responsibilities to include requirements for entry into the next stage, are detailed in Reference 13.

The basic technology used in the VF is well developed, as evidenced by ongoing GC production at both the SRS DWPF and at the West Valley Demonstration Facility. These facilities are both successfully producing and storing acceptable road-ready vitrified product (GCs), which will meet the DOE-EM and DOE-RW repository requirements (the Waste Acceptance Product Specifications for Vitrified High-Level Waste Forms, ${ }^{4}$ and the Waste Acceptance System Requirements Document. ${ }^{5}$ The risk of failure because of maturity of technology is perceived as low.

Based on guidance, ${ }^{13}$ the VWO vitrification technology is considered to be at the Demonstration (6) or Implementation (7) stage. Calcine blending, glass frit transport, calcine and frit metering and mixing, are not as developed as the vitrification technology and are estimated to range from the Exploratory Development (3) to the Demonstration (6) stage. The offgas system is estimated to be at the Engineering Development (5) or the Demonstration (6) stage. The vitrification technology is also the recognized best demonstrated available technology to treat HLW and has regulatory acceptance.

Most other aspects of the VF, such as remote decontamination, remote and hands on maintenance, remote handling, remote welding, remote leak checking, remote swiping, remote canister handling, and HLW radiation protection, are at the Implementation (7) stage in many existing DOE facilities.

\subsection{ES\&H Risk}

The ES\&H risks have not been identified for this option. 


\section{FAILURE MODES}

While possible failure scenarios were identified during this report, their evaluation was outside the report scope. Failure modes for the VWO will ultimately be addressed in the safety analysis reports for the facility. The VF design includes provisions to minimize the probability of a failure and mitigate the possible effects. The following is a sample of possible failure modes associated the VF:

- $\quad$ CRTS components in VF fail

- Calcine fluidized bed air injection system fails

- VF internal calcine pneumatic transport system fails

- Melter offgas system fails

- Mercury recovery system fails

- Glass frit transport conveyor system fails

- Glass frit or calcine metering, mixing or transport systems fail

- Calcine or glass frit rotary valves fail

- $\quad$ Primary of secondary HVAC system fails

- Empty canister is dropped

- Empty canister dropped onto operating hardware

- Full GC is dropped

- Full GC found to be out of specification

- Any cell crane or grapple fails

- Cell cover dropped by 75-ton maintenance /disassembly cell bridge crane

- 75-ton maintenance/disassembly cell bridge crane fails

- $\quad \operatorname{PaR}^{\circledR}$ manipulator fails

- Any handling cart or shuttle fails

- Any master-slave manipulator fails

- Welding, decontamination, or swipe station fails

- Standby power fails 
- Floor hatches fail to open or close

- Canister filling lifting mechanism fails

- Offgas system components fails

- $\quad$ Melter fails

- Melter inadvertently releases a glass batch into the canister filling and capping cell

- Normal power fails.

The GC must be qualified for a 7-m drop, but that distance could be exceeded by transfers from the welding cell to the canister filling and capping, or decontamination cells. A drop accident involving a GC will not inflict unacceptable physical damage to any of these items that would result in a safety concern to workers, the general population, or the environment. Each item is, or will have been, qualified for drop accidents that will encompass the report's activities. The facility will be designed for a combined planned and unplanned maintenance downtime of $50 \%$ which will allow time to recover from unanticipated scenarios without jeopardizing personnel safety or the HLW treatment target date of 2035.

An electrical power failure will shut down operations, but the melter lid heaters, HVAC fans, and I\&C will continue to operate on standby power supplied from ICPP utility support facilities (see the Utilities and Infrastructure Report ${ }^{10}$ ). No source-term releases are anticipated under any failure mode scenario. The major impact from a failure would be to the production schedule.

In an assumed catastrophic accident, the maximum total inventory of releasable radioactive material present in the facility will be $30.6 \mathrm{~m}^{3}$ of calcine plus any holdup in the calcine transport pipes, HVAC exhaust ducts, sintered metal filters, offgas system scrubber water, HEPA plenums, and HEPA filters. Other radioactive releasable material, besides the $30.6 \mathrm{~m}^{3}$ of calcine, consists of $20 \mathrm{Ci}$ of ${ }^{137} \mathrm{Cs}$ in the offgas system HEPA filters and $20 \mathrm{Ci}$ of ${ }^{137} \mathrm{Cs}$ in the offgas system scrubber water. These latter quantities are insignificant compared to the $30.6 \mathrm{~m}^{3}$ of calcine which consists of $14.9 \mathrm{~m}^{3}$ in each of the two fluidized bed blending tanks, and $0.8 \mathrm{~m}^{3}$ in the calcine weigh tank and the ribbon blender in the melter cell.

The estimated inventory of releasable hazardous or mixed hazardous material present in the facility at any one time is $10 \mathrm{gal}(\sim 1,130 \mathrm{lb})$ of elemental mercury, about 10,30 -gal overpack drums of mercury amalgam each containing about $500 \mathrm{lb}$, and about 1,000 gal of 0.5-1 Molar nitric and sulfuric acids (offgas scrubber water). 


\section{PROJECT DATA SHEET}

Table 5 is the PDS for the VWO VF. Data are presented for the construction, operation, and decommissioning phases of the project. Estimates are included for the following parameters:

- Cost

- $\quad$ Schedule

- $\quad$ Air emissions

- $\quad$ Liquid effluents

- Solid wastes

- Utilities used

- Manpower requirements

- Regulatory requirements.

Because this project is at a very preliminary stage of design, much of the information presented in this PDS is based on representative literature values, existing laboratory data, and engineering judgment. The cost data in this table were obtained from the cost estimates in Appendix F. Appendix $\mathrm{H}$ contains the support information for the remainder of the data in the table.

Project data sheets for the CRTS, ISF, and Utilities Support can be found in EDF-WTS-002 (Appendix A), the Interim Storage Study Report ${ }^{2}$, and the Utilities and Infrastructure Report, ${ }^{10}$ respectively. 
Table 5. Project Data Sheet for non-separations VWO Vitrification Facility.

\section{GENERIC INFORMATION}

Description/function

EIS Alternatives (A, B, etc.)

Project type or waste stream

Action type

Structure type

Size $\left(\mathrm{m}^{2}\right)$

Other features (e.g. pits, ponds, power/water/sewer lines)

Location

Inside/outside of fence

Inside/outside of building

Candidate for privatization?

CONSTRUCTION INFORMATION

Cost (\$): Pre-Operations (Other Project Costs) w/esc and contingency

Conceptual Design

Management for Project Development

Permitting and Documentation

SO Test \& Start-Up

Contingency

Total Pre-Operations

Cost (\$): Construction w/esc and contingency

ED\&I

Management (PM/CM)

Construction

G\&A/PIF

Procurement Fees, Management Reserve and Contingency

Total Construction (TEC)

Schedule start/end: Pre-Operations

Schedule start/end: Construction (includes Title design)

Schedule start/end: SO Test \& Start-up

Number of workers each year of construction

(new/existing)

Nonradiation

Number of radiation workers (construction)

Average annual worker radiation dose (rem/yr)

Heavy equipment

Equipment used
Vitrify HLW calcine in preparation for road-ready storage awaiting shipment to a permanent repository

Non-separations-Direct Vitrification Option

Vitrified HLW calcine.

New

$16,340 \mathrm{~m}^{2}$

None

Inside ICPP fence

Inside Vitrification Facility

Yes

$\$ 90,863,200$

$\$ 16,744,200$

$\$ 3,746,160$

$\$ 38,202,400$

$\$ 46,444,040$

$\$ 196,000,000$

$\$ 62,659,200$

$\$ 64,943,760$

$\$ 270,383,472$

$\$ 16,301,925$

$\$ 185,711,643$

$\$ 600,000,000$

January 1999 through December 2003

January 2004 through December 2009

January 2010 through June 2013

$100 \mathrm{New} \cdot$ workers/yr

None

None

Excavator, grader, crane, material delivery trucks 
Table 5. (continued).

Trips (construction materials delivery)

Hours of operation

Acres disturbed and duration of disturbance

New

Previous

Revegetated

Air emissions

Dust

Major gases $\left(\mathrm{CO}_{2}, \mathrm{H}_{2} \mathrm{O}, \mathrm{O}_{2}, \mathrm{~N}_{2}\right)$ from diesel exhaust

Contaminants (Particulates, $\mathrm{CO}, \mathrm{NO}_{\mathrm{x}}, \mathrm{SO}_{2}$, hydrocarbons)

from diesel exhaust.

SO testing air emissions (trace $\mathrm{SO}_{\mathrm{x}}, \mathrm{NO}_{2}$ )

Total air emissions

Effluents

SO testing process wastewater (non-radioactive)

Sanitary wastewater

Lube Oil

Solid wastes

Type - construction trash

Radioactive wastes

Hazardous/toxic chemicals and wastes (type)

Storage/inventory

Pits/Ponds created $\left(\mathrm{m}^{2}\right)$

Water usage:

Dust control

SO testing process water

Domestic water (construction and SO testing)

Hazardous/toxic chemicals and wastes

Hazardous waste (SO Testing)

Hazardous waste (construction)
2,073

11,789 hours (total)

January 2001 through December 2037

None

2.7 acres

None

153 tons (total)

9,352 tons (total)

55 tons (total)

7,852 tons (total)

17,412 tons (total)

$1,142,425$ liters (total)

$14,903,438$ liters (total)

1,417 liters (total)

$4,742 \mathrm{~m}^{3}$ (total)

None

$13 \mathrm{~m}^{3}$

None

605,600 liters (total)

2,084,631 liters (total)

$14,903,438$ liters (total)

$4.2 \mathrm{~m}^{3}$ (total)

$217 \mathrm{~m}^{3}$ (total)

\section{Energy requirements}

Electrical (MWh/yr)

$156 \mathrm{MWh} / \mathrm{yr}$ 
Table 5. (continued).

Steam usage (SO Testing)

Fossil fuel (liters)

Permits needed for construction

\section{OPERATIONAL INFORMATION}

Cost (\$): Operations (unescalated)

Faculty/Administration

Operations/Process Facility

Procurement, materials, utilities, maintenance

Total operations

Schedule start/end

Number of workers each year of operation (new/existing)

Operations

Maintenance

Support

Total

Number of radiation workers

Average annual work radiation dose (rem/yr)

Heavy Equipment

Air Emissions

Radioactive off-gas

Effluents

Sanitary Wastewater

Scrubber Blowdown (radioactive waste)

\section{Solid Wastes}

Sanitary/Industrial Trash

Radioactive wastes (canisters, amalgam)

HEPA filters

Hazardous/toxic chemicals and wastes
$184,320,000 \mathrm{~kg}$

365,411 liters (total)

NEPA documentation (prior to start of Title II construction); New stationary sources/PTC/NOC/PSD for non-rad air emissions; HAPs and TAPs and RCRA (part AA, BB, and CC for air) for hazardous air emissions; air operating permit; NESHAPs, NPDES, NESHAPs subpart $\mathrm{H}$ for rad air emissions; approval of Engineering. Plans; Cross Connection Control Plans; report and specifications for drinking water supply; RCRA Part A and Part B permits.

$\$ 26,430,000$

$\$ 335,606,000$

$\$ 495,038,000$

$\$ 857,074,000$

July 2013 through December 2033

44

44

36

124

100 (included in above total)

$0.19 \mathrm{rem} / \mathrm{yr}$ per worker

None

2,617 tons/yr

4,282,728 liters/yr

380,808 liters/yr $15,150 \mathrm{Ci} / \mathrm{yr}$

$671 \mathrm{~m}^{3} / \mathrm{yr}$

$509 \mathrm{~m}^{3} / \mathrm{yr} 1,196,869 \mathrm{Ci} / \mathrm{yr}$

$48 \mathrm{~m}^{3} / \mathrm{yr} 35 \mathrm{Ci} / \mathrm{yr}$ 
Table 5. (continued).

Pits/Ponds used $\left(\mathrm{m}^{2}\right)$

None

Spent Carbon (mixed waste)

$3 \mathrm{~m}^{3} / \mathrm{yr}<1 \mathrm{Ci} / \mathrm{yr}$

Water usage:

Process water

694,877 liters/yr

Domestic water

$4,282,728$ liters/yr

Energy Requirements:

Electrical (MWh/yr)

3,198 MWh/yr

Steam

Fossil fuel (liters/yr)

Permits needed (for facility operations)

$20,945,455 \mathrm{~kg} / \mathrm{yr}$

None

HAPs and TAPs and RCRA (part AA, BB, and CC for air) for hazardous air emissions; air operating permit; NESHAPs, NPDES, NESHAPs subpart $\mathrm{H}$ for rad air emissions; approval of Engineering Plans; Cross Connection Control Plans; report and specifications for drinking water supply; RCRA Part A and Part B permits.

DECONTAMINATION \& DECOMMISSIONING (D\&D) INFORMATION

Cost (\$): D\&D (unescalated)

Decommission

$\$ 52,480,000$

Decontamination

$\$ 116,200,000$

Demolition

$\$ 185,920,000$

Total D\&D

Schedule start/end: D\&D

Number of workers each year of D\&D (new/existing)

$\$ 354,600,000$

January 2034 through December 2038

Number of radiation workers (D\&D)

514 New workers/yr

345 New workers/yr

Average annual worker radiation dose (rem/yr)

$0.19 \mathrm{rem} / \mathrm{yr}$ per worker

Heavy equipment:

Equipment used

Trips, Roll-off trucks

Hours of operation (all heavy equipment)

Acres disturbed and duration of disturbance

New

Previous

Revegetated

Mobile Cranes, Roll-off trucks, Dozers, Loaders

15 per day

139,950 hours

January 2033 through December 2037

None

2.7 acres

None

Air emissions

non-radioactive Fuel combustion gases $\left(\mathrm{CO}_{2}, \mathrm{H}_{2} \mathrm{O}, \mathrm{O}_{2}, \mathrm{~N}_{2}\right)$

non-radioactive Fuel combustion contaminants ( $\mathrm{CO}$, particulates, $\mathrm{NO}_{x}, \mathrm{SO}_{2}$, hydrocarbons)

81,343 tons (total)

475 tons (total) 
Table 5. (continued).

radioactive HEPA filtered off-gas

Effluents

radioactive spent decontamination solution

non-radioactive Sanitary wastewater

non-radioactive Lube oil

Solid wastes:

radioactive

Non-radioactive (industrial)

Hazardous

Hazardous/toxic chemicals and wastes (type)

Storage/inventory

Pits/Ponds created $\left(\mathrm{m}^{2}\right)$

radioactive mixed waste

Water usage:

Process water

Domestic water

Source of water

Energy requirements:

Electrical (MWh/yr)

Fossil fuel (liters)

Permits needed (e.g. for facility closures, physical characteristics and quantities of radioactive and hazardous materials remaining after closure)
130,864 tons (total)

$8,516,250$ liters (total) $8,516 \mathrm{Ci}$

$54,729,197$ liters (total)

26,486 liters (total)

$29,421 \mathrm{~m}^{3} 294 \mathrm{Ci}$

$22,122 \mathrm{~m}^{3}$

$10 \mathrm{~m}^{3}$

$205 \mathrm{~m}^{3}$ (total)

None

$234 \mathrm{~m}^{3}$ (total) $2 \mathrm{Ci}$

$11,424,375$ liters (total)

$54,729,197$ liters (total)

ICPP site wells

$156 \mathrm{MWh} / \mathrm{yr}$

$3,178,265$ liters (total)

Work will be done under closure provisions of existing permits. 


\section{PROJECT-SPECIFIC OPTIONS}

Project-specific options were not assigned, identified, or evaluated. 


\section{POTENTIAL IMPACT OF NRC LICENSING}

The VF presented in this report is not NRC licensed and therefore, neither the VF design nor the cost estimates include NRC licensing. This section contains a brief discussion, gleaned from data contained in The Regulatory Requirements and Criteria for ICPP Proposed Waste Processing Facilities, EDF-WTS-003 in Appendix A, and from the Waste Treatment Facilities Feasibility Study Report, ${ }^{7}$ of the potential impacts of NRC licensing on the WTF.

Existing NRC regulations are compiled in $10 \mathrm{CFRs,} \mathrm{"Energy."} \mathrm{These} \mathrm{regulations} \mathrm{follow} \mathrm{a} \mathrm{similar}$ philosophy espoused by the DOE, the EPA, etc. The Commission has also issued regulatory guides (such as NUREGs) that provide acceptable methods to comply with the NRC regulations; they contain criteria for facility design, operations, and health and safety.

The only WTF-type activity that the NRC has routinely licensed is HLW waste storage. Currently, NRC regulations do not exist to license HLW separations or treatment facilities. The most applicable licensing process regulations are contained in: (1) $10 \mathrm{CFR} 2,10 \mathrm{CFR} 30,10 \mathrm{CFR} 51$, and $10 \mathrm{CFR} 61$ for LLW facilities, and (2) 10 CFR 2, 10 CFR 50, 10 CFR 52, 10 CFR 70, and 10 CFR 72 for HLW or HAW facilities. Licensing a nuclear facility requires preparing and submitting an application and supporting documents to the NRC, such as Safety Analysis Reports, an Environmental Reports, quality assurance documents, training plans, monitoring plans, and safeguards and security plans. The NRC licensing process is divided into four stages: pre-application stage, application review stage, construction and operating license stage, and decontamination and site closure stage. The licensing duration from submitting the application to receiving of the license is expected to take three to more five years, or longer. According to Reference 7 the benefits of NRC licensing are enhanced operating safety, strengthened relationships with stakeholders, and license-holder participation in future regulation development.

According to data developed in the Fluor Daniel Inc., Waste Treatment Facilities Feasibility Study Report, ${ }^{7}$ estimated capital cost percentage increases for NRC licensing of WTF facilities above current DOE requirements for those facilities are as follows:

Waste Separations

Low-Activity Waste treatment

High-Activity Waste Interim Storage

Low-Activity Waste Collection

Calcine Dissolution

CalcineTransfer

High-Activity Waste Treatment

Infrastructure (Utilities)
$21 \%$

$13 \%$

$26 \%$

$8 \%$

$15 \%$

$14 \%$

$26 \%$

$9 \%$

These estimates are hypothetical and highly speculative. The capitol costs here are equivalent to the escalated TEC in the cost estimate presented in Section 4 of this report. 
Reference 7 also estimated the operating schedule impact and dollar-value increase in annual operating costs for three groups of systems as follows:

$\begin{array}{lll}\text { Group I } & \text { Negligible Schedule Impact } & \$ 1.3 \mathrm{M} \\ \text { Group II } & \text { Minimal Schedule Impact } & \$ 2.7 \mathrm{M} \\ \text { Group III } & \text { Significant Schedule Impact } & \$ 4.7 \mathrm{M}\end{array}$

Group I includes the LAW collection, infrastructure, and tank heel; Group II includes the waste separations, LAW treatment, condensate collection, and environmental analysis Laboratory; and Group III includes the HAW interim storage, calcine dissolution, calcine transfer, and HAW treatment. Additional costs resulting from operating schedule impacts experienced due to NRC involvement are based on a "best guess" reflecting perceived likelihood of NRC's difficulty in assimilating the Group into their new regulatory framework. "Negligible" could range from no costs, to tens of thousands of dollars. "Minimal" could range from a few thousand dollars to several hundred thousand dollars. "Significant" could range from a hundred thousand to several million dollars.

The VWO is best characterized by Group III except it does not have a calcine dissolution system, so the portion of the increased cost associated with that facility must be subtracted from $\$ 4,700,000$ Group III cost to determine the VWO increase. Assuming the NRC licensing annual cost increase for the calcine dissolution system is one-third this total, the annual cost increase for the VWO (the remainder of the Group III system) is approximately $\$ 3,100,000$.

If the VWO is licensed by the NRC, the increase in capital cost (based on a $14 \%$ escalated total TEC cost increase for the CRTS, a $26 \%$ escalated total TEC cost increase for the ISF and the VF, and a $9 \%$ escalated total TEC cost increase for infrastructure) and the 20 -yr operating cost will be $\$ 355,000,000$ and $\$ 62,000,000$ respectively, totaling $\$ 417,000,000$.

Some of the potential major impacts associated with NRC licensing of waste treatment facilities, other than cost, are:

- Increased oversight, including more public involvement and input in all decision processes

- More restrictive physical limits on some parameters, including exposure limits, seismic, and tornado

- More strict radiation monitoring

- Restrictions on sharing utilities between facilities

- More stringent evaluations of the impact from off-site hazards.

- Full testing required for emergency utilities

- Physical changes to the plant and equipment

- More elapsed schedule time required 
- The methods to comply with some other codes and standards may be complicated and require more time

- Although the NRC may license the waste treatment facilities, it may not automatically inherit or adopt the same agreements and obligations with the State of Idaho and EPA Region 10 that are in place for DOE and INEEL. 


\section{CONCLUSIONS AND RECOMMENDATIONS}

\subsection{Vitrification Facility}

The non-separations alternative VWO consists of the CRTS, the VF, ISF, and Utilities Support. Designs were based on existing feasibility and conceptual designs for other facilities that have similar requirements. This report concentrates on the VF portion of the VWO.

The VF in this report will produce approximately 14,000 SRS DWPF GCs for the non-separations alternative, in its 20-yr operating life. This is equivalent to approximately 35,000 metric tons of $\mathrm{HLW}$. The glass filled DWPF canister will be an acceptable waste form for eventual offsite transport and disposal at the repository. The planned date for all HLW GCs to be in storage (in this case at the VWO ISF) is the end of 2032, which is ahead of the HLW treatment date of 2035 targeted by the DOE and the State of Idaho. ${ }^{3}$ The VWO VF will be designed to treat dry calcine from the ICPP CSSF only. This is because of the assumption that all SBW will have been calcined and placed in the CSSF before the start of VWO VF operation.

The maturity of the canisterized vitrified production is well established as evidenced by ongoing GC production at both the SRS DWPF and at the West Valley Demonstration Facility. These facilities are both successfully producing and acceptable road-ready vitrified product that will meet the DOE-EM and DOE-RW requirements or storing the repository requirements (the Waste Acceptance Product Specifications for Vitrified High-Level Waste Forms, ${ }^{4}$ and the Waste Acceptance System Requirements Document ${ }^{5}$ ). The total costs for the VWO are summarized as follows and include costs for the CRTF, the ISF, and the Utility Support:

- Total Cost (unescallated) is $\$ 2,586,060,000$

- Total Cost (with escalation, management reserve, \& contingency) is $\$ 6,802,205,000$

- Discounted Cost (escalated) is $\$ 1,894,379,000$.

As indicated above an additional cursory cost of $\$ 33,000,000$ was estimated for a grout facility, and LLW disposal of the PEW facility evaporator-bottoms. This cost is an addition to the costs listed in Table 3

The GCs produced by the VF will be NRC licensed for ISF storage under $10 \mathrm{CFR} 72$, and for transportation in a Type B shipping container under 10 CFR 71. The GC transportation package will also meet DOT HLW shipping regulations in $49 \mathrm{CFR} 173$.

\subsection{Future Studies}

During the course of this study, several topics for further investigation arose. Additional work is needed in these areas to support any future design efforts on non-separations vitrification of calcine. This section lists and discusses some of the more important of them.

Refine the ratio of calcine to glass frit mix to reduce number of GCs required-The batch calcine and glass frit formulations used in this report were based on preliminary crucible studies with alumina, zirconia, and SBW waste calcine. The waste loading values have not been optimized. Because of the expected high cost to dispose of GCs, a slight increase in waste loading can have a very significant impact 
on overall cost. It may also be possible to reduce the number of frit formulas (presently six) required to process calcine: effectively reducing the amount of capital equipment required.

Evaluate alternative kinds and sizes of melters to optimize the vitrification and canister filling process-The selection of a melter design is a subject that deserves a separate technical evaluation. This report was based on the designs of vitrification melters now in use in the DOE complex. No attempt was made to evaluate the state of development of alternative processes such as induction melting. The proposed new study should address all costs of any melter design, including operations dismantlement and disposal.

Simulate the production process, using current manufacturing engineering software, to better predict throughput rates and bottlenecks-The proposed VF manufacturing process is very complex. To identify potential operating problems, a manufacturing simulation model should be developed. Software packages such as ARENA ${ }^{\circledR}$ and SIMAN/Cinema ${ }^{\circledR}$ can evaluate operating scenerios and generate animated sequences describing proposed procedures. Problems can then be identified and corrected early in the design process. The model should determine if an average of $17,000 \mathrm{lb}$ of glass frit per day can be received by rail and conveyed to the silos and receiving tanks.

Study the impact of using the SRS DWPF process of sealing, leak checking, and welding the $G C s-T h i s$ Report retained the sealing, leak checking, and welding processes of the baseline VF design (the Raytheon Direct Vitrification Option Feasibility Study Report ${ }^{1}$ ). The SRS DWPF process uses a temporary plug, a 125-ton press, and a 230,000-amp resistance welder. It is not clear if the baseline design lid and lid-weld method (gas tungsten arc welding) will meet settlement agreement requirement to allow cask to be moved out of Idaho. If not, the DWPF method could be used in the VWO VF, but the equipment and facility changes would be costly.

Study the primary and secondary confinement HVAC design to try to reduce its complexity-The baseline facility HVAC design is complex. The basic design was preserved, although some individual flows were modified for the design in this report, but it should be able to be simplified without compromising safety or performance.

Study the GC closure-weld QA requirements-This study would determine GC closure-weld QA requirements to meet $10 \mathrm{CFR} 72$ for storage, and $10 \mathrm{CFR} 71$ and 49 CFR 173 , for shipping. If $100 \%$ volumetric weld inspection was required, a new remote ultrasonic inspection station may need to be added. The associated cost increase is expected to be a very small percentage of the total VF cost.

Determine if the nominal 16-ft ceiling height in the VF canister handling cells is adequate for the 10 -ft long SRS DWPF can-The head height of the canister handling cells was preserved (except for the transfer tunnel to the ISF) from those of the baseline design (the Raytheon Direct Vitrification Option Feasibility Study Report ${ }^{1}$ ). Since the baseline design used a 5-ft canister, handling the $10-\mathrm{ft}$ canister will be more difficult. The canister holders must be shorter, and the airlock, weld module, decontamination module, and cooling station, will have to be designed for side loading instead of top loading.

Determine if grinder(s) are needed to reduce and equalize the size of the calcine particles for proper blending and melting-Adding calcine grinders between the VF CRTS cyclones and the fluidized bed blenders will reduce the size of the calcine and promote more consistent particle size for more reliable blending, pneumatic transport in the VF, mixing in the ribbon blender, and more consistent melting (Some experts claim that unless the calcine is ground, it will not melt properly in the vitrification process). 
Study the effect of re-siting the VF to the west or southwest of its present location (Drawing $V W O-C-1)$ to accommodate the furthest position that a single stage CRTS can deliver the calcine-Without an intermediate transfer station, the CRTS can only reliably deliver calcine to the position of the Fluor Daniel Inc., ${ }^{7}$ waste separations facility.

Study the carbon dioxide pellet blast decontamination station proposed - The baseline design (the Raytheon Direct Vitrification Option Feasibility Study Report ${ }^{1}$ ) used a water and glass frit slurry blast to decontaminate the GCs. This will lead to major complications in a VWO VF because it processes dry waste only. This study will determine if the $\mathrm{CO}_{2}$ blast can successfully be used.

Determine a method to cool the GCs in the filling and capping cell that does not rely on the HVAC air-Special cooling for the GC cooling station in the canister filling and capping cell may be by fan coil cooling units that recirculate the room air for cooling purposes only.

Determine if a standard 15-ft long "Hanford" GC should be substituted for the 10-ft SRS DWPF $G C$ assumed in this report-Using the 15 - $\mathrm{ft}$ canister would increase the VF construction costs but would reduce the operation ( $\mathrm{GC}$ handling) costs, and greatly reduce offsite transportation and disposal costs. However, a large net cost saving, primarily because of reduced transportation and disposal costs, could be realized by using the $15-\mathrm{ft} \mathrm{GC}$. 


\section{RELATED DOCUMENTS}

The documents listed below are not cited in this report but are related to this work and may be mentioned in the appendices.

- $\quad$ Report of Advanced Conceptual Design Activities for the ICPP Spent Nuclear Fuel Dry Storage Project, LMITCO Report INEL-97/00177, February 1997.

- Idaho Chemical Processing Plant Feasibility Design Study for the Waste Immobilization Facility, Raytheon Engineers and Constructors, Inc. Western Operations, MS511.163, 9/27/94. 


\section{REFERENCES}

1. Raytheon Engineers and Constructors, Inc. Western Operations, Idaho Chemical Processing Plant Waste Immobilization Facility Direct Vitrification Option Feasibility Study Report, MS528.163, October 25, 1994.

2. J.K. Rawlins, Interim Storage Study Report, INEEL/EXT-97-01393, February 1998.

3. Consent Order and Settlement Agreement Between DOE and the State of Idaho Regarding Spent Fuel and Nuclear Waste Issues, October 17, 1995.

4. EM-WAPS Rev. 01, "Waste Acceptance Product Specifications for Vitrified High-Level Waste Forms,” May 1995.

5. DOE/RW-0351P Revision 02, "Waste Acceptance System Requirements Document," December 1996.

6. Fluor Daniel, Inc, Idaho Chemical Processing Plant Waste Treatment Facilities Feasibility Study Report, Government Services Operating Company, Delivery Order 94-36, 60\% Design Review Package, August 1997.

7. Fluor Daniel, Inc., Idaho Chemical Processing Plant Waste Treatment Facilities Feasibility Study Report, Government Services Operating Company, FDI Contract No. 04435336, December 12, 1997.

8. R.E. Dafoe, D.A. Lopez et al, DPC Loading Feasibility Study Report, INEEL/EXT-97-01251, November 1997.

9. $\quad$ N.E. Russel, T.G. McDonald et al, Waste Disposal Options Feasibility Study, INEEL/EXT-9701145 , October 1997.

10. R.S. Garcia, Utilities and Infrastructure Report, INEEL/EXT-97-01398, February 1998.

11. Standard Criteria of Candidate Repositories and Environmental Regulations for the Treatment and Disposal of ICPP Radioactive Mixed Waste, INEEL/EXT-97-01147, December 1997.

12. Stockpile Report to the Congress - Fiscal Year 1996.

13. Interim Guidance-Office of Science and Technology Technical Decision Process, DOE Standard Operating Procedure, May 8, 1997. 
Appendix A

Engineering Design Files 


\section{Appendix A}

\section{Engineering Design Files}

The engineering design files (EDFs) prepared for this study and the other non-separations alternatives referred to in this study are listed below and included in this Appendix.

\begin{tabular}{ll}
\hline EDF Serial No. & \\
\hline EDF-WTS-002 & Calcine Retrieval and Transport \\
EDF-WTS-003 & $\begin{array}{l}\text { Regulatory Requirements for the Design, Construction, and Operations of the ICPP Proposed } \\
\text { Waste Processing Facilities }\end{array}$ \\
EDF-WTS-004 & Regulatory and Design Requirements for Waste Treatment Facilities \\
EDF-VWO-001 & Estimate of Product Glass Volume and Number of Vitrified Glass Canisters \\
EDF-VWO-002 & Direct Vitrification Process Description \\
EDF-VWO-003 & Conference Call with Mr. D. Bickford of SRS re: SRS-DWPF Melter Design \\
EDF-VWO-004 & Estimate of Total Staffing Requirement for the VWO Vitrification Facility \\
EDF-VWO-005 & Electrical Study \\
EDF-VWO-006 & Fluidized Bed Blending Tank Cell Shielding Calculation \\
EDF-VWO-007 & Bulk Material Transportation: Glass Frit \\
\hline
\end{tabular}


Project/Task Waste Treatment Facility Study

Subtask Retrieve calcine from CSSFs and deliver it to the Waste Treatment Facility

\section{Title: Calcine Retrieval and Transportation}

Summary:

A calcine retrieval and transportation system is presented to retrieve calcine from the CSSFs and transport it to the Waste Treatment Facility. The calcine retrieval and transportation system is designed to supply calcine to the treatment options currently understudy \{Cementitious Waste Option (CWO), Direct Cementitious Waste Option (DCWO), Hot Isostatic Press (HIP) Waste Option (HWO), Vitrification Waste Option (VWO), and TRU Separations options). The system is divided into three subsystems: CSSF access method, calcine retrieval system, and calcine transportation system. During CSSF access, the buildings, equipment, and piping are removed from the superstructure of each CSSF. Retrieval risers are installed and accessed. The CSSFs are prepared for calcine retrieval. The calcine retrieval system presents a viable method to retrieve calcine from the CSSFs. The system relies on an air jet and a suction nozzle. The calcine transportation system is a pneumatic system similar to one currently used at the ICPP for transportation of calcine. A process data sheet and cost estimate were developed for the calcine retrieval and transportation system.

Three cost estimates are presented to meet the needs of each waste treatment option. Each waste treatment option requires the same access activities for the seven CSSFs. The retrieval method is the same for each waste treatment option. The locations of the waste treatment facilities developed by each option necessitates variations in the transport system. The length of the transport system is the basic difference between the transport systems. The cost estimate includes costs associated with removing corrosion coupons prior to retrieving the calcine and installing D\&D risers after retrieval activities are complete.

The first cost estimate was developed to meet the 5-year operating schedule of the Cementitious Waste Option (CWO). This system delivers calcine from the CSSFs to an NWCF addition. A second estimate was developed to deliver calcine to the TRU Separations options' calcine dissolution facility. A third cost estimate for the calcine retrieval and transportation system is presented for the DCWO, HWO, and VWO options which require an intermediate transport station (ITS) to deliver the calcine to the Waste Treatment Facility.

The CWO option has a five year operating period that begins 1/1/2013. The total unescalated cost for the calcine retrieval and transportation system is $\$ 176,566,000$. The total cost including escalation, management reserve, and contingency is $\$ 348,880,000$. The discounted annual cost is $\$ 166,409,000$.

The TRU-Separations Options have twenty year operating periods that begin $1 / 1 / 2013$. The total unescalated cost for the calcine retrieval and transportation system is $\$ 237,389,000$. The total 
Project File Number $02 \mathrm{BD} 7$

cost including escalation, management reserve, and contingency is $\$ 531,023,000$. The discounted annual cost is $\$ 192,309,000$.

The DCWO, HWO, and VWO options have twenty year operating periods that begin 1/1/2013. The total unescalated cost for the calcine retrieval and transportation system is $\$ 243,039,000$. The total cost including escalation, management reserve, and contingency is $\$ 543,371,000$. The discounted annual cost is $\$ 196,878,000$.

The scope of this study was limited to the Fluor-Daniels feasibility design. The purpose was to compare this system directly to the Fluor-Daniels system. However, two issues that warranted further review and inclusion in the cost estimate were identified. Separate cost estimates were developed for the removal of corrosion coupons from the bins and installation of D\&D risers. Distribution (complete package): A complete copy of this EDF will be included in the following reports:

R. E. Dafoe, Direct Cementitious Waste Option Study Report, INEEL/EXT-97-01399, February 1998.

W. H. Landman, TRU Separations Options Study Report, INEEL/EXT-97-01428, February 1998.

A. E. Lee, Cementitious Waste Option Preliminary Study Report, INEEL/EXT-9701400 , February 1998.

D. A. Lopez, Vitrified Waste Option Study Report, INEEL/EXT-97-01389, February 1998.

N. E. Russell, Hot Isostatic Press (HIP) Waste Option Study Report, INEEL/EXT-9701392 , February 1998.

Distribution (summary package only):

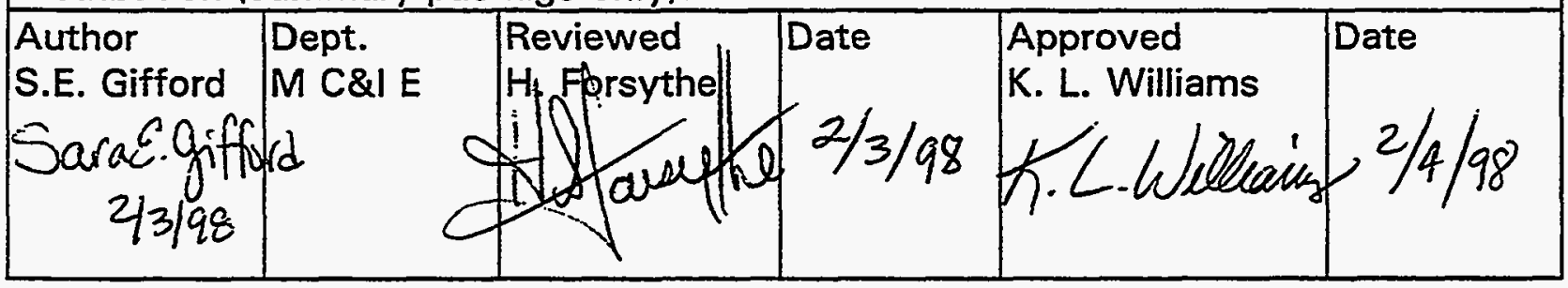

See Management Control Procedure (MCP) 6 for instructions on use of this form. 


\section{Outline}

\subsection{Introduction}

1.1 Background

1.2 Purpose and Scope

2.0 Design Basis

2.1 Design Criteria

2.2 Key Assumptions

2.3 Requirements

3.0 Process Design

3.1 CSSF Access

3.1.1 Process Basis

3.1.2 Process Description

3.1.3 Process Equipment Description

3.1.4 Process Issues

3.2 Calcine Retrieval

3.2.1 Process Basis

3.2.2 Process Description

3.2.3 Process Equipment Description

3.2.4 Process Issues

3.3 Calcine Transport

3.3.1 Process Basis

3.3.2 Process Description

3.3.3 Process Equipment Description

3.3.4 Process Issues

\subsection{Implementation}

4.0 Input to Project Data Sheet

5.0 Program Schedule

6.0 Costs

7.0 Recommendations for Further Study

8.0 Uncertainties

8.1 Maturity of Technology

8.2 Risk Assessment

8.2.1 Project Risk

8.2.2 Technical Risk

8.2.3 ES\&H Risk

8.3 Failure Modes

8.4 Cost Estimate Uncertainties

9.0 Potential Impacts of NRC Licensing

10.0 Summary and Conclusions

Appendices
A. Drawings
B. References
C. Equipment List 
431.02\#

$01 / 29 / 98$

Rev. $\# 00$
ENGINEERING DESIGN FILE

D. Background Information for Project Data Sheet

E. Risk Assessment Data Sheets

F. Cost Estimate
Function File Number - SPR-WTS-01 EDF Serial Number - EDF-WTS-002

Page 4 of 62 


\section{Acronyms}

$\begin{array}{ll}\text { CSSF } & \text { Calcined Solids Storage Facility } \\ \text { CWO } & \text { Cementitious Waste Option } \\ \text { DCWO } & \text { Direct Cementitious Waste Option } \\ \text { HAW } & \text { High Activity Waste } \\ \text { HLW } & \text { High Level Waste } \\ \text { HWO } & \text { Hot Isostatic Pressing (HIP) Waste Option } \\ \text { ICPP } & \text { Idaho Chemical Processing Plant } \\ \text { INEEL } & \text { Idaho National Engineering and Environmental Laboratory } \\ \text { ITS } & \text { Intermediate Transport Station } \\ \text { LAW } & \text { Low Activity Waste } \\ \text { NRC } & \text { Nuclear Regulatory Commission } \\ \text { NWCF } & \text { New Waste Calcining Facility } \\ \text { SBW } & \text { Sodium Bearing Waste } \\ \text { VDA } & \text { Vertical Deployment Apparatus } \\ \text { VIC } & \text { Ventilation Instrumentation and Control Building } \\ \text { VWO } & \text { Vitrified Waste Option } \\ \text { WCF } & \text { Waste Calcining Facility } \\ \text { WTF } & \text { Waste Treatment Facility (generic facility name for the facility developed in each } \\ & \text { waste treatment option) } \\ \text { WTS } & \text { Waste Treatment Study }\end{array}$




\subsection{Introduction}

At the ICPP, a fluidized bed calcination process changes the chemical composition of high-level radioactive mixed liquid waste generated from the reprocessing of spent nuclear fuel and sodium bearing waste (SBW) generated from decontamination activities. The calcination process converts the liquid waste to a solid waste and reduces the volume of the waste by a factor of 7 . After the calcination process, the resulting solid waste, called calcine, is pneumatically transported from the calciner to one of seven storage facilities, named calcined solids storage facilities (CSSF).

The settlement agreement between the Department of Energy and the State of Idaho mandates that high level waste be ready for removal from Idaho by a target date of 2035 for disposal. The calcine in the CSSFs must be retrieved from the CSSFs and treated. This EDF details a method to access and prepare the CSSFs for calcine retrieval, a calcine retrieval system, and a transport system to deliver the calcine to the Waste Treatment Facility. The information presented is applicable to the non-separations waste treatment options (DCWO, HWO, and VWO) and the TRU Separations waste treatment options.

\subsection{Background Information}

The calcine is stored in cylindrical steel bins within a CSSF. The number of separate, self contained bins in a CSSF varies from 3 to 7 . The bins are either cylindrical or annular. The outside diameter of the bins is approximately $12 \mathrm{ft}$. The length of the bins range from $24 \mathrm{ft}$ to 61 $\mathrm{ft}$. A passive convection cooling system is used to cool the bins inside a large concrete vault. Above the bin vault are structures that house the necessary equipment to receive the calcine. These structures form the superstructure of each CSSF. Figure 1 shows a sketch of each CSSF.

Calcine production began in November $1963^{1}$. The first six CSSFs store several forms of calcine. Currently, CSSF 6 is being filled while CSSF 7 remains empty. As of 1996, the CSSFs housed approximately $134,500 \mathrm{ft}^{3}$ of calcine. There are three main calcine types: alumina calcine, zirconia calcine, and calcine blends. The amount of calcine stored in each CSSF is shown in Table 1. The information for this Table was taken from reference 1. 

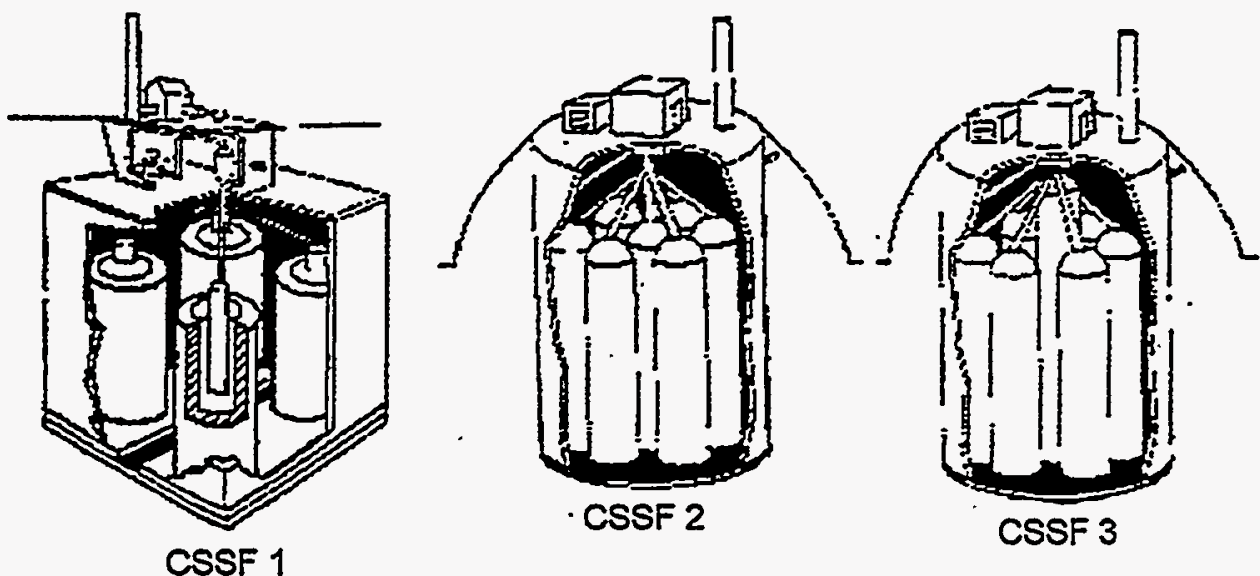

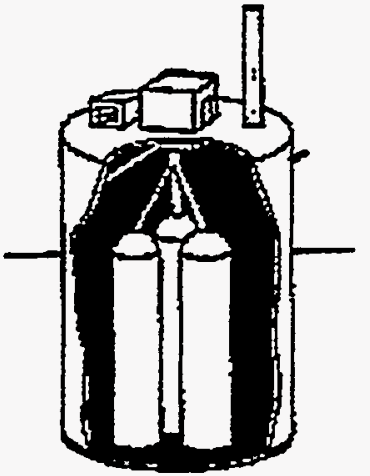

CSSF 4

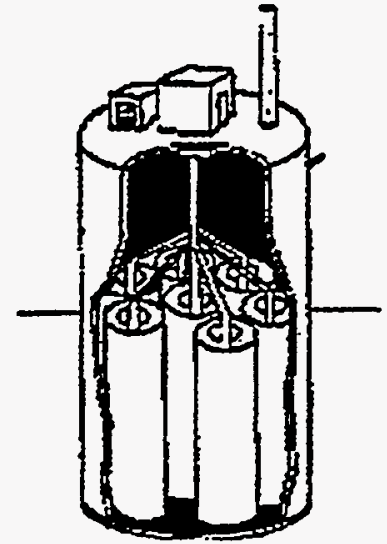

CSSF 5

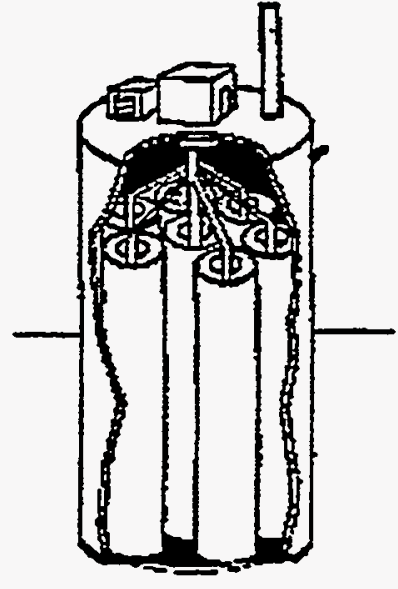

CSSF 6

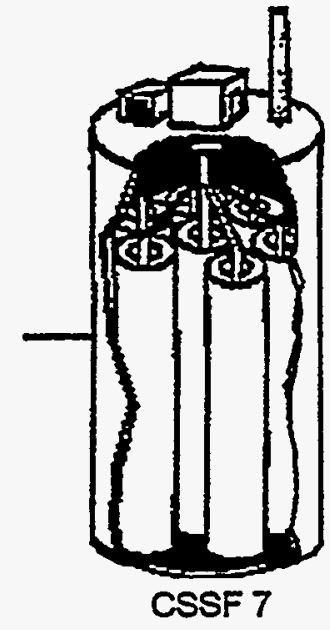

Figure 1. Calcined Solids Storage Facilities (CSSFs).

Table 1. Volume of Calcine Type in Each CSSF As of 1997.

\begin{tabular}{|c|c|c|c|c|c|c|}
\hline CSSF & $\begin{array}{c}\text { Alumina } \\
\text { Calcine } \\
\left(\mathrm{ft}^{3}\right)\end{array}$ & $\begin{array}{c}\text { Zirconia } \\
\text { Calcine } \\
\left(\mathrm{ft}^{3}\right)\end{array}$ & $\begin{array}{l}\text { Other } \\
\left(\mathrm{ft}^{3}\right)\end{array}$ & $\begin{array}{c}\text { Calcine } \\
\text { Blends } \\
\left(\mathrm{ft}^{3}\right)\end{array}$ & $\begin{array}{c}\text { Cold/ } \\
\text { Dolomite } \\
\left(\mathrm{ft}^{3}\right)\end{array}$ & $\begin{array}{l}\text { Total } \\
\left(\mathrm{ft}^{3}\right)\end{array}$ \\
\hline & & & & Description & & \\
\hline 1 & 7292 & & & & 373 & 7665 \\
\hline$\overline{2}$ & 10,754 & 18,582 & & & 900 & 30,236 \\
\hline 3 & 2,250 & 24,844 & 50 & $\begin{array}{r}5,580 \\
Z \mathrm{Zr}-\mathrm{SBW}\end{array}$ & 5,810 & 38,534 \\
\hline 4 & & 5,210 & & $\begin{array}{c}11,130 \\
1 \% \mathrm{Al}-\mathrm{Zr} \& \\
99 \% \mathrm{Zr}-\mathrm{SBW}\end{array}$ & 910 & 17,250 \\
\hline 5 & & & 50 & $\begin{array}{c}31,303 \\
\text { Alil-Zr-SBW }\end{array}$ & 3,670 & 35,023 \\
\hline 6 & & & & $\begin{array}{c}5,010 \\
\mathrm{Al}-\mathrm{Zr}-\mathrm{SBW}\end{array}$ & 730 & 5,740 \\
\hline 7 & & & & & & 0 \\
\hline
\end{tabular}


431.02\#

$01 / 29 / 98$

Rev. \#00
Function File Number - SPR-WTS-01 EDF Serial Number - EDF-WTS-002

Page 8 of 62

\subsection{Purpose and Scope}

The purpose of this study is to define a calcine retrieval and transportation plan that is compatible with the calcine processing options currently under study by the WTF program (namely the CWO, DCWO, HWO, VWO, and the TRU Separations Options). The plan will consist of accessing the calcine in each CSSF, removing the calcine from the bins, and transporting the calcine from each CSSF to the Waste Treatment Facility (the processing facility developed in each option study). Three versions of this plan were necessary to meet the needs of each waste treatment option. The equipment necessary for CSSF access, calcine retrieval and transportation will be approximately sized. A cost estimate for each option will be developed. The cost estimate will include capital equipment costs as well as operating and maintenance costs over the life of the project. As necessary, sketches will be included to clarify the systems and processes developed.

The scope of EDF is limited to the scope of the Fluor-Daniels ${ }^{2}$ design for the calcine retrieval and transportation system as presented in reference 2. The design presented in this EDF should not seek to define unique systems to accomplish the overall tasks. Modifications to the systems presented in the Fluor-Daniels ${ }^{2}$ design should only be made to accommodate the unique needs of the five processing options currently under study. The issues and recommendations for future study identified during this study will be documented. Additional activities, that are necessary to fully implement the calcine retrieval and transportation system but are beyond the scope of the Fluor-Daniels design, will be included in the cost estimate.

\subsection{Design Basis}

Although the overall design is based on the Fluor-Daniels ${ }^{2}$ design, design criteria and key assumptions were made. The requirements that must be met are explained in section 2.3. The criteria, assumptions, and requirements were independently developed and applied to the calcine retrieval and transportation system.

\subsection{Design Criteria}

The design criteria are listed below. All portions of the design must satisfy criteria in the general category. These criteria are essential to satisfy ES\&H goals.

\section{General:}

1. Minimize worker radiation exposure and spread of contamination.

2. The systems should be designed to withstand any credible fire or other applicable accidents and still serve as a confinement barrier.

3. The systems should be designed to withstand appropriate natural phenomena hazards.

4. Provide primary and secondary confinement at all times while minimizing the confinement volumes.

5. Adequately heat and cool occupied areas of enclosures.

6. Provide instrumentation and control for operation and data acquisition. 
7. Facility equipment and calcine retrieval and transport systems must be capable of being decontaminated and/or replaced safely and easily.

8. The systems should minimize the generation of hazardous wastes.

Retrieval:

1. Minimize the amount of remote mechanical equipment placed in the bins. In effect, minimize the potential for equipment breakdown.

2. The bin pressure must remain slightly more negative than the surrounding vault space during retrieval. Controls are required to maintain the negative-pressure confinement.

3. Calcine will be retrieved from one bin in a CSSF a time. Although, calcine from more than one CSSF can be retrieved from at a given time.

4. Retrieval will be performed only if the transportation systems are operational.

5. Retrieve and deliver calcine to the Waste Treatment Facility according to the demand of the process.

\section{Transportation:}

1. Design the transportation system for a 30 year service life.

2. The transportation system should be readily maintainable.

3. Provide the appropriate amount of rod-out stations for the pneumatic transport system.

\subsection{Key Assumptions}

The scope of this study mandates the first and foremost assumption is that Fluor-Daniels ${ }^{2}$ has developed a viable and competitive option for calcine retrieval and transportation. The remaining assumptions are outlined below. They are divided into three categories: CSSF access, calcine retrieval, and transportation. A basis for each assumption is provided.

\begin{tabular}{|c|c|}
\hline Assumption & Basis \\
\hline \multicolumn{2}{|l|}{ CSSF Access: } \\
\hline $\begin{array}{l}\text { Installation of risers can be accomplished } \\
\text { with little modification to existing } \\
\text { technology. }\end{array}$ & $\begin{array}{l}\text { Similar risers were installed on hazardous } \\
\text { waste bins. The technology was developed } \\
\text { by West Valley Nuclear, Inc. and applied } \\
\text { to the CSSFs by Raytheon Engineers and } \\
\text { Constructors. } \\
\text { References: } 3 \text { and } 4\end{array}$ \\
\hline $\begin{array}{l}10 \% \text { of the ground fill removed for } \\
\text { construction and CSSF } 1 \text { access is } \\
\text { contaminated. }\end{array}$ & References: 2 and 3 \\
\hline $\begin{array}{l}\text { Transport piping from WCF and NWCF to } \\
\text { the CSSFs will be decontaminated as }\end{array}$ & $\begin{array}{l}\text { Closure plans of WCF and NWCF } \\
\text { Reference: } 5 \text { and } 6\end{array}$ \\
\hline
\end{tabular}




\begin{tabular}{|c|c|}
\hline $\begin{array}{l}\text { outlined in the WCF and NWCF closure } \\
\text { plans. This piping will remain accessible } \\
\text { for D\&D without endangering personnel. }\end{array}$ & \\
\hline $\begin{array}{l}\text { Access activities do not reduce CSSF } \\
\text { integrity. Additionally, superstructure } \\
\text { demolition reduces static stress on the } \\
\text { CSSF. }\end{array}$ & $\begin{array}{l}\text { Shoring activities will occur during fill } \\
\text { removal. The Raytheon study analyzed the } \\
\text { roof of CSSF } 1 \text { and found that these } \\
\text { activities would help to stabilize CSSF } 1 \text {. } \\
\text { Reference: } 3\end{array}$ \\
\hline $\begin{array}{l}\text { An adequate place for retrieval riser } \\
\text { attachment can be located on each bin. } \\
\text { Piping inside the bin vault will not interfere } \\
\text { with riser location. }\end{array}$ & $\begin{array}{l}\text { The exact location of retrieval risers was } \\
\text { not determined because it is highly } \\
\text { dependent on the requirements of the riser } \\
\text { welding method. This method is currently } \\
\text { being studied at the ICPP. However, } \\
\text { locations for } 40 \text { retrieval risers were found } \\
\text { for CSSF } 1 \text {. This number far exceeds the } \\
24 \text { retrieval risers required for CSSF1. The } \\
\text { remaining CSSFs at most require an } \\
\text { additional } 8 \text { retrieval risers to be installed. } \\
\text { Reference: } 3\end{array}$ \\
\hline $\begin{array}{l}\text { Bins will not be structurally weakened by } \\
\text { the attachment of retrieval risers. Measures } \\
\text { to avoid this (support retrieval riser weight } \\
\text { above bin and installation of a self- } \\
\text { supporting floor) can be taken but are not } \\
\text { documented. }\end{array}$ & Reference: 3 and 4 \\
\hline $\begin{array}{l}\text { Remote equipment can be sized } \\
\text { appropriately from equipment developed } \\
\text { for previous projects. }\end{array}$ & Reference: 4 \\
\hline \multicolumn{2}{|l|}{ Retrieval: } \\
\hline $\begin{array}{l}\text { All types of calcine in all the bins are } \\
\text { retrievable as a dilute phase using the } \\
\text { retrieval method provided. }\end{array}$ & Reference: 2 \\
\hline $\begin{array}{l}\text { The retrieval method is a viable option for } \\
\text { all bin shapes. This is pertinent to the } \\
\text { cylindrical bins. }\end{array}$ & $\begin{array}{l}\text { Reference: } 8 \text { and S. E. Gifford, telephone } \\
\text { conversation with Dan Griffith, INEEL. }\end{array}$ \\
\hline $\begin{array}{l}\text { Relocation of retrieval equipment (VDA } \\
\text { and jumper) from one CSSF to another will } \\
\text { take approximately } 1 \text { week. }\end{array}$ & $\begin{array}{l}\text { In the Fluor-Daniels }{ }^{2} \text { cost estimate } \\
\text { relocation of the confinement enclosure } \\
\text { and all associated equipment is } \\
\text { accomplished in two weeks. } \\
\text { Reference: } 2\end{array}$ \\
\hline $\begin{array}{l}\text { Calcine is assumed to have remained } \\
\text { unchanged. This mainly means that it has } \\
\text { not agglomerated in any of the CSSFs. }\end{array}$ & $\begin{array}{l}\text { This assumption allows the same retrieval } \\
\text { equipment design to be used in all the } \\
\text { CSSFs. Samples from CSSF } 2 \text { indicate } \\
\text { that the calcine can remain unchanged }\end{array}$ \\
\hline
\end{tabular}




\begin{tabular}{|c|c|}
\hline & $\begin{array}{l}\text { during storage. Samples from all CSSFs } \\
\text { are necessary to validate this assumption } \\
\text { for future studies. } \\
\text { Reference: } 7\end{array}$ \\
\hline $\begin{array}{l}\text { During calcine retrieval no less than } 95 \% \\
\text { of the calcine in a bin will be removed. } \\
\text { Beyond this level, as much of the calcine as } \\
\text { is reasonable will be retrieved. }\end{array}$ & $\begin{array}{l}\text { The } 95 \% \text { of the calcine in a bin has been } \\
\text { demonstrated to be retrievable at a high } \\
\text { rate. The next } 4.7 \% \text { of the calcine is } \\
\text { retrievable at a significantly lower rate. } \\
\text { Reference: } 8\end{array}$ \\
\hline $\begin{array}{l}\text { No internal obstructions (stiffening rods, } \\
\text { thermowells, etc.) will interfere with } \\
\text { extending the retrieval lines into the bins. }\end{array}$ & $\begin{array}{l}\text { The internal obstructions are well } \\
\text { documented. It is anticipated that the } \\
\text { retrieval risers can be located to avoid these } \\
\text { obstructions. The scope of this study does } \\
\text { not permit an in depth examination of this } \\
\text { issue. } \\
\text { Reference: INEEL drawings }\end{array}$ \\
\hline $\begin{array}{l}\text { No miscellaneous materials will enter the } \\
\text { suction nozzle. Where possible, such } \\
\text { material will be removed from the bins } \\
\text { prior to retrieval activities. }\end{array}$ & $\begin{array}{l}\text { The scope of this study does not permit an } \\
\text { in depth examination of this issue. } \\
\text { However, this is necessary that } \\
\text { miscellaneous materials present in the bins } \\
\text { do not enter the transportation system. } \\
\text { References: } 3 \text { and S. E. Gifford, separate } \\
\text { conversations with Dan Griffith and Dan } \\
\text { Staiger, INEEL. }\end{array}$ \\
\hline \multicolumn{2}{|l|}{ Transportation: } \\
\hline $\begin{array}{l}\text { All above ground piping must be shielded. } \\
\text { The concrete chase and earthen berm are } \\
\text { adequate to meet the radiological shielding } \\
\text { needs of dilute phase calcine. }\end{array}$ & Reference: 3 \\
\hline $\begin{array}{l}\text { All directional changes will utilize blinded } \\
\text { tees and laterals. All components, } \\
\text { including the cyclone, should be reinforced } \\
\text { with nitronic wear plates to prevent erosion } \\
\text { failures. }\end{array}$ & Reference: 11 \\
\hline
\end{tabular}

\subsection{Requirements}

Statutory law, DOE orders, and the Batt Agreement establish the requirements for the calcine retrieval and transportation system. These requirements are examined in reference 9. 


\subsection{Process Design}

The process design has been split into three sections to provide clarity to the description. CSSF access (section 3.1) will prepare each bin for calcine retrieval by decontaminating the CSSF superstructure and installing or accessing the retrieval risers. Calcine retrieval (section 3.2) will remove the calcine from each bin and place it directly in the transportation system. The transportation system (section 3.3) will deliver the calcine to the Waste Treatment Facility and provide the motive for $r$. A basis, process description, equipment description, and process issues are detailed for each section of the design.

\subsection{CSSF Access}

\subsubsection{Process Basis}

CSSF access prepares each bin for calcine retrieval by reducing radiation exposure, adding necessary retrieval risers, and accessing existing retrieval risers. The CSSFs will be prepared for calcine retrieval by erecting permanent confinement enclosures. The access method presented by Fluor-Daniels ${ }^{2}$ was originally developed in the Raytheon ${ }^{3}$ design for CSSF 1 . The specific details for each CSSF may vary but the overall the process is the same for all CSSFs.

\subsubsection{Process Description}

The primary goal of this phase of the retrieval and transport system is to prepare the CSSFs for retrieval. Bin vault ventilation systems will be replaced, confinement enclosures will be constructed, and retrieval lines will be installed and accessed. All modifications to the CSSFs and construction of new buildings will comply with the general design criteria outlined in reference 10. The CSSF access process is outlined in 9 steps. In order to protect the integrity of each CSSF some of these steps may overlap in the schedule.

1. Earthwork. Extensive excavation of CSSF 1 will expose the superstructure down to the bin vault roof. The excavation necessary to reach CSSF 1 will affect the earthen berms of CSSFs 2 and 3. Retaining walls must be installed to preserve these shielding berms. The uncontaminated portion of excavated fill, which must be covered, is estimated at $90 \%$. The contaminated fill must be disposed of appropriately. This work begins in an uncontaminated work area. Shoring of the CSSFs, construction of the retaining wall for CSSF 1, and removal of $10 \%$ contaminated fill require work in a radiation zone. Therefore, shielded or remote equipment should be used during this step.

An equipment ramp must be built to CSSF 1. This ramp will be used during the installation of the bridge crane and the construction of the confinement buildings. For CSSF 2-7, a mobile crane will place the equipment on the CSSF roof. This work will primarily occur under a temporary decontamination tent. The cooling air stacks will interfere with locating the confinement enclosure on the bin vault roof. Relocation of the cooling air stacks will begin in this step. 
2. Construct ventilation, instrumentation, and control (VIC) building for each CSSF. The . primary purpose of the VIC building is to house the ventilation, instrumentation, and control equipment. It will be a pre-manufactured steel building placed adjacent to each CSSF. During this step the HVAC, instrumentation, and control equipment will be installed. The HVAC equipment will regulate and decontaminate air from the bin vault, confinement enclosure, and this building. The interface between the VIC building and confinement enclosure for each CSSF is shown in sketch CRT-01. Temperature control will be maintained in the control room and operating areas with this system. Air flow will be monitored to minimize the risk of contamination spread by circulating air from low risk areas to high risk areas. Sampling ports will be provided to ensure the HVAC equipment is compliant with the applicable standards.

Installation of instrumentation will.consist of relocating panels and rewiring because the instrumentation is functional in each CSSF. The control room will house the remote operations control and instrumentation. It will allow for internal viewing of the bins through the CCTV system as well as aide in installation of retrieval risers. Construction of this building includes floor, lights, windows, doors, $\mathrm{OH}$ doors, insulation, and fire protection. For all the CSSFs, this building will have the same layout and size. The VIC building for all CSSFs will require electricity, water, heating and/or cooling, breathing air, and plant air.

3. Construct confinement enclosure for each CSSF. The confinement enclosure is a nonreactor nuclear facility. It is pictured in figure 2 as it would appear on CSSF 5, 6, or 7 . For CSSFs 1, 2, 3, and 4 the confinement enclosure will be constructed on the roof of the bin vault. It acts as a confinement barrier during retrieval activities. This enclosure is a premanufactured steel building. This enclosure also includes ladder, guardrail, steel plate, and structural steel. It will be complete with fire protection equipment, lighting, equipment wiring and CCTV capabilities. The interior of the confinement enclosure will be coated with strippable coatings for decontamination purposes.

A negative pressure will be maintained inside the enclosure in order to reduce the risk of contamination spread. The confinement enclosure will house a bridge crane, core drilling platform, welding equipment, vertical deployment equipment, and shielded jumpers. The bridge crane will be installed for use during decontamination of the superstructure equipment and piping, core drilling procedures, and calcine retrieval.

This building will be decontaminated several times throughout the calcine retrieval process. The confinement enclosures for all the CSSFs will require electricity, water, breathing air, plant air, high pressure steam, service water, and instrument air. After construction of the confinement enclosure, the temporary confinement tent over the construction site may be removed.

4. Access vaults that require decontamination and decommissioning. In this step, equipment inside the vaults will not be disturbed. CSSFs 1,2,3, and 4 require installation of access ways to the vaults. This will be accomplished by core drilling into the inaccessible rooms. Existing access ways to the vaults (CSSFs 5, 6, and 7) will be cleared. Necessary portable shielding should be placed at the vault entry locations. For all CSSFs, external 
431.02\#

$01 / 29 / 98$

Rev. $\# 00$
ENGINEERING DESIGN FILE

Function File Number - SPR-WTS-01

EDF Serial Number - EDF-WTS-002

Page 14 of 62

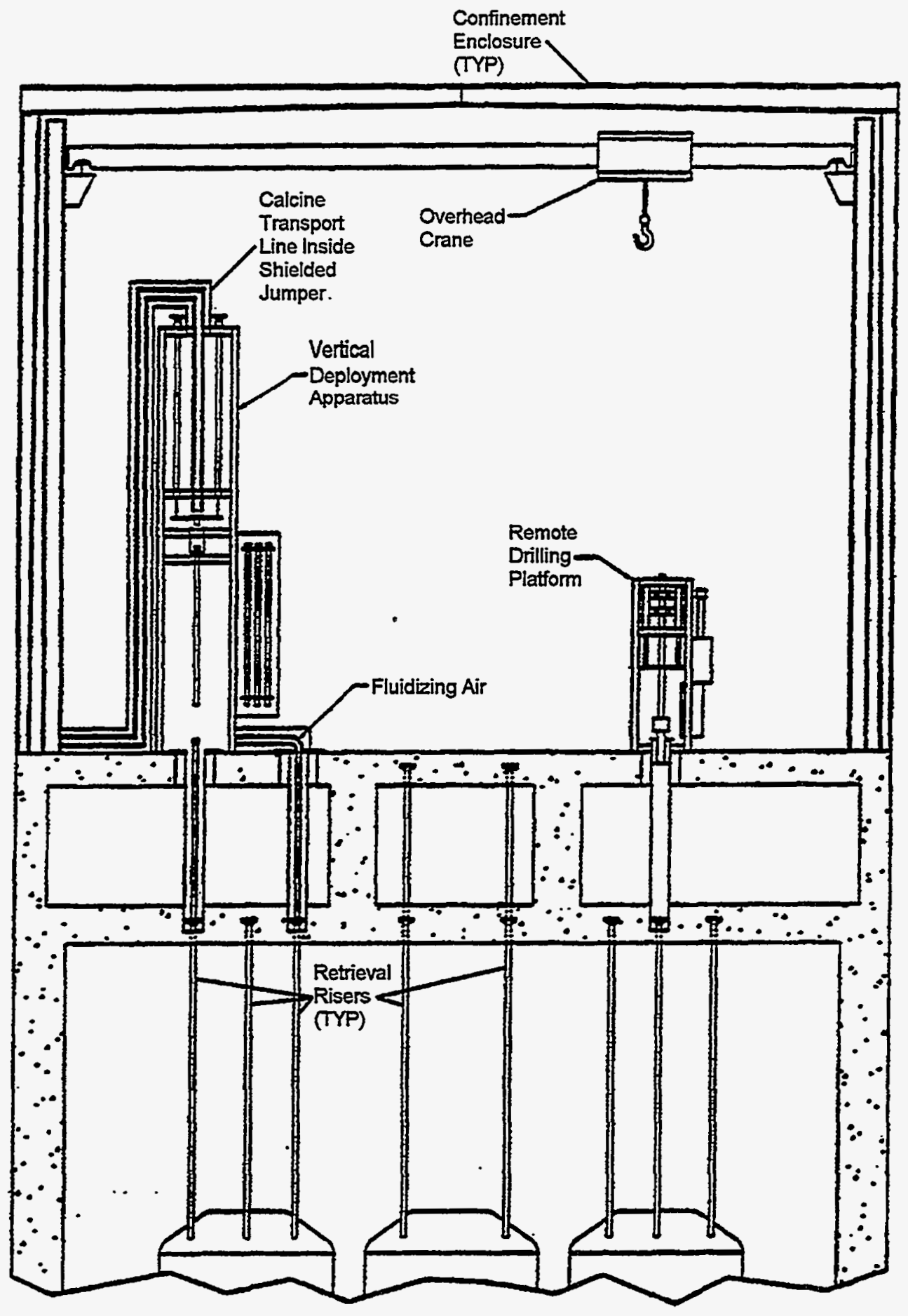

Figure 2. Confinement Enclosure and equipment pictured for CSSF 5,6 , or 7 . 
structures and equipment such as corrugated metal buildings, cooling stack ductwork, cooling air blowers, and their associated ductwork will be removed. As necessary, installation of plugs in ductwork penetrations will reduce worker exposure. Lead brick and conduit will be removed during this step. This work will be performed in a low radiation zone.

5. Decontaminate superstructure vaults and rooms. The vaults and rooms above the large concrete vault housing the bins comprise the superstructure of the CSSFs. The cyclone vault, equipment vault, instrument room, fan room, inlet plenum room, and exhaust plenum room will be decontaminated during this step. The vault that contains the calcine storage bins will not be decontaminated during CSSF access. Portable shielding should be placed in the vaults to reduce the exposure to acceptable limits. Remotely vacuum vault floors before entering with HEPA filtered vacuums. These vacuums have the ability to remove small debris and dust but not large objects. Strippable coating should be applied to the walls and floors of vaults that will be entered. Cut existing transport, probe, off-gas, rod out, monitoring and other nonessential piping that penetrate vault and room floors. The cut lines should then be plugged to prevent contamination spread during calcine retrieval. In CSSF 1,2,3, and 4 the pipes must be accessible after the new concrete floor is poured for closure activities. Access to the pipes should be provided in a similar manner to the accesses of existing retrieval lines in CSSFs 5,6 , and 7 .

Once access to the vaults has been gained, decontamination activities begin. These activities require extensive shielding if it is to be accomplished manually. A better alternative is to employ remote equipment. This remote equipment must be designed and tested. The relative level of radiation in the superstructure vault is shown in Table 2. These relative levels of radiation are based on the function of the vault and if calcine was ever present in the vault. In the high radiation areas, shielding concrete floors should be poured before temporary shielding is installed. Furthermore, Table 2 notes vaults that may have solids accumulations ${ }^{2}$. These accumulations are a result of damage to transport piping during filling of several CSSFs. Efforts may have been made to clean and repair these vaults but a conservative approach is to assume these vaults are extremely contaminated.

During this step, piping, vessels, and conduit will be disassembled and packaged in appropriate containers. The bridge crane will be used to remove the packages from the CSSF. Wall penetrations should be plugged when the piping is removed. Contaminated lines that lead away from the CSSFs (such as transport lines from the WCF or the NWCF) should be decontaminated and flushed. Flushing activities are discussed in section 3.1.4. 
Table 2. Assumed Bin Vault Relative Radiation Levels

\begin{tabular}{|c|c|c|c|}
\hline CSSF & $\begin{array}{c}\text { Low } \\
\text { Radiation } \\
\text { Zone }\end{array}$ & $\begin{array}{c}\text { High } \\
\text { Radiation } \\
\text { Zone }\end{array}$ & $\begin{array}{c}\text { Known } \\
\text { Solids } \\
\text { Accumulations }\end{array}$ \\
\hline 1 & Ventilation Exhaust Room & Cyclone Vault & \\
\hline 2 & Instrument Building & Cyclone Vault & Cyclone Vault \\
\hline 3 & $\begin{array}{l}\text { Instrument Building } \\
\text { Equipment Vault }\end{array}$ & Cyclone Vault & Cyclone Vault \\
\hline 4 & Instrument Building & $\begin{array}{l}\text { Cyclone Vault } \\
\text { Ventilation } \\
\text { Equipment Room }\end{array}$ & \\
\hline 5 & $\begin{array}{l}\text { Instrument Room } \\
\text { Access Cell }\end{array}$ & Cyclone Vault & \\
\hline 6 & $\begin{array}{l}\text { Instrument Room } \\
\text { Fan Room } \\
\text { Inlet Plenum Room } \\
\text { Exhaust Plenum Room }\end{array}$ & $\begin{array}{l}\text { Cyclone Vault } \\
\text { Off-Gas Filter Room }\end{array}$ & \\
\hline 7 & $\begin{array}{l}\text { Instrument Room } \\
\text { Fan Room } \\
\text { Inlet Plenum Room } \\
\text { Exhaust Plenum Room }\end{array}$ & $\begin{array}{l}\text { Cyclone Vault } \\
\text { Off-Gas Filter Room }\end{array}$ & \\
\hline
\end{tabular}

6. Demolish CSSF superstructure. This step will only be conducted for CSSF 1. The superstructures of CSSF 2,3, and 4 will have been removed during step 1, as the superstructure enclosures are metal buildings and not concrete. During step 5 , the superstructure vaults of CSSF 5, 6 , and 7 will be decontaminated. The superstructures of the last 3 CSSFs are much more robust than superstructures of previous CSSFs. The walls and roof of these will be left in place.

For CSSF 1, the temporary shielding and structural support steel will be removed from the vaults with the bridge crane. Demolish vault roof and walls. It is not necessary to demolish the CSSF superstructure for CSSFs 5, 6 , and 7 because of the lower radiation levels in these CSSFs. The vault superstructure is a more permanent and integral part of the CSSF structure. At this point, the superstructure roof of CSSFs 5,6 , and 7 will be core drilled to allow access to the existing retrieval risers located in the superstructure floor.

7. Prepare confinement enclosure for bin access. This is accomplished by removing and replacing strippable coatings. Portable $\mathrm{CO}_{2}$ decontamination equipment will be used to remove any residue contamination on the walls and floors. After the confinement enclosure is decontaminated, the shielding concrete pad will be poured on the bin vault roof. Attention must be given to maintaining access to all piping exiting the bin vault through the floor and existing retrieval risers. The concrete pad will be 21 in. thick for CSSF 1 and 18 in. thick for 
CSSFs 2,3 , and 4. CSSFs 5,6 , and 7 do not require shielding floors because the superstructure will provide shielding.

8. Access bins. The distinction between CSSFs is significant in this step. CSSF 1 requires all new access lines. Retrieval lines must be uncapped for CSSFs 4, 5, 6, and 7. In CSSFs 2 and 3 , the existing retrieval lines must be uncapped and new retrieval lines must be added. Table 3 details the location of existing risers by CSSFs and superstructure location. Retrieval lines in CSSFs 5, 6, and 7 have multiple lengths. The shorter lines rise from the bins to the floor - of the superstructure. The longer lines pass through the cyclone vault.

\section{Table 3. Location of Existing Retrieval Risers}

\begin{tabular}{|c|c|c|c|c|c|c|c|}
\hline CSSF & 1 & 2 & 3 & 4 & $\overline{5}$ & 6 & 7 \\
\hline Vault Roof & & 7 & 7 & 6 & & & \\
\hline $\begin{array}{c}\text { Instrument } \\
\text { Room }\end{array}$ & & & & & 13 & 7 & 7 \\
\hline $\begin{array}{c}\text { Cyclone } \\
\text { Room Floor }\end{array}$ & & & & & & 4 & 2 \\
\hline $\begin{array}{c}\text { Cyclone } \\
\text { Room Roof }\end{array}$ & & & & & 6 & 4 & 4 \\
\hline Fan Room & & & & & & 6 & 8 \\
\hline Access Cell & & & & & 9 & & \\
\hline $\begin{array}{l}\text { Exhaust } \\
\text { Plenum }\end{array}$ & & 0 & & & & 4 & 4 \\
\hline $\begin{array}{c}\text { Off-Gas } \\
\text { Filter Room }\end{array}$ & & & & & & 1 & 1 \\
\hline Inlet Plenum & & & & & & 2 & 2 \\
\hline $\begin{array}{c}\text { Total } \\
\text { Existing } \\
\text { Retrieval } \\
\text { Risers }\end{array}$ & $\overline{0}$ & $\begin{array}{c}7 \\
(1 / \mathrm{bin})\end{array}$ & $\begin{array}{c}7 \\
\text { (1/bin) }\end{array}$ & $\begin{array}{c}6 \\
(2 / \mathrm{bin})\end{array}$ & $\begin{array}{c}28 \\
\text { (4/bin) }\end{array}$ & $\begin{array}{c}28 \\
(4 / \mathrm{bin})\end{array}$ & $\begin{array}{c}28 \\
(4 / \mathrm{bin})\end{array}$ \\
\hline $\begin{array}{c}\text { Additional } \\
\text { Lines } \\
\text { Required } \\
\text { (Length) } \\
\end{array}$ & $\begin{array}{c}24 \\
(8 \operatorname{are~} 16 \mathrm{ft} \\
\& \\
16 \operatorname{are} 23 \mathrm{ft})\end{array}$ & $8(26 \mathrm{ft})$ & $7(20 \mathrm{ft})$ & 0 & 0 & 0 & 0 \\
\hline $\begin{array}{c}\text { Retrieval } \\
\text { Line } \\
\text { Required per } \\
\text { Bin }\end{array}$ & $\overline{2}$ & $\begin{array}{l}2 \text { in WC- } \\
136-1 \text { and } \\
1 \text { in the } \\
\text { remaining } \\
\text { bins }\end{array}$ & 1 & 0 & 0 & 0 & 0 \\
\hline $\begin{array}{l}\text { Current Rise } \\
\text { in Retrieval } \\
\text { Line from } \\
\text { Bin to End }\end{array}$ & 0 & $28 \mathrm{ft}$ & $18 \mathrm{ft}$ & $18 \mathrm{ft}$ & $\begin{array}{l}4 \text { are } 38 \mathrm{ft} \\
2 \operatorname{are} 37 \mathrm{ft} \\
22 \text { are } 24 \mathrm{ft}\end{array}$ & $\begin{array}{l}4 \text { are } 39 \mathrm{ft} \\
24 \text { are } 26 \mathrm{ft}\end{array}$ & $\begin{array}{l}4 \operatorname{are} 39 \mathrm{ft} \\
24 \text { are } 26 \mathrm{ft}\end{array}$ \\
\hline $\begin{array}{l}\text { Total Length } \\
\text { of Retrieval }\end{array}$ & $1016 \mathrm{ft}$ & $959 \mathrm{ft}$ & $1038 \mathrm{ft}$ & $438 \mathrm{ft}$ & $1232 \mathrm{ft}$ & $1309 \mathrm{ft}$ & $1309 \mathrm{ft}$ \\
\hline
\end{tabular}




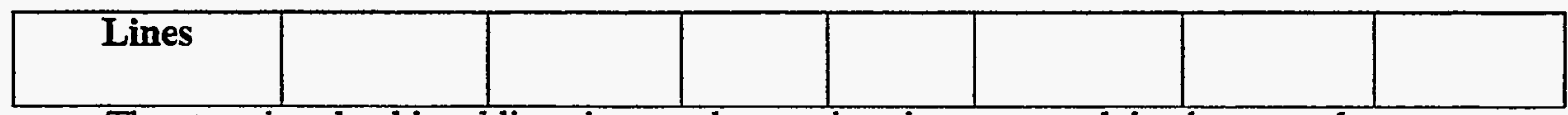

The steps involved in adding risers and accessing risers are explained separately.

Additional Retrieval Line Access: The core drilling equipment will be placed with the overhead crane. A 1 in. pilot hole will be drilled through the concrete floor to the bin vault. A 9 in. diameter hole will then be drilled through the concrete floor. Core capture equipment will prevent the core from falling into the bin vault and damaging the bins. The 8 in. retrieval lines will be extended and welded to the top of each bin. Inspection of the welds is necessary to ensure that calcine will not be released. Each bin requires two retrieval risers for calcine retrieval. The system used to install the risers will require further development and testing. It was used to access bins at the West Valley Demonstration Project ${ }^{4}$. In that project, the pipe diameter was half the size and the concrete floor was nearly twice as thick. A throughway between the riser and the bin will be made with remote equipment. A remotely operated hole saw could be used to cut a hole in the bin. Then a plug will be placed on the top end of the retrieval riser to minimize contamination of the confinement enclosure. CSSFs 1-3 and the bins will be inspected for safety hazards prior to welding and cutting operations. If hazards are identified (such as the presence of explosive gases) these hazards will be mitigated or a different welding or cutting method will be used.

Existing Retrieval Line Access: The flanged and welded terminations of the existing retrieval lines should have been located in the vault demolition step. These lines will be opened and capped until needed for calcine retrieval. It:will be necessary to core drill through the confinement enclosure floor to access some of the retrieval lines in CSSF 5, 6, and 7. The existing retrieval risers will be plugged with steel lined, concrete plugs. At the conclusion of each of these activities the radiation levels of the confinement enclosure should be inspected. If they are found to be excessive the enclosure should be decontaminated.

At the conclusion of step 9, the CSSF is prepared for calcine retrieval activities. The retrieval lines will remain in the bins. The retrieval risers will be plugged with the steel lined, concrete, stepped plugs. Step 10 occurs during CSSF closure.

9. CSSF D\&D preparation. The bins will be prepared for D\&D by adding 18 in. diameter risers. The method used to install retrieval risers will be used to install the D\&D risers. It is anticipated the same core drilling platform can be used to install the D\&D risers and the new retrieval risers. However, a larger drill bit will be required. The riser will be welded to the bin and extended to the floor of the confinement enclosure. A steel lined plug will be placed on top of the riser. As a safety precaution, the bin will not be opened into the D\&D risers until D\&D begins. Annular bins require two D\&D risers (CSSF 1, 5, 6, and 7). Cylindrical bins require one D\&D riser (CSSF 1 center bins, 2, 3, and 4). The riser will be used to insert a robot to aid in the retrieval of the final $5 \%$ of the calcine in the bins. The installation of the $D \& D$ risers is essential to CSSF closure plan presented in reference 12 . The cost of installing the D\&D risers is included in the cost estimate (see section 6.0). 
The retrieval system will be available for $D \& D$. The positive displacement blower, vertical . deployment apparatus (VDA), and shielded jumper will be available for D\&D. The retrieval lines will remain in each bin. The retrieval lines are basically too hot to do anything else. Some minor adjustment to the retrieval system may be necessary (such as relocating the shielded jumper and VDA within a CSSF). The installation of the D\&D risers are costed separately from the capital equipment. The operation of the retrieval system, once the CSSF is declared empty, is the responsibility of the CSSF closure team. These costs are documented in section 6.0 .

\subsubsection{Process Equipment Description}

The equipment necessary for CSSF access mainly consists of ventilation and riser installation equipment. The ventilation equipment will satisfy the ventilation requirements of the bin vault and the confinement enclosure. This equipment is described in the equipment list in appendix A. The riser installation equipment consists of an overhead crane (used to remove packaged, contaminated equipment and place the remote drilling platform), remote drilling platform, and remote welding equipment.

The remote drilling platform will drill penetrations through the bin vault roof $(2 \mathrm{ft}$ to $3 \mathrm{ft}$ of concrete) of each CSSF. Retrieval risers and D\&D risers will be inserted through these penetrations. The basic operation is as follows: drill a pilot hole ( 1 in. to 2 in.), insert a toggle type capture mechanism (to prevent the core from falling into the CSSF and damaging the bins), finally, drill a larger diameter hole (allowing installation of the risers). Secondary confinement will be provided during drilling operations by a tent confinement around the drilling platform. The tent confinement will reduce exposure to workers and contamination spread within the confinement enclosure. The remote drilling platform will be relocated from bin to bin within a CSSF. This will require coordinating the construction schedules. The platform will be secured to the confinement enclosure floor with anchor bolts. Safety barriers and warning signs will prevent exposure to shine radiation directly above the open penetration. A riser plug will be installed to provide a shielding barrier once the penetrations have been drilled.

The remote welding device will weld the new risers to the bins. Commercially, resistance welding is often used to join tubs to surfaces in a hands on manner. A test program is currently underway at the INEEL to better understand the parameters involved in converting this technique to remote operation. In general terms, flanged risers, approximately $4 \mathrm{ft}$ to $5 \mathrm{ft}$ long, will be welded to the top of each bin. The remaining length of the riser will be bolted to the flanged riser. It is anticipated that the welds will need to be inspected prior to opening the bins through the risers. At this stage, a remote weld inspection technique has not been identified. However, it should be a simple matter to convert a test method for remoter inspection of the welds. The best time to develop a remote weld inspection method is during the weld test program.

The remote hole drill will be used to provide a throughway into the bin from the new retrieval riser. It will cut a circular hole, inside a new retrieval riser, on the top of a bin. The retrieval lines will be inserted into the bins through these holes. Bins with existing retrieval risers will not require the use of this equipment. This equipment should be purchased off-the-shelf and then converted for remote operation. The core should be captured to prevent it from falling into the 
bins.

\subsubsection{Process Issues}

The CSSF access plan described above is not perfect, complete, or final. It is based on methods developed by Raytheon and Fluor-Daniels ${ }^{2}$ in previous and current studies. The details of the CSSF access plan are broad. They do not address the requirements of each CSSF individually. The specific points remain to be identified in a feasibility report. This section attempts to point out potential errors and concerns in the CSSF access method. They are not expected to impact the cost or schedule of the project but they warrant further examination and study.

\section{Radiation Levels in CSSF Superstructure:}

The radiation levels vary throughout the vault superstructure of each CSSF. The cost of demolishing the vault superstructure increases as the radiation level increases. At this stage in the design process, relative radiation levels were used to develop the cost estimate. The function of the room and evidence of operational anomalies determined the relative radiation level. Not all of the CSSFs contain all of these rooms. For future studies and cost estimates, a survey of each superstructure vault should be completed to quantify the level of radiation in the vaults.

The cyclone vault and the off-gas filter room were considered to be the highest radiation areas. These areas were exposed to the greatest levels of calcine solids. The cyclone vault houses the cyclone and the distribution piping. In CSSF 2 and 3, erosion failures are known to have occurred in this vault ${ }^{2}$. The accumulated calcine was cleaned up but higher levels should be expected in the cyclone vault for CSSF 2 and 3. All equipment housed in this vault should be considered highly contaminated. During filling, the bins were vented through filters in the offgas filter room. The HEPA filters in this room are highly contaminated. After filling, this room was isolated to minimize contamination spread. Shielding is necessary for work in this room. The cyclone vaults and the off-gas filter rooms should be considered high radiation areas.

The instrument room, equipment room, and access cell are assumed to be low radiation zones. These rooms house the instrumentation and equipment used to monitor the CSSF. Calcine did not enter these rooms. The inlet and exhaust plenum rooms are used to passively cool the bin vault. It is unlikely these rooms have levels of contamination beyond that of a radiation area. The fan room contains HEPA filters used only if contamination is detected in the exhaust plenum room. This system has never permanently activated in any of the CSSFs. It is unlikely the HEPA filters in this room are contaminated but they should be treated as such for disposal purposes. The equipment and ductwork downstream from the HEPA filters should be considered uncontaminated. The remaining rooms in the superstructure are assumed to be radiation areas. Unless noted above, the piping or bins in the vault are assumed to be intact.

Existing Lines from the Calcining Facilities (WCF \& NWCF) to the CSSFs: The CSSF access plan calls for the original calcine transport lines to be cut and capped at the CSSFS. The cost of cutting and capping these lines is reflected in the cost estimate (section 6.0). However, the cost of decontaminating these lines is not included. The cost of decontaminating, cutting, and

\footnotetext{
a Staiger, D., "Review of High-Level Wastes Stored at the ICPP", draft, September 1997.
} 
capping the lines from the NWCF to the CSSFs is part of the NWCF closure cost. The WCF closure plan calls for the line from CSSF 1 to be used to flush the calcine transport line back to the WCF. The line will be flushed with a grout slurry. Eventually, the line will back up. The grout slurry will solidify just past the first wye. This makes it difficult to flush the lines that run from CSSFs 2 and 3 to the WCF. It would be advantageous to develop detailed plans to flush and properly close these lines. Closure plans for other contaminated lines should be developed as they are identified.

Weight Loading of CSSFs: The weight loading on the CSSFs during access activities and retrieval operations is not expected to be a significant problem. The amount of equipment used during these activities has been minimized to reduce the weight loading on the CSSFs. The final design of the calcine retrieval and transportation system will incorporate the weight loading restrictions of the CSSFs. This issue will be resolved during the design stages of the calcine retrieval and transportation system.

\subsection{Calcine Retrieval}

\subsubsection{Process Basis}

The calcine retrieval system will remove the calcine from a bin and place it directly in the pneumatic transport system. The system minimizes the number of moving parts used to retrieve the calcine to reduce the risk of failure and downtime. The remote operation design of the calcine retrieval system reduces worker exposure.

The calcine retrieval system consists of the equipment necessary to remove calcine from a bin. Each CSSF is equipped with a complete set of retrieval equipment. The retrieval system relies on the transport system to provide the means for the calcine retrieval. There are two transport systems. The calcine retrieval system and the calcine transportation system are separate and distinct. Neither system can operate without the other. The interface between the calcine retrieval system and the calcine transportation system is shown in sketches CRT-02 and CRT-03.

Several modifications have been made to Fluor-Daniels ${ }^{2}$ design to satisfy the needs of the processing options. The basic design, equipment, and process are based on the Fluor-Daniels ${ }^{2}$ design for calcine retrieval. The Fluor-Daniels ${ }^{2}$ design specifies that alumina calcine and zirconia calcine are retrieved and transported using separate systems. The overall system will be more efficient if there are no restrictions placed on the type of calcine that can be retrieved and transported by a system. The alumina calcine system would be idle a large part of the time because the CSSFs contain more zirconia calcine. The duplicated systems allow two bins, in separate CSSFs, to be retrieved from at one time. Safety and efficiency issues require that one bin be completely emptied before another bin is retrieved from within a CSSF.

\subsubsection{Process Description}


Calcine retrieval will be accomplished pneumatically with a suction nozzle and an air jet. The air jet will fluidize the calcine inside the bin. The suction nozzle will lift the fluidized calcine out of the bin. Calcine will enter the transport system through a shielded jumper from the retrieval line. A retrieval system has been mocked up at the INEEL as a pilot plant facility. It is the only system to have successfully demonstrated solids retrieval from a full-scale bin model.

Two retrieval lines will be placed $180^{\circ}$ apart inside the bin. The retrieval lines will be composed of rigid, concentric pipes. The outer diameter of the retrieval lines will be 5 in.. The inner pipe will function as the suction line. It will be fitted with a nozzle designed to prevent clogging and uptake of miscellaneous items in the bins. The annulus will be an air jet. It will be fitted with an appropriate fluidizing nozzle. At a given time, a retrieval line will function as a suction line or an air jet. The suction nozzle and air jet will not be housed in the same retrieval line. The function of the retrieval lines will alternate, one line will act as the suction line while the other acts as the air jet. Calcine retrieval will be more efficient. Each line will have the capability to sweep a full circle but it will not be continuously rotating. This will aid in fluidizing agglomerated calcine.

The pressure inside a bin during retrieval should be slightly negative. The negative pressure reduces the risk of contamination spread while a vault is open for retrieval. The negative pressure will provide an additional safety if the confinement were to fail. The negative pressure must not maximum exceed the design pressure of the bins. The design pressure rating varies by CSSF.

A vertical deployment apparatus (VDA) will be used to keep the retrieval lines near the surface of the bulk calcine. This equipment is similar to well-drilling equipment. The retrieval lines will be sectioned. The length of each retrieval line can be extended as the calcine is retrieved. The retrieval system functions most effectively when the suction nozzle and air jet are near the calcine surface. However, it is necessary to adjust the level of each line independently. After the bin is emptied, the lines will be disconnected from the VDA and remain in the bin. The retrieval risers will be plugged, with steel-lined stepped plugs, before the VDA is decontaminated and moved to the next bin.

The calcine will be retrieved at a rate of $2700 \mathrm{~kg} / \mathrm{hr}$ from each bin. When both transport systems are operating, calcine will be delivered to the Waste Treatment Facility at a rate of $5400 \mathrm{~kg} / \mathrm{hr}$. The retrieval rate is set by Fluor-Daniels ${ }^{2}$. The mock-up tests ${ }^{8}$ reveal that retrieval rates above $2300 \mathrm{~kg} / \mathrm{hr}$ can be achieved with $3 \mathrm{in}$. retrieval lines and a maximum air flow rate of $300 \mathrm{scfm}$ at $12-15 \mathrm{psig}$. The higher retrieval rate could be reached by increasing the air flow rate and the blower capacity. More testing is necessary to show that this is a sustainable retrieval rate. The retrieval rate is dependent upon how agglomerated the calcine is. This issue is discussed further in section 3.2.3.

The retrieval system will retrieve at least $95 \%$ of the calcine each bin. This estimate is based on results from a pilot plant program (reference 8 ). The $1 / 4$ and full-scale mockup tests provide the best information about the amount of calcine that can be retrieved using this retrieval method. The details of the tests are not explained in this EDF. The target retrieval rate was not maintained after $95 \%$ of the solids were retrieved. In the $1 / 4$ scale test, less than $1 \%$ of the initial retrieval 
rate could be maintained during retrieval of the final $3 \%$ of solids. A significant amount of time is necessary to retrieve the final $3-4 \%$ of calcine at the bottom of the bin. For the full-scale tests, the retrieval rate dropped as the amount of solids in the bin decreased. The retrieval rate dropped below the target retrieval rate when $95.8 \%$ of the solids had been retrieved.

A conservative retrieval estimate is $95 \%$. A conservative approach is taken for several reasons. The calcine in the "nooks and crannies" created by thermowells, internal stiffening rods, and the bottom of the bins will be difficult to remove with this retrieval method. This system has not been tested on a caked material. It is highly possible that calcine in some of the bins may be caked. Such a material would have a greater tendency to stick to the walls, floors, and internal structure of the bins. It should be noted that in the actual operation of the retrieval system, retrieval should continue as long as a reasonable retrieval rate can be maintained. The schedule and other processing requirements must define that rate.

Throughout calcine processing, retrieval will switch from CSSF to CSSF as CSSFs are emptied or different calcine types are reached. For example, the CWO option requires frequent switching between CSSFs to achieve the correct calcine blend. The other processes need to switch CSSFs once a CSSF is emptied. Safety issues prevent switching from bin to bin within a CSSF before the first bin is emptied. Additionally, such a feature is not necessary to meet the process requirements. The process of switching the retrieval to another CSSF is outlined below: Let bin $A$ be the bin that is currently being retrieved and let bin $B$ be the bin that retrieval is being switched to.

1. Turn off retrieval system for bin A: This is accomplished by shutting off the transport air blower connected to the suction nozzle and air jet. Flush the shielded jumper and upper line with dolomite to remove any calcine deposited in the lines. Close the valve at the CSSF transport line connection. Disconnect the vertical deployment apparatus from the retrieval lines. The lines will rest on the bottom surface of the bin. Place the steel-lined, concrete plugs on the retrieval risers. Disconnect the shielded jumper from the VDA. Decontaminate and relocate the VDA to bin $B$.

2. Adjust Transport System: Diverter valves will be used to connect the CSSF leads to the main transport system. The diverter valves will be pneumatically controlled from the control room adjacent to each CSSF. The steam traced lines in the transportation system will condensation in the return air lines.

3. Turn on retrieval system for bin B: If necessary, the VDA must be transported to and correctly positioned at bin $\mathrm{B}$. The correct set of retrieval line extensions must be placed in the extension tube carousel. The confinement tenting will be replaced around the VDA. The shielded jumper will connect the retrieval lines to the transport system. The plugs on the retrieval risers will be pulled. Retrieval lines will be extended to the top of the calcine in bin B. The power to the retrieval blower and suction jet will be turned on. Retrieval from bin B begins.

\subsubsection{Process Equipment Description}

The Vertical Deployment Apparatus (VDA) will extend the retrieval lines into the bins during calcine retrieval. The VDA will extend the retrieval lines independently. The equipment is 
similar to well drilling equipment. Temporary ventilation and confinement shielding is required. This will be accomplished with a confinement tent and a portable blower. A catch pan will collect radioactive dust and runoff water introduced in the VDA confinement area. The VDA is relocated with the bridge crane. It will be stabilized with anchor bolts attached to the confinement enclosure floor. The apparatus is $5 \mathrm{ft}$ to $6 \mathrm{ft}$ square and $25 \mathrm{ft}$ tall. External shielding panels, $2 \frac{1 / 2}{2}$ in. thick, reduce radiation fields inside the confinement enclosure during retrieval. An external ladder and gate provide maintenance access to the VDAs. When the plug is removed from the retrieval riser, the confinement area within the VDA has the same ventilation requirements as the calcine bin.

The VDA is equipped with a plug removal hoist, extension tube carousel, and extension tubes and couplings. A detailed description of their function appears in reference 3 . The plug removal hoist lifts the plug from the retrieval riser and stores it inside the VDA. The motor, brake, controls, and cable require periodic inspection. The load carrying capacity should also be regular checked. The extension tube carousel stores the extension tubes for the risers and retrieval lines.

The extension tubes with couplings form the retrieval line sections. As the retrieval lines are lowered into the bins, a section of tube is added. Each CSSF requires a particular set of extension tubes. These must be loaded into the VDA each time it is relocated.

The shielded jumper connects the discharge of the calcine retrieval line (top of the VDA) to the transport line. The jumper configuration will allow this connection to be made regardless of location of VDA. The shielded jumper is made of double walled, heavy pipe. The jumper is composed of $4 \mathrm{ft}$ to $5 \mathrm{ft}$ sections that are equipped with lifting lugs for easy handling. The jumper must be flushed with high velocity dolomite to reduce the amount of contamination in the line before it is moved.

The CCTV system contains a camera, light, boom, and control system. This system is installed to allow viewing inside the bins. It is not an essential component for the retrieval operation but it will be useful if unforeseen problems develop.

The retrieval equipment described in this section is located inside the confinement enclosure. This equipment must interface with the transport system in order for calcine to be retrieved.

\subsubsection{Process Issues}

The calcine retrieval system described has been tested at the INEEL. Even so, some unresolved issues exist regarding the system. Raytheon ${ }^{3}$ developed the equipment used in this system in a previous study. The purpose of this section is to ensure the feasibility of the calcine retrieval system by expressing concerns and issues that warrant further examination and study.

Corrosion Coupons and Miscellaneous Items in CSSFs:

Calcine retrieval will be hampered by internal obstructions inside the bins. At some point during the retrieval process, these obstructions should be removed from the bins. For example, the corrosion coupons should be retrieved from each CSSF prior to decontamination of the confinement enclosure during CSSF access. The corrosion coupons in each bin are hung from $1 / 4$ 
in. J hooks. In 1978, some of the corrosion coupon sets were retrieved from CSSF 2. A crane was used to pull the coupons from the bins. However, at least one of the coupon sets was dropped during this operation. In order to minimize the risk of dropping additional corrosion coupon sets the CCTV system should oversee the corrosion coupon removal. The bridge crane can be used to retrieve the corrosion coupons sets. Upon removal of the corrosion coupons, they should be placed in a shielded cask. The coupons should be examined for evidence of corrosion. This information is valuable for retrieval and closure of the CSSFs. The analysis should take place at ICPP in a shielded cell. After the coupons have been analyzed they should be disposed of as radioactive waste. Table 4 describes the corrosion coupons in each CSSF.

\section{Table 4. Corrosion Coupon Description}

\begin{tabular}{|c|c|l|l|}
\hline CSSF & $\begin{array}{c}\text { Number Remaining } \\
\text { in Bin }\end{array}$ & \multicolumn{1}{|c|}{ Bin Location } & \multicolumn{1}{|c|}{ Description } \\
\hline 1 & 0 & & \\
\hline 2 & $3 /$ bin & $\begin{array}{l}\text { VES-WCS-136-1 and } \\
\text { VES-WCS-136-4 }\end{array}$ & Wall mounted \\
\hline 3 & 5 & VES-WC-140-1 & Inside riser \\
\hline 4 & $5 /$ bin & All bins & Wall mounted \\
\hline 5 & $5 /$ bin & $\begin{array}{l}\text { VES-WS5-149 and } \\
\text { VES-WS5-151 }\end{array}$ & $\begin{array}{l}\text { Corrosion coupon } \\
\text { retrieval through nozzle } \\
\mathrm{J}(6 \text { in. Sch 40) }\end{array}$ \\
\hline 6 & $5 /$ bin & $\begin{array}{l}\text { VES-WS5-156 and } \\
\text { VES-WS6-159 }\end{array}$ & $\begin{array}{l}\text { Corrosion coupon } \\
\text { retrieval through nozzle } \\
\mathrm{J}(8 \text { in. })\end{array}$ \\
\hline 7 & 5 & VES-WS7-164 & $\begin{array}{l}\text { Corrosion coupons in } \\
\text { retrieval nozzle F }\end{array}$ \\
\hline
\end{tabular}

There are other miscellaneous items (such as rodout lines, weighted lines, lost samplers and penetrometer points) in the bins ${ }^{b}$. These items will not be as easy to retrieve as the corrosion coupons because their location is not known. Some of these items may be below the calcine surface while others may be on the surface of the calcine. Something must be done to reduce the risk of these items damaging the bins, the retrieval lines, and the transportation system. The air jet could pick up these items. The bin walls may not survive an impact. The bin could be breached. If these items enter the transportation system they could clog or puncture the system. The ideal solution is to detect and remove these items from the bins.

It is necessary to remove the corrosion coupons from the bins before retrieval begins. It is assumed that this activity will occur during the construction phase of the project for each CSSF. For purposes of developing a bounding cost estimate, the corrosion coupon removal activity was included in the cost estimate. A cost estimate was developed to remove the corrosion coupons. The escalated cost of planning and equipment to remove the corrosion coupons from all the

\footnotetext{
b Staiger, D. "Review of High-Level Wastes Stored at the ICPP", draft, September 1997.
} 
CSSFs is $\$ 1,620,000$. This activity was also included in the operating and maintenance cost estimate (See section 6.0 for details).

\section{Control of Retrieval Rate:}

The retrieval rate cannot be rigidly controlled due to the nature of the system. The retrieval rate depends upon several factors. As the calcine supply in the bin diminishes the retrieval rate decreases. The retrieval rate also depends upon how free flowing the calcine is. This retrieval method has been extensively tested with free flowing solids. It is anticipated that agglomerated calcine can be broken up and placed in a dilute phase by the air jet. However, retrieval of agglomerated solids in this manner has not been tested. This issue has not been examined because of the difficulty of simulating agglomerated solids on a large scale. The bins should be sampled to determine if the calcine has agglomerated. If agglomerated calcine is found, a pilot plant study should be conducted to determine the ability of agglomerated calcine to be retrieved with this retrieval method.

\section{Location and Number of Retrieval Lines:}

Limited testing has been conducted to identify the optimum location and number of retrieval lines. The number, size and location of the air jet and suction nozzles will effect the efficiency of the calcine retrieval system. It is necessary to determine if the most efficient configuration has been selected. Reference 8 suggests that two suction nozzles located $\pm 90^{\circ}$ from the air jet may be more efficient. The costs associated with this activity are included in the cost estimate for the design of the retrieval system.

Additionally, the performance of the retrieval system in a cylindrical bin is not known. Tests ${ }^{3}$ have been conducted on an annular bin mock-up. Preliminary indications from the annular bin mock up tests suggest that the retrieval system will be even more effective for these bins. This is a source of concern because the optimal suction nozzle and air jet configuration may vary significantly from that of the annular bin.

\section{CSSF Retrieval Order:}

The order that the CSSFs will be retrieved is not identified in this EDF. Each CSSF will be ready for retrieval by $1 / 1 / 2013$. The order of retrieval is heavily dependent upon the operation of the Waste Treatment Facility. The operation of the Waste Treatment Facility determines when the calcine will be retrieved. The majority of the treatment options do not require a specific blend of calcine. Therefore, they do not have a preference for the CSSF retrieval order. However, it would be beneficial to the Waste Treatment Facility operating crews to retrieve and process the more homogeneous calcine in CSSF 1 and 2 first. The closure study ${ }^{12}$ for the CSSF facilities would prefer the placement of class $C$ grout in the better constructed CSSF 5,6 , and 7 . The order the CSSFs should be retrieved to accommodate the closure schedule is CSSF1, CSSF $5, \operatorname{CSSF} 6, \operatorname{CSSF} 7, \operatorname{CSSF} 2, \operatorname{CSSF} 3$, and finally CSSF 4 . This is an issue that must be coordinated between the waste treatment options and CSSF closure. Political input should be considered a major factor in determining the retrieval order. 


\subsection{Calcine Transport}

\subsubsection{Process Basis}

The calcine transportation system will deliver the retrieved calcine from the CSSFs to the calcine Waste Treatment Facility with a pneumatic transport system. It also provides the motivation for the suction nozzle and air jet necessary for calcine retrieval (see sketches CRT-02 and CRT-03). Pneumatic transport systems have been used to transport calcine from the calcining facility (NWCF or WCF) to the CSSFs for more than 30 years. Additionally, Raytheon ${ }^{3}$ studied the advantages and disadvantages of open-loop, closed-loop, and combined loop (combining a retrieval system with a closed-loop transport system) pneumatic transportation systems. The combined loop pneumatic transport system provides the best alternative for calcine transportation because recycling of the transport air minimizes the amount of air released.

The Fluor-Daniels ${ }^{2}$ design consists of two independent transportation systems. The independent transportation systems were specified to transport zirconia and alumina calcine separately. There appears to be no advantage, to the non-separations options and TRU Separations options, to keep the zirconia calcine separate from the alumina calcine. The two independent transportation systems, in this study, will allow retrieval and transportation of calcine from 2 CSSFs at one time.

\subsubsection{Process Design}

The calcine transport system will deliver calcine from the CSSFs to the Waste Treatment Facility. Each CSSF will be connected to one of the two pneumatic transport systems. The double transport systems will provide greater flexibility during calcine retrieval (allow more desirable calcine blends to be achieved) and CSSF closure (allow retrieval of the remaining 5\% of calcine in the bins during off-peak hours).

The pneumatic transport system reduces the risk of calcine release by conveying the calcine under negative pressure. If a break develops in the transport line, air will flow in rather than out. This minimizes the risk of calcine release by reducing the potential for calcine to leave the transport line. The momentum of large particles may overcome the negative pressure and escape at an erosion failure (particularly those in bends or other direction changes). The risk of calcine release is lower for a vacuum system than for a pressure system. In a pressure system the calcine particles would be pushed out of the transport system at all erosion failures. Additionally, erosion failures in the transport piping can be minimized through proper layout of the transport system ${ }^{11}$. The costs associated with properly designing the transport system are reflected in the cost estimate (section 6.0).

Each of the two transport systems will convey calcine in a $10 \mathrm{~mm}$ (4 in) 304L stainless steel line encased in $15 \mathrm{~mm}$ (6 in) 304L stainless steel line. Each transport system will have a backup calcine transport line, to be used if the original line becomes permanently clogged or otherwise unusable. Rod out stations will be placed along straight runs to clear clogged transport lines. The transport lines will be accompanied by two return air lines, one for each transport system. 
The return air lines will be $20 \mathrm{~mm}$ ( $8 \mathrm{in}$ ) $304 \mathrm{~L}$ stainless steel. These lines will be steam-traced to prevent water from condensing.

The transport lines and the return air lines will be surrounded by a concrete pipe chase. The pipe chase will be designed to allow access to the diverter valves and rod out stations. The pipe chase will minimize "shine" radiation at accessible locations. An earthen berm will shield the pipe chase. Raytheon ${ }^{3}$ examined many routings and found a large number of obstructions from CSSF 1 to CSSF 6 that prevent burying the transport lines. For purposes of this study, it is assumed that it is more convenient and cost efficient to lay the transport lines above grade. Although, above ground placement does not preclude necessary relocation of some utility lines.

Diverter valves will be used to prevent back flow of calcine into CSSF connections. These valves will be manufactured out of stainless steel. Diverter valves are a typical component of pneumatic systems. Three diverter valves will be necessary to ensure that calcine can be transported from the CSSFs to the Waste Treatment Facility in either line of the transport system. These valves are ideal for use in the calcine transport system because they require little maintenance over their service life.

It is generally accepted in industry, that a vacuum transport system can transport fluidized solids up to $300 \mathrm{ft}$ efficiently. The CWO and TRU Separations options require calcine to be delivered to the NWCF and the Calcine Dissolution Facility, respectively. The site plan for the CWO option is shown in sketch CRT-05. The site plan for the TRU Separations options can be found in the TRU Separations options study report (sketches TRU-C-6 and TRU-C-12). Calcine can be transported from all the CSSFs to these facilities without exceeding the transport distance limitation. The Waste Treatment Facility in the DCWO, HWO, and VWO options are located in the north east corner of ICPP. The required transport distance from CSSF 3 to the Waste Treatment Facility is approximately $550 \mathrm{ft}$. An Intermediate Transport Station (ITS) and two separate transport system legs must be included in the transport system design to deliver calcine from the CSSFs to the Waste Treatment Facility for the DCWO, HWO, and VWO options. The relationship between the ITS and the transport system is shown in sketches CRT-03 and CRT-04.

For the DCWO, HWO, and VWO options, the calcine transport from the CSSFs to the Waste Treatment Facility is accomplished with two transport system legs (each leg contains piping and equipment for each transport system). The first leg transports calcine from the CSSFs to the ITS. At the ITS, the transport air is separated from the fluidized calcine with a cyclone and sintered metal filter. The calcine enters a storage hopper. As the calcine is metered out of the hopper it is fluidized by the second leg of the pneumatic transport system. The calcine is then transported from the ITS to the Waste Treatment Facility, as shown in CRT-04.

\subsubsection{Process Equipment Description}

For the CWO and TRU-Separations Options, there are two independent transportation systems. For the DCWO, HWO, and VWO options, there are four transportation systems (two from the CSSFs to the ITS and two from the ITS to the Waste Treatment Facility). Each transportation system has a backup calcine transport line installed. Two sets of transport equipment (transport air blower, cyclone, sintered metal filter, heat exchanger, and balancing air blower) are located 
inside the Waste Treatment Facility for all the waste treatment options. The DCWO, HWO, and: VWO options have two additional sets of transport equipment located in the ITS. The shielding concrete chase is located between the CSSFs and the Waste Treatment Facility.

The transport air blower is a positive displacement blower. It functions as the transport air blower. For the CWO and TRU Separations options, it also serves as the retrieval blower. It has a capacity of $800 \mathrm{cfm}$ and $150 \mathrm{kPa}$ (10psi). The blower sized in the Fluor-Daniels ${ }^{2}$ design was examined in reference 11. It was found that it is slightly oversized for the longest transport line length (CSSF 3 to the Calcine Dissolution Facility). The pressure drop and solids velocity are higher than optimum for a vacuum system. However, the blower is also used to retrieve the calcine from the bins. The extra capacity may be necessary to retrieve the calcine from the bottom of the bins.

The cyclone separates approximately $99 \%$ of the calcine solids from the transport air. It is sized at $2 \mathrm{ft} \mathrm{ID} \mathrm{X} 6 \mathrm{ft}$. This size is slightly higher than the one specified by Fluor-Daniels ${ }^{2}$. A larger cyclone is suggested by the Raytheon studies. It will be reinforced with nitronic plating to reduce the risk of erosion failures.

The sintered metal filter separates the entrained calcine particulates after the transport air leaves the cyclone. About $99.9 \%$ of these particles will be removed as the transport air passes through the sintered metal filter. Air will be back blown through the sintered metal filter to deliver calcine to the process batch bin.

The heat exchanger cools the air after it leaves the transport air blower. It is anticipated this will be water cooled heat exchanger. After the air leaves the heat exchanger it will be separated. Most of the air will be recycled but $10 \%$ of it will be exhausted through the process facility exhaust system.

The balancing air blower removes excess air from transport system. It is used to maintain a slightly negative pressure in the bin being retrieved. This is necessary to provide an additional contamination confinement.

The concrete shielding chase provides shielding to the transport lines that run from CSSFs to Waste Treatment Facility. The radiation fields are reduced to acceptable levels outside the chase. The design of the chase is similar to Raytheon design. The wall thickness is increased to account for the higher transport rate. It will protect the transport lines from weather damage.

\subsubsection{Process Issues}

Even though pneumatic transport systems have been used to transport calcine for over 30 years, some process issues remain for future study. Concerns and areas requiring further study that were identified during this study are detailed in this section.

\section{Centrally Locate the Waste Treatment Facility:}

Central location of the Waste Treatment Facility will serve to minimize the length of pipe runs. This will raise the efficiency of the transport equipment. Currently, the Waste Treatment Facility 
for the DCWO, HWO, and VWO options is located far from the CSSFs (as shown in sketch CRT-04). The location chosen by the TRU Separations Options (as shown in sketches TRU-C-6 and TRU-C-12.) is a better location considering the limitations of a vacuum transport system. However, even this location has its own unresolved issues. The requirements to move the ICPP fence must be identified. The Waste Treatment Facility will extend off the current ICPP site boundary marked by the fence. It is not known if the fence can simply be moved. The Waste Treatment Facility should be located as close to the CSSFs as possible.

\subsection{Implementation}

The calcine retrieval and transportation system could be implemented in several ways. Initially, two options were examined for the capital cost estimate. Alternative A was designed to meet the minimum need of the majority of the processing options (DCWO, HWO, VWO, and TRU Separations). Alternative $\mathrm{B}$ was designed to satisfy the requirements of CWO and CSSF closure activities. Both of these options differ from the implementation plan presented by FluorDaniels ${ }^{2}$. Alternative $B$ was selected as the best implementation plan. A cost estimate is included in section 6.0 based on alternative $B$.

Alternative $\mathrm{A}$ was based on the requirements of the majority of the waste treatment options. The DCWO, HWO, VWO, and TRU Separations options require a well-blended and accurately categorized batch of calcine. These treatment options do not require a specific blend of calcine. In alternative $A$, the CSSFs were accessed (a confinement enclosure and VIC building were constructed for each CSSF) during the construction phase of the project. Two sets of retrieval equipment (consisting of a VDA and a shielded jumper) will be purchased. The retrieval equipment will be moved from CSSF to CSSF as the CSSFs are emptied. The retrieval equipment must be decontaminated before relocation. Moving the retrieval equipment between CSSFs is assumed to take less than one week.

The drawback to this implementation alternative is the impact it will have on D\&D work. CSSF closure requires that as much calcine as possible be removed from each bin. After, calcine retrieval as much as $5 \%$ of the calcine may remain in each bin. The CSSF closure study ${ }^{12}$ expects to use the retrieval equipment to remove as much as possible of the remaining calcine. The capital cost estimate for alternative A was not significantly lower that the estimate for alternative B (a copy of the preliminary capital cost estimate for alternative $A$ is located in the project file). For these reasons, alternative A was not selected for further study.

Alternative B satisfies the requirements of the remaining waste treatment option, $\mathrm{CWO}$, and CSSF closure. CWO requires a specific blend of calcine for each processing batch. The calcine blend is achieved with calcine from up to four CSSFs (see reference 13 for details). Switching between CSSFs is required to maintain the blend as large layers of calcine are encountered in the bins. The large number of required moves between CSSFs make purchasing seven sets of retrieval equipment the most cost effective selection. It is not necessary, in this alternative to move the VDAs and shielded jumpers from CSSF to CSSF. The retrieval equipment will be moved between bins within a CSSF. It is expected that moving the retrieval equipment within a CSSF can be accomplished in less than a day. 
Alternative B does not adversely impact CSSF closures. Closure can begin on each CSSF when. it is emptied. The calcine remaining in the bins will be retrieved when the high calcine retrieval rate is not necessary. Alternative B also satisfies the requirements of the DCWO, HWO, VWO, and TRU Separations options. Table 5 outlines the similarities and differences between the implementation alternatives.

\section{Table 5. Characteristics of Calcine Retrieval System Options}

\begin{tabular}{|l|c|c|}
\hline \multicolumn{1}{|c|}{ Characteristic } & Option A & Option B \\
\hline $\begin{array}{l}\text { Retrieval Rate / Transport } \\
\text { System }\end{array}$ & $2700 \mathrm{~kg} / \mathrm{hr}$ & $2700 \mathrm{~kg} / \mathrm{hr}$ \\
\hline $\begin{array}{l}\text { Number of Independent } \\
\text { Transport Systems }\end{array}$ & 2 & 2 \\
\hline $\begin{array}{l}\text { Number of Confinement } \\
\text { Enclosure and VIC } \\
\text { Building Sets }\end{array}$ & 7 & 7 \\
\hline Number of VDAs Required & 2 & 7 \\
\hline $\begin{array}{l}\text { Relocation of VDAs } \\
\text { between CSSFs (Relocation } \\
\text { Time) }\end{array}$ & $\begin{array}{c}\text { Yes } \\
\text { decontamination activities) }\end{array}$ & Not required \\
\hline $\begin{array}{l}\text { CSSFs Costed with New } \\
\text { VDAs }\end{array}$ & 1 and 2 & $1,2,3,4,5,6$, and 7 \\
\hline VDAs Relocated to CSSFs & $3,4,5,6$, and 7 & - \\
\hline $\begin{array}{l}\text { Tasks to Utilize Alternative } \\
\text { DCWO, HWO, VWO, } \\
\text { TRU Separations }\end{array}$ & $\begin{array}{c}\text { CWO (also DCWO, HWO, } \\
\text { VWO, TRU Separations) }\end{array}$ \\
\hline $\begin{array}{l}\text { Transport System Available } \\
\text { for Closure of CSSFs } \\
\text { during operations }\end{array}$ & No & Yes \\
\hline
\end{tabular}

Alternative B was selected as the best implementation option. It was used as the basis for the cost estimate.

\subsection{Input to Project Data Sheet}

A project data sheet was not completed for the calcine retrieval and transportation system. Instead the data was appended to the project data sheets for each waste treatment option. Table 6 shows the data that should be incorporated into the project data sheets of the each waste treatment option. It summarizes construction, operations, and some D\&D project data. Appendix D contains the calculations and justification for the data presented in Table 6.

The closure of the CSSFs is currently being studied, therefore, the D\&D project data for the CSSFs will be reported in reference 12. Reference 12 will cover closing of the CSSF structures, added confinement enclosures, VIC buildings, and the retrieval equipment. D\&D project data is included in Table 6 for closure of the transport lines, ITS (building and transport equipment), and 
transport equipment located in the WTF. The D\&D project data included in Table 6 is not comprehensive because a closure method for the transport lines, ITS, and transport equipment has not been developed. It was assumed that the D\&D portion of the project would have a 1year duration. The work may be more effectively accomplished over a longer period of time. A comprehensive examination of the $D \& D$ requirements of the transportation system, based on a closure method, should be completed.

\section{Table 6. Input to Project Data Sheets}

\section{Generic Information}

Structure Size $\left(\mathrm{m}^{2}\right)$

Location

\section{Construction Information}

Cost (\$): Preconstruction (escalation included)

Conceptual Design

Project Management

Permitting and Documentation

Start Up Activities

Contingency

Total Preconstruction

Cost (\$): Construction (escalation included)

Engineering, Design, and Inspection

Management Reserve (PM/CM)

Construction

Government Furnished Eqiupment

G\&A/PIF
Seven Confinement Enclosures which are each 40 ft X $40 \mathrm{ft}$ ( $978 \mathrm{~m}^{2}$ total)

Seven VIC Buildings which are each $40 \mathrm{ft} \times 60 \mathrm{ft}$ (1560 $\mathrm{m}^{2}$ total)

One ITS Building that is $600 \mathrm{ft}^{2}\left(55.7 \mathrm{~m}^{2}\right)$

A Confinement Enclosure will be built on the roof of each CSSF.

A VIC Building will be built adjacent to each CSSF.

An ITS Building will be built mid way between the CSSFs and the Waste Treatment Facility.

CWO, DCWO, HWO, VWO \& TRU Separations Options

\$ $18,000,000$

$\$ 2,700,000$

$\$ 4,800,000$

$\$ 5,100,000$

$\$ 10,500,000$

$\$ 41,100,000$

CWO \& TRU

DCWO, HWO, \& VWO Separations Options
$\$ 18,500,000$
$\$ 19,400,000$
$\$ 22,900,000$
$\$ 23,500,000$
$\$ 104,200,000$
$\$ 106,500,000$
$\$ 18,200,000$
$\$ 19,300,000$
\& $10,400,000$
$\$ 10,700,000$ 
Procurement Fees, Management Reserve, and Contingency

\section{Total Construction}

Schedule start/end: Preconstruction

Schedule start/end: Construction

Number of workers each year of construction

Number of radiation workers (construction)

Average annual worker radiation dose (rem/yr)

Heavy equipment

Equipment used

Trips

Hours of operation

Acres disturbed and duration of disturbance

Air emissions

Major gases (CO2, $\mathrm{H} 2 \mathrm{O}, \mathrm{O} 2, \mathrm{~N} 2)$

Contaminants (Particulates, $\mathrm{CO}, \mathrm{NOx}$, $\mathrm{SO}$, hydrocarbons)

Radioactive wastes

Type

Energy requirements

Electrical (MWh/yr)

Fossil fuel (liters)

Permits needed for construction
\$ $64,600,000$

$\$ 238,800,000$

$1 / 1 / 2004-12 / 31 / 2007$

$1 / 1 / 2008-12 / 32 / 2012$

100 workers per year

90 workers per year

$252 \mathrm{mrem} / \mathrm{yr}$ per worker

Mobile crane, roll off truck, loader, bulldozer, and cement truck

Cycle time/operation not applicable

$12,480 \mathrm{hr}$ (total)

0.5 acres for VIC Buildings, Transport Line Chase, ITS building and ramps

7,255 tons

42.5 tons

Contaminated fill (1500 $\left.\mathrm{yd}^{3}\right)$

Steel/asbestos $(279,000 \mathrm{lb})$

Lead bricks/mixed wastes $(4,900 \mathrm{lb})$

\section{$156 \mathrm{MWh} / \mathrm{yr}$}

283,452 liters (total)

NEPA documentation (prior to start of Title II construction); New stationary

sources/PTC/NOC/PSD for non-rad air emissions; HAP's and TAP's and RCRA (part AA, BB, and $C C$ for air) for hazardous air emissions; air operating permit; NESHAP's, NPDES, NESHAP's subpart $\mathrm{H}$ for rad air emissions; approval of Engineering Plans; Cross Connection Control Plans; reports and specifications for drinking water supply; RCRA Part A and Part B permits.

\section{Operational Information}

Cost (\$): Operations (not escalated)

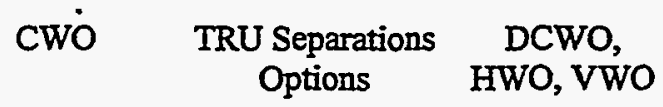


Facility Operations

Utilities

Maintenance of Equipment

Building Maintenance

Total Operations

Schedule start/end

Number of workers each year of operation

Managers

Engineers and other technicians

Supervisors and Administation/Support

Operators

Maintenance

Number of radiation workers

Average annual work radiation dose (rem/year)

Air Emissions

Type (radioactive/chemical)

Quantity (Ci/year, ton/year)

Energy Requirements

Electrical (MWh/yr)

Permits needed (for facility operations)
\$ $1,218,000$
$\$ 4,661,000$
$\$ 4,761,000$
\$ $1,054,000$
$\$ 4,158,000$
$\$ 4,158,000$
$\$ 7,866,000$
$\$ 28,840,000$
$\$ 28,840,000$
$\$ 9,255,000$
$\$ 33,933,00$
$\$ 35,120,000$
$\$ 19,393,000$
$\$ 71,594,000$
$\$ 72,781,000$

5-Year Operation: 1/1/2013 - 12/31/2017

20-Year Operation: 1/1/2013-12/31/2032

5-Year Operation 20-Year Operation

$0.5 \quad 0.25$

$0.75 \quad 0.5$

32

63

11

5-Year Operation: 10 workers

20-Year Operation: 6 workers

$192 \mathrm{mrem} / \mathrm{year}$ per worker

Calcine

CWO Option: $5.6 \times 10^{-6}$ ton/year

TRU Separations Options: $1.4 \times 10^{-6}$ ton/year

DCWO, HWO, VWO Options: $2.8 \times 10^{-6}$ ton/year

Release of $\mathrm{Ci} /$ year dependent on the type and storage length of the calcine released.

CWO Option: $93.2 \mathrm{MWh} / \mathrm{yr}$

TRU Separations Options: 74.1 MWh/yr

DCWO, HWO, VWO Options: 88.7 MWh/yr

HAP's and TAP's and RCRA (part AA, BB, and $C C$ for air) for hazardous air emissions; air operating permit; NESHAP's, NPDES, NESHAP's subpart $H$ for rad air emissions; approval of Engineering Plans; Cross Connection Control Plans; report specifications for drinking water supply; RCRA Part A and Part B permits.

Decontamination \& Decommissioning (D\&D) Information 
Cost (\$): DD\&D (Unescalated)

Decommission

Decontamination

Demolition

Total DD\&D

Schedule start/end: D\&D

Number of workers each year of D\&D (new/existing)

Number of radiation workers (D\&D)
CWO

$$
\begin{array}{cc}
\text { TRU- } & \text { DCWO, HWO, } \\
\text { Separations } & \& \text { VWO } \\
\text { Options } &
\end{array}
$$

$\$ 14,713,000 \quad \$ 21,335,000 \quad \$ 21,960,000$

CWO: $1 / 1 / 2018-12 / 31 / 2018$

TRU-Separations Options: 1/1/2034-12/31/2034

DCWO, HWO, \& VWO: 1/1/2034-12/31/2034

CWO: 108

TRU-Separations Options: 155

DCWO, HWO, \& VWO: 160

CWO: 75

TRU-Separations Options: 104

DCWO, HWO, VWO: 102

Average annual worker radiation dose (rem/yr) $252 \mathrm{mrem} / \mathrm{yr}$ for each worker

Heavy equipment

Equipment used

Hours of operation

Acres disturbed and duration of disturbance

Air emissions

Major gases (CO2, $\mathrm{H} 2 \mathrm{O}, \mathrm{O} 2, \mathrm{~N} 2)$
Mobile Cranes, Roll-off Trucks, Dozers, Loaders, cement trucks, and other specialty equipment used during $D \& D$

CWO: $4,992 \mathrm{hr}$

TRU-Separations Options: $6,240 \mathrm{hr}$ DCWO, HWO, \& VWO: $7,488 \mathrm{hr}$

CWO \& TRU-Separations Options (transport lines only): 0.09 acre

DCWO, HWO, \& VWO (ITS \& transport lines): 0.11 acre

CWO: 2,902 tons (total)

TRU-Separations: 3,627 tons (total)

DCWO, HWO \& VWO: 4,353 tons (total)

CWO: 17 tons (total)

TRU-Separations: 21 tons (total)

DCWO, HWO, \& VWO: 25 tons (total)

Solid wastes 


\author{
Type \\ Quantity $\left(\mathrm{m}^{3}\right)$ \\ Radioactive wastes \\ Type and Quantity \\ Energy requirements \\ Electrical (MWh/yr) \\ Fossil fuel (liters)
}

Permits needed (e.g. for facility closures, physical characteristics and quantities of radioactive and hazardous materials remaining after closure)
Metal building and uncontaminated transport equipment

CWO \& TRU-Separations Options: $45 \mathrm{~m}^{3}$

DCWO, HWO, \& VWO options: $90 \mathrm{~m}^{3}$

Cyclones, metal filters, and hoppers from transport system

CWO \& TRU-Separations Options: $1.2 \mathrm{~m}^{3}$

DCWO, HWO, \& VWO options: $2.6 \mathrm{~m}^{3}$

$156 \mathrm{MWh} / \mathrm{yr}$ (based on John Duggan's estimate of $3000 \mathrm{kWh} / \mathrm{wk}, 52 \mathrm{wk} / \mathrm{yr}$ )

CWO: 113,380 liters

TRU-Separations Options: 141,725 liters

DCWO, HWO, \& VWO: 170,070 liters

Work will be done under closure provisions $f$ existing permits

Some differences are present between the input to project data sheets and the more formal project data sheet. The primary difference involves the waste streams generated by the system. Quantities for effluents, solid wastes, hazardous/toxic chemicals and wastes, and pits/ponds were not reported. These values are negligible, therefore, the categories have been eliminated from Table 6. The most significant waste stream is the radioactive waste removed from the CSSFs during construction activities.

\subsection{Program Schedule}

The calcine retrieval and transportation system will observe the same construction schedule for each waste treatment option (CWO, DCWO, HWO, VWO, and TRU Separations Options). The DCWO, HWO, VWO and TRU Separations options operate under a 20-year schedule. The CWO option has a 5-year operational schedule. The calcine retrieval system has the capacity to meet both of these schedules.

\author{
Conceptual Design \\ Title Design \\ Construction \\ Operations
}

$$
\begin{aligned}
& 1 / 1 / 2004-12 / 31 / 2005 \\
& 1 / 1 / 2006-12 / 31 / 2007 \\
& 1 / 1 / 2008-12 / 31 / 2012 \\
& 1 / 1 / 2013-12 / 31 / 2032 \text { or } 1 / 1 / 2013-12 / 31 / 2017
\end{aligned}
$$

At the end of construction all of the CSSFs should be ready for retrieval by $1 / 1 / 2013$. SO testing and operational readiness reviews will be conducted during the construction period. The waste treatment options require that calcine retrieval begin on 1/1/2013 to allow time for D\&D of the 
Waste Treatment Facility and the CSSFs by the target date of 2035 for storage of road ready HIW.

The calcine retrieval and transportation system described above has the capacity to retrieve the estimated total volume of calcine during the operations time period. The total estimated volume of calcine present in the CSSFs by 2013 is $5435 \mathrm{~m}^{3}$ (determined in reference 14). The average bulk density of calcine is $1400 \mathrm{~kg} / \mathrm{m}^{3}$ (according to reference 1). The calcine retrieval and transportation system has the capacity to retrieve calcine at a combined retrieval rate of 5400 $\mathrm{kg} / \mathrm{hr}$ (two independent systems with a retrieval rate of $2700 \mathrm{~kg} / \mathrm{hr}$ ). The calcine retrieval and transportation system will need to operate for $1409 \mathrm{hr}$ to retrieve the total estimated volume of calcine. The waste treatment facilities generally assume a downtime factor of $50 \%$ to allow for equipment maintenance. Accounting for the $50 \%$ downtime factor, the calcine retrieval and transportation system will need to operate for $10.8 \mathrm{hr} / \mathrm{wk}$ and $2.7 \mathrm{hr} / \mathrm{wk}$ for the 5 -year and 20year operation schedules, respectively. The short operating time suggests that the optimum retrieval rate could be reduced without adversely impacting the schedule. The calcine retrieval and transportation system has the capacity to retrieve the total estimated volume of calcine during the required operational periods.

A retrieval schedule for the CSSFs not presented in this EDF. There are too many unknown parameters to develop a complete and optimum calcine retrieval schedule. The retrieval schedule must be coordinated between the Waste Treatment Facility and the CSSF closure study ${ }^{12}$. This section is merely intended to show that the proposed retrieval system has the capacity to retrieve the estimated volume of calcine in the time period outlined by the Consent Order. The Consent Order requires that all high level waste be placed in a road ready form by a target date of 2035. The above calculation shows the total estimated calcine volume can be retrieved and delivered to the Waste Treatment Facility in the necessary time frame.

\subsection{Costs}

The cost estimate for the calcine retrieval and transportation system was completed in modular sections to accommodate the differences in the waste treatment options. Each CSSF was independently evaluated. CSSFs 5, 6, and 7 are similar therefore one cost estimate, which may be applied to CSSF 5, 6, and 7, was developed. Two transport system costs were developed. Transport system A reflects the cost of transporting calcine from the CSSF to the necessary facilities for the CWO and TRU Separations options. Transport system B reflects the cost of transporting calcine from the CSSFs to the Waste Treatment Facility for the DCWO, HWO, and VWO options. Estimates to purchase and install D\&D risers and remove corrosion coupons are also included. The cost estimate from implementation alternative B (see section 4.0) is presented below. A preliminary cost estimate for implementation of alternative $A$ can be found in the project file.

Appendix F contains the Cost Estimate Support Data Recapitulation, summary sheets, and contingency analysis for each module of the capital cost estimate and the complete life cycle cost estimate. The detail sheets used to develop the capital cost estimate are not included in this EDF. They are located in the project file and are available upon request. 
Although the Fluor-Daniels study was the basis for this study, the total estimated cost (TEC) of the calcine retrieval and transportation system developed in this EDF is nearly twice the TEC for the Fluor-Daniels ${ }^{2}$ design. The higher cost estimate can be attributed to 4 factors. First, more demolition work during the CSSF access phase was estimated for this design than for the FluorDaniels design. The higher cost of demolition work is a result of higher estimated radiation levels in the superstructure and removal of more equipment (including the cyclone and its associated piping). Second, Fluor-Daniels specified that 2 sets of retrieval equipment (confinement enclosures, bridge cranes, VDAs, and shielded jumpers) were necessary. The sets of retrieval equipment would be moved from CSSF to CSSF. Seven sets of retrieval equipment were necessary for the design presented in this EDF because of the interfaces with the Waste Treatment Facility and the CSSF closure study. Third, the location of the Waste Treatment Facility for the DCWO, HWO, and VWO options requires an intermediate transport station to deliver the calcine to the Waste Treatment Facility. This resulted in 2 more sets of transport equipment (transport air blowers, balancing air blowers, HEPA filters, heat exchangers, cyclones, and sintered metal filters) as well as additional transport piping. This additional equipment resulted in a higher cost for the transport system. Fourth, the Fluor-Daniels study did not examine removal of corrosion coupons or installation of D\&D risers. During this study it was found to be necessary to remove the corrosion coupons prior to retrieval activities. The corrosion coupons present a significant risk to the safe and efficient operation of the calcine retrieval and transportation system. D\&D risers, installed after retrieval operations are complete, are necessary to interface with the CSSF closure project. The TEC of the calcine retrieval and transportation system developed in this EDF is nearly twice the TEC for Fluor-Daniels ${ }^{2}$ calcine retrieval and transportation system. 
Table 7. Cost Summary of the Calcine Retrieval and Transportation System

(Costs Shown are x1000)

\begin{tabular}{|c|c|c|c|c|c|}
\hline Costitem & EWo & Dewo & JAWO & IVWo & Thu separations \\
\hline $\begin{array}{l}\text { OPC (unescalated) } \\
\text { OPC Escalation } \\
\text { OPC Mgmt Reserve } \\
\text { OPC Contingency } \\
\text { Total OPC }\end{array}$ & $\begin{array}{r}21,257 \\
9,358 \\
0 \\
10,475 \\
41,100\end{array}$ & $\begin{array}{r}21,267 \\
9,358 \\
0 \\
10,475 \\
41,100\end{array}$ & $\begin{array}{r}21,267 \\
9,358 \\
0 \\
10,475 \\
41,100\end{array}$ & $\begin{array}{r}27,267 \\
9,358 \\
0 \\
10,475 \\
41,100\end{array}$ & \begin{tabular}{r|}
21,267 \\
9,358 \\
0 \\
10,475 \\
41,100
\end{tabular} \\
\hline $\begin{array}{l}\text { TEC (unescalated) } \\
\text { TEC Escalation } \\
\text { TEC Mgmt Reserve } \\
\text { TEC Contingency } \\
\text { Total TEC }\end{array}$ & $\begin{array}{r}123,193 \\
52,330 \\
13,406 \\
49,992 \\
238,921\end{array}$ & $\begin{array}{r}127,031 \\
53,841 \\
13,788 \\
51,611 \\
246,271\end{array}$ & $\begin{array}{r}127,031 \\
53,841 \\
13,788 \\
51,611 \\
246,271\end{array}$ & $\begin{array}{r}127,031 \\
53,841 \\
13,788 \\
51,611 \\
246,271\end{array}$ & $\begin{array}{r}123,193 \\
52,330 \\
13,406 \\
49,992 \\
238,921\end{array}$ \\
\hline $\begin{array}{l}\text { TPC (unescalated) } \\
\text { TPC Escalation } \\
\text { TPC Mgmt Reserve } \\
\text { TPC Contingency } \\
\text { Total TPC }\end{array}$ & $\begin{array}{r}144,460 \\
61,688 \\
13,406 \\
60,467 \\
280,021\end{array}$ & $\begin{array}{r}148,298 \\
63,199 \\
13,788 \\
62,086 \\
287,371\end{array}$ & $\begin{array}{r}148,298 \\
63,199 \\
13,788 \\
62,086 \\
287,371\end{array}$ & $\begin{array}{r}148,298 \\
63,199 \\
13,788 \\
62,086 \\
287,371\end{array}$ & $\begin{array}{r}144,460 \\
61,688 \\
13,406 \\
60,467 \\
280,021\end{array}$ \\
\hline $\begin{array}{l}\text { Operations (unescalated) } \\
\text { Operations Escalation } \\
\text { Operations Contingency } \\
\text { Total Operations }\end{array}$ & $\begin{array}{r}19,393 \\
11,085 \\
9,143 \\
39,621\end{array}$ & $\begin{array}{r}72,781 \\
71,923 \\
43,411 \\
188,115\end{array}$ & $\begin{array}{r}72,781 \\
71,923 \\
43,411 \\
188,115\end{array}$ & $\begin{array}{r}72,781 \\
71,923 \\
43,411 \\
188,115\end{array}$ & $\begin{array}{r}71,594 \\
70,751 \\
42,704 \\
185,049\end{array}$ \\
\hline $\begin{array}{l}\text { Post Operations (unescalated) } \\
\text { Post Operations Escalation } \\
\text { Post Operations Contingency } \\
\text { Total Post Operations }\end{array}$ & $\begin{array}{r}14,713 \\
10,712 \\
3,814 \\
29,239\end{array}$ & $\begin{array}{r}21,960 \\
37,071 \\
8,855 \\
67,886\end{array}$ & $\begin{array}{r}21,960 \\
37,071 \\
8,855 \\
67,886\end{array}$ & $\begin{array}{r}21,960 \\
37,071 \\
8,855 \\
67,886\end{array}$ & $\begin{array}{r}21,335 \\
36,016 \\
8,603 \\
65,954\end{array}$ \\
\hline $\begin{array}{l}\text { Total Cost (unescalated) } \\
\text { Total Cost (w/escalation, mgt reserve, \& contingency) } \\
\text { Discounted Cost (escalated) }\end{array}$ & $\begin{array}{l}778,566 \\
348,880 \\
166,409\end{array}$ & $\begin{array}{l}243,039 \\
543,379 \\
196,876\end{array}$ & $\begin{array}{l}243,039 \\
543,371 \\
196,876\end{array}$ & $\begin{array}{l}243,039 \\
543,371 \\
196,876\end{array}$ & $\begin{array}{l}237,389 \\
531,023 \\
192,309\end{array}$ \\
\hline
\end{tabular}

\subsection{Recommendations for Further Study}

Issues that should be further studied are identified in sections 3.1.4, 3.2.4, and 3.3.4. The majority of these issues will be resolved as feasibility studies and title design are completed. Several have significantly more impact on whether or not the design is viable. Efforts should be made to characterize the state of calcine in the bins as well as the radiation levels in the CSSF superstructures. The limits on the transport length of a vacuum system should be identified. The feasibility of an intermediate transport station and its configuration should be examined. A closure method should be developed for the transportation system. There are several issues that require coordination with the Waste Treatment Facility and the CSSF closure study ${ }^{12}$. These issues must be resolved before title design can begin.

\subsection{Uncertainties}

Many issues and their associated uncertainties were discussed in sections 3.1.4, 3.2.4, and 3.3.4. These issues will not be repeated in this section. The major uncertainties, which apply to the overall project, will be discussed in this section. 


\subsection{Maturity of Technology}

Guidance for determining the maturity of technology is found in the U.S. Department of Energy Standard Operating Procedure, Interim Guidance, Office of Science and Technology,Technology Decision Process, May 8, 1997. The technological maturity is classified into stages 1 through 7. They are titled Basic Research, Applied Research, Exploratory Development, Advanced Development, Engineering Development, Demonstration, and Implementation. This reference details the minimum goals, objectives, measures of effectiveness, actions, and responsibilities to include requirements for entry into the next stage.

The basic technologies (brief descriptions of these basic technologies can be found in sections 3.1.2, 3.2.2, and 3.3.2) necessary to implement the calcine retrieval and transportation system are generally well developed. The classifications of the various technologies range from the "Exploratory Development" stage to the "Implementation" stage. Some of these technologies (particularly the remote welding device and VDA) have been proven in industry in hands on applications. They must be converted for remote use prior to implementation in the calcine retrieval and transportation system. The majority of the remote technologies necessary for decontamination have been demonstrated at the INEEL and other facilities. Applied research on INEEL surrogate calcine has shown that free flowing calcine is retrievable using this technology. These systems require development and testing to ensure their reliability and performance in this application. Some aspects of engineering development require considerably more work.

\subsection{Risk Assessment}

Schedule and cost risks are identified in this EDF. They are categorized below according to the source of the risk. The risks are the same for both implementation options and project schedules. Risk Assessment Forms for all identified risks are included in Appendix E along with an explanation of the Risk Rating calculation method.

The risk ratings can vary from " 1 " to "9". The highest risk in each category is rated at " 4 ". The risks with the highest ratings will be discussed in this section.

\subsubsection{Project Risk}
P.1 Integrity of CSSF maintained
risk $=3$
P.2 Location of retrieval risers
risk $=3$
P.3 Estimated retrieval percentage too high
risk $=2$
P.4 Internal obstructions prevent retrieval
risk $=2$
P.5 Waste Treatment Facility too slow
risk $=2$
P.6 Miscellaneous materials prevent retrieval
risk $=4$

This risk is discussed in some detail in section 3.2.4. However, it bears repeating here. During filling of the CSSFs, miscellaneous materials entered the bins. No attempt has been made to remove these materials from the bins. There is a high potential that the material is scattered throughout the bins. These materials may damage the bins or the calcine retrieval and transportation system if they were to be picked by the suction nozzle or air jet. Therefore, this 
risk was assigned a probability of " 2 ." There is some potential that the schedule will be disrupted, costs will increase, and the performance of the system may be degraded. The impact of this risk is rated at " 2 " because the calcine retrieval and transportation system minimizes the impact. The potential for schedule disruption and increased costs are reduced because each transport system has a back up transport line and retrieval could be switched to another bin or CSSF.

\subsubsection{Technical Risk}

T.1 Objective retrieval rate too high

risk $=3$

T.2 All calcines are not retrievable

risk $=4$

This risk is based on an assumption. It was necessary to assume at the onset that all types of calcine could be retrieved with one system. It is possible that some of the calcine in the CSSFs is agglomerated. If it is agglomerated the potential exists that it is not retrievable. Schedule disruptions and increased costs are possible if a significant amount of calcine is not retrievable using the calcine retrieval and transportation system. This risk was assigned a probability and impact of " 2 " because it is possible that it will occur and adversely affect the schedule and costs.

\subsubsection{ES\&H Risk}

\section{ESH. 1 Construction radiation dose rates incorrect risk $=4$}

The radiation levels in the CSSF superstructures are not known. A comprehensive survey of these areas has not been conducted. The relative radiation levels used to develop the cost estimates were assumed. It is likely that these levels were incorrectly estimated. The radiation levels may be significantly higher in the CSSF superstructure. If the actual radiation levels are different from the estimated levels there is a potential to impact the schedule and costs. Therefore, the probability and impact were each assigned a value of " 2 ." The risk is given a value of "4."

\subsection{Failure Modes}

Possible failure scenarios are identified in this section. It is outside the work scope of this study to evaluate these scenarios. However, efforts have been made to ensure that double confinement of the calcine is maintained at all times. This reduces the risk of a source-term release due to a failure of the calcine retrieval and transportation system. The failure modes include:

- Loss of negative pressure in the confinement enclosure

- Leakage in the confinement enclosure

- Bin breach caused during installation of additional retrieval risers leading to a calcine release into the bin vault

- Loss of calcine confinement around the retrieval equipment during operation of retrieval equipment

- Erosion failure in the transport lines 
- Erosion failure in the cyclone

- Power failure during calcine retrieval

A failure would most significantly affect the schedule. The level of significance is dependent upon the failure. Any failure is expected to halt all activities involving calcine retrieval and transportation until the cause of the failure is resolved and necessary modifications are made. The current schedule for calcine retrieval allows $50 \%$ downtime for maintenance. This allows some slack time for unanticipated failures.

\subsection{Cost Estimate Uncertainties}

Competent cost estimators who are familiar with work conducted at the ICPP prepared the cost estimate. Efforts have been made to ensure the cost estimate for the calcine retrieval and transportation system is consistent with the cost estimates for the non-separations options and the TRU Separation option. Radiation zone work has been conservatively estimated based on known incidents during filling of the CSSFs (Dan Staiger's draft report "Review of High Level Wastes Stored at the ICPP"). The assumptions used to develop the cost estimate are outlined in the introductory letter. The cost estimate is well detailed.

\subsection{Potential Impacts of NRC Licensing}

Licensing a nuclear facility requires preparing and submitting an application and supporting documents to the NRC, such as Safety Analysis Reports, an Environmental Reports, quality assurance documents, training plans, monitoring plans, and safeguards and security plans. The NRC licensing process is divided into four stages: pre-application stage, application review stage, construction and operating license stage, and decontamination and site closure stage. The licensing duration from submitting the application to receiving the license is expected to require a minimum of an additional three to five years. The benefits of NRC licensing are enhanced operating safety, strengthened relationships with stakeholders, and license-holder participation in future regulation development.

According to data developed by Fluor-Daniels ${ }^{2}$, the estimated cost for NRC licensing is $14 \%$ of the escalated Total Estimated Cost to comply with the NRC requirements that exceed the current DOE requirements. A NRC licensed facility will experience greater costs during the operating period. These additional costs are discussed in the reports for the separate processing options (in the section titled "Potential Impacts of NRC Licensing").

Some of the potential major impacts associated with NRC licensing of Waste Treatment Facilities, other than cost, are:

- Increased oversight, including more public involvement and input in all decision processes

- More restrictive physical limits on some parameters, including exposure limits, seismic, and tornado 
- More strict radiation monitoring

- Restrictions on sharing utilities between facilities

- More stringent evaluations of the impact from off-site hazards.

- Full testing required for emergency utilities

- Physical changes to the plant and equipment

- More elapsed schedule time required

- The methods to comply with some other codes and standards may be complicated and require more time

- Although the NRC may license the WTS facilities, it may not automatically inherit or adopt the same agreements and obligations with the State of Idaho and EPA Region 10 that are in place for DOE and INEEL

\subsection{Summary and Conclusions}

The calcine retrieval and transportation system presented above combines the best elements of previous studies (references 2,3, and 8), pilot plant tests, and experience. The system meets the requirements set forth in the Consent Order, statutory law, and DOE orders. The assumptions used to develop this system have strong bases.

The system was discussed in three sections: CSSF access, calcine retrieval system, and calcine transportation system. During CSSF access, the CSSFs will be prepared for calcine retrieval. Superstructure buildings, equipment, and piping will be decontaminated and removed from CSSFs 1-4. The concrete vaults of CSSFs 5-7 will be decontaminated but not removed. Existing retrieval lines will be accessed. New retrieval lines will be added to CSSFs 1,2, and 3 . The calcine retrieval and transportation systems will function simultaneously. Calcine will be retrieved from the CSSFs using a fluidizing air jet and a suction nozzle. Then the calcine will be directly placed in the pneumatic transport system for transport to the Waste Treatment Facility.

There are several issues that must be resolved before the calcine retrieval and transportation system can be termed feasible. A plan to deal with the corrosion coupons and other miscellaneous items in the bins should be developed. These items should be removed from the bins or prevented from entering the transport system. The transport system currently calls for longer transport distances than are accepted by industry. It was proposed that testing be done to verify that a vacuum system (with intermediate transport stations, if necessary) can be efficiently used over long distances. Resolving these issues will increase the feasibility of the calcine retrieval and transportation system. The remaining issues (sections 3.1.4, 3.2.4, and 3.3.4) should be resolved over the course of feasibility studies and title design. 
The cost estimate was developed in modules to allow an "apples to apples" comparison with the Fluor-Daniels retrieval and transportation system. Initially, two alternatives for implementation were examined. The first alternative was removed from consideration. It did not satisfy all the processing options and adversely impacted CSSF closure study ${ }^{12}$ because only 2 sets of retrieval equipment were specified. The second alternative represents a retrieval and transportation system that interfaces with the Waste Treatment Facility and the CSSF closure study ${ }^{12}$. A cost estimate based on the second alternative bounds the cost of the project. Separate capital cost estimates were developed for installation of D\&D risers and removal of corrosion coupons.

Life cycle costs for construction, operation, and closure of the calcine retrieval and transportation system were developed. Removal of corrosion coupons and installation of D\&D risers are included in the life cycle cost estimate for each waste treatment option.

The CWO option requires a 5-year operating period. This option uses transport system A to deliver the calcine from the CSSFs to the NWCF. The total unescalated cost for the CWO option is $\$ 178,566,000$. The total cost with escalation, management reserve, and contingency is $\$ 348,880,000$. The discounted annual cost for the CWO option is $\$ 166,409,000$.

The TRU-Separations Options requires the calcine retrieval and transportation system to operate for 20 years. This option employs transport system A to deliver the calcine from the CSSFs to the Calcine Dissolution Facility. The total unescalated cost for the CWO option is $\$ 237,389,000$. The total cost with escalation, management reserve, and contingency is $\$ 531,023,000$. The discounted annual cost for the CWO option is $\$ 192,309,000$.

The DCWO, HWO, and VWO options have a 20 year operating period. These options require transport system $B$ to deliver the calcine from the CSSFs to the Waste Treatment Facilities. The total unescalated cost for the CWO option is $\$ 243,039,000$. The total cost with escalation, management reserve, and contingency is $\$ 543,371,000$. The discounted annual cost for the CWO option is $\$ 196,876,000$. 


\section{Appendix A}

\section{Drawing}

CRT-01 HVAC Flow Diagram

CRT-02 Pneumatic Transport System

CRT-03 Intermediate Transport Station (ITS)

CRT-04 Site Plan for DCWO, HWO, and VWO

CRT-05 Site Plan for CWO 


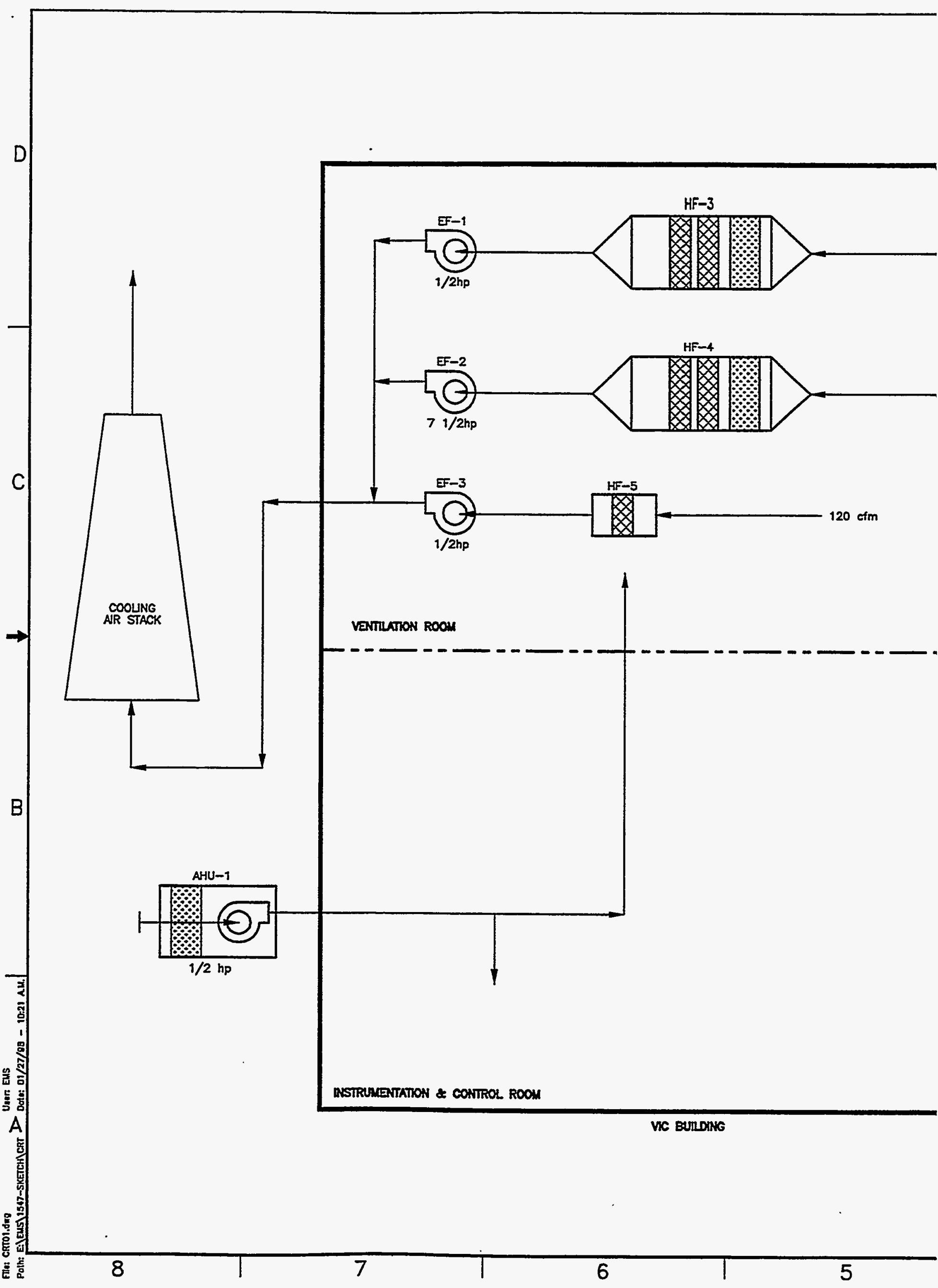




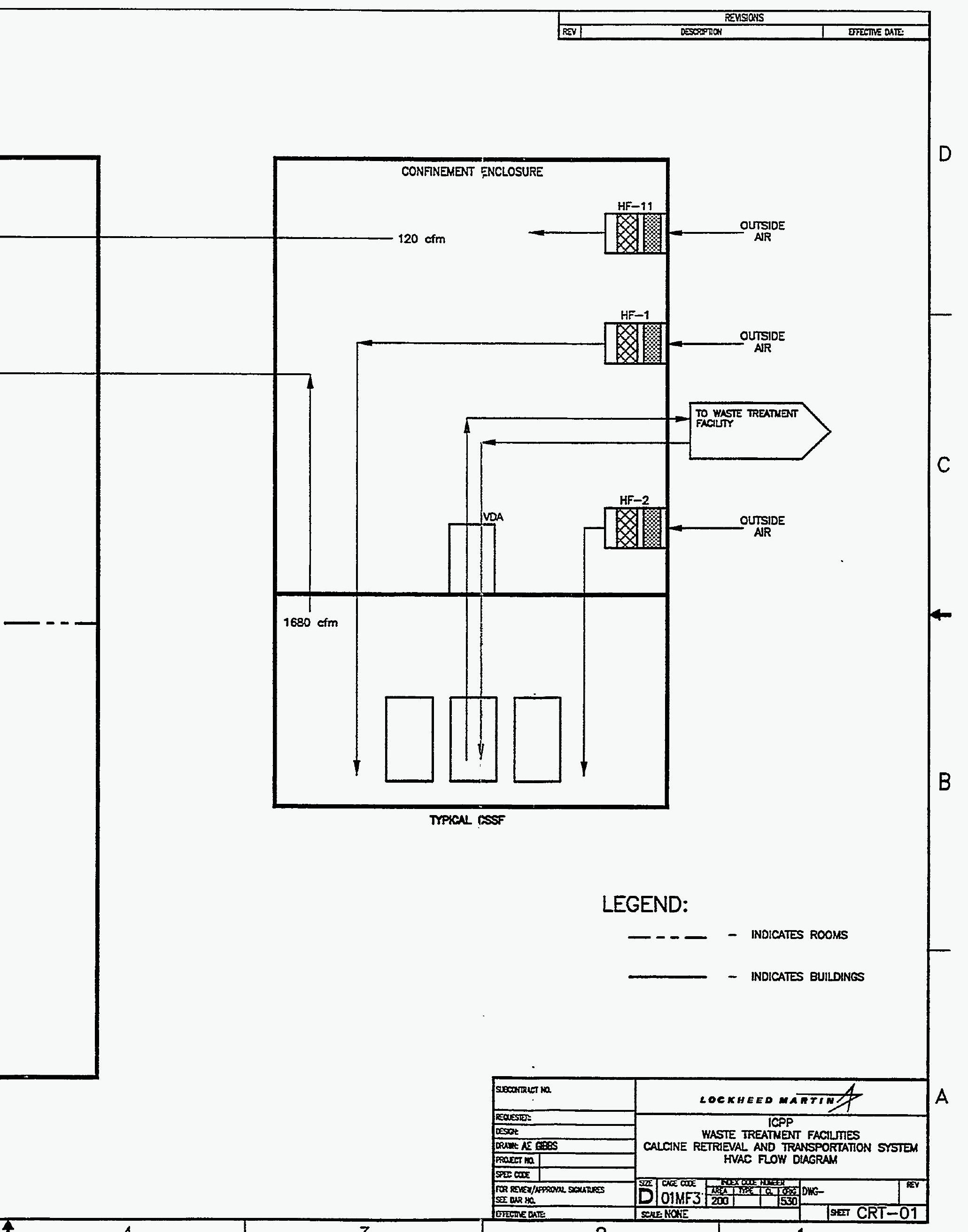




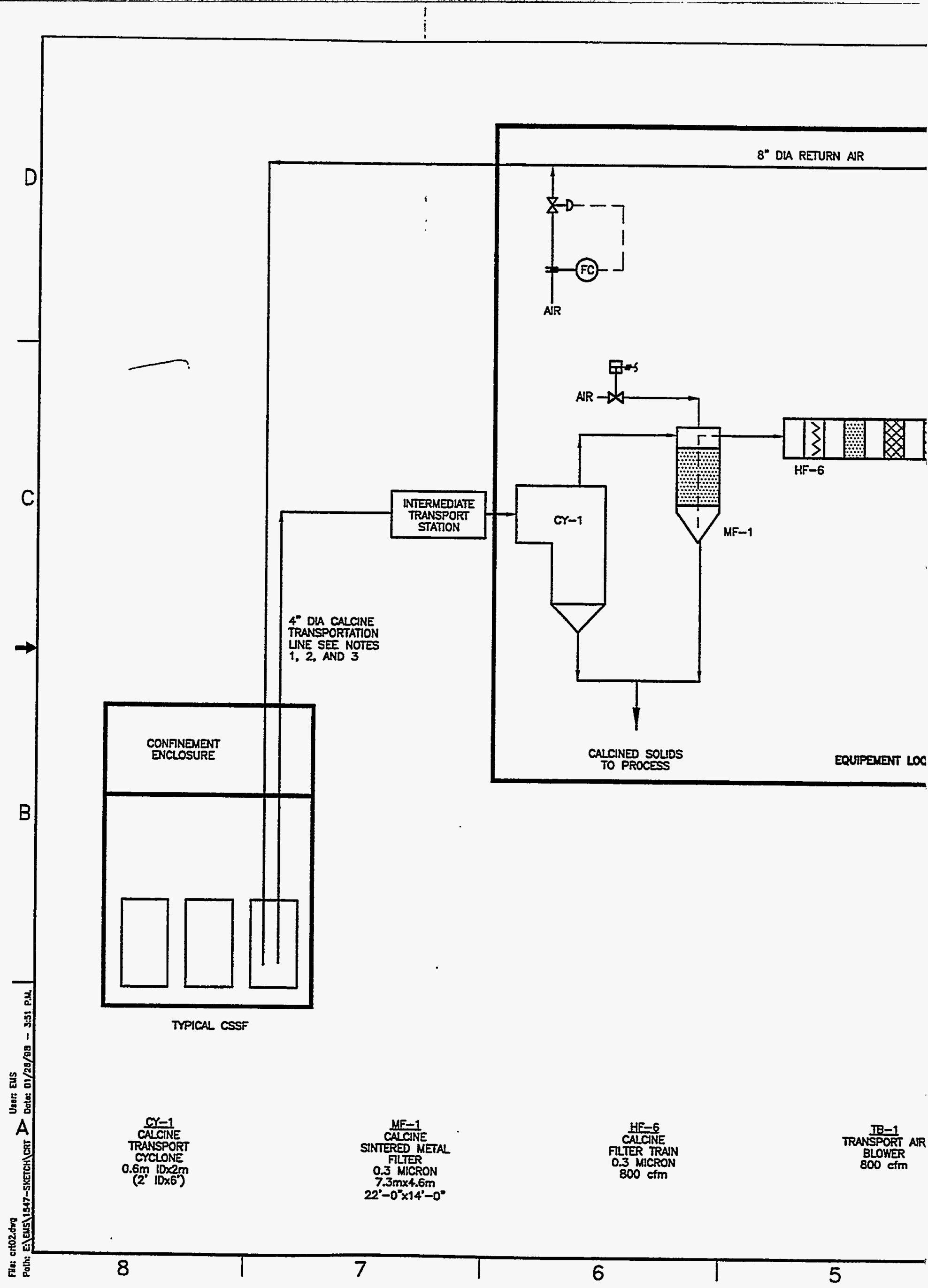




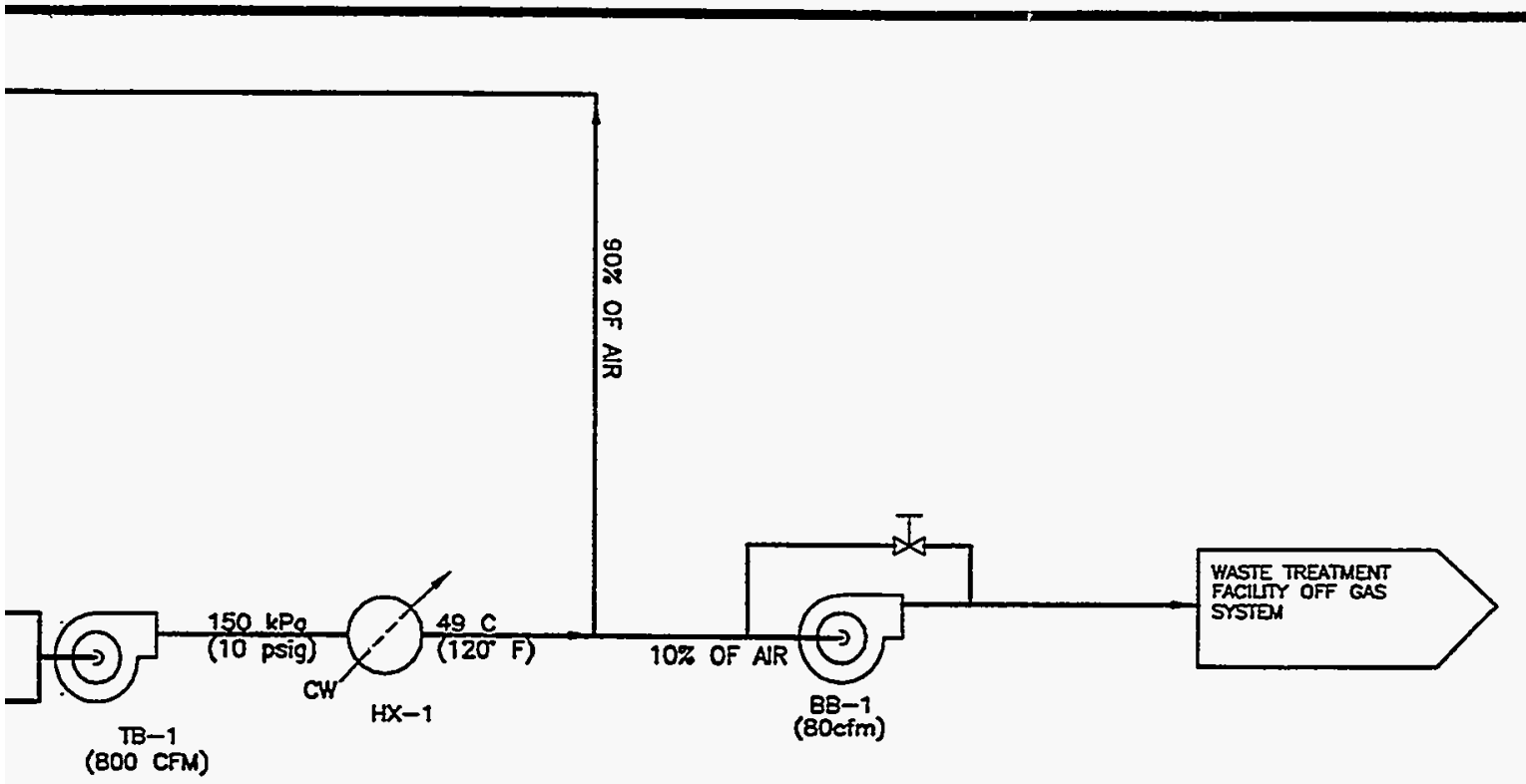

NOTES:

1. CALCINE TRANSPORT EQUIPMENT AND LNE STZES BASED ON $2700 \mathrm{~kg} / \mathrm{HR}$ CALCINE FLOWRATE AND THE LONGEST TRANSPORT ROUTE (CSSF 3 TO WASTE TREATMEVT FACILTY)

2. BACKUP CALCINE TRANSPORT LINE INSTAUED.

3. ROD OUT STATIONS LOCATED EVERY 200 FT ON STRAGHT RUNS.

4. TWO SETS OF TRANSPORT EQUIPNENT ARE PRESENT IN THE PROCESSING FACIUTT. 


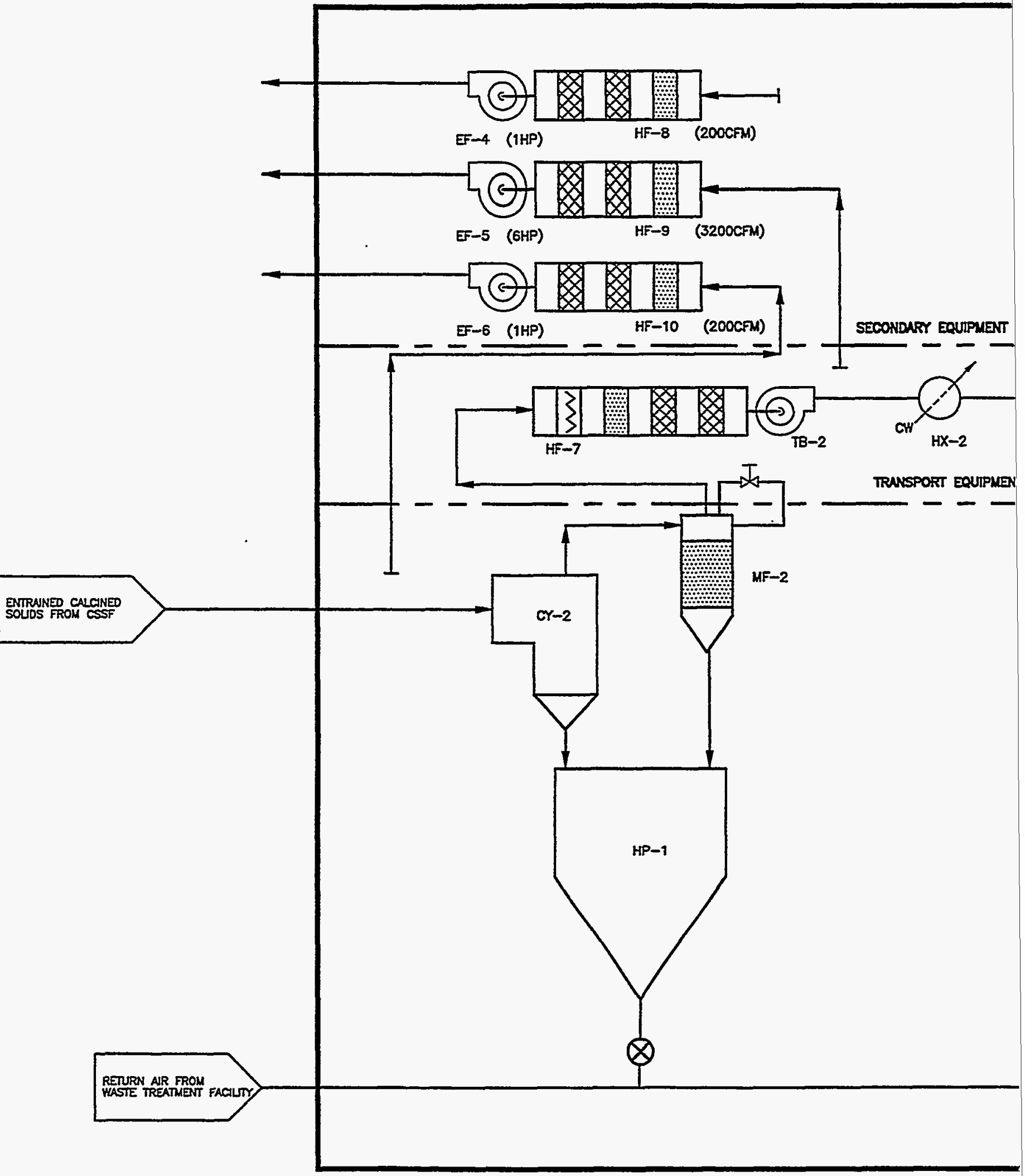

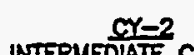

INTERMEDIATE CALCINE

TRANSPORT

CrCLONE

. $6 \mathrm{~m}^{1} 10 \times 2 \mathrm{~m}$

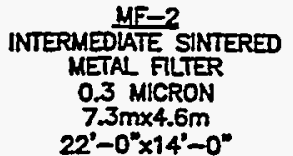

INTERMEDUATE SINTERED

METAL FLLTER

7.3mx4.6m
NTERMEOIB-2 AR BLOHER $800 \mathrm{~cm}$
INTERMEDLATE BALANGIN AR BLOHER $80 \mathrm{cfm}$ 


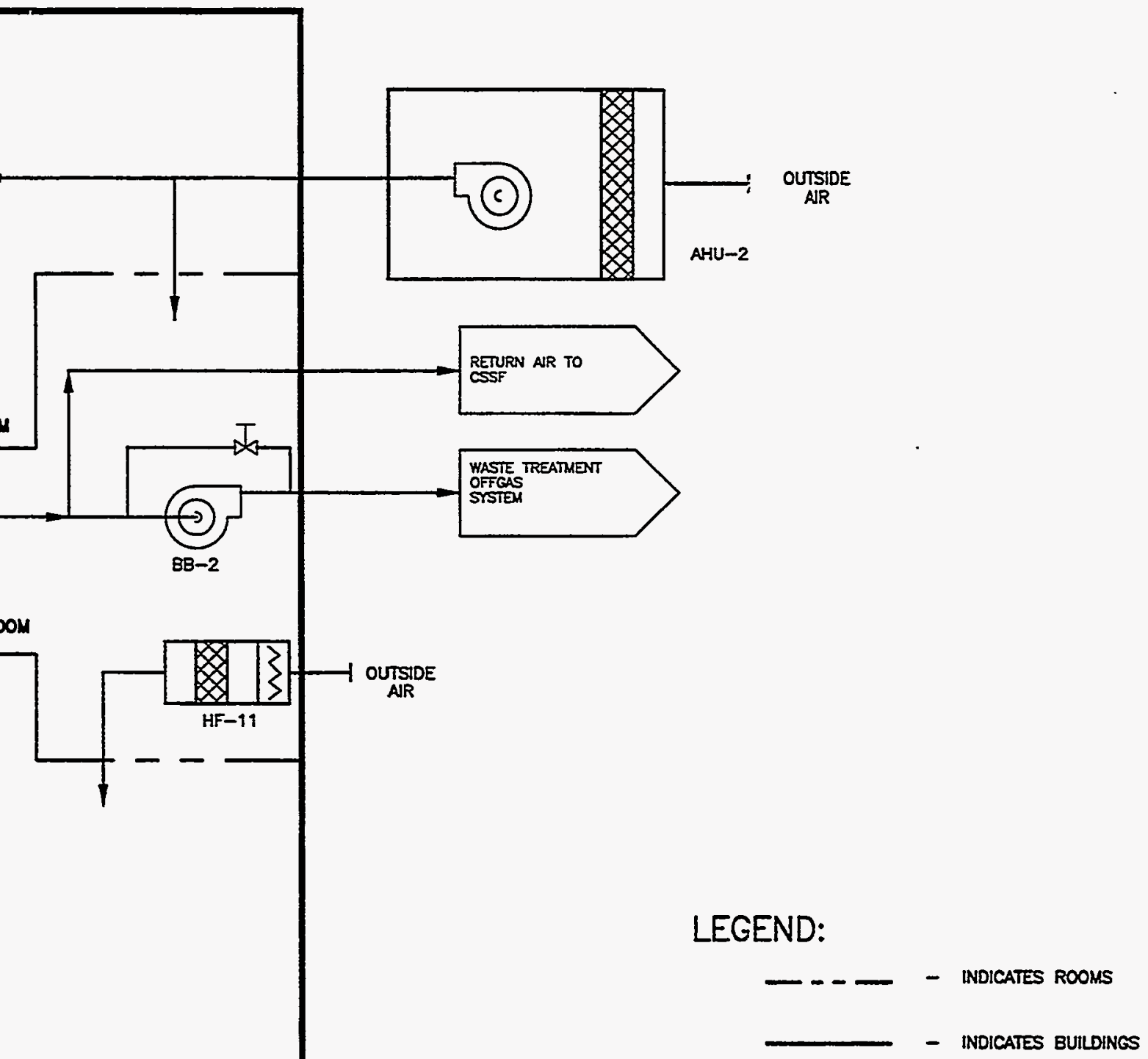

NOTES:

1. ALL EQUIPMENT SHOWN IN TRANSPORT EQUIPMENT ROOM AND TRANSPORT ROOM ARE DUPLICATED TO ACCOMODATE TWO INDEPENDENT TRANSPORT SYSTEMS.

FUIDIZED CALCINE

TO WASTE TREATMENT

FACITI

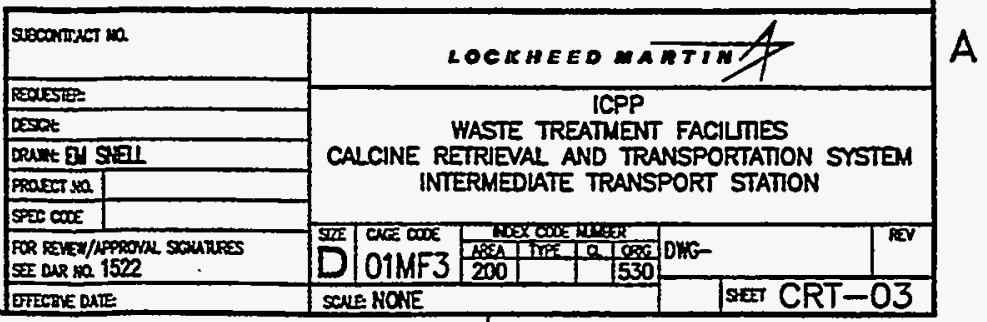




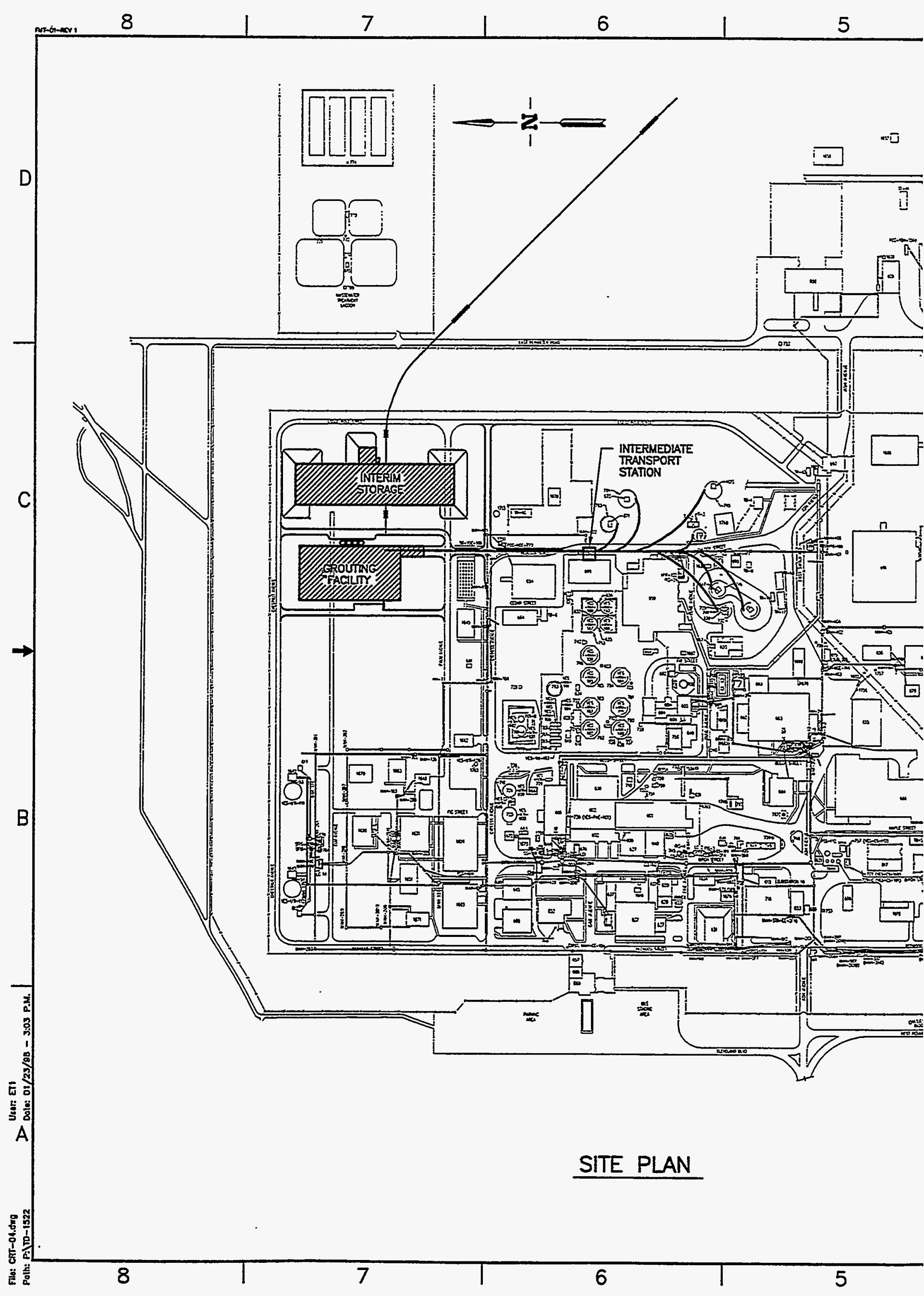




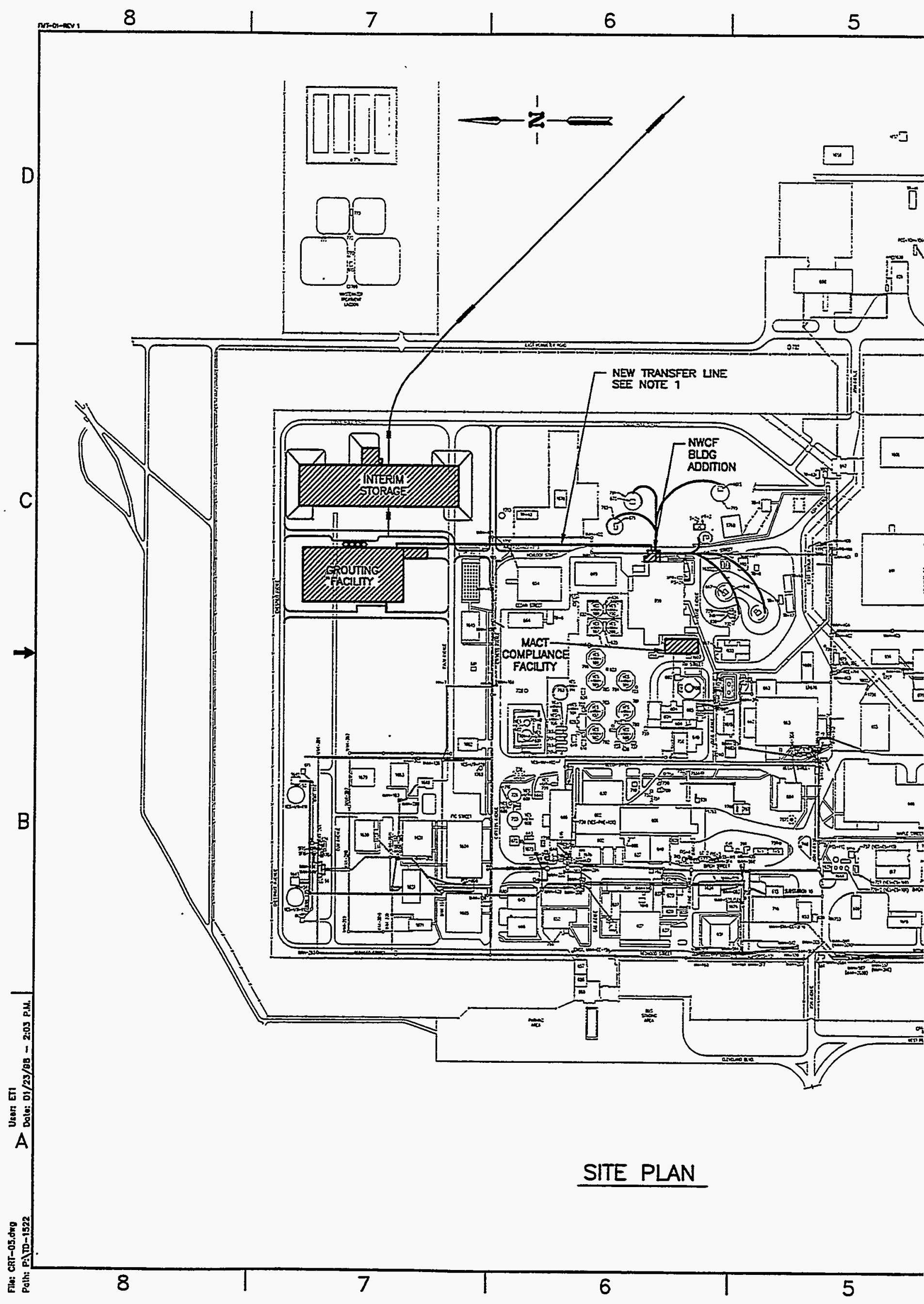




\section{Appendix B}

\section{References}

1. INEEL, Waste Inventories / Characterization Study, INEEL/EXT-97-00600, September 1997.

2. Fluor-Daniels, Inc. (Government Services Operating Company), Idaho Chemical Processing Plant Waste Treatment Facilities Feasibility Study, Delivery Order 94-36, 30\% Design Review Package, June 1997, 60\% Design Review Package, August 1997, and 90\% Design Review, October 1997.

3. Raytheon Engineers and Constructors, Inc., Idaho Chemical Processing Plant Bin Set 1 Calcine Recovery Project: Phase I and II Special Studies Report Volume I, DE-AC07-89ID12679, February 1995.

4. West Valley Nuclear Services Inc., West Valley Nuclear Services, Inc. Remote Installation of Risers on Underground Nuclear Waste Storage Tanks, DOE/NE/44139-45 (DE88010531), 1988.

5. INEEL, HWMA Closure Plan for the Waste Calcining Facility at the Idaho National Engineering and Environmental Laboratory rev 2, INEEL-96/0189, June 1997.

6. INEEL, New Waste Calcining Facility Deactivation Option for Low-level Waste Grout Disposal, INEEL/EXT-97/01076, December 1997.

7. Westra, A.G., J.S. Schofield, S.J. Horn, J.A. Hendricks, G.S. Pomiak, Sampling of Stored High-Level Radioactive Calcined Waste at ICPP, ICP-1186, May 1979

8. D. L. Griffith, Status of Calcine Retrieval Development Work-DLG-06-96, September 1996.

9. Regulatory Requirements and Standard Criteria for the ICPP Proposed Waste Processing Facilities, EDF-WTF-003.

10. Regulatory Design Requirements for Waste Treatment Facilities, EDF-WTS-004.

11. Calculations by Dan Griffith, December 1997 (included in this Appendix).

12. INEEL, Calcined Solids Storage Facility Closure Study, INEEL/EXT-97-01296, 1998.

13. INEEL, Cementitious Waste Option Study Report, INEEL/EXT-97-01400, 1998.

14.Estimates of Feed and Waste Volumes, Compositions, and Properties, EDF-FDO-011 rev. 1, 1998. 


\section{Memo of Conversation}

Name Organization Phone

Dan Griffith $\quad$ LMITCO Chief Engineer $\quad 6-3760$

$\begin{array}{lll}\text { Sara Gifford } \quad \text { MC\&I Engineering } & \text { 6-5162 }\end{array}$

Date: $\quad$ 12 November 1997

Subject: Nozzle design and retrieval system efficiency

\section{Discussion:}

In the mock up facility, the retrieval method appears to be just as efficient (if not more so) for cylindrical bins as it is for annular bins. This is evidenced by returning the solids to the outer bin.

Previous designs indicate that it is not too difficult to design a nozzle that will prevent uptake of extraneous materials. The nozzles used in the Rover project shown that it not be a significant design effort to develop a nozzle for the retrieval lines. 
Date: $\quad$ November 19, 1997

To: $\quad$ Sara Gifford

From: Dan Griffith

Subject: Pressure Drop in Proposed Preumatic Transport System

As requested I have calculated pressure drop for four cases as shown below. All cases are vacuum systems with a length of 315 fet. Inlet pressure to the transport line is 12.3 psia. I assumed the transfer line was steel pipe.

\begin{tabular}{|c|c|c|c|c|c|c|}
\hline $\begin{array}{l}\text { Diameter } \\
\text { Inches }\end{array}$ & $\begin{array}{l}\text { Flow Rate } \\
\text { at Blower } \\
\text { gim }\end{array}$ & $\begin{array}{l}\text { Solids } \\
\text { to Air Ratio } \\
\text { Ib/lb }\end{array}$ & $\begin{array}{l}\text { Solids } \\
\text { Flow } \\
\text { kg/hr }\end{array}$ & $\begin{array}{l}\text { Inlet } \\
\text { Velocity } \\
\text { fom }\end{array}$ & $\begin{array}{l}\text { Out } \\
\text { Vel. } \\
\text { fum }\end{array}$ & $\begin{array}{l}\text { Pres. } \\
\text { Drop } \\
\text { peis }\end{array}$ \\
\hline 4.026 & 800 & 3.9 & 2700 & 4635 & 9049 & 6.0 \\
\hline 4.026 & 350 & 6.0 & 2700 & 2993 & 3959 & 3.0 \\
\hline 4.026 & 350 & 2.7 & 1360 & 3380 & 3959 & 1.8 \\
\hline 3.068 & 175 & 2.7 & 680 & 2896 & 3409 & 1.9 \\
\hline
\end{tabular}

These results do not include a return air line.

Note that for the first two cases the pressure at the blower will fall below 10 psia which is the pressure you specified. The first case may not be feasible for a vacumn system because of the high pressure drop. The second case may not be feasible for a vacumm system because the high solids to air ratio might result in transport line plugging. The other two cases also have a fairly high solids to air ratios, but I believe they are feasible. If it is important to achieve such high transfer rates, we should mock this up. I could test anything but the first case in my existing pilot plant. All we would need is a feeder to meter solids in at the desired rate and 300 fect of pipe. We could consider using plastic pipe to save money. We probably have components in the old pilot plant which we could use for the feeder. 
431.02\#

$02 / 37 / 98$

Rev. \#00

\section{ENGINEERING DESIGN FILE}

Appedix C

Equipment List
Function File Number - SPR-WTS-01

EDF Serial Number - EDF-WTS-002

Page 47 of 62 


\section{Appendix C}

\section{Equipment List}

\begin{tabular}{|c|c|c|c|c|}
\hline $\begin{array}{l}\text { Equipment } \\
\text { ID }\end{array}$ & Equipment Titie & Description & Qty. & Remarks \\
\hline \multicolumn{5}{|c|}{ CSSF Access Method: HVAC } \\
\hline AHU-1 & Air Handling Unit & $\begin{array}{l}\text { Air handing unit consists of a } \\
\text { supply fan, heating coil, } \\
\text { cooling coil, filters, and dampers }\end{array}$ & 7 & $\begin{array}{l}100 \% \text { outside air unit } \\
\text { to fumish air to the } \\
\text { VIC buildings }\end{array}$ \\
\hline $\mathrm{HF}-1, \mathrm{HF}-2$ & HEPA Filter Unit & $\begin{array}{l}\text { Unit consists of a prefilter, one } \\
\text { stage of HEPA filter, and contro! } \\
\text { dampers. } 840 \mathrm{CFM}\end{array}$ & 14 & $\begin{array}{l}\text { These units filter } \\
\text { outside air supplied } \\
\text { to each CSSF. }\end{array}$ \\
\hline $\mathrm{HF}-3$ & HEPA Filter Unit & $\begin{array}{l}\text { Unit consists of a prefilter, two } \\
\text { stages of HEPA filter, and control } \\
\text { dampers. } 1680 \mathrm{CFm}\end{array}$ & 7 & $\begin{array}{l}\text { This unit filters } \\
\text { exhaust air from each CSSF. }\end{array}$ \\
\hline $\mathrm{HF}-4$ & HEPA Filter Unit & $\begin{array}{l}\text { Unit is a canister type consisting } \\
\text { of one stage HEPA filter. } 120 \mathrm{CFM}\end{array}$ & 14 & $\begin{array}{l}\text { This unit filters } \\
\text { exhaust air from the } \\
\text { vault ventilation shack. }\end{array}$ \\
\hline$E F-1, E F-3$ & Exhaust Fan & $\begin{array}{l}\text { Centrifugal exhaust fan } \\
1 / 2 \mathrm{hp}\end{array}$ & 14 & $\begin{array}{l}\text { The fan is part of the } \\
\text { exhaust filter train for } \\
\text { each CSSF. }\end{array}$ \\
\hline EF-2 & Exhaust Fan & $\begin{array}{l}\text { Centrifugal exhaust fan } \\
71 / 2 \mathrm{hp}\end{array}$ & 7 & $\begin{array}{l}\text { The fan is part of the } \\
\text { exhaust filter train for } \\
\text { the vault ventilation } \\
\text { equipment enclosure. }\end{array}$ \\
\hline \multicolumn{5}{|c|}{ CSSF Access Method: Mechanical } \\
\hline & Bridge Crane & 10 ton cap. $30^{\prime}$ span & 7 & $\begin{array}{l}\text { Drilling platform } \\
\text { placement and } \\
\text { corrosion coupon retrieval }\end{array}$ \\
\hline & $\begin{array}{l}\text { Portable } \mathrm{CO} 2 \\
\text { Decontamination System }\end{array}$ & Decontaminate vaults & 1 & $\begin{array}{l}\text { Reuseable from CSSF to } \\
\text { CSSF }\end{array}$ \\
\hline & New Retrieval Risers & $8^{\prime \prime} \operatorname{Sch} 40$ & $830^{\prime}$ & $\begin{array}{l}\text { W/ couplings each end } \\
\text { 304L steel lines }\end{array}$ \\
\hline & Shielded Windows & $\begin{array}{l}\text { View inside confinement } \\
\text { enclosure }\end{array}$ & 14 & \\
\hline \multicolumn{5}{|c|}{ CSSF Retrieval System: Remote Equipment } \\
\hline & $\begin{array}{l}\text { Remote Drilling Platform } \\
\text { a. Plug Removal Hoist } \\
\text { b. Drill Motor } \\
\text { c. Drill Bit Turret } \\
\text { d. Remote Operating } \\
\text { Station }\end{array}$ & $\begin{array}{l}\text { Remotely drill through vault roof } \\
8^{n} \text { Core w/ } 1^{\prime \prime} \text { pilot hole } \\
\text { Bridge crane placement } \\
\text { Remote drill bit exchange }\end{array}$ & 1 & $\begin{array}{l}\text { Ventilation confinement } \\
\text { Floor anchor bolts } \\
\text { Core capture feature } \\
\text { Safety barriers } \\
\text { (handrail \& signs) } \\
\text { Maintain negative pressure } \\
\text { Reuseable }\end{array}$ \\
\hline & $\begin{array}{l}\text { Protable Drilling Dust } \\
\text { Collector with Exhaust Fan }\end{array}$ & $\begin{array}{l}\text { Controls contamination spread } \\
2000 \text { CFM w/ HEPA filter }\end{array}$ & 2 & $\begin{array}{l}\text { Availvable on site } \\
\text { Reuseable }\end{array}$ \\
\hline
\end{tabular}




\begin{tabular}{|c|c|c|c|c|}
\hline $\begin{array}{c}\text { Equipment } \\
\text { ID }\end{array}$ & Equipment Titte & Description & Qty. & Remarks \\
\hline & $\begin{array}{l}\text { Remote Welding } \\
\text { Equipment including } \\
\text { Weld Inspection Unit } \\
\text { Remote Hole Saw } \\
\\
\text { cCTV Equipment } \\
\text { a. Camera Lens \& Lighting } \\
\text { b. Extension Tubes } \\
\text { c. Video Workstation wI } \\
\text { Camera } \\
\text { d. Switching Panel, } 2 \\
\text { Monitors, Light Control } \\
\text { e. TPZ Head Control, } \\
\text { Drive Interface Patch } \\
\text { Panel }\end{array}$ & $\begin{array}{l}\text { Remotely welds the risers to the } \\
\text { bins. Then inspect the integrity } \\
\text { of the welds. } \\
\text { Open bins into added retrieval } \\
\text { risers } \\
\text { Direct during retrieval riser } \\
\text { installation, View inside of bins to } \\
\text { ensure retrieval is complete. }\end{array}$ & 7 & $\begin{array}{l}\text { Similar technology used in } \\
\text { Reference } 4 \\
\text { Reuseable } \\
\text { Capture core to prevent } \\
\text { problems during retrieval } \\
\text { Reuseable } \\
\text { Inspect riser welds }\end{array}$ \\
\hline Calcine Retr & $\begin{array}{l}\text { rieval System: Mechanical } \\
\text { Retrieval lines }\end{array}$ & $\begin{array}{l}\text { rigid lines that form } \\
\text { the suction and air } \\
\text { jet lines; stainless steel }\end{array}$ & $2310^{\prime}$ & $\begin{array}{l}\text { coupling at each end } \\
\text { size:5" diameter }\end{array}$ \\
\hline Calcine Retr & $\begin{array}{l}\text { rieval System: Remote Equipr } \\
\text { Vertical Deployment } \\
\text { Apparatus } \\
\text { a. Plug Removal Hoist } \\
\text { b. Rotation Drive } \\
\text { c. Extension Tube } \\
\text { Carousel/Turret } \\
\text { d. Air Supply House Reel } \\
\text { e. Confinement Casing } \\
\text { f. Ladder \& Platforms } \\
\text { g. Extemal Drives } \\
\text { h. Telescoping Line with } \\
\text { Lower Seal } \\
\text { i. Vertical Position Indicator } \\
\text { Shielded Jumper }\end{array}$ & $\begin{array}{l}\text { Deploys extension pipe for } \\
\text { retrieval risers } \\
25^{\prime} \text { tall, } 6 \text { 'X6' base maximum } \\
\text { Vestibule houses carousel } \\
\text { Ventilation connection } \\
\\
\text { Connects discharge } \\
\text { of retrieval system to } \\
\text { the transport system }\end{array}$ & 7 & $\begin{array}{l}\text { Ventilation confinement } \\
\text { SS casing for shielding } \\
\text { Anchor to floor bolts } \\
\text { Safety barrier } \\
\text { (handrail \& signs) } \\
\text { Should be fitted so that it } \\
\text { can be used to install } \\
\text { retrieval risers as well as } \\
\text { extend retrieval lines. } \\
\\
\text { double wall, heavy wall } \\
\text { pipe, shielded and } \\
\text { independently mounted } \\
\text { (steel fianged, gasketed) }\end{array}$ \\
\hline \begin{tabular}{l|} 
Calcine Tran \\
HF -6
\end{tabular} & $\begin{array}{l}\text { sportation System: HVAC (e } \\
\text { Filter Train }\end{array}$ & $\begin{array}{l}\text { Prefilter and } 2 \text { stage } \\
\text { HEPA filters } \\
380 \mathrm{~L} / \mathrm{s}(800 \mathrm{cfm}) \\
304 \mathrm{~L} \text { stainless steel }\end{array}$ & $\begin{array}{l}\text { cility) } \\
2\end{array}$ & $\begin{array}{l}\text { Filter air before entering } \\
\text { transport air blower } \\
380 \mathrm{~s}(800 \mathrm{~cm})\end{array}$ \\
\hline $\begin{array}{l}\text { Calcine Tran } \\
\text { BB-1 } \\
\text { TB-1 }\end{array}$ & $\begin{array}{l}\text { Salancing Air Blower } \\
\text { Transport Air Blower }\end{array}$ & $\begin{array}{l}\text { (equipment located in Waste Trea } \\
80 \mathrm{cfm} \\
380 \mathrm{Ls}(800 \mathrm{cfm}) \\
\text { at } 69 \mathrm{kPa} \text { (10psi) } \\
304 \mathrm{~L} \text { stainless steel }\end{array}$ & $\begin{array}{c}2 \\
2 \\
2\end{array}$ & $\begin{array}{l}\text { Provide transport } \\
\text { air for system as well as } \\
\text { suction and air jets }\end{array}$ \\
\hline
\end{tabular}




\begin{tabular}{|c|c|c|c|c|}
\hline $\begin{array}{l}\text { Equipment } \\
\text { ID }\end{array}$ & Equipment Titte & Description & Qty. & Remarks \\
\hline MF-1 & Sintered Metal Filter & $\begin{array}{l}0.3 \text { micron } \\
380 \text { Us }(800 \mathrm{cfm}) \\
22^{\prime \prime} \times 14^{\prime} \\
304 L \text { stainless steel }\end{array}$ & 2 & $\begin{array}{l}\text { Removes calcine fines } \\
\text { entrained in air exiting the } \\
\text { cyclone and delivers to hopper }\end{array}$ \\
\hline$C Y-1$ & Cyclone & $\begin{array}{l}0.3 \mathrm{~m} \text { ID } \times 0.6 \mathrm{~m} \\
\left(1^{\prime} \text { iD } \times 22^{\prime}\right) \\
\text { Raytheon recommends } \\
\text { a longer length } 3^{\prime}-6^{\prime}\end{array}$ & 2 & $\begin{array}{l}\text { Separates calcine from } \\
\text { transport air and delivers it } \\
\text { to facility hopper }\end{array}$ \\
\hline \multirow[t]{5}{*}{$H X-1$} & Heat Exchanger & $\begin{array}{l}38 \mathrm{~kW}(0.13 \mathrm{Mbtu} / \mathrm{hr}) \\
0.3 \mathrm{~m} \times 2.4 \mathrm{~m} \\
380 \mathrm{~L} / \mathrm{s}(800 \mathrm{cfm}) \\
304 \mathrm{~L} \text { stainless steel }\end{array}$ & 2 & $\begin{array}{l}\text { Cools air from transport } \\
\text { blower to acceptable } \\
\text { operating temperature } \\
\text { of the balancing air blower }\end{array}$ \\
\hline & $\begin{array}{l}\text { Flat Side } \\
\text { Diverter Valve }\end{array}$ & $\begin{array}{l}\text { Two-way stainless } \\
\text { steel valve, electric } \\
\text { motor controlled }\end{array}$ & 21 & $\begin{array}{l}\text { Air tight valves } \\
\text { void of leakage } \\
\text { motor located outside of } \\
\text { shielding to ease repair and } \\
\text { maintenance }\end{array}$ \\
\hline & Transport Air Lines & $\begin{array}{l}20 \mathrm{~mm} \text { ( } 8 \text { in) } 304 \mathrm{~L} \\
\text { stainless steel } \\
\text { (length depends on location of } \\
\text { Waste Treatment Facility) }\end{array}$ & 2 & $\begin{array}{l}\text { Provides air for the } \\
\text { pneumatic transport } \\
\text { system; recyeled to reduce } \\
\text { releases to the environment }\end{array}$ \\
\hline & Calcine Transport Lines & $\begin{array}{l}10 \mathrm{~mm} \text { ( } 4 \mathrm{in} \text { ) } 304 \mathrm{~L} \\
\text { stainless stee! } \\
\text { (length depends on location of } \\
\text { Waste Treatment Facility) }\end{array}$ & 4 & $\begin{array}{l}\text { Transport calcine from the } \\
\text { CSSF to processing } \\
\text { facility }\end{array}$ \\
\hline & Encasement Lines & $\begin{array}{l}15 \mathrm{~mm} \text { (6 in) 304L stainless } \\
\text { steel } \\
\text { (length depends on location of } \\
\text { Waste Treatment Facility) }\end{array}$ & 4 & Encase calcine transport lines \\
\hline \multicolumn{5}{|c|}{ Calcine Transportation System: HVAC (Additional for DCWO, HWO, WWO: equipment located in Intermediate Transport Station) } \\
\hline AHU-2 & Air Handling Unit & $\begin{array}{l}\text { Air handling unit consists of a } \\
\text { supply fan, heating coil, cooling } \\
\text { coil, filters, and dampers }\end{array}$ & 1 & $\begin{array}{l}100 \% \text { outside air unit } \\
\text { to furnish air to the ITS }\end{array}$ \\
\hline HF-7 & Filter Train & $\begin{array}{l}\text { Prefilter and } 2 \text { stage } \\
\text { HEPA filters } \\
380 \mathrm{Ls}(800 \mathrm{cfm}) \\
304 \mathrm{~L} \text { stainless steel }\end{array}$ & 2 & $\begin{array}{l}\text { Filter air before entering } \\
\text { transport air blower } \\
380 \mathrm{~L} / \mathrm{s}(800 \mathrm{cfm})\end{array}$ \\
\hline HF-8 & Filter Train & $\begin{array}{l}\text { Prefilter and } 2 \text { stage } \\
\text { HEPA filters } \\
200 \mathrm{cfm}\end{array}$ & 1 & $\begin{array}{l}\text { Filter air exiting Secondary } \\
\text { Equipment Room in ITS }\end{array}$ \\
\hline HF-9 & Filter Train & $\begin{array}{l}\text { Prefilter and } 2 \text { stage } \\
\text { HEPA filters } \\
3200 \mathrm{cfm}\end{array}$ & 1 & $\begin{array}{l}\text { Filter air exiting Transport } \\
\text { Equipment Room in ITS }\end{array}$ \\
\hline $\mathrm{HF}-10$ & Filter Train & $\begin{array}{l}\text { Prefilter and } 2 \text { stage } \\
\text { HEPA filters } \\
200 \mathrm{cfm}\end{array}$ & 1 & $\begin{array}{l}\text { Filter air exiting Transport } \\
\text { Room in ITS }\end{array}$ \\
\hline
\end{tabular}




\begin{tabular}{|c|c|c|c|c|}
\hline $\begin{array}{l}\text { Equipment } \\
\text { ID }\end{array}$ & Equipment Title & Description & Qty. & Remarks \\
\hline$H F-11$ & Prefilter & $\begin{array}{l}\text { Prefilter and single } \\
\text { stage HEPA filter }\end{array}$ & 1 & $\begin{array}{l}\text { Filter air entering Transport } \\
\text { Room in ITS }\end{array}$ \\
\hline$E F-4$ & Exhaust Fan & $\begin{array}{l}\text { Centrifugal exhaust fan } \\
1 \mathrm{hp}\end{array}$ & 1 & $\begin{array}{l}\text { Exhaust fan for Secondary } \\
\text { Equipment Room in ITS }\end{array}$ \\
\hline EF-5 & Exhaust Fan & $\begin{array}{l}\text { Centrifugal exhaust fan } \\
6 \text { hp }\end{array}$ & 1 & $\begin{array}{l}\text { Exhaust fan for Transport } \\
\text { Equipment Room in ITS }\end{array}$ \\
\hline$E F-6$ & Exhaust Fan & $\begin{array}{l}\text { Centrifugal exhaust fan } \\
1 \mathrm{hp}\end{array}$ & 1 & $\begin{array}{l}\text { Exhaust fan for Transport } \\
\text { Room in ITS }\end{array}$ \\
\hline \multicolumn{5}{|c|}{ Calcine Transportation System: Mechanical (For DCWO, WWO, HWO: equipment located in Intermediate Transport Station) } \\
\hline BB-2 & Balancing Air Blower & $80 \mathrm{cfm}$ & 2 & \\
\hline TB-2 & Transport Air Blower & $\begin{array}{l}380 \mathrm{~L} / \mathrm{s}(800 \mathrm{cfm}) \\
\text { at } 69 \mathrm{kPa}(10 \mathrm{psi}) \\
304 \mathrm{~L} \text { stainless steel }\end{array}$ & 2 & $\begin{array}{l}\text { Provide transport } \\
\text { air for system as well as } \\
\text { suction and air jets }\end{array}$ \\
\hline MF-2 & $\begin{array}{l}\text { Sintered Metal Filter } \\
\end{array}$ & $\begin{array}{l}0.3 \text { micron } \\
380 \mathrm{Ls}(800 \mathrm{cfm}) \\
22^{\prime \prime} \times 14^{\prime} \\
304 \mathrm{~L} \text { stainless steel }\end{array}$ & 2 & $\begin{array}{l}\text { Removes calcine fines } \\
\text { entrained in air exiting the } \\
\text { cyclone and delivers to hopper }\end{array}$ \\
\hline $\mathrm{CY}-2$ & Cyclone & $\begin{array}{l}0.3 \mathrm{~m} \text { ID } \times 0.6 \mathrm{~m} \\
\left(1^{\prime} \text { ID } \times 2^{\prime}\right) \\
\text { Raytheon recommends } \\
\text { a longer length } 3^{\prime}-6^{\prime}\end{array}$ & 2 & $\begin{array}{l}\text { Separates calcine from } \\
\text { transport air and delivers it } \\
\text { to facility hopper }\end{array}$ \\
\hline$H X-2$ & Heat Exchanger & $\begin{array}{l}38 \mathrm{~kW}(0.13 \mathrm{Mbtu} / \mathrm{hr}) \\
0.3 \mathrm{~m} \times 2.4 \mathrm{~m} \\
380 \mathrm{Ls}(800 \mathrm{cfm}) \\
304 \mathrm{~L} \text { stainless steel }\end{array}$ & 2 & $\begin{array}{l}\text { Cools air from transport } \\
\text { blower to acceptable } \\
\text { operating temperature } \\
\text { of the balancing air blower }\end{array}$ \\
\hline$H P-1$ & Transport Hopper & $4.8 \mathrm{~m} 3$ & 2 & $\begin{array}{l}\text { Collects calcine from first leg of } \\
\text { transport system and delivers it } \\
\text { to the second leg of the transport } \\
\text { system }\end{array}$ \\
\hline
\end{tabular}




\section{Appendix D \\ Background for Project Data Sheets}

Table 6 is repeated here for convenience. The justifications for the data entered in this table are found below along with brief explanations. Reference letters coordinate the data.

\section{Table D-1. Input to Project Data Sheet}

\section{Generic Information}

Structure Size $\left(\mathrm{m}^{2}\right)$

Location

\section{Construction Information}

Cost (\$): Preconstruction (escalated included)

Conceptual Design

Project Management

Permitting and Documentation

Start Up Activities

Contingency

Total Preconstruction

Cost (\$): Construction (escalation included)

Engineering, Design, and Inspection

Management Reserve (PM/CM)

Construction

Government Furnished Eqiupment

G\&A/PIF
Seven Confinement Enclosures which are each $40 \mathrm{ft}$ X 40

$\mathrm{ft}$

(978 $\mathrm{m}^{2}$ total)

Seven VIC Buildings which are each $40 \mathrm{ft}$ X $60 \mathrm{ft}$ (1560 $\mathrm{m}^{2}$ total)

One ITS Building that is $600 \mathrm{ft}^{2}\left(55.7 \mathrm{~m}^{2}\right)$

A

A Confinement Enclosure will be built on the roof of each CSSF.

A VIC Building will be built adjacent to each CSSF.

An ITS Building will be built mid way between the CSSFs and the Waste Treatment Facility.

CWO, DCWO, HWO, VWO \& TRU Separations Options

B

\$ $18,000,000$

$\$ 2,700,000$

$\$ 4,800,000$

$\$ 5,100,000$

$\$ 10,500,000$

$\$ 41,100,000$

CWO \& TRU Separations Options

DCWO, HWO, \& VWO
$\$ 18,500,000$
S $19,400,000 \mathrm{C}$
$\$ 22,900,000$
$\$ 23,500,000$
$\$ 104,200,000$
$\$ 106,500,000$
$\$ 18,200,000$
$\$ 19,300,000$
$\$ 10,400,000$
$\$ 10,700,000$ 
Procurement Fees, Management Reserve, and Contingency

Total Construction

Schedule start/end: Preconstruction

Schedule start/end: Construction

Number of workers each year of construction

Number of radiation workers (construction)

Average annual worker radiation dose (rem/yr)

Heavy equipment

Equipment used

Trips

Hours of operation

Acres disturbed and duration of disturbance

Air emissions

Major gases (CO2, $\mathrm{H} 2 \mathrm{O}, \mathrm{O} 2, \mathrm{~N} 2)$

Contaminants (Particulates, $\mathrm{CO}, \mathrm{NO}, \mathrm{SO} 2$ hydrocarbons)

Radioactive wastes

Type (Quantity)

Energy requirements

Electrical (MWh/yr)

Fossil fuel (liters)

Permits needed for construction
Contaminated fill (1500 $\left.\mathrm{yd}^{3}\right)$

Steel/asbestos $(279,000 \mathrm{lb})$

Lead bricks/mixed wastes $(4,900 \mathrm{lb})$

$\$ 64,600,000$

\$ $66,600,000$

$\$ 238,800,000$

$\$ 246,100,000$

$1 / 1 / 2004-12 / 31 / 2007$

$1 / 1 / 2008-12 / 31 / 2013$

100 workers per year

$\mathrm{D}$

90 workers per year

$252 \mathrm{mrem} / \mathrm{yr}$ per worker

$\mathrm{E}$

F

Mobile crane, roll off truck, loader, bulldozer, and cement truck

Cycle time/operation not applicable

$12,480 \mathrm{hr}$ (total)

0.5 acres for VIC Buildings, Transport Line Chase, ITS building and ramps

7,255 tons (total)

42.5 tons (total)

$\mathrm{H}$

I

$\mathbf{J}$

$156 \mathrm{MWh} / \mathrm{yr}$

283,452 liters (total)

NEPA documentation (prior to start of Title II construction); New stationary sources/PTC/NOC/PSD for non-rad air emissions; HAP's and TAP's and RCRA (part $A A, B B$, and $C C$ for air) for hazardous air emissions; air operating permit; NESHAP's, NPDES, NESHAP's subpart $\mathrm{H}$ for rad air emissions; approval of Engineering Plans; Cross Connection Control Plans; reports and specifications for drinking water supply; RCRA Part A and Part $B$ permits.

\section{Operational Information}


Cost (\$): Operations (includes contingency but not escalation)

Facility Operations
Utilities
Maintenance of Equipment
Building Maintenance
Total Operations

Schedule start/end

Number of workers each year of operation (new/existing)

Managers

Engineers and other technicians

Supervisors and Administration/Support

Operators

Maintenance

Number of radiation workers

Average annual work radiation dose (rem/yr)

Air Emissions

Type (radioactive/chemical)

Quantity (Ci/year, tons/year)

Energy Requirements

Electrical (MWh/yr)

Permits needed (for facility operations)
CWO TRU Separations DCWO, HWO, VWO Options

$\mathrm{K}$
$\$ 1,218,000$
$\$ 4,661,000$
$\$ 4,761,000$
$\$ 1,054,000$
$\$ 4,158,000$
$\$ 4,158,000$
\$ $7,866,000$
$\$ 28,840,000$
$\$ 28,840,000$
$\$ 9,255,000$
$\$ 33,933,00$
$\$ 35,120,000$
$\$ 19,393,000$
\$ $71,594,000$
S $72,781,000$

5-Year Operation: 1/1/13-1/1/18

20-Year Operation: 1/1/13-1/1/33

5-Year Operation

20-Year Operation

0.5

0.25

0.75

0.5

3

6

2

3

1

1

5-Year Operation: 10 workers

20-Year Operation: 6 workers

$192 \mathrm{mrem} / \mathrm{year}$ per worker

Calcine

CWO Option: $5.6 \times 10^{-6}$ ton/year

TRU Separations Options: $1.4 \times 10^{-6}$ ton/year

DCWO, HWO, VWO Options: $2.8 \times 10^{-6}$ ton/year

Release of $\mathrm{Ci} /$ year dependent on the type and storage length of the calcine released.

CWO Option: $93.2 \mathrm{MWh} / \mathrm{yr}$

TRU Separations Options: $74.1 \mathrm{MWh} / \mathrm{yr}$

DCWO, HWO, VWO Options: $88.7 \mathrm{MWh} / \mathrm{yr}$

HAP's and TAP's and RCRA (part AA, BB, and CC for air) for hazardous air emissions; air operating permit; NESHAP's, NPDES, NESHAP's subpart $H$ for rad air emissions; approval of Engineering Plans; Cross Connection Control Plans; report specifications for drinking water supply; RCRA Part $A$ and $P$ art $B$ permits. 
Decontamination \& Decommissioning (D\&D)

Information

Cost (\$): DD\&D (Unescalated)

CWO

TRU-Separations Options

DCWO, HWO, \& VWO $\mathrm{P}$

Decommission

\$ $2,555,000$

\$ $2,555,000$

\$ $2,681,000$

Decontamination

\$ $7,223,000$

$\$ 7,223,000$

\$ $7,415,000$

Demolition

$\$ 4,935,000$

$\$ 11,557,000$

$\$ 11,864,000$

Total DD\&D

\$ $14,713,000$

$\$ 21,335,000$

$\$ 21,960,000$

Schedule start/end: D\&D

Number of workers each year of D\&D (new/existing)

Number of radiation workers (D\&D)

Average annual worker radiation dose (rem/yr)

Heavy equipment

Equipment used

Hours of operation

Acres disturbed and duration of disturbance

Air emissions

Major gases ( $\mathrm{CO} 2, \mathrm{H} 2 \mathrm{O}, \mathrm{O} 2, \mathrm{~N} 2)$
CWO: $1 / 1 / 2018-12 / 31 / 2018$

TRU-Separations Options: 1/1/2034-12/31/2034

DCWO, HWO, \& VWO: 1/1/2034-12/31/2034

CWO: 108

TRU-Separations Options: 155

DCWO, HWO, \& VWO: 160

CWO: 75

TRU-Separations Options: 104

DCWO, HWO, VWO: 102

$252 \mathrm{mrem} / \mathrm{yr}$ for each worker

$\mathrm{R}$

$\mathbf{S}$

Mobile Cranes, Roll-off Trucks, Dozers, Loaders, cement trucks, and other specialty equipment used during D\&D

CWO: $4,992 \mathrm{hr}$

TRU-Separations Options: $6,240 \mathrm{hr}$

DCWO, HWO, \& VWO: $7,488 \mathrm{hr}$

CWO \& TRU-Separations Options (transport lines only):

0.09 acre

$\mathrm{T}$

DCWO, HWO, \& VWO (ITS \& transport lines): 0.11 acre

CWO: 2,902 tons (total)

TRU-Separations: 3,627 tons (total)

DCWO, HWO \& VWO: 4,353 tons (total)

Contaminants (Particulates, $\mathrm{CO}, \mathrm{NO}$, $\mathrm{SO} 2$, hydrocarbons)

CWO: 17 tons (total)

TRU-Separations: 21 tons (total)

DCWO, HWO, \& VWO: 25 tons (total) 
Solid wastes

Type

Quantity $\left(\mathrm{m}^{3}\right)$

Radioactive wastes

Type and Quantity

Energy requirements

Electrical (MWh/yr)

Fossil fuel (liters)

Permits needed (e.g. for facility closures, physical characteristics and quantities of radioactive and hazardous mäterials remaining after closure)

\section{V}

Metal building and uncontaminated transport equipment

CWO \& TRU-Separations Options: $45 \mathrm{~m}^{3}$

DCWO, HWO, \& VWO options: $90 \mathrm{~m}^{3}$

Cyclones, metal filters, and hoppers from transport system

W

CWO \& TRU-Separations Options: $1.2 \mathrm{~m}^{3}$

DCWO, HWO, \& VWO options: $2.6 \mathrm{~m}^{3}$

$\mathrm{X}$

$156 \mathrm{MWh} / \mathrm{yr}$ (based on John Duggan's estimate of $3000 \mathrm{kWh} / \mathrm{wk}, 52 \mathrm{wk} / \mathrm{yr}$ )

CWO: 113,380 liters

TRU-Separations Options: 141,725 liters

DCWO, HWO, \& VWO: 170,070 liters

Work will be done under closure provisions $f$ existing permits

A. Confinement Enclosures: ( $30 \mathrm{ft} 6$ in. $X 30 \mathrm{ft} 6$ in. $)+6(40 \mathrm{ft} X 40 \mathrm{ft})=10530 \mathrm{ft}^{2}=978 \mathrm{~m}^{2}$ VIC Buildings: $7(40 \mathrm{ft} X 60 \mathrm{ft})=16,800 \mathrm{ft}^{2}=1560 \mathrm{~m}^{2}$

ITS building: $600 \mathrm{ft}^{2}=55.7 \mathrm{~m}^{2}$

B. Preconstruction costs taken from the Cost Estimate prepared by Frosty Hanson (see escalated summary sheets in Appendix F). The reported costs reflect the cost associated with CSSFs 1-7, installation of D\&D risers, removal of corrosion coupons, and the appropriate transportation system. The values reported include escalation, contingency, and management and management reserve.

C. Construction costs taken from the Cost Estimate prepared by Frosty Hanson (see escalated summary sheets in Appendix F). The reported costs reflect the cost associated with CSSFs $1-7$, installation of D\&D risers, removal of corrosion coupons, and the appropriate transportation system. The values reported include escalaton.

D. The number of construction workers per year was developed from information provided by F. P. Hanson in the capital cost estimate. A spreadsheet details how the number of construction workers was developed. The number of rad workers was taken as a high percentage (90\%) of the total number of workers due to the nature of the construction work. Typically, the number of rad workers is closer to $80 \%$ of the total work force. In this case, the electricians, welders, and other finishing personnel should receive rad worker training. 
E. Entry into and demolition work will occur in highly contaminated areas throughout the construction phase of the project. The historical dose rates at ICPP were examined to develop a reasonable estimate of the worker dose. The average annual worker dose rates at ICPP were examined for the period 1994-1996. The dose rates were highest in 1995 when a significant amount of work was completed on the tank farm. It was assumed that the 1995 dose would be representative of the average annual worker dose rate during construction. The average annual worker dose rates for 1994-1996 at ICPP are reported in a memo "Average Worker Dose Rate at ICPP" dated 11/24/97.

F. The most prominent pieces of heavy equipment used during the construction phase of this project include a mobile crane, roll off truck, loader, bulldozer, and cement truck. It is estimated that at any given time an average of 4 vehicles will be in operation during the 5year construction period. Each vehicle was assumed to operate for $624 \mathrm{hr} / \mathrm{yr}$ (which is approximately $1 / 3$ of a man-year). The hours of operation are (4 vehicles)(624 $\mathrm{hr} /$ vehicle $\left.{ }^{*} \mathrm{yr}\right)(5 \mathrm{yr})=12,480 \mathrm{hr}$.

G. For CWO and TRU-Separations Options:

VIC Buildings: $1560 \mathrm{~m}^{2}=0.39$ acre (approximately the VIC building footprint)

Transport Lines: $(800 \mathrm{ft})(5 \mathrm{ft})=4000 \mathrm{ft}^{2}=0.09$ acre (approximately the footprint of the shielding chase)

Total $=0.48$ acre which is approximately 0.5 acre

For DCWO, HWO, and VWO options:

VIC Buildings: $1560 \mathrm{~m}^{2}=0.39$ acre (approximately the VIC building footprint)

Transport Lines: $(925 \mathrm{ft})(5 \mathrm{ft})=4625 \mathrm{ft}^{2}=0.1$ acre (approximately the footprint of the shielding chase)

ITS building: $600 \mathrm{ft}^{2}=0.01$ acre

Total $=0.5$ acre

H. The construction air emissions are primarily derived from emissions of heavy equipment. A spreadsheet was developed by Rod Kimmitt to analyze the air emissions produced by heavy equipment. A copy of the spreadsheet is attached for the calcine retrieval and transportation system.

I. An estimate of the radioactive wastes removed from CSSF 1 is made in reference 3. This estimate includes removal of equipment and concrete vaults. The removed contaminated fill is estimated to be $1,500 \mathrm{yd}^{3}$. The removed steel and suspected asbestos material is estimated to weigh $5,300 \mathrm{lb}$. The lead bricks are estimated to weigh $300 \mathrm{lb}$. These estimates were used as the basis for the radiactive wastes removed from CSSF 2-7.

CSSF 2 and 3 are estimated to be similar to CSSF 1 because similar construction will occur on these CSSFs. However, the amount of contaminated fill is assumed to be negligible. There is no need to (except no contaminated fill is removed).

CSSF 4, 5, 6, and 7 are expected to have less concrete and steel removed because the superstructure vaults will not be demolished. There is no fill removal for these CSSFs. 
Equipment (steel) that is removed is estimated to weigh about $3,000 \mathrm{lb}$. The lead bricks are assumed to weigh $1,000 \mathrm{lb}$.

Contaminated fill:

Steel and suspected asbestos material:

Lead bricks and mixed waste:

$$
\begin{aligned}
& 1,500 \mathrm{yd}^{3} \\
& 3(5,300 \mathrm{lb})+4(3,000 \mathrm{lb})=279,000 \mathrm{lb} \\
& 3(300 \mathrm{lb})+4(1,000 \mathrm{lb})=4,900 \mathrm{lb}
\end{aligned}
$$

J. The electrical energy requirement is derived from John Duggan's suggestion that construction requires $3000 \mathrm{kWh} / \mathrm{wk}$. $(3000 \mathrm{kWh} / \mathrm{wk})(52 \mathrm{wk} / \mathrm{yr})=156 \mathrm{MWh} / \mathrm{yr}$. The estimated fossil fuel consumed during the construction phase of this project was determined from an average value for fuel consumption of heavy equipment. The John Deere Construction equipment web page (www.deere.com) indicates an average fuel consumption of heavy equipment to be $6 \mathrm{gal} / \mathrm{hr}$. $(6 \mathrm{gal} / \mathrm{hr})(12,480 \mathrm{hr})=74,880 \mathrm{gal}=283,452$ liters.

K. Operational costs are derived from the Cost Estimate prepared by Bob Turk. The operational costs associated with retrieving calcine from CSSF 1-7 and transport system, installation of $D \& D$ risers, and removal of corrosion coupons are included. These values are not escalated.

L. Operational crew requirements were developed with the assistance of Jack Prendergast for the 5-year and 20-year operations options. The number of radiation workers was derived from the number of operators, maintenance workers, and other technicians.

M. The average value of the average annual dose rates at ICPP for 1994-1996 was used to determine the average annual work radiation does rate during operations. The average over the 3 year period is more representative of work that would occur during the operations phase of the calcine retrieval and transportation system. $(180 \mathrm{mrem} / \mathrm{yr}+252 \mathrm{mrem} / \mathrm{yr}+143$ $\mathrm{mrem} / \mathrm{yr}$ ) $/ 3=192 \mathrm{mrem} / \mathrm{yr}$. See attached memo (also referenced in E).

N. During normal operations and idle time for each CSSF, air emissions are assumed to be negligible due to the multiple layers of confinement. These layers include several stages of HEPA filters. Air emissions were estimated for the exhausted transport air. This estimate is developed for the transport air after it has been through a two stage HEPA filter. The air emissions are primarily composed of calcine particles. The radioactivity of the calcine emitted to the environment varies depending upon the type of calcine and its length of storage.

Assuming the cyclone will have $99 \%$ efficiency, the sintered metal filter will have $99.9 \%$ efficiency, and the HEPA filter will have $99.97 \%$ efficiency. Rod Kimmitt provided these efficiencies.

Calcine remaining in the transport air after HEPA filters: $(0.01)(0.001)(0.0003)(2700 \mathrm{~kg} / \mathrm{hr})=0.009 \mathrm{~g} / \mathrm{hr}$

Total hours each transport system must operate: $\left(5435 \mathrm{~m}^{3}\right)\left(1400 \mathrm{~kg} / \mathrm{m}^{3}\right)(1 \mathrm{hr} / 5400 \mathrm{~kg})=1409 \mathrm{hr}$ 
For CWO (5-Year Operations):

Assuming all the transport air is exhausted through the Waste Treatment Facility off-gas system.

The transportation system will release:

$$
2(0.009 \mathrm{~g} / \mathrm{hr})(1409 \mathrm{hr})=25 \mathrm{~g}=2.8 \times 10^{-5} \text { ton }
$$

The total air emissions from both transportation systems are $2.8 \times 10^{-5}$ ton for 5-years (5.6 $\mathrm{x} 10^{-6}$ ton/yr).

For TRU Separations Options (20-Year Operation):

Assuming all the transport air is exhausted through the Waste Treatment Facility off-gas system.

The transportation system will release:

$$
2(0.009 \mathrm{~g} / \mathrm{hr})(1409 \mathrm{hr})=25 \mathrm{~g}=2.8 \times 10^{-5} \text { ton }
$$

The total air emissions from both transportation systems are $2.8 \times 10^{-5}$ ton for 20-years $\left(1.4 \times 10^{-6}\right.$ ton/yr).

For DCWO, HWO, and VWO (20-Year Operation):

Assuming all the transport air is exhausted through the Waste Treatment Facility off-gas system.

The transportation system will release:

$$
4(0.009 \mathrm{~g} / \mathrm{hr})(1409 \mathrm{hr})=50 \mathrm{~g}=5.6 \times 10^{-5} \text { ton }
$$

The total air emissions from the 4 transportation system legs are $5.6 \times 10^{-5}$ ton for 20 -years $\left(2.8 \times 10^{-6}\right.$ ton $\left./ y x\right)$.

For actual operations the air emissions would be much lower because $90 \%$ of the air is recycled in the transportation system. These calculations assume that all of the transport air is released through the facility off-gas system.

0 . The power requirement is determined by the power needs of the transportation equipment, ventilation equipment, and VDA. The transport air blower and balancing air blower require $37.8 \mathrm{~kW}$ and $4 \mathrm{~kW}$ of power, respectively. The exhaust fans (EF-1 and EF-3) require $50 \mathrm{~W}$ of power. The remaining exhaust fan (EF-2) requires $1 \mathrm{~kW}$. The VDA is estimated to require $15 \mathrm{~kW}$. These power consumption values used to compute the power requirement are estimates based on manufacturer specifications.

For CWO (5-Year Operation):

The transportation system operates $10.8 \mathrm{hr} / \mathrm{wk}$ for $26 \mathrm{wk} / \mathrm{yr}$. The ventilation blowers in each VIC building operated $24 \mathrm{hr} /$ day everyday. The VDA is estimated to be in operation approximately $3 \mathrm{hr} /$ wk during calcine retrieval. 


$$
\begin{aligned}
& \text { Power }=2\left(10.8 \frac{h r}{w k}\right)\left(26 \frac{w k}{y r}\right)(37.8 k W+4 k W) \\
& +7\left(24 \frac{h r}{d a y}\right)\left(365 \frac{d a y}{y r}\right)(2(0.05 k W)+1 k W) \\
& +2\left(3 \frac{h r}{w k}\right)\left(26 \frac{w k}{y r}\right)(15 k W)=93.2 \frac{M W \cdot h r}{y r}
\end{aligned}
$$

For TRU Separations Options (20-Year Operation):

The transportation system operates $2.7 \mathrm{hr} / \mathrm{wk}$ for $26 \mathrm{wk} / \mathrm{yr}$ in this alternative. The ventilation blowers in each VIC building operate $24 \mathrm{hr} /$ day every day. The VDA is estimated to be in operation approximately $1 \mathrm{hr} / \mathrm{wk}$ during calcine retrieval.

$$
\begin{aligned}
& \text { Power }=2\left(2.7 \frac{h r}{w k}\right)\left(26 \frac{w k}{y r}\right)(37.8 k W+4 k W) \\
& +7\left(24 \frac{h r}{d a y}\right)\left(365 \frac{d a y}{y r}\right)(2(0.05 k W)+1 k W) \\
& +2\left(1 \frac{h r}{w k}\right)\left(26 \frac{w k}{y r}\right)(15 k W)=74.1 \frac{M W \cdot h r}{y r}
\end{aligned}
$$

For DCWO, HWO, VWO (20-Year Operation):

There are 4 transportation system legs operating $2.7 \mathrm{hr} / \mathrm{wk}$ for $26 \mathrm{wk} / \mathrm{yr}$ in these alternatives. Therefore, there are 4 transport air blowers and 4 balancing air blowers. The ventilation blowers in each VIC building operate $24 \mathrm{hr} /$ day every day. The VDA is estimated to be in operation approximately $1 \mathrm{hr} / \mathrm{wk}$ during calcine retrieval. Additionally, the ventilation blowers in the ITS run $24 \mathrm{hr} /$ day every day. The power requirement for EF-4 and EF-6 is estimated to be $100 \mathrm{~W}$ each. The power requirement for EF- 5 is estimated to $800 \mathrm{~W}$ based on the estimate for EF-2.

$$
\begin{aligned}
& \text { Power }=4\left(2.7 \frac{h r}{w k}\right)\left(26 \frac{w k}{y r}\right)(37.8 k W+4 k W) \\
& +7\left(24 \frac{h r}{d a y}\right)\left(365 \frac{d a y}{y r}\right)(2(0.05 k W)+1 k W) \\
& +2\left(1 \frac{h r}{w k}\right)\left(26 \frac{w k}{y r}\right)(15 k W)+\left(24 \frac{h r}{d a y}\right)\left(365 \frac{d a y}{y r}\right)(2(0.1 k W)+0.8 k W) \\
& =88.7 \frac{M W \cdot h r}{y r}
\end{aligned}
$$


P. D\&D costs taken from life cycle cost estimate developed by Bob Turk. See Appendix F. The numbers presented are not escalated.

Q. The number of workers needed during D\&D was developed from the unescalated D\&D costs (See Appendix F). The unescalated costs for each option was inputed into a spreadsheet developed by Rod Kimmitt. The spreadsheets are attached.

R. D\&D work will occur in highly contaminated areas of the transportation system. The historical dose rates at ICPP were examined to develop a reasonable estimate of the worker dose. The average annual worker dose rates at ICPP were examined for the period 19941996. The dose rates were highest in 1995 when a significant amount of work was completed on the tank farm. It was assumed that the 1995 dose would be representative of the average annual worker dose rate during construction. The average annual worker dose rates for 1994-1996 at ICPP are reported in a memo "Average Worker Dose Rate at ICPP" dated $11 / 24 / 97$. The dose during the D\&D phase was assumed to be the same as during the construction phase of the project.

S. The most prominent pieces of heavy equipment used during the $D \& D$ phase of this project include a mobile crane, roll off truck, loader, bulldozer, cement trucks, and other specialized demolition equipment.

For the CWO options, it is estimated that at any given time an average of 8 vehicles will be in operation during the 1-year construction period. Each vehicle was assumed to operate for $624 \mathrm{hr} / \mathrm{yr}$ (which is approximately $1 / 3$ of a man-year). The hours of operation are (8 vehicles $)(624 \mathrm{hr} /$ vehicle* $\mathrm{yr})(1 \mathrm{yr})=4,992 \mathrm{hr}$.

For the TRU-Separations Options, it is estimated that at any given time an average of 10 vehicles will be in operation during the 1-year construction period. Each vehicle was assumed to operate for $624 \mathrm{hr} / \mathrm{yr}$ (which is approximately $1 / 3$ of a man-year). The hours of operation are $(10$ vehicles $)\left(624 \mathrm{hr} /\right.$ vehicle $\left.^{*} \mathrm{yr}\right)(1 \mathrm{yr})=6,240 \mathrm{hr}$.

For the DCWO, HWO, and VWO options, it is estimated that at any given time an average of 12 vehicles will be in operation during the 1-year construction period. Each vehicle was assumed to operate for $624 \mathrm{hr} / \mathrm{yr}$ (which is approximately $1 / 3$ of a man-year). The hours of operation are (12 vehicles) $\left(624 \mathrm{hr} /\right.$ vehicle $\left.^{*} \mathrm{yr}\right)(1 \mathrm{yr})=7,488 \mathrm{hr}$.

T. For the CWO and TRU-Separations Options, only the transport lines are D\&D.

Transport Lines: $(800 \mathrm{ft})(5 \mathrm{ft})=4000 \mathrm{ft}^{2}=0.09$ acre (approximately the footprint of the shielding chase)

Total $=0.09$ acre which is approximately 0.5 acre

For DCWO, HWO, and VWO options:

Transport Lines: $(925 \mathrm{ft})(5 \mathrm{ft})=4625 \mathrm{ft}^{2}=0.1$ acre (approximately the footprint of the shielding chase)

ITS building: $600 \mathrm{ft}^{2}=0.01$ acre 
Total $=0.11$ acre

T. The D\&D air emissions are primarily derived from emissions of heavy equipment. A spreadsheet was developed by Rod Kimmitt to analyze the air emissions produced by heavy equipment. A copy of the spreadsheet is attached for D\&D work on the calcine transportation system.

U. For the CWO and TRU-Separations Options:

The solid wastes disposed of during the D\&D of the transport system include the 2 transport system blowers, 2 heat exchangers, and the associated piping and duct work. The transport equipment for a single transport system is located in a $10 \mathrm{ft} \mathrm{X} 20 \mathrm{ft}$ area. The equipment is assumed to be no greater than $5 \mathrm{ft}$ tall. The transport equipment is assumed to occupy $60 \%$ of the area. The associated piping is assumed to occupy $20 \%$ of the transport equipment area.

$$
\begin{aligned}
& \text { Volume }=2(0.6)(10 f t \times 20 f t \times 5 f t)+2(0.2)(10 f t \times 20 f t \times 5 f t) \\
& =1200 \mathrm{ft}^{3}+400 \mathrm{ft}^{3}=1600 \mathrm{ft}^{3}=45 \mathrm{~m}^{3}
\end{aligned}
$$

For the DCWO, HWO, and VWO options:

The solid wastes include metal from the metal building in the ITS, 4 transport system blowers, 4 heat exchangers, and the associated piping and duct work. The upper level of the ITS is $20 \mathrm{ft} \mathrm{X} 30 \mathrm{ft} \mathrm{X} 14 \mathrm{ft}$. It is assumed that the metal can be compacted into no more than $5 \mathrm{~m}^{3}$.

$$
\begin{aligned}
& \text { Volume }=4(0.6)(10 f t \times 20 f t \times 5 f t)+4(0.2)(10 f t \times 20 f t \times 5 f t)+5 m^{3} \\
& =2400 f^{3}+800 f^{3}+5 m^{3}=95 m^{3}
\end{aligned}
$$

W. For the CWO and TRU-Separations Options:

The radioactive wastes include the 2 cyclones and 2 sintered metal filters. The cyclone has a $2 \mathrm{ft}$ diameter and is $6 \mathrm{ft}$ long. The sintered metal filter has a volume of $3.1 \mathrm{ft}^{3}$. This equipment is located in the Waste Treatment Facility.

$$
\text { Volume }=(2)\left[\pi\left(\frac{2 f t}{2}\right)^{2}(6 f t)\right]+(2)\left(3.1 f^{3}\right)=44 f^{3}=1.2 m^{3}
$$

For the DCWO, HWO, and VWO options:

The radioactive wastes include 4 cyclones, 2 sintered metal filters, and hoppers. The additional equipment is located in the ITS. The hoppers hold $4.8 \mathrm{~m}^{3}$ it is assumed that it may be compacted $50 \%$.

$$
\text { Volume }=(4)\left[\pi\left(\frac{2 f t}{2}\right)^{2}(6 f t)\right]+(4)\left(3.1 f^{3}\right)+(0.5)(2)\left(4.8 m^{3}\right)=92.8 f^{3}=2.6 m^{3}
$$


$X$. The electrical energy requirement is derived from John Duggan's suggestion that construction requires $3000 \mathrm{kWh} / \mathrm{wk}$. $(3000 \mathrm{kWh} / \mathrm{wk})(52 \mathrm{wk} / \mathrm{yr})(1 \mathrm{yr})=156 \mathrm{MWh}$

The estimated fossil fuel consumed during the construction phase of this project was determined from an average value for fuel consumption of heavy equipment. The John Deere Construction equipment web page (www.deere.com) indicates an average fuel consumption of heavy equipment to be $6 \mathrm{gal} / \mathrm{hr}$.

For CWO: $(6 \mathrm{gal} / \mathrm{hr})(4,992 \mathrm{hr})=29,952 \mathrm{gal}=113,380$ liters

For TRU-Separations Options: $(6 \mathrm{gal} / \mathrm{hr})(6,240 \mathrm{hr})=37,440 \mathrm{gal}=141,725$ liters

For DCWO, HWO, and VWO options: $(6 \mathrm{gal} / \mathrm{hr})(7,488 \mathrm{hr})=44,928 \mathrm{gal}=170,070$ liters 


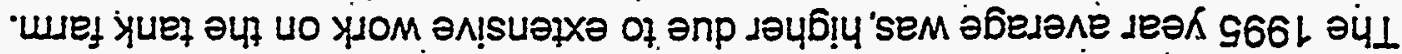

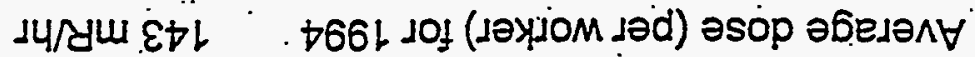

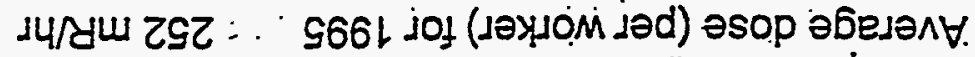

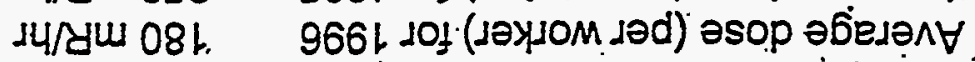

:ət!ls ddol

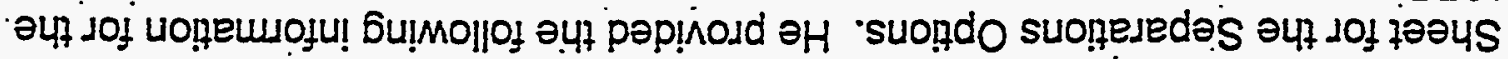

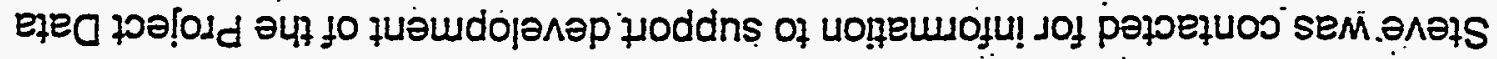

:Uo!̣snos!d

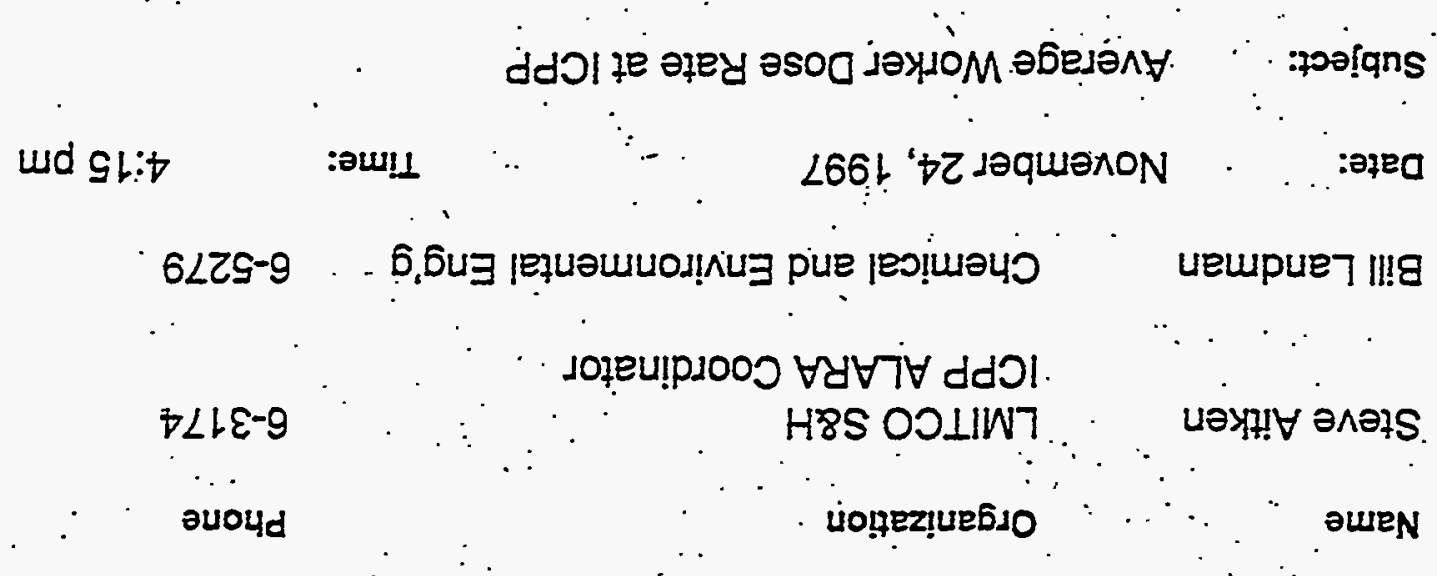

\section{uo!nessanuog auoudajo 1 to ourW}

$$
\text { 4. dnxpog }
$$


Back up to H

Construction

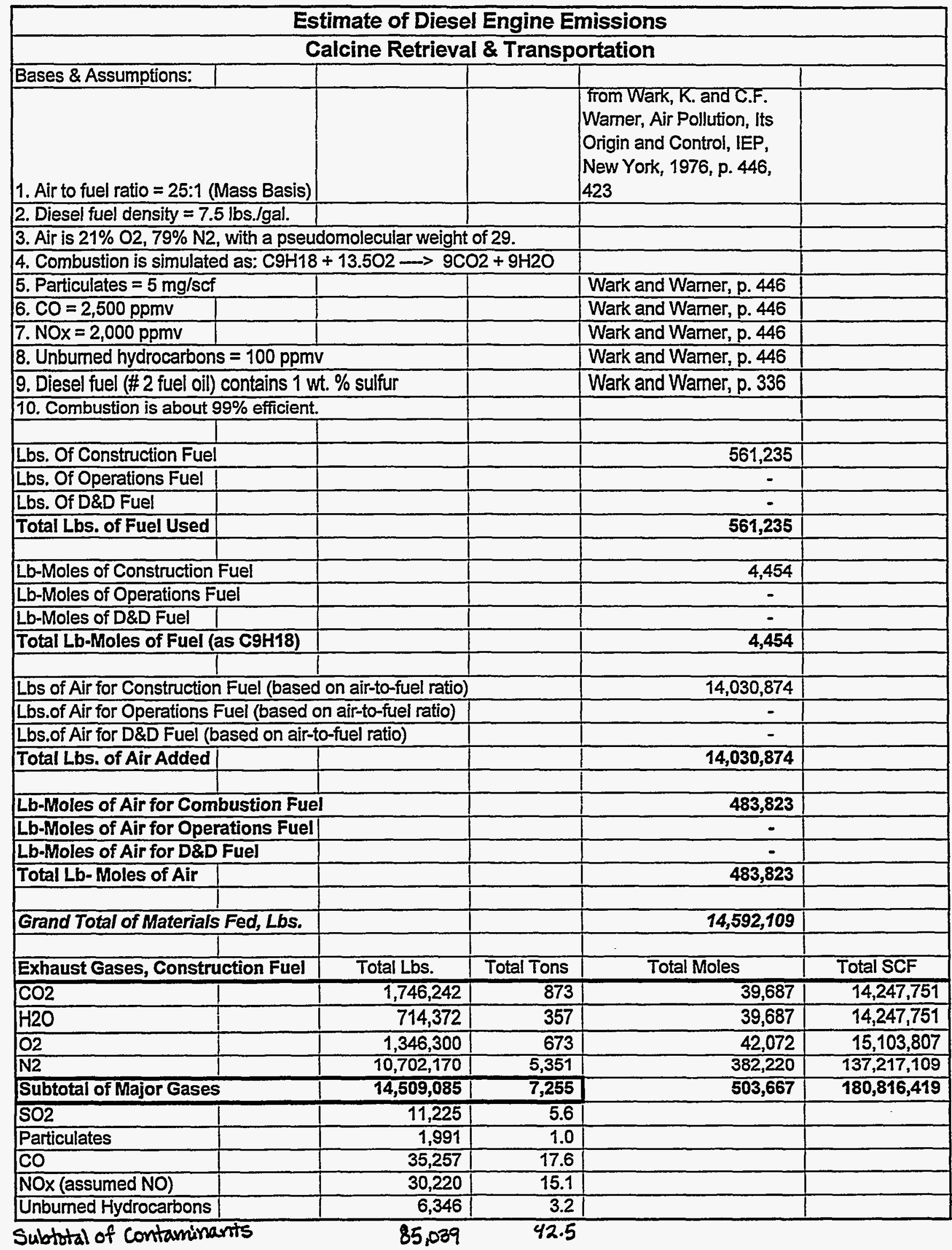




\begin{tabular}{|c|c|c|c|c|c|}
\hline & Project Data Sheet for $C$ & cine Retrieval. & - CWO & & \\
\hline Decontaminatic & on \& Decommissioning (D\&D) Information & & & & \\
\hline $\operatorname{cost}(S)$ :DeD $(1)$ & Indiscounted dollars) & & & & \\
\hline Decommission & & $\$ 2,555,000$ & & & \\
\hline Decontaminatior & & $\$ 7,223,000$ & & & \\
\hline Demolition & & $\$ 4,935,000$ & & & \\
\hline Total D\&D & & $\$ 14,713,000$ & & & \\
\hline Schedule startle & ind: D\&D & January 2033 throu & ugh Decembe & er 2037 & \\
\hline Number of work & ers each year of D\&D (new/existing) & 108 & New worker. & & \\
\hline Number of radia & tion workers (D\&D) & 75 & New worker: & & \\
\hline Average annual & worker radiation dose (rem/yr) & 0.19 & $\mid \mathrm{rem} / \mathrm{yr}$ & per worker & \\
\hline & & & & & \\
\hline Heavy equipmer & & & & & \\
\hline Equipment used & & Mobile Cranes, Rol & Il-off trucks, $\mathrm{D}$, & Jozers, Loader & \\
\hline & Roll-off trucks & 15 & |per day & & \\
\hline Hours of operati & on (all heavy equipment) & 27,990 & |Hours & & \\
\hline & & Ta & & & \\
\hline Acres disturbed & and duration of disturbance & January 2033 throt & ugh Decembe & er 2037 & \\
\hline Previous & & 2.7 & lacres & & \\
\hline Revegetated & & None & & & \\
\hline Air emissions & 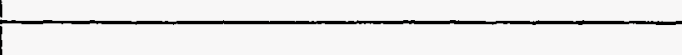 & & & & \\
\hline non-radioactive & Fuel combustion gases $\left(\mathrm{CO}_{2}, \mathrm{H}_{2} \mathrm{O}, \mathrm{O}_{2}, \mathrm{~N}_{2}\right)$ & 16,269 & tons (total) & & \\
\hline non-radioactive & $\begin{array}{l}\text { Fuel combustion contaminants (CO, } \\
\text { particulates, } \mathrm{NO}_{x} \mathrm{SO}_{2} \text {, hydrocarbons) }\end{array}$ & 95 & tons (totall) & & \\
\hline radioactive & HEPA filtered off-gas & 26,173 & tons (total) & & \\
\hline & & & & & \\
\hline $\begin{array}{l}\text { Emiluents } \\
\text { radioactive }\end{array}$ & Spent decontamination solution & $1,703,250$ & liters (total) & 1703 & $\overline{c i}$ \\
\hline non-radioactive & Sanitary wastewater & $2,295,160$ & liters (total) & & \\
\hline non-radioactive & Lube oil & 5,297 & liters (total) & & \\
\hline Solid wastes: & & & & & \\
\hline radioactive & & 29,421 & $\mathrm{~m}^{3}$ & 294 & $\overline{c i}$ \\
\hline Non-radioactive & (industrial) & 22,122 & $\mathrm{Im}^{3}$ & & \\
\hline \begin{tabular}{|l|} 
Hazardous \\
\end{tabular} & & 10 & $\mathrm{~m}^{3}$ & & \\
\hline Hazardous/toxic & chemicals and wastes (tvpe) & & & & \\
\hline Storage/invento & & 205 & $\mathrm{~m}^{3}$ (total) & & \\
\hline Pits/Ponds crea & $\operatorname{ted}\left(m^{2}\right)$ & None & & & \\
\hline radioactive & (mixed waste) & 47 & $\mathrm{~m}^{3}$ (total) & & Ci \\
\hline Water usage: & & & & & \\
\hline 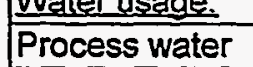 & & $\overline{2,284,875}$ & |liters (total) & & \\
\hline Domestic water & & $2,295,160$ & liters (total) & & \\
\hline Source of water & & ICPP site wells & & & \\
\hline nerov requiren & nent: & & & & \\
\hline
\end{tabular}




\section{D\&D Labor}

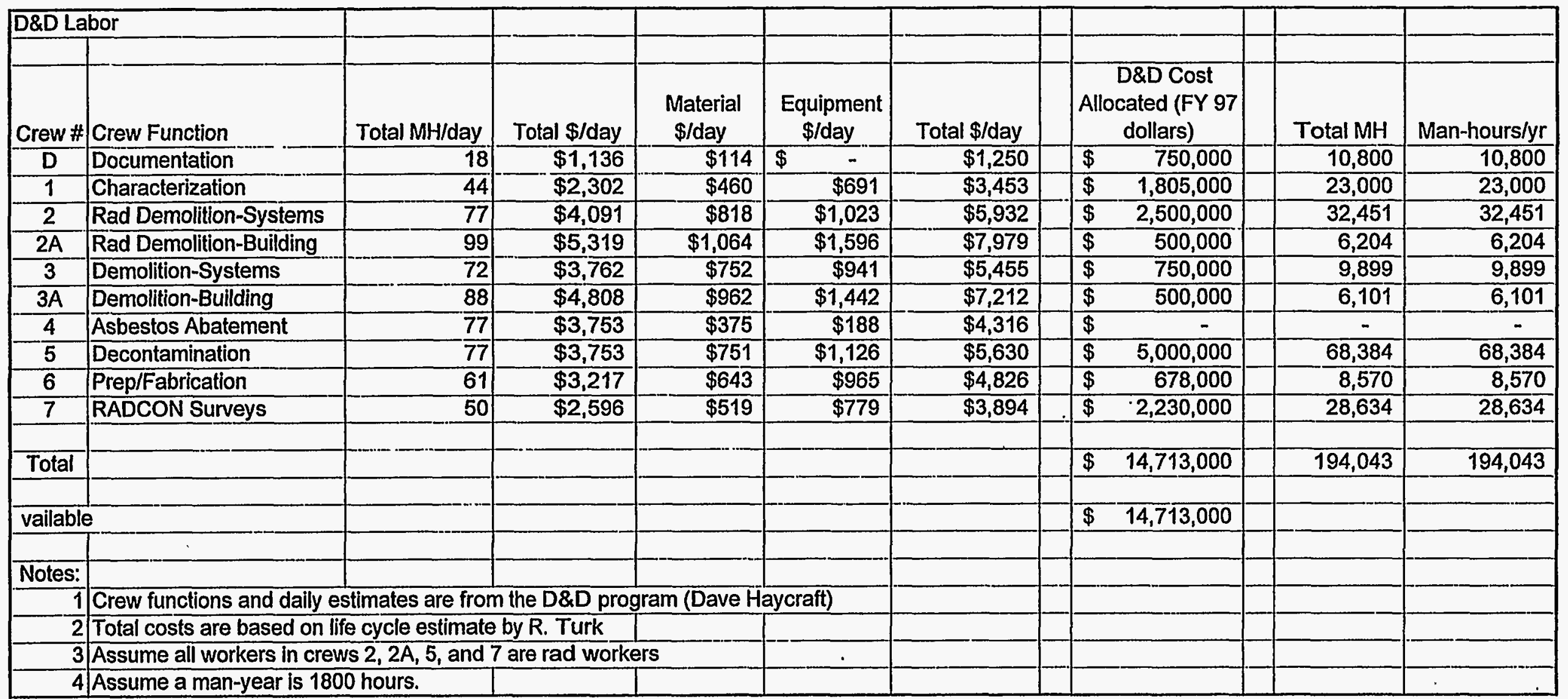




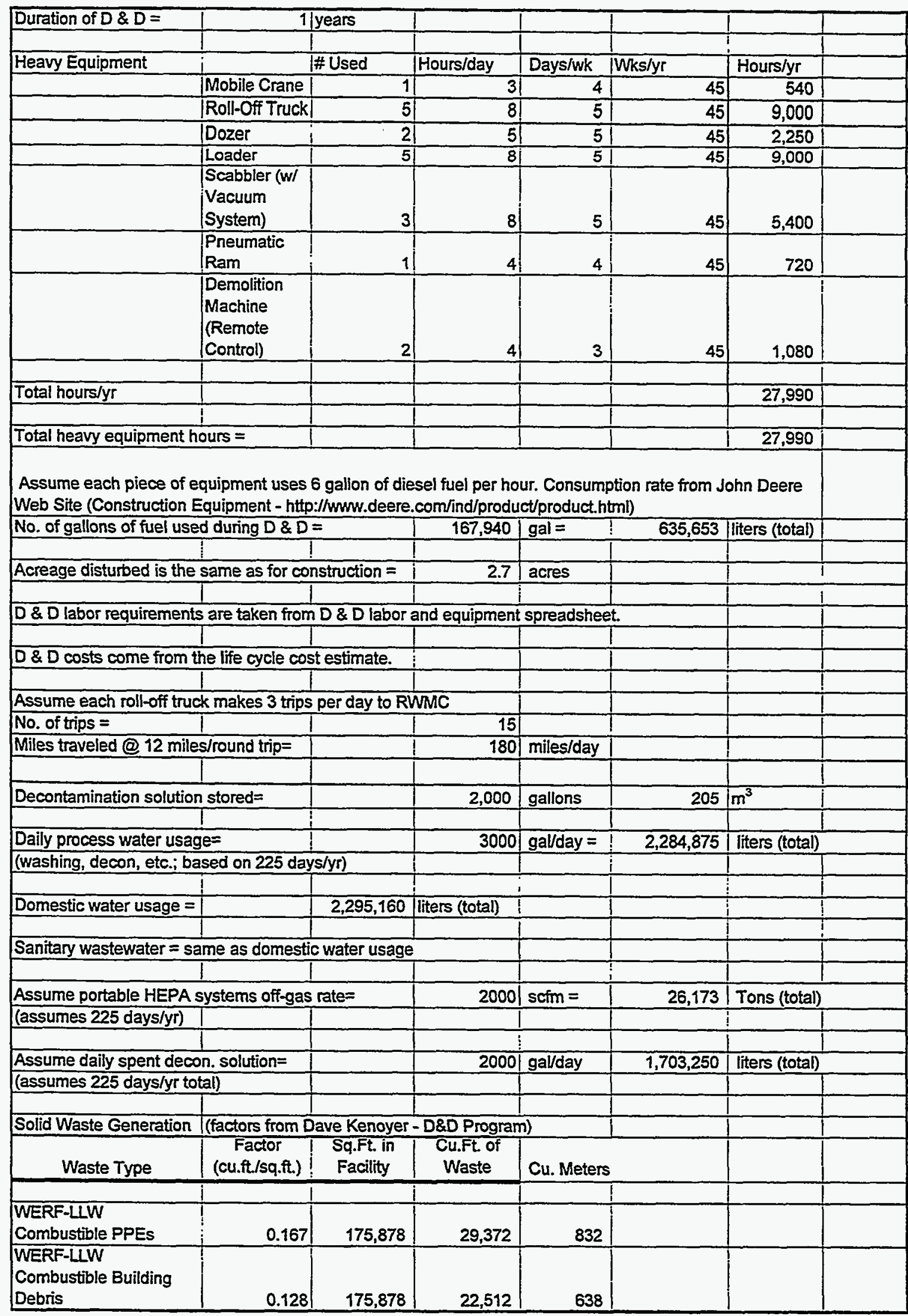




\begin{tabular}{|c|c|c|c|c|c|c|}
\hline $\begin{array}{l}\text { WERF-LLW } \\
\text { Compactable Building } \\
\text { Debris }\end{array}$ & 0.195 & 175,878 & 34,296 & 972 & & \\
\hline $\begin{array}{l}\text { RWMC-LLW Non- } \\
\text { Compactable Equipment }\end{array}$ & 0.513 & 175,878 & 90,225 & 2,556 & & \\
\hline $\begin{array}{l}\text { RWMC-LLW Non-Compt } \\
\text { Building Debris }\end{array}$ & 0.684 & 175,878 & 120,301 & 3,408 & & \\
\hline $\begin{array}{l}\text { RWMC-LLW Non-Compt } \\
\text { Concrete Rubble }\end{array}$ & 3.44 & 175,878 & 605,020 & 17,139 & $\begin{array}{l}\text { This factor is twice as large } \\
\text { as that recommended by } \\
\text { the D\&D program to } \\
\text { account for that large } \\
\text { amounts of concrete used. }\end{array}$ & \\
\hline $\begin{array}{l}\text { RWMC-LLW Non-Compt } \\
\text { Scrap Metal }\end{array}$ & 0.778 & 175,878 & 136,833 & 3,876 & & \\
\hline $\begin{array}{l}\text { RWMC-LLW } \\
\text { Asbestos/ACM Covered } \\
\text { Pipe }\end{array}$ & 이 & 175,878 & - & - & & \\
\hline $\begin{array}{l}\text { CFA Landfill Non-Compt } \\
\text { Building Debris }\end{array}$ & 1.99 & 175,878 & 349,997 & 9,915 & & \\
\hline $\begin{array}{l}\text { CFA Landfill Non-Compt } \\
\text { Concrete Rubble }\end{array}$ & 2.45 & 175,878 & 430,901 & 12,207 & $\begin{array}{l}\text { This factor is twice as large } \\
\text { as that recommended by } \\
\text { the D\&D program to } \\
\text { account for that large } \\
\text { amounts of concrete used. }\end{array}$ & \\
\hline CFA Landfill Asbestos & 0 & 175,878 & - & -1 & & \\
\hline $\begin{array}{l}\text { HWSF Hazardous Mtrls } \\
\text { (Hg/PCBs/etc) }\end{array}$ & 0.002 & 175,878 & .352 & 10 & & \\
\hline Metal Recycle & 0.022 & 175,878 & 3,869 & 110 & & \\
\hline$\overline{L L W}=$ & & & $1,038,560$ & 29,421 & & \\
\hline Non-Rad $=$ & & & 780,898 & 22,122 & $T$ & \\
\hline Hazardous $=$ & & & 352 & 10 & & \\
\hline Metal $=$ & & & 3,869 & 110 & & \\
\hline & & & & & & \\
\hline Electric power usage $=$ & 156,000 & $\mathrm{kWh} / \mathrm{yr}$ & 156 & MWh/yr & & \\
\hline \multirow{2}{*}{\multicolumn{7}{|c|}{ (based on $3,000 \mathrm{kWh} / \mathrm{wk}$ - John Duggan) }} \\
\hline & & & & & $i$ & \\
\hline \multicolumn{7}{|c|}{ Air emissions from fuel are based on the diesel emissions spreadsheet. } \\
\hline & & & & & & \\
\hline 1 manyear of labor = & 1800 & Imanhours & & & & \\
\hline & & & & & & \\
\hline \begin{tabular}{|l|l|} 
Lube oil $=$ \\
\end{tabular} & 5,297 & liters (total) & & & & \\
\hline \multicolumn{7}{|c|}{ (based on 3 gal for every 60 hours of operation) } \\
\hline & & & & & & \\
\hline Mixed waste $=$ & 12,375 & gal (total) $=$ & 47 & $\mathrm{~m} 3$ (total) & & \\
\hline \multicolumn{7}{|c|}{ (based on an assumed 555 -gallon drums generated per week... work only 45 weeks/yr) } \\
\hline & & & & & & \\
\hline \multicolumn{7}{|c|}{ Radioactivity associated with waste materials: } \\
\hline & & & & & & \\
\hline Spent decontamination so & olution $=$ & 1,703 & $\mathrm{Ci}$ & & & \\
\hline \multicolumn{7}{|c|}{ (based on an assumed average activity concentration of $1 \mathrm{uCi} / \mathrm{ml}$ ) } \\
\hline & & & & & & \\
\hline Radioactive solid waste $=$ & & 294 & $\mathrm{Ci}$ & & & \\
\hline \multicolumn{7}{|c|}{ (based in an assumed activity concentration of $0.01 \mathrm{uCi} / \mathrm{cc}\left[0.01 \mathrm{Ci} / \mathrm{m}^{3}\right]$ ) } \\
\hline & & & & & & \\
\hline \begin{tabular}{|l|l} 
Mixed waste $=$ \\
\end{tabular} & & 0 & $\mathrm{Ci}$ & & & \\
\hline (based on an assumed ac & ctivity concentr: & ration of $0.01 \mathrm{uc}$ & Cilce $[0.01 \mathrm{Cl} /$ & & - & \\
\hline
\end{tabular}




$$
\text { Backup to } Q
$$

\begin{tabular}{|c|c|c|c|c|c|}
\hline & Project Data Sheet for & cine Feed - TR & RU-Sep & & \\
\hline Decontaminatic & on \& Decommissioning (D\&D) Information & & & & \\
\hline Cost (\$): D\&D (L & Inescalated dollars) & & & & \\
\hline Decommission & & $\$ 2,555,000$ & & & \\
\hline Decontaminatior & & $\$ 7,223,000$ & & & \\
\hline Demolition & & $\$ 11,557,000$ & & & \\
\hline Total D\&D & & $\$ 21,335,000$ & & & \\
\hline Schedule start/e & and: D\&D $\quad \therefore$ & January 2033 throl & Igh Decemb & 2037 & \\
\hline Number of work & ers each year of D\&D (new/existing) & 155 & New worker & & \\
\hline Number of radia & tion workers (D\&D) & 104 & New worker & & \\
\hline Average annual & worker radiation dose (rem/yr) & 0.19 & rem/yr & per worker & \\
\hline & & & & & \\
\hline Heavy equipmer & & & & & \\
\hline Equipment used & & Mobile Cranes, Ro & II-off trucks, & Jozers, Loade & \\
\hline \begin{tabular}{|l|l|} 
Trips & \\
\end{tabular} & Roll-off trucks & & per day & & \\
\hline Hours of operatit & on (all heavy equipment) & 27,990 & Hours & & \\
\hline & & & & & \\
\hline Acres disturbed & and duration of disturbance & January 2033 thros & gh Decemb & 2037 & \\
\hline 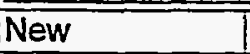 & & None & & & \\
\hline Previous & & 2.7 & acres & & \\
\hline Revegetated & & None & & & \\
\hline Air emissions & & 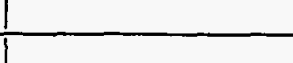 & & & \\
\hline non-radioactive & Fuel combustion gases $\left(\mathrm{CO}_{2}, \mathrm{H}_{2} \mathrm{O}, \mathrm{O}_{2}, \mathrm{~N}_{2}\right)$ & 16,269 & tons (total) & & \\
\hline non-radioactive & $\begin{array}{l}\text { Fuel combustion contaminants (CO, } \\
\text { particulates, } \mathrm{NO}_{x}, \mathrm{SO}_{2} \text {, hydrocarbons) }\end{array}$ & 95 & tons (total) & & \\
\hline radioactive & HEPA filtered off-gas & 26,173 & tons (total) & & \\
\hline & & & & & \\
\hline Effluents & & & & & \\
\hline radioactive & Spent decontamination solution & $1,703,250$ & |iters (total) & 1,703 & $\overline{C i}$ \\
\hline non-radioactive & Sanitary wastewater & $3,301,896$ & liters (total) & & \\
\hline non-radioactive & Lube oil & 5,297 & liters (total) & & \\
\hline Solid wastes: & & & & & \\
\hline radioactive & & 29.421 & $\mathrm{~m}^{3}$ & 294 & $\mathrm{Ci}$ \\
\hline Non-radioactive & (industrial) & 22,122 & $1 \mathrm{~m}^{3}$ & & \\
\hline \begin{tabular}{|l|} 
Hazardous \\
\end{tabular} & & 10 & $\mathrm{~m}^{3}$ & & \\
\hline Hazardous/toxic & chemicals and wastes (tvoe) & & & & \\
\hline Storage/inventol & & 205 & $\mathrm{~m}^{3}$ (total) & & \\
\hline Pits/Ponds creat & $\operatorname{ted}\left(m^{2}\right)$ & None & & & \\
\hline radioactive & (mixed waste) & 47 & $\mathrm{~m}^{3}$ (total) & 0 & Ci \\
\hline Water usage: & & & & & \\
\hline Process water & & $2,284,875$ & liters (total) & & \\
\hline Domestic water & & $3,301,896$ & liters (total) & & \\
\hline Source of water & & ICPP site wells & & & \\
\hline Eneray requirem & nents: & & & & \\
\hline
\end{tabular}


D\&D Labor

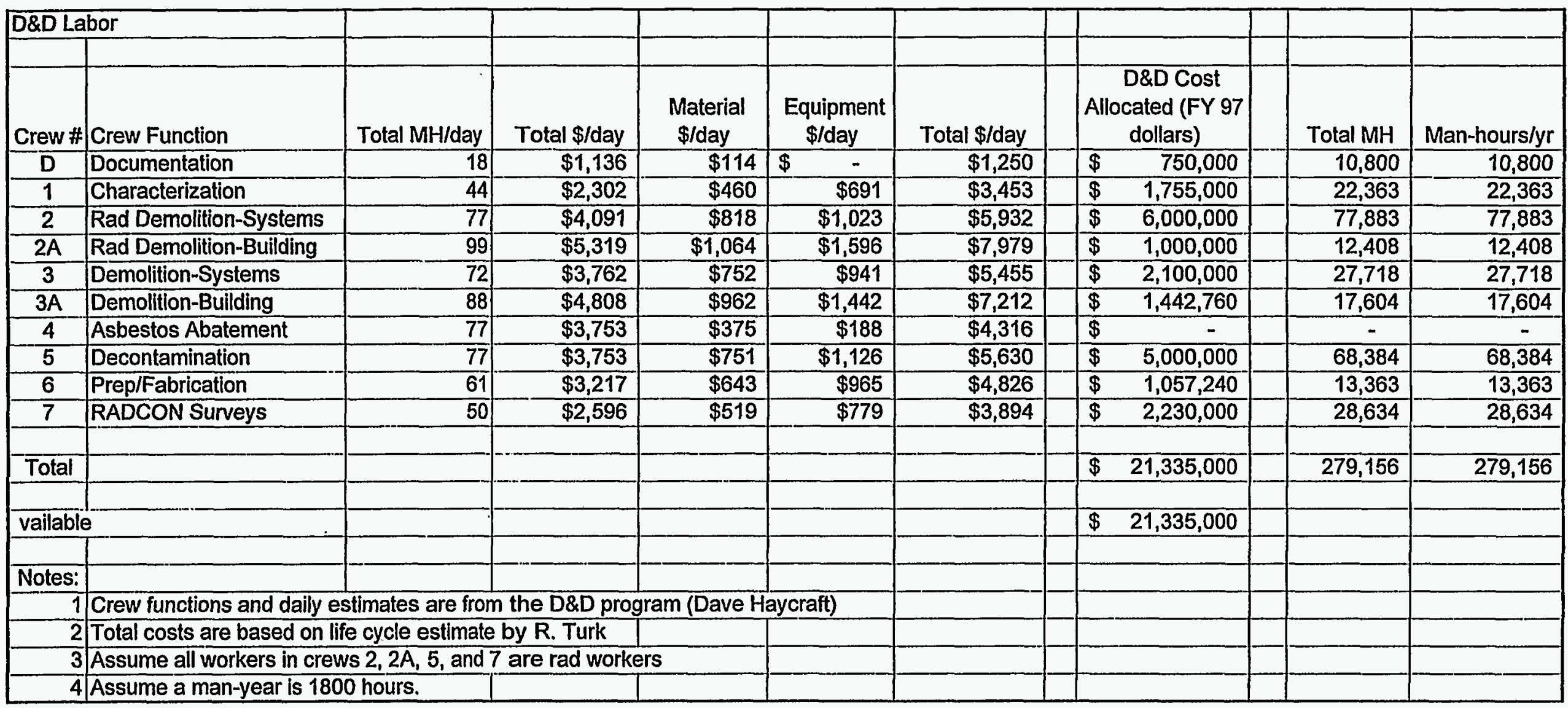




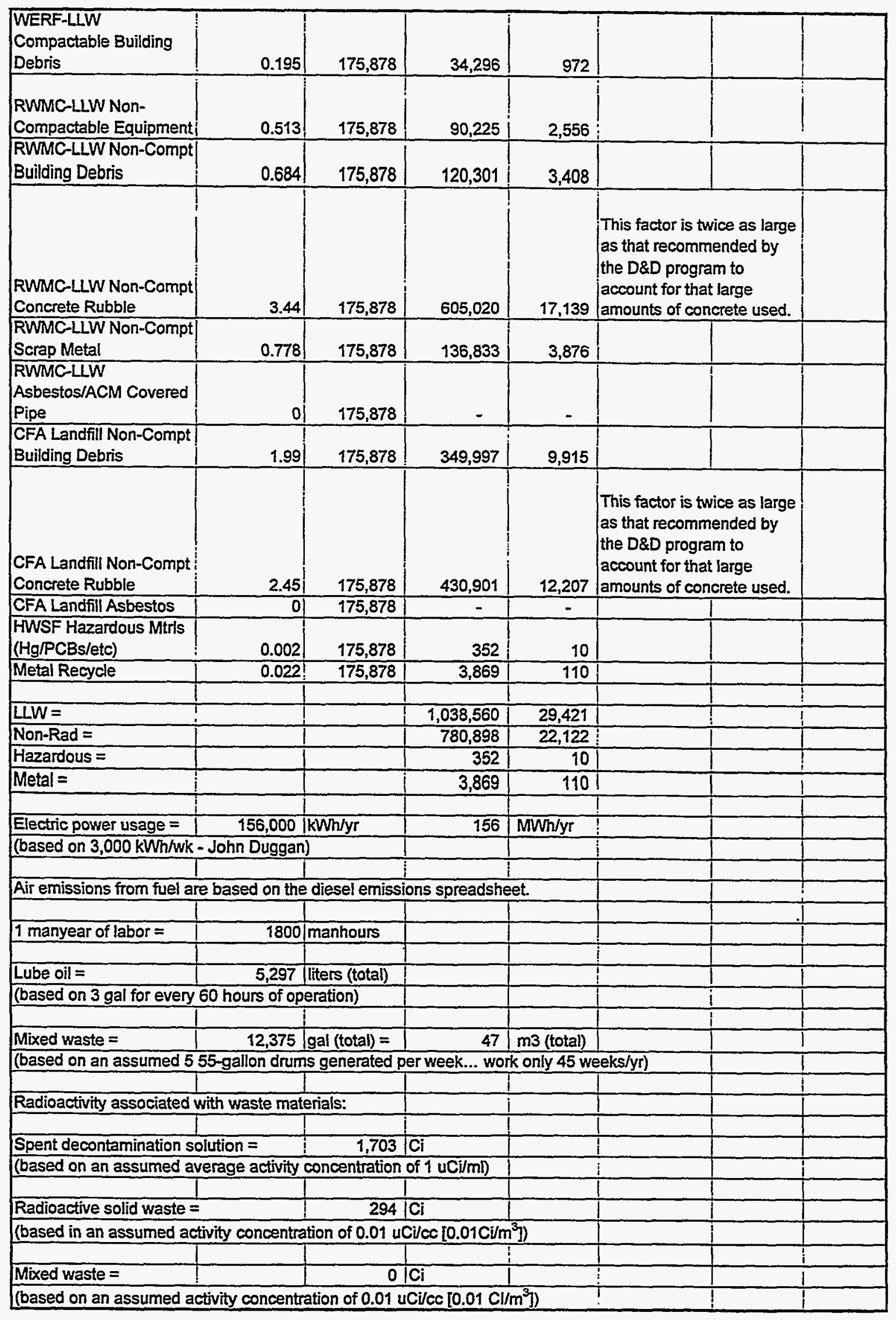




\begin{tabular}{|c|c|c|c|c|c|}
\hline & Project Data Sheet for Calcine & rieval - VWO, I & DCWO, H & AWO & \\
\hline Decontaminatio & on \& Decommissioning (D\&D) Information & & & & \\
\hline Cost (\$):D\&D (U) & Indiscounted dollars) & & & & \\
\hline Decommission & & $\$ 2,681,000$ & & & \\
\hline Decontamination & & $\$ 7,415,000$ & & & \\
\hline \begin{tabular}{l|l} 
Demolition \\
\end{tabular} & & $\$ 11,864,000$ & & & \\
\hline Total D\&D & & $\$ 21,960,000$ & & & \\
\hline Schedule start/el & nd: D\&D & January 2033 throu & gh December & r2037 & \\
\hline Number of worke & ers each year of D\&D (new/existing) & \begin{tabular}{r|}
160 \\
\end{tabular} & New workers & & \\
\hline Number of radiat & tion workers (D\&D) & 102 & New workers. & & \\
\hline Average annual & worker radiation dose (rem/yr) & 0.19 & rem/yr & per worker & \\
\hline & & & & & \\
\hline Heavy equipmen & & & & & \\
\hline Equipment used & & Mobile Cranes, Roll- & -off trucks, D & ozers, Loaders & \\
\hline \begin{tabular}{l|l} 
Trips & II \\
\end{tabular} & Roll-off trucks & 15 & per day & & \\
\hline Hours of operatic & on (all heavy equipment) & 27,990 & Hours & & \\
\hline & & & & & \\
\hline Acres disturbed: & and duration of disturbance & January 2033 throus & gh December & 2037 & \\
\hline \begin{tabular}{|l|l|l|} 
New & -1 \\
\end{tabular} & & \begin{tabular}{|l|l|} 
None & \\
\end{tabular} & & & \\
\hline Previous & & 2.7 & acres & & \\
\hline Revegetated & & None & & & \\
\hline Air emissions & & & & & \\
\hline non-radioactive & Fuel combustion gases $\left(\mathrm{CO}_{2}, \mathrm{H}_{2} \mathrm{O}, \mathrm{O}_{2}, \mathrm{~N}_{2}\right)$ & 16,269 & tons (total) & & \\
\hline non-radioactive & $\begin{array}{l}\text { Fuel combustion contaminants (CO, } \\
\text { particulates, } \mathrm{NO}_{x}, \mathrm{SO}_{2} \text {, hydrocarbons) }\end{array}$ & 95 & tons (total) & & \\
\hline radioactive & HEPA filtered off-gas & 26,173 & tons (total) & & \\
\hline Effluents & & & & & \\
\hline radioactive & Spent decontamination solution & $1,703,250$ & liters (total) & 1,703 & $\mathrm{Ci}$ \\
\hline non-radioactive & Sanitary wastewater & $3,412,304$ & liters (total) & & \\
\hline non-radioactive & Lube oil & 5,297 & liters (total) & & \\
\hline Solid wates- & & & & & \\
\hline Solid wastes: & & & & & \\
\hline radioactive & & 29,421 & $\mathrm{~m}^{3}$ & 294 & $\mathrm{Ci}$ \\
\hline Non-radioactive & (industrial) & 22,122 & $\mathrm{~m}^{3}$ & & \\
\hline \begin{tabular}{|l|l|} 
Hazardous \\
\end{tabular} & & 10 & $\mathrm{~m}^{3}$ & & \\
\hline Hazardous/toxic & chemicals and wastes (type) & & & & \\
\hline Storage/inventor & & 205 & $\mathrm{~m}^{3}$ (total) & & \\
\hline Pits/Ponds creat & $\operatorname{ted}\left(m^{2}\right)$ & None & & & \\
\hline \begin{tabular}{|l|l|} 
radioactive \\
\end{tabular} & (mixed waste) & 47 & $\mathrm{~m}^{3}$ (total) & 0 & $\mathrm{Ci}$ \\
\hline Water usage: & & & & & \\
\hline Process water & & $2,284,875$ & iiters (total) & & \\
\hline Domestic water & & $3,412,304$ & liters (total) & & \\
\hline Source of water & & ICPP site wells & & & \\
\hline & & & & & \\
\hline
\end{tabular}


D\&D Labor

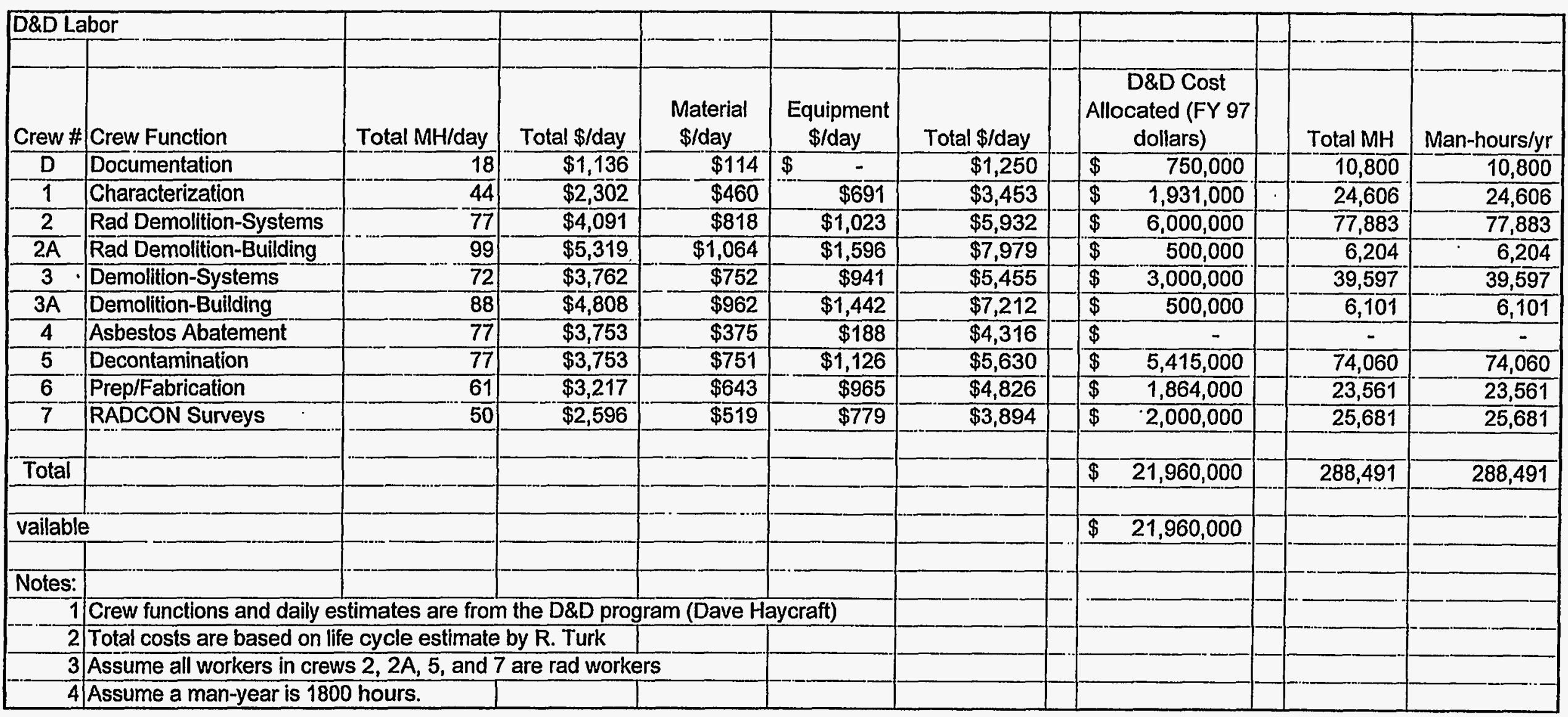




\begin{tabular}{|c|c|c|c|c|c|c|c|}
\hline Duration of $D \& D=$ & & years & & & & & \\
\hline Heavy Equipment & & \#Used & Hours/day & Days/wk & Wks $/ y r$ & Hours/yr & \\
\hline & Mobile Crane | & 1 & $3 \mid$ & 4 & 45 & 540 & \\
\hline & Roll-Off Truck & 5 & 8 & 5 & 45 & 9,000 & \\
\hline & Dozer & 2 & 5 & 5 & 45 & 2,250 & \\
\hline & Loader & 5 & 8 & 5 & 45 & 9,000 & \\
\hline & $\begin{array}{l}\text { Scabbler (WI } \\
\text { Vacuum } \\
\text { System) }\end{array}$ & 3 & 8) & 5 & 45 & 5,400 & \\
\hline & $\begin{array}{l}\text { Pneumatic } \\
\text { Ram }\end{array}$ & 1 & 4 & 4 & 45 & 720 & \\
\hline & $\begin{array}{l}\text { Demolition } \\
\text { Machine } \\
\text { (Remote } \\
\text { Control) }\end{array}$ & 2 & 4 & 3 & 45 & 1,080 & \\
\hline Total hours/yr & & & & & & 27,990 & \\
\hline Total heavy equipment he & ours $=$ & & & & & 27,990 & \\
\hline $\begin{array}{l}\text { Assume each piece of ed } \\
\text { Web Site (Construction E }\end{array}$ & $\begin{array}{l}\text { quipment uses } 6 \\
\text { quipment-http: }\end{array}$ & $\begin{array}{l}6 \text { gallon of die } \\
\text { s:/lunww.deere. }\end{array}$ & $\begin{array}{l}\text { sel fuel per hou } \\
\text { comind/produc }\end{array}$ & $\begin{array}{l}\text { ur. Consump } \\
\text { ct/product.ht }\end{array}$ & $\begin{array}{l}\text { stion rate from } \mathrm{Jc} \\
\text { (ml) }\end{array}$ & ohn Deere & \\
\hline No. of gallons of fuel usec & d during $D \& D=$ & & 167,940 & gal $=\quad$ & 635,653 & liters (total) & \\
\hline & & & & & & & \\
\hline Acreage disturbed is the & same as for con & nstruction = & 2.7 & acres & & & \\
\hline 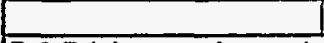 & & 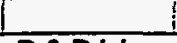 & 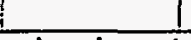 & & & & \\
\hline D\& D labor requirements & are taken from & nD \& D labora & and equipment & spreadshee & & & \\
\hline & & & & & & & \\
\hline$D \& D$ costs come from th & he life cycle cos & st estimate. & & & & & \\
\hline & & & & & & & \\
\hline Assume each roll-off truc & k makes 3 trips & per day to $\mathrm{RV}$ & MMC & & & & \\
\hline No. of trips $=$ & & & 15 & & & & \\
\hline Miles traveled @ 12 mile & s/round trip $=$ & & $180 \mid$ & miles/day & & & \\
\hline & & & & & & & \\
\hline Decontamination solution & stored = & & 2,000 & gallons & 205 & $\mathrm{~m}^{3}$ & \\
\hline & & & & & & & \\
\hline Dally process water usag & & & 3000 & gallday $=$ & $2,284,875$ & liters (total) & \\
\hline (washing, decon, etc.; ba & sed on 225 day & ys/yf) & & & & & \\
\hline I0motin untor uca & & 3412304 & liters (total) & & & & \\
\hline Domesuc water usage = & & $3,412,004$ & Inters (total) & & & & \\
\hline Sanitary wastewater $=$ sa & me as domestic & ic water usage & & & & & \\
\hline & & & & & & & \\
\hline Assume portable HEPAs & systems off-gas & $s$ rate $=$ & 2000 & scfm $=$ & 26,173 & Tons (total) & \\
\hline (assumes 225 days/yr) & & & & & & & \\
\hline Assume daily spent deco & n. solution= & & 2000 & aalday & 1.703 .250 & liters (total) & \\
\hline (assumes 225 days/yr to & & & & & & & \\
\hline & & & & & & & \\
\hline Solid Waste Generation & (factors from D & Jave Kenoyer & - D\&D Program & & & & \\
\hline Waste Type & $\mid \begin{array}{c}\text { Factor } \\
\text { (cu.ft/sq.ft.) }\end{array}$ & $\begin{array}{l}\text { Sq.Ft. in } \\
\text { Facility }\end{array}$ & $\begin{array}{c}\text { Cu.Ft. of } \\
\text { Waste }\end{array}$ & Cu. Meters & & & \\
\hline & & & & & & & \\
\hline $\begin{array}{l}\text { WERF-LLW } \\
\text { Combustible PPES }\end{array}$ & 0.167 & 175,878 & 29,372 & 832 & & & \\
\hline $\begin{array}{l}\text { WERF-LLW } \\
\text { Combustible Building } \\
\text { Debris }\end{array}$ & 0.128 & 175,878 & 22,512 & 638 & & & \\
\hline
\end{tabular}


D D Assumptions

\begin{tabular}{|c|c|c|c|c|c|c|}
\hline $\begin{array}{l}\text { WERF-LLW } \\
\text { Compactable Building } \\
\text { Debris }\end{array}$ & 0.195 & 175,878 & 34,296 & 972 & & \\
\hline $\begin{array}{l}\text { RWMC-LLW Non- } \\
\text { Compactable Equipment }\end{array}$ & 0.513 & 175,878 & 90,225 & 2,556 & & \\
\hline $\begin{array}{l}\text { RWMC-LLW Non-Compt } \\
\text { Building Debris }\end{array}$ & 0.684 & 175,878 & 120,301 & 3,408 & & \\
\hline $\begin{array}{l}\text { RWMC-LLW Non-Compt } \\
\text { Concrete Rubble }\end{array}$ & 3.44 & 175,878 & 605,020 & 17,139 & $\begin{array}{l}\text { This factor is twice as large } \\
\text { as that recommended by } \\
\text { the D\&D program to } \\
\text { account for that large } \\
\text { amounts of concrete used. }\end{array}$ & \\
\hline $\begin{array}{l}\text { RWMC-LLW Non-Compt } \\
\text { Scrap Metal }\end{array}$ & 0.778 & 175,878 & 136,833 & 3,876 & & \\
\hline $\begin{array}{l}\text { RWMC-LLW } \\
\text { Asbestos/ACM Covered } \\
\text { Pipe }\end{array}$ & 0 & 175,878 & 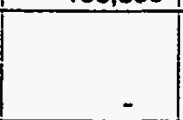 & 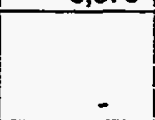 & & \\
\hline $\begin{array}{l}\text { CFA Landfill Non-Compt } \\
\text { Building Debris }\end{array}$ & 1.99 & 175,878 & 349,997 & 9,915 & & \\
\hline $\begin{array}{l}\text { CFA Landfill Non-Compt } \\
\text { Concrete Rubble }\end{array}$ & 2.45 & 175,878 & 430,901 & 12,207 & $\begin{array}{l}\text { This factor is twice as large } \\
\text { as that recommended by } \\
\text { the D\&D program to } \\
\text { account for that large } \\
\text { amounts of concrete used. }\end{array}$ & \\
\hline CFA Landfill Asbestos & 0 & 175,878 & - & - & & \\
\hline $\begin{array}{l}\text { HWSF Hazardous Mtrls } \\
\text { (Hg/PCBs/etc) }\end{array}$ & 0.002 & 175,878 & 352 & 10 & & \\
\hline Metal Recycle & 0.022 & 175,878 & 3,869 & 110 & & \\
\hline & & & & & & \\
\hline LLW $=$ & & & $1,038,560$ & 29,421 & & \\
\hline Non-Rad = & & & 780,898 & 22,122 & & \\
\hline Hazardous $=$ & & & 352 & 10 & & \\
\hline Metal $=$ & & & 3,869 & 110 & & \\
\hline & & 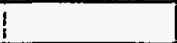 & & & & \\
\hline Electric power usage $=$ & 156,000 & $\mathrm{kWh} / \mathrm{yr}$ & 156 & MWh/yr & & \\
\hline (based on $3,000 \mathrm{kWh} / \mathrm{wk}$ - & John Duggan) & & & & & \\
\hline & & & & & & \\
\hline Air emissions from fuel are & based on the & diesel emissi & ons spreadshe & & & \\
\hline & & & & & & \\
\hline 1 manyear of labor $=$ & 18001 & Imanhours & & & & \\
\hline & & & & & & \\
\hline Lube oil $=$ & 5,297 & liters (total) & & & & \\
\hline (based on 3 gal for every & 60 hours of ope & eration) & & & & \\
\hline & & & & & & \\
\hline Mixed waste $=$ & 12,375 & Igal (total) $=$ & 47 & m3 (total) & & \\
\hline (based on an assumed 5 & 55-gallon drum & ns generated $p$ & er week... wor & rk only $45 \mathrm{wE}$ & eeks/yr) & \\
\hline & & & & & & \\
\hline Radioactivity associated $\mathrm{n}$ & vith waste mate & terials: & & & & \\
\hline & & & & & & \\
\hline Spent decontamination so & lution = & 1,703 & $\mathrm{Ci}$ & & & \\
\hline (based on an assumed av & erage activity & concentration & of $1 \mathrm{uCi} / \mathrm{ml})$ & & & \\
\hline & & & & & & \\
\hline Radioactive solid waste $=$ & & 294 & $\mathrm{ICi}$ & & & \\
\hline (based in an assumed act & ivity concentra & ation of $0.01 \mathrm{u}$ & $\mathrm{Ci} / \mathrm{cc}[0.01 \mathrm{Ci} / \mathrm{m}$ & & & \\
\hline & & & & & & \\
\hline Mixed waste $=$ & & & $\mathrm{Ci}$ & & & \\
\hline (based on an assumed ac & tivity concentre & ration of $0.01 \mathrm{u}$ & $\mathrm{Ci} / \mathrm{cec}[0.01 \mathrm{Cl}$ & $\left(m^{3} j\right)$ & & \\
\hline
\end{tabular}




\section{Estimate of Diesel Engine Emissions \\ Calcine Retrieval for CWO}

\begin{tabular}{|c|c|c|c|c|c|}
\hline \multicolumn{6}{|l|}{ Bases \& Assumptions: } \\
\hline \multicolumn{2}{|c|}{ 1. Air to fuel ratio $=25: 1$ (Mass Basis) } & & & $\begin{array}{l}\text { from Wark, K. and C.F. } \\
\text { Warner, Air Pollution, Its } \\
\text { Origin and Control, IEP, } \\
\text { New York, 1976, p. 446, } \\
423\end{array}$ & \\
\hline \multicolumn{6}{|c|}{ 2. Diesel fuel density $=7.5 \mathrm{lbs} . / \mathrm{gal}$. } \\
\hline \multicolumn{6}{|c|}{ 3. Air is $21 \% 02,79 \%$ N2, with a pseudomolecular weight of 29 . } \\
\hline \multicolumn{6}{|c|}{ 4. Combustion is simulated as: $\mathrm{CgH} 18+13.5 \mathrm{O} 2 \rightarrow 9 \mathrm{CO} 2+9 \mathrm{H} 2 \mathrm{O}$} \\
\hline \multicolumn{2}{|l|}{ 5. Particúlates $=5 \mathrm{mg} / \mathrm{scf}$} & & & Wark and Wamer, p. 446 & \\
\hline 6. $\mathrm{CO}=2,500 \mathrm{ppmv}$ & & & & Wark and Wamer, p. 446 & \\
\hline 7. NOX $=2,000 \mathrm{ppmv}$ & & & & Wark and Warner, p. 446 & \\
\hline \multicolumn{3}{|c|}{ 8. Unburned hydrocarbons $=100 \mathrm{ppmv}$} & & Wark and Wamer, p. 446 & \\
\hline \multicolumn{3}{|c|}{ 9. Diesel fuel (\# 2 fuel oil) contains 1 wt. \% sulfur } & & Wark and Wamer, p. 336 & \\
\hline \multicolumn{6}{|c|}{ 10. Combustion is about $99 \%$ efficient. } \\
\hline \multicolumn{6}{|c|}{\begin{tabular}{|l|l|}
$\cdot$ & \\
\end{tabular}} \\
\hline \multicolumn{2}{|l|}{ Lbs. Of Construction Fuel } & & & - & \\
\hline \multicolumn{2}{|l|}{ Lbs. Of Operations Fuel } & & & - & \\
\hline \multicolumn{2}{|l|}{ Lbs. OfD\&D'Fuel } & & & 224,492 & \\
\hline \multicolumn{2}{|l|}{ Total Lbs. of Fuel Used } & & & 224,492 & \\
\hline \multicolumn{2}{|c|}{ Lb-Moles of Construction Fuel } & & & - & \\
\hline \multicolumn{2}{|c|}{ Lb-Moles of Operations Fuel } & & & - & \\
\hline \multirow{2}{*}{\multicolumn{2}{|c|}{\begin{tabular}{|l|} 
Lb-Moles of D\&D Fuel \\
Total Lb-Moles of Fuel (as C9H18)
\end{tabular}}} & & & 1,782 & \\
\hline & & & & 1,782 & \\
\hline \multicolumn{4}{|c|}{ Lbs of Air for Construction Fuel (based on air-to-fuel ratio) } & - & \\
\hline \multicolumn{3}{|c|}{ Lbs.of Air for Operations Fuel (based on air-to-fuel ratio) } & & - & \\
\hline \multicolumn{3}{|c|}{ Lbs.of Air for D\&D Fuel (based on air-to-fuel ratio) } & & $5,612,310$ & \\
\hline Total Lbs. of Air Added & & & & $5,612,310$ & \\
\hline \multirow{2}{*}{\multicolumn{3}{|c|}{ Lb-Moles of Air for Combustion Fuel }} & & & \\
\hline Lb-Moles of Air for Operations Fuel & & & & - & \\
\hline \multicolumn{2}{|c|}{ Lb-Moles of Air for D\&D Fuel } & & & 193,528 & \\
\hline \multicolumn{2}{|c|}{\begin{tabular}{|l|l} 
Total Lb-Moles of Air \\
\end{tabular}} & & & 193,528 & \\
\hline \multicolumn{2}{|c|}{ Grand Total of Materials Fed, Lbs. } & & & $5,836,802$ & \\
\hline Exhaust Gases, Constr & Iction Fuel & Total Lbs. & Total Tons & Total Moles & Total SCF \\
\hline $\mathrm{CO} 2$ & & - & - & 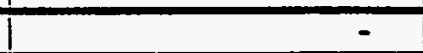 & - \\
\hline $\mathrm{H} 2 \mathrm{O}$ & & - & - & - & - \\
\hline$\overline{\mathrm{O} 2}$ & & - & - & - & - \\
\hline N2 & & $=$ & - & - & - \\
\hline Subtotal of Major Gase: & & - & - & - & - \\
\hline $\mathrm{SO2}$ & & - & - & & \\
\hline Particulates & & - & - & & \\
\hline $\mathrm{CO}$ & & - & - & & \\
\hline NOx (assumed NO) & & $=$ & - & & \\
\hline Unburned Hydrocarbons & & - & - & & \\
\hline
\end{tabular}




\begin{tabular}{|c|c|c|c|c|}
\hline Subtotal of Contaminants & - & - & & \\
\hline & & & & \\
\hline & & & & \\
\hline Exhaust Gases, Operations Fuel & Total Lbs. & Total Tons & Total Moles & Total SCF \\
\hline \begin{tabular}{l|l}
$\mathrm{CO} 2$ & \\
\end{tabular} & - & - & - & - \\
\hline $\mathrm{H} 2 \mathrm{O}$ & - & - & - & - \\
\hline 02 & - & - & - & - \\
\hline \begin{tabular}{|l|l}
$\mathrm{N} 2$ \\
\end{tabular} & - & - & - & - \\
\hline Subtotal of Major Gases & - & - & - & - \\
\hline SO2 I & - & - & & \\
\hline Particulates & - & - & & \\
\hline $\mathrm{CO}$ & - & - & & \\
\hline NOx (assumed NO) & - & - & & \\
\hline Unbumed Hydrocarbons & - & - & & \\
\hline Subtotal of Contaminants & $=$ & - & & \\
\hline 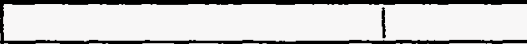 & & & & \\
\hline Exhaust Gases, D\&D Fuel & Total Lbs. & Total Tons & Total Moles & Total SCF \\
\hline \begin{tabular}{l|}
$\mathrm{CO} 2$ \\
\end{tabular} & 698,492 & 349 & 15,875 & $5,699,060$ \\
\hline $\mathrm{H} 2 \mathrm{O}$ & 285,747 & 143 & 15,875 & $5,699,060$ \\
\hline 02 & 538,516 & 269 & 16,829 & $6,041,480$ \\
\hline N2 & $4,280,837.83$ & 2,140 & 152,887 & $54,886,457$ \\
\hline Subtotal of Major Gases & $5,803,593$ & 2,902 & 201,465 & $72,326,057$ \\
\hline $\mathrm{SO} 2$ & 4,350 & 2.2 & & \\
\hline Particulates & 797 & 0.4 & & \\
\hline $\mathrm{CO}$ & 14,103 & 7.1 & & \\
\hline NOx (assumed NO) & 12,088 & 6.0 & & \\
\hline Unbumed Hydrocarbons & 2,538 & 1.3 & & \\
\hline Subtotal of Contaminants & 33,875 & 17 & & \\
\hline
\end{tabular}


Back up to u

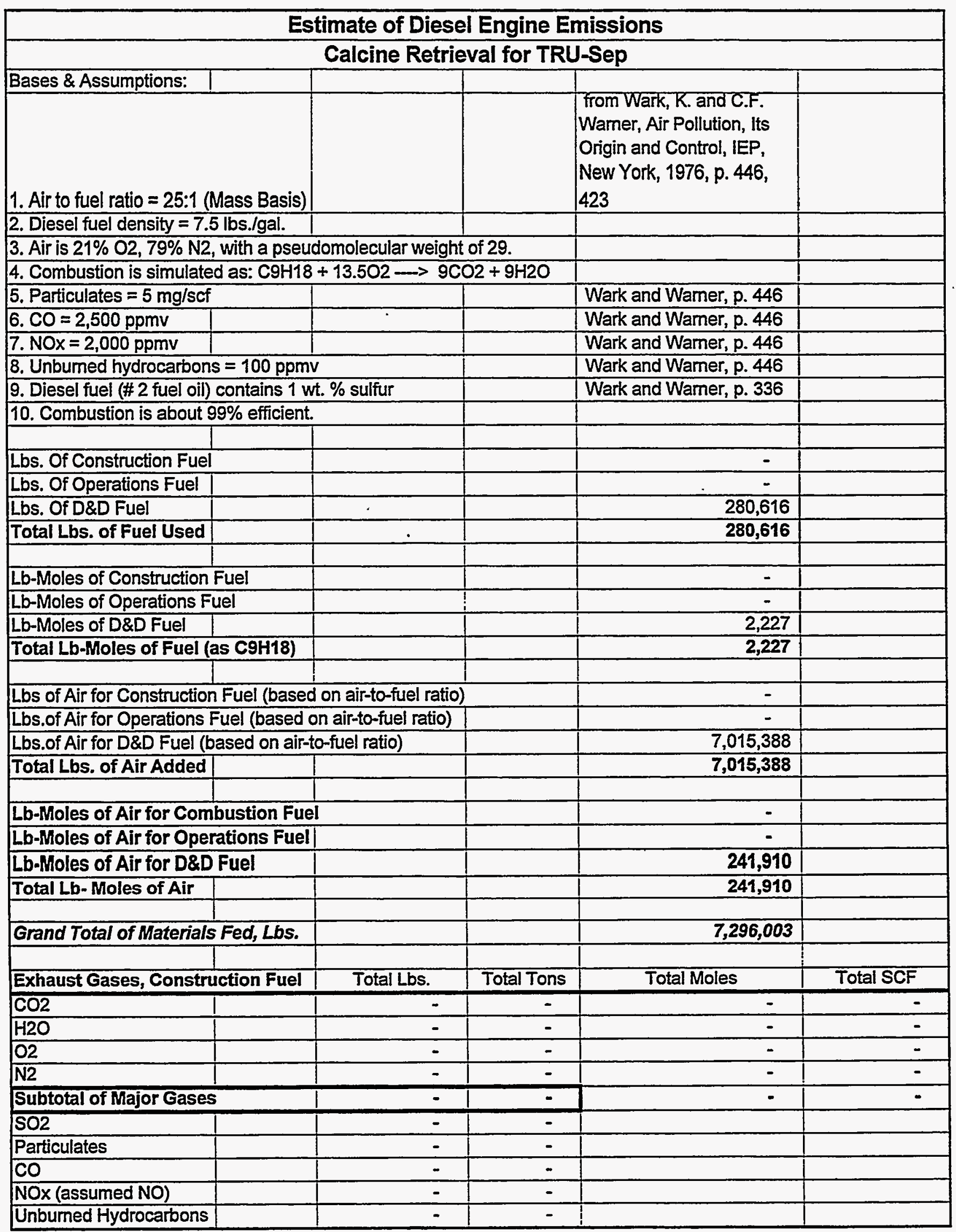




\begin{tabular}{|c|c|c|c|c|}
\hline Subtotal of Contaminants & - & - & & \\
\hline & & & & \\
\hline Exhaust Gases, Operations Fuel & Total Lbs. & Total Tons & Total Moles & Total SCF \\
\hline \begin{tabular}{|l|l}
$\mathrm{CO} 2$ & \\
\end{tabular} & - & - & 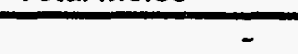 & - \\
\hline $\mathrm{H} 2 \mathrm{O}$ & - & - & 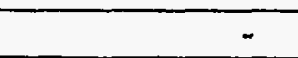 & - \\
\hline $\mathrm{O} 2$ & - & - & - & - \\
\hline \begin{tabular}{|l|l|}
$\mathrm{N} 2$ &
\end{tabular} & - & - & - & - \\
\hline Subtotal of Major Gases & - & - & - & - \\
\hline $\mathrm{SO} 2$ & $=$ & - & & \\
\hline Particulates & - & - & & \\
\hline $\mathrm{CO}$ & - & - & & \\
\hline NOx (assumed NO) & - & - & & \\
\hline Unbumed Hydrocarbons & - & - & & \\
\hline Subtotal of Contaminants & - & - & & \\
\hline & & & & \\
\hline & & & & \\
\hline Exhaust Gases, D\&D Fuel & Total Lbs. & Total Tons & Total Moles & Total SCF \\
\hline $\begin{array}{ll}\mathrm{CO} 2 \\
\end{array}$ & 873,115 & 437 & 19,844 & $7,123,825$ \\
\hline $\mathrm{H} 2 \mathrm{O}$ & 357,183 & 179 & 19,844 & $7,123,825$ \\
\hline 02 & 673,145 & 337 & 21,036 & $7,551,850$ \\
\hline N2 & $5,351,047.29$ & 2,676 & 191,109 & $68,608,071$ \\
\hline Subtotal of Major Gases & $7,254,491$ & 3,627 & 251,832 & $90,407,572$ \\
\hline \begin{tabular}{|l|l}
$\mathrm{SO} 2$ & \\
\end{tabular} & 5,437 & 2.7 & & \\
\hline Particulates & 996 & 0.5 & & \\
\hline $\mathrm{CO}$ & 17,628 & 8.8 & & \\
\hline NOx (assumed NO) & 15,110 & 7.6 & & \\
\hline Unburned Hydrocarbons & 3,173 & 1.6 & & \\
\hline Subtotal of Contaminants & 42,344 & 21 & & \\
\hline
\end{tabular}


Backup to $u$

\section{Estimate of Diesel Engine Emissions \\ Calcine Retrieval for WWO, HWO, DCWO}

Bases \& Assumptions:

1. Air to fuel ratio $=25: 1$ (Mass Basis)

from Wark, K. and C.F.

Warner, Air Pollution, Its

Origin and Control, IEP,

New York, 1976, p. 446,

2. Diesel fuel density $=7.5 \mathrm{lbs} . / \mathrm{gal}$.

3. Air is $21 \% 02,79 \% \mathrm{N2}$, with a pseudomolecular weight of 29 .

4. Combustion is simulated as: $\mathrm{C9H} 18+13.5 \mathrm{O} 2 \longrightarrow 9 \mathrm{CO} 2+9 \mathrm{H} 2 \mathrm{O}$

5. Particulates $=5 \mathrm{mg} / \mathrm{scf}$

6. $\mathrm{CO}=2,500 \mathrm{ppmv}$

7. NOX $=2,000 \mathrm{ppmv}$

8. Unbumed hydrocarbons $=100 \mathrm{ppmv}$

9. Diesel fuel (\# 2 fuel oil) contains $1 \mathrm{wt}$. \% sulfur

10 . Combustion is about $99 \%$ efficient.

Lbs. Of Construction Fuel

Lbs. Of Operations Fuel

Lbs. OfD\&D Fuel

Total Lbs. of Fuel Used

Lb-Moles of Construction Fuel

Lb-Moles of Operations Fuel

Lb-Moles of D\&D Fuel

Total Lb-Moles of Fuel (as C9H18)

Lbs of Air for Construction Fuel (based on air-to-fuel ratio)

Lbs.of Air for Operations Fuel (based on air-to-fuel ratio)

Lbs.of Air for D\&D Fuel (based on air-to-fuel ratio)

Total Lbs. of Air Added

Lb-Moles of Air for Combustion Fuel

Lb-Moles of Air for Operations Fuel

Lb:Moles of Air for D\&D Fuel

Total Lb- Moles of Air

Grand Total of Materials Fed, Lbs.

Exhaust Gases, Construction Fuel

$\mathrm{CO} 2$

H2O

02

N2

Subtotal of Major Gases

$\mathrm{SO} 2$

Particulates

CO

NOx (assumed NO)

Unbumed Hydrocarbons

423

Wark and Warner, p. 446

Wark and Warner, p. 446

Wark and Warner, p. 446

Wark and Warner, p. 446

Wark and Warner, p. 336

\begin{tabular}{|l}
\hline \\
\hline \\
\hline \\
\hline \\
\hline \\
\hline on air-to-fue \\
\hline
\end{tabular}

o) 1

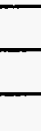




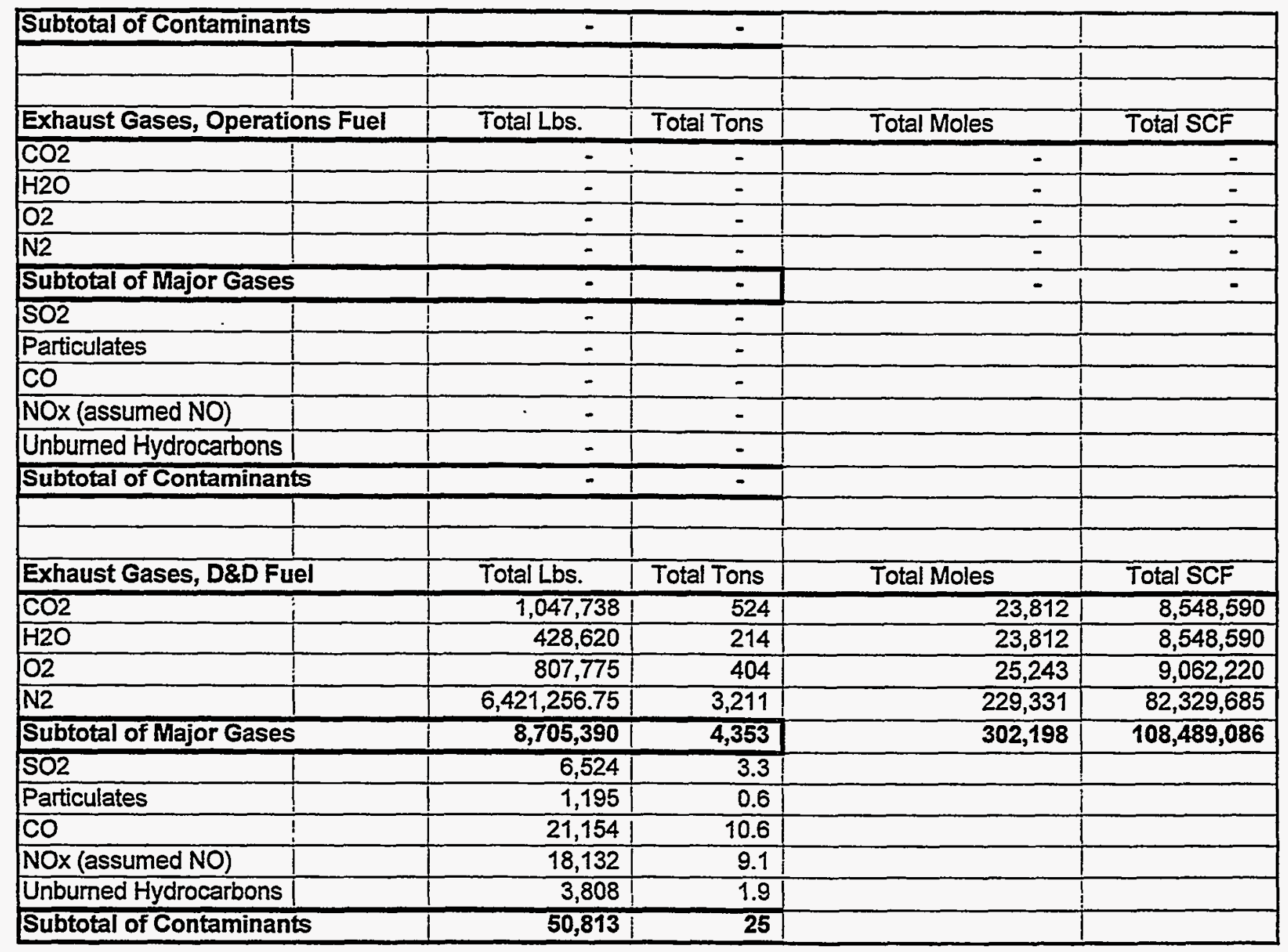




\section{Appendix E}

\section{Risk Assessment Data Sheets}

This appendix contains a Risk Assessment Form for each significant risk identified in the calcine retrieval and transportation system. The risks have been assigned to one of three categories:

Project, Technical, and ES\&H (Environmental, Health, and Safety).

Project Risk (cost or schedule):

P.1 Integrity of CSSF maintained

P. 2 Location of retrieval risers

P.3 Estimated retrieval percentage too high

P.4 Internal obstructions prevent retrieval

P.5 Waste Treatment Facility too slow

P.6 Miscellaneous materials prevent retrieval
Risk $=3$

Risk $=3$

Risk $=2$

Risk $=2$

Risk $=2$

Risk $=4$

Technical Risk:

T.1 Objective retrieval rate too high

Risk $=3$

T.2 All calcines are not retrievable

Risk $=4$

ES\&H Risk (environment, safety, or health):

ESH. 1 Construction radiation dose rates incorrect Risk $=4$

As risks were evaluated, the probability of occurrence and the impact if the risk is realized were rated. The probability and impact were assigned numerical values of " 3 " for high, " 2 " for medium, and " 1 " for low. The equation for risk calculation is Risk = Probability X Impact. The maximum risk rating is "9." 
The risk matrix, Table E-1, shows what action to take as a function of risk rating. These actions are defined in table E-2.

Table E-1. Risk Matrix

Risk $=$ Probability X Impact

\begin{tabular}{l|c|c|c|}
\multicolumn{3}{c}{ Probability } & \multicolumn{3}{c}{ Impact } \\
& Low (1) & Medium (2) & High (3) \\
\cline { 2 - 4 } High (3) & Evaluate (3) & Contingency Plan (6) & Eliminate Risk (9) \\
\cline { 2 - 4 } Medium (2) & Monitor (2) & Contingency Plan (6) & Contingency Plan (6) \\
\cline { 2 - 4 } Low (1) & Forget (1) & Monitor (2) & Evaluate (3) \\
\cline { 2 - 4 } & &
\end{tabular}

Table E-2. Risk Action Definition

\begin{tabular}{|c|l|}
\hline Risk Rating & \multicolumn{1}{|c|}{ Action } \\
\hline 9 & $\begin{array}{l}\text { Any risk determined to be in this category will be mitigated through } \\
\text { additional design or analysis until the risk is not longer in this category. }\end{array}$ \\
\hline 6 and 4 & $\begin{array}{l}\text { Risks in these categories will be mitigated to the extent feasible within } \\
\text { the cost and schedule guidelines. For those risks that cannot be } \\
\text { mitigated, contingency plans have been made to deal with the risk if it } \\
\text { occurs. }\end{array}$ \\
\hline 3 & $\begin{array}{l}\text { Risks in this category will be evaluated during the project to identify if } \\
\text { they are becoming problems. }\end{array}$ \\
\hline 2 & These risks will be monitored with no specific action identified. \\
\hline 1 & These risks are noted for interest only. \\
\hline
\end{tabular}




\section{Risk Assessment - Data Sheet}

Risk Type $\odot$ Project OTechnical OESH

RISK: Integrity of CSSFs maintained

Significant construction activities will occur on the roof of each CSSF. For nearly all CSSFs, 8 " holes must be drilled through the concrete roof. There is a possibility that the structural integrity of the CSSFs will be reduced.

\section{PREVENTIVE PLANS}

As part of locating the retrieval risers, a structural analysis of the CSSF roofs will be conducted.

\section{PROBABLE CAUSE(S):}

Structural integrity of the CSSF roofs will b compromised during access activities.

\section{CONSEQUENCES IF RISK NOT RESOLVED}

The schedule and cost would be effected by this risk. The CSS roof would need to be shored up. This would slow down the construction schedule and increase the cost.

\section{PROBABILITY}
High (3)
- Medium (2)
(-) Low (1)

\section{IMPACT}

$\begin{array}{ll}\bigcirc & \text { High (3) } \\ \bigcirc & \text { Medium (2) } \\ \bigcirc & \text { Low (1) }\end{array}$

\section{Risk $=3$}

Risk $=$ Probability $x$ Impact

Probability Definition

High - Likely to occur during the project.

Medium - Has the potential to occur during the project.

Low - Has little potential to occur during the project.

\section{Impact Definition}

High - Likely to cause significant disnuption of schedule, increase in cost, or degradation of performance.

Medium - Has the polential to cause some disrutpion to schedule. increase in cost, or degradation of performance.

Low - Has little potential to cause disnuption to schedule, increase in cost, or degradation of perfomance.

\section{CONTINGENCY PLAN(S) IF RISK IS REALIZED:}

The CSSF storage vault roof should be shored up.

\section{TRIGGER POINT(S) FOR EARLY RISK} IDENTIFICATION:

During feasibility studies, a structural analysis of the CSSF roofs should be conducted. 


\section{Risk Assessment - Data Sheet}

Risk Type $\odot$ Project OTechnical OESH

\section{RISK: Location of retrieval risers}

Locations for installation of retrieval risers must be identified. Enough locations may not exist on each bin to install the necessary retrieval risers.

\section{PREVENTIVE PLANS}

This risk has been significantly minimized by decreasing the number of retrieval lines need for calcine retrieval.

\section{PROBABLE CAUSE(S):}

The requirements for installing retrieval risers are not currently known. However, pipes in the bin vault may prevent the installation of the retrieval risers. There may not be adequate space on the bins to install the retrieval risers.

\section{CONSEQUENCES IF RISK NOT RESOLVED}

Calcine retrieval using the proposed calcine retrieval and transportation system would be prevented if the retrieval risers could not be installed. This would significantly impact the schedule and costs.

\section{PROBABILITY}

\section{IMPACT}

High (3)

Medium (2)

(-) Low (1)
(C) High (3)

Medium (2)

Low (1)

\section{CONTINGENCY PLAN(S) IF RISK IS REALIZED:}

Develop a less restrictive method for installing the retrieval lines.

\section{Risk $=3$}

Risk $=$ Probability $x$ Impact

\section{Probability Definition}

High - Likely to occur during the project.

Medium - Has the potential to ocour during the project.

Low - Has little potential to occur during the project.

Inpact Definition

High - Likely to cause significant disnuption of schedule, increase in cost, or degradation of perfomance.

Medium - Has the potential to cause some disrutpion to schedule, increase in cost, or degradation of performance.

Low - Has little potential to cause disnuption to schedule, increase in cost, or degradation of performance.

\section{TRIGGER POINT(S) FOR EARLY RISK IDENTIFICATION:}

The requirements of the riser installation process must be know prior to the early identification of this risk. 
RISK: Estimated retrieval percentage too high

It is estimated that $95 \%$ of the calcine in each bin can be retrieved. This estimate is based on the best available data fro pilot plant tests (ref. 9)

\section{PREVENTIVE PLANS}

The optimum configuration of suction nozzles and air jets should be identified through pilot plant study. The optimum configuratio should minimize the number of retrieval lines while maximizing the retrieval rate.

\section{PROBABLE CAUSE(S):}

Calcine may stick to the walls of the bin. It may get wedged in the "nooks and crannies" created by thermowells and intemal stiffening rings and rods. The more agglomerated the calcine is the harder it is to retrieve.

\section{CONSEQUENCES IF RISK NOT RESOLVED}

This risk will effect the closure of the CSSFs the most. The mor calcine left in each bin will increase closure costs and lengthen the closure schedule. Pilot plant tests show that $97 \%$ of the calcine (ref. 9) is retrievable at a high retrieval rate.

\section{PROBABILITY}

High (3)

- Medium (2)

- Low (1)

Risk $=2$

Risk $=$ Probability $\times 1$ Impact

\section{IMPACT}

\begin{tabular}{|ll|}
\hline$\bigcirc$ & High (3) \\
$\bigcirc$ & Medium (2) \\
$\bigcirc$ & $\operatorname{Low}(1)$ \\
\hline
\end{tabular}

\section{CONTINGENCY PLAN(S) IF RISK IS REALIZED:}

The best that can be done is to provide ample time in the schedule for CSSF closure.
Probability Definition

High - Likely to occur during the project.

Medium - Has the potential to occur during the project.

Low - Has little potential to occur during the project.

\section{Impact Definition}

High - Likely to cause significant disruption of schedule, increase in cost, or degradation of performance.

Medium - Has the potential to cause some disutpion to schedule, increase in cost, or degradation of performance.

Low - Has little potential to cause disnuption to schedule, increase in cost, or degradation of performance.

\section{TRIGGER POINT(S) FOR EARLY RISK} IDENTIFICATION:

During operation of the calcine retrieval and transportation system. 


\section{Risk Assessment - Data Sheet}

Risk Type OProject OTechnical OESH

\section{RISK: Internal obstructions prevent retrieval}

Internal obstructions may interfere with extension of the rigid retrieval lines into the bins.

\section{PREVENTIVE PLANS}

Examine the available CSSF drawings to determine retrieval ris locations that will not interfere with existing, internal obstructions

\section{PROBABLE CAUSE(S):}

Each bin has its own set of stiffening rods and thermowells. The retrieval lines may run into these internal obstructions.

\section{CONSEQUENCES IF RISK NOT RESOLVED}

Calcine retrieval may be completely stopped from a bin. This would adversely impact the schedule and drive costs up.

\section{PROBABILITY}

High (3)

Medium (2)

(-) Low (1)

\section{IMPACT}

$\begin{array}{ll}\bigcirc & \text { High (3) } \\ \bigcirc & \text { Medium (2) } \\ \bigcirc & \text { Low (1) }\end{array}$

Risk $=2$

Risk $=$ Probability $\times$ Impact

Probability Definition

High - Likely to occur during the project.

Medium - Has the potential to occur during the project.

Low - Has ittie potential to occur during the project.

\section{Impact Definition}

High - Likely to cause significant disruption of schedule, increase in cost, or degradation of performance.

Medium - Has the potential to cause some disutpion to schedule, increase in cost, or degradation of performance.

Low - Has little potential to cause discruption to schedule, increase in cost, or degradation of performance.

\section{CONTINGENCY PLAN(S) IF RISK IS REALIZED:} None.

\section{TRIGGER POINT(S) FOR EARLY RISK} IDENTIFICATION:

During operation of the calcine retrieval and transpotation system. 


\section{Risk Assessment - Data Sheet}

Risk Type $\odot$ Project OTechnical OESH

\section{RISK: Waste Treatment Facility too slow}

The waste treatment facility cannot process calcine fast enough. It falls behind the retrieval rate of calcine.

\section{PREVENTIVE PLANS}

The processing capacity of the Waste Treatment Facility should be defined during the conceptual design phase. The operation o the Waste Treatment Facility and the calcine retrieval and transportation system must be coordinated.

\section{PROBABLE CAUSE(S):}

The waste treatment facility may be slowed down by an equipment failure. The processing rate may be over estimated $i$ the adjoining scoping studies.

\section{CONSEQUENCES IF RISK NOT RESOLVED}

The calcine retrieval and transportation system should not operate unless the WTF requires additional calcine. The $50 \%$ u time estimate provides for some operational lapses. The risk is that the calcine batch bins will overflow with calcine. This will further contaminate the shielded cell when calcine is delivered $t$ the Waste Treatment Facility.

\section{PROBABILITY}
High (3)
Medium (2)
- Low (1)

\section{Risk $=2$}

Risk $=$ Probability $\times$ Impact

Probability Definition

High - Likely to occur during the project.

Medium - Has the potential to oceur during the project.

Low - Has little potential to occur during the project.

\section{Impact Definition}

High - Likely to cause significant disruption of schedule, increase in cost, or degradation of performance.

Medium - Has the potential to cause some disrutpion to schedule, increase in cost, or degradation of perfomance.

Low - Has little potential to cause disuption to schedule, increase in cost, or degradation of performance.

\section{TRIGGER POINT(S) FOR EARLY RISK}

\section{IDENTIFICATION:}

Changes in operations of the Waste Treatment Facility would identify the need to adjust the calcine retrieval rate. 


\section{Risk Assessment - Data Sheet}

Risk Type $\odot$ Project OTechnical OESH

RISK: Miscellaneous material prevents retrieval

The miscellaneous material may damage or plug the calcine retrieval and transportation system. Damage tot he calcine retrieval and transportation system or the bins may occur when this material is picked up by the air jet. Clogging can occur if an item enters the transportation system

\section{PREVENTIVE PLANS}

As much of this miscellaneous materias should be removed as possible.

\section{PROBABLE CAUSE(S):}

Over the years, non-calcine materials have entered the CSSFs 2 , and 3 . Rod out lines have been lost. Weighted lines have purposefully fallen into the bins. And other foreign materials hav entered the bins. This material is scattered throughout the calcine. It is at different levels. It is not known exactly what material entered the CSSFs 1,2 , and 3 .

\section{CONSEQUENCES IF RISK NOT RESOLVED}

The schedule can tolerate a fair amount of down time (currently operated $50 \%$ of the time). The backup transportation lines should minimize delays in the schedule. This will impact the cos if the damage is extensive.

\section{PROBABILITY}

$\begin{array}{ll}O & \text { High (3) } \\ 0 & \text { Medium (2) } \\ \bigcirc & \text { Low (1) }\end{array}$

High (3)

Low $(1)$

Risk $=4$

\section{IMPACT}

$\begin{array}{ll}\bigcirc & \text { High (3) } \\ \bigcirc & \text { Medium (2) } \\ \bigcirc & \text { Low (1) }\end{array}$

\section{CONTINGENCY PLAN(S) IF RISK IS REALIZED:}

Implement a method to remove these items before they enter th transport system.

Risk $=$ Probability $x$ Impact

Probability Definition

High - Likely to occur during the project.

Medium - Has the polential to occur during the project.

Low - Has fittle potential to occur during the project.

\section{Impact Definition}

High - Likely to cause significant disruption of schedule, increase in cost, or degradation of performance.

Medium - Has the potential to cause some disutpion to schedule, increase in cost, or degradation of performance.

Low - Has littie potential to cause disruption to schedule, increase in cost, or degradation of performance.

\section{IRIGGER POINT(S)FOR EARLY RISK} IDENTIFICATION:

During operation of the calcine retrieval and transport system. 


\section{Risk Assessment - Data Sheet}

Risk Type OProject OTechnical OESH

\section{RISK: Objective retrieval rate too high}

The objective retrieval rate is $2700 \mathrm{~kg} / \mathrm{hr}$. It is expected that calcine can be retrieved near this rate. This rate is based on the Fluor-Daniels design retrieval rate. Retrieval tests (ref. 9) show that it is difficult to maintain any given retrieval rate.

\section{PREVENTIVE PLANS}

A minimum and maximum retrieval rate should be defined. The operator should be able to control, to some extent, the retrieval rate by changing the heights of the suction and air jet nozzles.

\section{PROBABLE CAUSE(S):}

The retrieval rate appears to be directly related to the amount of calcine in the bin. The less calcine there is to retrieve the less calcine can be retrieved. Agglomerated calcine is more difficult to retrieve than free flowing calcine. The transport air blower, which provides the air jet and suction nozzles, may be undersized to retrieve such a large volume of calcine near the bottom of the bins.

\section{CONSEQUENCES IF RISK NOT RESOLVED}

The schedule should not be adversely impacted as long as the calcine can be retrieved at a rate greater than approximately 50 $\mathrm{kg} / \mathrm{hr}$. However, the cost will increase for operations if the calcine retrieval and transportation system must be operated for more than two $10 \mathrm{hr}$ days/week.

\section{PROBABILITY}

O High (3)

O Medium (2)

○ Low (1)

\section{IMPACT}

\begin{tabular}{|ll|}
\hline$\bigcirc$ & High (3) \\
$\bigcirc$ & Medium (2) \\
$\bigcirc$ & Low (1) \\
\hline
\end{tabular}

\section{CONTINGENCY PLAN(S) IF RISK IS REALIZED:}

Calcine retrieval will be conducted using extra shifts if the calcin can be retrieved at a reasonable rate. The reasonable rate will be determined by the needs of the waste treatment process. A good general number would be on the order of $500 \mathrm{lb} / \mathrm{hr}$.

\section{Risk $=3$}

Risk $=$ Probability $x$ Impact

Probability Definition

High - Likely to occur during the project.

Medium - Has the potential to occur during the project.

Low - Has little potential to occur during the project.

Impact Definition

High - Likely to cause significant disruption of schedule, increase in cost, or degradation of performance.

Medium - Has the potential to cause some disrutpion to schedule, increase in cost, or degradation of performance.

Low - Has Ittle potential to cause disruption to schedule, increase in cost, or degradation of performance.

\section{TRIGGER POINT(S) FOR EARLY RISK} IDENTIFICATION:

Operation of the calcine retrieval and transportation system 


\title{
Risk Assessment - Data Sheet
}

\author{
Risk Type OProject $\bigcirc$ Technical $\bigcirc E S H$
}

RISK: All calcines are not retrievable

All types of calcine are retrievable as a dilute phase using this calcine retrieval and transportation system.

\section{PREVENTIVE PLANS}

Pilot plant tests should be conducted on agglomerated calcine. Also samples of the calcine in the CSSFs should be taken and analyzed to determine if the calcine has agglomerated.

\section{CONSEQUENCES IF RISK NOT RESOLVED}

The retrieval rate could be significantly lower than expected. Th operating costs will increase. The schedule may fall behind.
The calcine may be agglomerated. It is anticipated that agglomerated calcine will not fluidize as readily as free flowing calcine

\section{PROBABILITY}
High (3)
- Medium (2)
Low (1)

\section{Risk $=4$}

Risk $=$ Probability $\times$ Impact

Probability Definition

High - Likely to occur during the project.

Medium - Has the potential to occur during the project.

Low - Has little potential to ocaur during the project.

\section{Impact Definition}

High - Likely to cause significant disruption of schedule, increase in cost, or degradation of perfomance.

Medium - Has the potential to cause some discutpion to schedule, increase in cost, or degradation of performance.

Low - Has Ittle potential to cause disruption to schedule, increase in cost, or degradation of performance.

\section{TRIGGER POINT(S) FOR EARLY RISK}

\section{IDENTIFICATION:}

Operation of the calcine retrieval and transportation system on actual calcine. 


\begin{tabular}{|c|c|c|c|c|c|c|c|c|c|c|c|c|c|c|c|}
\hline & & & & & & & & & & & & \multicolumn{4}{|c|}{$\begin{array}{r}\text { CSSF RETRIEVAL \& } \\
\text { CWO 5-YE }\end{array}$} \\
\hline ID & Task Name & 2003 & 2004 & 2005 & 2006 & 2007 & 2008 & 2009 & 2010 & 2011 & 2012 & 2013 & 2014 & 2015 & $\overline{2016}$ \\
\hline 1 & CALCINE TRANSPORT SYSTEM & & & & & & & & & & & & & & \\
\hline 2 & CONCEPTUAL DESIGN & & & & & & & & & & & & & & \\
\hline 3 & ADVANCED CONCEPTUAL DESIGN & & & & & & & & & & & & & & \\
\hline 4 & PM FOR PROJECT DEVELOPMENT & & & & & & & & & & & & & & \\
\hline 5 & PERMITTING & $6 / 2$ & 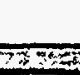 & 50 & & $x$ & & & & & & & & & \\
\hline 6 & PROJECT MANAGEMENT & & & & & & & & & & & & & & \\
\hline 7 & TITLE DESIGN & & & $12 / 28$ & & & & & & & & & & & \\
\hline 8 & CONSTRUCTION & & & & & & & & & & & & $3+\frac{1}{2}$ & & \\
\hline 9 & CORROSION COUPON REMOVAL & & & & & & & & & & & & & & \\
\hline 10 & D\&D RISER INSTALLATION & & & & & & & & & & & & & & \\
\hline 11 & CALCINE REMOVAL OPERATIONS & & & & & & & & & & & & & & \\
\hline
\end{tabular}




\begin{tabular}{|c|c|c|c|c|c|c|c|c|c|c|c|c|c|c|}
\hline ID & Task Name & 2003 & 2004 & 2005 & 2006 & 2007 & 2008 & 2009 & 2010 & 2011 & 2012 & 2013 & 2014 & 20 \\
\hline 1 & CALCINE TRANSPORT SYSTEM & & & & & & & & & & & & & \\
\hline 2 & CONCEPTUAL DESIGN & & & & & & & & & & & & & \\
\hline 3 & ADVANCED CONCEPTUAL DESIGN & & & & & & & & & & & & & \\
\hline 4 & PM FOR PROJECT DEVELOPMENT & & & & & & & & & & & & & \\
\hline 5 & PERMITTING & $6 / 2$ & & & & & & & & & & & & \\
\hline 6 & PROJECT MANAGEMENT & & & $12 / 2$ & & & & & & & & & & \\
\hline 7 & TITLE DESIGN & & & $12 / 2$ & & & & & & & & & & \\
\hline 8 & CONSTRUCTION & & & & & & & & & & & & & \\
\hline 9 & CORROSION COUPON REMOVAL & & & & & & & & & & & & & \\
\hline 10 & D\&D RISER.INSTALLATION & & & & & & & & & & & & & \\
\hline 11 & CALCINE REMOVAL OPERATIONS & & & & & & & & & & & & & \\
\hline 12 & BIN SET 1 & & & & & & & & & & & & & \\
\hline 13 & BIN SET 5 & & & & & & & & & & & & & \\
\hline 14 & BIN SET 6 & & & & & & & & & & & & & \\
\hline 15 & BIN SET 7 & & & & & & & & & & & & & \\
\hline 16 & BIN SET 2 & & & & & & & & & & & & & \\
\hline 17 & BIN SET 3 & & & & & & & & & & & & & \\
\hline 18 & BIN SET 4 & & & & & & & & & & & & & \\
\hline
\end{tabular}

This schedule represents calcine retrieval and transportation activities for the DCWO, HWO, VWO and TRU-Separations Options. Activities 12-18 represent retrieval of calcine from a specific CSSF. The CSSFs retrieval order has not been determined. The order must be coordinated between CSSF closure and the Waste Treatment Facility needs. All CSSFs will be prepared for retrieval by 1/1/2013. 
INTERDEPARTMENTAL COMMUNICATION

Date: January 24, 1998

To:

S. E. Gifford

MS 3765

$6-5162$

From:

F. P. Hanson

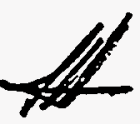

MS 3655

6-0548

Subject: HLW EIS WASTE TREATMENT SCOPING STUDIES - FPH-01-98

Reference: F. P. Hanson Tetter to S. E. Gifford, FPH-33-97, Same Subject, December 9, 1997

Cost Estimating has reviewed the referenced draft cost estimates and prepared the attached final Planning Cost Estimates for the subject project. Nine estimates have been prepared for the activities shown below; the work scope for each activity is described in the respective estimate.

1. Other Project Costs (OPC) including conceptual design, proof of process, permitting and documentation, start-up activities, and related project management costs.

2. One estimate each for Option B for Calcined Solids Storage Facilities (CSSFs) 1 through 4, and one estimate for CSSFs 5 through 7. Since the scope and nature of work for CSSFs 5 through 7 are nearly identical, one estimate has been prepared showing costs which may be applied to each of those CSSFs.

3. Installation of D\&D risers

4. Removal of corrosion coupons

5. One estimate each for Option A and Option B for the Calcine Transport System. Option B incorporates an Intermediate Transport Station with associated equipment.

The general scope of work covered by the estimates includes necessary modification of the CSSF vaults and CSSFs; construction of a new Containment Enclosure and a new Ventilation, Instrumentation, and Control (VIC) Building at each CSSF; construction of a new calcine transport system; and removal of corrosion coupons from the CSSFs.

The estimates incorporate all comments received to date, including your review of the draft estimates dated December 9, 1997 and intermediate draft estimates for the Calcine Transport System, as well as appropriate internal reviews. In addition, G\&A and Performance Incentive Factor (PIF) fees, not previously applied, have been added to the estimates as appropriate. 
S. E. Gifford

January 24, 1998

FPH-01-98

Page 2

Option A for modification of the CSSFs incorporated relocation and reuse of certain operational equipment. An examination of this option showed that it did not fully meet the needs of the system and was not sufficientiy cost effective to warrant further consideration; therefore, in accordance with your directive, estimates are provided for Option B only.

Assumptions which form the bases of the estimates and any concerns that may affect the costs are shown in the attached Support Data Recapitulation Sheets. Cost Estimate Summary Sheets, Detail Sheets, and Contingency Analysis Sheets for each estimate are also attached for your information. These describe in detail the scope of work and unit costs upon which the estimates are based. In addition, a Summary of Cost Estimates has been prepared showing the Total Project cost for each estimate. If you have further comments or questions regarding the estimates, please feel free to cal1.

fph

Attachment

cc: Estimate File \#2414-1 F. P. Hanson File

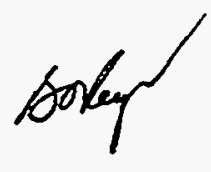


Lockheed Martin Idaho Technologies Co.

(Rev. 06/96)

\section{COST ESTIMATE SUPPORT DATA RECAPITULATIOH}

Project Title: HLW EIS Waste Treatment Scoping Studies

Calcine Retrieval and Transport

Type of Estimate: P1 anning

File No: 2414-1
Estimator: F. P. Hanson Date: 1-24-98

Approved By:

I. SCOPE OF WORK: Brief description of the proposed project.

This project will prepare Calcined Solids Storage Facilities (CSSFs) \#1 through $\$ 7$ for retrieval and transport of calcined waste to a processing facility. Each CSSF vault and CSSF will be modified as required, a new Containment Enclosure, and a new Ventilation, Instrumentation, and Control (VIC) Building will be constructed at each CSSF, and a new calcine transport system will be constructed. Construction of treatment and process facilities are not in the scope of the attached estimates.

II. BASIS OF THE ESTIMATE: Drawings, Design Report, Engineers notes, and/or other documentation upon which the estimate is originated.

a. Cost Estimate for Alternative 3, Phase I \& II Special Studies, Bin Set 1. Bin Set 1 Calcine Retrieval System, Raytheon Engineers and Constructors, Inc:, 11-8-94.

b. Feasibility Study Cost Estimate, Haste Treatment Facilities, Fluor Daniel Northwest, 10-22-97.

c. Draft Bin Set Access Plan with accompanying. tables, provided by S. E. Gifford, cognizant technical lead.

d. Drawings, sketches, and miscellaneous supporting information provided by $S$. E. Gifford.

e. Title II Cost Estimate, Waste Characterization Facility, Lockheed Idaho Technologies Co., 11-22-94. This estimate provides the basis for costs for. the Calcine Transport System Intermediate Transport Station. Costs are updated to current costs. 
Lockheed Martin Idaho Technologies Co.

COST ESTIMATE SUPPORT DATA RECAPITULATION

(CONTINUATION)

File No: $2414-1$

Page 2 of 6

III. ASSUMPTIONS: Condition statements accepted or supposed true without proof or demonstration. An assumption has a direct impact on total estimated cost.

1. The Raytheon estimate provides a comprehensive breakdown of work tasks and associated costs for work required to prepare CSSF \#1. The Fluor Daniel estimate addresses CSSFS $\# 2$ and $\# 3$, and closely reflects the Raytheon estimate, with no further scope or significant cost development. Because the Raytheon estimate represents the primary scope and cost development, it has been used as the basis of costs and scope of work addressed by the attached estimates. Hork scopes and associated labor and material costs have been adjusted as deemed appropriate for subsequent CSSFs.

2. It has been assumed that the Raytheon estimate was developed from a reasonably well developed description of work scope, therefore, quantities, unit costs, and labor effort have been incorporated as presented in the Raytheon estimate, except as otherwise determined by factors specific to this estimate effort. The costs provided in the attached estimates are dependent upon the underiying assumptions, inclusions, exclusions, and basis of quantity development and pricing for the Raytheon estimate.

3. Design, Title III Inspection, and Management costs were applied in the Raytheon estimate as a percentage of construction costs. Those rates have been modified for the attached estimates as follow: Tit7e Design at $20 \%$ of construction and GFE; Title III at $5 \%$ of construction and GFE; and PM and $C M$ each at $10 \%$ of construction and GFE. Title design modifications for CSSFs $\# 2$ through \#7 have been assumed at 20\% of Tit7e design costs for CSSF $\# 1$, assuming only relatively minor design modifications would be required.

4. Conceptual design and process development costs have been assumed at $30 \%$ of Title design costs for CSSF $\# 1$. It is assumed that conceptual design costs would not be impacted by subsequent Tit'le design modifications for the remaining CSSFs. See Section IV for further comments.

6. It has been assumed that removal of corrosion coupons will be accomplished by LMITCO operating personnel.

(Continued) 
Lockheed Martin Idaho Technologies Co.

\section{COST ESTIMATE SUPPORT DATA RECAPITULATION.}

(CONTINUATION)

File No: $2414-1$

Page 3 of 6

III. ASSUMPTIONS: (Continued)

5. It is assumed that all demolition and new construction work will be competitively bid and performed by a general contractor as the prime subcontractor, with specialty lower tier subcontractors as appropriate. One tier of subcontractor markups has been applied, at $40 \%$ for overhead and profit, plus $1 \%$ for bonding, in accordance with the Raytheon estimate.

7. The Raytheon estimate does not specifically identify costs for subcontractor supervision. It has been assumed that the labor figures incorporated include allowances for subcontractor project coordination and supervision. Costs for personnel OS\&H and site specific training have been included at $2 \%$ of project Tabor, per the Raytheon estimate, for CSSF $\# 1$, and at $1 \%$ of 1 abor for the remaining CSSFs, assuming primarily refresher and update training for subsequent CSSFs. . Construction of the CaTcine Transport System and installation of the D\&D risers are assumed to require additional personnel, therefor, the $2 \%$ allowance for training has been applied to those estimates.

8. Unit costs are assumed to include all costs necessary to accomplish the work including, but not necessarily limited to, site preparation; installation and removal of waste products, decontamination and cleanup, mobilization and demobilization, and cost of supporting organizations.

9. The labor hours shown in the Raytheon estimate have been incorporated; however, current INEEL Site Stabilization. Agreement rates have been used, which may differ from the rates shown in the reference.

10. Allowances for undefined costs and for NQA-1 have been applied as shown in the Raytheon estimate, and are assumed to be appropriate for the project.

11. Material costs have been applied as shown in the Raytheon estimate, as appropriate, and further escalated at approximately $1.5 \%$ per year from the date of the estimate to the current date.

12. The Raytheon estimate does not include costs for the Containment Enclosure or the VIC Building. The attached estimates assume both the structures to be pre-engineered metal buildings, complete with appropriate services nd equipment. The Containment Enclosure is assumed to be $30^{\prime} \times 30^{\prime}$ or $40^{\prime} \times$ $40^{\prime}$, depending upon the vault dimension, with a $60^{\prime}$ eave height. The VIC building is assumed to be $40^{\prime} \times 60^{\prime} \times 14^{\prime}$ eave height in all cases. Costs are based on historical data and estimating judgement. 
Lockheed Martin Idaho Technologies Co.

\section{COST ESTIMATE SUPPORT DATA RECAPITULATION}

(CONTINUATION)

File No: $2414-1$

Page 4 of 6

III. ASSUMPTIONS: (Continued)

13. It is assumed that minimal site preparation will be required. Costs have not been included for additional service and access roads.

14. The following equipment is associated with the Calcine Transport System and is to be located in the processing facility; costs are assumed to be addressed in the appropriate facility cost estimate and have not been included herein. Equipment numbers are identified in appropriate drawings and equipment 1ists.

- Air Handling Unit, 2,130 CFM

- Exhaust Fan, 830 CFM

- Exhaust. Fan, 230 CFM

- HEPA Filter w/Prefilter, 530 CFM

- HEPA Canisters w/Prefilters, 230 CFM

15. The cost estimate for Other Project costs (OPC) is intended to show all permitting costs associated with the entire CSSF modification and . construction of the transport system. Costs for permitting and documentation are assumed to encompass all activities required.

16. The estimates identify certain activities related to demolition, earthwork, and construction which are to be accomplished during the overal1 time frame shown, rather than showing labor hours for the specific activities. It is assumed that the time frames and labor loading shown are adequate to accomplish the activities.

17. The proposed schedule shown in the Raytheon estimate calls for engineering from 10/1997 to 10/1999, with a mid-pint of 10/1998, and all other activities from $12 / 2000$ to $5 / 2005$, with a mid-point of $11 / 2002$. Using the schedule of operations provided, the following activity mid-points have been established for purposes of calculating escalation:

- Conceptual design: 2003 - 2005, mid-point 2004.

- Tit7e design: 2005 - 2007, mid-point 2006.

- Construction: 2008 - 2013, mid-point 2011.

(Continued) 
Lockheed Martin Idaho Technologies Co.

\section{COST ESTIMATE SUPPORT DATA RECAPITULATION (CONTINUATION)}

File No: $2414-1$

Page 5 of 6

III. ASSUMPTIONS: (Continued)

- Insta77ation of D\&D risers: Mid-point of operations (2014 - 2033), 2023

- Removal of corrosion coupons: Mid-point of construction, 2011

19. It is assumed that the Calcine Transport System will consist of two separate systems. The quantities shown in the estimate reflect total quantities for the two systems.

21. It is assumed that the Intermediate Transport Station for Option B will be of reinforced concrete construction housing process equipment, with a preengineered metal building portion hoasing utilities and support equipment, and that the facility will require normal features for equipment shielding and accessibility, personnel protection, and normal utilities, HVAC, and electrical services.

20. Information available to the cognizant technical lead indicates that, due to corrosion failure of piping in CSSFs 2 and 3 , radiological conditions arising from contamination are similar to CSSF \#1. The estimates for CSSFs 2 and 3 have been prepared with that factor in mind, and labor allowances incorporated accordingly.

22. LMITCO G\&A has been applied at 23\% of construction and GFE, with a $\$ 500,000$ ceiling applied, and the Performance Incentive Fee (PIF) has been applied at $5.5 \%$. Procurement fees have been assumed at $1 \%$, as procurement support to DOE, rather than the normal $3 \%$ fee. Adders are applied to each estimate based on the assumption the work addressed therein wi11 be accomplished in one year. 
Lockheed Martin idaho Technologies Co.

\section{COST ESTIMATE SUPPORT DATA RECAPITULATION} (CONTINUATION)

File No: $2414-1$

Page 6 of 6

IV. CONTINGENCY GUIDELINE IMPLEMENTATION: The percentage used for contingency as determined by the contingency allowance guidelines can be altered to reflect the type of construction and conditions that may impact the total estimated cost.

Time constraints and lack of definitive design and project requirements have been taken into consideration in generating the costs and attendant rates of contingency shown in the estimate. Very little is known at this time regarding specific facility and process requirements, and there is a very real potential for encountering radiological conditions beyond those anticipated, resulting in increased labor and equipment costs. This, together with the unknowns associated with subsurface work and radiological. conditions, with the inherent possibility of encountering differing conditions as existing work is opened up, create a high potential for increased costs. Some equipment may not be standard and may require development, and the scheduTe extends over many years. For these reasons, the rate of contingency typically exceeds the guidelines for a planining estimate and extends into the range for special conditions, as defined by DOE/FM 50, Cost Estimating Guide, Vol. 6, and the INEEL Cost. Estimating Guide.

Overall contingency rates for escalated estimates are slightly higher than unescalated estimates, due to the assumed higher degree of associated risk as activities and costs are extended into the out years.

\section{OTHER COMMENTS/CONCERNS SPECIFIC TO THE ESTIMATE:}

Individual estimates have been prepared for Other Project costs (OPC); two options for the Calcine Transport System; and each of CSSFs 1 through 4. Since the scope and nature of work for CSSFs 5 through 7 are nearly identical, one estimate has been prepared showing costs which may be applied to each of those CSSFs. After analyzing draft cost estimates for Option A and Option B, for CSSF modifications, it was determined by the cognizant technical lead that Option A did not sufficiently meet system requirements and would not be further pursued; therefore, complete estimates are provided only for Option B for each case, and Summary Sheets are provided for both escalated and unescalated costs for each estimate. Separate estimates have also been prepared for installing D\&D risers and for removing corrosion coupons.

The allowance of $30 \%$ of construction for Title Design included in the Raytheon estimate appears excessive for this magnitude of work. It was determined by the cognizant technical lead that this allowance was based on the total lack of a.proven retrieval method at the time the Raytheon estimate was prepared. Because of subsequent design development, the allowance is reduced to $20 \%$ in the attached estimates. 
Lockheed Martin Idaho Technologies Co.

\section{SUMMARY OF COST ESTIMATES}

HLW EIS WASTE TREATMENT SCOPING STUDIES CALCINE RETRIEVAL AND TRANSPORT LOCATION: INEEL-ICPP REQUESTOR: K. L. WILLLAMS
PLANNING ESTIMATE

ESTIMATE NO. 24141

PREPARED BY: F.P. HANSON

\begin{tabular}{|c|c|c|}
\hline \multirow{2}{*}{ ACTIVITY } & \multicolumn{2}{|c|}{ OPTION B } \\
\hline & $\begin{array}{l}\text { UNESCALATED } \\
\text { COSTS }\end{array}$ & $\begin{array}{l}\text { ESCALATED } \\
\text { COSTS }\end{array}$ \\
\hline OTHĖR PROJECT COSTS (OPC) & $\$ 28,300,000$ & $\$ 41,100,000$ \\
\hline CSSF \#1 & $\$ 37,100,000$ & $\$ 52,750,000$ \\
\hline CSSF \#2 & $\$ 24,000,000$ & $\$ 34,000,000$ \\
\hline CSSF \#3 & $\$ 23,400,000$ & $\$ 33,100,000$ \\
\hline CSSF \#4 & $\$ 16,000,000$ & $\$ 22,500,000$ \\
\hline CSSF \#5 & $\$ 14,700,000$ & $\$ 21,000,000$ \\
\hline CSSF \#6 & $\$ 14,700,000^{\circ}$ & $\$ 21,000,000$ \\
\hline CSSF \#7 & $\$ 14,700,000$ & $\$ 21,000,000$ \\
\hline INSTALL D\&D RISERTS & $\$ 5,100,000$ & $\$ 10,300,000$ \\
\hline REMOVE CORROSION COUPONS & $\$ 1,125,000$ & $\$ 1,620,000$ \\
\hline $\begin{array}{l}\text { TOTAL PROJECT COST } \\
\text { (LESS TRANSPORT SYSTEM) }\end{array}$ & $\$ 179,125,000$ & $\$ 258,370,000$ \\
\hline CALCINE TRANSPORT SYSTEM OPTIONS & . & \\
\hline CWO \& TRU SEPARATION OPTIONS (A) & $\$ 15,300,000$ & $\$ 21,650,000$ \\
\hline HWO, WWO, DCWO OPTIONS (B) & $\$ 20,400,000$ & $\$ 29,000,000$ \\
\hline
\end{tabular}



Lockheed Martin ldaho Technologies Co. PRQUECT NAYE LOCATION 1: REQUESTOR
HLW EIS -WASTE TREATMENT SCOPING INEEL - ICPP

K. L WILLIAMS
COST ESTIMATE SUMMARY

PE OFESTIMATE: PLANNING PROAECT NO: 2414-1 (OPC) PREPARED BY F. P. HANSON REPORT NAME: Cost Estimate Summary

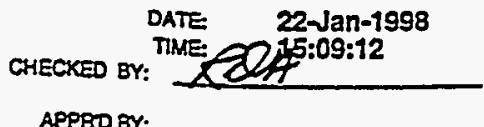

APPROBY:

\begin{tabular}{|c|c|c|c|c|}
\hline $\begin{array}{l}\text { WBS } \\
\text { Element }\end{array}$ & Cost Estimate Element & $\begin{array}{c}\text { Total } \\
\text { Unescalated } \\
\end{array}$ & Escalation & $\begin{array}{c}\text { Total } \\
\text { Incl Escalation } \\
\end{array}$ \\
\hline 1.1 & OTHER PROJECT COSTS - DESIGN & & & $\$ 18,000,000$ \\
\hline 1.1.1 & CONCEPTUAL DESIGN & $12,500,000$ & $5,500,000$ & $18,000,000$ \\
\hline 1.2 & OTHER PROJECT COSTS - MANAGEMENT & & & $\$ 2,700,000$ \\
\hline 1.21 & DESIGN PROJECT MANAGEMENT & $1,875,000$ & 825,000 & $2,700,000$ \\
\hline 1.3 & PERMITTING AND DOCUMENTATION & & & $\$ 4,809,600$ \\
\hline 1.3 .1 & PLANS AND SAFETY REVIEWS & $3,340,000$ & $1,469,600$ & $4,809,600$ \\
\hline 1.4 & STARTUP ACTTVITIES & & & $\$ 5,115,456$ \\
\hline 1.4.1 & SO TESTING AND ORR & $3,552,400$ & $1,563,056$ & $5,115,456$ \\
\hline 1.5 & G\&APIF & & & ș \\
\hline 1.5.1 & GEAVIF ADDER & 0 & 0 & 0 . \\
\hline 1.5 .2 & PROCUREMENT FEES & 0 & 0 & $\gg$ \\
\hline & $\begin{array}{l}\text { SUBTOTAL INCLUDING ESCALATION } \\
\text { PROJECT CONTINGENCY }\end{array}$ & $21,257,400$ & $9,357,656$ & $\gg \$ 30,625,056$ \\
\hline & MANAGEMENT RESERVE- & & & $\gg$ \\
\hline & CONTINGENCY & & & $\gg \quad \$ 10,474,944$ \\
\hline & TOTAL ESTIMATED COST - & & & $\$ 41,100,000$ \\
\hline
\end{tabular}

PROJECT COST PARAMETERS

EDI AS A \% OF CONST. + GFE= $\quad \cdots .+\cdots$ 
Lockheed Martin Idaho Technologies Co. PROSECT NAME: HLW EIS -WASTE TREATMENT SCOPING STUDIES TYPE OF ESTMMAE: LOCATION $1:$ CALCINE RETRIEVAL AND TRANSPORT

INEEL - ICPP

REOUESTOR: K. L. WILLAAMS
COST ESTIMATE SUMMARY

PLANNING PROUECTNO: PAEPAFED BY:

F. P. HANSON Cost Estumate Summary

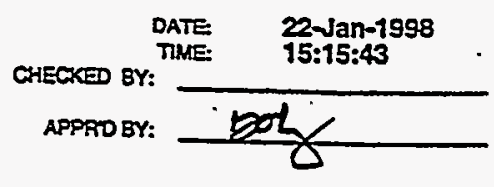

\begin{tabular}{|c|c|c|c|c|}
\hline $\begin{array}{l}\text { WBS } \\
\text { Element }\end{array}$ & Cost Estimate Element & $\begin{array}{c}\text { Total } \\
\text { Unescalated }\end{array}$ & Escalation & $\begin{array}{c}\text { Total } \\
\text { Incl Escalation } \\
\end{array}$ \\
\hline $\begin{array}{l}1.1 \\
1.1 .1 \\
1.2 \\
1.2 .1 \\
1.3 \\
1.3 .1 \\
1.4 \\
1.4 .1 \\
1.5 \\
1.5 .1 \\
1.5 .2\end{array}$ & $\begin{array}{l}\text { OTHER PROJECT COSTS-DESIGN } \\
\text { CONCEPTUAL DESIGN } \\
\text { OTHER PROJECT COSTS-MANAGEMENT } \\
\text { DESIGN PROJECT MANAGEMENT } \\
\text { PERMITTING AND DOCUMENTATION } \\
\text { PLANS AND SAFETY REVIEWS . } \\
\text { STARTUP ACTIUITIES } \\
\text { SO TESTING AND ORR } \\
\text { G\&ANPIF . } \\
\text { G\&APPIF ADDER } \\
\text { PROCUREMENT FEES }\end{array}$ & $\begin{array}{c}12,500,000 \\
1,875,000 \\
3,340,000 \\
3,552,400\end{array}$ & $\begin{array}{l}0 \\
0 \\
0 \\
0 \\
0 \\
0 \\
0\end{array}$ & 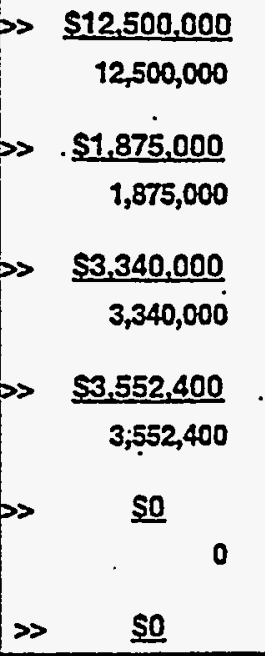 \\
\hline & $\begin{array}{l}\text { SUBTOTALINCLUDING ESCALATION } \\
\text { PROJECT CONTINGENCY }\end{array}$ & $21,267,400$ & 0 & >> $\$ 21,267,400$ \\
\hline & MANAGEMENT RESERVE & & & . so \\
\hline & CONTINGENCY- & & & $57,032,600$ \\
\hline & TOTAL ESTIMATED COST - & & & $\$ 28.300 .000$ \\
\hline
\end{tabular}

PROJECT COST PARAMETERS

EDI AS A \% OF CONST. + GFE= $\cdots$ 
Lockheed Martin Idaho Technologies Co.

LOCATION 1:

HLW EIS -WASTE TREATMENT SCOPINC
CALCINE RETRIEVAL AND TRANSPO

INEEL - ICPP

REOUESTOR:

$K$. L WILLAMS
COST ESTIMATE SUMMARY

TUDIES TYFE OFESTIMATE: PLANNING

$\begin{array}{ll}\text { PRE OF ESTIMATE: } & \text { PLANNING } \\ \text { PROETNO: } & 2414-1-1 \text { (CSSF 1) }\end{array}$

REPORT NAME: Cost Estimate Summary

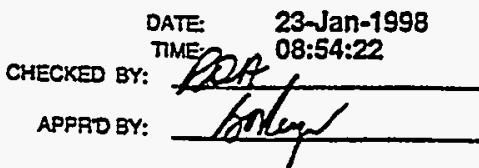

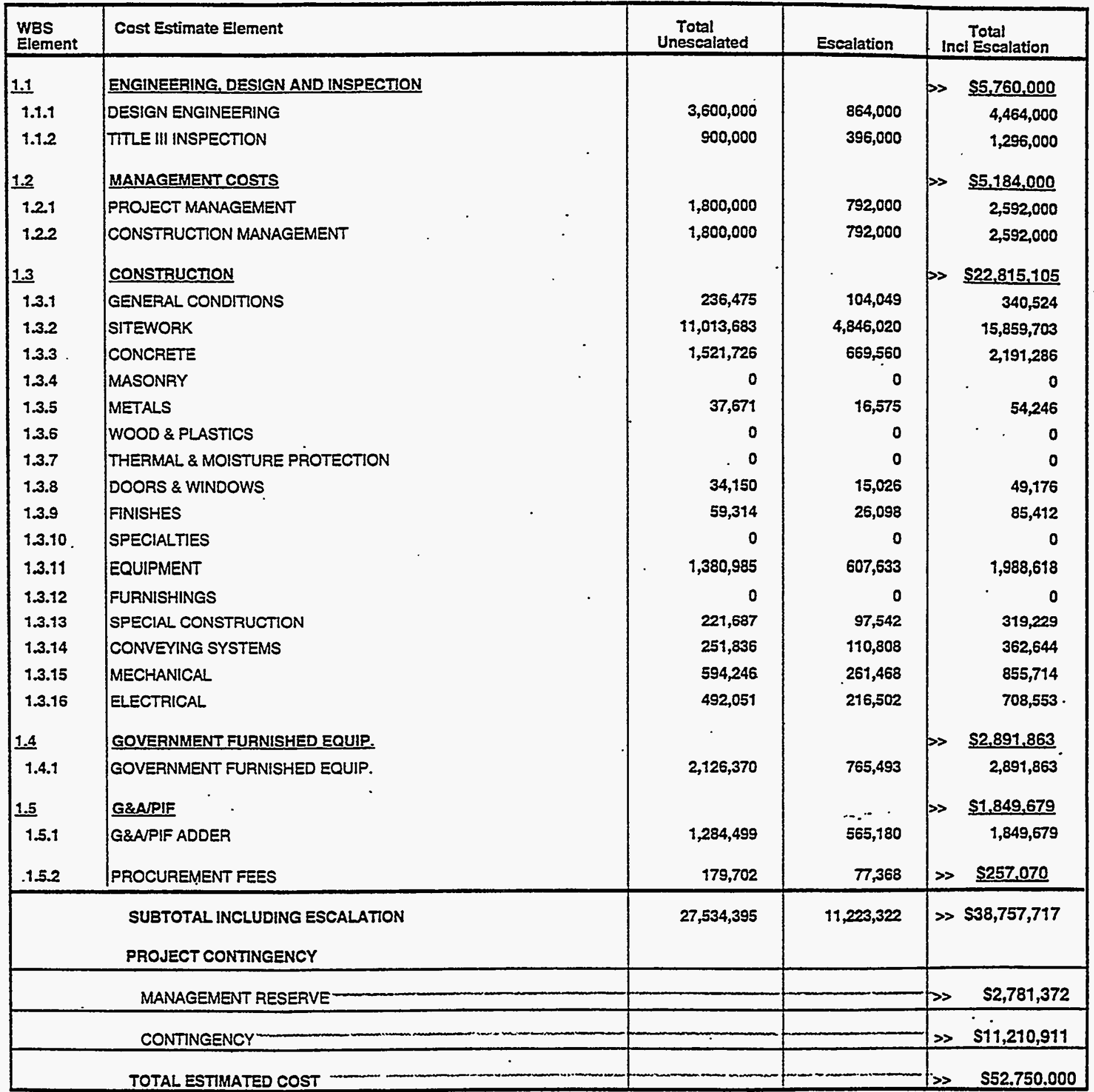

PROJECT COST PARAMETERS

EDI AS A \% OF CONST. + GFE $=22.00 \%$

CONTINGENCY $=36.10 \%$ 

Lockheed Martin Idaho Technologies Co. PROSECT NAME: HLW EIS -WASTE TREATMENT SCO

HLW EIS -WASTE TREATMENT SCOPING STUDIES TYPE OF ESTIMATE:

INEEL - ICPP LOCATON 1: REQUESTOR:

PAEPARED BY
COST ESTIMATE SUMMARY

PLANNING

2414-1-1 (CSSF 1)

F.P. HANSON

REPORT NAME: Cost Estimate Summary

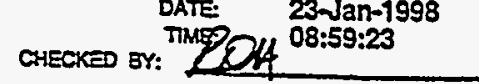

APPRD BY:

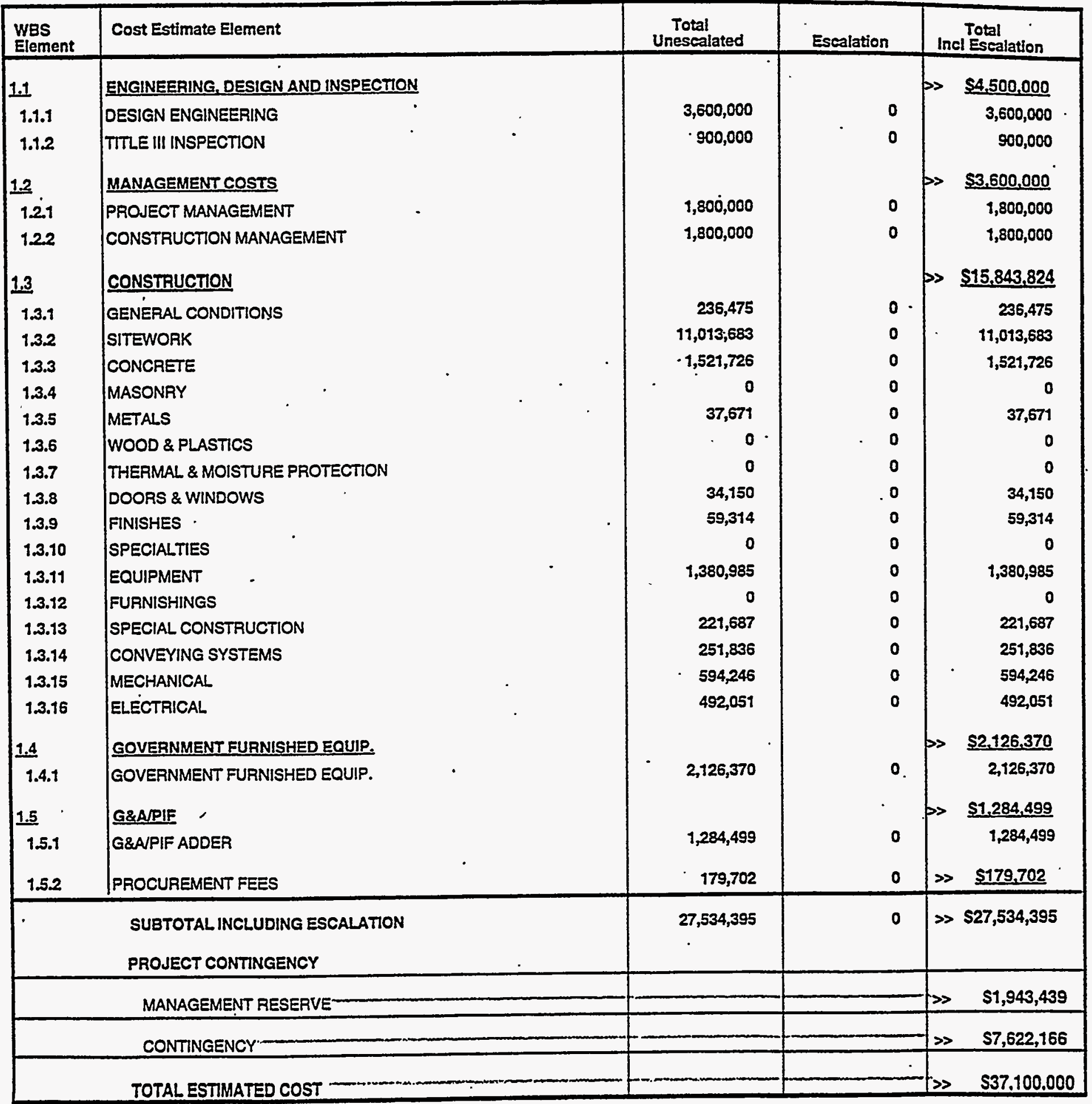

\section{PROJECT COST PARAMETERS}

EDI AS A \% OF CONST. + GFE= $25.00 \%$ 
Lockheed Martin Idaho Technologies Co.

COST ESTIMATE SUMMARY

PROSECT NAME: HLW EIS -WASTE TREATMENT SCOPING STUDIES TYPE OFESTIMATE: PLANNING CALCINE RETRIEVAL AND TRANSPORT-OPTION 3 PROSECT NO: 2414-1-2 (CSSF 2)

LCCATON I: INEEL - ICPP

REQUESTOR: K. L. WULUAMS

PREPAAED BY: F.P. HANSON

REPORT NAME: Cost Estimate Summary

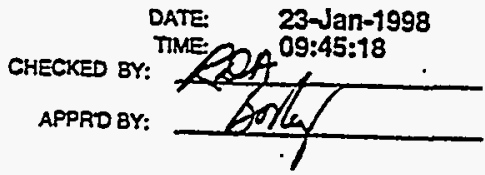

\begin{tabular}{|c|c|c|c|c|}
\hline $\begin{array}{l}\text { WBS } \\
\text { Element }\end{array}$ & Cost Estimate Element & $\begin{array}{c}\text { Total } \\
\text { Unescalated }\end{array}$ & Escalation & $\begin{array}{l}\text { Total } \\
\text { Incl Escalation }\end{array}$ \\
\hline 1.1 & ENGINEERING, DESIGN AND INSPECTION & & & $\$ 1,972,800$ \\
\hline 1.1.1 & DESIGN ENGINEERING & 720,000 & 316,800 & $1,036,800$ \\
\hline 1.1 .2 & TITLE III INSPECTION & 650,000 & 286,000 & 936,000 \\
\hline 1.2 & MANAGEMENT COSTS & & & $\$ 3,111,000$ \\
\hline 1.2 .1 & PROJECT MANAGEMENT & $1,275,000$ & 0 & $1,275,000$ \\
\hline 1.22 & CONSTRUCTION MANAGEMENT & $1,275,000$ & 561,000 & $1,836,000$ \\
\hline 1.3 & CONSTRUCTION & & & $\$ 15,903,115$ \\
\hline 1.3 .1 & GENERAL CONDITIONS & 79,168 & 34,834 & 114,002 \\
\hline 1.3.2 & SITEWORK & $6,912,013$ & $3,041,286$ & $9,953,299$ \\
\hline 1.3.3 & CONCRETE & $1,020,501$ & 449,020 & $1,469,521$ \\
\hline 1.3 .4 & MASONRY & 0 & 0 & 0 \\
\hline 1.3.5 & METALS & 37,671 & 16,575 & 54,246 \\
\hline 1.3 .6 & WOOD \& PLASTICS & 0 & $\therefore 0$ & 0 \\
\hline 1.3 .7 & THERMAL \& MOISTURE PROTECTION & 0 & 0 & 0. \\
\hline 1.3 .8 & DOORS \& WINDOWS & 34,150 & 15,026 & 49,176 \\
\hline 1.3 .9 & FINISHES & 64,411 & 28,341 & $\$ 2,752$ \\
\hline 1.3.10 & SPECIALTIES & 0 & 0 & 0 \\
\hline 1.3.11 & EQUIPMENT & $1,199,716$ & $\mathbf{5 2 7 , 8 7 5}$ & $1,727,599$ \\
\hline 1.3.12 & FURNISHINGS & 0 & 0 & 0 \\
\hline 1.3 .13 & SPECIAL CONSTRUCTION & 291,171 & 128,115 & 419,286 \\
\hline 1.3 .14 & CONVEYING SYSTEMS & 278,560 & 122,567 & 401,127 \\
\hline 1.3.15 & MECHANICAL & 596,103 & 262,285 & 858,388 \\
\hline 1.3.16 & ELECTRICAL & 530,366 & 233,364 & 763,727 \\
\hline 1.4 & GOVERNMENT FURNISHED EQUIP. & & & $\$ 2,290,530$ \\
\hline 1.4 .1 & GOVERNMENT FURNISHED EQUIP. & $1,684,213$ & 606,317 & $2,290,530$ \\
\hline 1.5 & G\&APIF & & & $\$ 1,412,031$ \\
\hline 1.5.1 & GEAPIF ADDER & 980,577 & 431,454 & $1,412,031$ \\
\hline 1.5 .2 & PROCUREMENT FEES & 127,280 & 54,656 & $\$ 181,936$ \\
\hline & $\begin{array}{l}\text { SUBTOTAL INCLUDING ESCALATION } \\
\text { PROJECT CONTINGENCY }\end{array}$ & $17,755,900$ & $7,115,512$ & $\gg \$ 24,871,412$ \\
\hline & MANAGEMENT RESERVE- & & & $\$ 1,978,761$ \\
\hline & CONTINGENCY - & & & $57,149,827$ \\
\hline & TOTAL ESTMMATED COST - & 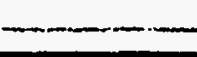 & & $\$ 34.000 .000$ \\
\hline
\end{tabular}

PROJECT COST PARAMETERS

EDI AS A \% OF CONST. + GFE= $11.00 \%$ 
Lockheed Martin Idaho Technologies Co. COST ESTIMATE SUMMARY

HLW EIS -WASTE TREATMENT SCOPING STUDIES TYPE OF ESTIMATE: PLANNING CALCINE RETRIEVAL AND TRANSPORT-OPTION B PROJECT NO: 2414-1-2 (CSSF 2)

LOCATION 1:

INEEL - ICPP

PREPARED BY:

F. P. HANSON

REQUESTOR:

K. L. WILLIAMS

REPORT NAME: Cost Estimate Summary

CHECKED BY: TMEO OA 09:47:27 $^{\text {23-1998. }}$

APPRD BY:

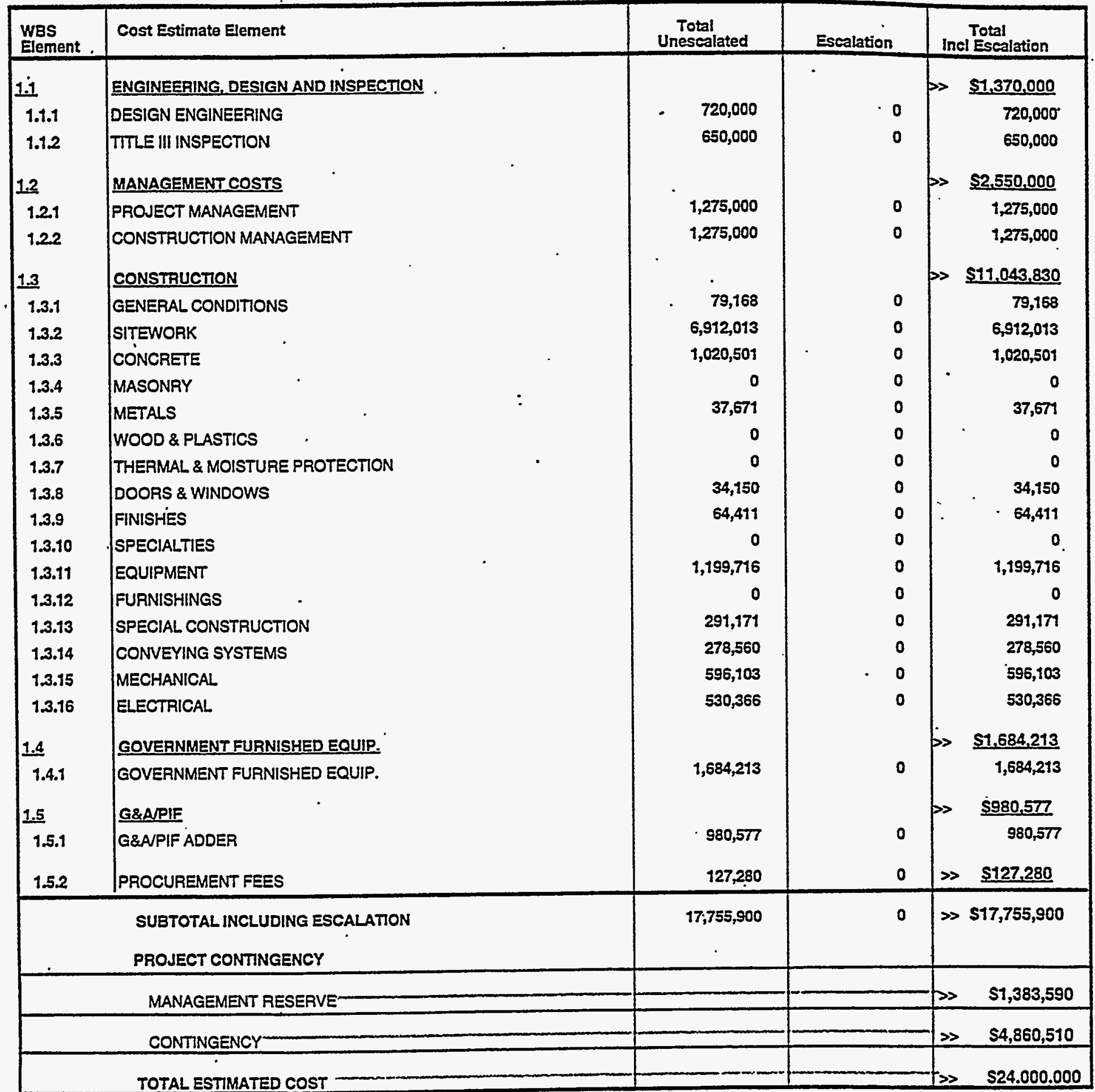

PROJECT COST PARAMETERS

EDI AS A \% OF CONST. + GFE $=11.00 \%$ 
Lockheed Martin Idaho Technologies Co.

FROSECT NANE

LOCATION 1:

REQUESTOR:

K. L WILUIAMS
COST ESTIMATE SUMMARY

HLW EIS -WASTE TREATMENT SCOPING STUDIES TYPE OF ESTIMATE: PLANNING

CALCINE RETRIEVAL AND TRANSPORT - OPTION B PRCECT NO:
INEEL - ICPP
PREPARED BY:
PREPARED 8Y:

F. P. HANSON

REPOAT NAME: Cost Estimate Summary

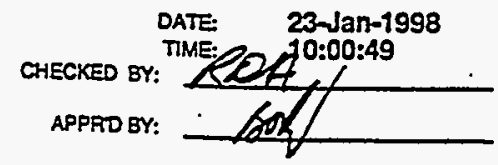

\begin{tabular}{|c|c|c|c|c|}
\hline $\begin{array}{l}\text { WBS } \\
\text { Element }\end{array}$ & Cost Estimate Element & $\begin{array}{c}\text { Total } \\
\text { Unescalated }\end{array}$ & Escalation & $\begin{array}{l}\text { Total } \\
\text { Inci Escalation }\end{array}$ \\
\hline 1.1 & ENGINEERING, DESIGN AND INSPECTION & & & $\$ 1,929,600$ \\
\hline 1.1 .1 & DESIGN ENGINEERING & 720,000 & 316,800 & $1,036,800$ \\
\hline 1.12 & TITLE III INSPECTION & 620,000 & 272,800 & . $\quad 892,800^{\circ}$ \\
\hline 1.2 & MANAGEMENT COSTS. & & & $\$ 3,050,000$ \\
\hline 1.21 & PROJECT MANAGEMENT & $1,250,000$ & 0 & $1,250,000$ \\
\hline 122 & CONSTRUCTION MANAGEMENT & $1,250,000$ & 550,000 & $1,800,000$ \\
\hline 1.3 & CONSTRUCTION & & & $\$ 15,447,410$ \\
\hline 1.3 .1 & GENERAL CONDITIONS & 79,215 & 34,855 & 114,070 \\
\hline 1.3 .2 & SITEWORK & $6,564,926$ & $2,888,557$ & $9,453,493$ \\
\hline 1.3 .3 & CONCRETE & $1,020,501$. & 449,020 & $1,469,521$ \\
\hline 1.3 .4 & MASONRY & 0 & 0 & 0 \\
\hline 1.3 .5 & METALS & 37,671 & 16,575 & 54,246 \\
\hline 1.3 .6 & WOOD \& PLASTICS & 0 & .0 & 0 \\
\hline 1.3 .7 & THERMAL \& MOISTURE PROTECTION & 0 & 0 & 0 \\
\hline 1.3 .8 & DOORS \& WINDOWS & 34,150 & 15,026 & 49,176 \\
\hline 1.3 .9 & FINISHES & 64,411 & 28,341 & 92,752 \\
\hline 1.3 .10 & SPECIALTIES & 0 & 0 & 0 \\
\hline 1.3.11 & EQUIPMENT & $1,207,349$ & 531,234 & $1,738,583$ \\
\hline 1.3.12 & FURNISHINGS & 0 & 0 & 0 \\
\hline 1.3.13 & SPECIAL CONSTRUCTION & 291,171 & 128,115 & 419,286 \\
\hline 1.3.14 & CONVEYING SYSTEMS & 278,560 & 122,567 & 401,127 \\
\hline 1.3.15 & MECHANICAL & 619,048 & 272,381 & 891,429 \\
\hline 1.3.16 & ELECTRICAL & 530,366 & 233,361 & 763,727 \\
\hline 1.4 & GOVERNMENT FURNISHED EQUIP. & & & $\$ 2,290,530$ \\
\hline 1.4.1 & GOVERNMENT FURNISHED EQUIP. & $1,684,213$ & 606,317 & $2,290,530$ \\
\hline 1.5 & G\&APIF & & & $\gg \quad \$ 1,385,611$ \\
\hline 1.5.1. & G\&AVIF ADDER & 962,230 & 423,381 & $1,385,611$ \\
\hline 1.5 .2 & PROCUREMENT FEES & 124,116 & 53,264 & $\$ 177,380$ \\
\hline & $\begin{array}{l}\text { SUBTOTAL INCLUDING ESCALATION } \\
\text { PROJECT CONTINGENCY }\end{array}$ & $17,337,927$ & $5,942,604$ & $\gg \$ 24,280,531$ \\
\hline & MANAGEMENT RESERVE & & & $\$ 1,930,093$ \\
\hline & CONTINGENCY - & & & S6,889,376 \\
\hline & TOTAL ESTIMATED COST & & & $\$ 33.100 .000$ \\
\hline
\end{tabular}

PROJECT COST PARAMETERS

EDI AS A \% OF CONST. + GFE $=11.00 \%$ 
Lockheed Martin Idaho Technologies Co.

PROSECT NANE

LOCATION 1: REQUESTOR

HLW ES -WASTE TREATMENT SCOPING STUDIES TPPE OFESTIMATE CALCINE RETRIEYAL AND TRANSPORT-OPTION B PROIECTNO

INEEL - ICPP

K. L. WILLIAMS
COST ESTMMATE SUMMARY

REPORT NAME

F. HANSON

Cost Estimate Summary

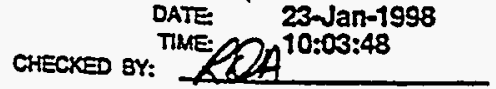

APPRD BY:

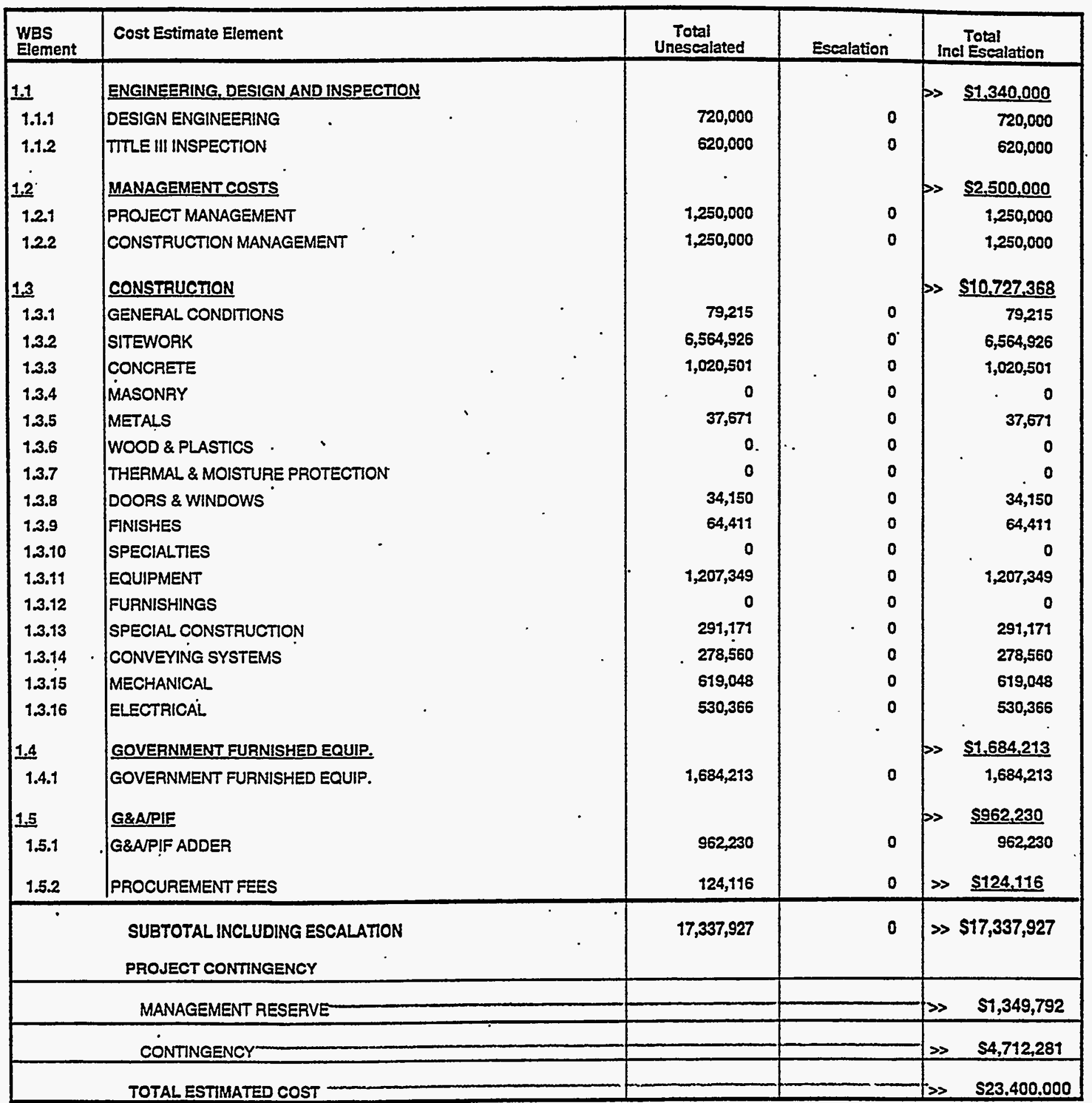

\section{PROJECT COST PARAMETERS}

EDI AS A \% OF CONST. + GFE $=11.00 \%$ 
Lockheed Martin ldaho Technologies Co.

PROSECT NAME

LOCATION 1:

REQUESTOR:

K.LWILLAAS
COST ESTIMATE SUMMARY

HLW EIS-WASTE TREATMENT SCOPING STUDIES TYPE OF ESTMATE: PLANNING

PREPARED BY:

2414-1-4 (CSSF 4 )

F.P. HANSON

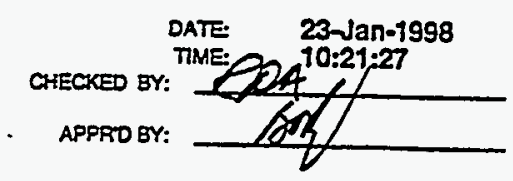

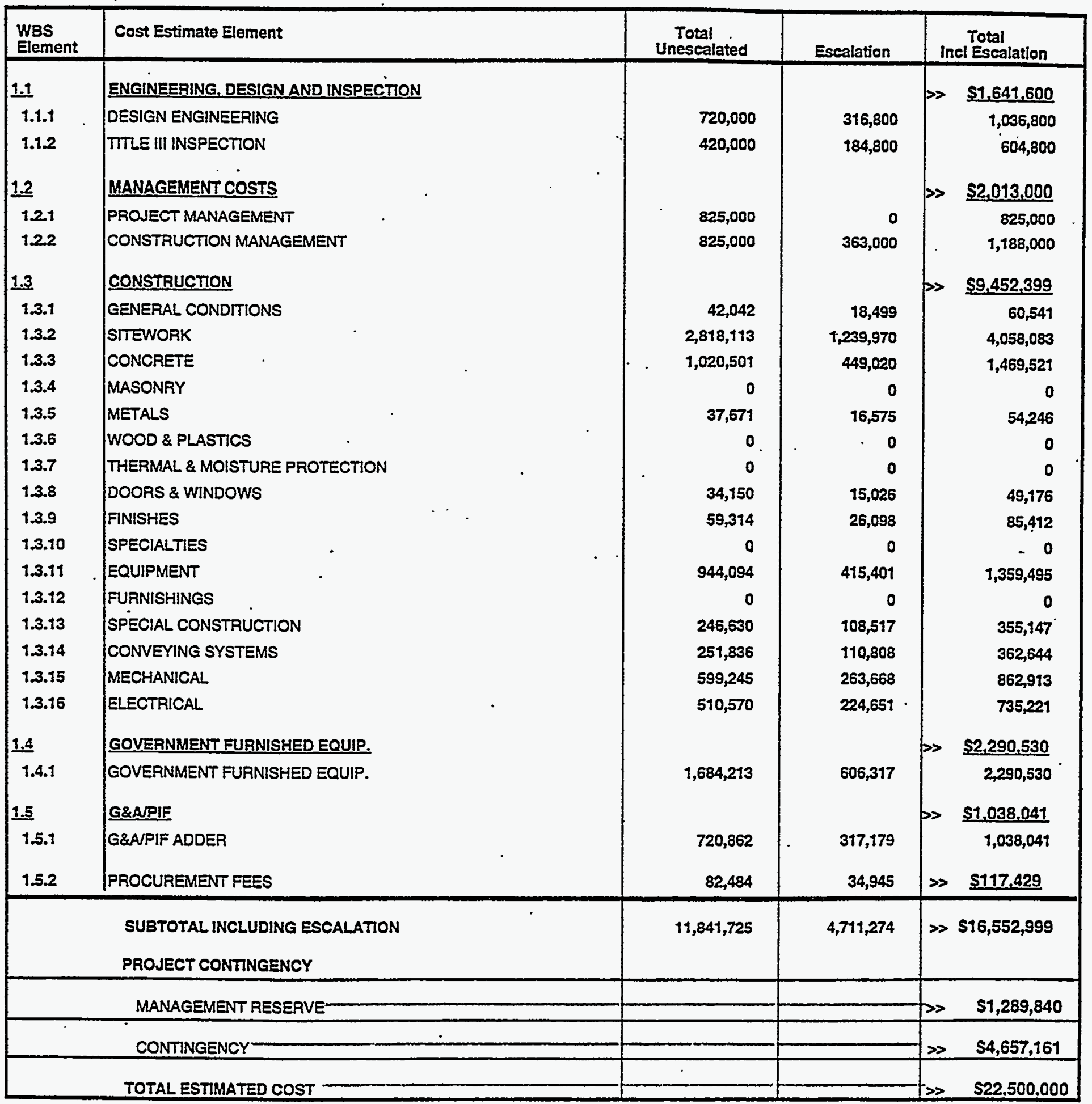

PROJECT COST PARAMETERS

EDI AS A \% OF CONST. + GFE $=14.00 \%$ 
Lockheed Martin Idaho Technologies Co.

COST ESTIMATE SUMMARY

PROUECT NAME: HLW EIS -WASTE TREATMENT SCOPING STUDIES TYPE OF ESTIMATE: PLANNING CALCINE RETRIEVAL AND TRANSPORT-OPTION B PROECTNO: 2414-1-4 (CSSF 4) LOCATION I: INEEL-ICPP

REQUESTOR: K. L. WILLIAMS REPORT NAME: Cost Estimate Summary

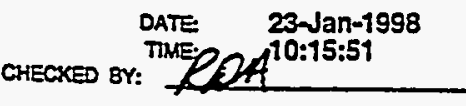

APPRD BY:

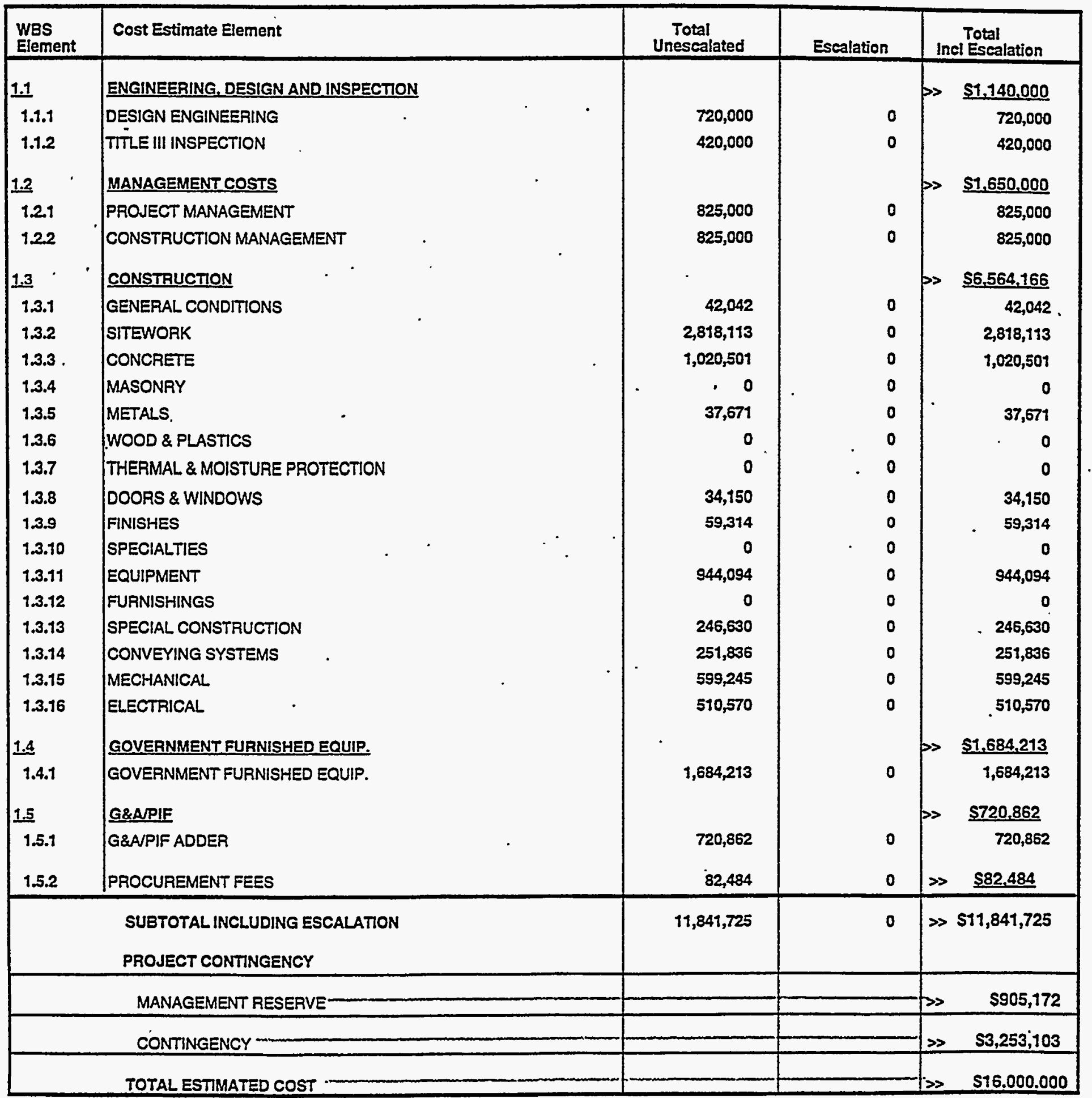

PROJECT COST PARAMETERS

EDI AS A $\%$ OF CONST. + GFE $=14.00 \%$ 
Lockheed Martin Idaho Technologies Co.

COST ESTIMATE SUMMARY

PROAECT NAME HLW ES -WASTE TREATMENT SCOPING STUDIES TYPE OF ESTIMATE: PLANNING

CALCINE RETRIEVAL AND TRANSPORT-OPTION B PROSECTNO: $2414-1-5$ (CSSFS $5-7$ )
INEEL - ICPP

LOCATION i: INEEL - ICPP

PREPARED BY:

REQUESTOR: K.L WILLIAMS REPORT NAME: Cost Estimate Summary

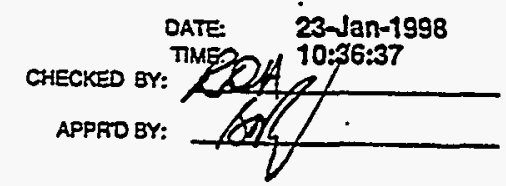

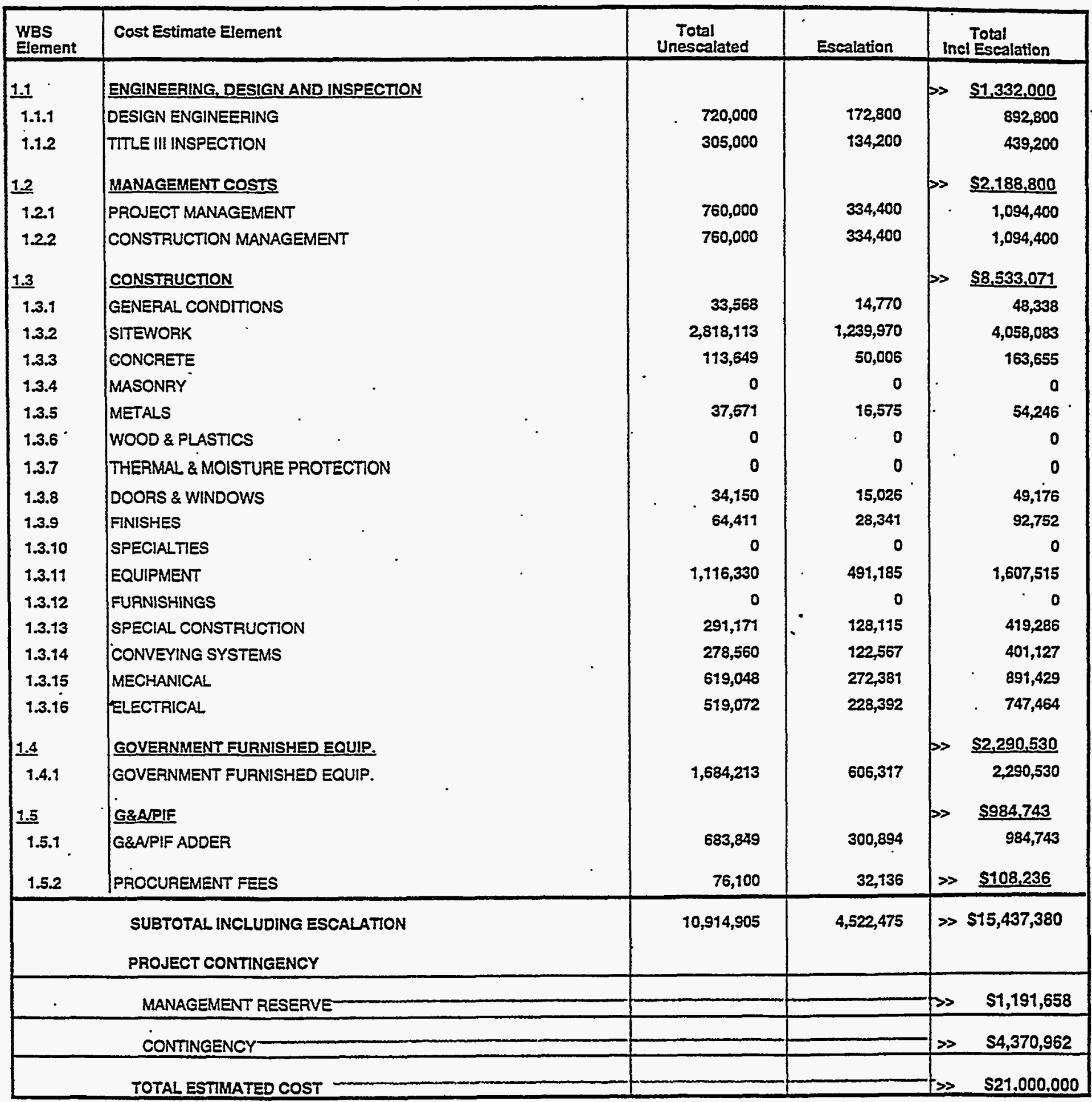

\section{PROJECT COST PARAMETERS}

EDI AS A \% OF CONST. + GFE $=12.00 \%$ 
Lockheed Martin Idaho Technologies Co.

PROECT NAME: HLW EIS -WASTE TREATMENT SCOPING STUDIES TYPE OF ESTIMATE: PLANNING

LOCATION 1:

CALCINE RE
INEEL - ICPP

FEQUESTOR:

K.L WILLIAMS

PROSECTNO:

PREPARED BY:

2414-1-5 (CSSFS

REPORT NAME: Cost Estimate Summary
CHECKED SY: ${ }^{\text {DATE: }}$ TIME: $^{\text {23-Jan-1998 }}$

AFPRD BY:

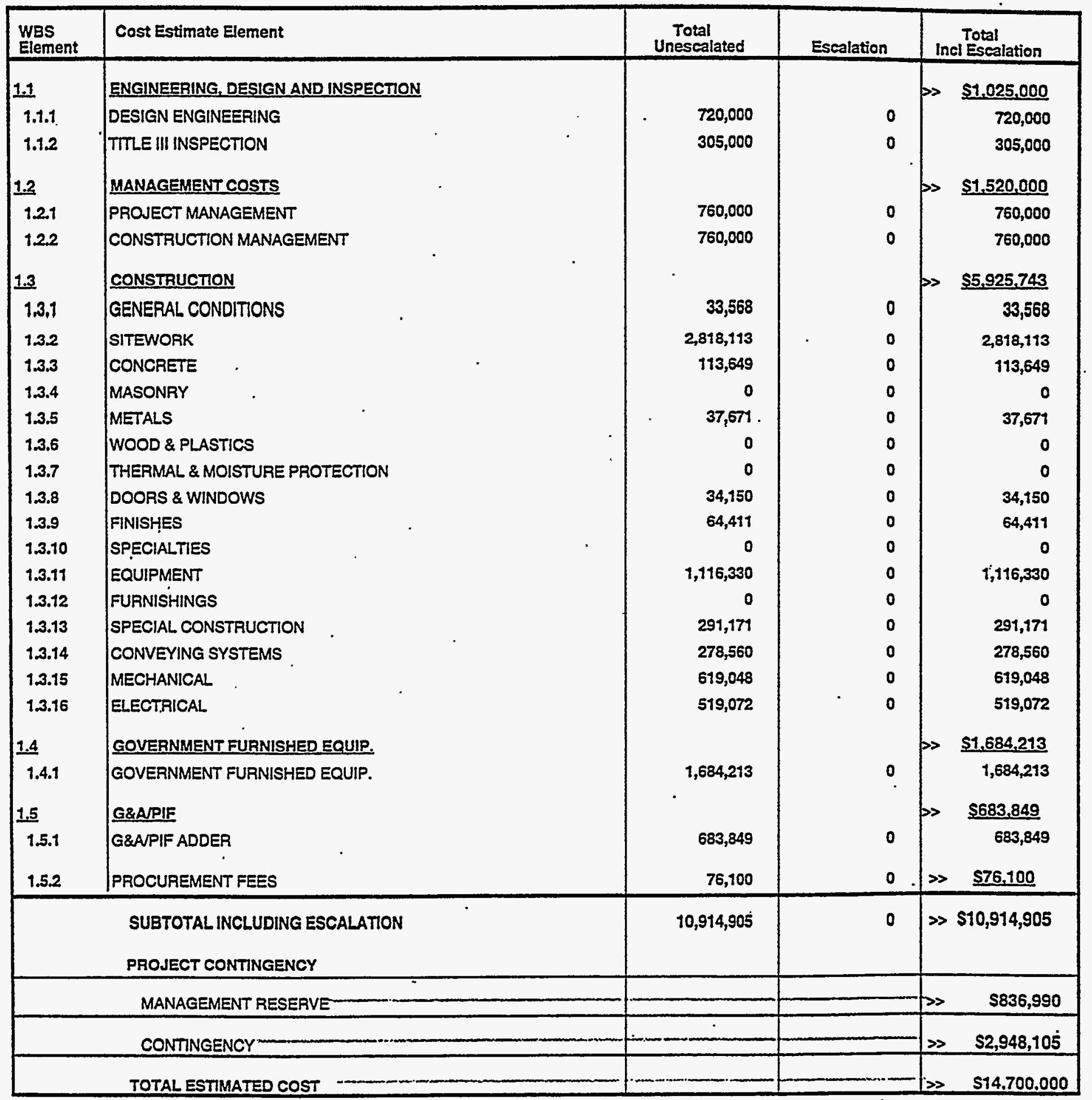

PROJECT COST PARAMETERS

EDI AS A $\%$ OF CONST. + GFE $=13.00 \%$

CONTINGENCY $=34.68 \%$ 
Lockheed Martin Idaho Technologies Co. PROSECT NAME: HLW EIS -WASTE TREATMENT SCOPING STUDIES TYPE OF ESTIMATE: LCCATON 1: RECUESTOR: CALCINE RETRIEVAL AND TRANSPORT INEEL - ICPP

K. L. WILLIAMS
COST ESTIMATE SUMMARY

PREPARED BY:

2414-1 (D\&D RISERS)

F. P. HANSON

REPORT NAME: Cost Estimate Summary

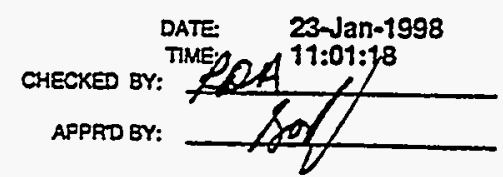

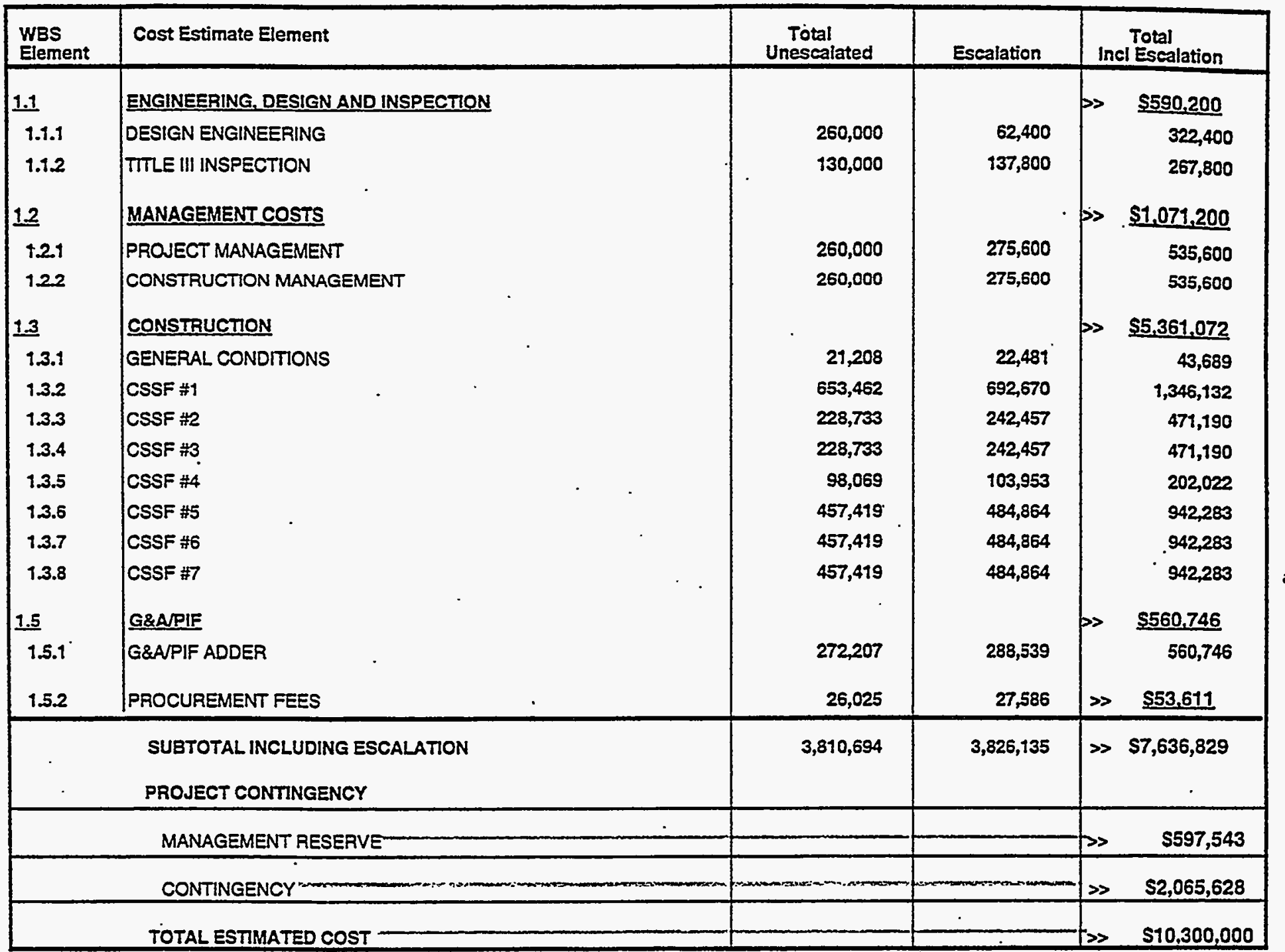

\section{PROJECT COST PARAMETERS}

EDI AS A \% OF CONST. + GFE $=11.00 \%$ 
Lockheed Martin Idaho Technologies Co. PROSECT NAME: HLW EIS -WASTE TREATMENT SCOPING STUDIES TYPE OF ESTIMATE. LOCATION 1: CALCINE RETIRIEVAL AND TRANSPORT INEEL - ICPP REQUESTOR:
COST ESTIMATE SUMMARY PRQECT NO: $2414-1$ (D\&D RISERS)
PREPARED BY: REPORT NAME: Cost Estimate Summary

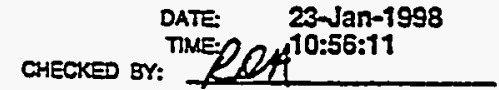

APPRO BY:

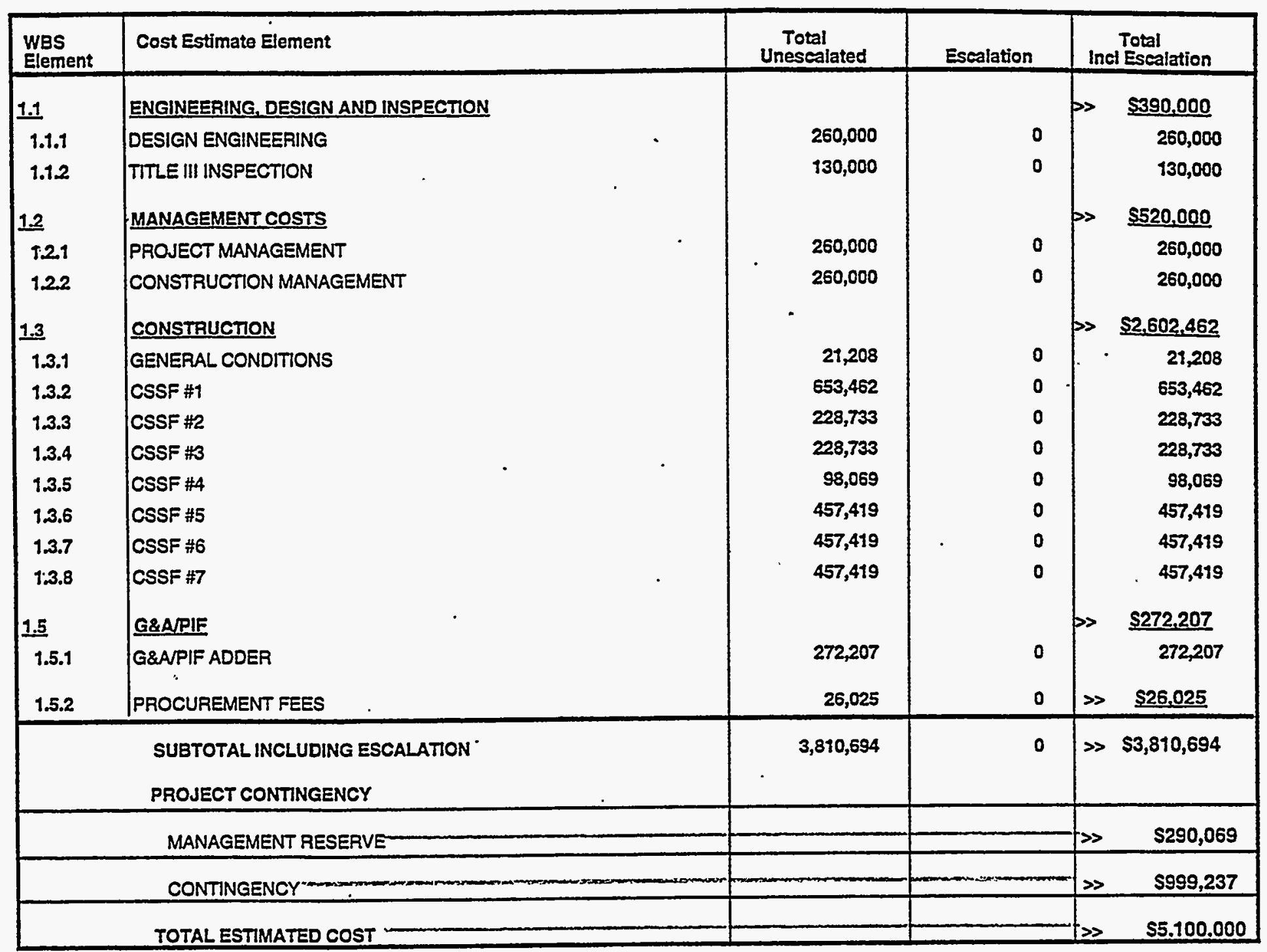

\section{PROJECT COST PARAMETERS}

EDI AS A \% OF CONST. + GFE= $15.00 \%$ 
Lockheed Martin Idaho Technologies Co.

PROIECT NAME: HLW EIS -WASTE TREATMENT SCOPING STUDIES TYPE OFESTIMATE. PLANNING

LOCATION 1: CALCINE RETRIEVAL AND TRANSPORT

INEEL - ICPP

K. L WILLIAMS
COST ESTIMATE SUMMARY

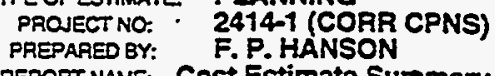

REPORT NAME: Cost Estimate Sunmary

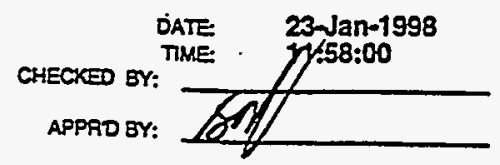

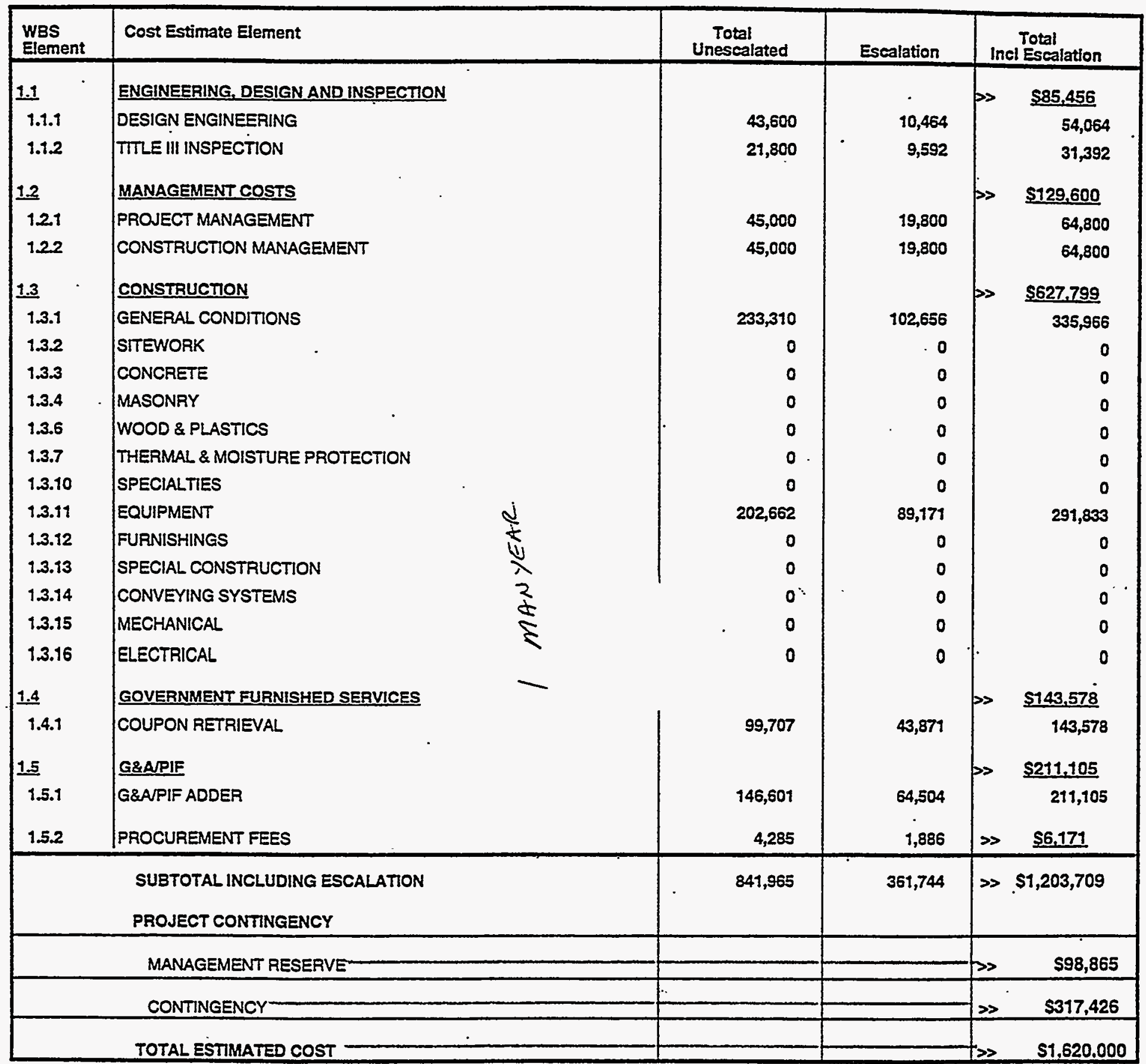

PROJECT COST PARAMETERS

EOI AS A $\%$ OF CONST. + GFE $=11.00 \%$ 
Lockheed Martin idaho Technologies Co.

COST ESTIMATE SUMMARY

WIS

$\begin{array}{lll} & \text { CALCINE RETRIEVAL AND TRANSPORT PRONECTNO: 2414-1 (CORR CPNS) } \\ \text { LOCATON 1: INEEL - ICPP } & \text { PREPARED BY: F.P.HANSON }\end{array}$

REQUESTOR: KL WILLIAMS

REPORT NAME: Cost Estimate Summary

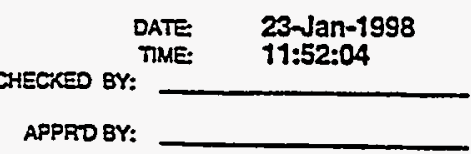

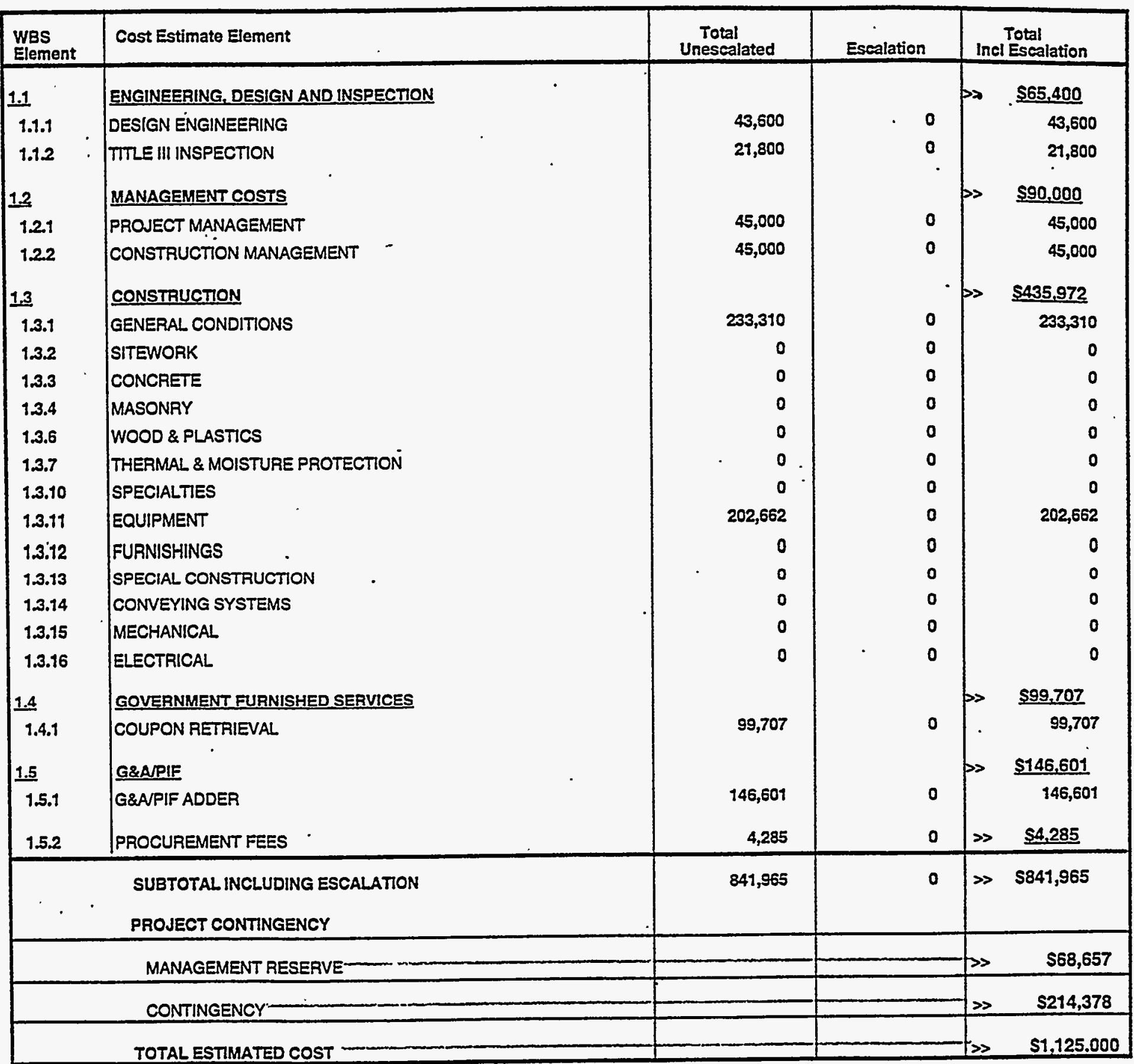

PROJECT COST PARAMETERS

EDI AS A \% OF CONST. + GFE $=1200 \%$ 
Lockheed Martin ldaho Technologies Co.

COST ESTIMATE SUMMARY

PROSECT NAME: HLW EIS -WASTE TREATMENT SCOPING STUDIES TYPEOFESTIMATE: PLANNING

CALCINERETRIEVAL AND TRANSPORT - OPTION B PRONECTNO: 2414-1 (TRANS SYS A)
LOCATION 1: INEEL-ICPP

REQUESTOR: K.LWILLAMS

AEPORT NAME: Cost Estimate Summary

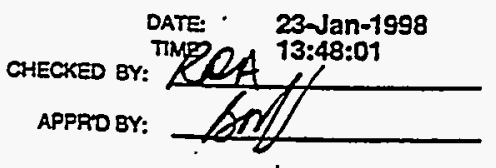

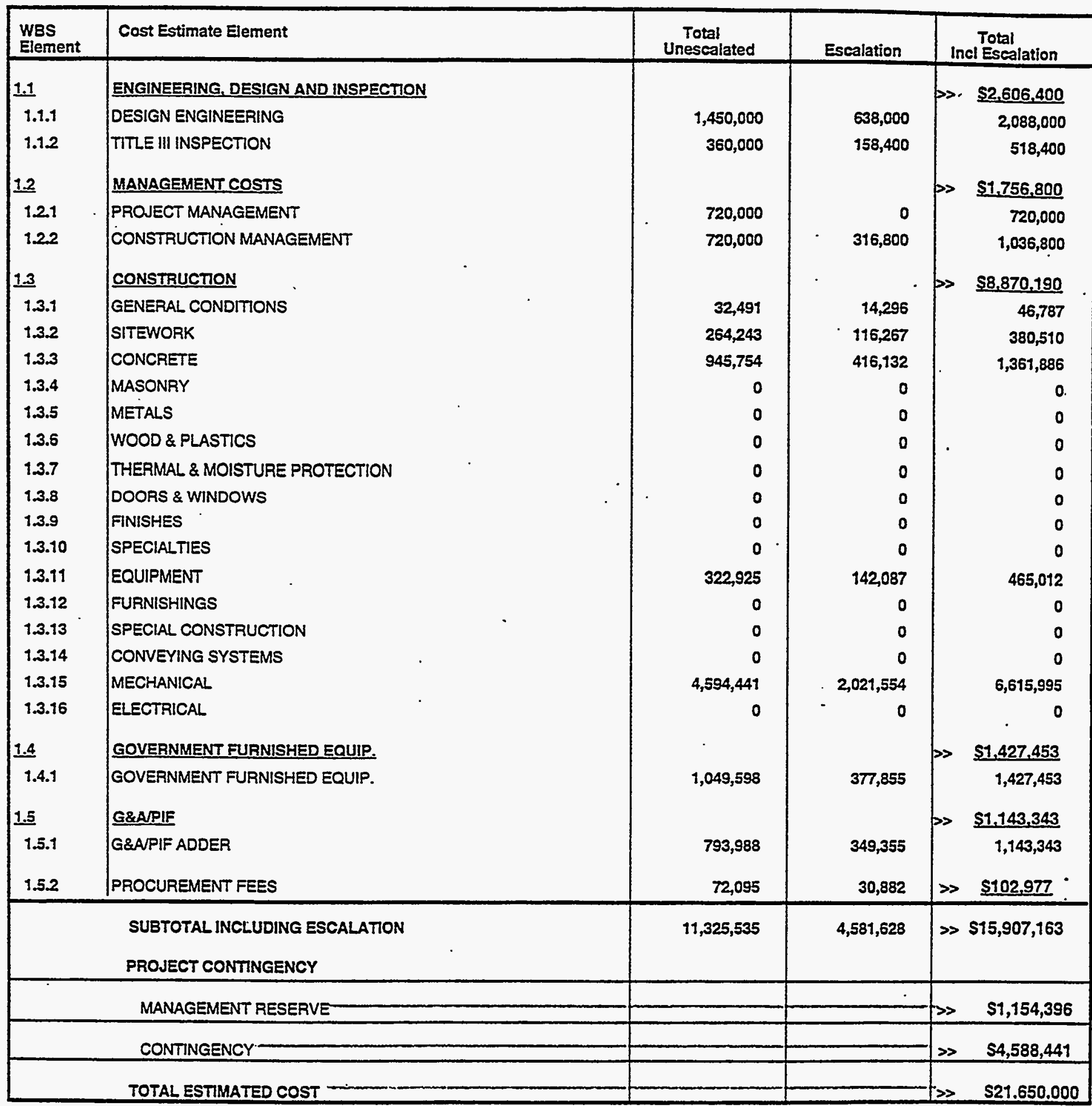

PROJECT COST PARAMETERS

EDI AS A \% OF CONST. + GFE $=25.00 \%$

CONTINGENCY $=36.10 \%$ 
Lockheed Martin ldaho Technologies Co.

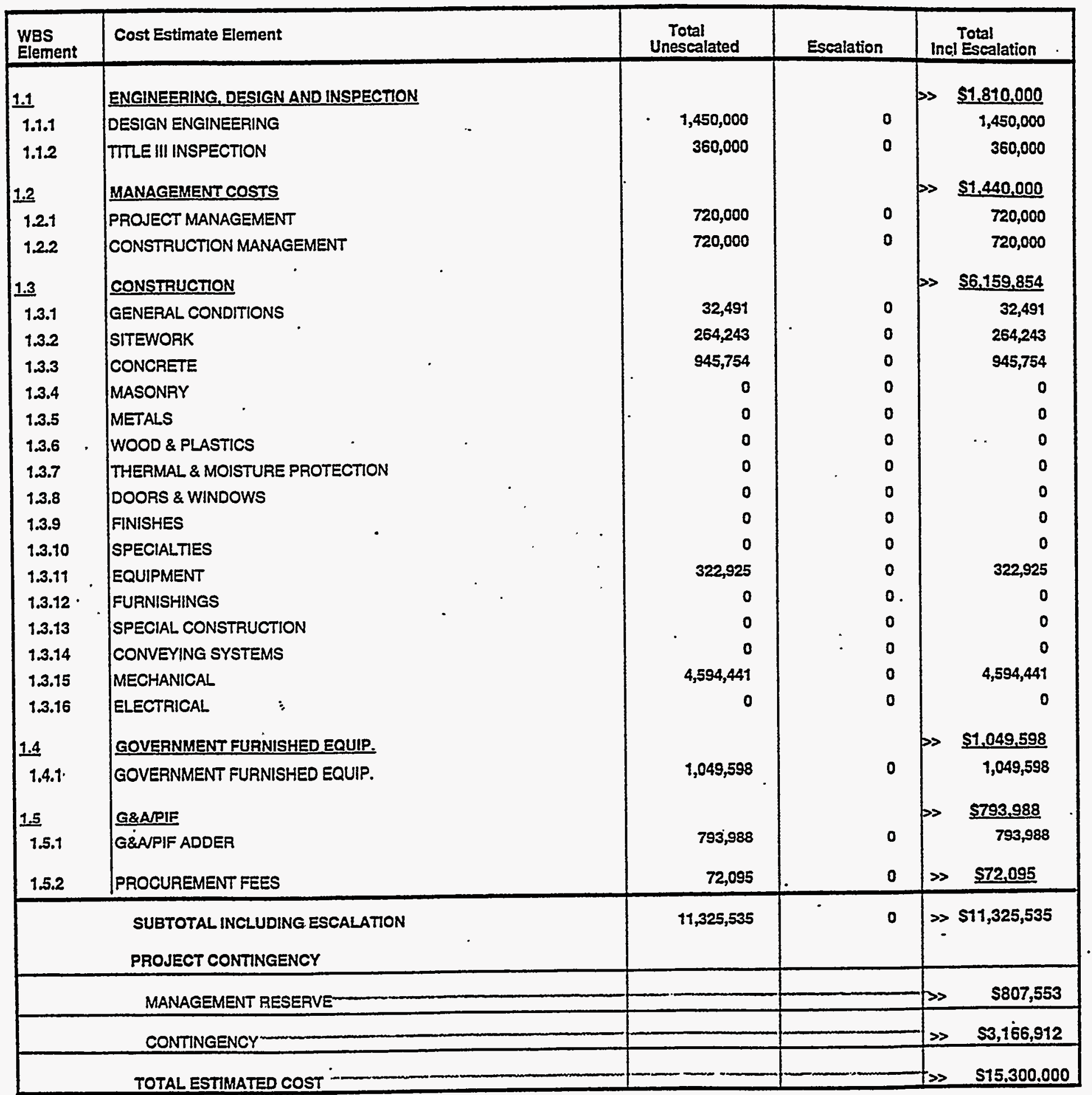

\section{PROJECT COST PARAMETERS}

EDI AS A \% OF CONST. + GFE $=25.00 \%$ 
Lockheed Martin Idaho Technologies Co.

COST ESTIMATE SUMMARY

Rev. 699

PROUECT NAME: HLW EIS -WASTE TREATMENT SCOPING STUDIES TYPE OF ESTIMATE:

LOCATION 1:

INEEL - ICPP

REQUESTCR:

$K$ WILUAMS

PREPARED BY: F. P. HANSON

REPORT NAME: Cost Estimate Summary

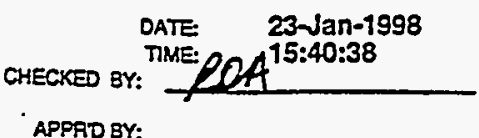

\begin{tabular}{|c|c|c|c|c|}
\hline $\begin{array}{l}\text { WBS } \\
\text { Element }\end{array}$ & Cost Estimate Element & $\begin{array}{c}\text { Total } \\
\text { Unescalated }\end{array}$ & Escalation & $\begin{array}{c}\text { Total } \\
\text { Incl Escalation }\end{array}$ \\
\hline 1.1 & ENGINEERING, DESIGN AND INSPECTION & & & $\$ 3,513,600$ \\
\hline 1.1.1 & DESIGN ENGINEERING & $1,950,000$ & 858,000 & $2,808,000$ \\
\hline 1.1 .2 & TITLE III INSPECTION & 490,000 & 215,600 & 705,600 \\
\hline 1.2 & MANAGEMENT COSTS & & & $\$ 2,379,000$ \\
\hline 1.21 & PROJECT MANAGEMENT & 975,000 & $\mathbf{0}$ & 975,000 \\
\hline 1.2 .2 & CONSTRUCTION MANAGEMENT & 975,000 & 429,000 & $1,404,000$ \\
\hline 1.3 & CONSTRUCTION & & & $\$ 11,345,257$ \\
\hline 1.3.1 & GENERAL CONDITIONS & 39,795 & 17,510 & $\mathbf{5 7 , 3 0 5}$ \\
\hline 1.3 .2 & SITEWORK & 342,206 & 150,571 & $492, \pi 77$ \\
\hline 1.3 .3 & CONCRETE & $1,009,448$ & 444,157 & $1,453,605$ \\
\hline 1.3 .4 & MASONRY - & 0 & 0 & 0 \\
\hline 1.3 .5 & METALS & 38,216 & 16,815 & 55,031 \\
\hline 1.3.6 & WOOD \& PLASTICS & 1,332 & 586 & 1,918 \\
\hline 1.3.7 & THERMAL \& MOISTURE PROTECTION & 4,808 & 2,115 & 6,923 \\
\hline 1.3.8 & DOORS \& WINDOWS & 8,801 & 3,872 & 12,673 \\
\hline 1.3 .9 & FINISHES & 12,391 & 5,452 & 17,843 \\
\hline 1.3.10 & SPECIALTIES & 0 & 0 & 0 \\
\hline 1.3.11 & EQUIPMENT & 660,480 & $.290,611$ & $951,091$. \\
\hline 1.3.12 & FURNISHINGS & 0 & 0 & 0 \\
\hline 1.3.13 & SPECIAL CONSTRUCTION & 28,952 & 12,739 & 41,691 \\
\hline 1.3.14 & CONVEYING SYSTEMS & 0 & 0 & 0 \\
\hline 1.3.15 & MECHANICAL & $5,656,948$ & $2,489,057$ & $8,146,005$ \\
\hline 1.3.16 & ELECTRICAL & 75,274 & 33,121 & 108,395 \\
\hline 1.4 & GOVERNMENT FURNISHED EQUIP. & & & $\$ 2,525,494$ \\
\hline 1.4 .1 & GOVERNMENT FURNISHED EQUIP. & $1,856,981$ & 668,513 & $2,525,494$ \\
\hline 1.5 & GEAPIF & & & $\$ 1,354,244$ \\
\hline 1.5 .1 & G\&APIF ADDER & 940,447 & 413,797 & $1,354,244$ \\
\hline 1.5 .2 & |PROCUREMENT FEES & 97,356 & 41,351 & $\$ 138,707$ \\
\hline & SUBTOTAL INCLUDING ESCALATION & $15,163,435$ & $6,092,867$ & $\gg \$ 21,256,302$ \\
\hline & PROJECT CONTINGENCY & & & \\
\hline & MANAGEMENT RESĖRVE- & & & $\mathbf{S 1 , 5 3 6 , 3 7 0}$ \\
\hline & CONTINGENCY - & & & $\$ 6,207,328$ \\
\hline & TOTAL ESTIMATED COST & & 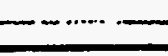 & $\$ 29.000 .000$ \\
\hline
\end{tabular}

PROJECT COST PARAMETERS

EDI AS A \% OF CONST. + GFE $=25.00 \%$

CONTINGENCY $=36.43 \%$ 
Lockheed Martin Idaho Technologies Co. PROIECT NAME: HLW EIS -WASTE TREATMENT SCOPING STUDIES TYPE OF ESTIMATE:

LOCATION 1: REQUESTOR:

NISTASTE TREATMENT SCOPING STUDIES TYPEOFESTIMATE PLANNING INEEL - ICPP CALCINE RETRIEVAL AND TRANSPORT-OPTION B PROECTNO: 2414-1 (TRANS SYS B)

PREPAFED BY: F. P. HANSON

REPORT NAME: Cost Estimate Summary

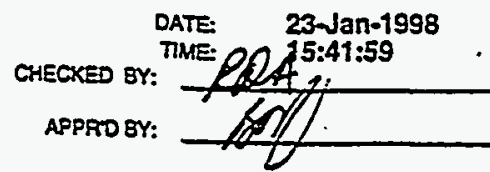

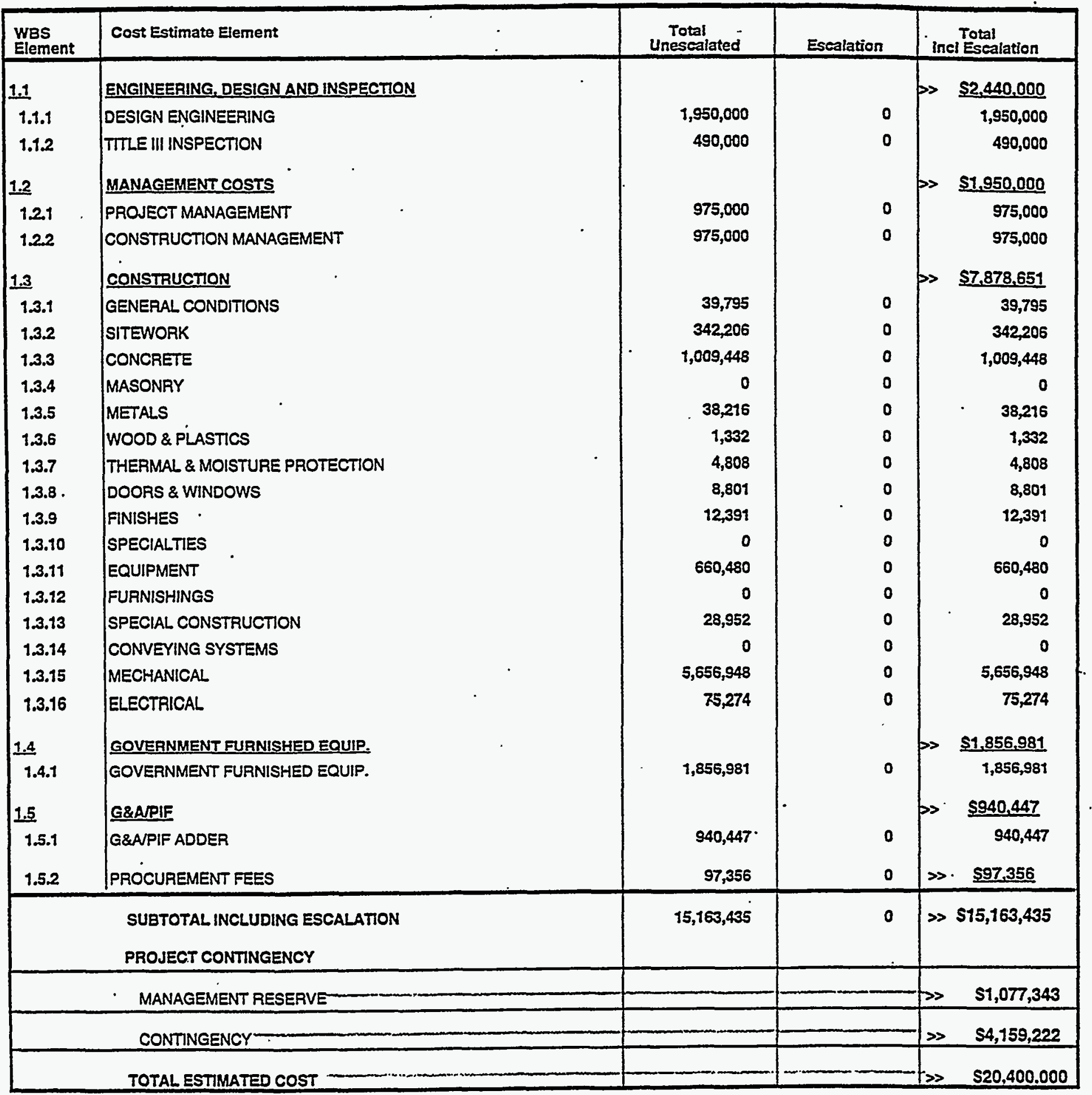

PROJECT COST PARAMETERS

EDI AS A \% OF CONST. + GFE $=25.00 \%$

CONTINGENCY $=34.53 \%$ 
Date: $\quad$ January 28,1998

$\begin{array}{lllc}\text { To: } & \text { S. E. Gifford } & \text { MS } 3765 & 6-5162 \\ \text { From: } & \text { R. J. Turk } & \text { MS } 3875 & 6-3611 \\ \text { Subject: } & \text { ECONOMTC AND LIFE CYCLE ANAL } & \text { RSIS CONDUCTED FOR CALCINE }\end{array}$

Purpose:

As requested an Economic and Life-Cycle Cost (LCC) has been conducted to evaluate the CALCINE RETRIEVAL SYSTEM. This process is proposed to retrieve calcine from the Calcine Solids Storage Facilities (CSSF) and transport it to the waste treatment facility. The calcine retrieval and transportation system is designed to supply calcine to the treatment options of Vitrification, Direct Cementitious, Cementitious, Hot Isostatic Pressing and TRU currently understudy. A five and a twenty-year option utilizing a transport system "A or B" per your direction was conducted to coincide with various waste treatment activities.

This economic analysis is based on information provided by Karen Williams, Sara Gifford, A. E. Lee, Ron DaFoe, Dan Griffith, D. Lopez, N. Russell, B. Landman, R. Kimmett and other team members.

F. P. Hanson provided cost estimates. Jack Prendergast provided process personnel modeling.

\section{Methodology:}

The Economic Evaluation assumed a five-year and a 20 -year operations period since this is the estimated time required to supply the calcine to the waste treatment options currently being evaluated. The ICC identifies and evaluates the initial development, construction, operation and post-operating costs over the life-cycle. A discounted LCC assumes a current 1998-dollar basis, discounted at $6.30 \%$ annually per the Office of Management and Budget (OMB) Circular A-94. All costs are conservatively discounted assuming the end-of-year convention. 


\section{Assumptions:}

The scope of work and requirements of all related activities are vague at this time. Facility and processing costs were developed from historical experience associated with DD\&D work at the INEEL. The LCC analysis was generated to match cost estimating cost structure. These costs include Permitting, Direct and Indirect Construction, G\&A, Procurement Fee, Engineering, Inspection, Project Management, Construction Management, Escalation and Contingency costs. The design period was assumed to be accomplished in five years with construction completed in six years, complete with eighteen months of start-up and testing. Labor rates were assumed as follows: Managers, $\$ 125 / \mathrm{hr}$; Engineers, $\$ 108$ \$ $/ \mathrm{hr}$; Other Technicians $\$ 85 / \mathrm{hr}$; Administration/Support staff $\$ 65 / \mathrm{hr}$; Operators and Maintenance personnel $\$ 65 / \mathrm{hr}$. The operational period for these facilities was modeled for five and twenty years, followed by one year of post-operations activities. Utilities were assumed to cost $\$ 3.00 /$ sf for the facility. Due to this projects lack of complexity and relative cleanliness this analysis assumed a decommissioning cost equal to $20 \%$ of the unescalated engineering design cost, decontamination costs equal to $5 \%$ of total unescalated pre-operation cost, and demolition costs equal to $8 \%$ of total unescalated pre-operation cost.

\section{Results:}

The Five-year operation of the CALCINE RETRIEVAL SYSTEM "A"Option has a Discounted LCC of $\$ 167$ million.

The Twenty-year operation of CALCINE RETRIEVAL SYSTEM "A" Option has a Discounted LCC of $\$ 192$ million.

The Twenty-year operation of CALCINE RETRIEVAL SYSTEM "B" Option has a Discounted LCC of \$ 197 million.

Attachments:

cc: R. J. Turk File 


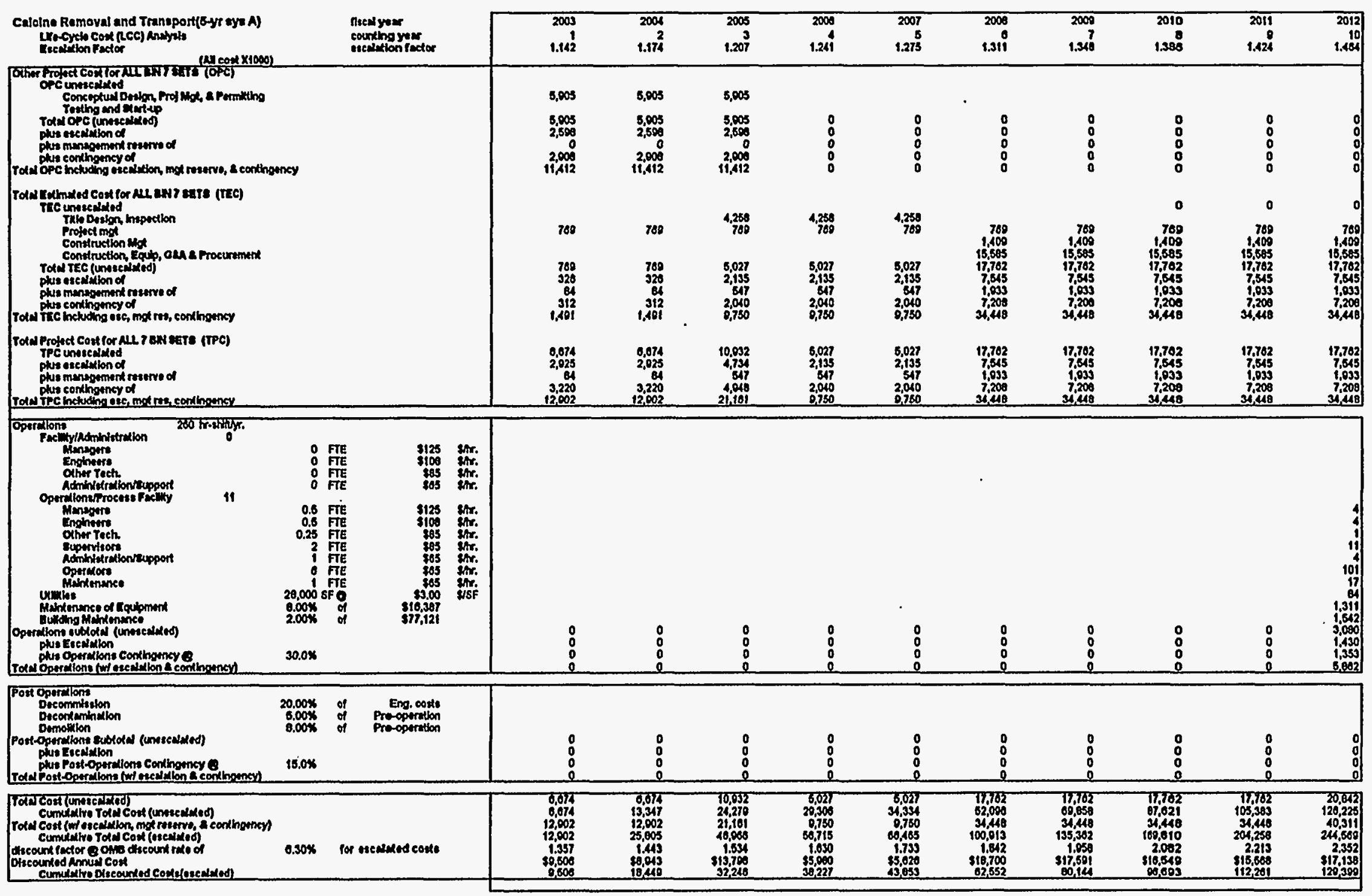




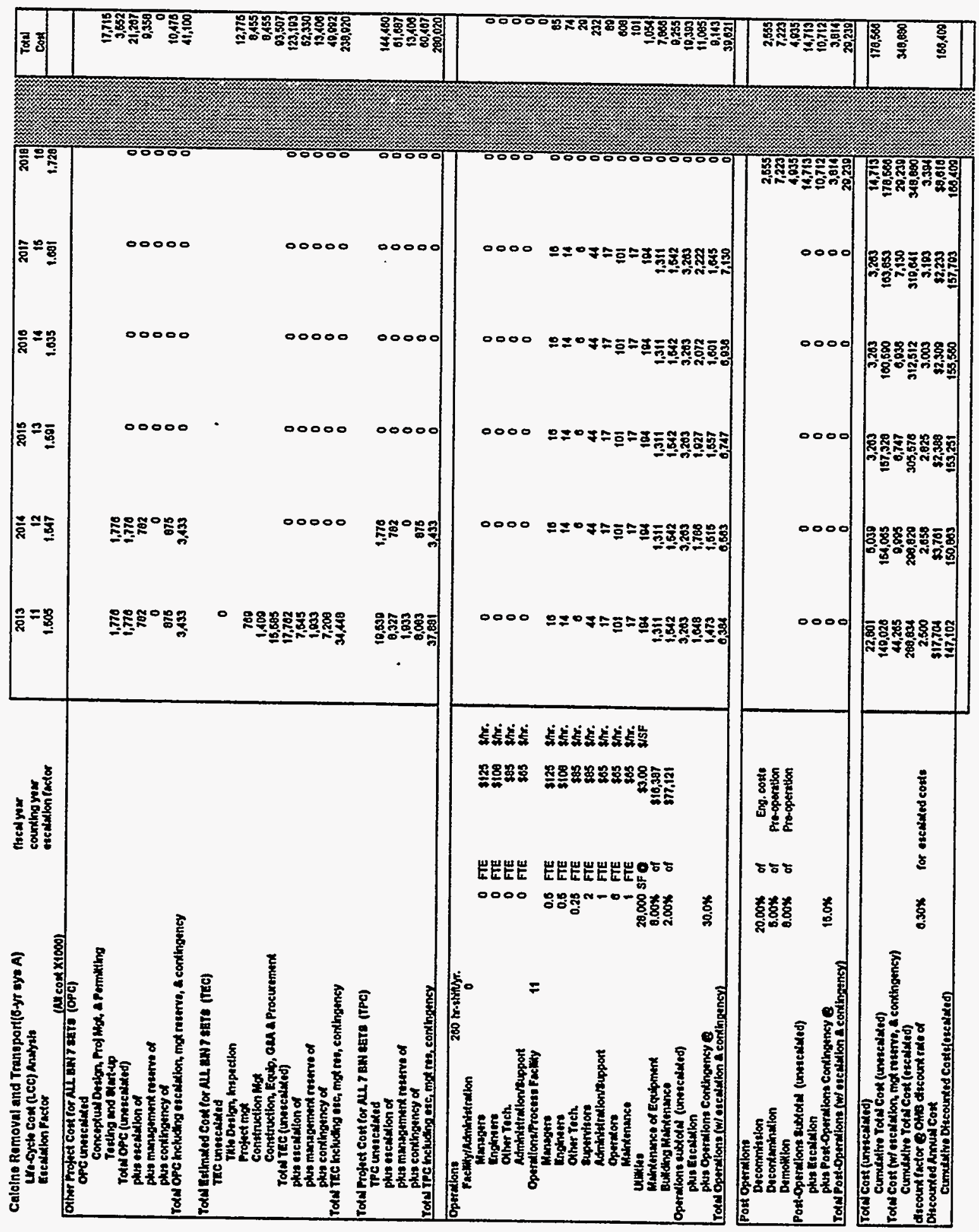




\section{TOTAL ANNUAL COST(escalated 5yr.) CALCINE RETRIEVAL AND TRANSPORT A \\ FACILITY}

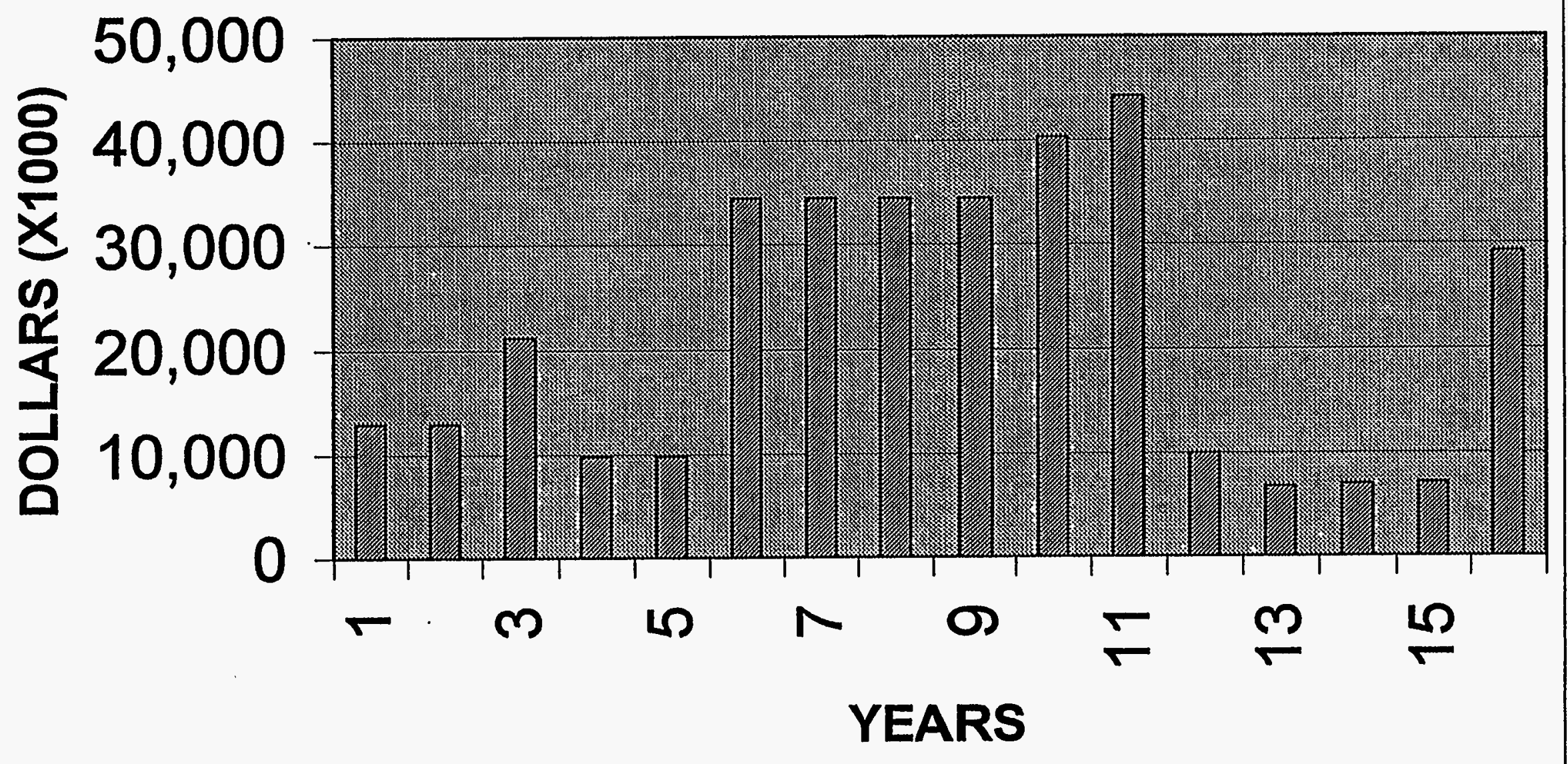




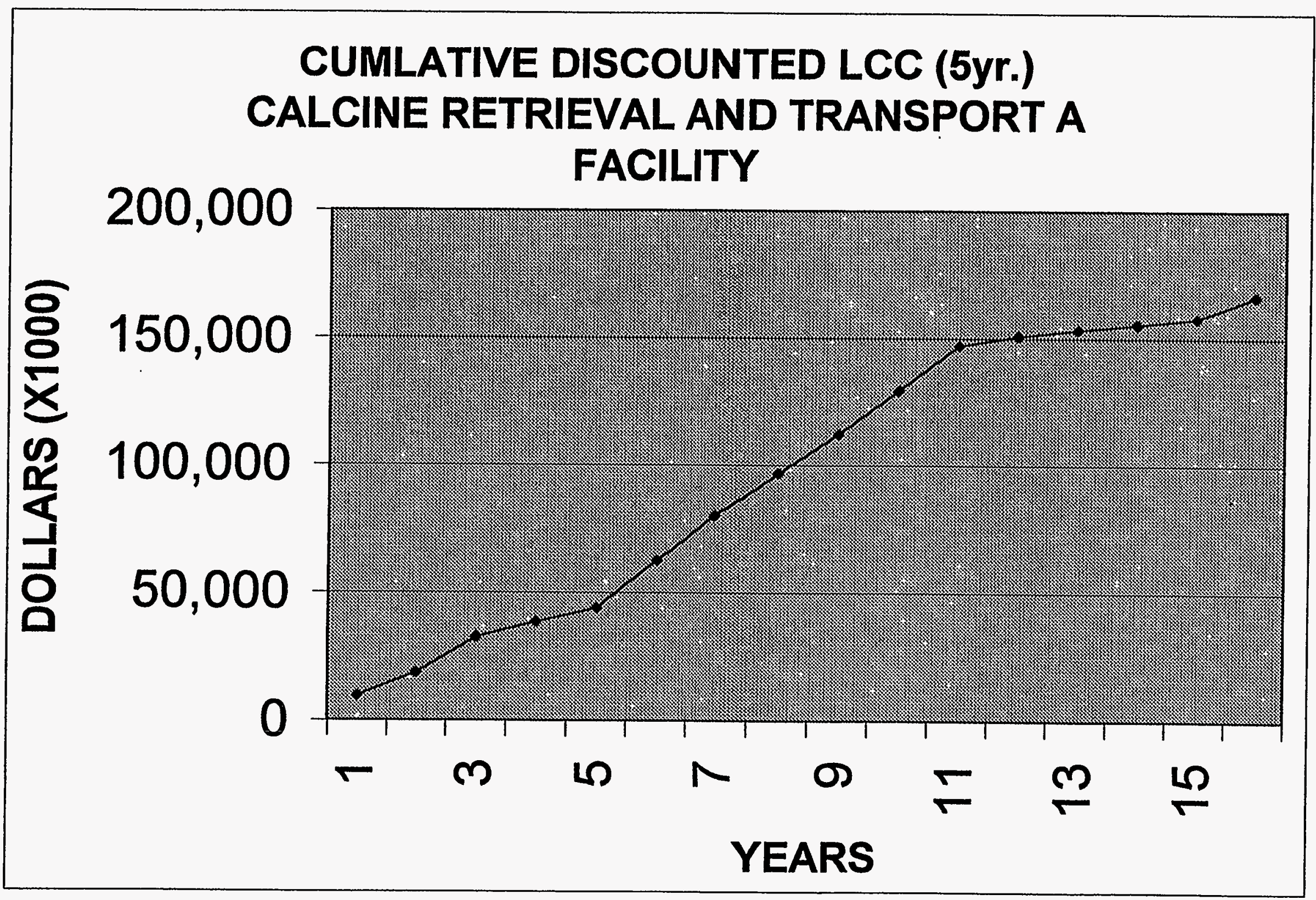




\begin{tabular}{|c|c|c|c|c|c|c|c|c|c|c|c|c|c|}
\hline 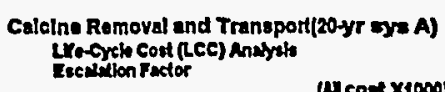 & \multicolumn{3}{|c|}{ 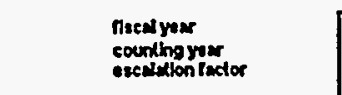 } & $\begin{array}{l}2000 \\
1.142\end{array}$ & $\begin{array}{l}2004 \\
1.114^{2}\end{array}$ & $\begin{array}{l}2005 \\
1.207\end{array}$ & $\begin{array}{l}2000 \\
1.241\end{array}$ & $\begin{array}{l}2007 \\
1.275\end{array}$ & $\begin{array}{l}2008 \\
.3 .311\end{array}$ & $\begin{array}{l}2000 \\
1.348\end{array}$ & $\begin{array}{l}2010 \\
1.308^{\circ}\end{array}$ & $\begin{array}{l}2011 \\
1,128\end{array}$ & $\begin{array}{r}2012 \\
10 \\
2.481\end{array}$ \\
\hline \multirow{3}{*}{\multicolumn{4}{|c|}{ 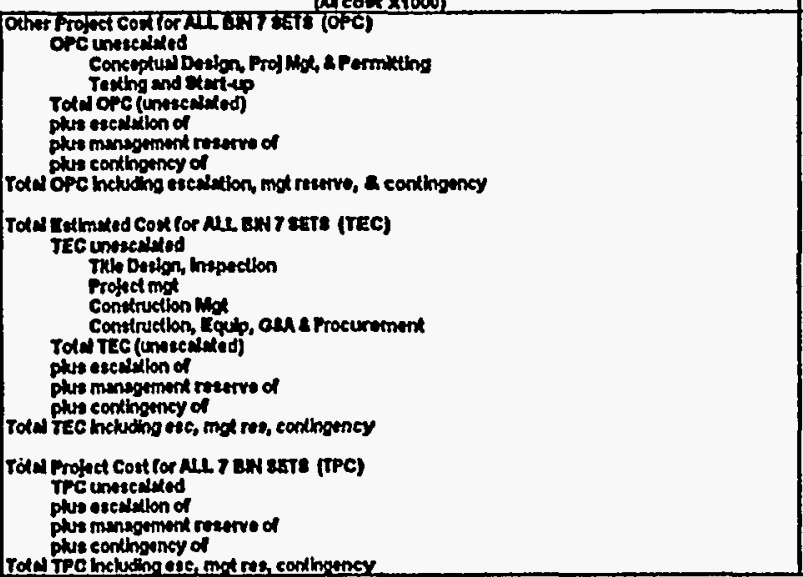 }} & $\begin{array}{r}3,005 \\
5,005 \\
2,606 \\
2,006 \\
11,412\end{array}$ & $\begin{array}{r}5,005 \\
5,005 \\
2,500 \\
0 \\
2,909 \\
11,412\end{array}$ & $\begin{array}{r}3,005 \\
8,005 \\
2,606 \\
0 \\
2,000 \\
11,412\end{array}$ & $\begin{array}{l}0 \\
0 \\
0 \\
0\end{array}$ & $\begin{array}{l}0 \\
0 \\
0 \\
0\end{array}$ & $\begin{array}{l}0 \\
0 \\
0 \\
0\end{array}$ & $\begin{array}{l}0 \\
: \\
: \\
0\end{array}$ & $\begin{array}{l}0 \\
0 \\
0 \\
0 \\
0\end{array}$ & $\begin{array}{l}0 \\
0 \\
0 \\
0 \\
0\end{array}$ & : \\
\hline & & & & $\begin{array}{r}709 \\
320 \\
912 \\
912 \\
1,491\end{array}$ & $\begin{array}{r}769 \\
320 \\
54 \\
312 \\
1,401\end{array}$ & $\begin{array}{l}5.027 \\
2,135 \\
547 \\
2,40 \\
0,750\end{array}$ & $\begin{array}{l}5,027 \\
2,135 \\
647 \\
2,090 \\
0,750\end{array}$ & $\begin{array}{l}5,027 \\
2,135 \\
647 \\
2,090 \\
0,750\end{array}$ & $\begin{array}{r}768 \\
1,400 \\
15,685 \\
17,702 \\
7,643 \\
1,933 \\
7,200 \\
3,4,46\end{array}$ & 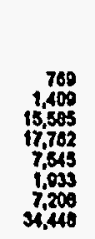 & $\begin{array}{r}0 \\
760 \\
1,400 \\
15,505 \\
11,702 \\
7,545 \\
1,023 \\
7,200 \\
3,4,48\end{array}$ & 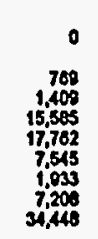 & 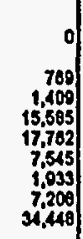 \\
\hline & & & & $\begin{array}{r}0,014 \\
2,025 \\
2,8 \\
3,220 \\
12,002 \\
\end{array}$ & $\begin{array}{r}0,074 \\
2,025 \\
3,24 \\
30,220 \\
12,002\end{array}$ & 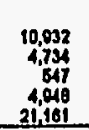 & $\begin{array}{l}5.027 \\
2,1,33 \\
547 \\
2,0,00 \\
0,750\end{array}$ & $\begin{array}{l}5,027 \\
2,135 \\
647 \\
2,090 \\
0,760\end{array}$ & 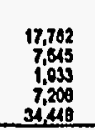 & 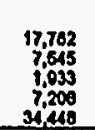 & 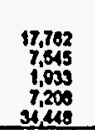 & $\begin{array}{r}17.762 \\
7.745 \\
7.033 \\
7.200 \\
34.418 \\
3.40\end{array}$ & 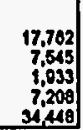 \\
\hline 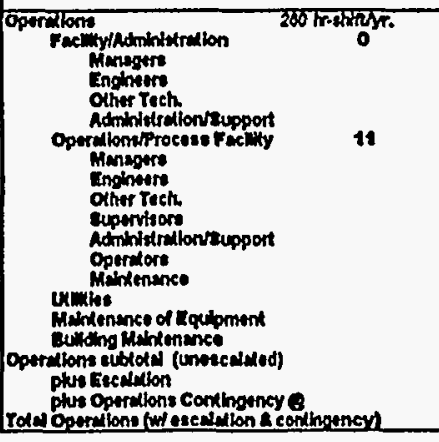 & 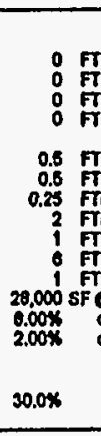 & 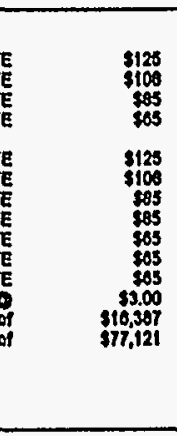 & 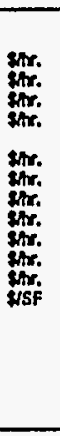 & $\begin{array}{l}0 \\
0 \\
0 \\
0\end{array}$ & $\begin{array}{l}0 \\
: \\
0 \\
\end{array}$ & $\begin{array}{l}0 \\
0 \\
0 \\
0 \\
\end{array}$ & $\begin{array}{l}0 \\
0 \\
0 \\
0 \\
\end{array}$ & $\begin{array}{l}0 \\
0 \\
0 \\
0\end{array}$ & $\begin{array}{l}0 \\
: \\
0 \\
0\end{array}$ & $\begin{array}{l}0 \\
0 \\
0 \\
0\end{array}$ & $\begin{array}{l}0 \\
0 \\
0 \\
0\end{array}$ & $\begin{array}{l}0 \\
: \\
0\end{array}$ & 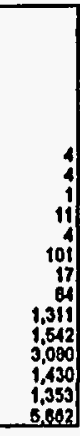 \\
\hline 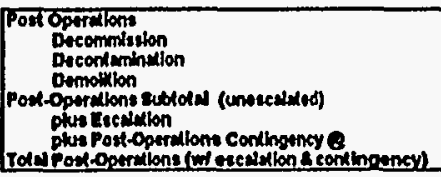 & $\begin{array}{r}20.00 \% \\
8.00 \% \\
0.00 \% \\
15.0 \%\end{array}$ & 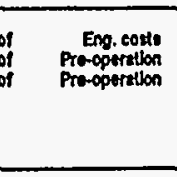 & & $\begin{array}{l}0 \\
: \\
0\end{array}$ & $\begin{array}{l}0 \\
0 \\
0 \\
0\end{array}$ & $\begin{array}{l}0 \\
0 \\
0 \\
0\end{array}$ & $\begin{array}{l}0 \\
0 \\
0 \\
0\end{array}$ & $\begin{array}{l}0 \\
0 \\
0 \\
0\end{array}$ & $\begin{array}{l}0 \\
0 \\
0 \\
0 \\
0\end{array}$ & $\begin{array}{l}0 \\
0 \\
0 \\
0\end{array}$ & $\begin{array}{r}0 \\
0 \\
0 \\
0 \\
0\end{array}$ & $\begin{array}{l}0 \\
0 \\
0 \\
0\end{array}$ & $\begin{array}{l}0 \\
0 \\
0 \\
0\end{array}$ \\
\hline 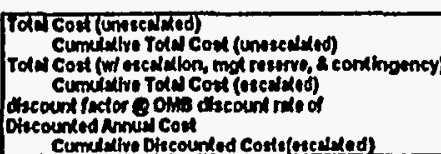 & $0.00 \%$ & for mented conts & & 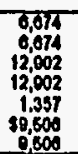 & 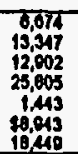 & 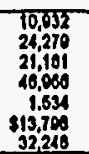 & 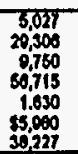 & $\begin{array}{l}5.027 \\
34,434 \\
0.750 \\
00,465 \\
1.733 \\
55,020 \\
43,033\end{array}$ & 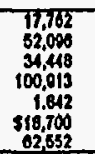 & 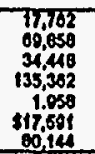 & 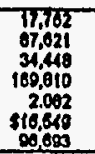 & 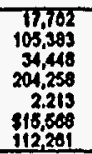 & 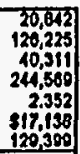 \\
\hline
\end{tabular}




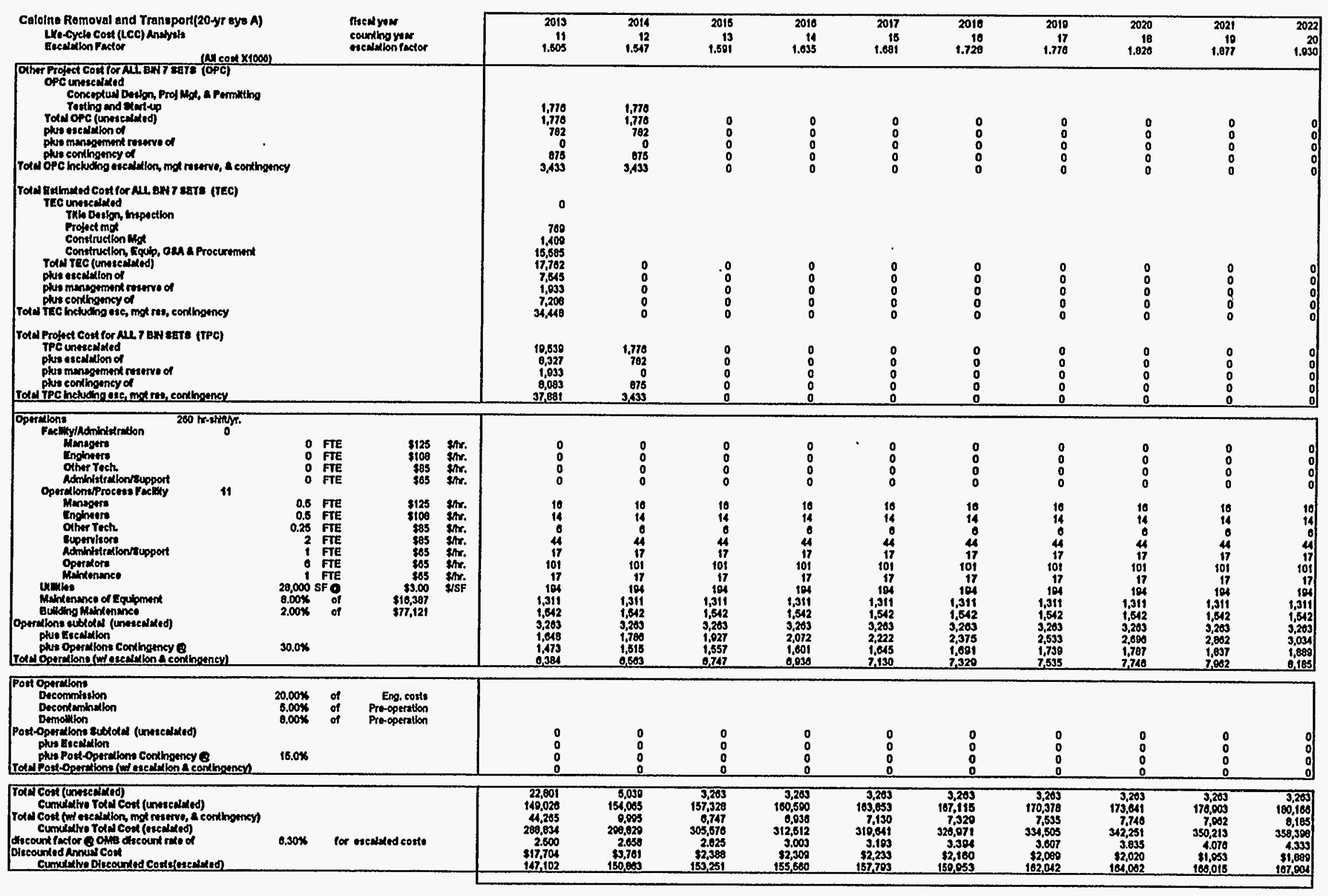




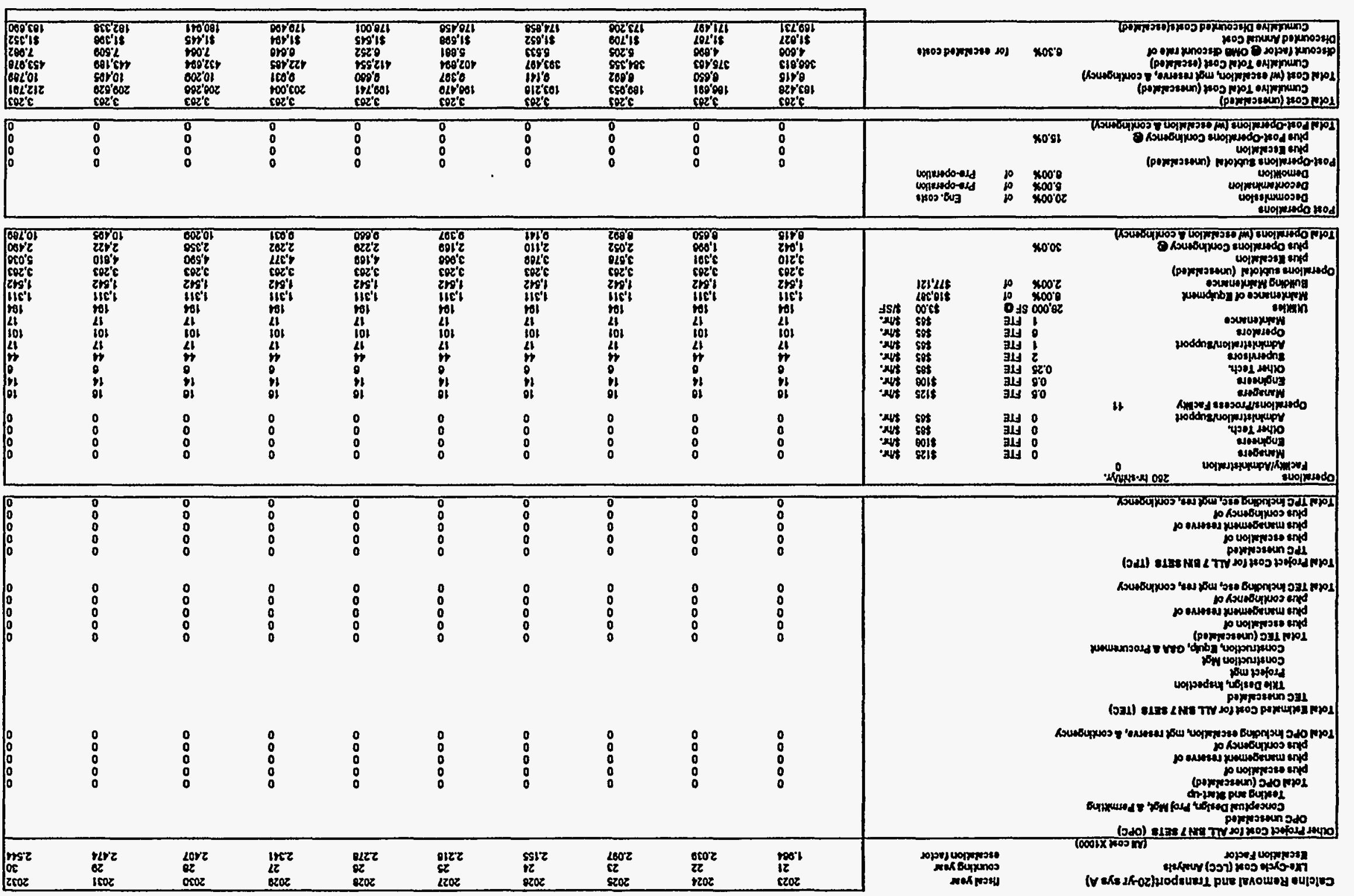




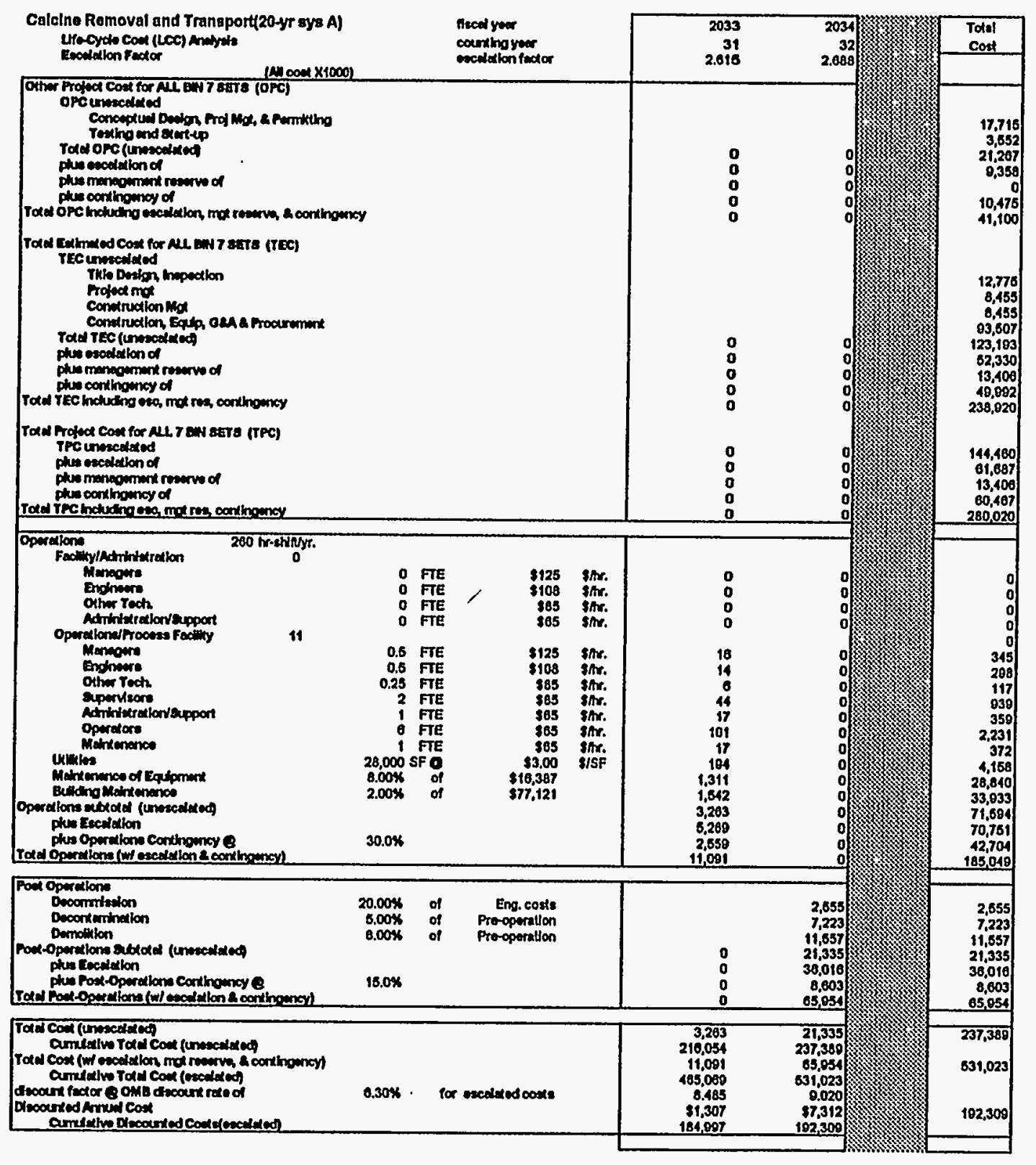




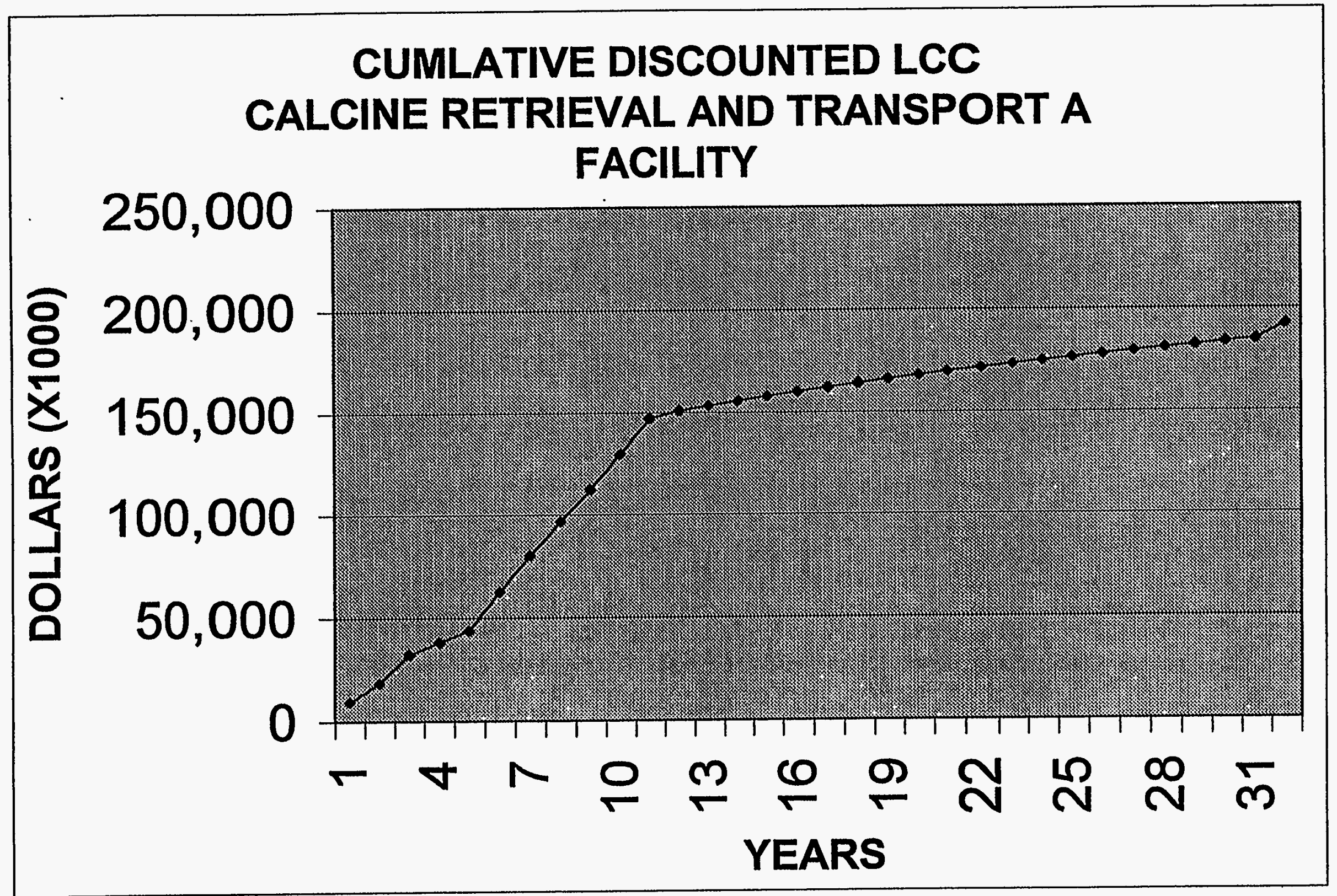




\section{TOTAL ANNUAL COST(escalated) CALCINE RETRIEVAL AND TRANSPORT A FACILITY}

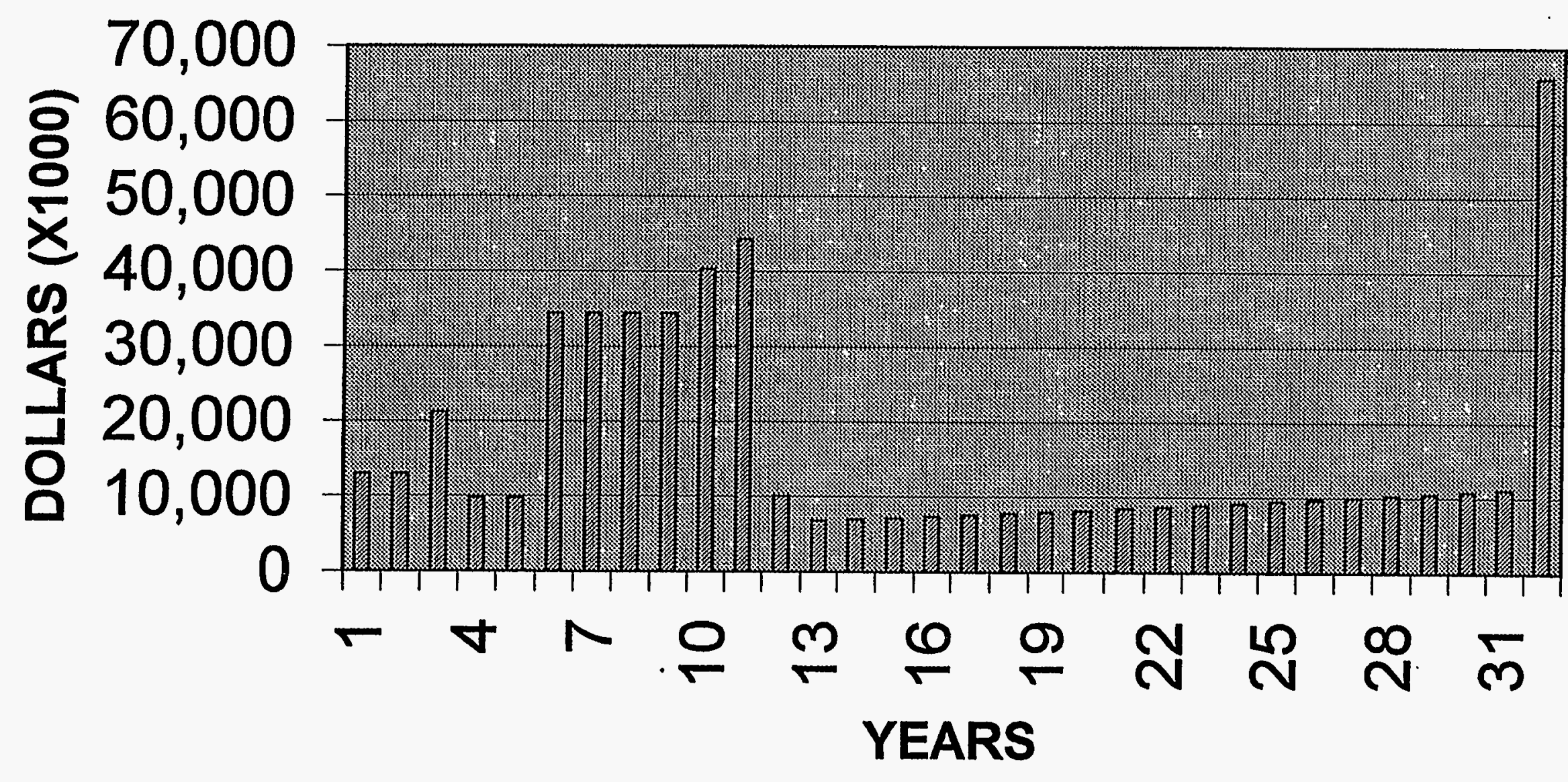




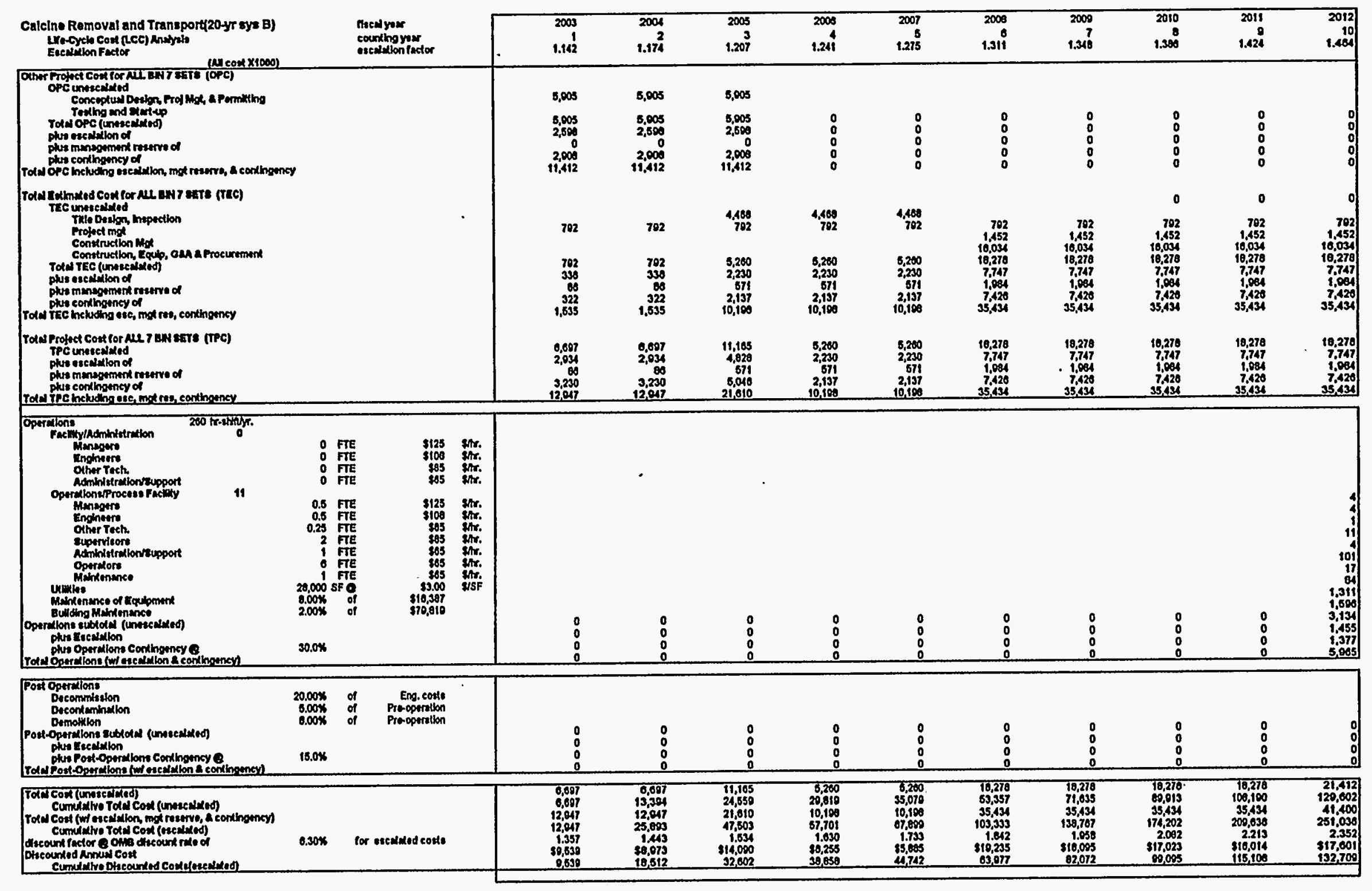




\begin{tabular}{|c|c|c|c|c|c|c|c|c|c|c|c|c|c|}
\hline 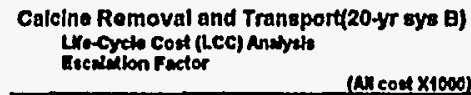 & & \multicolumn{2}{|l|}{ 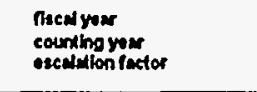 } & $\begin{array}{r}2013 \\
11 \\
1.805\end{array}$ & $\begin{array}{r}2014 \\
12 \\
1.647\end{array}$ & $\begin{array}{r}2015 \\
13 \\
1.691\end{array}$ & $\begin{array}{r}2016 \\
14 \\
1.035\end{array}$ & $\begin{array}{r}2017 \\
18 \\
1.681\end{array}$ & $\begin{array}{r}2018 \\
16 \\
1.728\end{array}$ & $\begin{array}{l}2010 \\
17 \\
1.770\end{array}$ & $\begin{array}{r}2020 \\
10 \\
1.820\end{array}$ & $\begin{array}{r}2021 \\
10 \\
2.677\end{array}$ & $\begin{array}{r}2022 \\
20 \\
1.030\end{array}$ \\
\hline \multicolumn{4}{|l|}{ 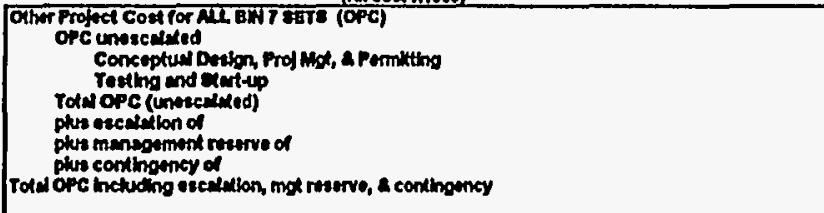 } & $\begin{array}{r}1,776 \\
1,776 \\
702 \\
0 \\
075 \\
3,433\end{array}$ & $\begin{array}{r}1,776 \\
1,776 \\
702 \\
0 \\
075 \\
3,433\end{array}$ & $\begin{array}{l}0 \\
0 \\
0 \\
0 \\
0\end{array}$ & $\begin{array}{l}0 \\
0 \\
0 \\
0 \\
0\end{array}$ & $\begin{array}{l}0 \\
0 \\
0 \\
0 \\
0\end{array}$ & $\begin{array}{l}0 \\
0 \\
0 \\
0 \\
0\end{array}$ & $\begin{array}{l}0 \\
0 \\
0 \\
0\end{array}$ & $\begin{array}{l}0 \\
0 \\
0 \\
0 \\
0\end{array}$ & $\begin{array}{l}0 \\
0 \\
0 \\
0 \\
0\end{array}$ & $\begin{array}{l}0 \\
0 \\
0 \\
0 \\
0\end{array}$ \\
\hline \multicolumn{4}{|l|}{ 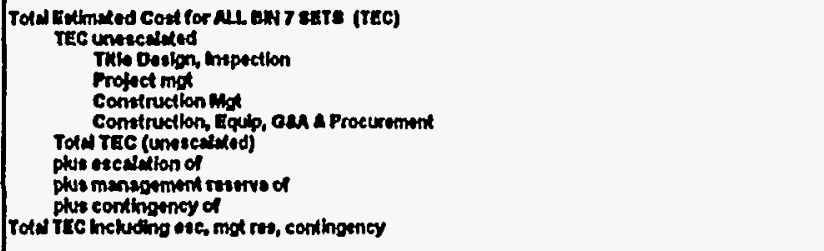 } & $\begin{array}{r}0 \\
702 \\
1,402 \\
10,034 \\
19,270 \\
7,747 \\
1,094 \\
7,426 \\
35,434\end{array}$ & $\begin{array}{l}0 \\
0 \\
0 \\
0 \\
0\end{array}$ & $\begin{array}{l}0 \\
0 \\
0 \\
0 \\
0\end{array}$ & $\begin{array}{l}0 \\
0 \\
0 \\
0 \\
0\end{array}$ & $\begin{array}{l}0 \\
0 \\
0 \\
0 \\
0\end{array}$ & $\begin{array}{l}0 \\
0 \\
0 \\
0 \\
0\end{array}$ & $\begin{array}{l}0 \\
0 \\
0 \\
0 \\
0\end{array}$ & $\begin{array}{l}0 \\
0 \\
0 \\
0 \\
0\end{array}$ & $\begin{array}{l}0 \\
0 \\
0 \\
0 \\
0\end{array}$ & \begin{tabular}{l|l}
0 \\
0 \\
0 \\
0 \\
0
\end{tabular} \\
\hline \multicolumn{4}{|l|}{ 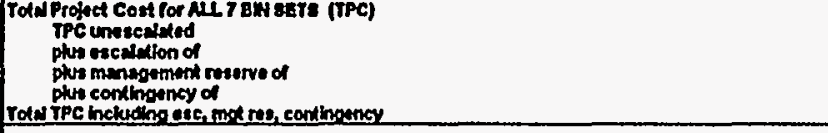 } & $\begin{array}{r}20,054 \\
8,528 \\
1,030 \\
8,301 \\
30,807 \\
\end{array}$ & $\begin{array}{r}1,770 \\
702 \\
0 \\
078 \\
3,433 \\
\end{array}$ & $\begin{array}{l}0 \\
0 \\
0 \\
0 \\
0 \\
\end{array}$ & $\begin{array}{r}0 \\
: \\
0 \\
0 \\
\end{array}$ & $\begin{array}{l}0 \\
0 \\
0 \\
0 \\
0\end{array}$ & $\begin{array}{l}0 \\
0 \\
0 \\
0\end{array}$ & $\begin{array}{l}0 \\
\vdots \\
0 \\
0\end{array}$ & $\begin{array}{l}0 \\
0 \\
0 \\
0 \\
0\end{array}$ & $\begin{array}{l}0 \\
0 \\
0 \\
0 \\
0\end{array}$ & $\begin{array}{l}0 \\
0 \\
0 \\
0 \\
\end{array}$ \\
\hline 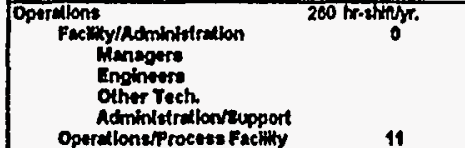 & $\begin{array}{ll}\text { 0 } & \text { FTE } \\
0 & \text { FTE } \\
0 & \text { FTE } \\
\text { O } & \text { FTE }\end{array}$ & $\begin{array}{r}\$ 125 \\
\$ 100 \\
\$ 105 \\
305\end{array}$ & 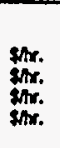 & $\begin{array}{l}0 \\
0 \\
0 \\
0\end{array}$ & $\begin{array}{l}0 \\
0 \\
0 \\
0\end{array}$ & $\begin{array}{l}0 \\
0 \\
0 \\
0\end{array}$ & $\begin{array}{l}0 \\
0 \\
0 \\
0\end{array}$ & $\begin{array}{l}0 \\
0 \\
0 \\
0\end{array}$ & $\begin{array}{l}0 \\
0 \\
0 \\
0\end{array}$ & $\begin{array}{l}0 \\
0 \\
0 \\
0\end{array}$ & $\begin{array}{l}0 \\
0 \\
0 \\
0\end{array}$ & $\begin{array}{l}0 \\
0 \\
0 \\
0\end{array}$ & $\begin{array}{l}0 \\
0 \\
0 \\
0\end{array}$ \\
\hline 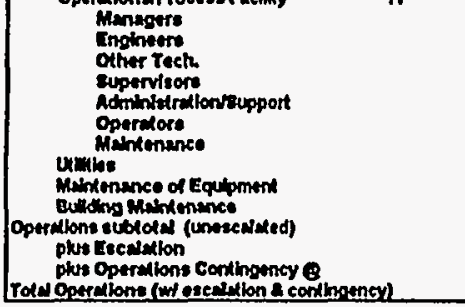 & 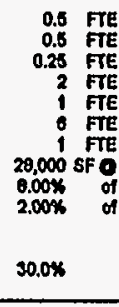 & 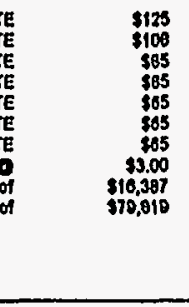 & 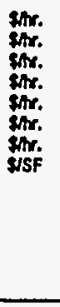 & $\begin{array}{r}10 \\
11 \\
6 \\
44 \\
17 \\
101 \\
17 \\
101 \\
1,911 \\
1,500 \\
0,317 \\
1,070 \\
1,400 \\
0,400 \\
\end{array}$ & $\begin{array}{r}16 \\
14 \\
6 \\
44 \\
17 \\
101 \\
17 \\
104 \\
1,311 \\
0,090 \\
0,317 \\
1,815 \\
1,640 \\
0,071 \\
\end{array}$ & 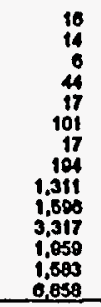 & $\begin{array}{r}10 \\
14 \\
8 \\
44 \\
17 \\
101 \\
17 \\
104 \\
1,311 \\
1,590 \\
3,317 \\
2,107 \\
1,027 \\
7,050 \\
\end{array}$ & $\begin{array}{r}10 \\
14 \\
0 \\
41 \\
17 \\
101 \\
17 \\
104 \\
1,311 \\
1,596 \\
0,317 \\
2,259 \\
1,073 \\
7,248 \\
\end{array}$ & $\begin{array}{r}10 \\
14 \\
8 \\
44 \\
17 \\
101 \\
17 \\
144 \\
1,311 \\
1,590 \\
0,317 \\
2,415 \\
1,719 \\
7,451 \\
\end{array}$ & $\begin{array}{r}10 \\
14 \\
6 \\
41 \\
17 \\
101 \\
17 \\
104 \\
1,311 \\
1,506 \\
3,317 \\
2,575 \\
1,760 \\
7,050 \\
\end{array}$ & $\begin{array}{r}10 \\
14 \\
0 \\
41 \\
17 \\
101 \\
17 \\
104 \\
1,311 \\
1,590 \\
3.317 \\
2,740 \\
1,617 \\
7,074 \\
\end{array}$ & $\begin{array}{r}10 \\
14 \\
6 \\
41 \\
17 \\
101 \\
17 \\
194 \\
1,341 \\
1,506 \\
3,317 \\
2,010 \\
1,868 \\
0,004 \\
\end{array}$ & 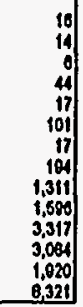 \\
\hline 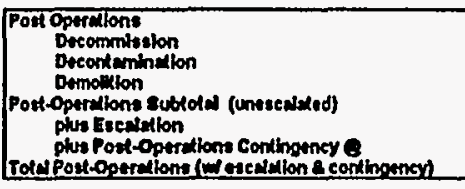 & $\begin{array}{r}20.00 \% \\
6.00 \% \\
0.00 \% \\
18.0 \%\end{array}$ & $\begin{array}{l}\text { Eng, cotse } \\
\text { Proopentilon } \\
\text { Pro-operation }\end{array}$ & & $\begin{array}{l}0 \\
0 \\
0 \\
0 \\
\end{array}$ & $\begin{array}{l}0 \\
0 \\
0 \\
0 \\
\end{array}$ & $\begin{array}{l}0 \\
0 \\
0 \\
0 \\
\end{array}$ & $\begin{array}{l}0 \\
0 \\
0 \\
0 \\
\end{array}$ & $\begin{array}{r}0 \\
0 \\
0 \\
0 \\
\end{array}$ & $\begin{array}{l}0 \\
0 \\
0\end{array}$ & $\begin{array}{l}0 \\
0 \\
0 \\
0\end{array}$ & $\begin{array}{l}0 \\
0 \\
0 \\
0\end{array}$ & $\begin{array}{l}0 \\
0 \\
0 \\
0 \\
\end{array}$ & $\begin{array}{l}0 \\
0 \\
0 \\
0\end{array}$ \\
\hline 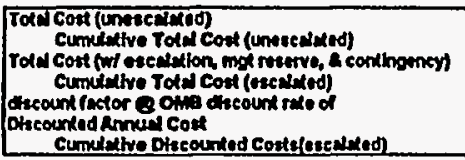 & $0.30 \%$ & for eseculued conts & & 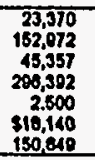 & 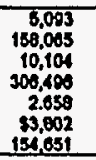 & 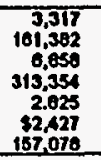 & $\begin{array}{r}3,317 \\
194,608 \\
7,0,050 \\
320,405 \\
32,05 \\
32,347 \\
159,428 \\
\end{array}$ & $\begin{array}{r}3,317 \\
168,015 \\
77,249 \\
327,652 \\
3.103 \\
32,270 \\
161,608 \\
\end{array}$ & $\begin{array}{r}3,317 \\
171,331 \\
7,451 \\
335,103 \\
3,39 \\
32,185 \\
103,809 \\
\end{array}$ & 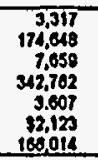 & 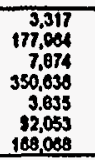 & 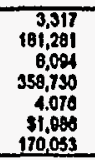 & 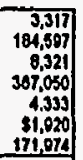 \\
\hline
\end{tabular}




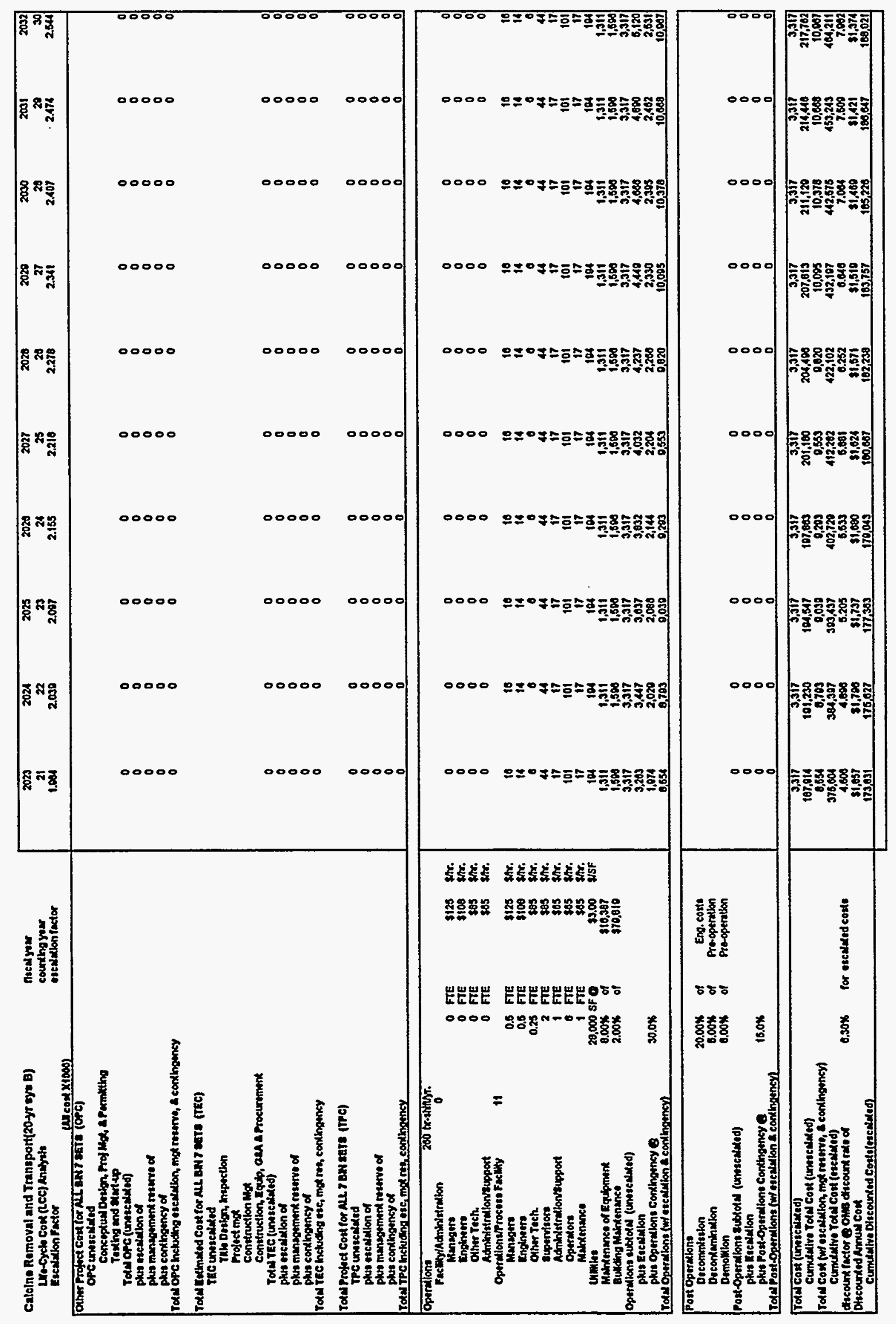




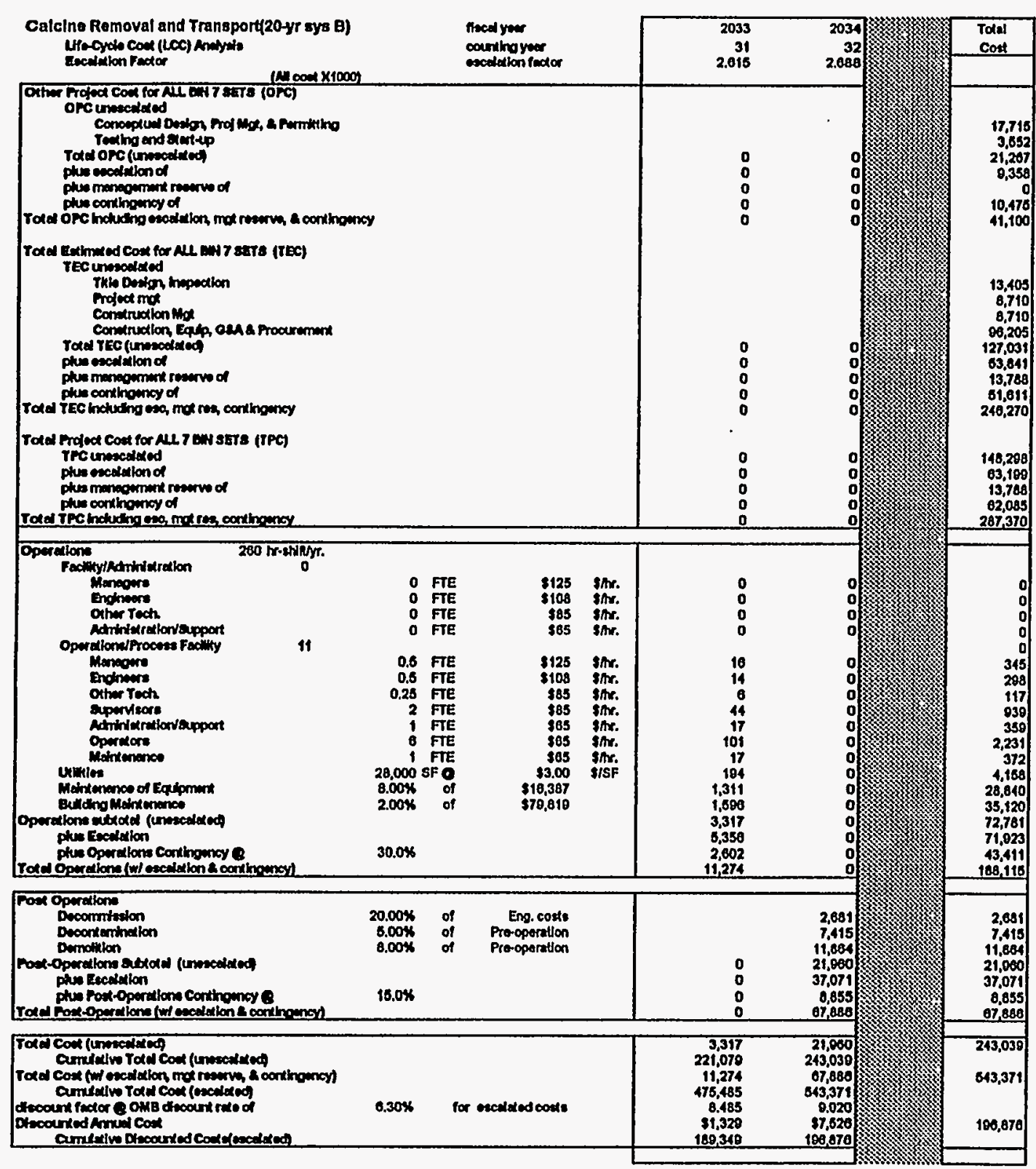




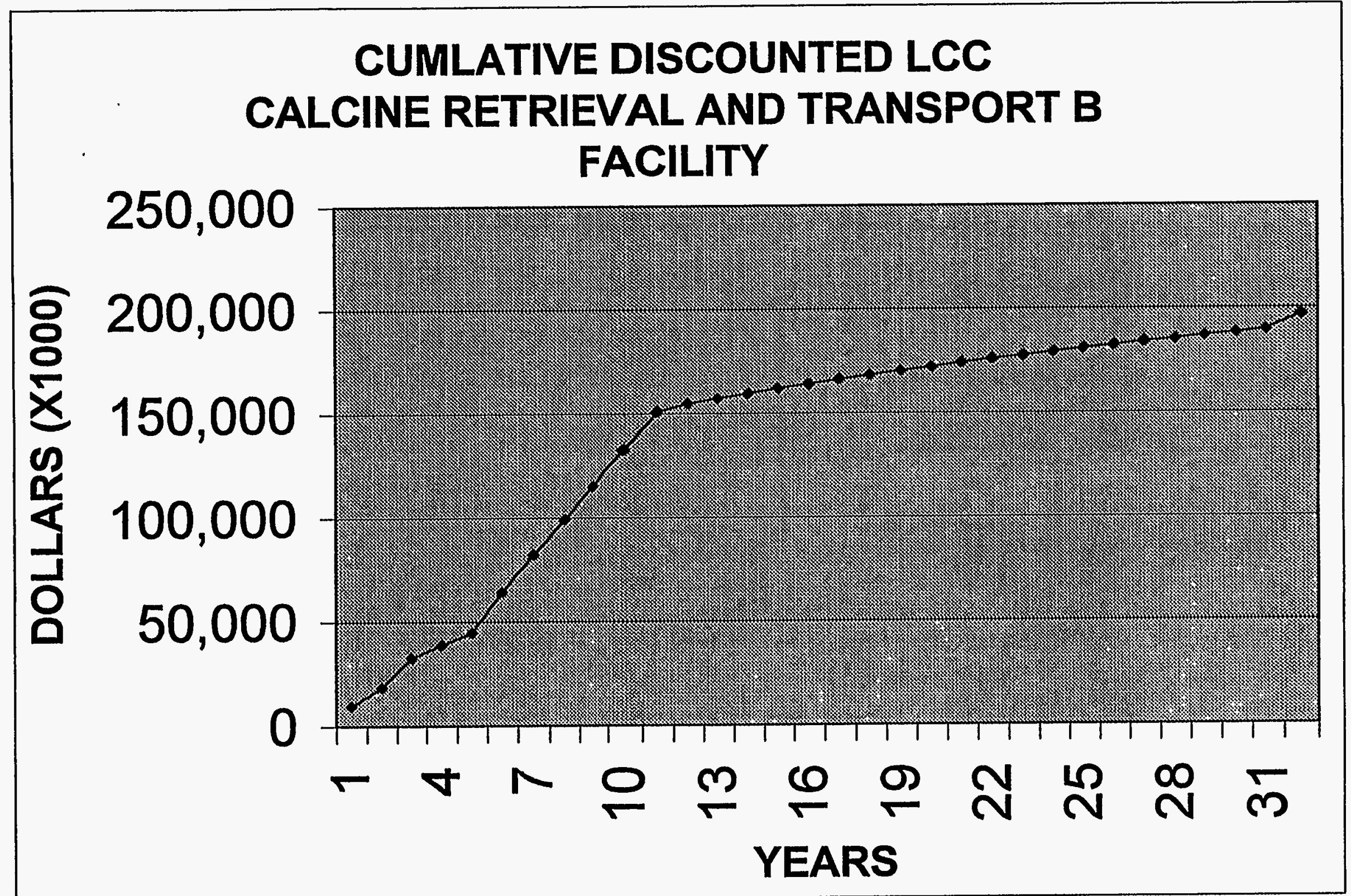




\section{TOTAL ANNUAL COST(escalated) CALCINE RETRIEVAL AND TRANSPORT B FACILITY}

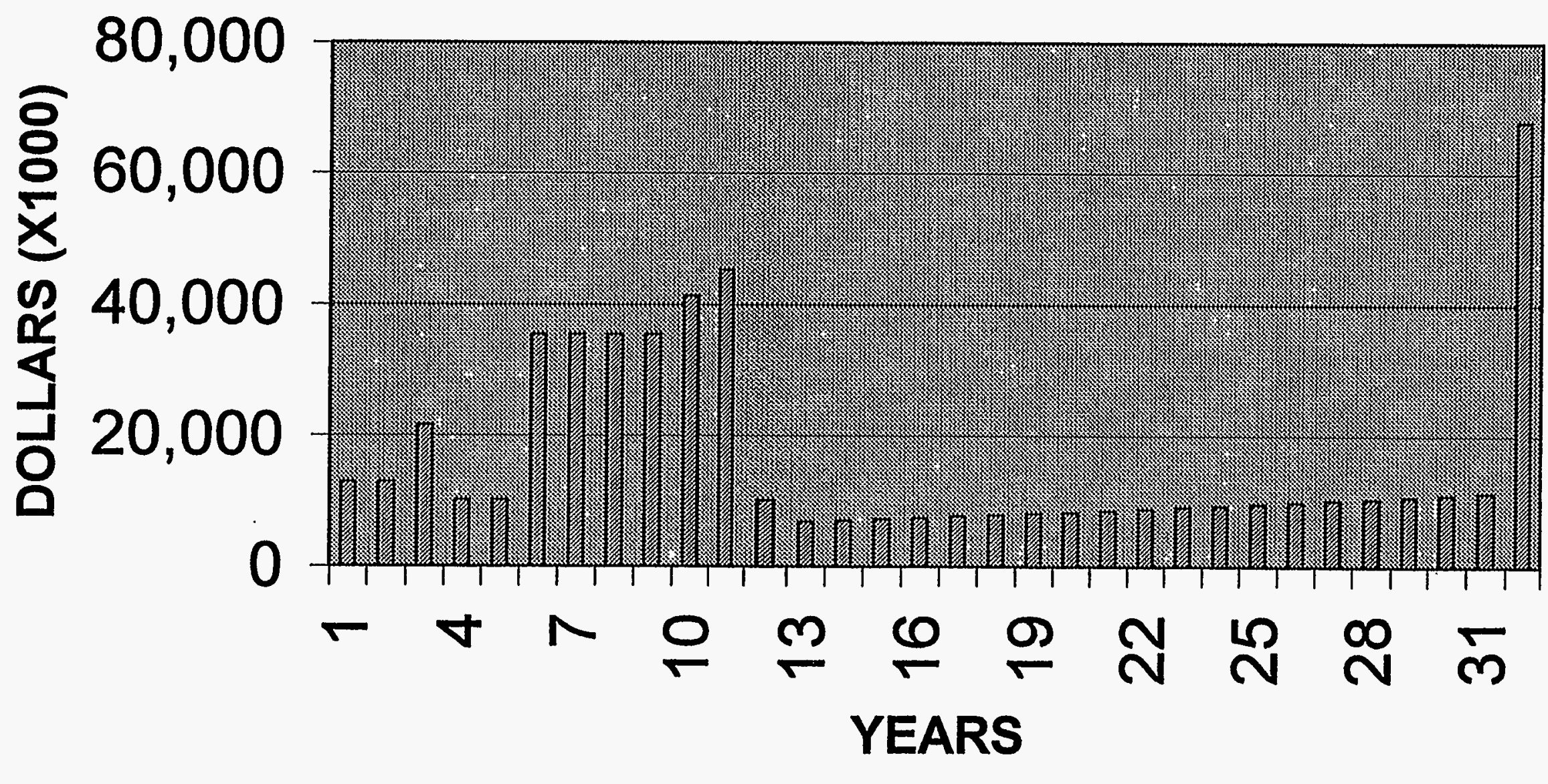


Project/Task HLW EIS Supporting Studies

Subtask

Title: Regulatory Requirements for the Design, Construction, and Operations of the ICPP Proposed Waste Processing Facilities

Summary: This EDF identifies and provides the existing environmental regulations and codes pertaining to the design, construction, operations, and performance of the proposed waste treatment and storage facilities at the Idaho Chemical Processing Plant (ICPP). This study also presents an assessment of the current NRC regulations and their potential applicability to the proposed facilities if the facilities were to be licensed by the NRC in the future. The NRC requirements for regulating DOE facilities or activities have not been defined yet. The NRC requirements to be applied will need to be determined by the appropriate NRC and DOE Task Forces.

The principal sources of requirements for the design, construction, and operations presented here are the Department of Energy (DOE), the DOE Idaho Operations Office (DOE-ID), the Environmental Protection Agency (EPA), the Idaho laws and regulations, the National Environmental Policy Act (NEPA), and other local codes and standards. The proposed facilities under consideration in this study will provide waste retrieval, treatment, and interim storage capabilities. They will process various wastes that are considered mixed wastes. These are wastes that contain both radioactive and RCRA hazardous constituents. The RCRA constituents include characteristic heavy metals and "listed" hazardous constituents, as defined in 40 CFR 261, subparts $C$ and $D$. The management of the wastes, as well as the facilities, is subject to the requirements of both the EPA and the Atomic Energy Act (AEA). The specific requirements for radioactive waste management developed under the AEA are administered through the DOE. The proposed treatment facilities are expected to process several types of waste and to convert them to distinct waste forms that are suitable for disposal. The regulatory requirements for the disposal of the various waste forms resulting from the proposed treatment options and the criteria of the potential target repositories are described in detail in INEEL/EXT-97-01147. It is assumed that the wastes resulting from the treatment options will be delisted and will no longer be considered RCRA hazardous waste prior to being sent to interim storage facilities.

Existing NRC requirements apply to commercial, non-DOE, facilities. The degree of applicability of these requirements to the proposed facilities should be determined by the NRC and the DOE, with input from the DOE contractor. Of the existing NRC regulations, it has been determined in this study that 10 CFR 61 will apply to the proposed near-surface disposal facility for the grouted Low-Activity Waste (LAW) or grouted LLW, and 10 CFR 72 will be applicable to the proposed interim storage facilities for the vitrified, Hot Isostatic Pressed (HIPed), or grouted High-Level Waste (HLW), and for the liquid High-Activity Waste (HAW) and vitrified HAW storage facilities. Independently, it was determined by Leroy and Morgan in "Nuclear Regulatory Commission (NRC) Licensing Assessment for the Idaho National Engineering and Environmental Laboratory (INEEL) High-Level Waste program," April 23, 1997, that 10 CFR 30 and 10 CFR 70 
will apply to the following facilities:

- 10 CFR 30 for the LAW collection and grouting facilities and for the collection and treatment of the LLW from the INEEL ongoing operations.

- 10 CFR 70 for the separations facility, for the interim storage of liquid HAW resulting from the separation processes, and for the HAW vitrification facility.

- 10 CFR 70 for the HLW vitrification, HIPing, or grouting facilities.

- 10 CFR 70 for the calcine retrieval and dissolution facilities.

Additional NRC regulations applicable to the proposed facilities are in 10 CFR 2, 10 CFR 19, 10 CFR 20, 10 CFR 21, 10 CFR 50, 10 CFR 51, 10 CFR 52, and 10 CFR 73. 10 CFR 71 and 49 CFR 173 (Department of Transportation) contain requirements for the packaging and transportation of waste. These requirements could have impact on the design and operations of the storage facilities. The existing facilities that will be modified to be used for storage of treated $\mathrm{HLW}$ or HAW are anticipated to be exempted by DOE from any further jurisdiction of NRC. Such a jurisdiction would be excessively difficult, costly, and complex to apply. All the work requirements for the modification of the existing facilities are expected to be performed in accordance with the DOE/RW/0333P, "Quality Assurance Requirements and Description."

If $\mathrm{DOE}$ facilities become regulated by $\mathrm{NRC}$, the jurisdiction of other currently government applicable authorities will not automatically or necessarily cease. In particular, it is expected that local, State, Federal EPA, and some DOE regulatory requirements would still apply.

In addition to all the regulatory requirements established by the various government authorities discussed above, the schedule of the construction and operations of the proposed facilities must meet the terms and the dates of the commitments as stated in the Settlement Agreement between the State of Idaho and the DOE.

Distribuition (complete package): HLW EIS Library, also contained in INEEL-EXT-01389 (VWO), INEELEXT-97-01392 (HWO), INEEL-EXT-97-01400 (CWO), INEEL-EXT-97-01399 (DCWO), and INEEL-EXT97-01428 (TRU Separations), S. L. Austad MS 3650, J. B. Bosley MS 3428, R. E. Dafoe MS 3765, W. H. Landman MS 3625, A. E. Lee MS 3765, D. A. Lopez MS 3765, B. R. Helm MS 3765, J. J. McCarthy MS 3625, T. A. Solle MS 3428, N. E. Russell MS 3765, D. S. Vandel MS 3625.

Distribution (summary package only): D. J. Harrell MS 3211, K. L. Williams MS 3765.
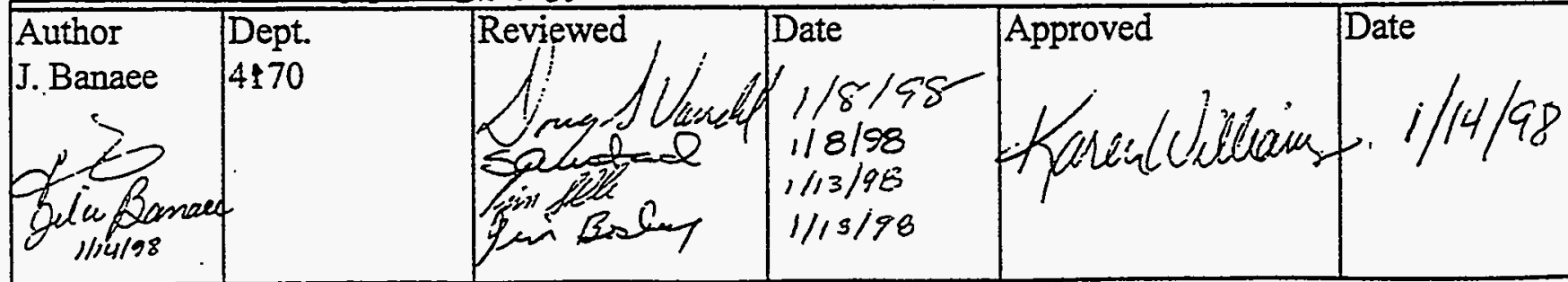


\section{INTRODUCTION}

This study identifies and presents the existing environmental regulations and standard codes for the design, construction, operations, and performance of the proposed waste treatment and storage facilities at the Idaho Chemical Processing Plant (ICPP). Also, it provides the applicable existing Nuclear Regulatory Commission (NRC) regulations and guidance documents to the proposed facilities if they were to be licensed by the NRC in the future. The existing licensing process and related licensing issues applicable to the proposed facilities are also discussed.

The environmental regulations are primarily based on safety and health considerations. The standards define the requirements that protect human health and the environment. The principal sources for the standard regulations and codes presented here are:

- Environmental Protection Agency

- Idaho Laws and regulations

- National Environmental Policy Act (NEPA)

- Department of Energy

- DOE Idaho Operations Office (DOE-ID)

- Other applicable standards and codes

In addition to the current regulations, the governing standards for the facility design and performance considerations of the future (i.e., DOE Orders 435.1) drafted at the time of preparation of this report are also presented.

The facilities under consideration in this study will provide waste retrieval, treatment, and interim storage capabilities. They will process various wastes that are considered mixed wastes. These are wastes that contain both radioactive and Resource Conservation and Recovery Act (RCRA) hazardous constituents. The RCRA constituents include characteristic heavy metals and "listed" hazardous constituents, as defined in 40 CFR 261, subparts C and D. The management of the wastes, as well as the facilities, is subject to the requirements of both the EPA and the Atomic Energy Act (AEA). The specific standards for radioactive waste management developed under AEA are administered through the DOE.

The proposed treatment facilities are expected to process several types of waste to convert them to distinct waste forms that are suitable for disposal. The wastes resulting from the proposed treatment options are assumed to be delisted prior to being transported to the proposed interim storage facilities. The waste forms are produced starting from a variety of mixed wastes including high-level liquid waste (HLLW), Sodium-bearing liquid waste (SBW), and other radioactive wastes form ongoing operations (1996-2012), known as the newly generated wastes (NGW). These wastes have been stored in the Tank Farm at the ICPP. Most of the HLLW have been calcined and stored at the Calcined Solids Storage Facility (CSSF).

The EPA has established treatment standards under the RCRA Land Disposal Restrictions (LDRs), in 40 CFR 268, for hazardous waste constituents prior to land disposal. The regulatory 
requirements for the disposal of the various waste forms resulting from the proposed options and the criteria of the potential target repositories are described in detail in INEEL/EXT-97-01147.

\section{PROPOSED WASTE TREATMENT OPTIONS}

Several treatment options are being proposed including four non-separations and two separation processes. In addition, a no-action alternative will likely be considered, defined as the continuation of the current practice of calcination and storage in stainless steel bins at ICPP. The non-separation options include: (a) vitrified waste option (VWO), (b) Hot Isostatic Pressed (HIP) waste option (HWO), (c) direct cementitious waste option (DCWO), and (d) cementitious waste option (CWO). The separation processes are expected to generate up to three different waste streams; designated as high activity waste (HAW), low activity waste (LAW), and transuranic (TRU) waste. These options are summarized below:

\section{Vitrified Waste Option}

This option involves the following steps: 1) calcination of HLLW, SBW, and the NGW, 2) vitrification of all the calcine wastes (existing and future) and placing in canisters $\left(2^{\prime} \times 10^{\prime}\right.$ or other canisters approved by the repository/NRC), and 3 ) interim storage prior to shipment to a HLW repository.

Process duration: 20 year Schedule

\section{HIP Waste Option (HWO)}

As in the VWO, the wastes will be calcined but instead of being vitrified, they will be directly HIP processed and placed in canisters ( $2^{\prime} \times 10^{\prime}$ or other canisters approved by the repository/NRC), and 3) will be sent to an interim storage facility prior to shipment to and disposal at a HLW repository.

Process duration: 20 year schedule

\section{Cementitious Waste Option (CWO)}

This option includes calcining the HLLW, retrieving the calcine wastes, and recalcining with the SBW in the modified New Waste Calcining Facility (NWCF), grouting in canisters (2' $x 10^{\prime}$ canisters), and sending to an interim storage facility for transport to and ultimate disposal at an off-site HLW disposal facility. It is proposed that the cementitious waste would be suitable for disposal at the Nevada Test Site (NTS) using Greater Confinement Disposal (GCD) facility. 
Currently, the GCD facility has not been approved for disposal of HLW and waste acceptance requirements for the GCD facility have not been defined. Pursuant to the 1987 Nuclear Waste Policy Amendments Act (NWPAA), the Yucca Mountain in Nevada is designated for characterization as the only candidate site for a $\mathrm{HLW}$ geologic repository. However, projections of future wastes suggests a need for a second repository at some time in the future, or expansion of the first potential repository. Criteria for acceptance and disposal of waste at the potential HLW repository at the Yucca Mountain have not been finalized. The current waste acceptance criteria are preliminary at the present time. These criteria are covered in detail in INEEL/EXT97-01147.

Process duration: 5 year schedule

\section{Direct Cementitious Waste Option}

The DCWO consists of step 1 of the VWO, then direct grouting of all the calcined wastes and packaging in canisters ( $2^{\prime} \times 10^{\prime}$ or other canisters approved by the repository/NRC), and interim storage prior to shipment to an off-site HLW repository such as the NTS-GCD, if approved for the HLW disposal, or possibly to a potential HLW geologic repository at the Yucca Mountain. This option is planned to have the same processing time as the CWO with the difference in starting date.

\section{Separations Options}

Two waste separation options have been proposed: HAW/LAW, known as full separations, and TRU separations. The full separations option involves calcining the HLW and SBW, retrieving and dissolving the calcine, and feeding the dissolved calcine and the remaining liquid SBW and the NGW to a waste separations facility to separate them into the HAW and LAW streams. The NGW, if classified as LLW, would bypass the separations facility and would ultimately be combined with the LAW.

In the TRU separations, as in the HAW/LAW separation option, the dissolved calcine and the remaining liquid SBW, and the NGW will be fed to a waste separations system. Two separation alternatives are being considered under this option, designated as (1) TRU/LAW Class C and (2) TRU/LAW Class A/HAW. In the first alternative, the wastes would be separated into TRU waste and LAW. The TRU waste fraction is expected to contain alpha-emitting TRU radionuclides with half-lives greater than twenty years. The remaining waste stream, designated as LAW Class C, would contain Cesium (Cs) and strontium (Sr) isotopes, and low activity waste portion. It is anticipated that the LAW in this alternative would meet the definition of NRC LLW Class C. In the second alternative, $\mathrm{Cs}$ and Sr will be separated as HAW, and the remaining waste from separations will be designated as TRU and LAW. The LAW is expected to meet the definition of NRC LLW Class A. 
The HAW is planned to be vitrified using the same process described in the VWO and be shipped to a HLW geological repository for permanent disposal. The HAW containing isolated $\mathrm{Cs}$ and $\mathrm{Sr}$ would be stored at the INEEL awaiting disposal in a HLW geologic repository or an alternate approved disposal facility. The TRU waste stream would be converted to a solid form to be send to the Waste Isolation Pilot Plant (WIPP) for disposal. The LAW would be grouted and shipped to a LLW disposal facility. The disposal options being considered for the grouted LAW are the CSSF, the tanks at ICPP, or a LLW near-surface disposal facility. The requirements for the design and operations of a near-surface LLW disposal facility are covered in detail in EDF-FDO-008. This reference is contained in INEEL/EXT-98-00051.

Based on the NRC source term definition of HLW (10 CFR 60.2), the HAW, LAW and the TRU waste streams are actually considered HLW. These wastes do not conform to the existing classification for radioactive waste. Although, the separations alternatives and the resultant waste streams may be technically and economically feasible and attractive, they will need to receive evaluation, redefinition of types of waste, and the concurrence of applicable government authorities. It is assumed that a determination will be made by the appropriate authorities (e.g., the DOE and the NRC) that the TRU waste and the LAW streams meet the TRU waste and the NRC LLW-Class A or Class C definition, respectively. The LAW also meets the definition of incidental waste in the NRC evaluation of HLW separation processes at Hanford Site (58 FR, "State of Washington and Oregon, Denial for Petition for Rulemaking," U.S. Nuclear Regulatory Commission," March 4, 1993, p. 12342.). The HAW would be considered HLW and can be classified as HLW.

\section{ASSUMPTIONS}

1) All of the wastes produced from the treatment and storage facilities will meet the requirements enforced by the EPA, the DOE, the DOT, the NRC, and other potential target repositories for the disposal.

2) Under EPA 40 CFR 268.42(b), an equivalency petition for using alternative waste treatment technologies including CWO and DCWO to borosilicate glass ${ }^{\mathrm{a}}$ will be granted by the EPA.

3) All of the wastes resulting from the various treatment options will be delisted prior to being transported to the interim storage facilities. The EPA Upfront Exclusions for the petitioned wastes will be granted to delist the RCRA listed hazardous waste codes. The EPA delisting criteria and processes for preparing a delisting petition are contained in "Petitions to Delist

\footnotetext{
${ }^{\text {a }}$ Vitrification using borosilicate glass technology is considered by the EPA a best demonstrated available technology (BDAT) for treatment of mixed HLW (55 Federal Register (FR), June 1, 1990, p.22627). DOE's studies of glassceramic process and comparison of glass-ceramic process and waste form with borosilicate glass waste have shown that glass-ceramic waste form meets the definition of EPA vitrification and borosilicate glass. EPA has concurred with the DOE conclusion and has determined that the glass-ceramic process is an acceptable technology to meet BDAT (see 57 FR, May 26, 1992, p. 22024).
} 
Hazardous Wastes: A Guidance Manual," Second Edition, PB93-169365, March 1993. The Upfront Exclusions may be granted for wastes and/or waste residues that have not been generated, but will be generated in the future. The EPA will evaluate the petitioned wastes based on available information such as the characteristics of the untreated wastes, process description, and bench-scale or pilot scale treatment data.

4) An off-site facility would need to be approved for the disposal of HLW resulting from the CWO, DCWO, and HWO.

\section{ENVIRONMENTAL REGULATIONS, DOE CRITERIA, AND OTHER STANDARD CODES}

\subsection{FEDERAL AND STATE LAWS AND REGULATIONS}

\section{Resource Conservation and Recovery Act}

The RCRA has established minimum national standard requirements which apply to owners or operators of all facilities that treat, store, or dispose of hazardous waste. The State of Idaho has the authority to implement the RCRA requirements through the Idaho Department of Health and Welfare (IDHW). The State of Idaho adopted the Federal RCRA regulations, pursuant to the Idaho Hazardous Waste Management Act of 1983. The regulations are incorporated by reference as provided in the Federal requirements under $40 \mathrm{CFR}$ into the "Idaho Rules and Standards for Hazardous Waste", under administrative code known as Idaho Administrative Procedures Act (IDAPA) 16.01.05.

The RCRA requirements applicable to the hazardous waste facilities are defined in 40 CFR 264 (IDAPA 16.01.05.008), "Standards for Owners and Operators of Hazardous Waste Treatment, Storage, and Disposal Facilities" and in 40 CFR 270 (IDAPA 16.01.05.012), "EPA Administered Permit Programs: the Hazardous Waste Permit Program."

40 CFR 264 sets regulatory requirements for the design, construction, and operation of the facility, quality assurance program, testing and maintenance of the equipment, air emission standards, groundwater protection standards, security, inspection, personnel training, preparedness and prevention, contingency plan and emergency procedures, manifest system and record keeping, closure and post-closure, financial requirements, and use and management of containers.

The existing hazardous waste facilities used for any future hazardous waste management activities can continue operations while meeting the requirements in 40 CFR 265 (16.01.05.009), "Interim Status Standards for Owners and Operators of Hazardous Waste Treatment, Storage, 
and Disposal Facilities". This will allow the existing facilities to continue operations while meeting minimum operational requirements defined in $40 \mathrm{CFR} 265$. To be qualified for interim status, the existing facility must have been in operation or under construction on November 19 , 1980 or have been in operation when the facility became subject to the RCRA requirements.

40 CFR 262.34 (subpart of 40 CFR 262 - IDAPA 16.01.05.006), "Accumulation Time" and 40 CFR 268.50 (subpart of 40 CFR 268 - IDAPA 16.01.05.011), "Prohibitions on Storage of Restricted Wastes" contain requirements, conditions, and time limits for storage of hazardous wastes. Based on 40 CFR 262.34, a generator may accumulate hazardous waste on-site for 90 days or less without a permit or an interim status, provided that the generator meet the conditions specified in 40 CFR 262.34. A generator who accumulates hazardous waste for more than 90 days is an operator of a storage facility and is subject to the requirements of 40 CFR 264 and 40 CFR 265, and the permit requirements of 40 CFR 270 unless the generator has been granted an extension to the 90-day period by the EPA. A 30-day extension may be granted at the discretion of the EPA on a case-by-case basis. A generator who accumulates hazardous waste greater than 100 kilograms but less than 1000 kilograms in a calendar month may accumulate hazardous waste on-site for 180 days or less without a permit or without an interim status provided the generator meets the requirements stated in 40 CFR 262.34.

Under 40 CFR 268.50, the storage of hazardous wastes such as those present in the Tank Farm is prohibited, unless the following conditions are met:

(1) A generator stores such wastes in tanks, containers, or containment buildings on-site solely to facilitate proper recovery, treatment, or disposal and the generator complies with the requirements in 40 CFR 262.34, 40 CFR 264, and 40 CFR 265.

(2) An owner/operator of a hazardous waste treatment, storage, or disposal facility stores such wastes in tanks, containers, or containment buildings to facilitate proper recovery, treatment, or disposal, and an owner/operator must comply with the operating record requirements specified in 40 CFR 264.73 and 40 CFR 265.73.

An owner/operator of a treatment, storage, or disposal facility may store hazardous waste restricted from land disposal beyond one year provided that the owner/operator proves to the EPA that such storage was solely for the purpose of facilitating proper recovery, treatment, or disposal.

The prohibition in storage does not apply to hazardous wastes that meet the LDR treatment standards and treatment equivalency as defined in 268.42 (b). However, if the waste is still listed, the generator must comply with the RCRA requirements for hazardous waste storage. 


\section{Permit Requirements}

Various permits are required prior to the construction and operations, and during the operations of the proposed facilities. These include RCRA permit, air emissions permit, wastewater discharges permit, etc. In addition, separate permits may be needed once the processes or activities are better known, as individual pilot plant operations or modifications to the existing facilities/systems may require separate permits. The applicable permit requirements are described below. A summary of the permit requirements and regulatory drivers is presented Section 5.

\section{$\underline{\text { RCRA Permit }}$}

All facilities that treat, store, or dispose of hazardous wastes are required to obtain a RCRA permit during the active life (including the closure period). 40 CFR 270 establishes the requirements for obtaining a Permit. A RCRA Permit application consists of two parts, Part A and Part B. Part A of the permit application is a short standard form that collects general information about the treatment, storage, or disposal facility. Part B of the permit application includes a much more detailed technical description of the facility. The permit application covers all aspects of the design, construction, operation, monitoring, and maintenance of the facility. The requirements for Part A permit application are in 40 CFR 270.13, and for Part B Permit application are in 40 CFR 270.14 through 29.

Once the owner or operator of a facility has submitted a permit application, the regulator conducts an in-depth evaluation to determine if the application satisfies the RCRA requirements. For the new hazardous waste facilities, Parts A and Part B of the permit application must be submitted a least 180 days prior to physical construction is expected to commence. For the existing hazardous waste facilities, the requirements to submit an application is satisfied by submitting only Part $\mathrm{A}$ application to operate under interim status until the permitting agency sets a date for submitting Part B of the application.

\section{$\underline{\text { Air Permit }}$}

Air permits will be required from the State of Idaho and/or EPA Region X prior to construction and operations of each of the treatment, storage, and disposal facilities with radioactive and nonradioactive emissions sources. The existing facilities that will be used for the proposed waste processing activities may require permit modification if the existing permit does not satisfy the permit requirements for the proposed use.

The Clean Air Act (CAA) sets permit requirements and emission standard limits. The CAA requirements are implemented by the $\mathrm{DHW}$ under Idaho codes (see Idaho Codes and regulations below) or by EPA Region X. The CAA implementing regulations are in 40 CFR 50, 52, 60, 61, $62,63,70,77$, and 124 . The air permit requirements are briefly described below. 
For nonrad emissions a Permit to Construct (PTC) will be required from the IDHW for each of the new emission points prior to the construction or modifications of a facility. Individual pilot plant systems may require separate PTCs once the processes are known. Hazardous Air Pollutants (HAPs) and the Toxic Air Pollutants (TAPs) will need to be quantified prior to permitting.

The National Emission Standards for Hazardous Air Pollutants (NESHAPs), Subpart H sets the standards for the radioactive air emissions. The proposed facilities will qualify as radiological sources if they emit any radiological emissions. They are regulated by the EPA under the NESHAPs and the State of Idaho for radioactive air emissions. The state of Idaho treats the INEEL as one large facility. Currently, the maximum off-site limits for the total INEEL radiological emissions is $10 \mathrm{mrem} / \mathrm{yr}$.

The National Ambient Air Quality Pollutants Standards (NAAQS) has established requirements for particulate matter, sulfur dioxide, ozone, nitrogen dioxide, carbon monoxide, fluoride, and lead. If their emissions are significant as defined in IDAPA 16.01.01.88, they must comply with the requirements of the Prevention to Significant Deterioration (PSD). The Best Available Control Technology (BACT) must be used to control pollutants if compliance with the PSD is required.

The air emissions must be calculated for each of the new facilities to determine the permit requirements and compliance with the regulatory standards, and to identify how they impact the sitewide total emissions at the INEEL because the State of Idaho treats the INEEL as one large facility. The determination of the expected air emissions is usually done during the Title II design.

Appendix D to $40 \mathrm{CFR} 61$ should be used for estimating the radionuclide emissions from the new sources to determine if a NESHAPs approval to construct is needed. If the estimated dose is greater than $0.1 \mathrm{mrem} /$ year, the NESHAPs application will be required. In such case, a PSD evaluation will required by the State of Idaho.

Some of the process vents associated with the hazardous waste treatment units must meet the RCRA air emission standards in 40 CFR 264/265 Subparts AA. A process vent is any openended stack or pipe that is vented to the atmosphere. 40 CFR 264/265 Subparts BB and CC contain air emissions standards which are applicable only to certain types of processes such as equipment leaks, tanks, and containers.

The EPA proposed MACT Rule which enforces limits on air pollutants applies to hazardous waste incinerators or other comparable facilities which burn hazardous waste and/or are qualified as an incinerator by the EPA. This study assumes that the MACT Rule will be applicable to the vitrification and HIPing facilities. The MACT Rule sets emission limits for dioxin/furan, hydrocarbons, chlorine, carbon monoxide, lead, cadmium, mercury, antimony, arsenic, beryllium, chromium, and particulate matter. 


\section{Wastewater Effluent Discharges and Drinking Water Permit}

The EPA has established requirements for stormwater and nonstormwater discharges into the environment under the National Pollution Discharge Elimination System (NPDES). The NPDES contains the requirements that control the discharge of pollutants to waters of the U.S. (e.g., Big Lost River) as defined in the Clean Water Act (CWA) in 40 CFR 122. These sources can include sanitary, industrial processes, and storm water runoff from industrial and construction areas.

A permit under the NPDES is required for storm and nonstorm waters (e.g., service water, sewer discharges). The INEEL has a general NPDES permit. Therefore, the existing INEEL NPDES permit should be evaluated to determine if there is a need for modifications of the INEEL permit or addendum to the permit to satisfy the permit requirements for the proposed facilities.

Wastewater Land Application Permits are required for construction, modifications, and operation of facilities that dispose of municipal and industrial wastewater to the land surface. The requirements are defined in 40 CFR 122 (CWA).

Pursuant to the CWA, the facilities that engage in storing, transferring, and consuming oil and oil products which could reasonably be expected to discharge oil in the Big Lost River or other waters of the U.S. must have Spill Control Prevention and Countermeasures Plans. The Plans are required if the oil discharges are in harmful quantities that violate the applicable water quality standards and cause harm to the human health and environment.

\section{Idaho Laws and Regulations}

This section lists the Idaho codes and standards for air and water pollution control and for releases into the environment. The standards are based on the Federal requirements established by the CAA, the CWA, and the RCRA.

Idaho Code 39-44, "Hazardous Waste Management Act" IDAPA 16.01.05, "Rules and Standards for Hazardous Waste" DAPA 16.01.01, "Rules for the Control of Air Pollution in Idaho" DAPA.16.01.01.161, "Toxic Substances" IDAPA 16.01.01.210, "Demonstration of Reconstruction Compliance with Toxic Standards" IDAPA 16.01.01.575, "Air Quality Standards and Area Classification"

IDAPA 16.01.01.650, "Rules for Control of Fugitive Dust"

DAPA 16.01.09, "Idaho Radiation Control Rules"

Idaho Code 39-36, "Water Quality Act"

IDAPA 16.01.02, "Water Quality Standards and Wastewater Treatment"

IDAPA 16.01.08.500, "Design Standards for Public Drinking water Systems"

IDAPA 16.01.08.551, "Construction Requirement for Public Water Systems"

IDAPA 16.01.08, "Idaho Rules for Public Drinking Water Systems"

IDAPA 16.01.17, "Wastewater Land Application Permit Regulations" 
40 CFR 191, 'Environmental Radiation Protection Standards for Management and Disposal of Spent Nuclear Fuel, High-Level Waste and Transuranic Waste"

The EPA has set radiation protection requirements for management of radioactive waste in 40 CFR 191. The radiation protection standards for management and storage of radioactive wastes apply to:

(a) Radiation doses received by members of the public as a result of the management (except for transportation) and storage of spent nuclear fuel or HLW or TRU waste at any facility regulated by the NRC or by Agreement States, to the extent that such management and storage operations are not subject to the provisions of 40 CFR 190, "Environmental Radiation Protection Standards for Nuclear Power Operations"; and

(b) Radiation doses received by members of the public as a result of the management and storage of spent nuclear fuel or HLW or TRU waste at any disposal facility that is operated by the DOE and that is not regulated by the NRC or by Agreement States.

\section{CFR 257, "Criteria for Classification of Solid Waste Disposal Facilities and Practices"}

The proposed LLW land disposal facility at the INEEL will be comparable to the LLW disposal facility of the Radioactive Waste Management Complex (RWMC). The Idaho Department of Environmental Quality (DEQ) evaluated the applicability of federal and state regulations to the RWMC LLW disposal facility. The $\mathrm{DEQ}^{\mathrm{b}}$ has concluded that, in addition to other requirements, disposal of waste at RWMC is subject to Subtitle D landfill standards, 40 CFR 257. The environmental standards required by 40 CFR 257 are based on safety and health considerations which protect human health, wildlife, and the environment. The DOE or the NRC requirements for design and performance of a LLW disposal facility are much more stringent than those in 40 CFR 257 and supersede the subtitle D landfill standards.

40 CFR 257 requires that disposal facilities or practices in floodplains not restrict the flow of the base flood, reduce the temporary water storage capacity of the floodplain, or result in washout of solid wastes which pose a hazard to human life, wildlife, land or water resources. The disposal facilities shall not cause a discharge of pollutants into waters of the United States. Such a discharge would be a violation of the NPDES. Also, the facilities must not contaminate any underground drinking water source beyond solid waste facility boundary or beyond an alternative specified boundary.

\footnotetext{
${ }^{b}$ DEQ letter to Jay Mitchell, Manager of LMITCO NEPA/Permitting, July 23, 1996.
} 


\subsection{DEPARTMENT OF ENERGY}

The AEA of 1954 authorizes the DOE to establish standard criteria to ensure safe operations of its facilities, and to protect human health and to minimize dangers to life and property. The DOE has developed a series of Orders and Directives. They contain standards that require the planning, design, and construction of DOE facilities be performed in a manner that will satisfy all applicable Federal, State, and local environmental, safety and health laws and regulations, and the DOE criteria. The DOE and DOE-ID standards applicable to this study include the following:

\section{DOE Order 6430.1A, “General Design Criteria”}

Compliance with DOE Order 6430.1A is mandatory under the current LMITCO contract. DOEID Notice 430.1A, "Life Cycle Asset Management- ID expectations," requires that for facilities under the purview of the Defensec Nuclear Facilities Safety Board (DNFSB), the DOE Order 6430.1A remains effective until 10 CFR 830.340, "Maintenance Management", and DOE Order 420.1, "Facility Safety", are finalized and incorporated into the LMTTCO contract.

DOE-ID Notice 430.1A establishes the DOE-ID expectations of the contractor in areas covered by DOE Order 430.1, "Life Cycle Asset Management", in managing the INEEL. This order incorporates private industry standards safety design criteria, and requires additional nuclear safety criteria for nuclear facilities.

DOE Order 6430.1A provides general and specific design standards, guidance, and practices for use in the DOE facilities. The standards are to provide levels of design for occupant life safety, reduction in loss of government property, functioning essential operations and confinement of radioactive and hazardous material. Division 13, Section 1300, General Requirements, and Section 1324, Radioactive Solid Waste Facilities, address general and specific design criteria. Also, Section 0900-99.0, Nonreactor Nuclear Facilities, contains additional criteria relevant to facility design. All of these criteria provide minimally acceptable requirements for the facility design. It should be noted that the applicable local building codes and models always take

\footnotetext{
"The term "defense" nuclear facility has not been defined anywhere in the regulations or by the DOE yet. I have spoken with a number of people in the LMITCO Mechanical, Civil, and Industrial Engineering Department and the DOE-ID (David Crandall, Scott. Jensen, Lee Williams, and others) to learn what might constitute a "defense" nuclear facility and to find out the difference between a defense nuclear facility and a nuclear facility. They were not sure about the definition of a "defense" nuclear facility. However, they all believe that the facilities under consideration in this study could be considered "defense" nuclear facilities because they will be used for management of the DOE defense related wastes. According to Scott Jensen, the RWMC LLW disposal facility is considered a "defense" nuclear facility.
}

The definition of a nuclear facility is in MCP-2446. Based on this document, a "nuclear facility" is a facility with operations that involve radioactive and/or fissionable material in such form and quantity that a nuclear hazard potentially exits to the employees or the general public. A nuclear facility includes nonreactor and reactor facilities. 
precedence on the issues covered in the DOE order and provide additional design requirements not covered in the DOE order.

\section{DOE-ID, “Architectural Engineering Standards” (AE)}

The $\mathrm{AE}$ contains general design requirements such as those defined in $\mathrm{DOE}$ Order $6430.1 \mathrm{~A}$, and additional specific construction codes. The following is a list of some of the applicable standards and codes included in the AE documents:

ICBO UBC, "Uniform Building Code, latest edition"

ICBO UFC, "Uniform Fire Code, latest edition"

29 CFR 1910, "Occupational Safety and Health Standards"

29 CFR 1926, "Safety and Health Regulations for Construction"

ADAAG, "Americans with Disabilities Act (ADA) -- Accessibility Guidelines"

ASCE-4-86, "Seismic Analysis of Safety-Related Nuclear Structures"

ASCE-7-93, "Minimum Design Loads for Buildings and Structures"

DOE-STD-93, "Natural Phenomena Hazard Performance categorization"

DOE-STD-1020-94, "Natural Phenomena Hazard Design and Evaluation Criteria for Department of Energy Facilities"

DOE-STD-1021-93, "Natural Phenomena Hazards Performance Categorization Guidelines for Structures, Systems, and Components"

\section{DOE Order 5820.2A, "Radioactive Waste Management"}

DOE Order 5820.2A established policies and criteria for management of HLW, TRU, and LLW. The Order requires that radioactive and mixed waste be managed in a manner that is in compliance with all applicable Federal, State, and local environmental, safety, and health regulations and laws and DOE criteria.

Design objectives for facilities shall assure protection of the public and operating personnel from hazards associated with normal HLW operations, accident conditions, and the effects of natural phenomena. Other objectives are compliance with the DOE policies regarding nuclear safety, quality assurance, contingency plans, training, fire protection, pollution control, and safeguards and security protection for waste and protection of essential operations from the effects of potential accidents.

The development of large scale waste treatment facilities shall be supported by the appropriate documentation such as NEPA documentation, construction design report including projected waste throughputs, and treatment methods, construction and operating cost estimates, and Safety Analysis Report (SAR). 
All new HLW handling, transfer, and storage facilities shall be doubly contained. Where required, ventilation and filtration systems shall be provided to maintain radionuclide releases within the guidelines specified in DOE Order 5481.1B, "Safety Analysis and Review System", DOE Order 5480.23, "Nuclear Safety Analysis Report," and other applicable orders discussed in this EDF. Ventilation systems shall be provided where the possibility exists for generating flammable and explosive mixtures of gases (e.g., hydrogen or organic).

Nuclear criticality safety considerations and controls shall be evaluated for normal operations and, before any significant operational changes are made, to protect against an uncontrolled nuclear criticality incident. Each facility shall utilize remote maintenance features and other appropriate techniques to minimize personnel radiation exposure in accordance with DOE 5481.1B, "Environment, Safety, and Health Program for Department of Energy Operations," DOE Order 5480.23, and DOE Order 5480.24, "Nuclear Criticality Safety."

Monitoring, surveillance, and leak detection capability shall be incorporated in the engineering systems (e.g., liquid level sensing devices and alarms for high-level waste liquid systems) to provide rapid identification of failed containment, and measurement of abnormal temperatures. The following, at a minimum, shall be monitored: temperature; pressure; radioactivity in ventilation exhaust, and liquid effluent streams associated with HLW facilities. Where the possibility exists for the generation of flammable and explosive mixtures of gases, monitoring shall be conducted.

Training and qualification standards shall be developed and an up-to-date record of training status shall be maintained. Worker safety training must comply with the requirements of DOE 5480.1B and applicable Orders. Quality Assurance consistent with DOE Order 5700.6C, "Quality Assurance", shall be conducted in accordance with applicable requirements of the American National Standards Institute and other applicable codes.

As in HLW facilities, the TRU and LLW treatment and storage facilities must be equipped with monitoring, surveillance, and leak detection capabilities. The DOE Order 5820.2A requires that the TRU temporary storage area at the generator site, prior to shipment to the WIPP, be designed, constructed, operated, and monitored to minimize the possibility of fire, explosion, or accidental release of waste to the environment. The activities to assure the self storage of TRU waste shall also be consistent with the RCRA requirements and 40 CFR 191. In this study, no interim storage area is planned for the TRU waste because it expected that the TRU waste will be roadready for shipment to the WIPP. A temporary staging or package transfer area may be required for the waste container handling prior to the TRU waste transfer to the WIPP.

LLW disposal performance must be in a manner that assures external exposure to the waste and concentrations of radioactive material which may be released into surface water, ground, water, soil, plants and animals results in and effective dose equivalent that does not exceed $25 \mathrm{mrem} / \mathrm{yr}$ to any member of the public. Releases to the atmosphere shall meet the requirements of 40 CFR 61. Reasonable effort should be made to maintain releases of radioactivity in effluents to the general environment as low as is reasonably achievable. 


\section{DOE Order 435.1 (Draft), "Radioactive Waste Management"}

Currently, a draft DOE Order 435.1 has been issued by the DOE for review. This order will replace the current DOE Order 5820.2A, Radioactive Waste Management. The cancellation of this order does not, by itself modify or otherwise affect contractual obligation with the order. Therefore, the provisions of the $5820.2 \mathrm{~A}$ will remain in effect until the LMITCO contract is modified to delete the reference to the requirements in the canceled order.

DOE Order 435.1 requires that facility siting and design be in compliance with all federal, state, and local laws and regulations, and be performed in accordance with the requirements in DOE Manual 435.1, Radioactive Waste Management Manual, and with other applicable DOE Orders.

DOE Manual 435.1 further describes and establishes the requirements of DOE Order 435.1 for management of DOE HLW, TRU, and LLW. Based on the DOE Manual 435.1, waste storage, pre-treatment, and treatment facilities design and operation are required to comply with the following applicable Orders and regulations.

DOE O 151.1, "Comprehensive Emergency Management System"

DOE O 420.1", "Facility Safety"

DOE O 430.1, "Life-Cycle Asset Management"

DOE O 440.1, "Worker Protection Management for DOE Federal and Contractor Employees"

DOE O 460.1A, "Packaging and Transportation Safety"

DOE O 4330.4B, "Maintenance Management Program"

DOE O 5400.1, "General Environmental Protection Requirements"

DOE O 5400.5, "Radiation Protection of the Public and the Environment

DOE O 5480.19, "Conduct of Operations Requirements for DOE Facilities"

DOE O 5480.20A, "Personnel Selection, Qualification, and Training Requirements for DOE Nuclear Facilities"

DOE O 5480.21, "Unreviewed Safety Questions"

DOE O 5480.22, "Technical Safety Requirements"

DOE O 5480.23, "Nuclear Safety Analysis Reports"

DOE O 6430.1A, General Design Criteria"

10 CFR 820, "Procedural Rules for DOE Nuclear Activities"

10 CFR 830.120, "Quality Assurance Requirements 10 CFR 835, Occupational Radiation Protection"

10 CFR 1021, "National Environmental Policy Act Implementing Procedures"

29 CFR 1910, "Occupational Safety and Health Standards"

40 CFR 61, National Emission Standards for Hazardous Air Pollutants"

40 CFR 264, "Standards for Owners and Operators of Hazardous Waste Storage, Treatment, and Disposal Facilities"

40 CFR 265, "Interim Status Standards for Owners and Operators of Hazardous Waste Storage, Treatment, and Disposal Facilities"

'DOE Order 420.1 will replace DOE Order 5480.24, "Nuclear Criticality Safety." 
49 CFR 106 - 110 Subchapter A, "Hazardous Materials Transportation"

49 CFR 171-180 Subchapter C, "Hazardous Materials Regulations"

\section{DOE Order 5400.5, "Radiation Protection of the Public and the Environment"}

DOE Order 5400.5 establishes standards and requirements for operations of the DOE and contractors to protect the public and environment against undue risk from radiation

Chapter II, Requirements for Radiation Protection of the Public and the Environment, specifies that exposure of members of the public to radiation sources as a consequence of all routine DOE activities shall not cause, in a year, an effective dose equivalent greater than $100 \mathrm{mrem}$. The 100 mrem limit is the sum of the effective dose equivalent from exposure to radiation sources external to the body during the year plus the committed effective dose equivalent from radionuclides taken into the body (radioactive decay inside the body) during the year. Exposure of members of the public to radioactive materials released to the atmosphere as a consequence of routine DOE activities shall not cause members of the public to receive an effective dose equivalent greater than 10 mrem annually.

Chapter IV, Residual Radioactive Material, presents radiological protection requirements and guidelines for cleanup of residual radioactive material and management of the resulting residues and release of property. Basic dose limits, guidelines and authorized limits for allowable levels of residual radioactive material, and control of the radioactive wastes and residues are provided.

\section{DOE Order 5480.23, "Nuclear Safety Analysis Reports"}

This Order establishes requirements for DOE-owned nuclear facilities and operations, and for contractors responsible for the design, construction, operation, decontamination, or decommissioning of nuclear facilities to develop safety analyses that establish and evaluate the adequacy of the safety bases of the facilities. The SAR required by this Order documents the results of the safety analysis. 


\section{DOE Order 5480.28, "Natural Phenomena Hazard Mitigation"}

The requirements provided in this order shall be used in conjunction with the general design criteria in DOE 6430.1A and other departmental design criteria as applicable. DOE Order 5480.28 requires that facilities structures, systems, and components (SSCs) be designed and constructed to withstand the effects of natural phenomena hazards. An objective for all SSCs is to prevent loss of structural integrity endangering life safety. An additional objective for selected SSCs or site activities is to prevent loss of capability to perform functions consistent with: (1) importance to safety for workers and the public; (2) impact on the environment; (3) repair/replacement costs; or (4) programmatic mission.

\section{DOE Order 5700.6C, “Quality Assurance”}

The provisions of this Order apply to the work performed by all Departmental Elements and management and operating (M\&O) contractors as provided by law and/or contract and as implemented by the Department's Contracting Officer. If conflicts between this and other Departmental Orders exist, the quality assurance requirements of DOE $5700.6 \mathrm{C}$ take precedent. Work licensed by the NRC or an NRC Agreement State and subject to the quality assurance requirements of that agency are excluded from this Order.

\subsection{NATIONAL ENVIRONMENTAL POLICY ACT}

Under 10 CFR 1021, the NEPA establishes national policy procedures promoting awareness of the environmental impacts of major federal activities during the planning and decisionmaking stages of a project. The NEPA requires all agencies of the federal government prepare a detailed EIS describing potential effects of the proposed major federal actions that may be significantly affect the quality of the human environment.

All federal facilities under the NEPA are encouraged, to the extent practicable, to incorporate Pollution Prevention/Waste Minimization (P2/WMin) criteria and recycling in the planning stages and in the design of the new facilities or modifications to the existing facilities. The P2/WMin and recycling activities will make facilities more efficient and compatible with future environmental regulations and increase energy efficiency and conservation.

\subsection{OTHER STANDARDS AND CODES}

In addition to the requirements discussed above, this section provides a list of other applicable standard codes pertinent to health and safety. 


\section{1) General design of structures, systems, and components}

Uniform Building Code, International Conference of Building Officials American Institute of Steel Construction American Welding Society Standards American Concrete Institute DOE-ID Welding Procedure Specification Manual DOE-STD-1027-92, "Hazard Categorization and Accident Analysis Techniques" for Compliance with DOE Order 5480.23, "Nuclear Safety Analysis Reports"

The hazard categorization is based on a simple approach which is intended to meet DOE Order 5480.23 requirements for a preliminary assessment and hazard categorization. DOE Order 5480.23 , states that a hazard categorization of the DOE facilities is to be performed on processes, operations, or activities and not necessarily whole facilities.

DOE-STD-3007-93, “Guidelines for Preparing Criticality Safety Evaluations at Department of Energy Non-Reactor Nuclear Facilities"

DOE-STD-3009-94, "Preparation Guide for U.S. DOE Nonreactor Nuclear Facility Safety Analysis Reports"

\section{2) Radiological control design features}

INEL Radiological Control Manual 10 CFR 835e, "Occupational Radiation Protection"

\section{3) Fire design features}

Uniform Fire Code, Western Fire Chiefs Association and International conference of Building Officials

National Fire Protection Association (NFPA)

Uniform Building Code, Section 505 (e)

DOE Order 5480.7A, "Fire Protection"

\section{4) Seismic design feature, Flood design features, and Wind design features}

DOE-STD-1020-94(CH-1) Natural Phenomena Hazards Design and Evaluation Criteria for Department of Energy Facilities

40 CFR 264.18

40 CFR 270.14

\footnotetext{
'DOE Order 5480.11 has been canceled and replaced by 10 CFR 835 .
} 


\section{SUMMARY OF REGULATORY DRIVERS AND PERMIT REQUIREMENTS}

The following table presents a summary of the Federal and State regulatory requirements applicable to the construction and operations of the proposed facilities.

\begin{tabular}{|c|c|c|c|c|}
\hline $\begin{array}{l}\text { Media or type } \\
\text { of stream }\end{array}$ & $\begin{array}{c}\text { Requirements prior } \\
\text { to: }\end{array}$ & $\begin{array}{l}\text { Permit, approval, } \\
\text { or requirements }\end{array}$ & $\begin{array}{c}\text { Regulatory } \\
\text { Agency }\end{array}$ & Regulatory citation \\
\hline NEPA & $\begin{array}{l}\text { Title II Design and } \\
\text { procurement }\end{array}$ & NEPA documentation & DOE & 10 CFR 1021 \\
\hline $\begin{array}{l}\text { Nonrad air } \\
\text { emissions }\end{array}$ & Construction and operation & $\begin{array}{l}\text { PTC for new emission } \\
\text { sources }\end{array}$ & IDHW, EPA & $\begin{array}{l}40 \text { CFR } 50 \\
40 \text { CFR } 60 \\
40 \text { CFR } 62 \\
40 \text { CFR } 63 \\
40 \text { CFR } 70 \\
40 \text { CFR } 77 \\
40 \text { CFR } 124\end{array}$ \\
\hline $\begin{array}{l}\text { Nonrad air } \\
\text { emissions }\end{array}$ & Construction and operation & $\begin{array}{l}\text { NAAQS, PSD (if } \\
\text { significant emissions) }\end{array}$ & $\mathrm{IDHW}, \mathrm{EPA}$ & 40 CFR 52 \\
\hline $\begin{array}{l}\text { Nonrad air } \\
\text { emissions }\end{array}$ & Construction and operation & HAPs and TAPs & IDHW, EPA & $\begin{array}{l}40 \text { CFR } 61 \\
40 \text { CFR } 63 \\
\text { IDAPA } 16.01 .01\end{array}$ \\
\hline $\begin{array}{l}\text { Hazardous waste air } \\
\text { emissions }\end{array}$ & Construction and operation & $\begin{array}{l}\text { Treatment, storage, and } \\
\text { disposal facilities }\end{array}$ & IDHW, EPA & $\begin{array}{l}40 \text { CFR } 264,40 \text { CFR } 265 \\
\text { (Subparts AA, BB, and CC), } \\
\text { IDAPA } 16.01 .01 \\
\text { IDAPA } 16.01 .05\end{array}$ \\
\hline $\begin{array}{l}\text { Radioactive air } \\
\text { emissions }\end{array}$ & Construction and operation & NESHAPs & IDHW, EPA & $\begin{array}{l}40 \text { CFR 61, Subpart H } \\
\text { IDAPA } 16.01 .01\end{array}$ \\
\hline All air emissions & Operations & Air Operating Permit & IDHW, EPA & $\begin{array}{l}40 \text { CFR } 70 \\
\text { IDAPA } 16.01 .01\end{array}$ \\
\hline Asbestos & Renovation and demolition & $\begin{array}{l}\text { Notification prior to } \\
\text { renovation or demolition }\end{array}$ & IDHW, EPA & 40 CFR 61, Subpart M \\
\hline $\begin{array}{l}\text { Ozone depleting } \\
\text { substances }\end{array}$ & $\begin{array}{l}\text { Operation, reporting, } \\
\text { training }\end{array}$ & $\begin{array}{l}\text { Release prevention, } \\
\text { recovery/recycle, } \\
\text { Certificate labeling }\end{array}$ & IDHW, EPA & 40 CFR 82 \\
\hline $\begin{array}{l}\text { Sanitary wastewater } \\
\text { discharges }\end{array}$ & Discharges & NPDES Permit & EPA, IDHW & $\begin{array}{l}40 \text { CFR } 122, \text { and } 125 \\
\text { IDAPA } 16.01 .02\end{array}$ \\
\hline $\begin{array}{l}\text { Land surface } \\
\text { wastewater } \\
\text { discharges }\end{array}$ & $\begin{array}{l}\text { Construction and } \\
\text { Operations }\end{array}$ & NPDES Permit & EPA, IDHW & $\begin{array}{l}40 \text { CFR } 122 \\
\text { IDAPA } 16.01 .02\end{array}$ \\
\hline
\end{tabular}


431.02\#

$06 / 17 / 97$

Rev. \#04

\section{ENGINEERING DESIGN FILE}

Function File Number - SRP-WTS-02 EDF Serial Number - EDF-WTS-003

\begin{tabular}{|c|c|c|c|c|}
\hline $\begin{array}{l}\text { Storm wastewater } \\
\text { and nonstorm } \\
\text { wastewater } \\
\text { discharges }\end{array}$ & $\begin{array}{l}\text { Construction and } \\
\text { Operations }\end{array}$ & $\begin{array}{l}\text { NPDES Permit or } \\
\text { compliance with Idaho } \\
\text { Water Quality Standards }\end{array}$ & EPA & 40 CFR 122 \\
\hline $\begin{array}{l}\text { Drinking water } \\
\text { supply }\end{array}$ & $\begin{array}{l}\text { Construction and } \\
\text { operations }\end{array}$ & $\begin{array}{l}\text { Approval of Engineering } \\
\text { Plans, Cross Connection } \\
\text { Control Plans, Report, } \\
\text { and Spec. }\end{array}$ & IDHW, EPA & $\begin{array}{l}40 \text { CFR 141, } \\
40 \text { CFR 143, } \\
\text { IDAPA 16.01.08 }\end{array}$ \\
\hline $\begin{array}{l}\text { Hazardous waste } \\
\text { treatment, storage, } \\
\text { Disposal }\end{array}$ & $\begin{array}{l}\text { Construction, operation, } \\
\text { and maintenance of new } \\
\text { facilities or modifications } \\
\text { of existing facilities }\end{array}$ & $\begin{array}{l}\text { Hazardous Waste Permit } \\
\text { (Part A and B) }\end{array}$ & IDHW, EPA & $\begin{array}{l}40 \text { CFR } 270 \\
40 \text { CFR } 264 \\
40 \text { CFR } 265\end{array}$ \\
\hline $\begin{array}{l}\text { Underground } \\
\text { storage Tanks } \\
\text { (UTSs) }\end{array}$ & $\begin{array}{l}\text { Construction and } \\
\text { operations }\end{array}$ & Technical standards & IDHW, EPA & 40 CFR 280 \\
\hline $\begin{array}{l}\text { Land disposal of } \\
\text { waste }\end{array}$ & $\begin{array}{l}\text { Construction, operations, } \\
\text { disposal }\end{array}$ & LDRs & IDHW, EPA & $\begin{array}{l}40 \text { CFR } 268,40 \text { CFR } 257, \\
\text { IDAPA } 16.01 .05,10 \text { CFR } 61\end{array}$ \\
\hline
\end{tabular}

\section{SETTLEMENT AGREEMENT}

The State of Idaho and the DOE signed an agreement on October 16, 1995. The Agreement contains several commitments for the treatment of the HLW and SBW and their transfer out of Idaho. Based on the Agreement, all remaining liquid HLW must be calcined by June 30, 1998, and calcination of all SBW must be completed by December 31, 2012. The Agreement requires that all HLW be treated and be roadready to be moved out of Idaho for disposal by the year 2035. The calcination and the proposed treatment shall provide for completion of treatment of all calcine wastes by December 31, 2035.

It is stated in the Agreement that the DOE, as soon as practicable, commence the procurement of a treatment facility at INEEL for the treatment of mixed waste. The DOE shall execute a procurement contract for the Facility by June 1, 1997, complete construction of the Facility by December 31, 2002, and commence operation of the Facility by March 31, 2003. Commencement of construction is contingent upon Idaho approving necessary permits.

Based on the Agreement, the DOE shall accelerate efforts to evaluate alternatives for the treatment of calcined waste so as to put it into a form suitable for transport to a permanent repository or an interim storage facility outside Idaho. To support this effort, the DOE shall solicit proposals for feasibility studies by July 1, 1997, and shall commence negotiating a plan and schedule with the State of Idaho for calcine treatment by December 31, 1999. The plan and schedule shall provide for completion of the treatment of all calcined waste located at the INEEL by a date established by the Record of Decision (ROD) for the EIS that analyzes the alternatives for treatment of such waste. The State of Idaho expressly reserves its right to seek appropriate 
relief from the Court in the event that the date established in the ROD for the EIS that analyzes the alternatives for treatment of such waste is significantly later than the DOE's target date.

\section{NUCLEAR REGULATORY COMMISSION}

The purpose of this study is to provide an assessment of the current NRC regulations and their potential applicability to the proposed facilities if the facilities were to be licensed by the NRC in the future. The NRC requirement for regulating the DOE facilities or activities have not been defined yet. The requirements will need to be determined by the NRC and DOE Task Forces. Existing NRC regulations apply to commercial, non-DOE, facilities. The degree of applicability of the NRC requirements to the proposed facilities should be determined by the NRC and DOE, with input from the $\mathrm{DOE}$ contractor. If $\mathrm{DOE}$ facilities become regulated by $\mathrm{NRC}$, the jurisdiction of other currently government applicable authorities will not automatically or necessarily cease. In particular, it is expected that local, State, Federal EPA, and some DOE regulatory requirements would still apply.

Currently, the NRC is not authorized by law to license DOE facilities for:

- $\mathrm{HLW}$ processing such as those for vitrification, solidification, $\mathrm{Cs}$ and $\mathrm{Sr}$ extraction,

- short term storage of HLW, for TRU waste storage and disposal from DOE activities, and

- DOE LLW processing, storage, and disposal.

However, based on the recent DOE proposal, the NRC could take responsibilities for regulating the DOE nuclear facilities. Existing NRC regulations are compiled in 10 CFR, titled "Energy". These regulations follow a similar philosophy as the DOE, the EPA, and other codes and standards previously discussed above. The Commission has also issued a number of regulatory guides (e.g., NUREG) and other guidance documents which provide acceptable methods for complying with the NRC regulations. They contain criteria for facility design, operations, and for safety and health.

Of the existing NRC regulations, it has been determined in this study that 10 CFR 61 will apply to the proposed LAW or the LLW disposal facility, and 10 CFR 72 will be applicable to the proposed interim storage facilities for the vitrified, HIPed, or grouted $H L W$, and for the liquid HAW and vitrified HAW storage facilities. Independently, it was determined by Leroy and Morgan in "Nuclear Regulatory Commission (NRC) Licensing Assessment for the Idaho National Engineering and Environmental Laboratory (INEEL) High-Level Waste program," April 23, 1997, that 10 CFR 30 and 10 CFR 70 will apply to the following facilities:

- 10 CFR 30 for the LAW collection and grouting facilities and for the collection and treatment of the LLW from the INEEL ongoing operations. 
- 10 CFR 70 for the separations facility, for the interim storage of liquid HAW from the separation processes, and for the HAW vitrification facility.

- 10 CFR 70 for the HLW vitrification, HIPing, or grouting facilities.

- 10 CFR 70 for the calcine retrieval and dissolution facilities.

I 10 CFR 30, "Rules of General Applicability to Domestic Licensing of Byproduct Material", and 10 CFR 70, "Domestic Licensing of Special Nuclear Material", are not specifically or directly applicable to the facilities listed above. According to Steve LeRoy (personal communication, $12 / 03 / 97$ ), they are the only ones which came close to being applicable to the proposed treatment, separations, and retrieval facilities. It is believed that certain elements of 10 CFR 30 and 10 CFR 70 could potentially be applicable to licensing of the proposed facilities. The fact remains that NRC will most likely have to promulgate new regulations specifically for the DOE HLW, LLW, and calcine retrieval and treatment facilities or to revise the requirements of 10 CFR 30 and 10 CFR 70 if they were to apply them to the proposed facilities.

Additional NRC regulations that are applicable to all of the proposed facilities are in $10 \mathrm{CFR} 2$, 10 CFR 19, 10 CFR 20, 10 CFR 21, 10 CFR 50, 10 CFR 51, 10 CFR 52, and 10 CFR 73. 10 CFR 71 and 49 CFR 173 (Department of Transportation) contain requirements for the packaging and transportation of radioactive wastes. These requirements would have impact on the design and operations of the storage facilities.

Appendix A provides a detailed source list of the regulations used by the NRC in commercial, non-reactor, nuclear facilities. The regulations are primarily based on the health and safety considerations. The list includes applicable parts and subparts of 10 CFR 20,21,30,50,51,61, 70 , and 72 as well as related guidance documents. The requirements and guidance documents are listed under the following categories: 1) radioactive waste management ,2) design of structures, components, equipment, and systems, 3) electric power, utility services, and fire protection, 4) radiation protection, 5) conduct of operation, 6) safety analysis report criteria, 7) quality assurance, and 8 ) decommissioning.

The existing facilities that will be modified to be used for storage of HLW are expected to be exempted by DOE from any further jurisdiction of NRC. Such a jurisdiction would be excessively difficult, costly, and complex to apply. All the work requirements for the modification of the existing facilities are expected to be performed in accordance with the DOE/RW/0333P, "Quality Assurance Requirements and Description." The requirements in DOE/RW/0333P are endorsed by the Office of Civilian Radioactive Waste Management (OCRWM) which carries out the DOE mission for safe design and operation of a HLW geologic repository and a HLW storage facility.

\footnotetext{
'Byproduct material means any radioactive material (except special nuclear material) yielded in or made radioactive by exposure to the radiation incident to the process of producing or utilizing special nuclear material. Special nuclear material means (1) plutonium, uranium 233, uranium enriched in the isotope 233 or in the isotope 235, and any other material which the Commission determines to be special nuclear material, but does not include source material; or.(2) any material artificially enriched by any of the foregoing but does not include source material.
} 
431.02\#

$06 / 17 / 97$

Rev. \#04
ENGINEERING DESIGN FILE
Function File Number - SRP-WTS-02

EDF Serial Number - EDF-WTS-003

Page 24 of 44

\section{Current Licensing Process}

Most of the discussion in this section is based on the information contained in the DOE-STD101-92, "Compilation of Nuclear Safety Criteria Potential Application to the DOE Nonreactor Facilities" and in the report by Morgan and LeRoy, "Nuclear Regulatory Commission (NRC) Licensing Assessment for the Idaho National Engineering and Environmental Laboratory (INEEL) High-Level Waste program," April 23, 1997.

The applicable NRC regulations that define licensing processes are in 10 CFR 2, 10 CFR 30, 10 CFR 51, and 10 CFR 61 for LLW facilities and in 10 CFR 2, 10 CFR 50, 10 CFR 52, 10 CFR 70, and $10 \mathrm{CFR} 72$ for HLW or HAW facilities. The licensing of a nuclear facility requires preparation and submittal of an application and a number of supporting documents to the NRC such as SAR, environmental report (ER), quality assurance document, training plan, monitoring plan, and safeguards and security plan. The following is a generic description of the various documents that will be applicable to the proposed facilities.

The ER must meet the NRC requirements in 10 CFR 51. Appendix A, Section 7 provides regulatory sources containing quality assurance procedures for the facility design, construction, and operations. The quality assurance requirements in DOE/RW-0333P are expected to be used for the existing facilities that will be modified to be used for storage of HLW or HAW. The SAR documents the adequacy of safety analysis for a nuclear facility to ensure that the facility can be designed, constructed, operated, maintained, shut down, and decommissioned safely and in compliance with applicable laws and regulations. The SAR criteria must meet the regulations listed in Appendix A, Section 6. The training, monitoring, and safeguards and security plans used by the license applicant to protect health and minimize danger to life or property must be developed in accordance with the applicable regulations. The training program should include an analysis of the job, learning objectives and performance criteria, procedures for personnel monitoring, procedures to avoid accidents, etc. It is assumed that the DOE will retain the responsibility for safeguard and security for its facilities.

The NRC licensing process is divided into four stages: pre-application stage, application review stage, construction and operating license stage, and decontamination and site closure stage. The licensing duration from submittal of the application to receipt of the license is expected to take three to five years or longer.

Pre-application stage is prior to filing a license application with the NRC. It entails the development of the license application and the pre-submittal communications with the NRC. This includes the NRC and DOE interactions to clearly define the NRC acceptance criteria against which the ICPP proposed facilities license application will be reviewed.

The application review stage describes the activities after submittal of the license application to the NRC. A notification will be published in the Federal Register for public hearing when the $\mathrm{NRC}$ receives the application. This application review stage begins with a review process 
referred to as a "Docketing Review" which is usually performed within 1 to 3 months. This review is to ensure that the application is complete and contains the necessary information. The Docketing Review process is followed by a detailed safety review of the application by the NRC staff. The NRC will ensure that the regulatory requirements are met as established in the regulations. The NRC usually requests additional information during this review which can be extensive and delay the review. Submittal of high quality, complete, and detailed SAR will reduce the request for additional information, hence the review time.

The construction and operating license stage follows the receipt of the license. The NRC will have the regulatory oversight during construction and operations.

NRC issues a license for certain time period. Before a facility license expires, a decommissioning plan will be developed by the DOE for review by the NRC. It is expected that the EPA will regulate the decontamination and decommissioning activities. Before the final closure, the DOE must submit a closure plan to the NRC for review. The closure plan must describe how the owner/operator will conduct clean-up, what clean-up levels will be attained, and how clean-up will be verified. The plan also includes a post-closure, and long term monitoring and maintenance. Upon review and acceptance, the NRC will authorize closure. Monitoring will be performed during the post-closure plan in accordance with the applicable requirements. When all the monitoring and control requirements are met, the license will be terminated.

\section{LLW Near-Surface Disposal}

\section{CFR 61, Licensing Requirements for Land Disposal of Radioactive Waste}

10 CFR 61 contains specific technical requirements and performance objectives applicable to near-surface disposal of radioactive wastes. It contains requirements for design, operation, closure and post-closure, and monitoring. Near-surface disposal involves disposal of waste in the uppermost portion of the earth, approximately 30 meters or 100 feet of natural grade. The NRC maintains that the use of shallow land disposal is adequate for protection of individuals and the public, when properly sited, designed, and operated, as required by 10 CFR 61 .

Design, operation, and closure of the land disposal facility must ensure protection of any individual inadvertently intruding into the disposal site and occupying the site or contacting the waste at any time after active institutional controls over the disposal site are removed. Operations at the land disposal facility must be conducted in compliance with the standards for radiation protection set in 10 CFR 20 , except for releases of radioactivity in effluents from the land disposal facility, which shall be governed by 10 CFR 61.41. At the time a license application is submitted, the applicant shall have conducted a preoperational monitoring program to provide basic environmental data on the disposal site characteristics. The applicant shall obtain information about the ecology, meteorology, climate, hydrology, geology, geochemistry, and seismology of the disposal site. For those characteristics that are subject to seasonal variation, data must cover at least a twelve month period. 
The regulations for near surface disposal of radioactive wastes include a waste classification system which divides the wastes into three classes: Class $\mathrm{A}, \mathrm{B}$, and $\mathrm{C}$. The classification system is based on the overall disposal hazards of the wastes. Certain minimum requirements must be met for all waste Classes as provided in $10 \mathrm{CFR}$ 61.56 (a). In addition, Class B and C wastes are required to have structural stability as discussed in $10 \mathrm{CFR} 61.56(\mathrm{~b})$. The detailed information regarding the NRC requirements for a LLW disposal facility can be found in EDF-FDO-008.

\section{HUW Storage}

10 CFR 72, "Licensing Requirements for the Independent Storage of Spent Nuclear Fuel and High-Level Radioactive Waste"

10 CFR 72 contains regulations and procedures that are applicable to HLW or HAW interim storage facilities. The regulations in this part establish requirements for the issuance of licenses to the DOE to receive, transfer, package, and possess HLW, spent fuel, and other radioactive materials associated with spent fuel and $\mathrm{HLW}$ storage, in a monitored retrievable storage facility (MRS)g. This part also defines requirements for the safety design features of the facility structure and equipment. It requires that structures, systems, and components be designed, fabricated, erected, and tested to provide protection against environmental conditions and natural phenomena such as earthquakes, tornadoes, lighting, hurricanes, and floods. The facilities should also be designed to prevent massive collapse of building structures or the dropping of heavy objects as a result of building structural failure on the spent fuel or high-level radioactive waste or on to structures, systems, and components important to safety. If the facilities are located over an aquifer which is a major water resource, measures must be taken to preclude the transport of radioactive materials to the environment through this potential pathway.

Structures, systems, and components against fires and explosions must be designed and located so that they can continue to perform their safety functions effectively under credible fire and explosion exposure conditions. Noncombustible and heat-resistant materials must be used wherever practical, particularly in locations vital to the control of radioactive materials and to the maintenance of safety control functions. Explosion and fire detection, alarm, and suppression systems shall be designed and provided with sufficient capacity and capability to minimize the adverse effects of fires and explosions on structures, systems, and components important to safety.

Other features that are important to safety must be designed to permit inspection, maintenance, and testing. Emergency capability must be designed to provide for accessibility to the equipment of onsite and available offsite emergency facilities and services such as hospitals, fire and police departments, ambulance service, and other emergency agencies.

\footnotetext{
${ }^{g}$ Pursuant to the Nuclear Waste Policy Act, a MRS is an option for providing safe and reliable long-term storage of HLW or spent nuclear fuel. However, disposal of HLW and spent fuel in a repository should proceed regardless of any construction of a MRS pursuant to the Act.
} 
Ventilation systems and off-gas systems must be provided where necessary to ensure the confinement of airborne radioactive particulate materials during normal or off-normal conditions. Storage confinement systems must have the capability for continuous monitoring in a manner such that the licensee will be able to determine when corrective action needs to be taken to maintain safe storage conditions. Instrumentation and control systems must be provided to monitor systems that are important to safety over anticipated ranges for normal operation and offnormal operation. Those instruments and control systems that must remain operational under accident conditions must be identified in the SAR.

Control room or control area must be designed to permit occupancy and actions to be taken to monitor the facilities under normal conditions, and to provide safe control of the facilities under off-normal or accident conditions. Utility or other services must be designed to meet emergency conditions.

It is required that $\mathrm{HLW}$ be packaged in a manner that allows handling and retrievability without the release of radioactive materials to the environment or radiation exposures in excess of 10 CFR 20, "Standards for Protection Against Radiation", limits. The package must be designed to confine the high-level radioactive waste for the duration of the license. During normal operations and anticipated occurrences, the annual dose equivalent to any real individual who is located beyond the controlled area must not exceed $25 \mathrm{mrem}$ to the whole body, $75 \mathrm{mrem}$ to the thyroid and $25 \mathrm{mrem}$ to any other organ as a result of exposure to planned discharges of radioactive materials and decay products excepted, to the general environment, and direct radiation from operations. Operational restrictions must be established to meet as low as is reasonably achievable (ALARA) objectives for radioactive materials in effluents and direct radiation levels associated with storage operations. Operational limits must be established for radioactive materials in effluents and direct radiation levels associated operations to meet the limits given above.

10 CFR 72.124, "Criteria for nuclear criticality safety"

The design of handling, packaging, transfer, and storage systems must include margins of safety for the nuclear criticality parameters that are commensurate with the uncertainties in the data and methods used in calculations. It must demonstrate safety for the handling, packaging, transfer and storage conditions and in the nature of the immediate environment under accident conditions.

When practicable the design of an MRS must be based on favorable geometry, permanently fixed neutron absorbing materials (poisons), or both. Where solid neutron absorbing materials are used, the design shall provide for positive means to verify their continued efficacy.

A criticality monitoring system shall be maintained in each area where special nuclear material is handled, used, or stored which will energize clearly audible alarm signals if accidental criticality occurs. Monitoring of dry storage areas where special nuclear material is packaged in its stored configuration under a license issued under this subpart is not required. 
10 CFR 72.128, "Criteria for spent fuel, high-level radioactive waste, and other radioactive waste storage and handling"

The regulations of this subpart require that $\mathrm{HLW}$ storage and other systems that might contain or handle radioactive materials be designed to ensure adequate safety under normal and accident conditions. These systems must be designed with: (1) a capability to test and monitor components important to safety, and suitable shielding for radioactive protection under normal and accident conditions, (2) confinement systems, (3) a heat-removal capability having testability and reliability consistent with its importance to safety, and (4) means to minimize the quantity of radioactive wastes generated. Provisions must be made for the packing of site-generated lowlevel wastes in a form suitable for storage onsite awaiting transfer to disposal sites. 


\section{APPENDIX A}

The following lists the current NRC requirements and guides applied to the areas of safety addressed in the SAR. The requirements are listed under the following categories: 1) radioactive waste management , 2) design of structures, components, equipment, and systems, 3) electric power, utility services, and fire protection, 4) radiation protection, 5) conduct of operation, 6) safety analysis report criteria, 7) quality assurance, and 8) decommissioning.

\section{1) Radioactive waste management}

This section identifies criteria for the control, collection, handling, processing, storage, and disposal of liquid, gaseous, and solid wastes that may contain radioactive materials, and the instrumentation used to monitor the release of radioactive materials. Also, as previously discussed, all RCRA hazardous and radioactive waste (mixed waste) management facilities are also subject to EPA RCRA regulations.

10 CFR 30, "Rules of General Applicability to Domestic Licensing of Byproduct Material"

10 CFR 61, "Licensing Requirements for Land Disposal of Radioactive Waste"

10 CFR 70.59, "Effluent Monitoring Reporting Requirements"

10 CFR 72.104, "Criteria in Effluents and Direct Radiation in Effluents and Direct Radiation from an ISFSI or MRS"

D. 10 CFR 72.128, "Criteria for Spent Fuel, High-Level Radioactive Waste, and Other Radioactive Waste Storage and Handling"

Regulatory Guide 1.21, "Measuring, Evaluating, and Reporting Radioactivity in Solid Wastes and Releases of Radioactive Materials in Liquid and Gaseous Effluents from Light-WaterCooled Nuclear Power Plants."

Regulatory Guide 1.143, "Design Guidance for Radioactive Waste Management Systems, Structures, and Components Installed in Light-Water-Cooled Nuclear Power Plants."

Regulatory Guide 3.10, "Liquid Waste Treatment Design Guide for Plutonium Processing and Fuel Fabrication Plants."

Regulatory Guide 3.13, "Guide for Acceptable Waste Storage Methods at UF6 Production Plants."

Regulatory Guide 3.20, "Process Off-gas Systems for Fuel Reprocessing Plants." 
Regulatory Guide 3.49, "Design of an Independent Spent Fuel Storage Installation (Water-Basin Type)."

Regulatory Guide 3.60, "Design of an Independent Spent Fuel Storage Installation (Dry Storage)."

Regulatory Guide 4.18, "Standard Format and Contents of Environmental Reports for Nearsurface Disposal of Radioactive Waste."

NUREG-1199, "Standard Format and Content of a License Application for a Low-level Radioactive Waste Disposal Facility."

NUREG-1200, "Standard Review Plan for the Review of a License Application for a Radioactive Low-level Waste Disposal Facility."

NUREG-1300, "Standard Review Plan for the Review of a License Application for a Radioactive Low-level Waste Disposal Facility."

NUREG-0800, Section 11.2, "Liquid Waste Management Systems."

NUREG-0800, Section 11.3, “Gaseous Waste Management Systems.”

NUREG-0800, Section 11.4, "Solid Waste Management Systems."

NUREG-0800, Section 11.5, "Process and Effluents radiological Monitoring."

NUREG-1567, "Offgas Treatment and Ventilation."

\section{2) Design of structures, components, equipment and systems}

10 CFR 21, "Reporting of Defects and Noncompliance"

10 CFR 50.34, "Contents of Applications: Technical Information"

10 CFR 50, Appendix F, "Policy Relating to the Siting of Fuel Reprocessing Plants and Related Waste Management Facilities"

10 CFR 61.51, "Disposal Site Design for Land Disposal"

10 CFR 61.52, "Land Disposal Facility Operation and Disposal Site Closure"

10 CFR 61.54, "Alternative Requirements for Design and Operations" 
10 CFR 70, "Domestic Licensing of Special Nuclear material"

10 CFR 72, "Licensing Requirements for the Independent Storage of Spent Nuclear Fuel and High-Level Radioactive Waste"

10 CFR 72.120, "General Considerations"

10 CFR 72.122, "Overall Requirements"

10 CFR 72.124, "Criteria for Nuclear Criticality Safety"

10 CFR 72.126, "Criteria for Radiological Protection"

10 CFR 72.128, "Criteria for Spent Fuel, High-Level Radioactive Waste, and Other Radioactive Waste Storage and Hand-ling"

10 CFR 72.130, "Criteria for Decommissioning"

Regulatory Guide, 3.10, "Liquid Waste Treatment System Design Guide for Plutonium Processing and Fuel Fabrication Plants."

Regulatory Guide 3.12, "General Design Guide for Ventilation Systems of Plutonium Processing and Fuel Fabrication Plants."

Regulatory Guide 3.20, "Process Off-gas Systems for Fuel Reprocessing Plants"

Regulatory Guide 3.32, "General Design Guide for Ventilation Systems for Fuel Reprocessing Plants."

Regulatory Guide 3.38, "General Fire Protection Guide for Fuel Reprocessing Plants."

Regulatory Guide 3.56, "General Guidance for Designing, Testing, Operating, and Maintaining Emission Control Devices at Uranium Mills."

Regulatory Guide 5.25, "Design Considerations for Minimizing Residual Holdups of Special Nuclear Material in Equipment for Wet process Operations."

\section{$\underline{\text { Seismic systems criteria }}$}

10 CFR 61.12, "Specific Technical Information"

10 CFR 72.120, "General Considerations"

Regulatory Guide 1.29, "Seismic Design Classification." 
Regulatory Guide 3.14, "Seismic Design Classification for Plutonium Processing and Fuel Fabrication Plants.

\section{Wind and Tornado Loading criteria}

10 CFR 61.12, "Specific Technical Information"

10 CFR 72.40, "Issuance of License"

10 CFR 72.90, "General Considerations"

10 CFR 72.92, "Design Basis External Natural Events"

10 CFR 72.98, "Identifying Regions Around an ISFSI or MRS Site"

10 CFR 72.122, "Overall Requirements"

Regulatory Guide 1.76, "Design Basis Tornado for Nuclear Power Plants."

Regulatory Guide 3.10, "Liquid Waste Treatment Design Guide for Plutonium Processing and Fuel Fabrication Plants."

Regulatory Guide 3.12, "General Design Guide for Ventilation Systems of Plutonium Processing and Fuel Fabrication Plants."

Regulatory Guide 3.16, "General Fire Protection Guide for Plutonium Processing and Fuel Fabrication Plants."

Regulatory Guide 3.18, "Confinement Barriers and Systems for Fuel Reprocessing Plants.

Regulatory Guide 3.20, "Process Offgas Systems for Fuel Reprocessing Plants."

Regulatory Guide 3.31, "Emergency Water Supply Systems for Fuel Reprocessing Plants."

Regulatory Guide 3.32, "General Design Guide for Ventilation Systems for Fuel Reprocessing Plants."

Regulatory Guide 3.38, "General Fire Protection Guide for Fuel Reprocessing Plants."

Regulatory Guide 3.49, "Design of an Independent Spent Fuel Storage Installation, (Water Basin Type)." 
Regulatory Guide 3.53, "Applicability of Existing Regulatory Guides to the Design and Operation of an Independent Spent Fuel Storage Installation."

Regulatory Guide 3.60, "Design of an Independent Spent Fuel Storage Installation (Dry Storage)."

NUREG/CR-3874, "Near-Ground Tornado Wind Fields," McDonald, J.R., Texas Tech. University, July 1984.

NUREG/CR-3848, "Experimental Investigation of Unsteady Tornadic Wind Loads on Structures," Jischke, M.C., Oklahoma Teaching Hospitals, June 1984.

NUREG/CR-3058, "A Methodology for Tornado Hazard Probability Assessment," McDonald, J.R., Texas Tech. University, October 1983.

NUREG/CR-2944, "Tornado Damage Risk Assessment," Reinhold, T.A. and Ellingwood, B., National Bureau of Standards, February 1983.

NUREG/CR-2565, "Structural Performance of HEPA Filters Under Simulated Tornado Conditions," Horak, H.L. and Smith, P.R., Los Alamos National Laboratory, May 1982.

NUREG/CR-2014, "Kinematics of Translating Tornado Wind Fields," Peterson, R.E., Texas Tech. University, April 1981.

NUREG/CR-1585, "Modeling Tomado Dynamics," Aeronautical Research Association, September 1980.

\section{Water level (flood) design}

10 CFR 61.12, "Specific Technical Information"

10 CFR 61.50, "Disposal Site Suitability Requirements for Land Disposal"

10 CFR 72.40, "Issuance of License"

10 CFR 72.90, "General Considerations"

10 CFR 72.92, "Design Basis External Natural Events"

10 CFR 72.94, "Design Basis External Man-Induced Events"

10 CFR 72.98, "Identifying regions Around and ISFSI or MRS Site"

10 CFR 72.122, “Overall Requirements" 
Regulatory Guide 3.10, "Liquid Waste Treatment Design Guide for Plutonium Processing and Fuel Fabrication Plants."

Regulatory Guide 3.11, "Design, Construction, and Inspection of Embankment Retention Systems for Uranium Mills."

Regulatory Guide 3.18, "Confinement Barriers and Systems for Fuel Reprocessing Plants.

Regulatory Guide 3.31, "Emergency Water Supply Systems for Fuel Reprocessing Plants."

Regulatory Guide 3.40, "Design Basis Floods for Fuel Reprocessing Plants and for Plutonium Processing and Fuel Fabrication Plants."

Regulatory Guide 3.49, "Design of an Independent Spent Fuel Storage Installation, (Water Basin Type)."

Regulatory Guide 3.53, "Applicability of Existing Regulatory Guides to the Design and Operation of an Independent Spent Fuel Storage Installation."

Regulatory Guide 3.60, "Design of an Independent Spent Fuel Storage Installation (Dry Storage)."

NUREG/CR-2678, "Flood Risk Analysis Methodology Development Project - Final Report," Wagner, D.P. et al., Oak Ridge National Laboratory, July 1982.

\section{Missile protection}

10 CFR 61.12, "Specific Technical Information"

10 CFR 72.40, "Issuance of License"

10 CFR 72.90, "General Considerations"

10 CFR 72.92, "Design Basis External Natural Events"

10 CFR 72.94, "Design Basis External Man-Induced Events"

10 CFR 72.98, "Identifying Regions Around an ISFSI or MRS Site"

10 CFR 72.122, "Overall Requirements"

Regulatory Guide 3.10, "Liquid Waste Treatment Design Guide for Plutonium Processing and Fuel Fabrication Plants." 
Regulatory Guide 3.12, "General Design Guide for Ventilation Systems of Plutonium Processing and Fuel Fabrication Plants."

Regulatory Guide 3.16, "General Fire Protection Guide for Plutonium Processing and Fuel Fabrication Plants."

Regulatory Guide 3.18, "Confinement Barriers and Systems for Fuel Reprocessing Plants." Regulatory Guide 3.20, "Process Off-gas Systems for Fuel Reprocessing Plants." Regulatory Guide 3.31, "Emergency Water Supply Systems for Fuel Reprocessing Plants." Regulatory Guide 3.32, "General Design Guide for Ventilation Systems for Fuel Reprocessing Plants."

Regulatory Guide 3.38, "General Fire Protection Guide for Fuel Reprocessing Plants."

Regulatory Guide 3.49, "Design of an Independent Spent Fuel Storage Installation, (Water Basin Type)."

Regulatory Guide 3.53, "Applicability of Existing Regulatory Guides to the Design and Operation of an Independent Spent Fuel Storage Installation."

Regulatory Guide 3.60, "Design of an Independent Spent Fuel Storage Installation (Dry Storage)."

NUREG-0533, "Aircraft Impact risk Assessment, Data Base for Assessment of Air Carrier Impact Risk in the Vicinity of Airports," USNRC, July 1979.

NUREG/CR-2462, "Capacity of Nuclear Power Plant Structures to Resist Blast Loading," Kennedy, R.P. et al., Sandia National Laboratories, September 1983.

NUREG/CR-2859, "Evaluation of Aircraft Crash Hazards for Nuclear Power Plants," Kot, C.A. et al., Argonne National Laboratory, September 1982.

\section{$\underline{\text { Seismic design }}$}

10 CFR 61.12, "Specific Technical Information"

10 CFR 70.22, "Contents of Applications"

10 CFR 70.23, "Requirements for the Approval of Applications" 
10 CFR 72.40, "Issuance of License"

10 CFR 72.90, “General Considerations”

10 CFR 72.92, "Design Basis External Natural Events"

10 CFR 72.98, "Identifying Regions Around an ISFSI or MRS Site"

10 CFR 72.102 "Geological and Seismological Characteristics"

10 CFR 72.122, “Overall Requirements"

Regulatory Guide 3.10, "Liquid Waste Treatment Design Guide for Plutonium Processing and Fuel Fabrication Plants."

Regulatory Guide 3.12, "General Design Guide for Ventilation Systems of Plutonium Processing and Fuel Fabrication Plants."

Regulatory Guide 3.14, "Seismic Design Classification for Plutonium Processing and Fuel Fabrication Plants."

Regulatory Guide 3.16, "General Fire Protection Guide for Plutonium Processing and Fuel Fabrication Plants."

Regulatory Guide 3.17, "Earthquake Instrumentation for Fuel Reprocessing Plants."

Regulatory Guide 3.18, "Confinement Barriers and Systems for Fuel Reprocessing Plants.

Regulatory Guide 3.20, "Process Off-gas Systems for Fuel Reprocessing Plants."

Regulatory Guide 3.31, "Emergency Water Supply Systems for Fuel Reprocessing Plants."

Regulatory Guide 3.32, "General Design Guide for Ventilation Systems for Fuel Reprocessing Plants."

Regulatory Guide 3.38, "General Fire Protection Guide for Fuel Reprocessing Plants."

Regulatory Guide 3.49, "Design of an Independent Spent Fuel Storage Installation, (Water Basin Type)."

Regulatory Guide 3.53, "Applicability of Existing Regulatory Guides to the Design and Operation of an Independent Spent Fuel Storage Installation."

Regulatory Guide 3.60, "Design of an Independent Spent Fuel Storage Installation (Dry Storage)." 
NUREG/CR-1069, "Effects of Earthquakes on Underground Facilities: Literature Review and Discussion," Carpenter, D.W. and Chung, D.C., Lawrence Livermore National Laboratory, June 1986.

\section{Ventilation and process off-gas systems}

10 CFR 72.132, "Overall Requirements"

Regulatory Guide 1.140, "Design, Testing, and Maintenance for Normal Ventilation Systems."

Regulatory Guide 1.52, "Design, Testing, and Maintenance a Criteria for Post-accident engineered Safety Feature Ventilation Systems."

Regulatory Guide 3.12, "General Design Guide for Ventilation Systems of Plutonium Processing and Fuel Fabrication Plants."

Regulatory Guide 3.20, "Process Off-gas Systems for Fuel Reprocessing Plants."

Regulatory Guide 3.32, "General Design Guide for Ventilation Systems for Fuel Reprocessing Plants."

Regulatory Guide 3.49, "Design of an Independent Spent Fuel Storage Installation (Water Basin Type)."

Regulatory Guide 3.60, "Design of an Independent Spent Fuel Storage Installation (Dry Storage)."

NUREG-1567, Section 11.4.1.3 (DRAFT), "Ventilation offgas System Design Feature."

\section{3) Electrical power, utility services, and fire protection}

10 CFR 50.55(a), "Codes and Standards"

10 CFR 72.122, "Overall Requirements"

Regulatory Guide 1.108, "Periodic Testing of Diesel Generator Units Used as Onsite Electric Power Systems at Nuclear Power Plants."

Regulatory Guide 3.14, "Seismic Design Classification for Plutonium Processing and Fuel Fabrication Plants." 
Regulatory Guide 3.16, "General Fire Protection Guide for Plutonium Processing and Fuel Fabrication Plants."

Regulatory Guide 3.38, "General Fire Protection Guide for Fuel Reprocessing Plants."

\section{4) Radiation protection}

The criteria identified in this chapter are for the radiation protection of operating, construction, and maintenance personnel during normal and anticipated operational occurrences. The compilation includes criteria for facility equipment design and programs to minimize and monitor radiation exposure to meet the standards for protection against radiation of 10 CFR 20 .

10 CFR 19.12, "Instructions to Workers"

10 CFR 20, "Standards for Protection Against Radiation"

10 CFR 61.41, "Protection of the General Population From Releases of Radioactivity"

10 CFR 61.43, "Protection of Individuals During Operations"

10 CFR 72.44, "License Conditions"

10 CFR 72.104, "Criteria for Radioactive Materials in Effluents and Direct Radiation from an ISFSI or MRS"

10 CFR 72.126, "Criteria for Radiological Protection"

Regulatory Guide 3.6, "Content of Technical Specifications for Fuel Reprocessing Plants."

Regulatory Guide 8.1, "Radiation Symbol."

Regulatory Guide 8.2, "Administrative Practices in Radiation Monitoring."

Regulatory Guide 8.10, “Operating Philosophy for Maintaining Occupational Radiation Exposures as Low as is Reasonably Achievable."

Regulatory Guide 8.24, "Health Physics Surveys During Enriched Uranium Processing and Fuel Fabrication."

\section{5) Conduct of operations}

The criteria identified in this chapter address training, emergency planning, plant procedures, and the maintenance of records and reporting. 
10 CFR 61, "Licensing Requirements for Land Disposal of Radioactive Waste"

10 CFRR 51, "Environmental Protection Regulations for Domestic Licensing and Related Regulatory Functions"

10 CFR 70, "Domestic Licensing of Special Nuclear Material"

10 CFR 72.190, "Operator Requirements"

10 CFR 72.192, "Operator Training and Certification Program"

10 CFR 72.194, "Physical Requirements."

Regulatory Guide 3.28, "Welder Qualification for Welding in Areas of Limited Accessibility in Fuel Reprocessing Plants and in Plutonium Processing and Fuel Fabrication Plants."

Regulatory Guide 3.42, "Emergency Planning for Fuel Cycle Facilities and Plants Licensed Under 10 CFR Parts 50 and 70.

\section{6) Safety analysis report criteria}

10 CFR 20, "Standards for Protection Against Radiation"

10 CFR 30, "Rules of General Applicability to Domestic Licensing of Byproduct Material"

10 CFR 50.33, "Contents of Application, General Information"

10 CFR 50.36(b), "Environmental Conditions"

10 CFR 50.55, "Conditions of Construction Permits"

10 CFR 50.71, "Maintenance of Records, making Reports"

10 CFR 61, "Licensing Requirements for Land Disposal of Radioactive Waste"

10 CFR 61.10, "Contents of Application"

10 CFR 70, "Domestic Licensing of Special Nuclear Material"

10 CFR 70.22, "Contents of Application"

10 CFR 70.23, "Requirements for the Approval of Applications" 
10 CFR 72, "Licensing Requirements for the Independent Storage of Spent Nuclear Fuel and High-Level Radioactive Waste"

10 CFR 72.22, "Contents of Application: General and Financial Information"

10 CFR 72.24, "Contents of Application: Technical Information"

10 CFR 72.30, "Decommissioning Planning, Including Financing and Record Keeping"

10 CFR 72.48, "Changes, Tests, and Experiments"

Regulatory Guide 3.15, "Standard Format and Content of License Application for Storage Only of Unirradiated Power Reactor Fuel and Associated Radioactive Material."

Regulatory Guide 3.25, "Standard Format and Content of Safety Analysis Reports for Uranium Enrichment Facilities."

Regulatory Guide 3.26, "Standard Format and Content of Safety Analysis Reports for Fuel Reprocessing Plants."

Regulatory Guide 3.39, "Standard Format and Content of License Applications for Plutonium Processing and Fuel Fabrication Plants."

Regulatory Guide 3.44, "Standard Format and Content for the Safety Analysis Report for an Independent Spent Fuel Storage Installation (Water Basin Type)."

Regulatory Guide 3.48, "Standard Format and Content for the Safety Analysis Report for an Independent Spent Fuel Storage Installation or Monitored Retrievable Storage Installation (Dry Storage)."

Regulatory Guide 3.50, "Standard Format and Content for a License Application to Store Spent Fuel and High-Level Radioactive Waste."

Regulatory Guide 3.52, "Standard Format and Content for the Health and Safety Sections of License Renewal Applications for Uranium Processing and Fuel Fabrication."

Regulatory Guide 3.55, "Standard Format and Content for the Health and Safety Sections of License Renewal Applications for Uranium Hexafluoride Production."

Regulatory Guide 3.61, "Standard Format and Content for a Topical Safety Analysis Report for a Spent Fuel Dry Storage Cask."

Regulatory Guide 3.62, "Standard Format and Content for the Safety Analysis Report for Onsite Storage of Spent Fuel Storage Casks." 


\section{Accident analysis}

The criteria in this chapter are for initiating events that result in a criticality accident.

10 CFR 50.34, "Contents of Applications: Technical Information"

10 CFR 61.13, "Technical Analyses"

10 CFR 70.22, "Content of Applications"

10 CFR 70.23, "Requirements for the Approval of Applications"

10 CFR 72.24, "Contents of Application: Technical Information"

10 CFR 100.11, "Determination of Exclusion Area, Low Population Zone, and Population Center Distance"

Regulatory Guide 1.25, “Assumptions Used for Evaluating the Potential Radiological Consequences of a Fuel-Handling Accident in the Fuel-Handling and Storage Facility for Boiling and Pressurized Water Reactors."

Regulatory Guide 1.91, "Evaluations of Explosions Postulated to Occur on Transportation Routes Near Nuclear Power Plants."

Regulatory Guide 1.113, "Estimating Aquatic Dispersion of Effluents from Accidental and Routine Releases."

Regulatory Guide 1.145, "Atmospheric Dispersion Models for Potential Accident Consequence Assessments at Nuclear Power Plants."

NUREG-1320, "Nuclear Fuel Cycle Facility Accident Analysis Handbook," USNRC, May 1988.

NUREG-1179, "Rupture of Model 48Y UF6 Cylinder and Release of Uranium Hexafluoride," USNRC, February 1986.

NUREG-0772, "The Effects of Natural Phenomena on the Exxon Nuclear Company MixedOxide Fabrication Plant at Richland Washington," USNRC, September 1980.

NUREG/CR-4303, "High-Level Waste Preclosure Systems Safety Analysis, " GA Technologies, Inc., September 1985.

NUREG/CR-3682, "Nuclear Fuel Cycle Risk Assessment-Review and Evaluation of Existing Methods," Pelto, P.J. et al., Battelle Pacific Northwest Laboratories, May 1984. 
NUREG/CR-3210, “Low-Level Waste Risk Methodology Development,” Cox, N.D. et al., EG\&G Inc., May 1983.

NUREG/CR-3139, "Scenarios and Analytical Methods for UF6 Releases at NRC-Licensed Fuel Cycle Facilities," Simantov, M. et al., Oak Ridge National Laboratory, July 1984.

\section{7) Quality assurance during design, construction, and operation}

10 CFR 50.4, "Written Communications"

10 CFR 50.55, "Conditions of Construction Permits"

10 CFR 50, Appendix B, “Quality Assurance Criteria for Nuclear Power Plants and Fuel Reprocessing Plants"

10 CFR 61.12, "Specific Technical Information"

10 CFR 72.40, "Issuance of License"

10 CFR 72 Subpart G, "Quality Assurance"

Regulatory Guide 1.30, "Quality Assurance Requirements for the Installation, Inspection, and Testing of Instrumentation and Electric Equipment."

Regulatory Guide 2.3, "Quality Verification for Plate-Type Uranium-Aluminum Fuel Elements for Use in Research Reactors."

Regulatory Guide 3.3, "Quality Assurance Program Requirements for Fuel Reprocessing Plants and for Plutonium Processing and Fuel Fabrication Plants."

Regulatory Guide 3.10, "Liquid Waste Treatment System Design Guide for Plutonium Processing and Fuel Fabrication Plants.

Regulatory Guide 3.12, "General Design Guide for Ventilation Systems or Plutonium Processing and Fuel Fabrication Plants."

\section{8) Decommissioning}

10 CFR 50, Appendix F, "Policy Relating to the Siting of Fuel Reprocessing Plants and Related Waste Management Facilities."

10 CFR 50.75, "Reporting and Record Keeping for Decommissioning Planning" 
10 CFR 50.82, "Application for Termination of Licenses"

10 CFR 61.12, "Specific Technical Information"

10 CFR 61.14, "Institutional Information"

10 CFR 61.23, "Standards for Issuance of a License"

10 CFR 61.24, "Conditions of Licenses"

10 CFR 61.28, "Contents of Application for Closure"

10 CFR 61.29, "Post Closure Observation and Maintenance"

10 CFR 61.30, "Transfer of License"

10 CFR 61.31, "Termination of License"

10 CFR 61.40, "General Requirement"

10 CFR 61.42, "Protection of Individuals From Inadvertent Intrusion"

10 CFR 61.44, "Stability of the Disposal Site After Closure"

10 CFR 61.52, "Land Disposal Facility Operation and Disposal Site Closure"

10 CFR 61.53, "Environmental Monitoring"

10 CFR 61.62, "Funding for Disposal Site Closure and Stabilization"

10 CFR 70.25, "Financial Assurance and Record Keeping for Decommissioning"

10 CFR 70.38, "Expiration and Termination of Licenses"

10 CFR 72.30, "Decommissioning Planning Including Financing and Record Keeping"

10 CFR 72.40, "Issuance of License"

10 CFR 72.54, "Application for Termination of License"

10 CFR 72.130, "Criteria for Decommissioning"

Regulatory Guide 3.65, "Standard Format and Content of Decommissioning Plans for Licensees Under 10 CFR Parts 30, 40, and 70." 
NUREG-0436, Rev. 1 and Supplements 1 and 2, "Plan for Reevaluation of NRC Policy on Decommissioning of Nuclear Facilities," USNRC, December 1978.

NUREG-0278, Vol. 1 \& Vol. 2, "Technology, Safety, and Costs of Decommissioning a Reference Nuclear Fuel Reprocessing Plant," Schneider, K.J. et al., Battelle Pacific Northwest Laboratory, October 1977.

NUREG/CR-1754, Addendum 1, "Technology, Safety, and Costs of Decommissioning Reference Non-Fuel-Cycle Nuclear Facilities," Short, S.M., Pacific Northwest Laboratory, October 1989. 
Project File Number $\quad$ 02BD7

Project/Task Waste Treatment Project Feasibility Studies

\section{Subtask WTF Design Requirements}

\section{Title: \\ Regulatory and Design Requirements for Waste Treatment Facilities \\ SUMMARY: The purpose of this document is to delineate the design requirements for the non- separations and TRU only separations options for the Waste Treatment Facilities (WTF) feasibility studies. The facilities will be designed and constructed under one of three possible regulatory scenarios: 1) performance against US Department of Energy (DOE) Orders with maintenance of status-quo interfaces with other regulatory and oversight agencies such as the EPA (State of Idaho)

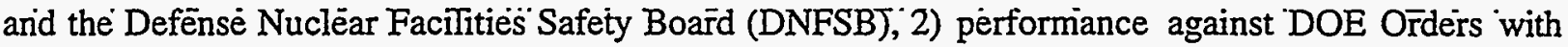 all current regulatory/oversight relationships maintained and or Nuclear Regulatory Commission (NRC) oversight to achieve "NRC Equivalency" or, 3) NRC licensing though replacement of DOE Orders with NRC Regulations and replacement of DNFSB oversight with NRC licensing process. For the purposes of this study and at the direction of the high level waste alternatives feasibility studies project manager, the base case for this study is performance against DOE Orders (scenario 1, above). This is consistent with the approach taken by Fluor Daniel, Inc., at the direction of the HIL Program in the preparation of the planning alternative and will provide an apples-to-apples comparison of the alternatives.}

\section{TABLE OF CONTENTS:}

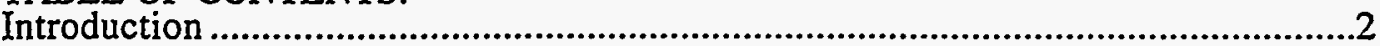

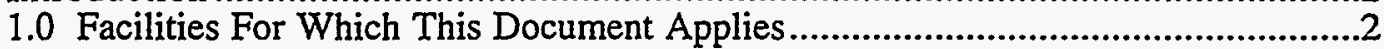

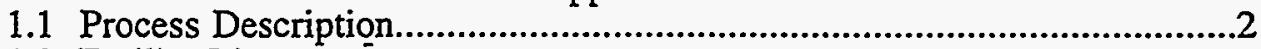

1.2 Facility List................................................................................

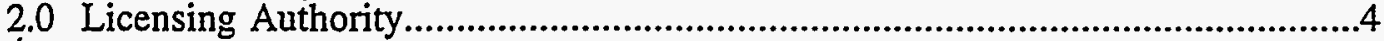

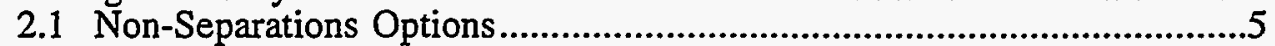

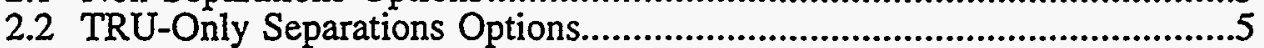

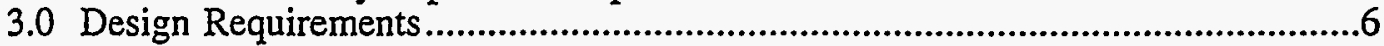

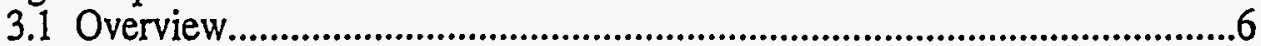

3.2 Non-Separations Options Waste Stabilization Facility ..............................7

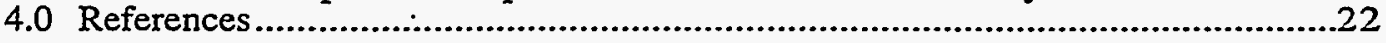

Distribution (complete package):

Distribution (summary package only):

\begin{tabular}{|c|c|c|c|c|c|}
\hline $\begin{array}{l}\text { Author } \\
\text { P.M. Rice } \\
\text { S.L. Austad, P.E. } \\
\text { L.E, Guillen, P.E. }\end{array}$ & $\begin{array}{l}\text { Dept. } \\
4130\end{array}$ & $\begin{array}{l}\text { Reviewed } \\
\text { B.L. Blakely, } \\
\text { R.A. B. Relly }\end{array}$ & \begin{tabular}{|l} 
Date \\
$1 / 27 / 98$
\end{tabular} & Approved & $\mid 2 / 2 / 98$ \\
\hline 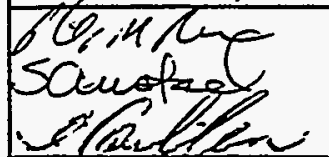 & & $\begin{array}{l}\text { LMITCO } \\
\text { Review }\end{array}$ & Date & $\begin{array}{l}\text { LMITCO } \\
\text { Approval }\end{array}$ & Date \\
\hline
\end{tabular}




\section{Introduction}

The purpose of this document is to delineate the design requirements for the non-separations and TRU only separations options for the Waste Treatment Facilities (WTF) feasibility studies. The facilities will be designed and constructed under one of three possible regulatory scenarios: 1) performance against US Department of Energy (DOE) Orders with maintenance of status-quo interfaces with other regulatory and oversight agencies such as the EPA (State of Idaho) and the Defense Nuclear Facilities Safety Board (DNFSB), 2) performance against DOE Orders with all current regulatory/oversight relationships maintained and or Nuclear Regulatory Commission (NRC) oversight to achieve "NRC Equivalency" or, 3) NRC licensing though replacement of DOE Orders with NRC Regulations and replacement of DNFSB oversight with NRC licensing process. For the purposes of this study and at the direction of the high level waste alternatives feasibility studies project manager, the base case for this study is performance against DOE Orders (scenario 1, above). This is consistent with the approach taken by Fluor Daniel, Inc., at the direction of the HLW Program in the preparation of the planning alternative and will provide an apples-to-apples comparison of the alternatives.

With the ground rules clearly established above, the following is a discussion of how they will be selectively applied/ignored.

This EDF will identify the applicable DOE orders, regulations and guidance documents that would be used in the design of the facilities. There are currently no NRC regulations in place for the licensing of waste processing facilities such as those discussed herein. The only WTF activities for which the NRC has been routinely involved is the licensing of waste storage and disposal facilities. Never-the-less, NRC requirements are looming on the horizon. In addition, the waste products to be produced are in many cases destined for NRC licensed storage facilities. Therefore, there are some NRC requirements that just cannot be ignored. Thus, where appropriate, NRC regulations are explicitly specified in the design requirements. Where specific design criteria is provided under NRC regulations and guidance documents whether directly applicable or for similar facilities, it will be referenced. This will be useful in helping to determine the cost differential between DOE regulatory/oversite and NRC licensing requirements.

\subsection{Facilities For Which This Document Applies}

\subsection{Process Description}

The following is a very brief description of each of the processes that this document will consider:

Direct Vitrification Direct vitrification is a process for converting calcine into a glass waste. In the direct vitrification process, calcine is mixed with "frit" materials and fed to a melter, which would operate at a temperature of around $1100^{\circ} \mathrm{C}$. Numerous small-scale tests have been performed to determine frit formulations and glass properties, primarily leachability. No pilot data or design data is available for direct vitrification of calcine. 
Direct Grout Grouting is an ambient temperature process for solidifying or stabilizing a waste material. Grouting utilizes hydraulic cement that hardens by chemical interactions with water, and various additives which may aid dispersion, control hardening, control pumping characteristics" or enhance retention of certain"contaminants in-the' waste. -

Cementitious Waste Process Darryl Siemer has proposed a direct grouting process ${ }^{33}$ with differences from that described above. Siemer suggests mixing existing calcine with existing SBW, and recalcining the resulting slurry in the existing calciner, using sugar as additive to permit calcination of high-sodium waste. This recalcined waste would then be mixed with a combination of cementitious agents and water, and transferred to a stainless steel can. After setting at ambient temperature, the can is transferred to an autoclave and cured with steam. If further processed by HIPing, the can would be vented and placed in a furnace to remove volatiles. Then the can would be transferred to the HIP chamber, an inert gas added to pressurize to $30-125 \mathrm{MPa}(4350-18,100$ $\mathrm{psi}$ ), and the can heated at $850-1050^{\circ} \mathrm{C}$ for the required "soak" time.

Hot Isostatic Press (HIP). The HIP process uses high pressure and high temperature to convert calcine or other solid wastes to a glass-ceramic waste form. In a conceptual flowsheet proposed for processing calcine, calcine from storage is mixed with frit or other additives, fed to a HIP can, the can sealed and decontaminated, and then isostatically pressed in a furnace. Processing temperatures for the HIP process are similar to vitrification, typically $1050-1100^{\circ} \mathrm{C}$. The typical HIP operating pressure is 20,000 psi.

TRU Waste Alternative In this alternative, calcine is dissolved and actinides removed from the resulting solution by the TRUEX process. TRUEX wash effluents and raffinate along with other ICPP low level wastes, are evaporated, denitrated and grouted. The TRUEX strip effluent is evaporated, denitrated and then packaged for shipment to WIPP. An alternative to denitration would be to neutralize and evaporate the effluents from separation.

\subsection{Facility List}

Below is a list of the primary, main ancillary, and common support facilities that will be required for each of the options discussed herein:

1. Non-Separations Direct Vitrification Option:

- Vitrification Facility

2. Non-Separations Direct Grout Option:

- Grouting Facility

3. Non-Separations Calcine Hot Isostatic Press (HIP) Option:

- Calcine HIP Facility 
4. Non-Separations Cementitious Waste Option:

- Calcine Slurry and Grouting Facility

5. TRU-Only Separations:

- TRU Separations Facility

- TRU Product Handing, Packaging and Lag Storage Facility (TRU-only Separations Option):

- Class C Grouted Waste Interim Storage Facility:

In addition, a number of common support facilities/systems will be required to support the above facilities which include:

- Calcine Retrieval System (may vary depending on the process design for each option)

- Temporary Calcine (surge or staging) Storage

- Interim HLW Storage Facility

Note: For all of these alternatives, the study ends with interim storage of the waste product prior to shipment. Thus none of the studies includes facilities for receiving and internment of the final waste product at a repository.

\subsection{Licensing Authority}

As previously stated, for the purposes of this effort, the base case for this study is performance against DOE Orders. The following discussion is presented to defined under what NRC regulations each of the above referenced facilities would be licensed if NRC licensing were the preferred approach. This information is provided for reference only.

In early 1997 the INEEL Spent Nuclear Fuel, High-Level Waste and Related Programs prepared a licensing assessment report for proposed INEEL ICPP High Activity Waste Treatment Facilities (Idaho Chemical Processing Plant High Activity Waste Treatment Project Regulatory Assessment Report, prepared by R. G. Morgan and S. E. Leroy, Duke Engineering Services, Inc. S. E. Leroy letter to V. L. Jacobson, dated April 25, 1997) (1). The report provided an assessment of how the proposed ICPP Waste Treatment Facilities could be licensed under existing NRC regulations and processes. The report identifies the applicable NRC regulations and guidance documents that would be used in the licensing process. It also identifies those areas where additional NRC guidance documents, regulations, or rulemaking may be necessary.

The above referenced report specifically addresses the facilities defined in the 'preferred alternative', whereas this EDF is examining other methods of processing and disposing of the 
calcined wastes at ICPP. For the purpose of defining the licensing criteria for the options discussed in this EDF, the above referenced report will be used. Licensing criteria will be based on similarities between the preferred alternative facilities and the facilities described here.

\subsection{Non-Separations Options (Primary and Ancillary Facilities)}

The non-separations options include: 1) direct vitrification, 2) direct grouting, 3) calcine HIPing, and 4) the Cementitious Waste options. Each option will include a facility to perform the appropriate operations to produce the end product (e.g., vitrification facility, direct grouting facility, HIPing facility, and a calcine slurry and grouting facility for the Cementitious Waste option).

The non-separations options are similar in scope to the High Activity Waste Treatment (HAWT) Facilities described in reference 1. The HAWT facilities include a calcine retrieval, transport, and receiving system; a calcine dissolution process; a high activity waste vitrification process; and vitrified product storage. The non-separations options include a calcine retrieval, transport, and receiving system; a waste stabilization process (vitrification, grouting, HIPing); and product storage.

The facilities which will be licensed are the Waste Stabilization (WS) Facilities (e.g., the vitrification, grouting, HIPing facilities), the temporary calcine (surge or staging) storage tanks associated with the receipt of the feed stock, the calcine retrieval system, and the interim HLW storage facility.

Based on the existing NRC regulations and rulemaking activities, it is expected that the following licenses would be required to support the non-separations option plan:

- Waste Stabilization (WS) Facilities (e.g., the vitrification, grouting, HIPing facilities) would require a 10 CFR Part 70 license

- Temporary calcine (surge or staging) storage tanks associated with the receipt of the feed stock would require a 10 CFR Part 70 license.

- Calcine retrieval system would require a 10 CFR Part 70 license.

- Interim (temporary) HLW storage facility would require a 10 CFR Part 72 license.

Other NRC regulations that are applicable to the design, licensing, and operations of the facilities will be addressed later in this EDF.

\subsection{TRU-Only Separations Options (Primary and Ancillary Facilities)}

As with the non-separations options, the TRU-only separations options licensing requirements were derived by similarity to the preferred option HAWT facilities.

The facilities which will be licensed are the TRU Separations (TS) facility, TRU product handing, packaging and lag storage facility, class $\mathrm{C}$ grouted waste interim storage facility, the 
temporary calcine (surge or staging) storage tanks associated with the receipt of the feed stock, and the calcine retrieval system.

Based on the existing NRC regulations and rulemaking activities, it is expected that the following licenses would be required to support the non-separations option plan:

- TRU Separations (TS) facilities, including product handling, packaging, and lag storage would require a 10 CFR Part 70 license

- Temporary calcine (surge or staging) storage tanks associated with the receipt of the feed stock would require a $10 \mathrm{CFR}$ Part 70 license.

- Calcine retrieval system would require a $10 \mathrm{CFR}$ Part 70 license.

Other NRC regulations that are applicable to the design, licensing, and operations of the facilities will be addressed later in this EDF.

\subsection{Design Requirements}

\subsection{Overview}

The criteria contained in this document are based only on the rudimentary descriptions of the processes presented in section 1.1. As the design is developed further, some of the criteria may become nonapplicable, and others will be identified. The purpose here is to provide a set of highlevel requirements to guide the development of the conceptual designs of the facilities and provide a reasonable basis for cost estimating purposes. In general this document will not attempt to cover criteria outside of the design and construction of the facilities. Process criteria such as the waste form acceptance criteria, treatment standards and so forth will be addressed by others.

\subsubsection{A Note on NRC Regulations}

NRC regulations are contained in Title 10, Energy of the Code of Federal Regulations. CFR's have the authority of legal mandates, and require compliance, under penalty of law, by all affected parties. NRC generates guidance documents as needed to provide clarification and elaboration of the regulations, describe information to be included in the reports, and give acceptance criteria. These publications truly are guidance documents which are not required to be followed but provide suggested methods for achieving successful licensing. Guidance documents include:

\section{NRC Regulatory Guides}

Regulatory Guides delineate acceptable methods of meeting NRC requirements. Different methods for meeting these requirements may be used if justified but the licensees usually attempt to use the Regulatory Guide methods because alternate approaches require extensive justification and additional NRC review. The use of the guides simplifies and shortens the licensing process. 
There are over 480 Regulatory Guides that have been issued to support the licensing of commercial nuclear facilities. While many of the guides apply to nuclear reactors, others, such as those describing waste storage may be viewed as applicable to the WTF. However, no definitive guidance is available for the type of facilities discussed below.

\section{NRC Reports}

NRC Reports (NUREGs) and other NRC reports developed by contractors are published on a variety of technical and regulatory issues. They may pertain to specific proceedings such as Safety Evaluation reports or Environmental Impact statements.

\section{NRC Technical Positions}

Technical Position and Staff Position Papers are also prepared by the NRC as a means of providing guidance on requirements for specific facilities regulated by the agency.

\section{Generic Communications}

NRC Generic communications include NRC Information Notes, Generic Letters and NRC Bulletins. These documents provide the licensees with specific information on problems or matters of interest to the licensee.

\section{National Standards}

NRC regulations and documents often incorporate or refer to national codes such as the ASME boiler and pressure vessel codes. These codes then become a requirement and are used in developing design criteria. If the licensee wishes an exception, the exception must be identified and basis for the exception agreed to during the licensing process.

\subsection{Non-Separations Options Waste Stabilization Facility}

The non-separations options include: 1) direct vitrification, 2) direct grouting, 3) calcine HIPing, and 4) the Cementitious Waste options. Each option will include a facility to perform the appropriate operations to produce the end product (e.g., vitrification facility, direct grouting facility, HIPing facility, and a calcine slurry and grouting facility for the Cementitious Waste option). The requirements for supporting (ancillary) facilities will be discussed under separate headings.

\subsubsection{Civil Requirements}

\subsubsection{Site Development}

A suitable site shall be located for the Waste Stabilization Facility at the INEEL in the vicinity of the Idaho Chemical Processing Plant (ICPP) with the proximity to waste sources, utilities, other facilities, vehicular access, shipping and storage capability, and future growth. A study of the impact of this facility on site utilities and infrastructure shall be performed. Information regarding 
topography, soil conditions, subsurface rock formations, road and structure locations shall be included in the- final site-decision process.

\subsubsection{Flood Design}

Flood design shall be in accordance with DOE-STD-1020. Additionally, if the facility is a RCRA facility, design shall be in accordance with 40 CFR 270.14. This standard requires the facility to be located above the 100 -yr flood elevation or for engineered barriers against flooding of the site to be constructed. If the facility is a TSCA facility, $40 \mathrm{CFR} 761.65$ requires the facility to be located above the 100-yr flood elevation with no allowance for engineered barriers against flooding.

\subsubsection{Surface Drainage}

Design for surface drainage from local precipitation shall be in accordance with DOE-STD1020 and should be consistent with the ICPP site drainage plan. The INEEL site specific local precipitation standard for a 25 -year, 6-hour storm is 1.4 inches total.

\subsubsection{Subsurface Investigation and Surveying}

Surveying and subsurface investigation for design shall be conducted to determine depth of rock, confirm soil characteristics and evaluate existing soil for chemical and radiological contamination. Locations of ground surface interferences and site characteristics shall be determined with a survey of the site.

\subsubsection{Soil Excavation and Shoring}

Specifications for excavation work shall require that excavations comply with OSHA Standards, 29 CFR 1926, Subpart P (and Subpart U if blasting is necessary), Subsection 1926.641. Where major complex temporary support systems such as shoring, cribbing, sheet piling, etc. are required, they shall be fully design by the $A E$ as part of the design package.

\subsubsection{Paving and Surfacing}

Paving shall be provided around the building for parking areas and access roads. All paved areas adjacent to buildings and structures shall have a $1 \%$ minimum slope away from the buildings or structures... Unpaved areas_shall.be sloped $2 \%$. minimum.

Design for paved roads shall conform to Idaho State Highway Standard Specifications and AASHTO HS-20 loading. Geometric design of all roads, streets, access drives and parking areas shall comply with AASHTO. Other loadings such as those imposed by transfer cask operations shall be incorporated into pavement design where applicable.

\subsubsection{Slabs, Sidewalks, and Stoops}


Sidewalks, door stoops, and approaches shall be provided at all building personnel exits or vehicle openings. Sidewalks shall be installed to provide a safe and efficient means for personnel to access doorways and walk to other nearby facilities. Concrete slabs, door stoops, truck ramps, etc., shall be sloped at least $2 \%$.

\subsubsection{Physical Protection}

The facility shall be located within the ICPP security system and fence. Construction of the new facility may take place outside of the existing main security fence if an equivalent level of security protection is established.

\subsubsection{Underground Utilities}

Existing underground ICPP utilities (sewer, potable and fire water systems) shall be extended as necessary to provide necessary services. Design of potable systems shall be in accordance with the State of Idaho Department of Health and Welfare, Idaho Regulations for Public Drinking Water Systems. Sanitary waste water shall be routed to the ICPP sewage treatment system. Water used for cleaning of the hot cells, if applicable, shall be removed by floor drains or sumps, filtered, contained in double containment tanks, monitored for hazardous materials, and if allowable, routed to the sanitary sewer system:...

\subsubsection{Site Demolition}

Site demolition, as required, will be dependent of the final site location.

\section{2:3 Architectural Requirements .}

\subsubsection{General _.....}

Architectural designs shall be in accordance with the DOE-ID Architectural Engineering Standards, DOE 6430.1A, and the following design criteria. The facility shall have a minimum design life of 40 years. Interim Storage Facility design life shall be 50 years minimum: The facility shall be planned and laid out on the basis of repetitive or discrete processing steps. The need for safe normal and emergency access, egress and internal traffic flow shall be considered.

Energy conservation shall be given attention during planning and design in accordance with 10 CFR 435, Energy Conservation Voluntary Performance Standards for New Buildings, Mandatory for Federal Buildings.

\subsection{Hot Cell.}

Hot Cell design shall be based upon a Uniform Building Code (UBC) occupancy classification of Group $\mathrm{H}$, Division 7. Occupancy separations and construction types shall be designed in accordance with the UBC. 
Layout of the Hot Cell area shall include a buffer area for personnel entering and exiting the cell and shielded viewing windows for remote operations.

The Hot Cell shall include shielded, impervious and decontaminable walls, floors and ceilings as appropriate. The hot cell walls shall provide sufficient shielding to protect personnel from gamma and neutron radiation. The dose rate at the exterior of the Hot Cell wall in the operating gallery shall be below $0.1 \mathrm{mrem} / \mathrm{hr}$.

\subsection{Buffer Area.}

A Buffer Area shall be provided between the Hot Cell and other areas. Design shall be based upon a UBC occupancy classification of Group $\mathrm{H}$, Division 7. Facilities for changing anti-c clothing and personnel monitoring (frisking) devices shall be provided adjacent to the Hot Cell. A shielding labyrinth leading from the Hot Cell to the Buffer Area and then to an Anti-C Change Room shall be provided. These areas. shall. be separated from each other and the pressure barriers-maintained.

The Buffer Area shall provide space for discarded protective clothing used in the Hot Cell and a step off pad for frisking of contamination by PCM machine. All surfaces in the Buffer Area shall be impervious and decontaminable as well as the floors and walls of the Anti-C room.

\subsection{Operating Galleries.}

Operating galleries shall be provided as required by view angles and retraction/repair of remote equipment. Space and utilities shall be provided to accommodate remote equipment operations. Operating galleriès shall be separated from the Hot Cell by a concrete shielded wall.

\subsection{Utility Supp̄ort Arèas.}

Utility Support Areas design shall be based upon a UBC occupancy classification of $\mathrm{H}-7$ and shall be designed to accommodate remote and contact maintenance of equipment.

\subsection{Equipment Maintenance Areas.}

Crane maintenance areas shall be provided to support maintenance of in-cell equipment.

\subsection{Administrative Areas.}

The Administrative Area design, which includes office and support areas, shall be based upon a UBC occupancy classification of Group B.

The Administrative Area shall include a minimum of three offices for a shift supervisor and HP support personnel. A Ready Room shall be provided for conduct of meetings and work breaks. Men's and women's lavatories, showers, lockers, and change facilities shall be provided. Storage space and a janitor's room shall also be provided. 


\subsubsection{Building Features}

Materials selected for the walls shall address durability, low maintenance, shielding, insulation and decontamination. The walls shall meet the recommended $R$ value of the DOE-ID A/E Standards. The UBC Construction Type of II-N shall be used for the Facility.

The entire surface area of the contaminated work areas shall be decontaminable. Where wash down or decontamination activities are to be located, the floors shall be sloped to drains that lead to appropriate holding tanks.

Devices (such as door types or air lock arrangements) shall maintain pressure barriers for the hot cell and operating gallery areas.

\subsubsection{Structural-Requirements:-}

\subsubsection{General}

Structural design shall be in accordance with the DOE-ID Architectural Engineering Standards, DOE O 420.1, and DOE-STD-1020.

\subsubsection{Classification and Design Loads}

The performance categories for SSCs shall be established using DOE-STD-1021, Natural Phenomena Hazards Design and Evaluation Criteria for Department of Energy Facilities." Sitespecific studies and hazard assessments.of the site, as needed, shall.be developed in accordance with DOE-STD-1022, "Natural Phenomena Hazards Site Characterization Criteria" and DOE-STD1023, "Natural Phenomena Hazards Assessment Criteria."

All permanent and transient loads that could exist or be developed during normal operations of the facility shall be considered in the design of the facility. Loads to be considered shall include: dead, live, thermal, lateral soil, snow, natural phenomena, seismic, wind, flood, off-normal operating and accident loads, and load combinations.

Dead and live loads shall be determined in accordance with ANSI/ASCE 7, "Minimum Design Loads for Buildings and Other Structures." Loadings due to natural phenomena hazards (wind, seismic, flood, etc.) shall be determined in accordance with DOE-STD-1020, Natural Phenomena Hazards Design and Evaluation Criteria for Department of Energy Facilities."

In accordance with DOE-STD-1020, the Uniform Building Code shall be used as the basis for seismic design for Performance Category 1 and 2 SSCs. The seismic input control motion for the INEEL for Performance Category 3 SSCs is specified by appropriately scaling the USNRC R.G. 1.60 horizontal spectra $(0.18 \mathrm{~g})$. The input motion is assumed to occur in the free-field at the top of a real or hypothetical rock outcrop near the facility location. The vertical input spectra shall be taken as $2 / 3$ of the horizontal spectra. A detailed soil amplification analysis or the soil surface spectra shall be taken to equal the rock outcrop spectra multiplied by: 
(a) 1.2 for soil overburden up to $20 \mathrm{ft}$.

(b) 1.5 for soil overburden between $20 \mathrm{ft}$ and $50 \mathrm{ft}$.

Snow loads shall be determined in accordance with ANSV/ASCE 7, with a ground snow load of 35 psf and a minimum roof snow load of 30 psf. Tornado loads are not anticipated and need not be included. Load combinations shall be determined in accordance with ANSU/ASCE 7.

3.2.4.2.I NRC Specific-To meet NRC requirements, seismic loads shall be determined in accordance with 10 CFR 72, Subparts D and E, 10 CFR 100, and USNRC Reg. Guide 1.6. Tornado loads shall be determined in accordance with ANSI/ANS-2.3. Load combinations shall be designed using applicable load combinations and stress limits stipulated in ANSI/AISC N690 and ANSUACI349.

\subsubsection{Footings and Foundations}

Footings shall be designed to support the structure and keep differential settlement within allowable limits. Design frost depth shall be 5-ft below grade. The Hot Cell and shielded storage areas shall be provided with continuous reinforced grade beams or wall footings as required for shielding.

\subsubsection{Structural Features}

The Hot Cell walls and roof design shall be consistent with shielding and loading requirements. Other shielded area walls and roofs shall be designed consistent with shielding and loading requiremients. The structural design must support crane systems.

\subsubsection{Handling Requirements}

\subsubsection{Cranes (Critical Lift Devices Only)}

All crane designs shall meet the ASME NOG-1 and where applicable, CMAA 70, Crane Manufacturers Association of America, Inc., Specification for Electric Overhead Traveling Cranes and CMAA 74-1987, Specifications for Top Running and Under Running Single Girder Electric Overhead Traveling Cranes Utilizing Under Running Trolley Hoist.

In addition, all cranes shall meet the requirements of NUREG-0612, Control of Heavy Loads at Nuclear Power Plants.

Cranes shall have true vertical lift on the hoist and all motions shall be the slowest that are commercially available to allow for more precise control when placing or picking objects.

\subsubsection{Work Platforms}


The facility shall be equipped with decontaminable work platforms that shall provide a safe and convenient elevated work area for personnel as required. Design of the platforms and their means of access shall be in accordance with OSHA 1910. Removable guard rails may be utilized as necessary to meet process and handling requirements.

\subsubsection{HVAC Requirements}

All HVAC systems shall be in accordance with Regulatory Guides RG 1.140 Design, testing, and maintenance for normal ventilation systems, RG 1 Design, testing, and maintenance criteria for post-accident engineered safety feature ventilation systems, NUREG-0800 Section 9.4.3 Auxiliary and radioactive waste area ventilation, NUREG-0800 Section 11.3 Gaseous waste management systems, NUREG 0800 Section 11.5 Process and effluent radiological monitoring, NUREG-1567 Offgas treatment and ventilation, NUREG-1567 (Draft) Section 11.4.1.3, Ventilation offgas system design features.

HVAC systems shall be in accordance with 29 CFR 1910, Occupational Safety and Health Standards for General Industry, Subpart G (Occupational Health and Environmental Control) and Subpart $Z$ (Toxic and Hazardous Substances).

The HVAC systems shall meet the air quality requirements addressed in 40 CFR 50-53, and 58.

The HVAC systems shall be in accordance with ANSI/ASME N509-1989, Nuclear Power Plant Air Cleaning Units and Components and ANSI/ASME N510-1989, Testing of Nuclear AirCleaning Systems.

The HVAC systems shall meet the requirements of Idaho Administrative Procedures Act (IDAPA) 16.01.01000-01999.

The HVAC systems shall be in accordance with MIL-F-51068C (Filter: Particulate High Efficiency, Fire Resistant) and MIL-F-51079A (Filter Medium: Fire Resistant, High Efficiency).

The Hot Cell atmospheric pressure shall be controlled during hot operations to $-0.6 \mathrm{~W}$. G. (or lower) below atmospheric pressure.

Heating loads shall be based on a minimum winter outdoor design temperature of $-14^{\circ} \mathrm{F}$. Cooling loads shall be based on temperatures of $93^{\circ} \mathrm{F}$ dry bulb and $61^{\circ} \mathrm{F}$ wet bulb. The HVAC system should maintain a minimum temperature of $65^{\circ} \mathrm{F}$ in the winter and approximately $76^{\circ} \mathrm{F}$ in the summer in the operations area (not including the vitrification cell). The HVAC system must maintain a minimum temperature of $65^{\circ} \mathrm{F}$ in the winter and approximately $72^{\circ} \mathrm{F}$ in the summer in the Administrative areas. HVAC design for indoor temperature conditioning shall be based on ASHRAE 90. 
Air shall flow from areas of least contamination potential to areas of highest contamination potential. The HVAC system shall collect exhaust air from contamination control areas and pass it through HEPA filters prior to discharge to the atmosphere.

\subsubsection{Mechanical Utilities Requirements}

Mechanical utilities systems shall meet the requirements of the ASME Code for Pressure Piping B31.

\subsubsection{Compressed Air}

Compressed air for plant and instrument air shall be provided for pneumatically operated HVAC system equipment and other pneumatic operations in the facility. The system design for compressed air shall be in accordance with 29 CFR 1910, Occupational Safety and Health Standards for General Industry, Subpart M (Compressed Gas and Compressed Air Equipment). Instrument air shall be ISO-141 Grade or better.

\subsubsection{Compressed Gas}

Argon compressed gas shall be supplied for welding processes

Helium compressed gas shall be supplied for pressure testing and inerting operations.

The system design for compressed gas shall be in accordance with 29 CFR 1910, Occupational Safety and Health Standards for General Industry, Subpart H (Hazardous Materials) and Subpart M (Compressed Gas and Compressed Air Equipment).

\subsubsection{Potable Water}

Potäble water, including hot water where applicable, shall be provided to the facility to service water closets, urinal(s), sinks, showers, shower/eyewash facilities, evaporative coolant units, drinking fountains, and miscellaneous ports.

Cross-connection control shall be in accordance with the Idaho Code (IDAPA 16.01.08), "The Cross Connection Control Manual, Accepted Procedure and Practice" (Pacific Northwest Section of American Water Works Association), and the Foundation for Cross Connection Control and Hydraulic Research (University of Southern California.)

\subsubsection{Waste Systems}

3.2.9.4.1 Liquid Waste-Liquid waste system(s) shall be provided for in the Hot Cells and other process areas. The liquid waste systems shall be designed in accordance with NUREG-0800 Section 11.2 Liquid waste management systems. Condensate from HVAC equipment shall be disposed of using the liquid waste system. Liquid waste shall be collected and tested prior to being pumped into the waste line 
3.2.9.4.2 Sanitary Systems-The sanitation system design shall be in accordance with 29 CFR 1910, Occupational Safety and Health Standards for General Industry, Subpart J (General Environmental Controls). Sanitary sewer drains, cleanouts, and vents shall be provided as needed .

\subsubsection{Fire Protection}

Fire water shall be provided in accordance with DOE 6430.1A, DOE Order 420.1, and the DOE-ID Architectural Engineering Standards. Fire protection systems shall ensure nuclear criticality and suppressant-HLW chemical reactions cannot occur. All underground fire water lines shall be cathodically protected and meet State of Idaho requirements for minimum distances from potable water piping.

\subsubsection{Steam}

Steam shall be provided and routed to the HVAC system as required. The steam lines shall be insulated.

\subsubsection{Electrical Requirements}

The criteria for the electrical design of the WTF is based on requirements from NFPA, ANSI, Factory Mutual (FM), DOE O 420.1 and 29 CFR 1910, Occupational Safety and Health Standards for General Industry, Subpart $S$ (Electrical).

Electrical design and installation shall incorporate the most efficient methods of penetration, shielding integrity retention, efficiency, and operational convenience.

The facility shall require an electrical room a communications room, and an Uninterruptable Power Supply (UPS) room.

\subsubsection{Power}

The electric power system shall be designed to provide standard power to the facility and emergency electrical supply to essential instrumentation, emergency lighting, emergency communications, and physical security systems. Standby power shall be supplied for the Hot Cells, process areas, and HVAC system exhaust fan.

An Uninterruptable Power Supply (UPS) shall provide emergency power. The UPS shall support the Fire Alarm, Voice Paging, HVAC, Radiation Monitoring and Alarm, and security systems. There shall sufficient battery capacity to carry the rated load for a minimum of 30 minutes.

\subsubsection{Grounding} standards.

Grounding shall be provided in accordance with the DOE-ID Architectural Engineering 


\subsubsection{Cathodic Protection}

Utility piping shall be protected through connection to the existing ICPP cathodic protection system. A testing/bonding station shall be included to periodically monitor the cathodic protection system.

\subsubsection{Lighting}

Interior and exterior lighting shall be designed and included in accordance with current Illuminating Engineering Society (IES) recommendations. Emergency and exit lighting shall be provided at each means of egress. Hot Cell lighting shall be provided by high-pressure sodium fixtures.

\subsubsection{Lightning Protection}

A lightning protection system shall be included and shall be designed in accordance with NFPA 780.

\subsubsection{HVAC Controls}

A HVAC control system shall be provided. It shall be a smart system that can automatically generate control signals to change HVAC equipment operating parameters based on signal received from various monitors. A computer monitor shall be provided in the Shift Supervisor's office for reviewing the operating status of the system and making adjustments to control setpoints.

Instrumentation shall be provided to detect and alarm both high and low differential pressure across filters in the HVAC system. Instrumentation shall be provided to initiate isolation of the HVAC system filters in the event of fire detection.

\subsubsection{Equipment Controls}

Facility control, process control, and data acquisition systems shall be provided.

Remotely controlled CCTV cameras shall be provided in the Hot Cells and process areas for general visual observation, operations, inspection, and documentation. Each Hot Cell window shall be equipped with a visual inspection station which shall include two high resolution cameras; a monitor; camera controls for pan, tilt, and zoom functions; and recording capability for archival purposes. earthquake.

Instrumentation shall be provided to measure and record the facility structural response to an

A system shall be provided for the collection of alarms from the HVAC system and other alarms. This shall be located in the Shift Supervisor's office. 


\subsubsection{Radiation Monitoring and Alarms}

Radiation detection instrumentation shall be provided to wam operating personnel of radiation and airborne radioactivity levels above set limits. The RAMs shall alarm locally and remotely in the RadCon office.

Stack monitoring shall be provided for the detection of radioactive particulates in the air exhaust stream. These instruments shall comply with ANSI-N42.17B-1989.

Provisions shall be made in the design for monitoring groundwater in the vicinity of the storage area for radioactive contamination.

Activity monitors shall be provided in the wash water collected from the Hot Cells and process areas.

\subsubsection{Communications and Alarms}

Voice and data telecommunications lines shall be provided throughout the occupied areas of the facility. The existing. Broadband..Local Area.Network (LAN) shall be made available. in the facility. Access ports shall be provided in all normally occupied offices.

Fire alarm, emergency voice paging, and evacuation alarm systems shall be compatible with existing systems at ICPP.

\subsubsection{Data Acquisition and Recording}

A data entry station shall be provided to record and monitor all fuel movements. The stations shall be linked for data communications.

\subsubsection{Security Systems}

Physical protection of the facility shall be in accordance with 10 CFR 73 and 10 CFR 72 , Subpart H.

\subsubsection{Design Life Requirements}

Design life of the facility and equipment shall be 30 years and have maintainable or replaceable life of 60 years

\subsubsection{Safety Requirements}

\subsubsection{Safety Classification}

The facility is assumed to be a Hazard Category 2 . 


\subsubsection{Construction}

The design of utility services and distribution systems that are important to safety shall include redundant systems to the extent necessary to maintain, with adequate capacity, the ability to perform safety functions assuming a single failure.'

The facility and its systems important to safety ${ }^{2}$ shall be designed to be evaluated by appropriate tests or by other means acceptable to the NRC to demonstrate that they will reasonably maintain confinement of radioactive material under normal, off-normal, and credible accident conditions.

Structures, systems, and components important to safety shall be designed and located so that they can continue to perform their safety functions effectively under credible fire and explosion exposure conditions.

The design of the facility shall include provisions to protect against nuclear criticality that might otherwise result from the operation or the failure of fire suppression or decontamination systems.

Material handling, packaging, transfer, and storage systems shall be designed to be maintained subcritical under the worst case moderated and reflected conditions, and to ensure that, before a nuclear criticality accident is possible, at least two unlikely, independent, and concurrent or sequential changes must occur in the conditions essential to nuclear criticality safety.

Each entrance or access point into a high radiation area shall have either a control device that energizes a conspicuous visible or audible alarm signal so that the individual entering the high radiation area and the supervisor of the activity are made aware of the entry; or entryways that are locked, except during periods when access to the areas is required, with positive control over each individual entry.

Process materials that are reactive with water or other chemicals shall be protected from exposure to those materials.

The facility shall be designed to prevent the dropping of critical loads under normal and off normal conditions including the design basis accidents (DBAs) that they shall withstand.

1. A single failure is an occurrence that results in the loss of capability of a component to perform its intended safety function(s). A multiple failure, i.e., loss of capability of several components, resulting from a single occurrence, is considered to be a single failure. Systems are considered to be designed against an assumed single failure if neither (1) a single failure of any active component (assuming passive components function properly) nor, (2) a single failure of any passive component. (assuming active components function properly) results in loss-of the system's capability to perform its safety function(s).

2. Structures, systems, and components important to safety mean those features of the Storage Facility whose function is: (1) To maintain the conditions required to store spent fuel safely, (2) To prevent damage to the spent fuel waste container during handling and storage, or (3) To provide reasonable assurance that spent fuel can be received, handled, packaged, stored, and retrieved without undue risk to the health and safety of the public. 
The facility shall be designed to prevent the dropping of critical loads under normal and off normal .conditions. including the design basis accidents (DBAs) that they..shall-withstand;...

The facility shall be designed to be able to recover from accidents involving dropping of critical loads.

In-cell equipment shall be designed for recovery from all possible conditions to the extent that manned entry into the cell, for maintenance, can be accomplished.

Fire doors shall be provided as required by UBC, UFC, NFPA-80, and NFPA-101. In addition, all fire doors and frames shall meet all requirements of the Underwriters Laboratories and shall bear the UL or FM label. Fire doors and frames shall be constructed from metal. Structural members, such as steel channels embedded in wall openings, shall not substitute as door frames. All fire doors shall be provided with fitted frames which are anchored to, but separate from, the building structural members. Thë fïre doors shäll contain windows fitted with UL" approved safety glass which is not removable from the outside of the door. Their installation shall meet all of the requirements of NFPA-80 and NFPA-101.

The facility design shall mitigate natural phenomena hazards. The design shall address common cause effects and interactions for: earthquakes, volcanic events, tornadoes, hurricanes, high winds, floods, excessive rains, excessive snow, ice cover, lightning, and fires. The secondary natural phenomena include drought, fog, frost, high temperatures, low temperatures, landslides, subsidence, surface collapse, uplift, storm surges, and waterspouts. Damage and failure will be considered for systems, structures, and components. In addition, the facility shall have instrumentation or other means to detect and record the occurrence and severity of seismic events.

\subsubsection{Operation}

Radiation protection for occupational workers shall be per 10 CFR 835 (Occupational Radiation Protection) and the INEEL Radiological Control Manual

Facility design features and physical controls shall ensure occupational exposure is maintained ALARA during normal and off-normal operations

Personnel radiation exposure levels throughout facility shall not exceed $0.1 \mathrm{mr} / \mathrm{hr}$ for continuously-occupied areas.

Safe access will be provided to all packages, vehicles, and installed components for purposes of testing, inspection, and maintenance.

\subsubsection{Environmental Requirements}

Facility emission limits shall be per requirements listed in EDF-WTS-003, Section 5. 
Administrative controls and Best Available Control Technology shall be used to minimize the impacts of air emissions

The facility processes and equipment shall be designed to limit solid waste generation of LLW and industrial (cold) waste

Solid radioactive waste produced by operations shall be packaged in standard RWMC $4 \times 4$ $\times 8$-ft plywood boxes for contact-handled (CH) LLW or INEL Mark III concrete containers for remote-handled (RH) LLW, and shipped to RWMC for disposal

Means for measuring the amount and concentrations of radionuclides in effluents during normal operations, and under accident conditions, shall be provided for effluent control systems

Warm liquid waste shall be controlled and verified to meet the criteria for existing ICPP handling systems, and shall be transferred to those systems

If all or part of the facility is located outside of existing ICPP fences, the use of new land shall not exceed 551 acres when combined with other storage systems included in DOE/EIS-0203-F.

\subsubsection{Safeguards and Security}

The materials are not attractive. as defined in DOE Order 5633.3B. . .

A data management system shall be provided to keep records. The data management system shall meet the requirements of 10 CFR 72, Licensing Requirements for the Independent Storage of Spent Nuclear Fuel and High-Level Radioactive Waste, Subpart D (Records, Reports, Inspections, and Enforcement).

Dual records shall be maintained to ensure an off-normal event cannot result in the loss of the sole records. These records shall be retained for as long as the material is stored, and for a period of five years after the material is disposed of or transferred.

The following are NRC requirements that may or may not apply

Equipment shall be provided to conduct a physical inventory of all material in storage at intervals not to exceed 12 months unless otherwise directed by the Commission. A copy of the current inventory shall be retained as a record until the Commission terminates the license.

Physical protection of the facility and materials shall be in accordance with 10 CFR 72 , Licensing Requirements for the Independent Storage of Spent Nuclear Fuel and High-Level Radioactive Waste, Subpart H (Physical Protection); 10 CFR 73, Physical Protection of Plants and Materials; and 10 CFR 1046, Physical Protection of Security Interests.

\subsubsection{Quality Assurance Requirements}


The applicable portions of DOE/RW-0333P, Quality Assurance Requirements and Description, shall be invoked as the baseline requirements document for developing and implementing quality assurance programs. These requirements apply to activities related to interim storage or disposal, including characterization for data collection, conditioning, or placing into a form for disposal. In addition, the EM-WAPS Rev. 01, Waste Acceptance Product Specifications for Vitrified High-Level Waste Forms, May 1995, also imposes a QA Program consistent with the QA requirements under the DOE/RW-0333P.

All purchased items will be restricted to those not suspect/counterfeit, misrepresented, used, or other than represented/advertised in accordance with INEL-95/227, "Guidelines for Identifying Suspect/Counterfeit Material."

Records, reports, and inspections shall be done in accordance with 10 CFR 72, Licensing Requirements for the Independent Storage of Spent Nuclear Fuel, Subpart D (Records, Reports, Inspections, and Enforcement).

Training of personnel shall be performed in accordance with 10 CFR 72, Licensing Requirements for the Independent Storage of Spent Nuclear Fuel, Subpart I (Training and Certification of Personnel). 


\subsection{References}

Nuclear Regulatory -Commission-(NRC) -Licensing Assessment for the Idaho -National Engineering and ... Environmental Laboratory (INEEL) High-Level Waste Program, prepared by R. G. Morgan and S. E. Leroy, Duke Engineering Services, Inc., April 23, 1997. Referenced in Idaho Chemical Processing Plant High Activity Waste Treatment Project Regulatory Assessment Report - SEL-11-97, prepared by S. E. Leroy, dated April 25, 1997. 
Project File Number $\quad$ 02BFO

Project/Task Non-separation Alternatives

Subtask Vitrified Waste Option

Title: Estimate of Product Glass Volume and Number of Vitrified Glass Canisters

Summary: This EDF describes the current estimate of high level waste generated if a direct vitrification option is selected for processing stored calcine prior to disposal. The estimate is based on the latest estimates of the amount of calcine that will be in storage in 2012 and on current development data for vitrification formulas. The amount of glass to be generated is 10,163 cubic meters, and the total number of vitrified glass canisters (VGC's) generated is estimated at 14,115 .

Distribution (complete package):WTP EIS Studies library, C. Barnes MS 3625. A copy of this EDF will be included in Report INEEL/EXT-97-01389.

Distribution (summary package only):

\begin{tabular}{|c|c|c|c|c|c|}
\hline $\begin{array}{l}\text { Author } \\
\text { R. R. } \\
\text { Kimmitt } 12 / 3 / 9 . \\
\text { KRThmntf }\end{array}$ & $\begin{array}{l}\text { Dept. } \\
\text { Chemical \& } \\
\text { Envir. Engr. }\end{array}$ & $\begin{array}{l}\text { Reviewed } \\
\text { emBans }\end{array}$ & $\begin{array}{l}\text { Date } \\
1 / 6 / 98\end{array}$ & $\begin{array}{l}\text { Approved } \\
\text { D. Lopez } \\
\text { SCLLLape }\end{array}$ & $\begin{array}{l}\text { Date } \\
1 / 29 / 98\end{array}$ \\
\hline
\end{tabular}

See Management Control Procedure (MCP) 6 for instructions on use of this form. 


\section{Design Bases}

Charles Barnes produced an EDF that provided the quantity and density data available for the existing calcine as well as estimated values for calcine produced in the current campaign and future campaigns (EDF-FDO-001).

Glass formulations are based on development work done to date. Frit 127 is the basis for the glass produced from zirconia calcine ${ }^{1}$. The waste loading used is $31 \%$. Alumina calcine is combined with Frit 532 , and the waste loading is only $20 \%^{2}$. The glass waste loading for SBW calcine is $30 \%$ and is based on work performed by $\mathrm{K}$. Vinjamuri ${ }^{3}$. All of the formulations used are estimates and are subject to change based on future development work.

\section{Glass Volume Estimate}

Using the information referenced above, the following table shows the current estimates for the volume of glass and number of VGC's to be produced from direct vitrification of calcine:

\begin{tabular}{|c|c|c|c|c|c|c|}
\hline Calcine Type & $\begin{array}{l}\text { Calcine } \\
\text { Volume, } \\
\text { cu.meter }\end{array}$ & $\begin{array}{c}\text { Calcine } \\
\text { Density, } \\
\text { kg/cu.meter }\end{array}$ & $\begin{array}{c}\text { Kg Glass per } \\
\text { Kg Calcine }\end{array}$ & $\begin{array}{l}\text { Glass Density, } \\
\text { kg/cu.meter }\end{array}$ & $\begin{array}{l}\text { Volume of } \\
\text { Glass } \\
\text { Produced, } \\
\text { cu. meters }\end{array}$ & \# of VGC's \\
\hline Existing $\mathrm{Zr}$ Calcine & 2,891 & 1,600 & 3.23 & 2,600 & 5,746 & 7,981 \\
\hline Existing Al Calcine & 918 & 1,090 & 4.76 & 2,600 & 1,832 & 2,544 \\
\hline WM-188 Calcine $(\mathrm{Zr})$ & 166 & 1,650 & 3.23 & 2,600 & 340 & 473 \\
\hline WM-189 Calcine (Na) & 160 & 1,200 & 3.33 & 2,600 & 246 & 342 \\
\hline SBW Calcine & 700 & 1,200 & 3.33 & 2,600 & 1,076 & 1,494 \\
\hline $\begin{array}{l}\text { Calcine from Waste } \\
\text { Generated } 1997-2012\end{array}$ & 600 & 1,200 & 3.33 & 2,600 & 922 & 1,281 \\
\hline Totals & 5,435 & & & & 10,162 & 14,115 \\
\hline Note: Usable volume o & $\mathrm{C}$ is $0.72 \mathrm{cu}$ & meters. & & & & \\
\hline
\end{tabular}

The volume of glass is larger than the estimate made by Charles Barnes in the EDF referenced above. The difference is due to lower waste loading factors (pounds of calcine per pound of final glass product) used in this estimate. 
431.02\#

$06 / 17 / 97$

Rev. \#04
ENGINEERING DESIGN FILE
Function File Number - ED-01 EDF Serial Number - EDF-VWO-001

Page 3 of 3

' Staples, B.A., Pavlica, D.A., and H.S. Cole, Properties of Formula 127 Glass Prepared with Radioactive Zirconia Calcine, ENICO-1120, September, 1982.

${ }^{2}$ Letter, B. Staples to R. Kimmitt, Comments on HLW Calcine Compositions for Total Vitrification Feasibility, dated 10/01/97

${ }^{3}$ Vinjamuri, K., Glass Waste Forms for the Na-bearing High Activity Waste Fractions, INEL-95/0214, June, 1995 
Project File Number $\quad$ 02BFO

Project/Task Non-Separation Alternatives

Subtask Vitrified Waste Option

Title: Direct Vitrification Process Description

Summary: This EDF provides the design bases, assumptions, and overall process description for the direct vitrification option. Also included are material and energy balance flowsheets and a description of major pieces of process equipment.

Distribution (complete package): WTP ElS Studies Library, C. Barnes MS 3625. A copy of this EDF will be included in Report INEEL/EXT-97-01389

Distribution (summary package only):

\begin{tabular}{|c|c|c|c|c|c|}
\hline $\begin{array}{l}\text { Author } \\
\text { R. R. } 1 / 29 / 9 s \\
\text { Kimmitt } \\
\text { X. A. Y }\end{array}$ & $\begin{array}{l}\text { Dept. } \\
\text { Chem. \& } \\
\text { Env. Engr. }\end{array}$ & $\begin{array}{l}\text { Reviewed } \\
\text { em } \\
\text { Bannes }\end{array}$ & $\begin{array}{l}\text { Date } \\
1 / 29 / 98\end{array}$ & $\begin{array}{l}\text { Approved } \\
\text { D. Lopez } \\
\text { DaLLaps }\end{array}$ & $\begin{array}{l}\text { Date } \\
1 / 29 / 98\end{array}$ \\
\hline
\end{tabular}

See Management Control Procedure (MCP) 6 for instructions on use of this form. 


\section{Direct Vitrification Alternative Feasibility Study Process Design}

\section{Design Bases and Assumptions}

\subsection{Design Bases}

(a) The total amount of calcine to be processed is estimated at 5435 cubic meters. ${ }^{1}$ This includes existing alumina and zirconia calcine plus additional calcine generated from sodium-bearing waste (SBW).

(b) The design process rate is 4,676 pounds of waste calcine per day (1.3-1.8 cubic meters per dayl, 180 days per year. Waste calcine will be processed 24 hours per day. At this rate the calcine will be treated in 20 years. The process will generate between 16,000 pounds and 22,000 pounds of product glass per day, depending on the type of calcine treated and the glass formulation used.

(c) The vitrification system included in the process design package is a cold-cap, joule heated melter. This type of design has the advantage of reducing the loss of volatile species from the melt, particularly Cs.

(d) Waste will be drawn from 1 or 2 bins to fill a calcine receiving and mixing hopper. Two such hoppers will be provided with the system.

(e) For the purpose of sizing equipment, a material balance based on the "Frit 532" alumina calcine glass will be used. The melter material balance for this formulation is provided in this EDF, along with material balances for use with zirconia calcine and sodium calcine. The Frit 532 material balance will be used as the design basis because it represents the largest daily production rate of glass. ${ }^{2}$

(f) One storage hopper will be provided outdoors, outside the process building for each of the frit formulations. Frit will be delivered by rail car.

(g) A feed hopper for each of the frit formulations will be provided inside the process building, in an un-shielded area. Capability will be provided to weigh material as it is fed to the ribbon blender, where the frit will be blended with calcine.

\footnotetext{
${ }^{1}$ EDF-VWO-001

${ }^{2}$ Letter, B.A. Staples to R.R. Kimmitt, Comments on HLW Calcine Compositions for Total Vitrification Feasibility, dated 10/01/97.
} 
(h) All hoppers and silos will be fitted with live "bin bottoms" to eliminate bridging and channeling of the dry materials used in the process.

(i) Batch will be prepared by blending frit with calcine in the ribbon bender (or similar blending device) immediately before the melter. This will reduce the potential for stratification of frit and calcine before the batch enters the melter. The concern over stratification after blending stems from the significant difference in the specific gravity values of frit and calcine ( $\sim 2.5$ and $\sim 1.2$, respectively).

(j) All feed materials will be handled in dry form in the system.

(k) The melter will be designed to allow removal of product glass, slag, and liquid metal as separate materials. All materials will drain by gravity from the melter. Provision will be made to drain the entire contents of the melter bath in an emergency situation.

(I) Two identical melters will be installed in the system. One will be an installed spare.

(m) The melter bath electrodes will have a maximum electrical demand of 10,250 $\mathrm{kWh} /$ day $(427 \mathrm{~kW})$. This is based on an electrical energy requirement of $920 \mathrm{kWh}$ per short ton of glass produced ${ }^{3}$. The capability will be provided to vary the power level of the electrodes.

(n) The melter lid (headspace) heaters will typically be used during cold start-up and when power to the melter electrodes is lost. Emergency diesel generators will be provided to supply power to the lid heaters in the event of site a power outage. The capability will be provided to vary the power level of the lid heaters.

(o) The design basis for sizing the melter is 0.6 square meters of melt bath surface per metric ton of glass produced per day ${ }^{4}$.

(p) The system will include equipment for wet scrubbing of off-gas from the melter and for treatment of scrubber blowdown solution.

\subsection{Assumptions}

(a) Analytical data will be available when needed.

\footnotetext{
${ }^{3}$ Pincus, A.G. and G.M. Diken, eds., Electric Melting in the Glass Industry, Magazines for Industry, Inc., New York, 1976, p. 57.

${ }^{4}$ EnvitCo, Inc., Waste Vitrification Training Program, presented initially to Parsons Power, Inc., 1995., p. IX-20.
} 
(b) The total power requirement for the lid heaters is 1.5 million BTU/hr ( $440 \mathrm{~kW})$.

(c) Six different frit compositions will be required to accommodate the variability in the calcine chemical composition. Separate storage silos and feed hoppers will be provided for each of these materials.

(d) Two hundred fifty SCFM of ambient air will be pulled into the headspace of the melter, which will be operated under a slight vacuum. The air will cool instrument penetrations and control the temperature of the cold cap.

(e) A process waste evaporator will be available for use. It is assumed that this evaporator will already be in use at the ICPP and will have adequate capacity to accept scrubber blowdown sludge from this process.

\section{Process Description}

This study describes a process for vitrifying stored calcine directly, without any pretreatment. The term "batch" is typically used in the glass industry to refer to the homogenized material fed to a melting tank to make glass. For this process, the batch will consist of waste calcine and frit material. The frit is powdered, commercially produced glass of specific compositions for use in this process. This material will be procured from an outside vendor. It is assumed that 6 frit formulations or recipes will be required to cover all possible mixtures of zirconia calcine, alumina calcine, and SBW calcine from the bin sets. The product glass will be poured directly into canisters suitable for disposal in the high level waste repository.

\subsection{Calcine Management}

Calcine will be transferred pneumatically to one of two receiving and mixing . hoppers at the vitrification facility. At any given time, one hopper will be available to receive calcine from the bin sets, and the other will be fully characterized and available for transfer to the melter. Both hoppers will be sized to hold about 8 days of calcine feed (i.e., 37,500 pounds of calcine). Mixing of the calcine in the hoppers will be necessary, since the material will not be homogeneous as received. Mixing will be done pneumtically. When needed, the calcine will be conveyed from the mixing hoppers through a weighing mechanism to a ribbon blender for combination with frit before addition to the melter.

\subsection{Frit Management}


Commercially manufactured frit will be delivered to the vitrification facility by rail car. The material will be sampled and analyzed to assure it meets specification before it is added to the contents of one of 6 storage silos. One silo will be provided for each of six frit compositions. Frit will be conveyed to feed hoppers inside the process building. One feed hopper will be connected to each of the six storage silos. Each feed hopper will be sized to hold 1-2 days of frit feed ( about 32,000 pounds) to the melter. No mixing capability will be provided for the feed hoppers, since the material will be homogeneous as received from the vendor.

\subsection{Melter Feed}

Frit from the appropriate feed hopper and fully characterized calcine will be separately conveyed to a ribbon blender for addition to the melter. A weigh belt feeder or similar device will be attached to each conveyor to permit accurate measurement of the feed rates of each material. The conveyors will be interlocked to assure that the materials are being fed to the blender in the correct proportions for suitable glass production.

\subsection{Melter Operation}

Electric resistance (called joule heating in the glass industry) will heat the melt bath. Two banks of horizontally mounted, rod-type electrodes will be used in the melt bath. A separate bank of electric lid heaters will be installed in the headspace above the bath. These will be used for start up and for keeping the bath hot in the event of a loss of power to the bath electrodes. Emergency generators will be provided to power the lid heaters in the event that commercial power is lost.

Dry batch will be conveyed from the ribbon blender to the melter. The melter will be operated so that the batch forms a cold cap floating on top of the molten glass bath. This cold cap will reduce the volatility of species such as mercury and cesium present in the calcine.

The melter will be designed with separate forehearths for removal of slag and product glass. Another drain will be provided for completely draining the melter or for removal of elemental metal, should it form in the melter during abnormal operations.

The melter will routinely operate around the clock at a melt bath temperature between $1100^{\circ} \mathrm{C}$ and $1200^{\circ} \mathrm{C}$.

\subsection{Off-Gas Treatment}


A wet scrubber system will be installed for removal of contaminants from the melter off-gas. The off-gas temperature will vary from $400^{\circ} \mathrm{C}$ to $1,000^{\circ} \mathrm{C}$, so a quench vessel will be needed. A venturi scrubber is included to remove gross particulates, and a packed bed will be used for removal of volatile contaminants. An activated carbon vessel will be included to remove trace amounts of mercury.

The off-gas system will also include a demister, electric heaters upstream of the GAC bed to reduce relative humidity, and HEPA filters to contain radioactive particulates. A vacuum will be maintained on the melter and off-gas equipment by an induced-draft fan.

The alumina calcine contains approximately $3 \% \mathrm{HgO}$, which will decompose in the melter; consequently, the scrubber water can become heavily laden with mercury. Scrubber blowdown will be treated with a sulfide salt to precipitate the mercury as insoluble $\mathrm{HgS}$. A hydrocyclone will concentrate the solids in a slurry before evaporation. The SBW calcine and zirconia calcine contain less than $0.5 \%$ mercury, so the mercury content of the alumina calcine represents a bounding case.

\subsection{Product Canister Management}

Product glass will be poured directly into the $2 \mathrm{ft}$. diameter $\times 10-\mathrm{ft}$. long canisters currently designated for materials intended for disposal at the proposed Yucca Mountain facility. Equipment will be supplied to position the canisters below the glass drain on the melter and to measure the amount of material added to each canisters. Approximately 0.72 cubic meters of glass will be loaded into each canister. Equipment will also be provided to transport empty canisters into the melter cell and remove full canisters from the melter cell.

Filled canisters will be moved to an area for cooling, welding on lids, and surface decontamination.

\subsection{Block Flow Diagram}

This diagram presents to overall flow of material through the process. Material handling equipment (e.g., conveyors, cranes, pumps) are not shown. 


\subsection{Material and Energy Balances}

4.1 Product Glass. The alumina calcine case is the design basis, since it results in the largest daily glass production rate. However, material balances for production of glass from zirconia calcine and sodium-bearing calcine are also shown to indicate the process variability likely to be encountered in routine operation. 


\subsection{Process Equipment Description}

This spreadsheet lists the major pieces of process equipment, along with general dimensions and material capacities. Where appropriate, the fundamental design parameters and any assumptions used in determining equinment size are listed. 


\begin{tabular}{|c|c|c|c|c|c|c|c|c|c|}
\hline \multicolumn{10}{|c|}{ Direct Vitrification Process Equipment List } \\
\hline Item & $\begin{array}{l}\text { Equipment } \\
\text { Number }\end{array}$ & $\begin{array}{l}\text { Number of } \\
\text { Units }\end{array}$ & Capacity & $\begin{array}{c}\text { Capacity } \\
\text { Units }\end{array}$ & $\begin{array}{c}\text { Diameter, } \\
\mathrm{ft} .\end{array}$ & Height, ft. & $\begin{array}{c}\text { Power } \\
\text { Requirement, } \\
\text { hp }\end{array}$ & $\begin{array}{l}\text { Material of } \\
\text { Construction }\end{array}$ & $\begin{array}{l}\text { Sketch } \\
\text { Number }\end{array}$ \\
\hline Auger Conveyor & CO-801 & 1 & & & & & 10 & CS & WWO-08 \\
\hline Frit Storage Silo & B-801 A-F & 6 & 20,000 & gal & 13 & 20 & & CS & WO-08 \\
\hline Bucket Conveyor & $\mathrm{CO}-802$ & 1 & & & & & 10 & CS & WWO-08 \\
\hline Frit Feed Hopper & B-802 A-F & 6 & 2000 & gal & 6 & 9 & & CS & WO-08 \\
\hline Auger Conveyor & CO-802 & 1 & & & & & 10 & $\mathrm{CS}$ & WWO-08 \\
\hline Frit Load Hopper & B-803 & 1 & 300 & gal & 3 & 5 & & CS & WWO-08 \\
\hline Ribbon Blender & $M-801 A, B$ & 2 & 2 & cu.ft & 2 & 4 & 2 & $\mathrm{CS}$ & WWO-08 \\
\hline Glass Melter & $V-801 A, B$ & 2 & 11 & tons/day & 13 & 23 & $950 \mathrm{~kW}$ & $\mathrm{CS}$, refractory & WWO-08 \\
\hline $\begin{array}{l}\text { Calcine Receiving/Mixing } \\
\text { Tank }\end{array}$ & T-701 A,B & 2 & 7000 & gal & 10 & 12 & & 304 SS & WW-07 \\
\hline Blending Cyclone & $C Y-701$ A,B & 2 & & & 2 & 4 & & 304 SS & WWO-07 \\
\hline Sintered Metal Filter & F-701 A,B & 2 & & & 2 & 4 & & 304 SS & WWO-07 \\
\hline $\begin{array}{l}\text { Calcine Fines Collection } \\
\text { Tank }\end{array}$ & T-702 A,B & 2 & 200 & gal & 3 & 4 & & 304 SS & WWO-07 \\
\hline Sintered Metal Filter & $F-702 A, B$ & 2 & & & 2 & 4 & & 304 SS & WWO-07 \\
\hline Calcine Feed Cyclone & CY-702 A,B & 2 & & & 2 & 4 & & 304 SS & WWO-07 \\
\hline Calcine Load Hopper & $B-701 A, B$ & 2 & 200 & gal & 3 & 4 & & 304 SS & WWO-07 \\
\hline Calcine Blending Blower & BL-701 & 2 & 4000 & scfm & & & 40 & 304 SS & WWO-07 \\
\hline HEPA Filter & F-703 & 1 & 4000 & scfm & & & & 304 SS & WWO-07 \\
\hline HEPA Filter & F-704 & 1 & 4000 & scfm & & & & 304 SS & WWO-07 \\
\hline Calcine Blending ID Fan & $B L-702$ & 1 & 4000 & scfm & & & 40 & 304 SS & WWO-07 \\
\hline Calcine Load ID Fan & $B L-703$ & 1 & 4000 & scfm & & & 40 & 304 SS & WWO-07 \\
\hline Quench Column & $V-401 A B$ & 2 & & & 2 & 10 & & 304 SS & MNO-04 \\
\hline Venturi Scrubber & $E J-401 A, B$ & 2 & & & 2 & 8 & & 304 SS & WWO-04 \\
\hline Packed Absorber & $T-401 \mathrm{~A}, \mathrm{~B}$ & 2 & & & 2.5 & 10 & & 304 SS & WWO-04 \\
\hline Demister & $F-401 A, B$ & 2 & & & 2 & 4 & & 304 SS & WWO-04 \\
\hline Heater & $E H-401$ A,B & 2 & & & & & & 304 SS & WWO-04 \\
\hline $\begin{array}{l}\text { Granular Activated Carbon } \\
\text { Column }\end{array}$ & $T-402 A, B$ & 2 & 1500 & gal & 4 & 10 & & 304 SS & WWO-04 \\
\hline HEPA Filter & $F-402$ A,B & 2 & 250 & scfm & & & & 304 SS & WWO-04 \\
\hline ID Fan & $B L-401$ A,B & 2 & 250 & scfm & & & 3 & 304 SS & WWO-04 \\
\hline Scrub Solution Tank & $T-403 \mathrm{~A}, \mathrm{~B}$ & 2 & 1000 & gal & 5 & 7 & & 304 SS & WWO-04 \\
\hline Centrifugal Pump & P-401 A-D & 4 & 15 & $\mathrm{gpm}$ & & & 1 & 304 SS & WWO-04 \\
\hline
\end{tabular}

Page 1 of 2 


\begin{tabular}{|c|c|c|c|c|c|c|c|c|c|}
\hline \multicolumn{10}{|c|}{ Direct Vitrification Process Equipment List } \\
\hline Item & $\begin{array}{c}\text { Equipment } \\
\text { Number }\end{array}$ & $\begin{array}{c}\text { Number of } \\
\text { Units }\end{array}$ & Capacity & \begin{tabular}{|c|} 
Capacity \\
Units
\end{tabular} & $\begin{array}{c}\text { Diameter, } \\
\mathrm{ft.}\end{array}$ & Height, ft. & $\begin{array}{l}\text { Power } \\
\text { Requirement, } \\
\text { hp }\end{array}$ & $\begin{array}{l}\text { Material of } \\
\text { Construction }\end{array}$ & $\begin{array}{l}\text { Sketch } \\
\text { Number }\end{array}$ \\
\hline Caustic Tank & $T-404$ & 1 & 100 & gal & \begin{tabular}{r|}
2 \\
\end{tabular} & 5 & & $304 S S$ & VWO-04 \\
\hline Caustic Metering Pump & $P-402 A, B$ & 2 & 0.5 & gpm & & & 0.5 & $304 S S$ & WO-04 \\
\hline Mercury Separation Tank & $T-601$ & $T$ & 1500 & gal & 6 & 7 & & 304 SS & WNOQ-0 \\
\hline $\begin{array}{l}\text { Positive Displacement } \\
\text { Pump }\end{array}$ & $P-601 \mathrm{~A}, \mathrm{~B}$ & 2 & 2 & $\mathrm{gph}$ & & & 0.25 & 304 SS & WWo-06 \\
\hline Mercury Precipitation Tank & $T-602$ & 1 & 1500 & gal & 6 & 7 & & 304 SS & WWo-06 \\
\hline $\begin{array}{l}\text { Mercury Precipitation Tank } \\
\text { Pump }\end{array}$ & $P-602 A, B$ & 2 & 50 & $\mathrm{gpm}$ & & & 2 & 304 SS & InWO-06 \\
\hline $\begin{array}{l}\text { Mercury Precipitation Tank } \\
\text { Agitator }\end{array}$ & $M-601$ & 1 & & & & & 5 & 304 SS & WWO-06 \\
\hline $\begin{array}{l}\text { Mercury Wash Tank } \\
\text { Agitator }\end{array}$ & M-602 & 1 & & & & & 2 & 304 SS & WWo-06 \\
\hline Mercury Wash Tank & $T-603$ & 1 & 50 & gal & 2 & 3 & & 304 SS & WWO-06 \\
\hline Wash Water Recycle Tank & $T-604$ & 1 & 50 & gal & 2 & 3 & & 304 SS & WWO-06 \\
\hline Mercury Wash Tank Pump & $P-603 A, B$ & 2 & 5 & gpm & & & 0.5 & 304 SS & WW0-06 \\
\hline $\begin{array}{l}\text { Wash Water Recycle } \\
\text { Pump }\end{array}$ & P-604 A,B & 2 & 5 & $\mathrm{gpm}$ & & & 0.5 & 304 SS & WWO-06 \\
\hline $\begin{array}{l}\text { Washed Mercury Hold } \\
\text { Tank }\end{array}$ & $T-605$ & 1 & 10 & gal & 1 & 2 & & 304 SS & WWO-06 \\
\hline $\begin{array}{l}\text { Amalgam Jar Roller } \\
\text { Conveyor }\end{array}$ & Co-601 & 1 & & & & & 1 & 304 SS & WWO-06 \\
\hline Jar Mill & $M-603$ & 1 & & & & & 0.5 & 304 SS & WWO-06 \\
\hline Copper Feed Hopper & $B-601$ & 1 & 100 & gal & 2.5 & 3 & & 304 SS & WWO-06 \\
\hline Weigh Belt Feeder & CO-602 & 1 & & & & & 0.5 & 304 SS & WWO-06 \\
\hline Sulfide Solution Tank & $T-606$ & 1 & 50 & gal & 2 & 3 & & 304 SS & WWO-06 \\
\hline Metering Pump & $P-605 A, B$ & 2 & 2 & gph & & & 0.25 & 304 SS & WWO-06 \\
\hline
\end{tabular}


Quench Water-Startup

\begin{tabular}{|c|c|c|c|c|c|c|c|c|}
\hline \multicolumn{9}{|c|}{ Estimating Quench Water Requirements (Vitrification) } \\
\hline \multicolumn{9}{|c|}{ Start Up Operations (Headspace Gas $=1000$ Degrees C) } \\
\hline Gas & $\begin{array}{c}\text { Decomposition } \\
\text { Gas Flow } \\
\text { Rate,Lb- } \\
\text { moles/hr }\end{array}$ & $\begin{array}{c}\text { Volume Flow of } \\
\text { Decomposition } \\
\text { Gas, SCFM }\end{array}$ & $\begin{array}{l}\text { Dilution Air } \\
\text { Flow Rate, } \\
\text { Lb-moles/hr. }\end{array}$ & $\begin{array}{c}\text { Volume Flow } \\
\text { of Dilution } \\
\text { Air,SCFM }\end{array}$ & $\begin{array}{c}\text { Cp, } \\
\text { BTU/lb- } \\
\text { mole-F }\end{array}$ & $\begin{array}{c}\text { "Lid" Gas } \\
\text { Teperature, F }\end{array}$ & $\begin{array}{c}\text { Heat Gained } \\
\text { by Dilution } \\
\text { Gas, BTU }\end{array}$ & $\begin{array}{c}\text { Energy Lost by } \\
\text { Gas in } \\
\text { Quench, } \\
\text { BTU/hr. }\end{array}$ \\
\hline & & & & & & & & \\
\hline N2 & 0.00 & - & 32.8 & 196 & 7.23 & 1832 & 417,308 & 391,256 \\
\hline $\mathrm{H} 2 \mathrm{O}$ & 0.16 & 0.9 & - & & 8.67 & 1832 & - & 2,255 \\
\hline $\mathrm{O} 2$ & 0.08 & 0.5 & 8.7 & 52 & 7.61 & 1832 & 116,760 & 110,437 \\
\hline$\overline{\mathrm{CO} 2}$ & 0.04 & 0.2 & - & & 10.96 & 1832 & & 730 \\
\hline$\overline{\mathrm{SO} 2}$ & 0.04 & 0.2 & - & & 7.61 & 1832 & & 507 \\
\hline NO2 & 0.09 & 0.5 & - & & 7.61 & 1832 & 417,308 & 1,093 \\
\hline $\mathrm{Hg}$ & 0.03 & 0.2 & & & & & & \\
\hline & & & & & & & & \\
\hline Totals & 0.4 & 2.4 & 41.5 & 248 & & & 534,069 & 506,277 \\
\hline & & & & & & & & \\
\hline \multicolumn{3}{|c|}{ Evaporative water demand (gal $/ \mathrm{min})=$} & 0.92 & & & & & \\
\hline & & & & & & & & \\
\hline \multicolumn{9}{|c|}{ Assumptions: } \\
\hline \multirow{2}{*}{\multicolumn{9}{|c|}{$\begin{array}{l}\text { 1. Energy gain by water }=1,100 \mathrm{BTU} / \mathrm{b} \text {. } \\
\text {. Gas leavina the quench is at } 180 \mathrm{~F}\end{array}$}} \\
\hline & & & & & & & & \\
\hline \multicolumn{9}{|c|}{ 3. This calculation ignores ambient heat losses. } \\
\hline \multicolumn{9}{|c|}{ 4. The amount of dilution air is assumed. } \\
\hline 5. Dec & omposition gas is & sassumed to be & "lid" tempera & ature as it enter & s the lid. & & & \\
\hline
\end{tabular}




\begin{tabular}{|c|c|c|c|c|c|c|c|c|}
\hline \multicolumn{9}{|c|}{ Estimating Quench Water Requirements (Vitrification) } \\
\hline \multicolumn{9}{|c|}{ Steady State Operations (Headspace Gas $=400$ Degrees $C$ ) } \\
\hline Gas & $\begin{array}{c}\text { Decomposition } \\
\text { Gas Flow } \\
\text { Rate,Lb- } \\
\text { moles/hr }\end{array}$ & $\begin{array}{c}\text { Volume Flow of } \\
\text { Decomposition } \\
\text { Gas, SCFM }\end{array}$ & $\begin{array}{l}\text { Dilution Air } \\
\text { Flow Rate, } \\
\text { Lb-moles/hr. }\end{array}$ & $\begin{array}{c}\text { Volume Flow } \\
\text { of Dilution } \\
\text { Air,SCFM }\end{array}$ & $\begin{array}{c}\text { Cp, } \\
\text { BTU/lb- } \\
\text { mole-F }\end{array}$ & $\begin{array}{c}\text { "Lid" Gas } \\
\text { Teperature, F }\end{array}$ & $\begin{array}{l}\text { Heat Gained } \\
\text { by Dilution } \\
\text { Gas, BTU }\end{array}$ & $\begin{array}{c}\text { Energy Lost by } \\
\text { Gas in } \\
\text { Quench, } \\
\text { BTU/hr. }\end{array}$ \\
\hline N2 & 0.00 & - & 32.8 & 196 & $\overline{7.23}$ & 752 & 161,523 & 135,471 \\
\hline $\mathrm{H} 2 \mathrm{O}$ & 0.16 & 0.9 & - & & 8.67 & 752 & - & 781 \\
\hline$\overline{\mathrm{O} 2}$ & 0.08 & 0.5 & 8.7 & 52 & 7.61 & 752 & 45,193 & 38,238 \\
\hline $\mathrm{CO} 2$ & 0.04 & 0.2 & - & & 10.96 & 752 & & 253 \\
\hline $\mathrm{SO} 2$ & $\overline{0.04}$ & 0.2 & - & & $7 . \overline{61}$ & 752 & & 175 \\
\hline NO2 & $\overline{0.09}$ & 0.5 & - & & $\overline{7.61}$ & 752 & & 379 \\
\hline $\mathrm{Hg}$ & 0.03 & 0.2 & & & & & & \\
\hline & & & & & & & & \\
\hline Totals & 0.4 & 2.4 & 41.5 & 248 & & & 206,717 & 175,297 \\
\hline \multicolumn{3}{|c|}{ Evaporative water demand (gal/min) $=$} & 0.32 & & & & & \\
\hline & & & & & & & & \\
\hline \multicolumn{9}{|c|}{ Assumptions: } \\
\hline \multicolumn{9}{|c|}{ 1. Energy gain by water $=1,100 \mathrm{BTU} / \mathrm{lb}$. } \\
\hline \multicolumn{9}{|c|}{ 2. Gas leaving the quench is at $180 \mathrm{~F}$. } \\
\hline \multicolumn{9}{|c|}{ 3. This calculation ignores ambient heat losses. } \\
\hline \multicolumn{9}{|c|}{ 4. The amount of dilution air is assumed. } \\
\hline 5. Dec & omposition gas i & assumed to be & at "lid" tempera & ture as it enter & the lid. & & & \\
\hline
\end{tabular}


Zirconia with Frit

\begin{tabular}{|c|c|c|c|c|c|c|c|c|c|c|c|c|c|}
\hline & A & $\mathbf{B}$ & C & Di & $\mathbf{F}$ & $\mathbf{G}$ & $\begin{array}{lll}H & \end{array}$ & $\mathrm{~J}$ & $\mathrm{~K}$ & LL & $M$ & $\mathbf{N}$ & 0 \\
\hline 1 & \multicolumn{13}{|c|}{ Zirconia Calcine with Frit \#127 } \\
\hline 2 & $\begin{array}{c}\text { Feed Rate, lbs. per } \\
\text { day }\end{array}$ & 4676 & & $\begin{array}{c}\text { Fraction of Calcine in } \\
\text { Product }\end{array}$ & 0.30098 & & & & & & & & \\
\hline 3 & & & & & & & & & & & & & \\
\hline 4 & Calcine Composition & wt. \% & lbs. per day & Frit Composition & $w t \%$ & lbs. per day & Product Composition & wt.\% & Ibs. per day & & \begin{tabular}{|c|} 
Off-Gas \\
Composition \\
\end{tabular} & wt. \% & lbs. per day \\
\hline 5 & & & & Mass of Frit Used & $100 \%$ & 11,100 & & & & & & & \\
\hline 6 & $\mathrm{Al2O3}$ & 13.7 & 641 & & & & $\mathrm{Al} 2 \mathrm{O3}$ & $4.12 \%$ & 641 & & $\underline{02}$ & $10.40 \%$ & 25 \\
\hline 7 & $\mathrm{Al} 2(\mathrm{SO} 4) 3$ & 0 & - & & & & $\mathrm{Al} 2(\mathrm{SO} 4) 3$ & $0.00 \%$ & - & & $\overline{\mathrm{CO} 2}$ & $0.00 \%$ & - \\
\hline 8 & AIPO4 & 0 & - & & & & AIPO4 & $0.00 \%$ & - & & $\mathrm{H} 2 \mathrm{O}$ & $29.33 \%$ & 70 \\
\hline 9 & $\mathrm{B2O3}$ & 2.35 & 110 & $\mathrm{~B} 2 \mathrm{O} 3$ & $8.6 \%$ & 955 & $\overline{\mathrm{B} 2 \mathrm{O} 3}$ & $6.85 \%$ & 1,064 & & $\mathrm{Hg}$ & $0.91 \%$ & $\overline{2}$ \\
\hline 10 & $\mathrm{CaCO} 3$ & 0 & - & & & & $\mathrm{CaCO}$ & $0.00 \%$ & - & & NO2 & $59.37 \%$ & $\overline{142}$ \\
\hline 11 & CaF2 & 45 & 2,104 & & & & CaF2 & $13.54 \%$ & 2,104 & & $\mathrm{SO} 2$ & $0.00 \%$ & - \\
\hline 12 & $\mathrm{CaO}$ & 13.41 & 627 & & & & $\mathrm{CaO}$ & $4.04 \%$ & 627 & & & & \\
\hline 13 & $\mathrm{Ca} 3(\mathrm{PO} 4) 2$ & 0 & - & & & & $\mathrm{Ca}(\mathrm{PO} 4) 2$ & $0.00 \%$ & - & & & & \\
\hline 14 & $\mathrm{CdO}$ & 0 & - & & & & CdO & $0.00 \%$ & - & & & & \\
\hline 15 & $\mathrm{Cr} 2 \mathrm{O3}$ & 0.38 & 18 & & & & $\mathrm{Cr} 2 \mathrm{O3}$ & $0.11 \%$ & 18 & & & & \\
\hline 16 & CuO & 0 & - & $\mathrm{CuO}$ & $2.1 \%$ & 233 & CuO & $1.50 \%$ & 233 & & & & \\
\hline 17 & $\mathrm{Fe} 2 \mathrm{O3}$ & 0.53 & 25 & & & & $\mathrm{Fe} 2 \mathrm{O}$ & $0.16 \%$ & 25 & & & & \\
\hline 18 & Gd2O3 & 0.01 & 0 & & & & Gd2O3 & $0.00 \%$ & 0 & & & & \\
\hline 19 & $\mathrm{H} 2 \mathrm{O}$ & 1.5 & 70 & & & & $\mathrm{H} 2 \mathrm{O}$ & $0.00 \%$ & & & & & \\
\hline 20 & H3BO3 & 0 & - & & & & $\mathrm{H} 3 \mathrm{BO} 3$ & $0.00 \%$ & - & & & & \\
\hline 21 & $\mathrm{HgO}$ & 0.05 & 2 & & & & $\mathrm{HgO}$ & $0.00 \%$ & - & & & & \\
\hline 22 & KAIO2 & 0.8 & 37 & & & & KAIO2 & $0.24 \%$ & 37 & & & & \\
\hline 23 & $\mathrm{~K} 2 \mathrm{O}$ & 0 & - & & & & $\mathrm{K} 2 \mathrm{O}$ & $0.00 \%$ & - & & & & \\
\hline 24 & K2SO4 & 0 & - & & & & $\mathrm{K} 2 \mathrm{SO4}$ & $0.00 \%$ & - & & & & \\
\hline 25 & Li2O & 0 & - & Li20 & $6.2 \%$ & 688 & Li2O & $4.43 \%$ & 688 & & & & \\
\hline 26 & $\mathrm{Li} 2 \mathrm{CO} 3$ & 0 & - & & & & $\mathrm{Li} 2 \mathrm{CO} 3$ & $0.00 \%$ & - & & & & \\
\hline 27 & $\mathrm{MgO}$ & 0 & - & & & & $\mathrm{MgO}$ & $0.00 \%$ & - & & & & \\
\hline 28 & $\mathrm{MgCO}$ & 0 & - & & & & $\mathrm{MgCO}$ & $0.00 \%$ & - & & & & \\
\hline 29 & $\mathrm{MnO}$ & 0 & - & & & & $\mathrm{MnO}$ & $0.00 \%$ & - & & & & \\
\hline 30 & $\overline{\mathrm{MOO} 3}$ & 0 & - & & & & $\mathrm{MoO3}$ & $0.00 \%$ & - & & & & \\
\hline 31 & $\mathrm{Na} 2 \mathrm{O}$ & 0 & - & $\mathrm{Na2O}$ & $12.8 \%$ & 1,421 & $\mathrm{Na} 2 \mathrm{O}$ & $9.76 \%$ & 1,516 & & & & \\
\hline 32 & NaAlO2 & 1.09 & 51 & & & & NaAlO2 & $0.33 \%$ & 51 & & & & \\
\hline$\overline{33}$ & $\mathrm{NaCi}$ & 0 & - & & & & $\mathrm{NaCl}$ & $0.00 \%$ & - & & & & \\
\hline$\overline{34}$ & $\mathrm{Na} 2 \mathrm{CO} 3$ & 0 & - & & & & $\mathrm{Na} 2 \mathrm{CO} 3$ & $0.00 \%$ & - & & & & \\
\hline 35 & $\mathrm{Na2B} 407$ & 0 & - & & & & $\mathrm{Na2B} 407$ & $0.00 \%$ & - & & & & \\
\hline$\overline{36}$ & $\mathrm{NaF}$ & 0 & - & & & & $\mathrm{NaF}$ & $0.00 \%$ & $=$ & & & & \\
\hline 37 & $\mathrm{NaNO}$ & 5.61 & 262 & & & & NaNO3 & $0.00 \%$ & - & & & & \\
\hline 38 & $\mathrm{Na3}(\mathrm{PO} 4) 2$ & 0 & - & & & & $\mathrm{Na3}(\mathrm{PO} 4) 2$ & $0.00 \%$ & - & & & & \\
\hline 39 & $\mathrm{Na} 2 \mathrm{SO}_{4}$ & 0 & - & & & & $\mathrm{Na} 2 \mathrm{SO}_{4}$ & $0.00 \%$ & - & & & & \\
\hline 40 & $\mathrm{Nb2O5}$ & 0 & - & & & & $\mathrm{Nb205}$ & $0.00 \%$ & - & & & & \\
\hline 41 & NiO & 0 & - & & & & $\mathrm{NIO}$ & $0.00 \%$ & - & & & & \\
\hline 42 & P2O5 & 0 & - & & & & P205 & $0.00 \%$ & - & & & & \\
\hline$\overline{43}$ & $\mathrm{PbO}$ & 0 & - & & & & $\mathrm{PbO}$ & $0.00 \%$ & - & & & & \\
\hline 44 & $\mathrm{SiO} 2$ & 0 & - & $\mathrm{SiO} 2$ & $70.3 \%$ & 7,803 & $\mathrm{SIO} 2$ & $50.22 \%$ & 7,803 & & & & \\
\hline 45 & $\mathrm{SnO2}$ & 0.22 & 10 & & & & $\mathrm{SnO2}$ & $0.07 \%$ & 10 & & & & \\
\hline 46 & UO2 & 0 & - & & & & $\mathrm{UO2}$ & $0.00 \%$ & - & & & & \\
\hline 47 & $\mathrm{ZrO2}$ & 15.35 & 718 & & & & $\mathrm{ZrO2}$ & $4.62 \%$ & 718 & & & & \\
\hline 48 & Total & 100.00 & 4,676 & Total & $100.0 \%$ & 11,100 & Total & $100.00 \%$ & 15,537 & & Total & $100 \%$ & 239 \\
\hline
\end{tabular}




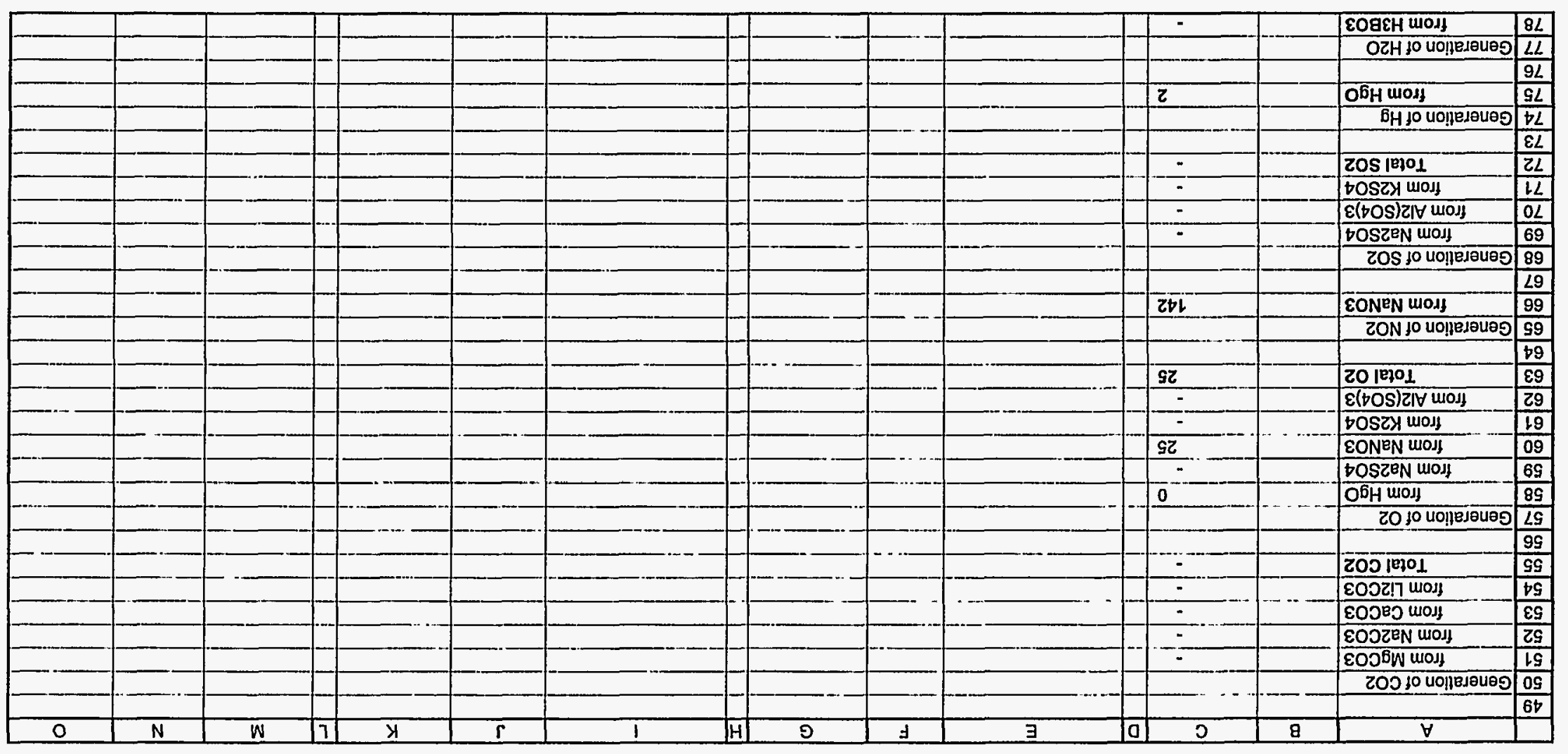

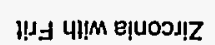


Zirconia with Frit

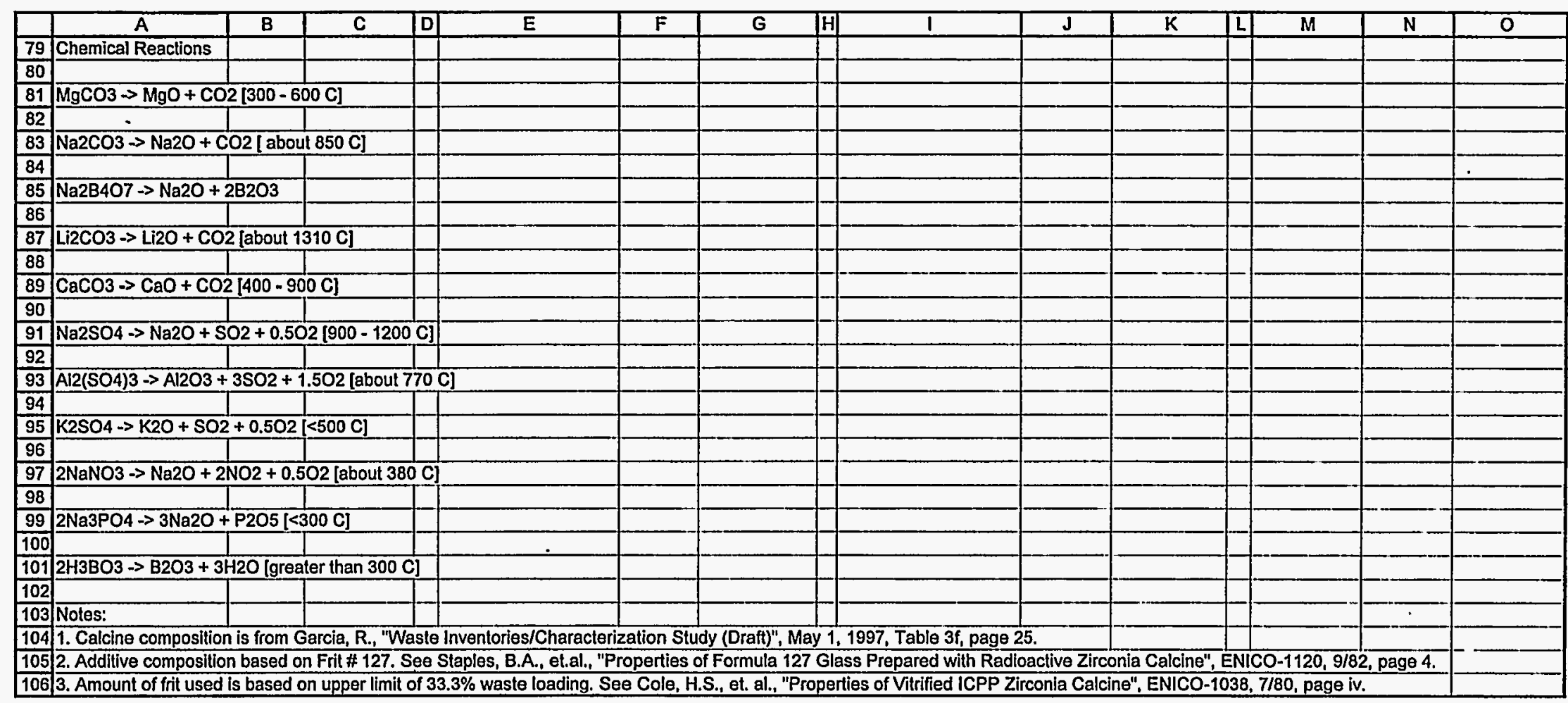


Alumina with Frit

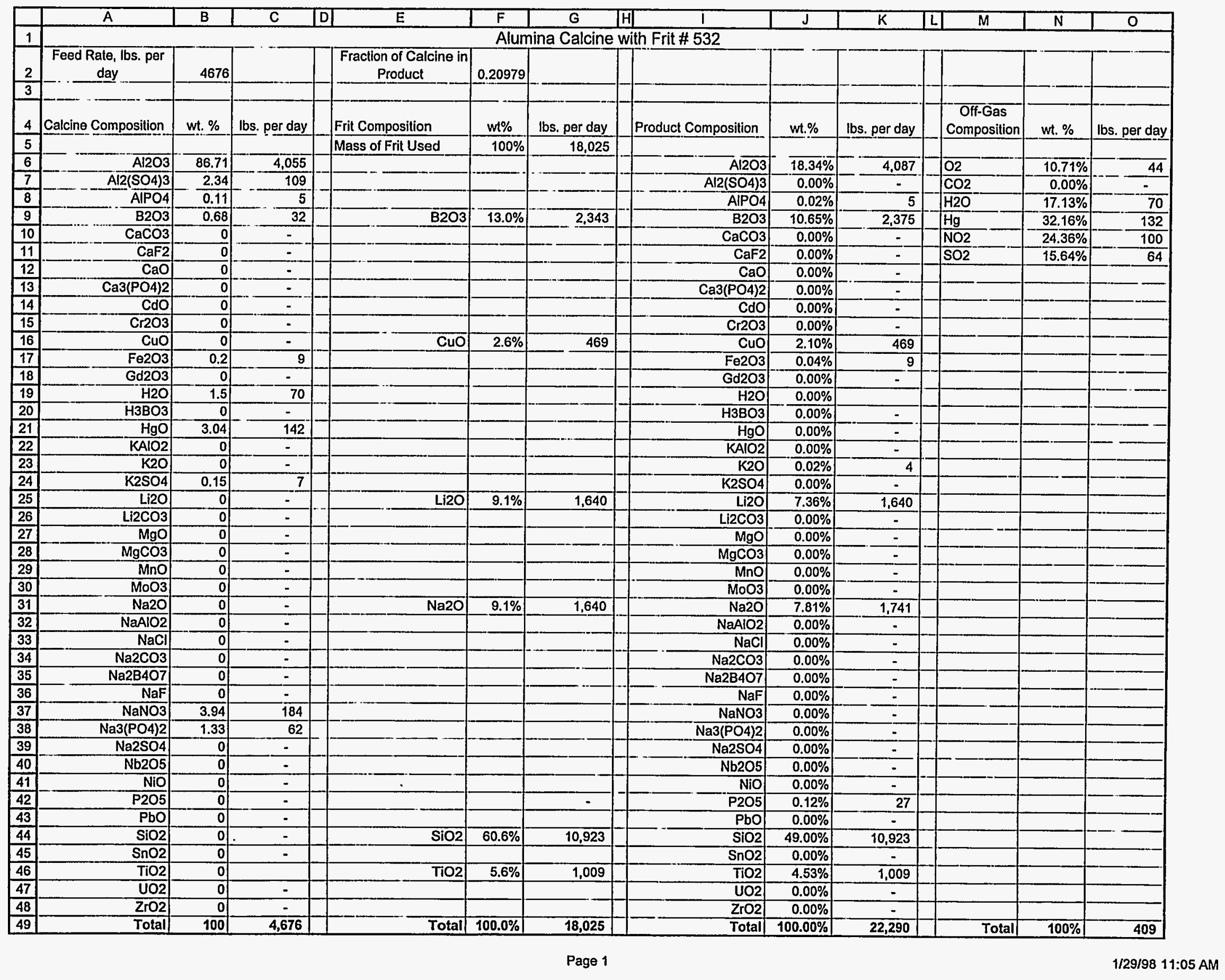




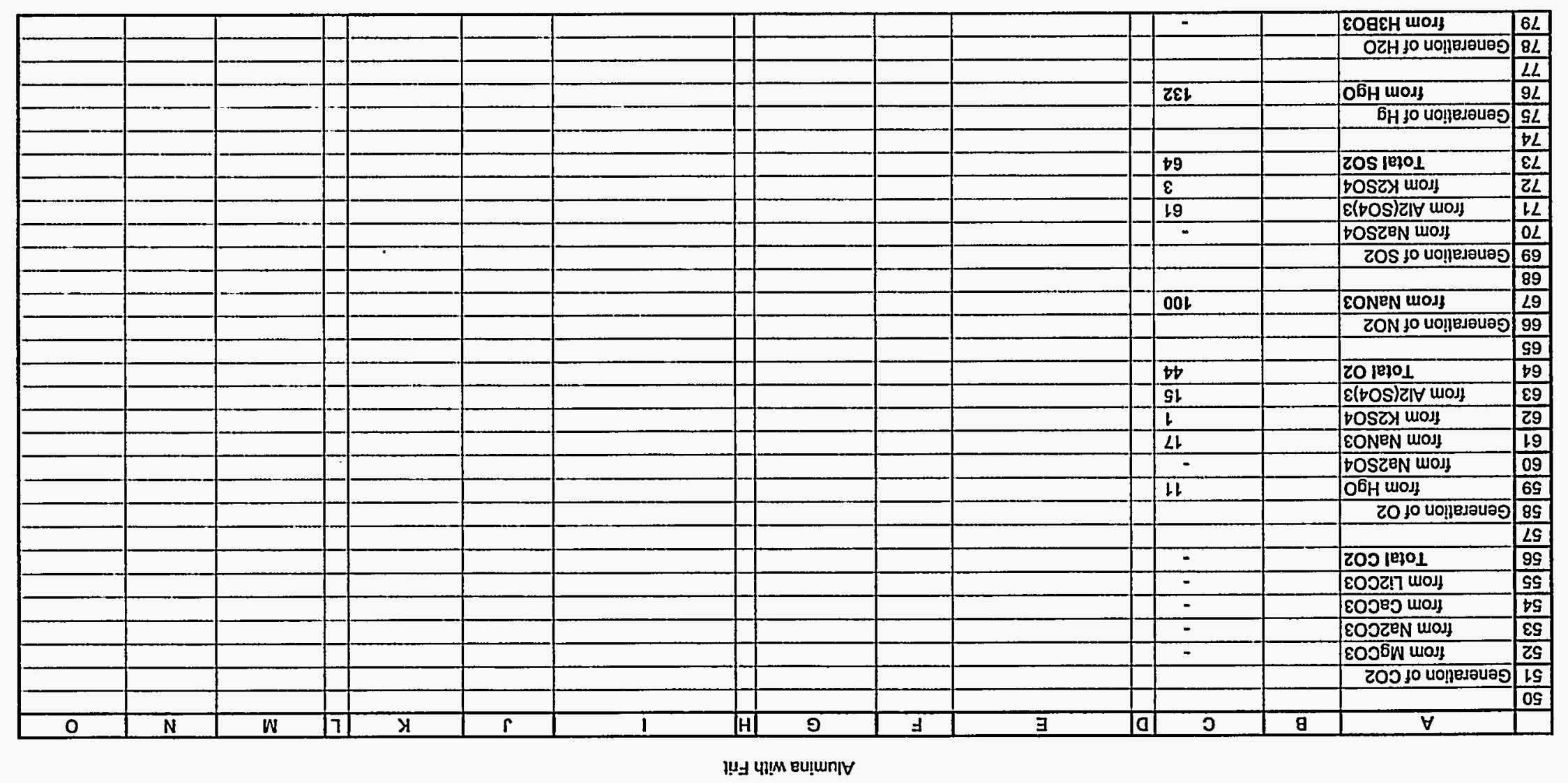




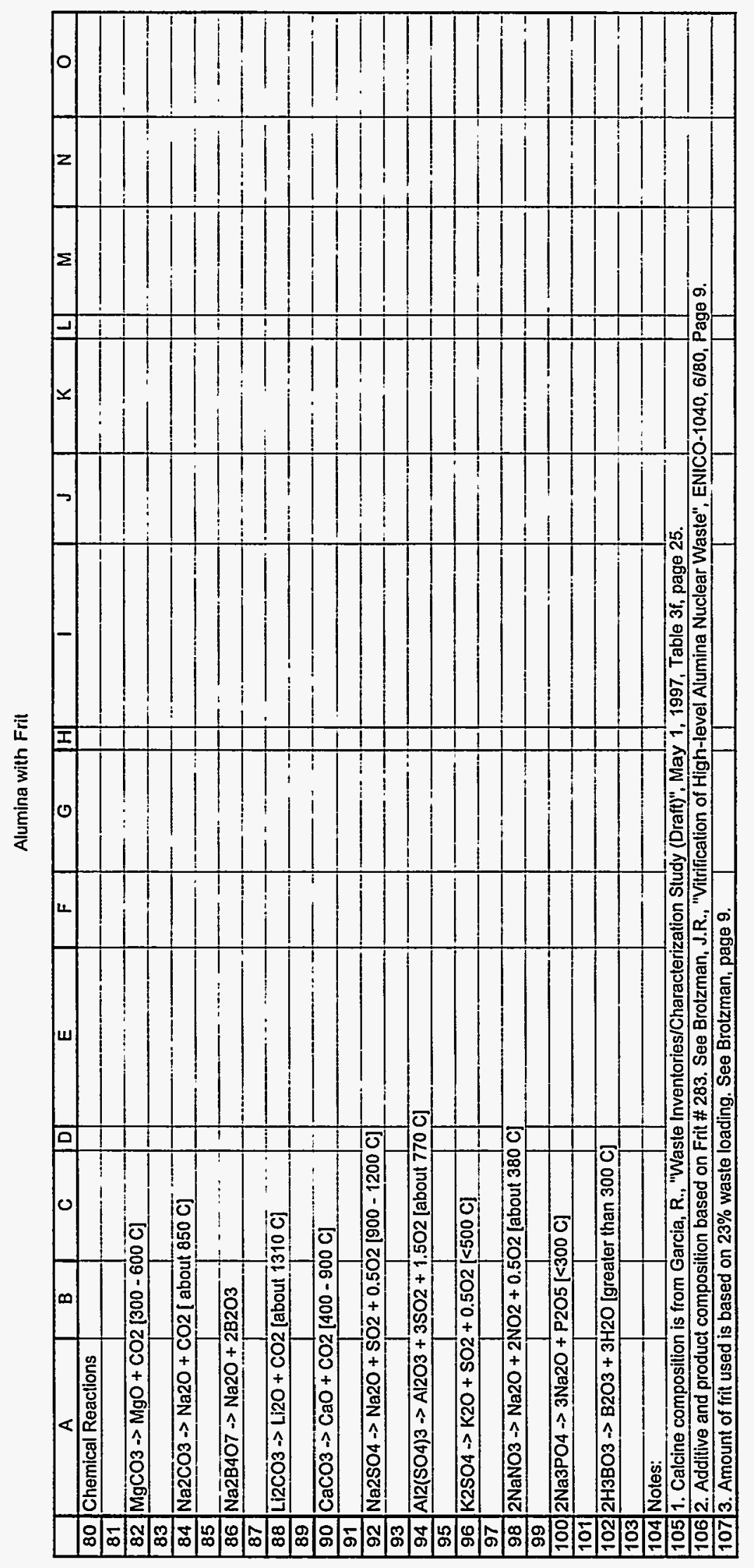


Na-Bearing with Frit

\begin{tabular}{|c|c|c|c|c|c|c|c|c|c|c|c|c|}
\hline & A & $\mathrm{B}$ & $\overline{\mathbf{C}}$ & DI & $F$ & $\mathbf{G} \cdot$ & [H] & $\mathrm{J}$ & $\mathrm{K}$ & L] & $\bar{N}$ & 0 \\
\hline 1 & \multicolumn{12}{|c|}{ Sodium-Bearing Calcine } \\
\hline 2 & $\begin{array}{l}\text { Feed Rale, lbs. per } \\
\text { day }\end{array}$ & 4676 & & $\begin{array}{c}\text { Fraction of Calcine in } \\
\text { Product }\end{array}$ & 0.30 & & & & & & & \\
\hline 3 & & & & & & & & & & & & \\
\hline 4 & Calcine Composition & wt. \% & Ibs. per day & Additive Composition & $w t \%$ & Ibs. per day & Product Composition & wt.\% & lbs. per day & \begin{tabular}{|c|} 
Off-Gas \\
Composition
\end{tabular} & wt. $\%$ & Ibs. per day \\
\hline 5 & & & & Mass of Frit Added & & 11,395 & & & & & & \\
\hline 6 & $\mathrm{Al} 2 \mathrm{O3}$ & 15.8 & 739 & & & & Al2O3 & $4.74 \%$ & 739 & $\mathrm{O2}$ & $13.49 \%$ & 65 \\
\hline 7 & $\mathrm{Al} 2\left(\mathrm{SO}_{4}\right) 3$ & 0 & - & & & & $\mathrm{Al2}(\mathrm{SO} 4) 3$ & $0.00 \%$ & - & $\overline{\mathrm{CO} 2}$ & $0.00 \%$ & - \\
\hline 8 & AIPO4 & 0 & - & & & & AlPO4 & $0.00 \%$ & - & $\mathrm{H} 2 \mathrm{O}$ & $14.53 \%$ & 70 \\
\hline 9 & $\mathrm{~B} 2 \mathrm{O3}$ & 2.26 & 106 & $\mathrm{~B} 2 \mathrm{O3}$ & $12 \%$ & 1,367 & $\mathrm{B2O3}$ & $9.45 \%$ & 1,473 & $\mathrm{Hg}$ & $1.71 \%$ & 8 \\
\hline 10 & $\mathrm{CaCO} 3$ & 0 & - & & & & $\mathrm{CaCO} 3$ & $0.00 \%$ & - & $\overline{\mathrm{NO2}}$ & $55.37 \%$ & 267 \\
\hline 11 & $\mathrm{CaF2}$ & 41.84 & 1,957 & & & & $\mathrm{CaF2}$ & $12.55 \%$ & 1,957 & 502 & $14.90 \%$ & 72 \\
\hline 12 & $\mathrm{CaO}$ & 8.87 & 415 & & & & $\mathrm{CaO}$ & $2.66 \%$ & 415 & & & \\
\hline 13 & $\mathrm{Ca3}(\mathrm{PO} 4) 2$ & 0.01 & 0 & & & & $\mathrm{Ca3}(\mathrm{PO} 4) 2$ & $0.00 \%$ & 0 & & & \\
\hline$\overline{14}$ & $\mathrm{CdO}$ & 2.5 & 117 & & & & $\mathrm{CdO}$ & $0.75 \%$ & 117 & & & \\
\hline 15 & $\mathrm{Cr} 2 \mathrm{O3}$ & 0.12 & 6 & & & & $\mathrm{Cr} 2 \mathrm{O} 3$ & $0.04 \%$ & 6 & & & \\
\hline 16 & $\mathrm{CuO}$ & 0 & - & & & & $\mathrm{CuO}$ & $0.00 \%$ & - & & & \\
\hline 17 & $\mathrm{Fe} 2 \mathrm{O3}$ & 0.57 & 27 & & & & $\mathrm{Fe2O3}$ & $0.17 \%$ & 27 & & & \\
\hline 18 & Gd2O3 & 0 & - & & & & $\mathrm{Gd} 2 \mathrm{O} 3$ & $0.00 \%$ & - & & & \\
\hline 19 & $\overline{\mathrm{H} 2 \mathrm{O}}$ & 1.5 & 70 & & & & $\mathrm{H} 2 \mathrm{O}$ & $0.00 \%$ & & & & \\
\hline 20 & H3BO3 & 0 & - & & & & H3BO3 & $0.00 \%$ & - & & & \\
\hline 21 & $\mathrm{HgO}$ & 0.19 & 9 & & & & $\mathrm{HgO}$ & $0.00 \%$ & - & & & \\
\hline 22 & KAIO2 & 0 & - & & & & KAIO2 & $0.00 \%$ & - & & & \\
\hline 23 & K2O & 0 & - & & & & $\mathrm{K} 2 \mathrm{O}$ & $0.29 \%$ & 45 & & & \\
\hline 24 & $\mathrm{~K} 2 \mathrm{SO4}$ & 1.78 & 83 & & & & $\mathrm{~K} 2 \mathrm{SO}_{4}$ & $0.00 \%$ & - & & & \\
\hline 25 & Li2O & 0 & - & & & & Li2O & $0.00 \%$ & - & & & \\
\hline 26 & $\mathrm{Li2} 2 \mathrm{CO}$ & 0 & - & & & & $\mathrm{Li} 2 \mathrm{CO} 3$ & $0.00 \%$ & - & & & \\
\hline 27 & $\mathrm{MgO}$ & o & - & & & & $\mathrm{MgO}$ & $0.00 \%$ & - & & & \\
\hline 28 & $\mathrm{MgCO} 3$ & 0 & - & & & & $\mathrm{MgCO} 3$ & $0.00 \%$ & - & & & \\
\hline 29 & $\mathrm{MnO}$ & 0.02 & 1 & & & & $\mathrm{MnO}$ & $0.01 \%$ & 1 & & & \\
\hline 30 & $\mathrm{MoO3}$ & 0 & - & & & & $\mathrm{MoO3}$ & $0.00 \%$ & - & & & \\
\hline 31 & $\mathrm{Na} 2 \mathrm{O}$ & 0 & - & & & & $\mathrm{Na2O}$ & $1.41 \%$ & 220 & & & \\
\hline 32 & NaAIO2 & 0.87 & 41 & & & & $\mathrm{NaAlO2}$ & $0.26 \%$ & 41 & & & \\
\hline 33 & $\mathrm{NaCl}$ & 0 & - & & & & $\mathrm{NaCl}$ & $0.00 \%$ & - & & & \\
\hline 34 & $\mathrm{Na2CO} 3$ & 0 & - & & & & $\mathrm{Na} 2 \mathrm{CO} 3$ & $0.00 \%$ & - & & & \\
\hline 35 & $\mathrm{Na2B} 407$ & 0 & - & & & & $\mathrm{Na2B4O7}$ & $0.00 \%$ & - & & & \\
\hline 36 & $\mathrm{NaF}$ & 0 & - & & & & $\mathrm{NaF}$ & $0.00 \%$ & - & & & \\
\hline 37 & $\mathrm{NaNO3}$ & 10.56 & 494 & & & & $\overline{\mathrm{NaNO} 3}$ & $0.00 \%$ & - & & & \\
\hline 38 & $\mathrm{Na3}(\mathrm{PO} 4) 2$ & 0 & - & & & & $\mathrm{Na3}(\mathrm{PO} 4) 2$ & $0.00 \%$ & - & & & \\
\hline 39 & $\mathrm{Na2SO4}$ & 1.96 & 92 & & & & $\mathrm{Na2SO4}$ & $0.00 \%$ & - & & & \\
\hline 40 & $\mathrm{Nb2O5}$ & 0.26 & 12 & & & & $\mathrm{Nb2O5}$ & $0.08 \%$ & 12 & & & \\
\hline 41 & $\mathrm{NiO}$ & 0.01 & 0 & & & & $\mathrm{NiO}$ & $0.00 \%$ & 0 & & & \\
\hline 42 & P2O5 & 0 & - & & & & $\mathrm{P2O5}$ & $0.00 \%$ & - & & & \\
\hline 43 & $\mathrm{PbO}$ & 0 & - & & & & $\mathrm{PbO}$ & $0.00 \%$ & - & & & \\
\hline 44 & $\mathrm{SiO} 2$ & 0 & - & $\mathrm{SiO} 2$ & $88 \%$ & 10,028 & $\mathrm{SiO} 2$ & $64.33 \%$ & 10,028 & & & \\
\hline 45 & $\mathrm{SnO2}$ & 0.15 & 7 & & & & $\mathrm{SnO} 2$ & $0.04 \%$ & 7 & & & \\
\hline$\overline{46}$ & UO2 & 0.01 & 0 & & & & $\mathrm{UO2}$ & $0.00 \%$ & 0 & & & \\
\hline 47 & $\mathrm{ZrO2}$ & 10.72 & 501 & & & & $\overline{\mathrm{ZrO} 2}$ & $3.22 \%$ & 501 & & & \\
\hline 48 & Total & 100 & 4,676 & Total & $100 \%$ & 11,395 & Total & $100.00 \%$ & 15,589 & Total & $100 \%$ & 483 \\
\hline
\end{tabular}




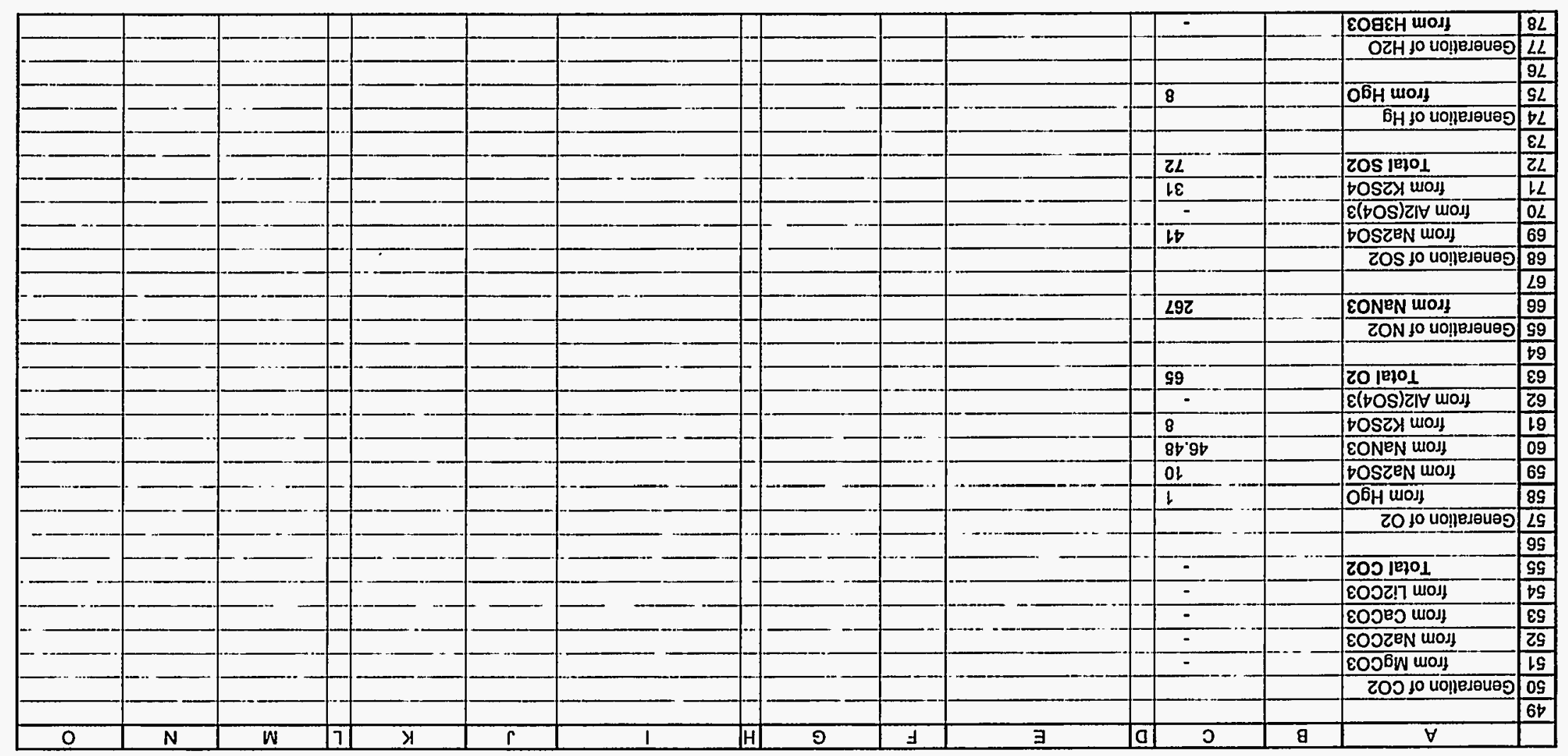




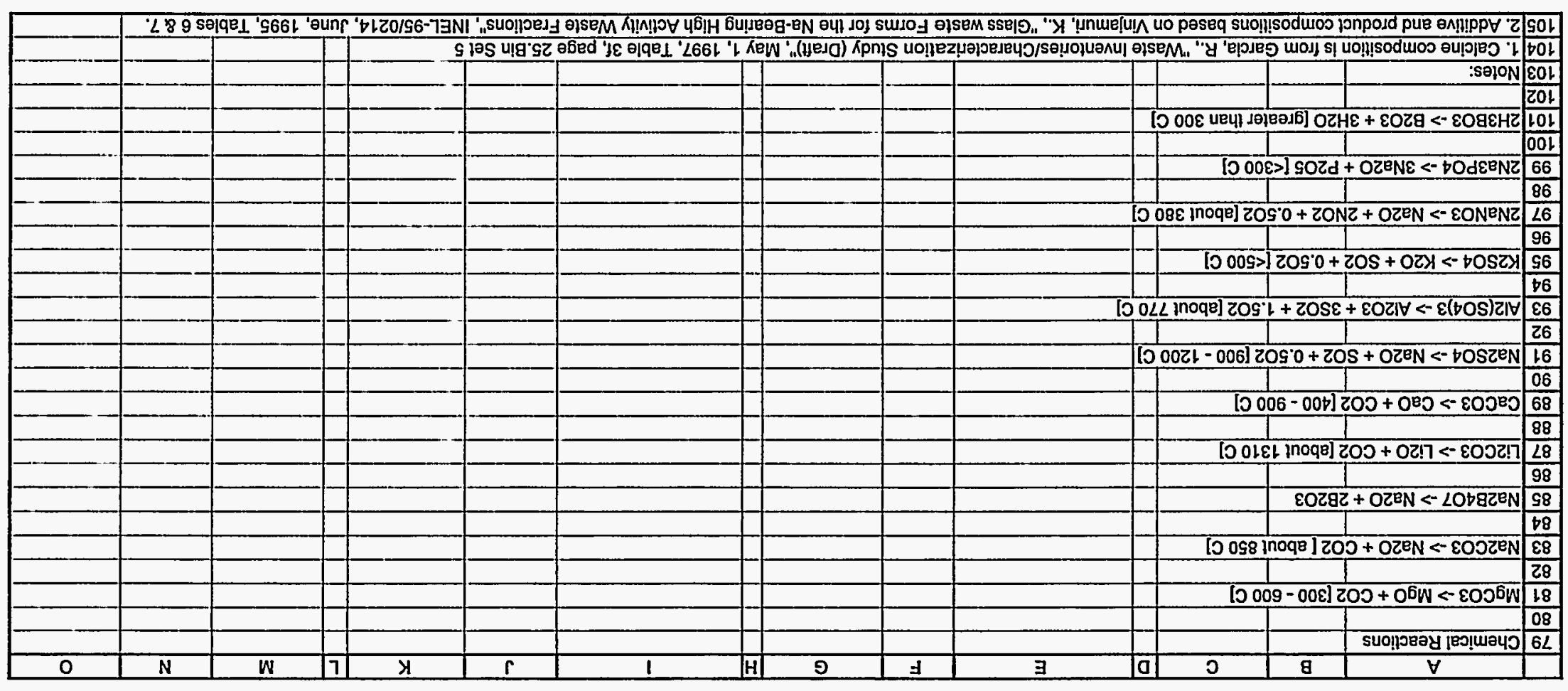

I!」 $41 \mathrm{M}$ Guyeeg-8N 


\begin{tabular}{|c|c|c|c|c|c|c|c|c|c|c|c|c|c|}
\hline Stream Number & $\frac{1}{\text { Ofl.Gas to }}$ & 2 & $\frac{3}{\text { Quonch Water }}$ & 4 & \begin{tabular}{|c|}
5 \\
Ventur Scrubber
\end{tabular} & $\frac{6}{\text { Off-Gas to }}$ & $\frac{7}{\text { Packed Bed }}$ & $\frac{8}{\text { Venturi Scrubber }}$ & $\frac{9}{\text { Packod Bod }}$ & $\frac{10}{\text { Scrubber Water }}$ & $\frac{11}{\text { Off-Gas to HEPA }}$ & $\frac{12}{\text { Off-Gas to GAC }}$ & $\frac{13}{\text { Scrubber Waler }}$ \\
\hline Description & Quench & Quench Wator & Rolum & Ofr-Gas to Venturi & Waler & Packed Bed & Scrubber Water & Waler Return & Water Retum & Foed & Fillors & Vessel & Blowdown \\
\hline Llquilds & & & & & & & & & & & & & \\
\hline Total Mass Flow Rato, $1 \mathrm{~b} / \mathrm{hr}$ & & $\frac{2500}{1138}$ & 2039 & $-\frac{2700}{1207}$ & $\frac{1039}{472}$ & & 3798 & 188 & 3800 & $\frac{7297}{217}$ & & & $\frac{159}{77}$ \\
\hline Total Mass Flow Rale, kg & & $\frac{1138}{0.12}$ & 827 & 1227 & 472 & & 1726 & 85 & 1727 & 3317 & & & 72 \\
\hline Sollds, lbsmir & 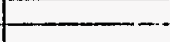 & $\begin{array}{l}0.12 \\
624\end{array}$ & & & & & & & & & & & 0.24 \\
\hline Densliy, Ib/cu.fi. & & 62.4 & 62.4 & & & & & & & & & & \\
\hline Densilly, kg/cu.meter & & & & & & & & & & & & & \\
\hline (2) & & . & & $\cdots$ & 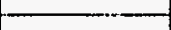 & & 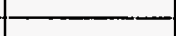 & $\ldots$ & & 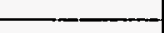 & & & \\
\hline Total Mass Flow Rate, lbMir & & & & & & & & & & & & & \\
\hline Total Mass Flow Rate, $\mathrm{kg} / \mathrm{hr}$ & & & & & & & & & & & & & \\
\hline Sollds Content, mglau. meter & 250 & & & 125 & & 63 & & & & & & & \\
\hline Hg Content, mg/cu. meler & 5606 & & & 280 & & 252 & & & & & & & \\
\hline NO2 Content, ppmv & 2080 & & & 1976 & & 1778 & & & & & & & \\
\hline SO2 Content,ppmv & 970 & & & 922 & & -829 & & & & & & & \\
\hline Densily, ib/cu.ft. & & & & & & & & & & & & & \\
\hline Densily, kg/cu.moter & & & & & & & & & & & & & \\
\hline Volume Flow Rale, ACFM & 275 & & & 367 & & $\begin{array}{r}340 \\
\end{array}$ & & & & & 350 & 350 & \\
\hline 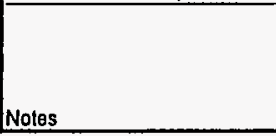 & $\begin{array}{l}\text { Solids loading } \\
\text { assumes } 250 \mathrm{mg} \\
\text { per cu. meler. }\end{array}$ & $\begin{array}{l}\text { Assume } 50 \% \text { of } \\
\text { sollds removed in } \\
\text { guench column }\end{array}$ & & $\begin{array}{l}\text { Quench removes } \\
5 \% \text { of NO2 \&SO2, } \\
\text { hall of sollds, and } \\
90 \% \text { of } \mathrm{Hg}\end{array}$ & & \begin{tabular}{|l|} 
Venluri removes \\
$10 \%$ of remaining \\
NO2\&SO2\&Hg, \\
$50 \%$ of remaining \\
sollds
\end{tabular} & $\begin{array}{l}\text { Gas now rale } \\
\text { based on input } \\
\text { from Sara Glfford. } \\
\end{array}$ & & & & & & $\begin{array}{l}\text { Basis is } 150 \\
\text { gallons of } \\
\text { blowdown every } 8 \\
\text { hours. }\end{array}$ \\
\hline
\end{tabular}




\begin{tabular}{|c|c|c|c|c|c|c|c|c|c|c|}
\hline & & & & & & & & & 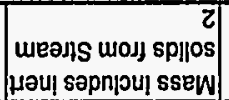 & selon \\
\hline & & & & & & & & & & 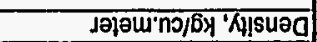 \\
\hline & & & & & & & & & & 'y'no/91 'Ki|suea \\
\hline & & & & & & & & 96 & $0, \mathbf{S}$ & 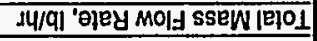 \\
\hline & & & & & & & & & & spllos \\
\hline & & & & & & & & & & \\
\hline & & & & & & & & & & 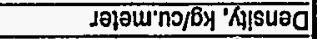 \\
\hline & & & & & & & & & & 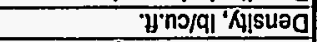 \\
\hline & & & & & & & & & & du/sq| 'sp!|IOS \\
\hline & & & & & & & & & & 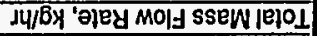 \\
\hline & & & & & & & & & & dy/q1 'ojey MOIJ Ssew lejo 1 \\
\hline & & & & & & & & & & spjnbi7 \\
\hline & & & & & & & & we6|ew & KnJJOW PaYSEM & uolidụosag \\
\hline & & & & & & & & 2I & $H$ & JaqunN WEEJIS \\
\hline & & & & & & & & & & \\
\hline & & & & & & & & & & \\
\hline & & & & & & & & & & \\
\hline & 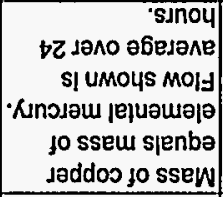 & & & & 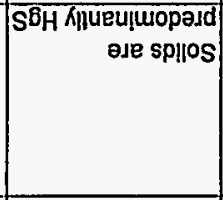 & & & 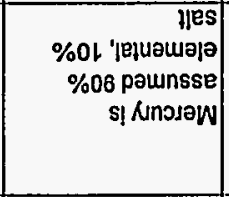 & 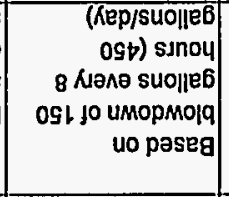 & SolON \\
\hline & & & & & & & & & & 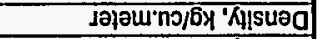 \\
\hline & & & & & & & & & & 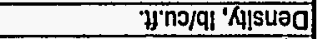 \\
\hline & & & & & & & & & & 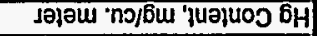 \\
\hline $60^{\circ} 0$ & $\bar{z} z$ & & & & & & & & & دu/6y 'כjey Mold ssew lelol \\
\hline 0 & 87 & & & & & & & & & 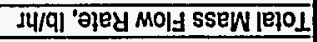 \\
\hline & & & & & & & & & & spllos \\
\hline & & & & & & & & & & \\
\hline & & & & & & & & & & 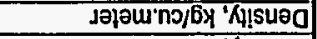 \\
\hline & & & & & & & & & & y'no/q1 K/!sueg \\
\hline & & & & & & & $\bar{s} 0$ & 8.6 & 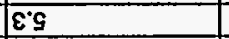 & 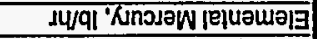 \\
\hline & & & & & $9 \cdot 0$ & & $60 \%$ & $02: 0$ & $+2 \%$ & du/sql 'sp!|jos \\
\hline & & bE & 91 & $9 \varepsilon h$ & 68 & 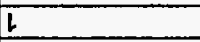 & DS & 81 & $Z L$ & 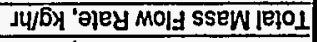 \\
\hline & & SL & SE & OOSZ & $96 !$ & 2 & $61 \mathrm{~L}$ & $0 t$ & 69l & Ju/ql 'ojey MOIf SSEW letol \\
\hline & & & & & & & & & & sp!nb!l] \\
\hline 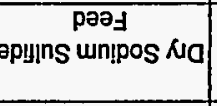 & $\begin{array}{c}\text { päs } \\
\text { Jəddoכ рәјәрмод }\end{array}$ & 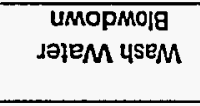 & $\begin{array}{l}\text { dnayew sajeM } \\
\text { paz!|еуәu!uəa }\end{array}$ & 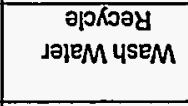 & 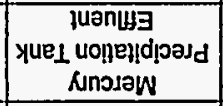 & $\begin{array}{l}\text { uolnnos paad } \\
\text { opunns un!pos }\end{array}$ & 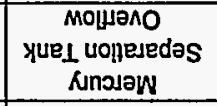 & $\begin{array}{c}\text { sulohlog } \\
\text { yue } \perp \text { uonejedas } \\
\text { Runosaw }\end{array}$ & 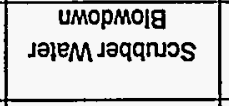 & uonnd!IJsad \\
\hline
\end{tabular}

\section{0-45-OM}


Material Balance

for

\begin{tabular}{|c|c|c|c|c|c|c|}
\hline Stream Number & 1 & 2 & 3 & 4 & 5 & 6 \\
\hline Description & $\begin{array}{l}\text { Calcine Transfer } \\
\text { from Bins }\end{array}$ & $\begin{array}{l}\text { Calcine Feed to } \\
\text { Load Hopper }\end{array}$ & Fluidizing Air & $\begin{array}{c}\text { Transfer Air } \\
\text { Exhaust }\end{array}$ & $\begin{array}{c}\text { Calcine to Ribbon } \\
\text { Blender }\end{array}$ & $\begin{array}{c}\text { Calcine Fines } \\
\text { Return }\end{array}$ \\
\hline \multicolumn{7}{|l|}{ Solids } \\
\hline Total Mass Flow Rate, Ib/hr & 2700 & 2700 & & & 188 & 50 \\
\hline Total Mass Flow Rate, kg/hr & 1227 & 1227 & & & 85 & 23 \\
\hline \multicolumn{7}{|l|}{ Density, lb/cu.ft. } \\
\hline \multicolumn{7}{|l|}{ Density, kg/cu.meter } \\
\hline & & & & & & \\
\hline \multicolumn{7}{|l|}{ Gases } \\
\hline \multicolumn{7}{|l|}{ Total Mass Flow Rate, Ib/hr } \\
\hline \multicolumn{7}{|l|}{ Total Mass Flow Rate, $\mathrm{kg} / \mathrm{hr}$} \\
\hline \multicolumn{7}{|l|}{ Density, lb/cu.ft. } \\
\hline \multicolumn{7}{|l|}{ Density, kg/cu.meter } \\
\hline Volume Flow Rate, SCFM & 1600 & 4000 & 4000 & 4000 & & 500 \\
\hline Notes & \begin{tabular}{|l|} 
Solid \& gas flow \\
rates based on \\
input from Sara \\
Gifford. Calcine \\
transfer occurrs \\
approximately \\
every 6 days.
\end{tabular} & & & $\begin{array}{l}\text { Flow rate based } \\
\text { on Ratheon } \\
\text { design. }\end{array}$ & & \\
\hline
\end{tabular}


Material Balance

for

Sketch WWO-SK-08

\begin{tabular}{|c|c|c|c|c|c|c|c|c|}
\hline Stream Number & 1 & 2 & 3 & 4 & 5 & 6 & 7 & 8 \\
\hline Description & $\begin{array}{l}\text { Frit Unloading to } \\
\text { Storage Silos }\end{array}$ & $\begin{array}{l}\text { Frit Transfer to } \\
\text { Feed Hoppers }\end{array}$ & $\begin{array}{c}\text { Frit Transfer to } \\
\text { Load Hopper }\end{array}$ & $\begin{array}{l}\text { Frit Transfer to } \\
\text { Ribbon Blender }\end{array}$ & $\begin{array}{c}\text { Calcine to Ribbon } \\
\text { Blender }\end{array}$ & $\begin{array}{c}\text { Batch Transfer to } \\
\text { Melter }\end{array}$ & $\begin{array}{c}\text { Glass Transfer to } \\
\text { Canisters }\end{array}$ & $\begin{array}{c}\text { Off-Gas to } \\
\text { Treatment System }\end{array}$ \\
\hline Mass Flow Rate, lb/hr & 15,000 & 4250 & 3000 & 751 & 195 & 946 & 929 & 1,229 \\
\hline Mass Flow Rate, $\mathrm{kg} / \mathrm{hr}$ & 6,818 & 1,932 & 1,364 & 341 & 89 & 430 & 422 & 559 \\
\hline Density, lb/cu.ft. & 162 & 162 & 162 & 162 & 87 & 156 & 162 & \\
\hline Density, kg/cu.meter & 2,581 & 2,581 & 2,581 & 2,581 & 1,390 & 2,482 & 2,581 & . \\
\hline Gas Flow Rate, SCFM & & & & & & & & 250 \\
\hline Notes & $\begin{array}{l}\text { Operation occurs } \\
\text { approximately } \\
\text { once every } 6 \\
\text { days. Assumes } \\
\text { unloading of rail } \\
\text { car in } 1 \text { shift. }\end{array}$ & $\begin{array}{l}\text { Operation occurs } \\
\text { approximately } \\
\text { once per day. } \\
\text { Assumes transfer } \\
\text { in } 1 / 2 \text { shift. }\end{array}$ & $\begin{array}{l}\text { Operation occurs } \\
\text { once per shift and } \\
\text { takes } \\
\text { approximately } 2 \\
\text { hours. }\end{array}$ & $\begin{array}{l}\text { Process is } \\
\text { continuous during } \\
\text { melter operation. }\end{array}$ & $\begin{array}{l}\text { Process is } \\
\text { continuous during } \\
\text { melter operation. }\end{array}$ & $\begin{array}{l}\text { Process is } \\
\text { essentially } \\
\text { continuous. } \\
\text { Interrupted only to } \\
\text { exchange a full } \\
\text { canister for an } \\
\text { empty one. }\end{array}$ & $\begin{array}{l}\text { Process is } \\
\text { essentially } \\
\text { continuous. } \\
\text { Interrupted only to } \\
\text { exchange a full } \\
\text { canister for an } \\
\text { empty one. }\end{array}$ & $\begin{array}{l}\text { Includes controlled } \\
\text { ambient air } \\
\text { inleakage plus } \\
\text { vapors and } \\
\text { particulates } \\
\text { generated by the } \\
\text { melter }\end{array}$ \\
\hline
\end{tabular}


Project File Number $\quad$ O2BFO

Project/Task Non-Separation Alternatives

Subtask Vitrified Waste Option

Title: Conference Call with Mr. D. Bickford of SRS re: SRS-DWPF Melter Design Summary:

This EDF provides the high-lites of a conference call with Mr. Dennis Bickford of SRS by the VWO project team that took place on October 30,1997 . The call was made to learn as much design and operation information as reasonable from the operation of the SRS Defense Waste Processing Facility Melter which vitrifies highlevel waste.

Distribution (complete package): WTP EIS Studies Library, V.L.Jacobson MS 3211, R.T.Jamison MS 4146, R.R.Kimmitt MS 3625, D.A.Lopez MS 3765, K.L.Williams MS 3765, W.J.Prendergast MS 3710

Distribution (summary package only): D.J.Harrell MS 3211, B.R.Helm MS 3765

\begin{tabular}{|c|c|c|c|c|c|}
\hline $\begin{array}{l}\text { Author } \\
\text { W. J. } \\
\text { Prendergast }\end{array}$ & $\begin{array}{l}\text { Dept. } \\
\text { Chemical \& } \\
\text { Env'mtl } \\
\text { Eng'ng } \\
\end{array}$ & $\begin{array}{l}\text { Reviewed } \\
\text { R.T.Jamison } \\
7 . T \text { Thmiston }\end{array}$ & Date & $\begin{array}{l}\text { Approved } \\
\text { D. Lopez } \\
24 \text { yopes }\end{array}$ & $\begin{array}{l}\text { Date } \\
12 / 22 / 97\end{array}$ \\
\hline 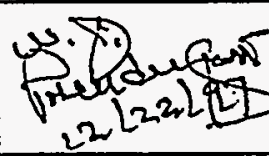 & & $\begin{array}{l}\text { LMITCO } \\
\text { Review } \\
12-22-97\end{array}$ & Date & $\begin{array}{l}\text { LMITCO } \\
\text { Approval }\end{array}$ & Date \\
\hline & & & & & \\
\hline
\end{tabular}

See Management Control Procedure (MCP) 6 for instructions on use of this form. 


\section{Summary}

This EDF addresses a conference call made to Mr. Dennis Bickford of the Savannah River Site (SRS) on October 30, 1997 by members of the VWO project team. Dennis Bickford is perhaps the most knowledgeable person about the design and operation of the melter used at the Defense Waste Processing Facility (DWPF) at SRS for the vitrification of highly radioactive waste sludge and precipitate. This call was made because it was believed it could provide the project team meaningful insight into the actual operation of a similar melter design to the one that is the subject of this feasibility study. A brief description of the SRS-DWPF melter process consists of the following steps: waste streams are mixed into a blend of high-level waste sludge and a precipitate from a dissolved saltcake; they are then mixed with tiny borosilicate glass beads and the mixture is then fed into a melter where it is heated to $1150 \mathrm{C}$. The resultant melt is poured into stainless steel canisters ( $10 \mathrm{ft}$ long by $2 \mathrm{ft}$ dia.) to cool and harden. The canisters are then sealed, decontaminated, welded shut and then stored on site in a building designed for safe interim storage until a federal repository is available. The DWPF melter was placed into operation in March, 1996.

Participating in this conference call for the project team were; Daryl Lopez, Raymond Kimmitt, Stephanie Austad, Michael Gifford, Mark Van Sickle and Jack Prendergast. The project team is most appreciative of Dennis Bickford's insight, knowledge and willingness to discuss key aspects of the SRS melter design and operation with us.

\section{Conference Call Results}

The conference call notes are presented below in a question and answer format to facilitate understanding. A list of proposed questions were presented to Dennis Bickford a day before the conference call was made and those questions were discussed sequentially during the conference call. Sometimes the answers deviate slightly from the questions but this is the way the call progressed so they are presented as discussed.

1. " $Q$ " What is the design basis for the on-stream operating time?

"A" A 70\% on-stream time is the design basis for the SRS melter. There is additional storage in tanks throughout the process to provide a good level of operating flexibility.

2. " $\mathrm{Q}$ " What is the redundancy (safety factor) design basis for a melter failure? What is the most probable failure mode? What is the expected useful life of the melter?

"A" A refractory failure is the most probable failure mode. The refractory is designed for $1 / 2$-inch loss per year @ $1150 \mathrm{C}$ operation whereas the maximum experienced loss is about $1 / 2$-inch in six years so there is a very healthy safety factor. The refractory is $30 \%$ chromium and $70 \%$ alumina. Since the normal 
operating temperature is $1150 \mathrm{C}$ and this is well below the design maximum operating refractory temperature of 1400 to $1500 \mathrm{C}$, the refractory should have a long life from that aspect of design. There is one complete melter in storage at present and another spare melter is currently being fabricated. The fabrication lead time is about 24 months so it was believed prudent to fabricate another unit. The melter system design package consists of infrastructure by Chicago Bridge and Iron, refractory by Carborundum, and the balance of the design requirements by the Toledo Engineering Company. The expected useful life is not known since the melter has been in operation less than two years and experienced failure rate cannot be adequately estimated.

3. " $\mathrm{Q}$ " What is the feed system redundancy design basis? Is there a provision for off-spec feed? Is there a a provision for off-spec blend storage? Is there a provision for off-spec product?

"A" The feed system redundancy consists of two blend tanks and a single melter feed vessel that are interchangeable if needed. After feed is tested good, it is pumped to a 7-day capacity melter feed tank. There is some free-board in the blend tanks to provisionally allow for feed recipe adjustment if necessary. The current raw waste tank has about two years of feed material for the melter. Since the analysis and quality control testing emphasis is placed heavily on the feed blend meeting specifications, essentially all melted material from the melter is assumed to be on-spec. This is an operating philosophy that SRS appears to practice and it has proven to be warranted. If there is an emergency shut-down of the melter or other serious melter problems, then the product is assumed to be offspec and the logistical issues for dealing with that issue is addressed below.

4. " $\mathrm{Q}$ " What melter process (total process plant) spare equipment is purchased in advance and stored on-site?

"A" The melter system only has additional spare stored on-site with another in the fabrication process now. The off-gas treatment system is completely backed-up on stream with another complete system installed and on stand-by duty. The feed storage has the built-in redundancy discussed above.

5. " $Q$ " What are the logistical issues for hot (rad-hot) equipment replacement? Feed and product system management? Melter handling provisional management/storage/decon \& return to service?

" $A$ " The melter is first drained at the bottom of the unit into special hold-up canisters ( 4 to 5 canisters are stored below the melter for this purpose). There is emergency back-up power that is activated to back-up a set of on-stream resistive heater electrodes to keep the glass molten without setting-up. There are four additional electric circuits for the back-up electrodes. If the melter system fails, it is temporarily stored in a below-grade vault and subsequently removed by rail-car in a special shipping cask where it is transported on-site to the storage decon 
area. There are two decon area remote cells at the DWPF for decon operations of this nature.

6. " $\mathrm{Q}$ " What is the approximate operating labor requirement? What is the total operating support labor requirement from all functions and oversight requirements?

"A" The total staffing requirement is approximately 700 personnel from all support and oversight requirements. This facility has around-the-clock coverage for operations. Preventive maintenance has been minimized by design where possible. The design is based upon a 16-year operating cycle without major maintenance. The system has been automated as much as it reasonably could be automated.

Note: In the SRS Defense Waste Processing Facility (DWPF), There are two major shared operating/processing plants; the Glass Plant and the Saltstone Plant. Per Dennis Bickford, there is no good way to estimate the break-out staffing required For either plant as a stand-alone plant.

7. "Q" If the system were designed again today, what would you do different? What are major operating issues and problems?

" $A$ " The materials of construction of the feed system and the mercury removal system has been very problematic requiring complete replacement of all the original and second generation materials of construction with Hastalloy 276. Interim ( $2^{\text {nd }}$ generation) replacement with a type of alloy steel (with $2 \%$ Copper) was a disaster and no improvement at all over the original stainless steel system. Chlorides and other halides caused much Chloride stress cracking and pitting-type failures of the stainless steel system. The alloy system was severely attacked by mercury reacting with copper present in the alloy. The Hastalloy 276 is holding up well and the corrosion issue has been effectively solved. Important design issues are providing enough hold-up capacity for the feed blends for all provisional criteria and in particular for testing/analysis which has gradually been reduced to a oneday turnaround time for the this requirement. Another important design issue is to provide enough lay-down area for equipment maintenance (including jumper storage) and enough area for jumper line installation for all operating scenarios. Another major design issue per Dennis Bickford's insight is solids mixing design needs. He stated that the Zirconium oxide particle size that we have may pose significant problems in obtaining a uniform melt to include their dissolution in the melt. He said that we should experience a melt rate increase of about $2 X$ faster than the SRS melter due to our dry feed. He stated very emphatically that both Westinghouse and Dupont (M\&O Contractors) discourage all use of fuel addition (hydrocarbons, in particular) to the mixed waste thermal treatment system. This comment was a response to our query about provisional use of propane as a backup heating source for the melter to typically be used after a power failure to maintain the molten material in the melter similar to the EnVitco Melter design. Dennis stated that SRS is currently evaluating, or planning to in the near future, the Stir Melter (trade name for Stir Melter Inc's melter) in conjunction with the 
Clemson Research Center in a development/demonstration project for the vitrification of solid waste like our calcine application.

\section{8. " $Q$ " What is the off-gas system design basis?}

"A" Dennis was requested to provide us with a brief description of what SRS' off-gas system. He said their off-gas system is composed of the following process steps; an off-gas cooler which receives melter off-gas at approximately $600 \mathrm{C}$ from the cold-cap melter operating at melt temperature of about $1100 \mathrm{C}$. The cooler is designed for laminar flow of steam and air at the entrance for the initial cooling to provide protection to the cooler walls, followed by the introduction of dilution air for quenching the temperature further, followed by a venturi scrubber which receives scrub liquid from the scrubber tank recirculation that first passes through a heat exchanger. The scrubber media is water. Next the off-gas flows into a knock-out tank and condensate is collected in a collection tank. The off-gas then flows through two high-efficiency sonic-mixing contact scrubbers employing steam as motive fluid which are each followed by condensers and cyclonic separators. Most of the residual mercury is trapped in condensate from these cooling steps. The gas is next passed through high efficiency demisters and then gas reheaters and finally through HEPA filter bank before passing into the emission stack. The final off-gas contains cell air which is combined with the gas prior to entering the stack.

9. "Q" What is Savannah River's basis for selecting plate electrodes for the melter?

"A" These electrodes are designed for very low amperage per square inch of surface ( 5 amps/in2) and are fabricated from Inconel 600 to potentially provide 500 years electrode life. The electrical circuitry supplying power to the main electrodes are for about 70 volts and 400 to 500 amps. Separate circuits are provided for the melter top (lid) heaters, which total about $1 / 2$ megawatt for the melter.

10. " $Q$ " What is SRS' waste throughput rate and canister fill rate?

"A" Their waste throughput rate is about $220 \mathrm{lbs} / \mathrm{hr}$ and their corresponding canister fill rate is about 1-canister/day. If we fill 5 canisters/day, he suggested that we should use a melter with a cavity which is about 3 cubic feet. 
11. " $Q$ " Does SRS operate with a cold-cap melter and why?

"A" Yes, because their inherent introduction of slurry water into the melter keeps the cap cold and it is also the most efficient system. The main "chokepoint" for handling the canisters is at the abrasive frit solution decontamination station. The decon is relatively fast but the work and paperwork associated with characterizing and handling the frit, and properly mixing it with the calcine for introduction into the melter, is very time consuming. 
Project File Number O2BFO

Project/Task Non-Separation Alternatives

Subtask Vitrified Waste Option

Title: Estimate of Total Staffing Requirement for the VWO Vitrification Facility

Summary:

This EDF addresses the estimate of the total staffing requirement for the Vitrification Waste Option (VWO). The estimate draws from several sources of engineering documentation that provide the general operating description for the VWO process. The primary sources used were the process flow diagrams depicting process streams flowing through all major equipment items, the approximate process equipment layout, worded description of the sequential operating steps, and actual operating experience gleaned from a discussion with Mr. Dennis Bickford of DOE Savannah River who is familiar with melter operations at that location. Staffing support requirements from eighteen different labor staffing categories were then estimated based on operating experience judgement and the information cited above. This staffing estimate is based upon around-the-clock ( 24 hours/day) operations for the VWO. This process has been designed for 180 days per year at 24 hours per day on-stream operating time. This staffing requirement is based upon operations 24 hours per day, 7 days per week, 365 days per year coverage such that when the plant is not operating the staff is busy performing training, maintenance and other activities required to operate the facility effectively and efficiently. The staffing for around-theclock coverage is made up of shift workers and non-shift workers. Shift worker personnel are comprised of 4 groups; 3 operating shifts of 8 hours/shift operations and a shift on their regular days-off following their working shift week. Non-shift staff personnel work straight day shitts only on a 40 hour/week schedule. The total staffing requirement for VWO is 124 personnel.

Distribution (complete package): WTP EIS Studies Library, R.T.Jamison MS, 4146 W.J.Prendergast MS 3710, A copy of this EDF will be included in Report INEEL/EXT-97-01389

Distribution (summary package only):

\begin{tabular}{|c|c|c|c|c|c|}
\hline $\begin{array}{l}\text { Author } \\
\text { W. J. } \\
\text { Prendergast }\end{array}$ & $\begin{array}{l}\text { Dept. } \\
\text { Chemical \& } \\
\text { Env'mtl } \\
\text { Eng'ng }\end{array}$ & $\begin{array}{l}\text { Reviewed } \\
\text { R. T. Jamison } \\
\text { R. }\end{array}$ & Date & $\begin{array}{l}\text { Approved } \\
\text { D. Lopez }\end{array}$ & $\begin{array}{l}\text { Date } \\
1-2 /-98\end{array}$ \\
\hline & 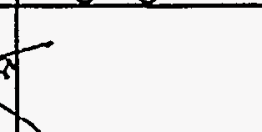 & $\begin{array}{l}\text { LMITCO } \\
\text { Review }\end{array}$ & Date & $\begin{array}{l}\text { LMITCO } \\
\text { Approval }\end{array}$ & Date \\
\hline
\end{tabular}


This EDF identifies a total staffing requirement of 124 personnel made up of the following categories; on-line operations, on-line maintenance, administration, supervision, engineering, security, health and safety (Radcon), industrial safety, process development, and facility maintenance. This estimate is based on a review of all available engineering documentation and per discussions with Mr. Dennis Bickford of DOE Savannah River who is very knowledgeable about Melter Design and Operations at Savannah River. In the breakout of staffing presented below, the number of personnel per shift are multiplied by 4 to arrive at the staffing for all shifts. This is based on 4 groupings of shift worker personnel; 3 operating shifts of 8 hours per shift to provide around the clock coverage and 1 shift of workers on their regular days-off. The non-shift worker personnel are straight day workers at 8 hours per day on a 40 -hour workweek.

The total breakout of staffing is as follows:

Operations:

- Feed Supply Systems; $1 /$ shift

- Melter Operations; $2 /$ shift

- Calcine Management; $1 /$ shift

- Waste Water Systems; 2/shift

- Canister Handling; 3/shift

- General Laborers; 2/shift

Maintenance:

- Mechanical Systems; 5/shift

- Inst. \& Elec. Control; 3/shift

- Pipe-Fitters; 3/shift

\section{All Shifts}

4

8

4

8

12

8

44 total

\section{Support Staffing:}

- Administration;

- Administration Support 3

- Supervision, $2 /$ shift 8

- Engineering Tech. Support 5

- Security; 1/shift 4

- Health \& Safety (Radcon); 2/shift 8

- Industrial Safety 2

- Process Development 2

- Facility Maintenance 2

36 total

Total Staffing Requirement: $\quad \overline{124 \text { total }}$ 
Project File Number $\quad$ 02BFO

Project/Task Non-Separation Alternatives

Subtask Vitrified Waste Option

Title: Electrical Study

Summary: This EDF evaluated the electrical requirements for the Vitrification

Facility. The connected loads were estimated to be $2.6 \mathrm{MVA}$, an

evaluation of the usage indicated that the demand would be approximately 2.0 MVA. The majority of the demand is from the melters. The Bath Electrode requires a source of standby power. The estimated standby requirement is $800 \mathrm{kVA}$. The standby power system at the ICPP is presently undergoing a complete redesign and the final configuration and spare capacity is not known. It would be safe to assume that a new standby generator would needed. This generator would be installed in the existing standby generator building and would be connected to the Substation 60 which distributes standby power to the ICPP. Normal power would be supplied from Substation 15 via two existing Power Sectionalizing Switches. These switches are located in the northeast quadrant of the ICPP and would supply a $13.8 \mathrm{kV}$ feed to the new load center. The load center would supply a secondary voltage of 480 Volts for building and process loads. Standby power would be supplied through this load center from Substation 60.

\section{Distribution (complete package):}

Distribution (summary package only):

\begin{tabular}{|c|c|c|c|c|c|}
\hline $\begin{array}{l}\text { Author } \\
\text { John E. } \\
\text { Duggan }\end{array}$ & $\begin{array}{l}\text { Dept. } \\
\text { AEDL }\end{array}$ & $\begin{array}{l}\text { Reviewed } \\
\text { Zisulifyed }\end{array}$ & $\begin{array}{l}\text { Date } \\
1-19-98\end{array}$ & Approved & $\begin{array}{l}\text { Date } \\
1-19-98\end{array}$ \\
\hline & $1 / 19 / 9$ & $\begin{array}{l}\text { LMITCO } \\
\text { Review }\end{array}$ & Date & $\begin{array}{l}\text { LMITCO } \\
\text { Approval }\end{array}$ & Date \\
\hline
\end{tabular}

See Management Control Procedure (MCP) 6 for instructions on use of this form. 


\section{VITRIFIED WASTE OPTION}

\subsection{ELECTRICAL REQUIREMENTS}

\subsection{EXISTING AND PLANNED ELECTRICAL UTILTIIES AT ICPP}

The ICPP ties into the $138 \mathrm{kV}$ INEEL loop at Substation 2 which is located outside the area fence to the south. Substation 2 transforms the $138 \mathrm{kV}$ to $13.8 \mathrm{kV}$ and provides power to Substation 10 which is located within the ICPP complex. Power at $13.8 \mathrm{kV}$ is than distributed from Substation 10 through the complex. The Electrical and Utility System Upgrade (EUSU) project is currently under construction. The EUSU project will install a new $13.8 \mathrm{kV}$ electrical distribution system throughout the complex. This new system will provide greater safety, additional capacity and greater reliability.

Currently, standby power is provided by each facility. Standby generators are located at various facilities and operate as an island of power during a normal power outage. The EUSU project will construct a standby power plant, install new standby generators and tie existing generators into the standby power system. Standby power will than be distributed through the complex by the new $13.8 \mathrm{kV}$ distribution system, The Utility Control System (UCS) will control the usage of standby power.

\subsection{POWER REQUIREMENTS}

\subsubsection{NORMAL POWER}

The electrical requirements of the Vitrification Facility were analyzed and determined to be $2,568 \mathrm{kVA}$ connected, with a demand projected to be $1,959 \mathrm{kVA}$. The results of the analysis are shown in Tables 1 and 2. The major loads with the Vitrification Facility are the HVAC equipment, and lighting.

Normal power will be supplied to the Vitrification Facility by $13.8 \mathrm{kV}$ feeders from Substation 15. A combination of new and existing duct banks will be used to route the feeders.

\subsubsection{STANDBY POWER}

The requirements for standby power for the Vitrification Facility were analyzed and determined to be $800 \mathrm{kVA}$. The results of the analysis are shown in Table 3. The standby loads for the Vitrification Facility will consist of the following:

- UPS Normal and Bypass feeders

- Selected lighting and miscellaneous loads

- Exhaust and exhaust fans

- Bath electrode

- Other loads as determined in later designs 
Standby power to the Vitrification Facility will be provided over the normal power distribution system from Substation 60, the Standby power plant substation via Substation 15. The standby power system is at or near capacity. Upon completion of the EUSU project, an evaluation of the spare capacity will be performed. If necessary, a $2000 \mathrm{kVA}$ diesel generator and associated equipment will be installed in the space available in the standby generator plant. Shedding of the non-essential loads will be performed by the UCS. The UCS will control the operation of circuit breakers and equipment to assure that only those loads requiring standby power remain in operation

\subsubsection{DISTRIBUTION SYSTEM}

Both normal and standby power will be provided by one set of redundant feeders. The EUSU project will install a redundant pair of sectionalizing switches in the north east quadrant of the complex. These switches, PSS-NCE-1507A and PSS-NCE-1557A are supplied by one set of 500KCMIL cables each. These switches are fed directly from Substation 15 and are very lightly loaded. New duct banks will be run from these switches to a new load center. The load center will be double ended and will provide a redundant source of power to the Vitrification facility.

\subsubsection{UNINTERRUBTABLE POWER SUPPLY (UPS)}

A solid state UPS with a static transfer switch will be provided. The UPS will be provided with a 20 minute battery backup. Both the normal feed and the bypass feed to the UPS will be on standby power. The UPS will feed a 208Y/120 Volt panel. The UPS and the panel will be located in the electrical room. The UPS will support the following loads: Voice paging/evacuation systems, environmental monitoring system and other critical loads.

\subsection{LIGHTING}

\subsubsection{INTERIOR LIGHTING}

Lighting in office areas and other low ceiling areas will be supplied by recessed of pendant mounted fluorescent fixtures. These fixtures will be operated at 277 Volts and will be locally switched. Motion detectors will be utilized areas of low occupancy. Lighting in high bay areas will be will be supplied by metal halide fixtures operating at 277 Volts. The metal halide fixtures will be switched at the lighting panel.

\subsubsection{CELL LIGHTING}

Lighting in the cells will be designed to allow for remote operation of the equipment via an in cell CCTV system or by operation through cell windows. Lighting of the cells will be provided utilizing fixtures mounted in " $K$ " plugs. The number, location, and size of the fixtures and associated " $\mathrm{K}$ " plugs will be coordinated with the cell design during the conceptual phase. The fixtures will be designed and fabricated to facilitate installation and removal for replacement of the light source. Metal Halide light sources are desired 
and will be given preference during the final design. The lighting design will take into account light loss through the translucent panels as well as the light lost in viewing operations through the cell windows.

\subsubsection{EXTERIOR LIGHTING}

The exterior of the building will be illuminated with high pressure sodium wall pack fixtures mounted over each personnel door. Loading areas will be provided with high pressure sodium wall pack fixtures on each side of the doors. The need for area lighting in maneuvering areas will be evaluated during the conceptual and final designs.

\subsubsection{EMERGENCY AND EXIT LIGHTING}

Emergency egress lighting will be in accordance with NFPA 101, Life Safety Code. In areas where illumination is provided by fluorescent fixtures, selected fixtures will be provided with integral battery back up. In areas where illumination is provided by metal halide fixtures, selected fixtures will be provided with a quartz lamp which will be used for emergency lighting. The quartz lamp will be connected to the UPS system or will be provided with an integral battery.

\subsection{DESIGN DESCRIPTION}

\subsubsection{SITE CONDITIONS}

Electrical equipment will be rated for continuous operation at an elevation of 5,000 feet above sea level.

\subsubsection{HAZARDOUS LOCATIONS}

Several areas within the facility will be used for storing or handling of hazardous materials. An evaluation will be performed during the conceptual design and the final design to determine the effects of these materials on the installation of electrical equipment. Flammable and Combustible Liquids Codes NFPA 30: National Electrical Code, NFPA 70; and Recommended Practice for Classification of Class I Hazardous Locations for Electrical Installations in Chemical Process Areas, NFPA 497A will be used in making the determination.

\subsubsection{SERVICES}

\subsubsection{PRIMARY SERVICE}

Two $13.8 \mathrm{kV}$ feeders will provided the primary service to the site. The feeders will originate from Substation 2 located outside the fence. Power for Vitrification Facility will be carried over existing feeders up to Substation 15. From Substation 15, new feeders will be routed through new and existing duct banks. 


\subsubsection{STANDBY POWER}

Standby power will be provided at $13.8 \mathrm{kV}$ over the existing primary distribution system. The existing UCS in conjunction with the Plant Control System which will be installed in the Vitrification Facility will control selected circuit breakers to limit the standby power distribution only to those loads deemed important.

\subsubsection{UTIIZATION VOLTAGES}

Three and possibly four utilization voltages will be provided for the Vitrification Facility. Transformers and load centers located near the facility will transform the $13.8 \mathrm{kV}$ to $480 \mathrm{Y} / 277$ Volt, transformers down stream will transform the 480 Volts to $208 \mathrm{Y} / 120$ Volts. The third and fourth utilization will be determined during the conceptual and title designs. $4160 \mathrm{Y} / 2400$ Volts is desired as the third utilization however, the ICPP currently utilizes 2400 Y/1386 Volts. Preferably, only one will be used. Equipment selection and operating personnel preference will determine the voltage to be utilized.

Electrical loads will be assigned voltages as follows:

- Motors $100 \mathrm{HP}$ and larger $-4160 \mathrm{~V}, 3$ phase or $2400 \mathrm{~V}, 3$ phase

- Resistive loads $100 \mathrm{kVA}$ and larger $-4160 \mathrm{~V}, 3$ phase or $2400 \mathrm{~V}, 3$ phase

- Motors $1 / 2 \mathrm{HP}$ to less than $100 \mathrm{HP}-480 \mathrm{~V}, 3$ phase

- Resistive loads $1 \mathrm{kVA}$ to less than $100 \mathrm{kVA}-480 \mathrm{~V}, 3$ phase

- Motors less than $1 / 2 \mathrm{HP} 120 \mathrm{~V}$, single phase

- Miscellaneous loads less than $1 \mathrm{kVA}-120 \mathrm{~V}$, single phase

- Lighting - 277V single phase.

In certain circumstances, 480V, 3 phase will be utilized for motors over $100 \mathrm{HP}$ and loads over $100 \mathrm{kVA}$. This will be determined on an individual basis after the effects have been evaluated.

\subsubsection{EQUIPMENT}

\subsubsection{LOAD CENTERS}

One load center will be provided. The load center will be located outside the Vitrification Facility and will be a NEMA 3R Walk-in type similar to the load centers currently in use at the ICPP. The load center will provide 480 Y/277 Volts and will be double ended. Each transformer will be sized to provide service to all loads on the load center. The load centers will be provided with all equipment and wiring to insure that it is fully compatible with the existing UCS System. 


\subsubsection{TRANSFORMERS}

Transformers 5,000 kVA and below will be cast coil, dry type transformers. Transformers over $5,000 \mathrm{kVA}$ will be oil filled.

\subsubsection{LIGHTING}

Lighting levels will conform the Illuminating Engineer's Society (IES) handbook and standard practices at the ICPP. In general, the design will provide the following illumination levels:

- Work Stations 70 foot candles

- Work Areas 30 to 50 foot candles depending on activity

- Non-Work Areas 10 foot candles, 50 where data is obtained

\subsubsection{GROUNDING}

Grounding at the ICPP is accomplished with bare copper conductors installed in all duct banks and ground rods installed in every manhole this in turn is solidly connected to the casing of the deep wells. Facilities and structures throughout the ICPP are connected to this ground system. As well, the Vitrification Facility will be connected to the ground system. Grounding within the facility and at the out door load centers and other structures will be accomplished in accordance with the National Electrical Code and IEEE Standard 142-1991, IEEE Recommended Practice for Grounding of Industrial and Commercial Power Systems.

\subsubsection{LIGHTNING PROTECTION}

Lightning protection will be provided in accordance with NFPA 78, Lightning Protection Code. 


\section{TABLE 1}

\section{WASTE TREATMENT PROJECT}

\section{CONNECTED LOAD \\ VITRIFIED WASTE OPTION}

\begin{tabular}{|l|r|}
\hline \multicolumn{1}{|c|}{ LOAD } & kVA \\
\hline General Building Lighting & 377 \\
215,576 sq. Ft @ 1.75 Watts per sq. Ft=377,258 Watts & 216 \\
\hline Miscellaneous Loads & \\
215,576 sq. Ft. @1.0 Watts per sq. Ft=215,576 Watts & 225 \\
\hline HVAC Loads: & 150 \\
Supply Fan Motors & \\
3@75 HP & 300 \\
3@50HP & \\
Exhaust Fan Motors & 150 \\
3@100 HP & 500 \\
Miscellaneous HVAC & 450 \\
150 HP small Motors & 170 \\
\hline Process Equipment: & 70 \\
Melters Bath Electrode 1@ 500 kW & \\
Lid Heater $1 @ 450 \mathrm{~kW}$ & \\
Pumps, Blowers and Conveyors 170 HP & \\
Cranes 70 HP & \\
\hline
\end{tabular}


ENGINEERING DESIGN FILE

TABLE 2

WASTE TREATMENT PROJECT

DEMAND

VITRIFIED WASTE OPTION
Function File Number - SPR-01

EDF Serial Number - EDF-VWO-005 Rev 1

\begin{tabular}{|c|c|c|}
\hline LOAD & DEMAND & kVA \\
\hline $\begin{array}{l}\text { General Building Lighting } \\
215,576 \text { sq. Ft @ } 1.75 \text { Watts per sq. Ft }= \\
377,258 \text { Watts }\end{array}$ & $\begin{array}{l}377,258 \text { Watts @ } 90 \% \text { Demand } \\
=339,532\end{array}$ & 340 \\
\hline $\begin{array}{l}\text { Miscellaneous Loads } \\
\text { 215,576 sq. Ft. @ } 1.0 \text { Watts per sq. Ft = } \\
\text { 215,576 Watts }\end{array}$ & $\begin{array}{l}215,576 \text { Watts @ 50\% demand = } \\
194,018\end{array}$ & 194 \\
\hline $\begin{array}{l}\text { HVAC Loads: } \\
\text { Supply Fan Motors } \\
3 @ 75 \mathrm{HP} \\
3 @ 50 \mathrm{HP} \\
\text { Exhaust Fan Motors } \\
\text { 3@100 HP } \\
\text { Miscellaneous HVAC } \\
\text { 150 HP small Motors }\end{array}$ & $\begin{array}{l}2 @ 75 \mathrm{HP} \\
2 @ 50 \mathrm{HP} \\
2 @ 100 \mathrm{HP} \\
150 \mathrm{HP} @ 75 \%\end{array}$ & $\begin{array}{l}150 \\
100\end{array}$ \\
\hline $\begin{array}{l}\text { Process Equipment: } \\
\text { Melters: Bath Electrode } 1 @ 500 \mathrm{~kW} \\
\text { Lid Heater 1@450 kW } \\
\text { Pumps, Blowers, and conveyors } 170 \mathrm{HP} \\
\text { Cranes } 70 \mathrm{HP} \\
\end{array}$ & $\begin{array}{l}1 @ 500 \mathrm{~kW} \\
1 @ 450 \mathrm{~kW} \\
25 \% \text { of } 170 \mathrm{HP} \\
1 @ 70 \mathrm{HP}\end{array}$ & $\begin{array}{r}500 \\
450 \\
43 \\
70 \\
\end{array}$ \\
\hline Total Demand kVA & & 1959 \\
\hline
\end{tabular}


TABLE 3

WASTE TREATMENT PROJECT

STANDBY POWER REQUIREMENTS

VITRIFIED WASTE OPTION

\begin{tabular}{|c|c|c|}
\hline LOAD & STANDBY POWER & kVA \\
\hline General Building Lighting & $10 \%$ of $377,258=37,726$ & 38 \\
\hline Miscellaneous Loads & $10 \%$ of $215,576=21,558$ & 22 \\
\hline $\begin{array}{l}\text { HVAC Loads } \\
\text { Sunnly Fan }\end{array}$ & 1 (ब) $75 \mathrm{HP}$ & 75 \\
\hline $3 @ 50$ HP & $1 @ 50 \mathrm{HP}$ & 50 \\
\hline Exhaust Fan Motors $1 @ 100 \mathrm{HP}$ & $1 @ 100 \mathrm{HP}$ & 100 \\
\hline Miscellaneous HVAC $10 \%$ of $150 \mathrm{HP}$ & $15 \mathrm{HP}$ & 15 \\
\hline Process Equipment Bath Electrode & $500 \mathrm{~kW}$ & 500 \\
\hline Total Standby kVA & & $\mathbf{8 0 0}$ \\
\hline
\end{tabular}




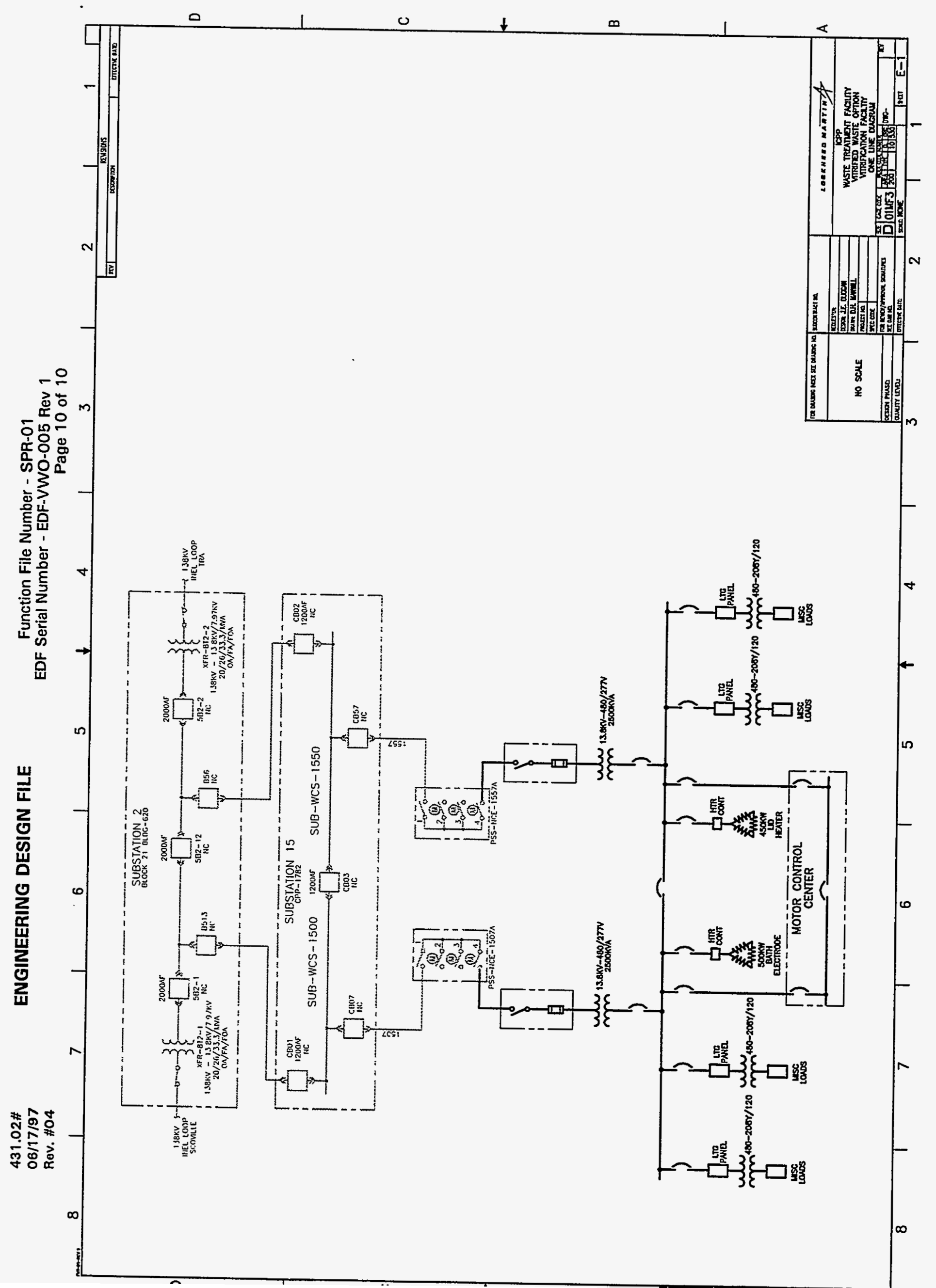


Project File Number $\quad$ 02BF0

Project/Task Non-Separation Alternative

Subtask Vitrified Waste Option

Title: $\quad$ Fluidized Bed Blending Tank Cell Shielding Calculation

Summary: This summary briefly defines the problem or activity to be addressed in the EDF, gives a summary of the activities performed in addressing the problem and states the conclusions, recommendations, or results arrived at from this task.

This EDF includes a calculated dose rate for a shielding configuration involving the Fluidized Bed Blending Tank Cell. The cell contains two 10.5-ft diameter cylindrical tanks filled to $6 \mathrm{ft}$ with alumina calcine. The cell is surrounded on all four sides by shielding walls consisting of standard concrete $(2.35 \mathrm{~g} / \mathrm{cm} 3)$. The source consists of alumina calcine with radionuclide activities taken from Table 7 in reference 1. Using the Microshield Version 5.01 computer code it was determined that a thickness of $93 \mathrm{~cm}$ (3.05 feet) or greater of concrete would be required to attenuate the source gamma radiation to less than $0.1 \mathrm{mR} / \mathrm{hr}$ at contact (1 centimeter) from the outside shielding surface. A copy of the computer run is included in the attachment.

Distribution (complete package): WTP EIS Studies Library, A copy of this EDF will be included in Report INEEL/EXT-97-01289, T. S. Bohn File (MS 4138), Radiological Support EDF File (MS 4138)

Distribution (summary package only): G. W. Clarke (MS 4138), W. C. Craft III (MS 4138), H. K. Peterson (MS 2107)

\begin{tabular}{|c|c|c|c|c|c|}
\hline $\begin{array}{l}\text { Author } \\
\text { T.S. Bohn } \\
\text { 9. Bohn }\end{array}$ & $\begin{array}{l}\text { Dept. } \\
1341 \\
1 / 29 / 98\end{array}$ & $\begin{array}{l}\text { Reviewed } \\
\text { H. K.Peterson }\end{array}$ & $1 / 29 / 98$ & $\begin{array}{l}\text { Approved } \\
\text { G.W. Clarke }\end{array}$ & $\begin{array}{l}\text { Date } \\
1-26-98\end{array}$ \\
\hline & & LMITCO Review & Date & LMITCO Approval & Date \\
\hline
\end{tabular}


Included in this EDF is a calculation to determine the minimum shielding wall thickness for the Fluidized Bed Blending Tank Cell that will attenuate the gamma radiation to $<0.1 \mathrm{mR} / \mathrm{hr}$ on contact ( 1 centimeter) from the outer surface of the shielding wall. The actual configuration and the computer model is shown in the figure shown below (not to scale).

The room is assumed to contain two tanks of alumina calcine. The tanks are $10.5 \mathrm{ft}$ in diameter and contain alumina calcine to the 6 - $\mathrm{ft}$ level. The tanks are 22 -ft center-to-center and are located 6-ft from the inside of the shielding walls. The source term of the alumina calcine were taken from Table 7 of reference 1 and physical properties were modeled as $1.09 \mathrm{~g} / \mathrm{cm} 3$ concrete. The alumina calcine radiation was assumed to be made up mostly of $0.6 \mathrm{MeV}(99 \%)$ gamma radiation. The shielding wall was considered to be standard concrete with a density of 2.35 $\mathrm{g} / \mathrm{cm} 3$. The calculation was performed using MicroShield, Version 5.01 (reference 2).

In order to model the above configuration with this code it was necessary to treat the volume of the source (alumina calcine) as a slab ( $173.4 \mathrm{~cm}$ thick) against the inside surface of the shielding. Preliminary scoping calculations demonstrated that if it were modeled in this way, it would approximately be equivalent to the two-tank configuration. The dose-rate was calculated at a point 3-ft above the floor and at the mid-width of the cell.

The concrete shield wall thickness needed to attenuate the gamma radiation from the two tanks of alumina calcine to a dose-rate of $<0.1 \mathrm{mR} / \mathrm{hr}$ was calculated to be $93 \mathrm{~cm}(3.05 \mathrm{ft})$.

Actual

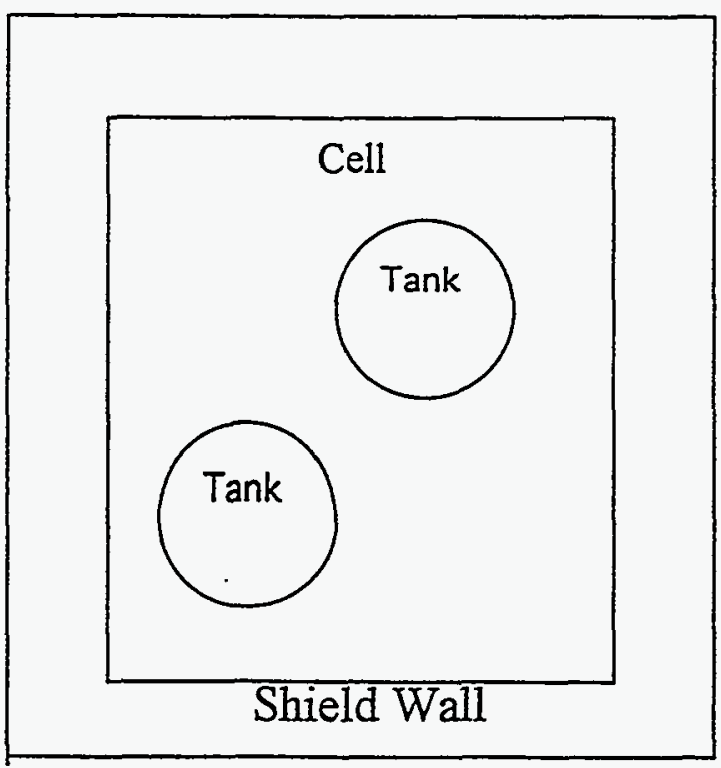

Computer Model

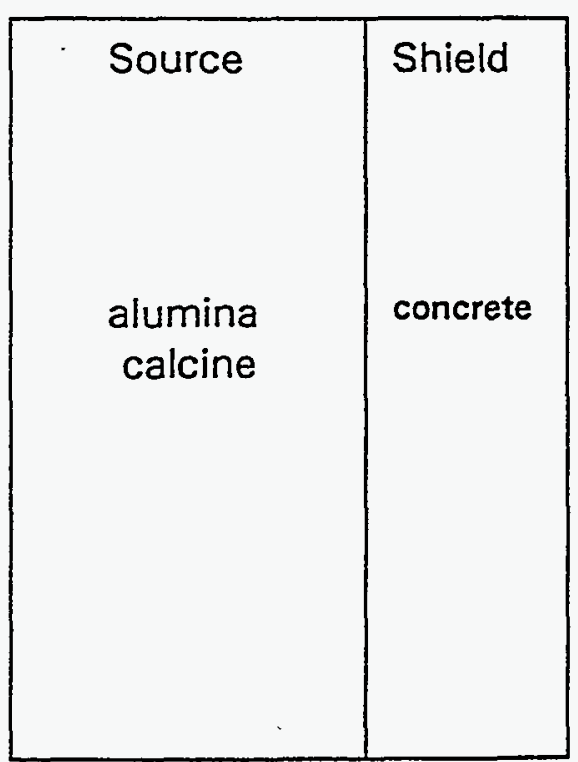




\section{References}

1. Estimates of Feed and Waste Volumes, Compositions and Properties, by C. M. Barnes, EDFFDO-001, Revision 1.

2. MicroShield, Version 5.01, Grove Engineering, Rockville, MD. 
Page : 1

DOS File : FLU2DTRM.MS5

Run Date: January 5, 1998

Run Time: 12:17:22 PM

Duration : 00:07:05
EDF-VWO-006:

Page 4 of 5

File Ref:

Date:2/3/98

By:

Checked:

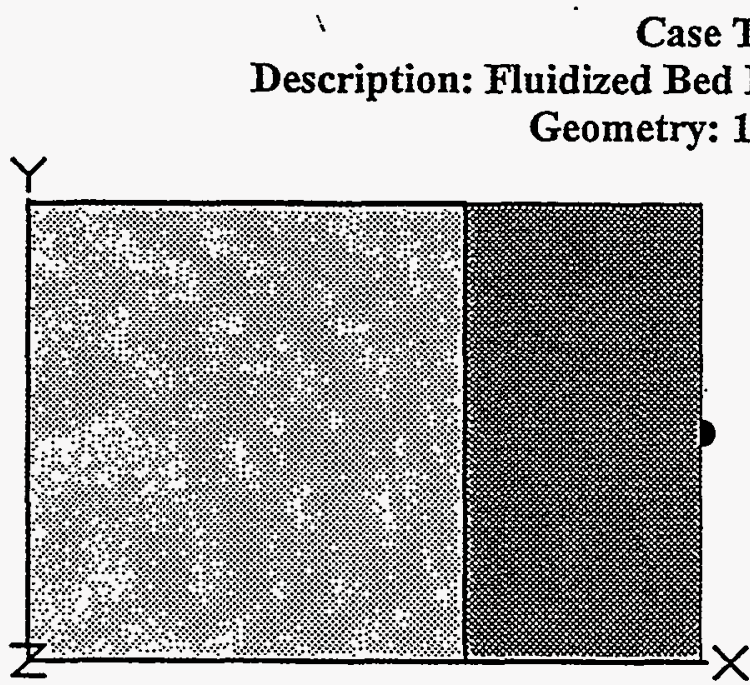

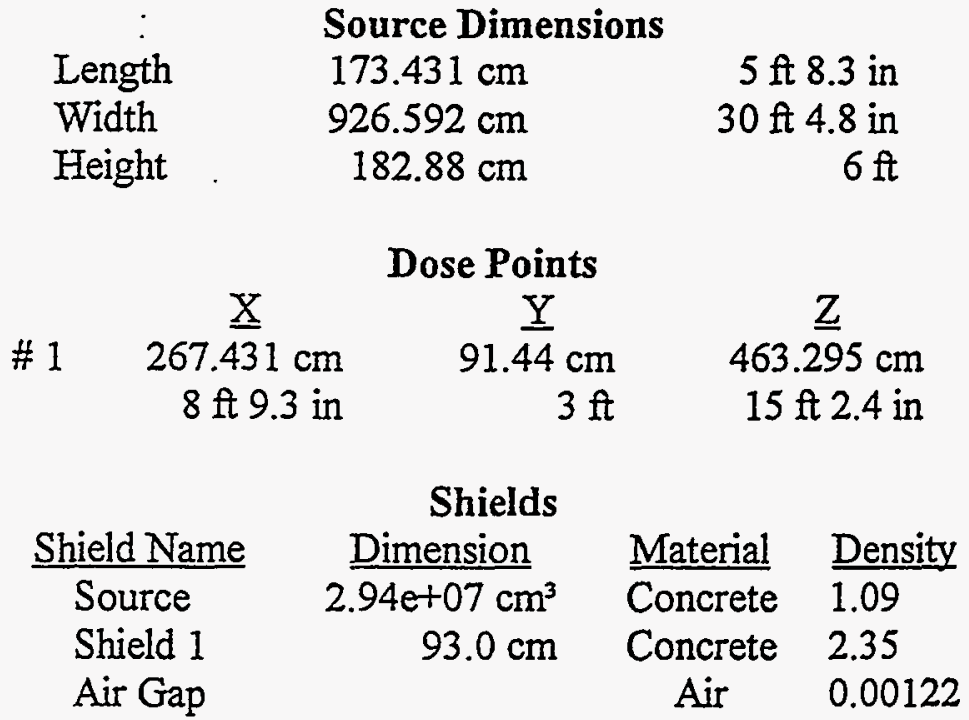

Source Input

Grouping Method : Standard Indices

Number of Groups : 25

Lower Energy Cutoff : 0.015

Photons $<0.015$ : Excluded

Nuclide

Ba- $137 \mathrm{~m}$

Cs-134

Cs-137

Eu-154

Eu-155

Sb-125

$\mathrm{Sm}-151$

$\mathrm{Sr}-90$

$\mathrm{Y}-90$

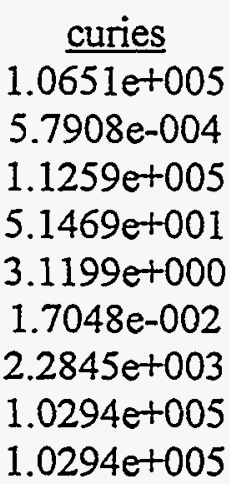

Library : Grove

becquerels

$3.9409 \mathrm{e}+015$

$2.1426 \mathrm{e}+007$

$4.1659 \mathrm{e}+015$

$1.9043 e+012$

$1.1544 \mathrm{e}+011$

$6.3079 \mathrm{e}+008$

$8.4527 \mathrm{e}+013$

$3.8088 \mathrm{e}+015$

$3.8088 \mathrm{e}+015$

\section{$\mu \mathrm{Ci} / \mathrm{cm}^{3}$}

$3.6242 \mathrm{e}+003$

$1.9704 \mathrm{e}-005$

$3.8311 \mathrm{e}+003$

$1.7513 \mathrm{e}+000$

$1.0616 \mathrm{e}-001$

$5.8010 \mathrm{e}-004$

$7.7734 \mathrm{e}+001$

$3.5027 \mathrm{e}+003$

$3.5027 \mathrm{e}+003$
$\mathrm{Bq} / \mathrm{cm}^{3}$

$1.3410 \mathrm{e}+008$

$7.2905 \mathrm{e}-001$

$1.4175 e+008$

$6.4798 \mathrm{e}+004$

$3.9279 \mathrm{e}+003$

$2.1464 \mathrm{e}+001$

$2.8762 \mathrm{e}+006$

$1.2960 \mathrm{e}+008$

$1.2960 \mathrm{e}+008$

Buildup

The material reference is : Shield 1

$X$ Direction

Integration Parameters

$Z$ Direction 
2age : 2

DOS File : FLU2DTRM.MS5

Run Date: January 5, 1998

.Run Time: 12:17:22 PM

Duration : 00:07:05
EDF-VWo-006

Page 5 of 5

\begin{tabular}{|c|c|}
\hline Energy & Activity \\
\hline $\mathrm{MeV}$ & photons/sec \\
\hline 0.02 & $2.499 e+10$ \\
\hline 0.03 & $2.321 e+14$ \\
\hline 0.04 & $5.519 e+13$ \\
\hline 0.05 & $1.052 \mathrm{e}+11$ \\
\hline 0.06 & $1.497 \mathrm{e}+09$ \\
\hline 0.08 & $3.584 \mathrm{e}+10$ \\
\hline 0.1 & $7.944 e+11$ \\
\hline 0.15 & $1.583 e+06$ \\
\hline 0.2 & $1.301 e+11$ \\
\hline 0.3 & $2.638 \mathrm{e}+06$ \\
\hline 0.4 & $1.378 \mathrm{e}+10$ \\
\hline 0.5 & $4.189 \mathrm{e}+09$ \\
\hline 0.6 & $3.546 e+15$ \\
\hline 0.8 & $7.426 \mathrm{e}+11$ \\
\hline 1.0 & $5.858 \mathrm{e}+11$ \\
\hline 1.5 & $7.431 \mathrm{e}+11$ \\
\hline
\end{tabular}

TOTAIS: $\quad 3.837 \mathrm{e}+15$

\begin{tabular}{c}
$\frac{\text { Fluence Rate }}{\mathrm{MeV} / \mathrm{cm}^{2} / \mathrm{sec}}$ \\
\hline$\frac{\text { No Buildup }}{0.000 \mathrm{e}+00}$ \\
$1.480 \mathrm{e}-106$ \\
$5.453 \mathrm{e}-52$ \\
$6.418 \mathrm{e}-35$ \\
$7.137 \mathrm{e}-28$ \\
$4.981 \mathrm{e}-19$ \\
$1.303 \mathrm{e}-14$ \\
$4.491 \mathrm{e}-17$ \\
$1.553 \mathrm{e}-10$ \\
$3.038 \mathrm{e}-13$ \\
$3.234 \mathrm{e}-08$ \\
$9.272 \mathrm{e}-08$ \\
$4.608 \mathrm{e}-01$ \\
$1.418 \mathrm{e}-03$ \\
$8.187 \mathrm{e}-03$ \\
$3.011 \mathrm{e}-01$
\end{tabular}

$7.715 \mathrm{e}-01$
Results

Fluence Rate

$\mathrm{MeV} / \mathrm{cm}^{2} / \mathrm{sec}$

With Buildup

6.805e-24

$1.397 \mathrm{e}-19$

$8.811 \mathrm{e}-20$

$5.493 \mathrm{e}-22$

$5.608 \mathrm{e}-23$

$4.473 \mathrm{e}-17$

$2.686 \mathrm{e}-12$

$1.888 \mathrm{e}-14$

$7.434 \mathrm{e}-08$

$1.028 \mathrm{e}-10$

$6.945 \mathrm{e}-06$

$1.340 \mathrm{e}-05$

$4.742 \mathrm{e}+01$

$8.552 \mathrm{e}-02$

$3.295 \mathrm{e}-01$

$6.193 \mathrm{e}+00$

$5.403 e+01$
Exposure Rate $\mathrm{mR} / \mathrm{hr}$

No Buildup

$0.000 \mathrm{e}+00$

$1.467 \mathrm{e}-108$

$2.412 \mathrm{e}-54$

$1.710 \mathrm{e}-37$

$1.418 \mathrm{e}-30$

$7.883 \mathrm{e}-22$

$1.994 \mathrm{e}-17$

$7.396 \mathrm{e}-20$

$2.741 \mathrm{e}-13$

5.762e-16

$6.301 \mathrm{e}-11$

$1.820 \mathrm{e}-10$

8.994e-04

$2.696 \mathrm{e}-06$

$1.509 \mathrm{e}-05$

$5.066 \mathrm{e}-04$

$1.424 \mathrm{e}-03$
Exposure Rate $\mathrm{mR} / \mathrm{hr}$ With Buildup

2.357e-25

$1.385 \mathrm{e}-21$

$3.897 \mathrm{e}-22$

$1.463 \mathrm{e}-24$

$1.114 \mathrm{e}-25$

$7.078 \mathrm{e}-20$

$4.110 \mathrm{e}-15$

3.109e-17

$1.312 \mathrm{e}-10$

$1.949 \mathrm{e}-13$

$1.353 \mathrm{e}-08$

$2.630 \mathrm{e}-08$

$9.256 \mathrm{e}-02$

$1.627 \mathrm{e}-04$

$6.073 \mathrm{e}-04$

$1.042 \mathrm{e}-02$

$1.038 \mathrm{e}-01$ 
Project File Number O2BD7

Project/Task Non-Separation Alternatives

Subtask Vitrified Waste Option

\section{Title: Bulk Material Transportation: Glass Frit}

Summary:

This study discusses the results of input from two different vendors for a bulk material transport system to move six different types of glass frit (powdered glass material) within the Vitrification Facility (VF). The VF is one of three facilities comprising the non-separations Vitrified Waste Option (VWO) for treating INEEL HLW calcine waste. The glass frit is ultimately mixed with calcine and the mixture is vitrified in a joule melter.

Bottom-discharge rail hopper cars will discharge glass frit into a sub-grade hopper outside the VF. A screw and bucket conveyor system will transport the frit from the hopper and discharge it into one of six adjacent storage silos. A screw and bucket conveyor systems from the outlet of each silo, (six systems total) connect to the inlet of one of six corresponding frit receiver tanks located at the 45- $\mathrm{ft}$ elevation inside the VF. Six auger conveyors, one from the outlet of each receiver tank, all discharge frit into a frit weigh tank. Frit is dispensed from the bottom of the weigh tank through a rotary metering valve and into a ribbon blender. There it is mixed with a predetermined amount of calcine that is fed to the blender by a separate metering system.

Budgetary estimates from two vendors, including sketches and ROM material costs, are attached. Estimates for costs of the material transfer systems are between $\$ 289,000$ and $\$ 587,000$. An estimate for the frit storage containers (silos, receiving tanks, and weigh tank) totaled $\$ 257,000$. The costs were provided to LMITCO estimators for consideration in the VF cost estimate. The proposed system is shown in the attached sketch and this EDF is incorporated into the VF report (INEEL/EXT-97-01389) and its process diagrams.

Attachment 1: System Sketch

Distribution (complete package): WTP EIS Studies Library, A copy of this EDF will be included in Report INEEL/EXT-97-01389

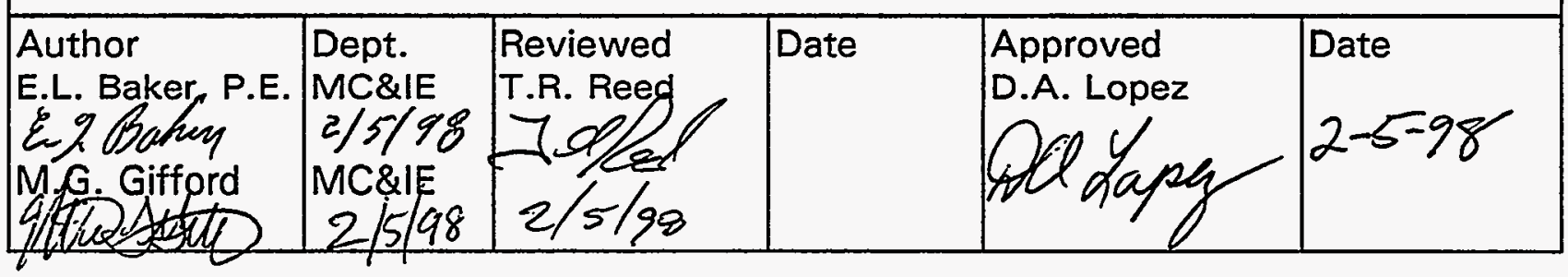


The non-separations VWO vitrification process will combine calcine from the CSSF with a specified glass frit determined from the type of calcine that will be processed. Six types of glass frit material will be shipped by rail to the INEEL for use in the vitrification process. The frit has a density of approximately $156 \mathrm{lbs} / \mathrm{ft}^{3}$, which is about as dense as ordinary silica sand and very abrasive, can be conveyed quite easily using conventional bulk material conveying systems. Each of the six types of frit will be specially blended such that any variety of the calcine may be vitrified in a chemically stable, self-contained waste form.

The glass frit that will be used in the vitrification process will be brought to the INEEL by rail. Rail cars used to transport the frit to the VF will be bottom dump type that will dump directly into an underground receiving hopper. A screw type conveyor, sometimes called an auger, will pick up the frit from the hopper and convey the frit into the bottom of a bucket conveyor. The bucket conveyor will elevate the frit up above the frit storage silos and gravity feed it into one of the six storage silos (depending upon the blend of the frit) through a selector valve. $A$ bucket conveyor is an enclosed conveyor consisting of a series of buckets mounted on a roller type chain that will convey material vertically. The distribution method from the rail cars to the storage silos will minimize the space required for the railroad spur unloading station while still limiting cross-contamination of frit.

The six storage silos will be located outside the VF at ground level. Each frit storage silo will contain a different blend of glass chemistry and hold approximately 20,000 gallons of frit material. The transportation of frit from the rail car receiving hopper to the storage silos will occur at an approximate mass flow rate of 15,000 $\mathrm{lb} / \mathrm{hr}$. The ability to convey glass frit by a screw conveyor is limited to approximately a $30^{\circ}$ angle. For this reason, bucket type conveyors will be utilized in all portions of the transfer system design when large elevation increases are required.

The glass frit in the six storage silos will be conveyed to receiving tanks located above the glass melter in the VF. Six of the receiving tanks will located at the 45' floor elevation of the building. These frit receiving tanks will be located inside the building above and outside of the cell in which the melter is located, in a noncontaminated area. Each receiving tank will contain a different blend of frit, and have a capacity of approximately 2,000 gallons. Each type of glass frit will have a separate transfer system from the appropriate storage silo to the respective receiving tank. By providing a separate transfer system for each type of frit, crosscontamination of the different types of frit is eliminated. This portion of the conveyance system will consist of screw conveyors to deliver the frit from underneath the storage silos. The screw conveyors will feed bucket conveyors that will lift the material above and into each of the corresponding frit receiving tanks. The frit will be gravity fed into these tanks from the end of the bucket 
conveyors. The mass flow rate for this portion of the frit transfer is approximately $4,250 \mathrm{lb} / \mathrm{hr}$. The receiving tanks will have a level detection system to control the amount of frit delivered into the tanks.

Six separate conveying systems will be required for transferring the frit from the receiving tanks to a single metering vessel called a weigh tank. The weigh tank will utilize a load cell for weight measurements of the frit material that will be mixed with the calcine. By using six sets of screw conveyors, cross-contamination of the frit will be eliminated from this phase of the transfer. Depending on the analysis results of the calcine contained in the calcine load hopper, one of the frit receiving tanks will be selected as the frit supply tank so that the proper glass chemistry will be achieved in the melter. This transfer will occur at approximately $3,000 \mathrm{lb} / \mathrm{hr}$. All frit conveying and storage equipment up to this point will remain in a contamination clean shielded area so it can be easily maintained.

The frit flows through a rotary valve in the weigh tank and will be gravity fed into the ribbon blender. At this point in the material flow process, the glass frit enters the radation zone. Calcine will be mixed with a measured amount of one of the six types of glass frit and placed into the ribbon blender to obtain the correct glass chemistry. The mixture of frit and calcine will be gravity fed through a pipe that penetrates the melter lid. The ribbon blender vessel will have the capability to provide the calcine/frit mixture to either of two melter cells. 


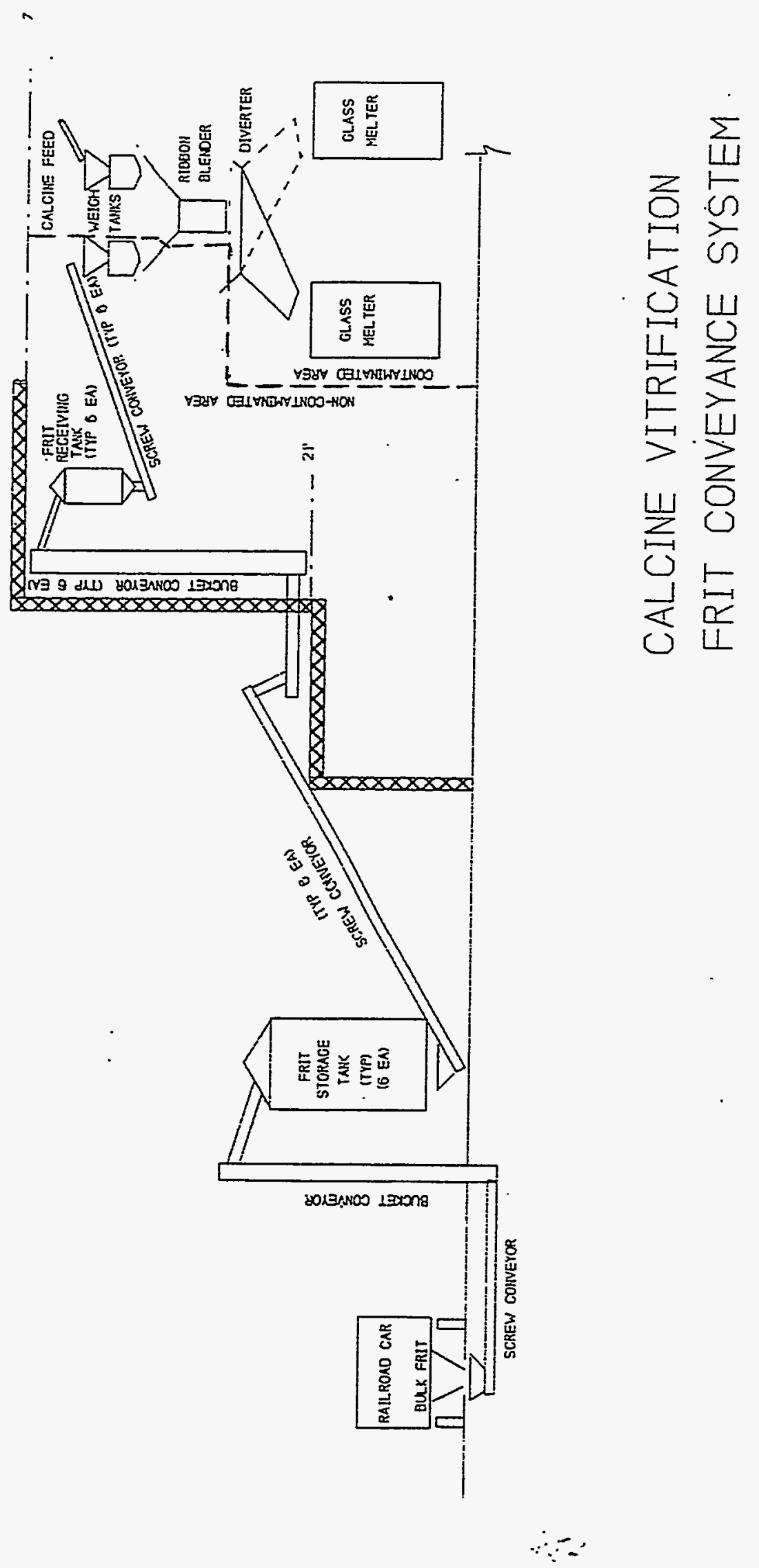


Appendix B

Drawings 


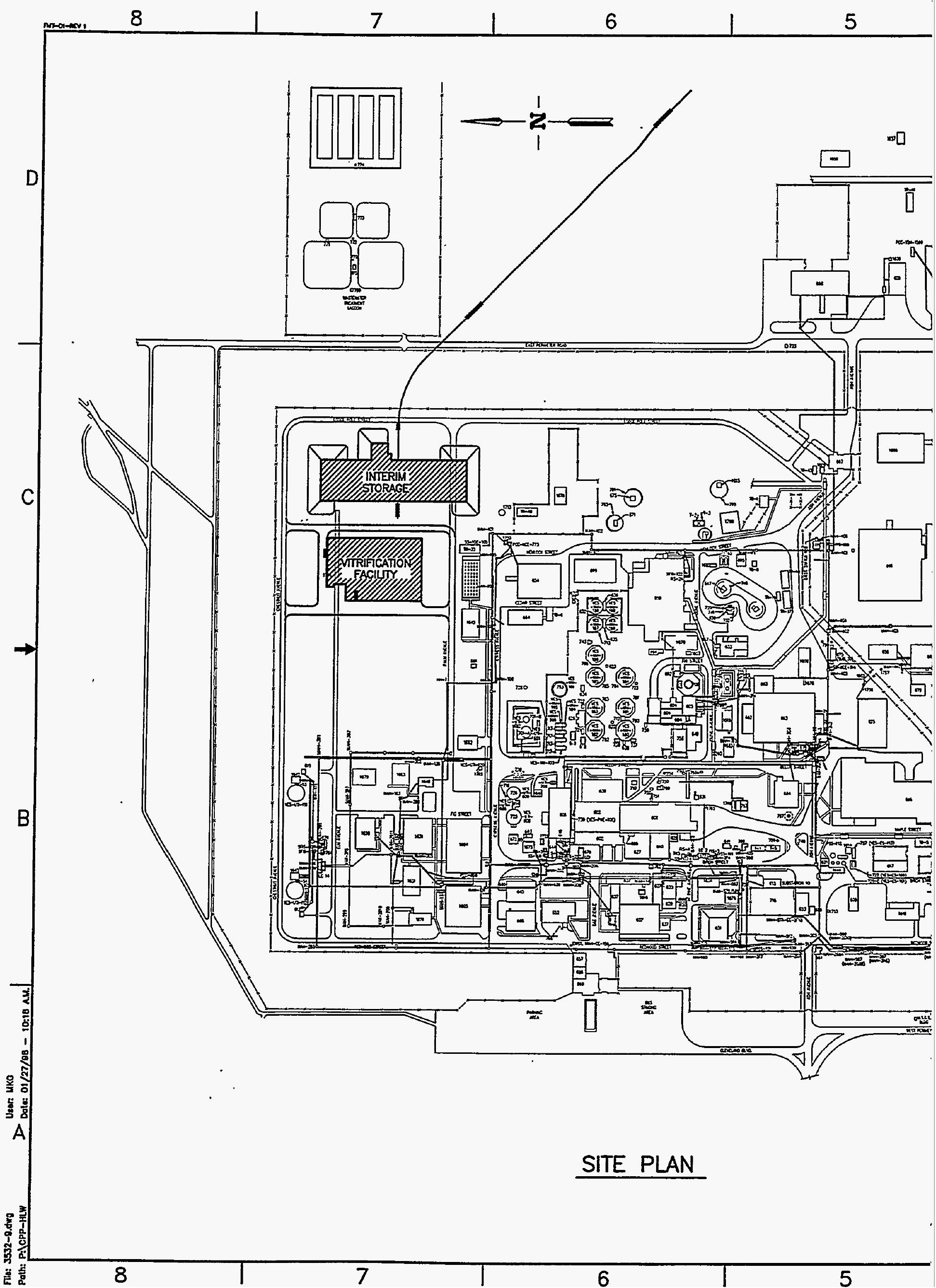




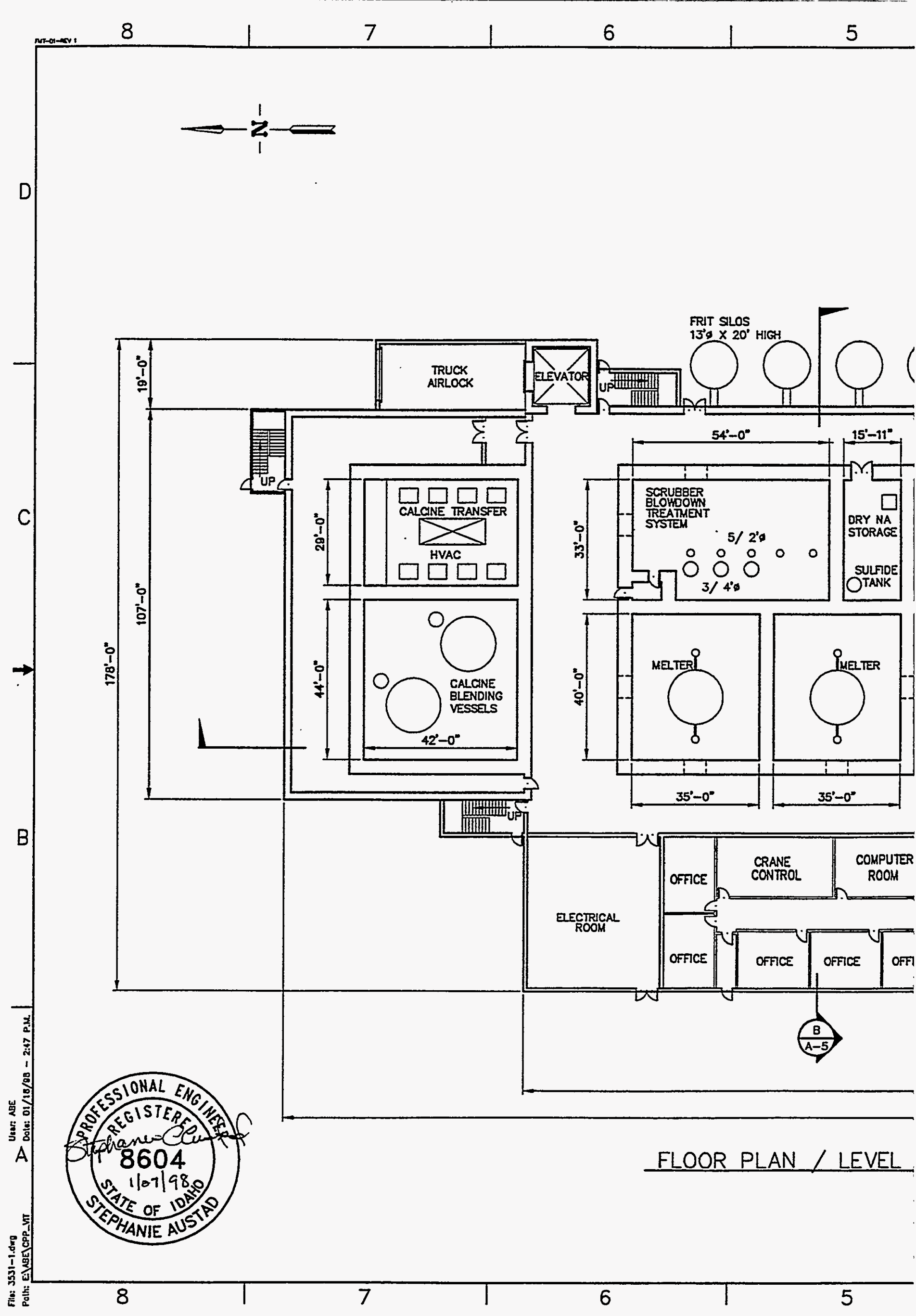




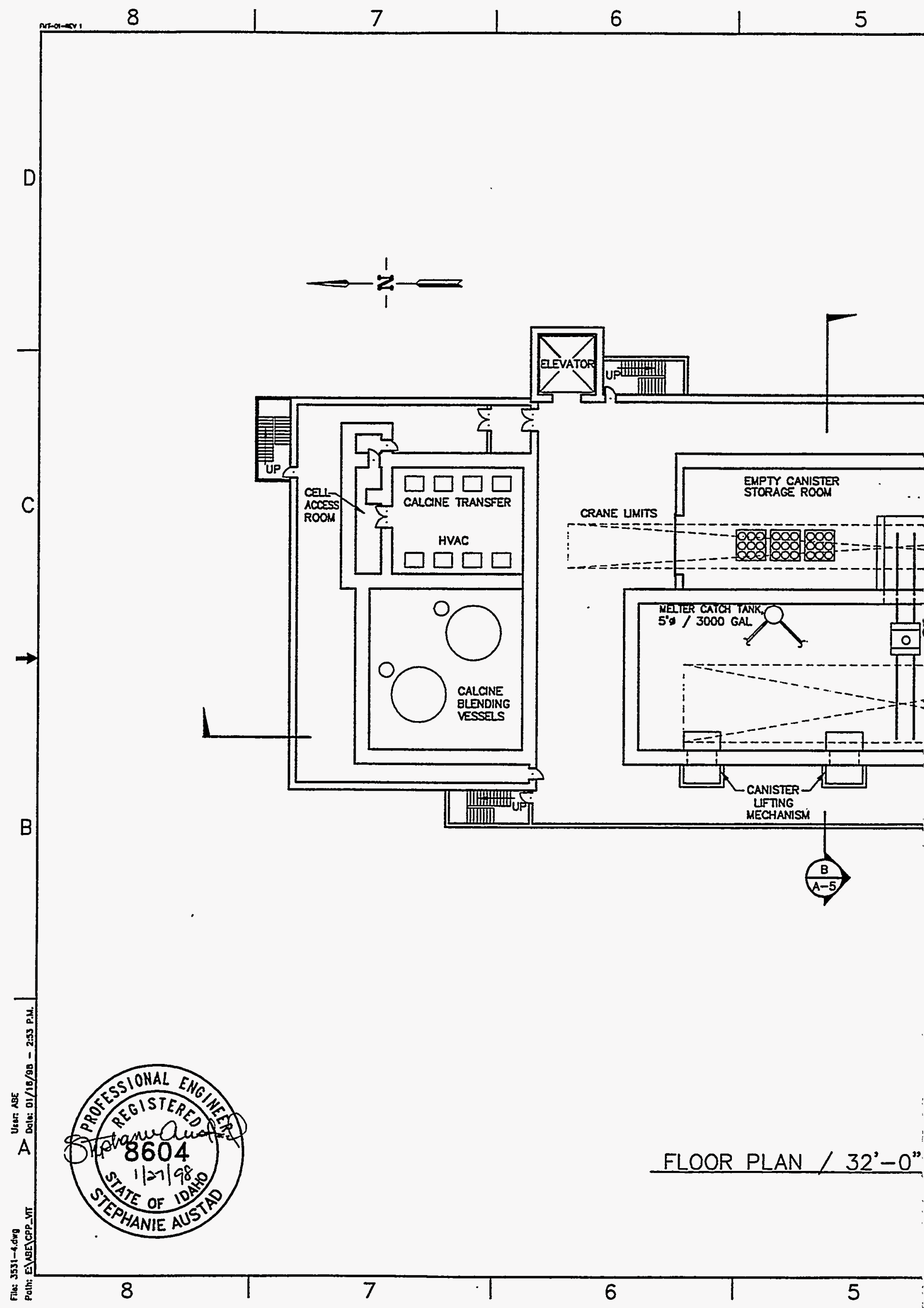




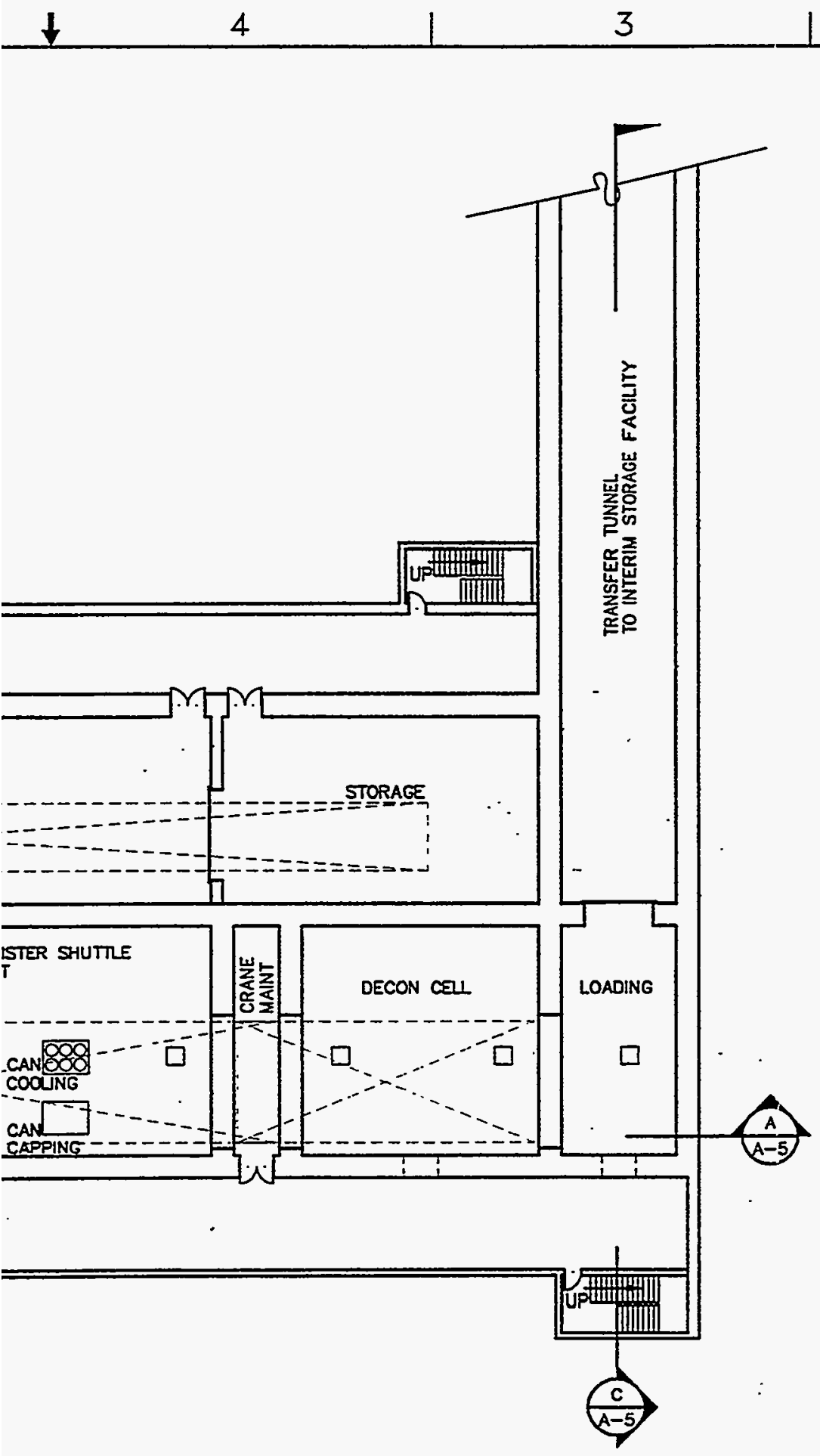

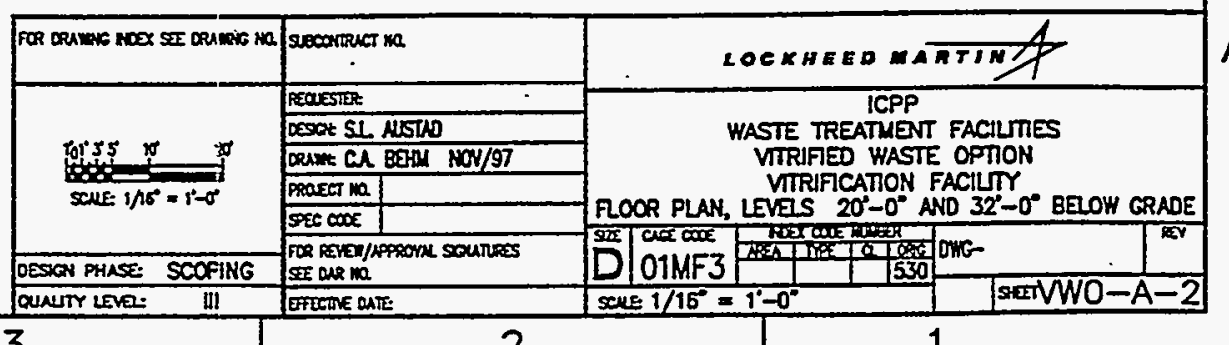




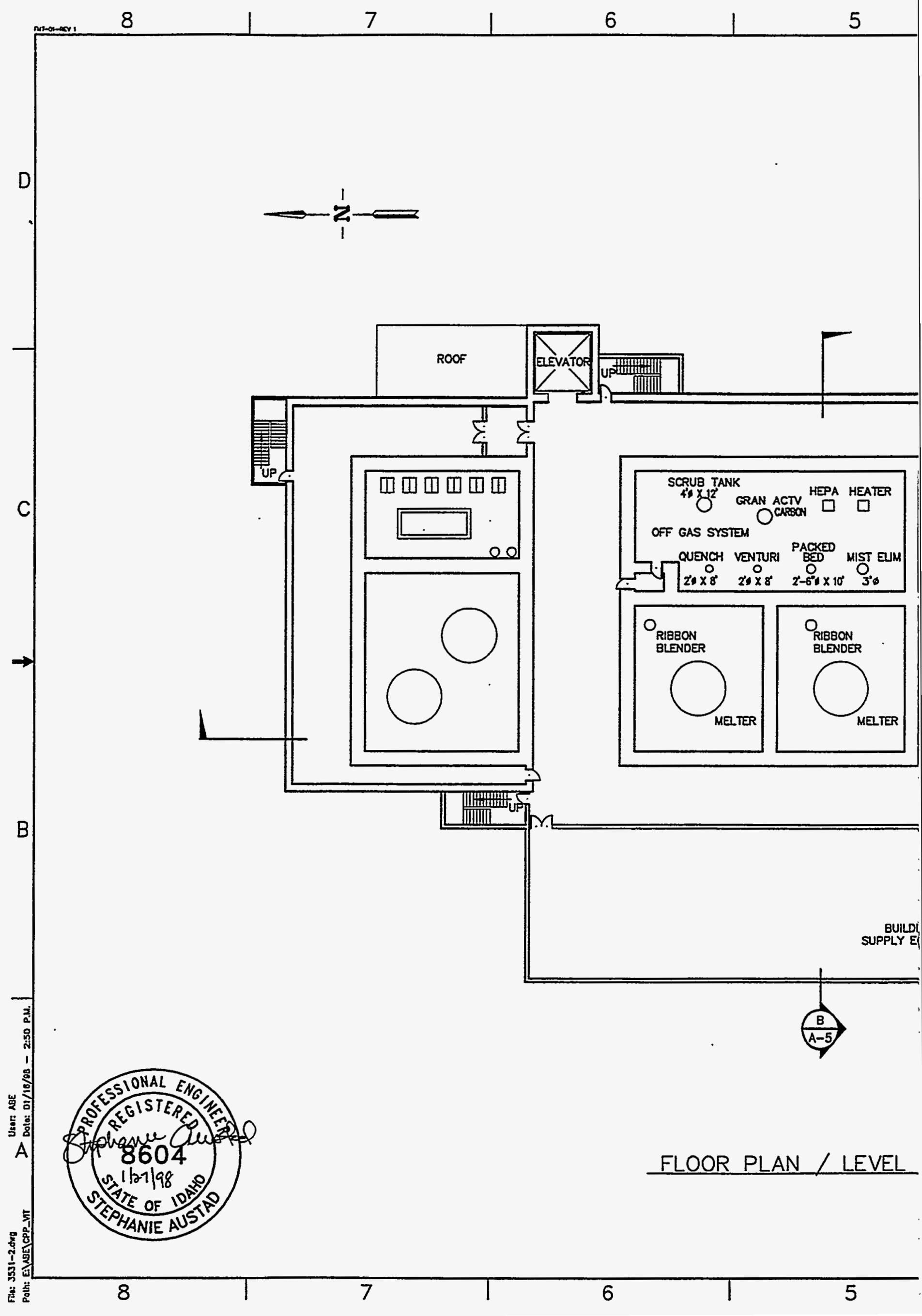




\begin{tabular}{llll|l|l|}
4 & 1 & 3 & 2 & 2 & 1
\end{tabular}

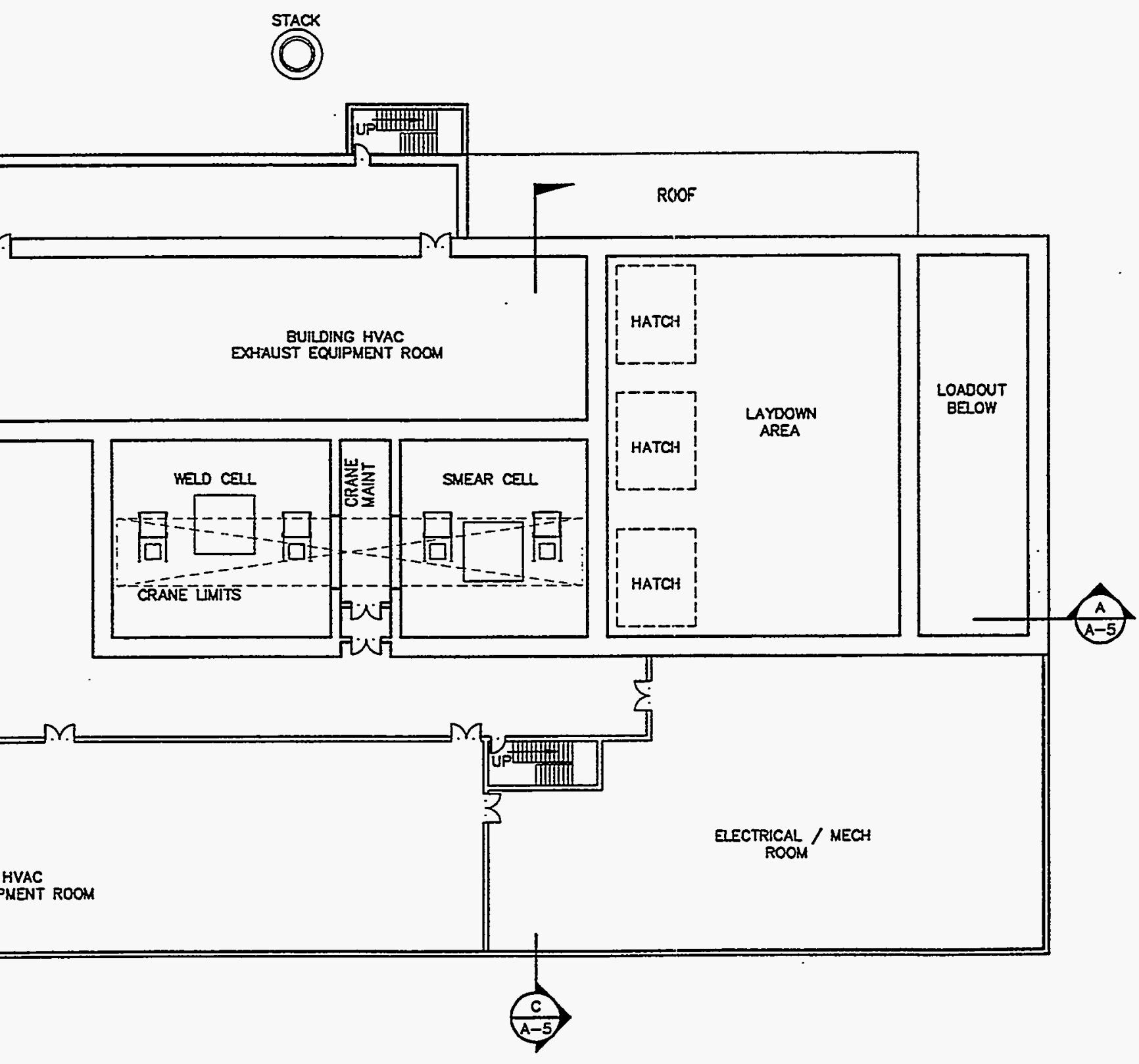

$21^{\prime}-0^{\prime \prime}$

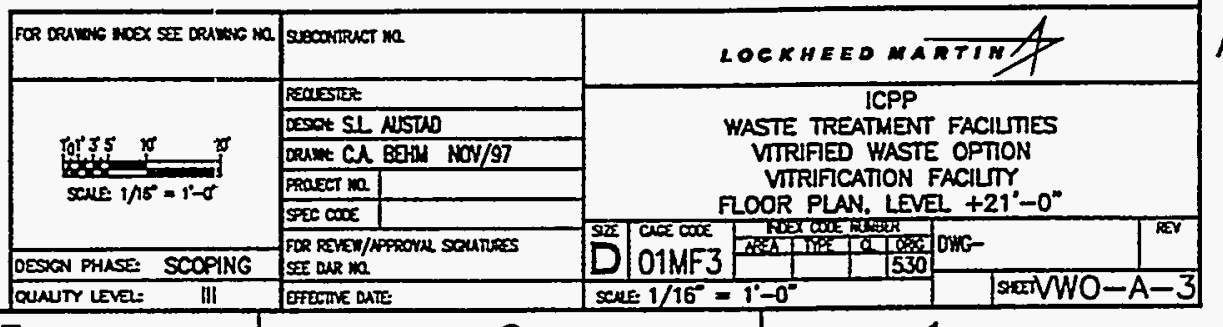




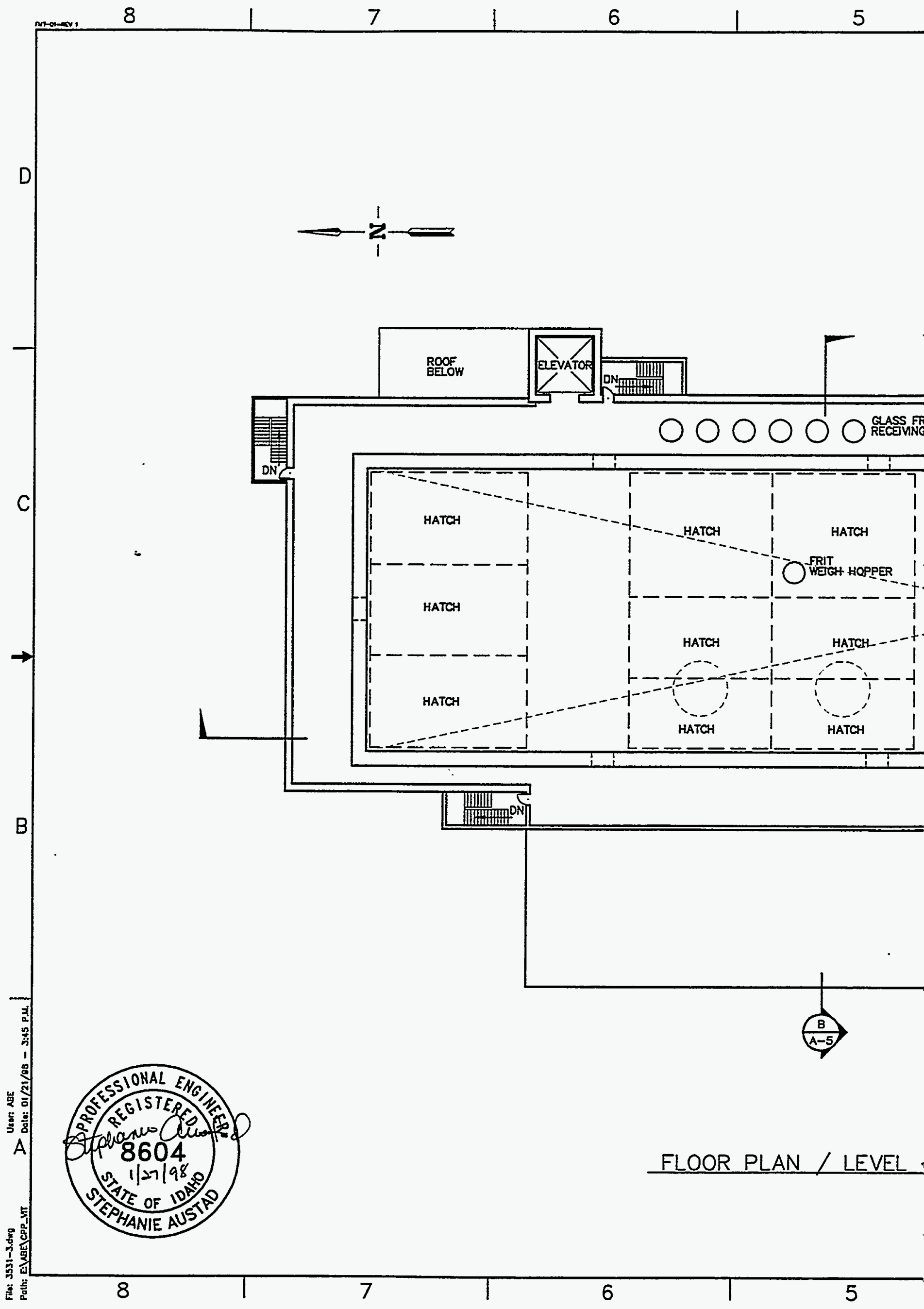




\begin{tabular}{c|c|c|c|}
4 & 3 & 2 & 1 \\
\hline
\end{tabular}

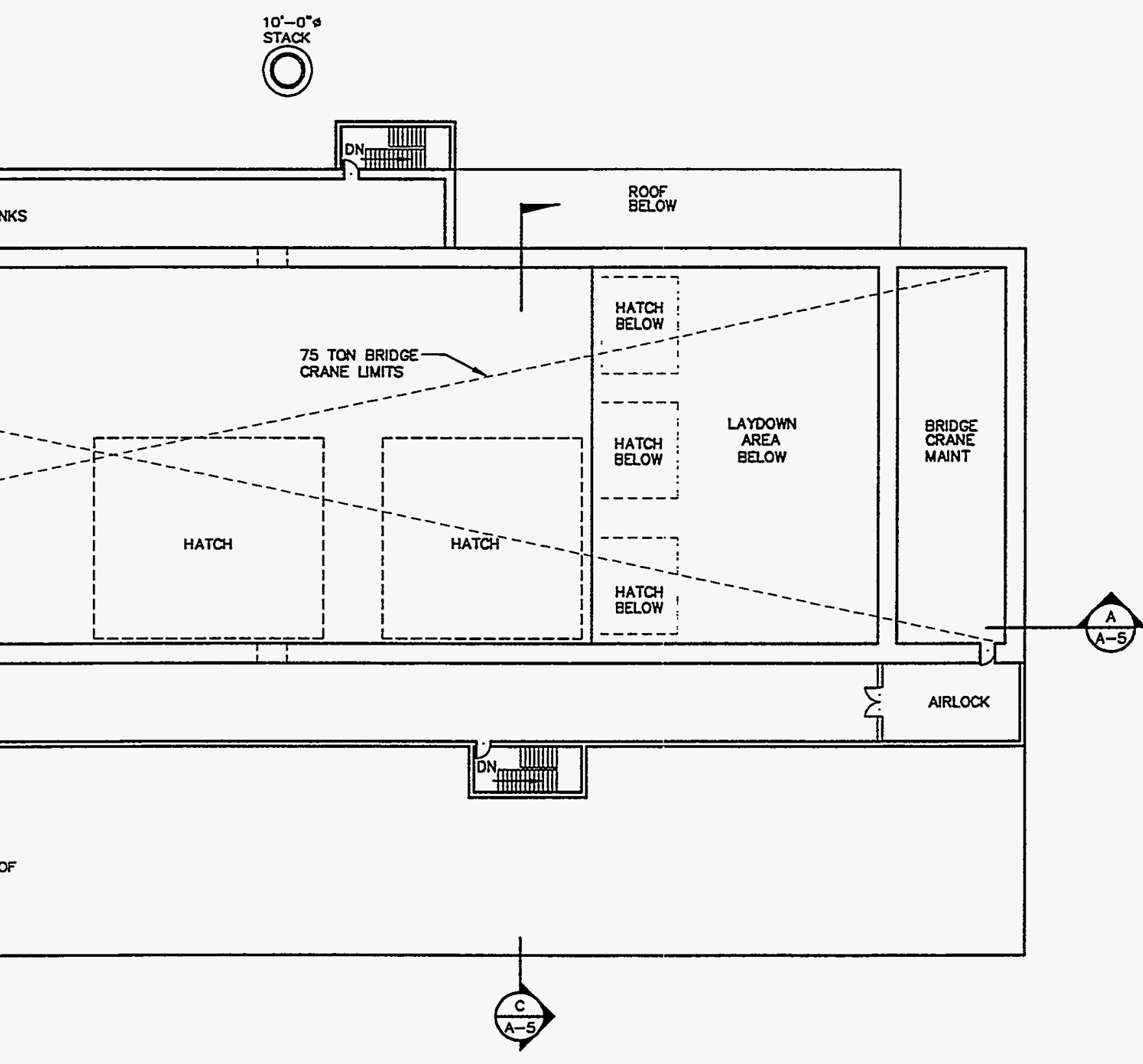

$45^{\prime}-0^{\prime \prime}$

\begin{tabular}{|c|c|c|c|c|}
\hline FOR DRU WAE HOOX STE DRUIAG HO & ssocontret ma & \multicolumn{3}{|c|}{ LOEKHEGO MARTIN/ } \\
\hline \multirow{5}{*}{$\underbrace{2 t}_{\text {sects } 1 / 15=10-5}$} & \multirow{2}{*}{ Dessot SL NISTD } & \multirow{5}{*}{\multicolumn{2}{|c|}{$\begin{array}{l}\text { ICPP } \\
\text { WASTE TREATMENT FACIUTES } \\
\text { VITIFED WASTE OPTION } \\
\text { VIRIFCATION FACIUTY } \\
\text { FLOR PLAN. LEVE + }+45^{\circ}-0^{*} \\
\text { FOOR }\end{array}$}} & \\
\hline & & & & \\
\hline & Den: GA 827N NOV/97 & & & \\
\hline & \multirow{2}{*}{\begin{tabular}{|l|l|} 
propet ma & \\
Sprec coce & \\
\end{tabular}} & & & \\
\hline & & & & \\
\hline DESTON PHNSE SCOPING & 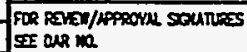 & 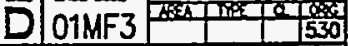 & Hows & \\
\hline QUNUTY LEVZ: III & EFectac arte & $\operatorname{sen} 1 / 16^{\infty}=1^{-}-0^{-}$ & sETh & $1-4$ \\
\hline
\end{tabular}

A 


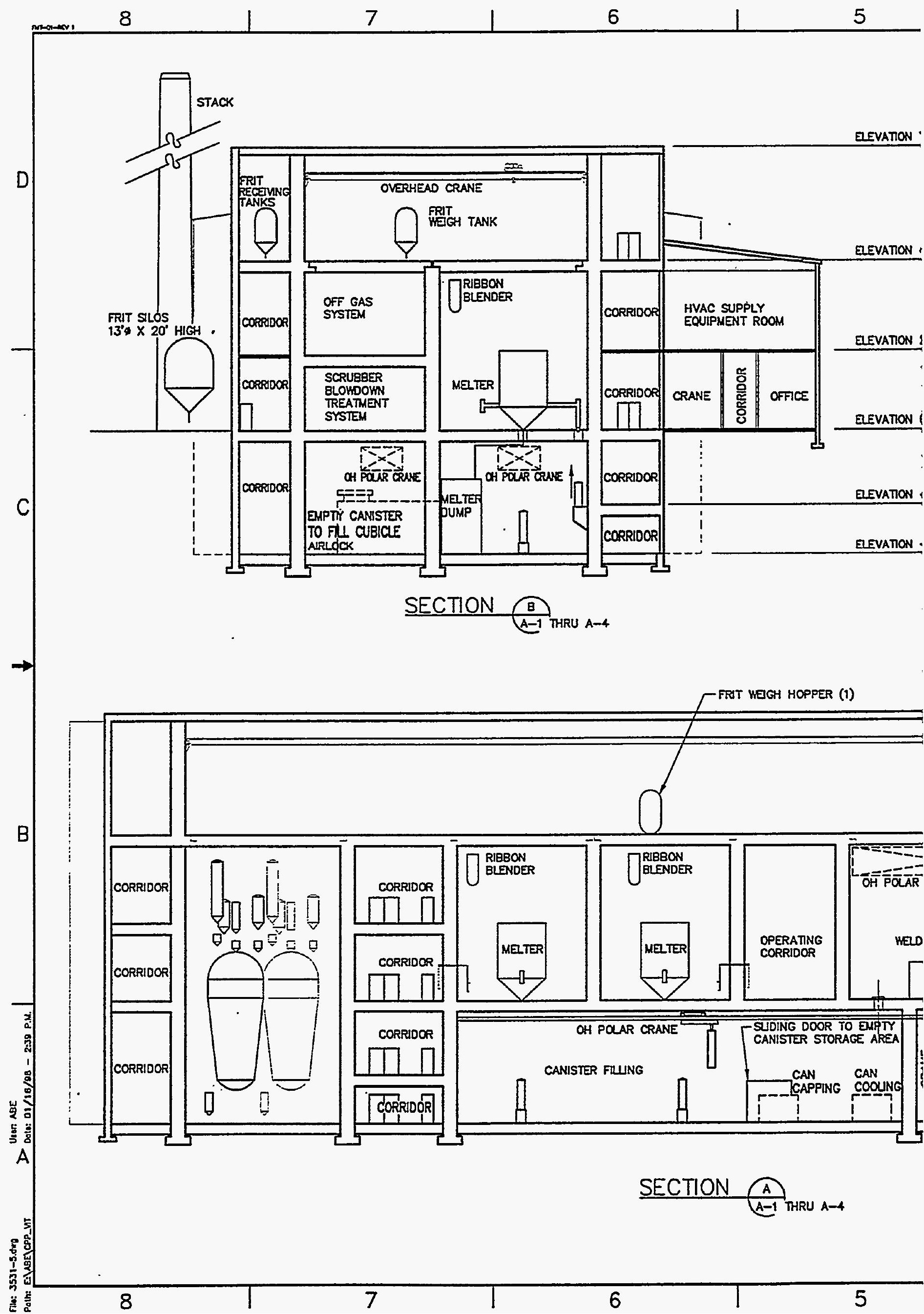




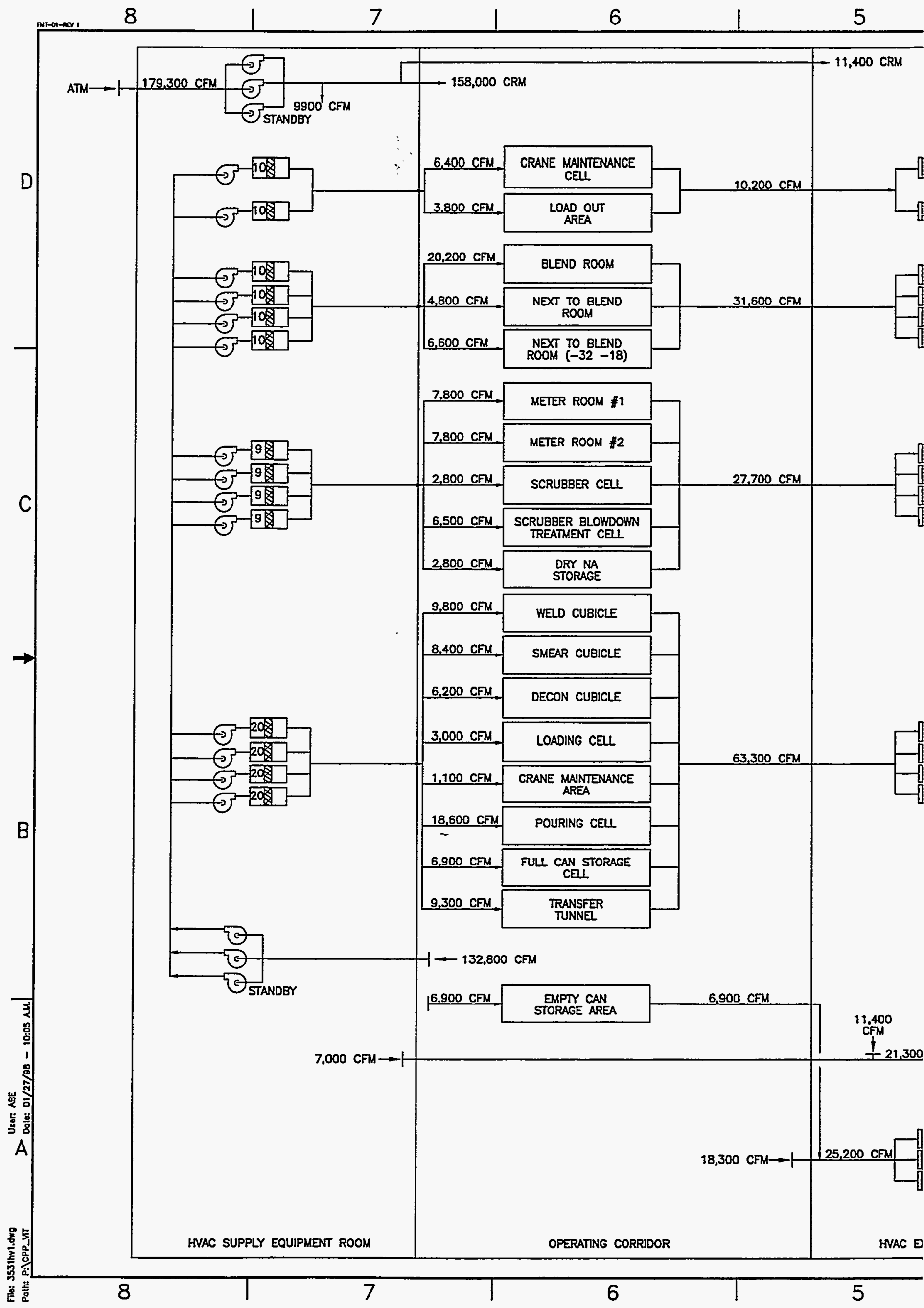




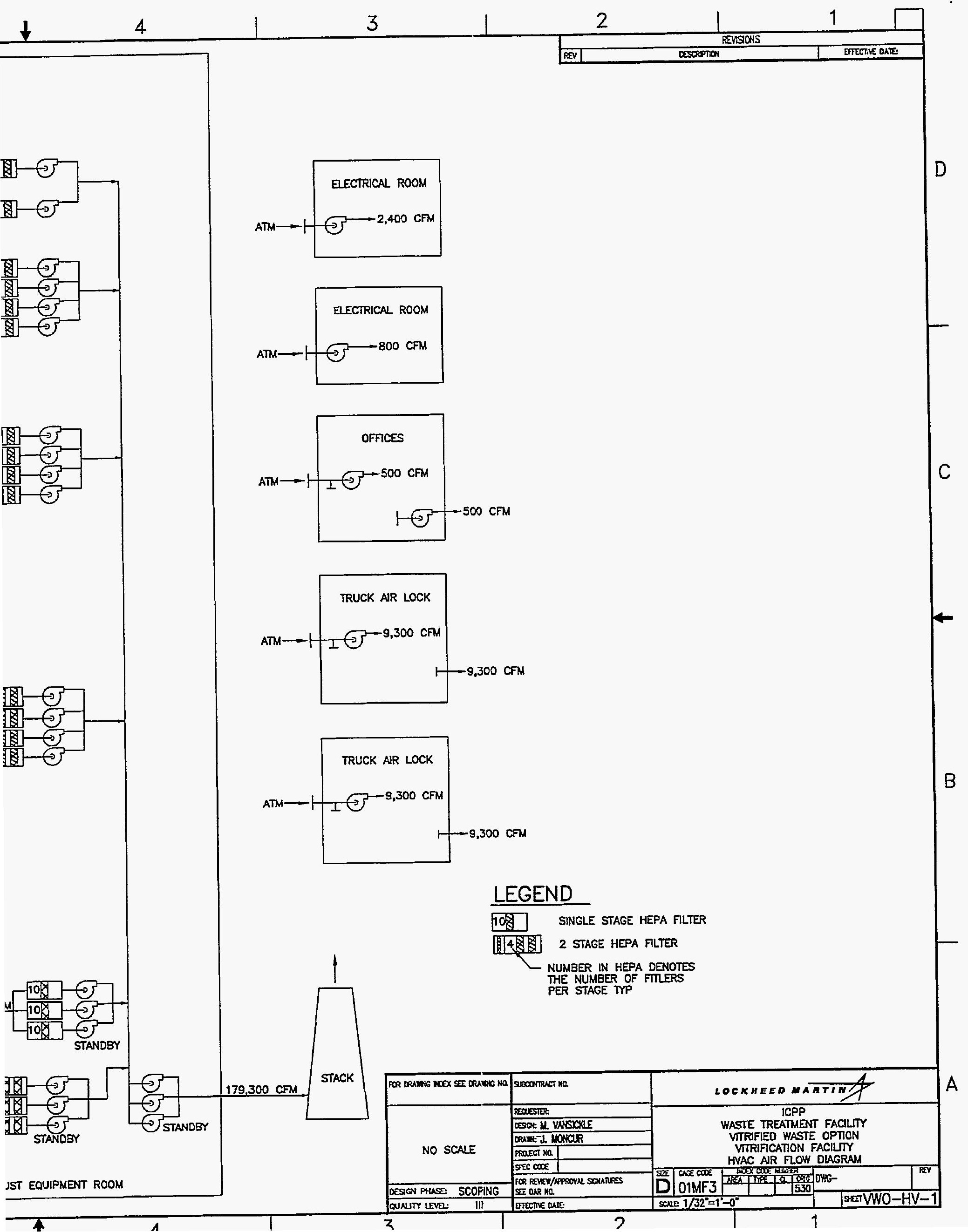


Average Calcine density $=1,408 \mathrm{k}$ Calcine volume $=5,435 \mathrm{~m}^{3}$

Off-gas Treatment

\section{Retrieve Calcine}

Stored in CSSF

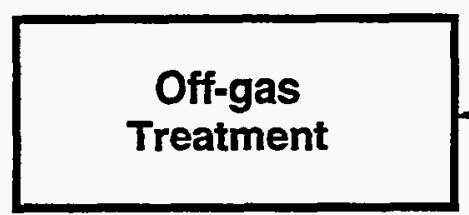

Canister capacity $=0.72 \mathrm{~m}^{3}$ Number of canisters $=14,000$ 


\section{Assumptions}

- All listed hazardous materials will be de-listed

- Non-listed hazardous materials will be treated to meet acceptance criteria

- All waste will be calcined before vitrification

- This option will not process new waste generated after 2012

- All vitrification processes will occur from 2013 through 2032

- Off-gas wastes will be treated for disposal on-site as LLW

- Glass waste form will be $0.6 \mathrm{~m}$ diameter by $3 \mathbf{~ m}$ long, including steel jacket

- The vitrified waste form will be ready to be moved out of Idaho for disposal by a target date of 2035

$30 \mathrm{~m}^{3}$

$\mathrm{kg} / \mathrm{m}^{3}$

$30 \mathrm{wt} \%$

$\mathrm{t}=6$ to $172 \mathrm{R} / \mathrm{Hr}$

1.1 to $34.5 \mathrm{R} / \mathrm{Hr}$

canister $=0.6$ to 14.7 Watts

\section{ICPP Waste Treatment Facilities}

Vitrified Waste Option

Vitrification Facility Flow Diagram 


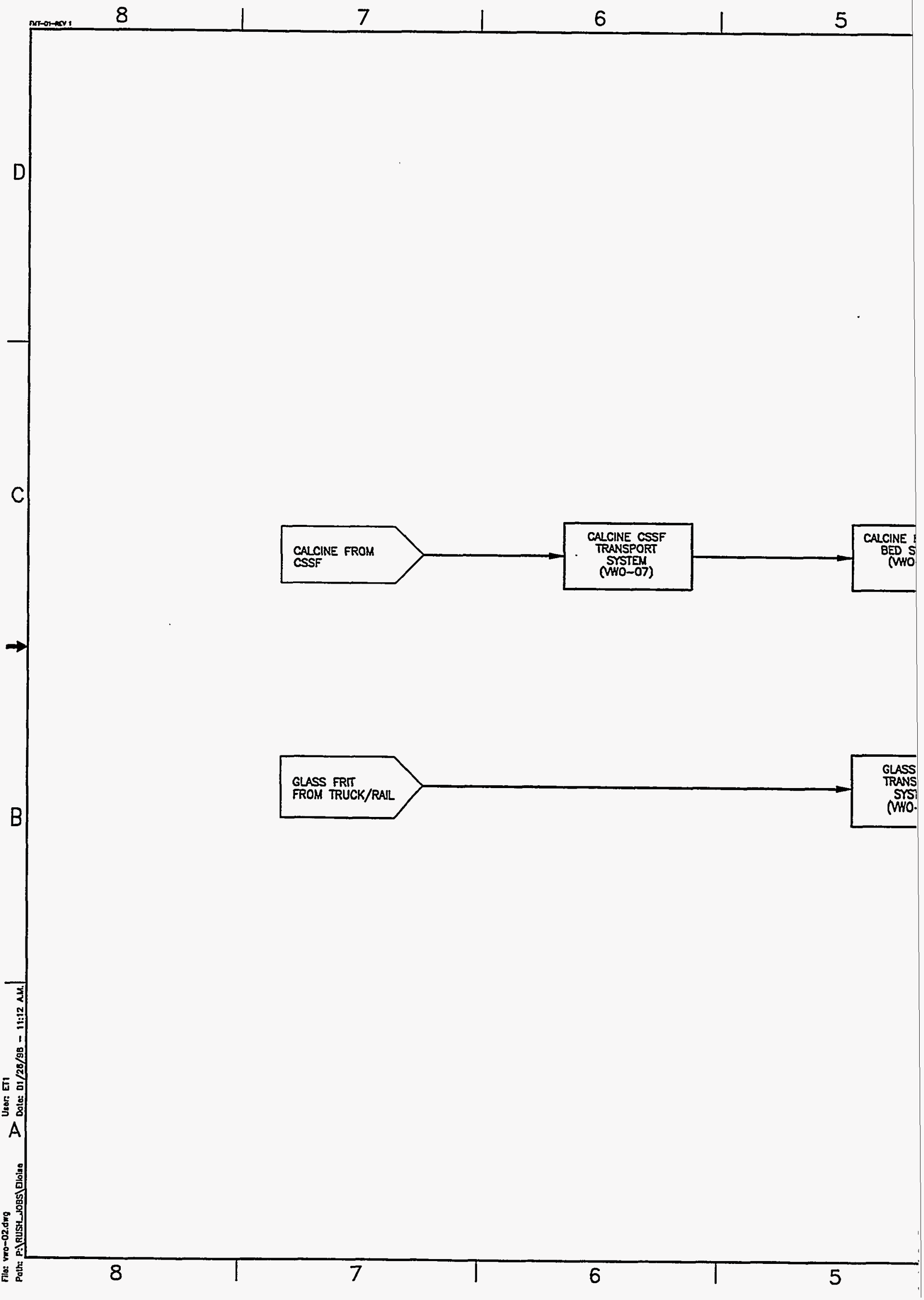




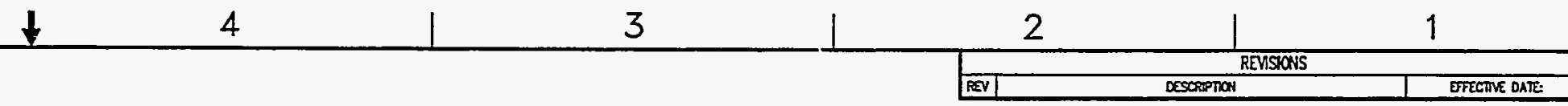

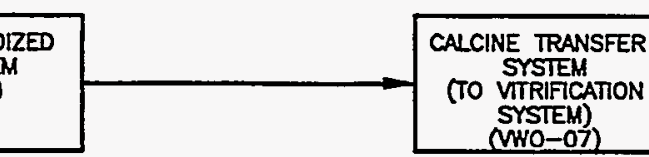

TO VIRIFCATION STSTEM

\begin{tabular}{|c|c|}
\hline SPCOARRAT KR & LOCKHEED MATTINT \\
\hline Fatsib: & $1 \mathrm{CPP}$ \\
\hline Deseret & WASTE TREATMENT FACILTIES \\
\hline DRAW EN SEII & VIRIFIED WASTE OPTION \\
\hline Faret Ma & VTRIFICATION FACILTTY \\
\hline SPSc coos & MIX CALCINE WITH GLASS FRT (FROM WHO-01) \\
\hline 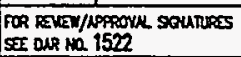 & 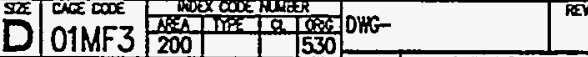 \\
\hline ETECTNE DATE & SEET VWO-02 \\
\hline
\end{tabular}




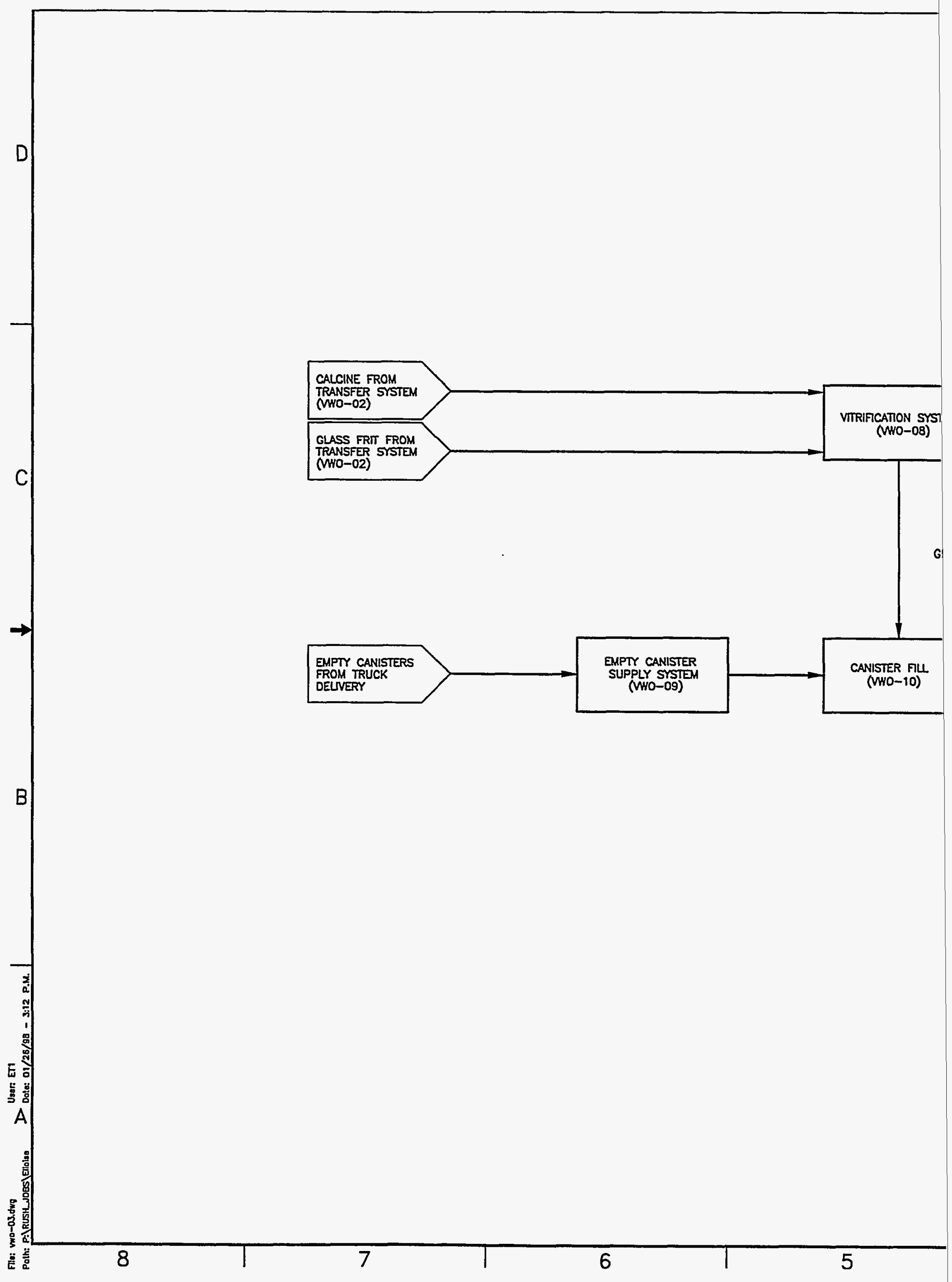




\begin{tabular}{|c|c|c|c|}
\hline sescortruet no. & \multicolumn{3}{|c|}{ LOCKHEED WATTIN/ } \\
\hline DEarster: & \multirow{4}{*}{\multicolumn{3}{|c|}{$\begin{array}{l}\text { ICPP } \\
\text { WASTE TREATMENT FACILMES } \\
\text { VIRRIFED WASTE OPTION } \\
\text { VIRIFCATION FACIUTY } \\
\text { VIRIFY (FROM VWO-01) }\end{array}$}} \\
\hline 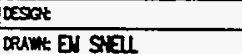 & & & \\
\hline Faset Ha & & & \\
\hline Spex coot & & & \\
\hline 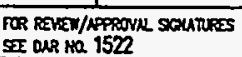 & 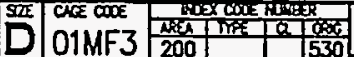 & Dive- & REV \\
\hline BFECTIE OATE: & SeNE: NOHE & SE्त V & .03 \\
\hline
\end{tabular}


D

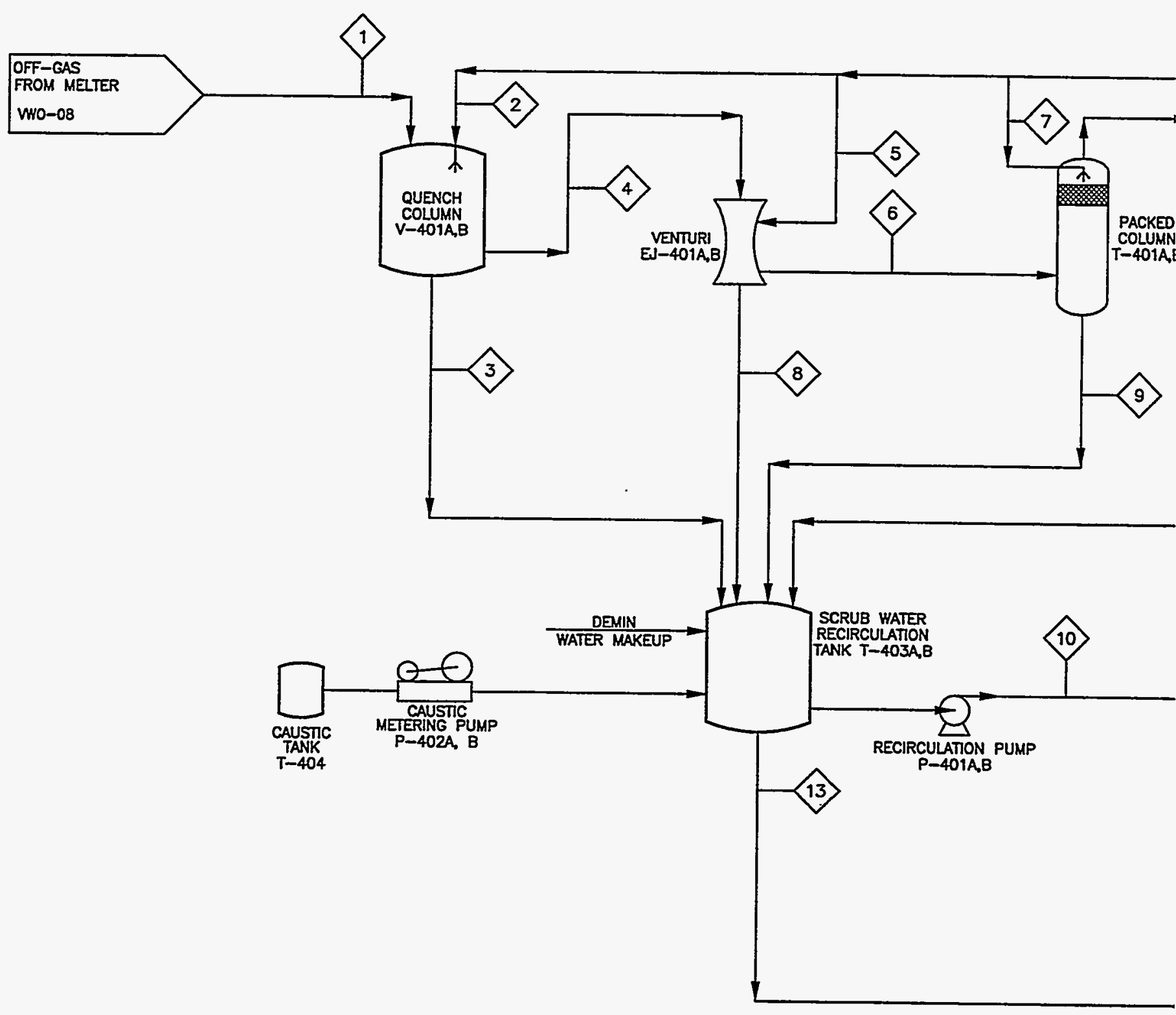

C
$\Rightarrow$
$B$

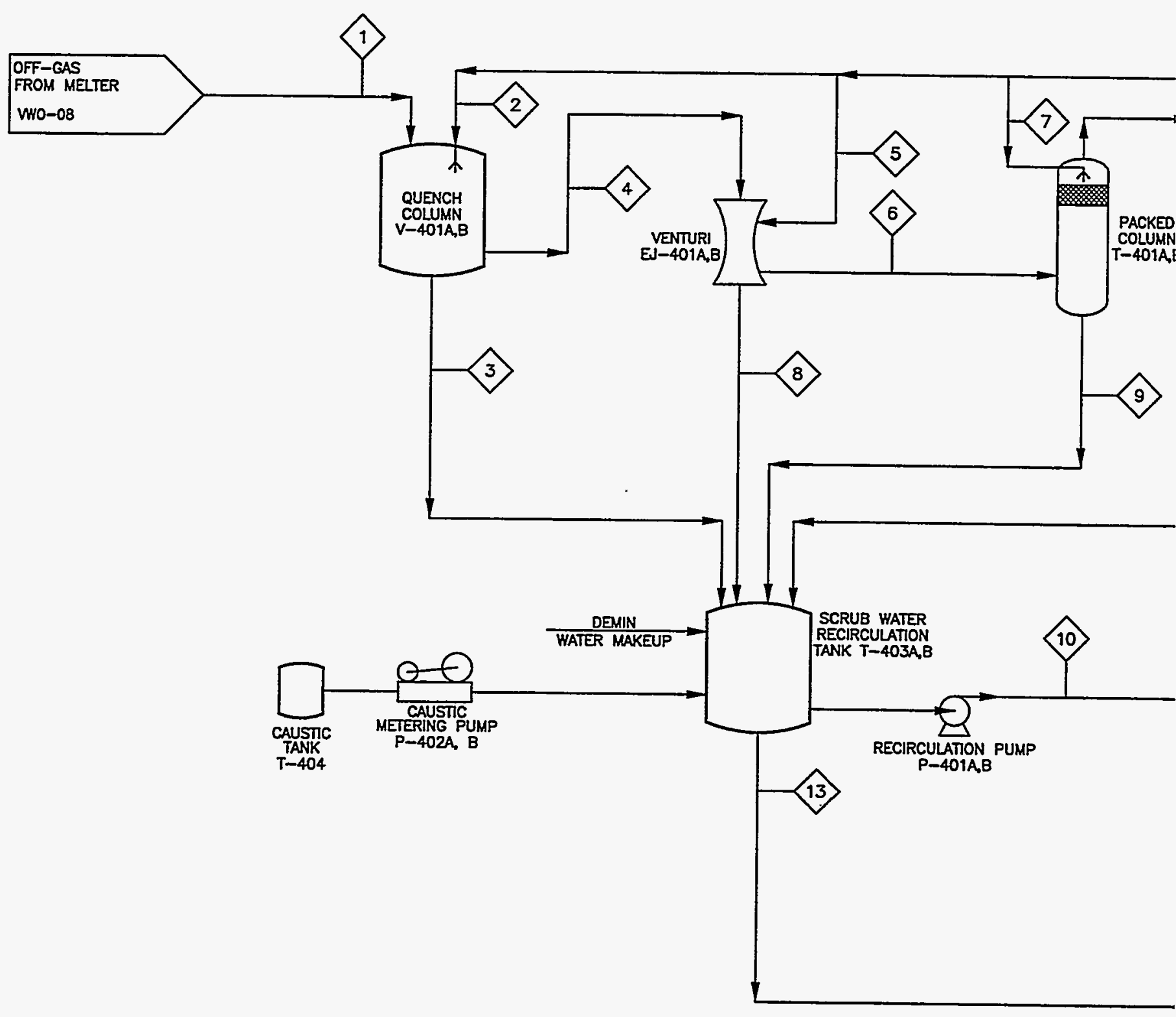

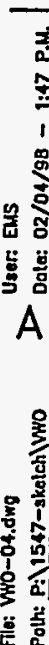

B 


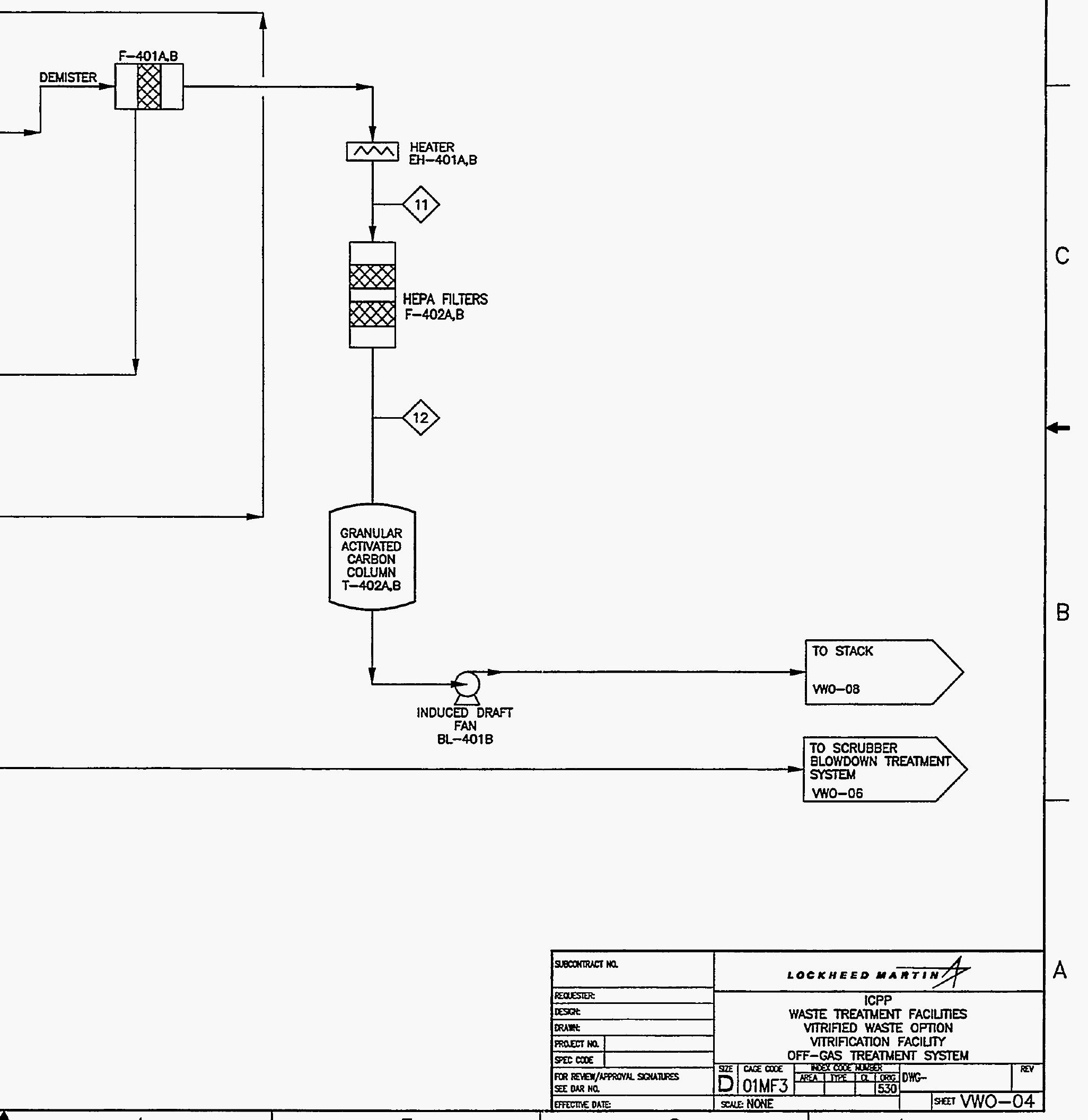


DRAWING WWO-05

LEFT INTENTIONALLY

BLANK 
-nw0-04

C
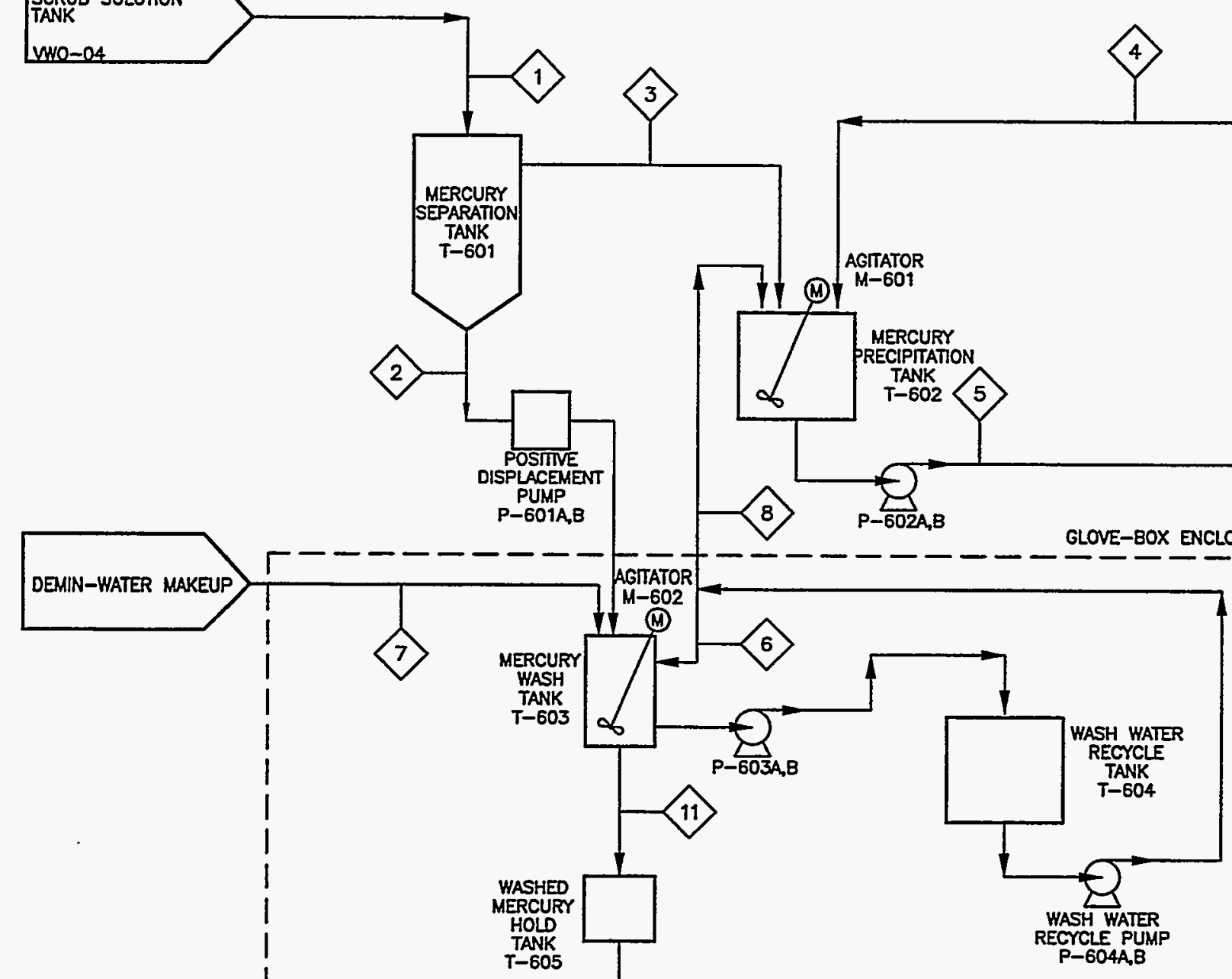

(1)

1

1
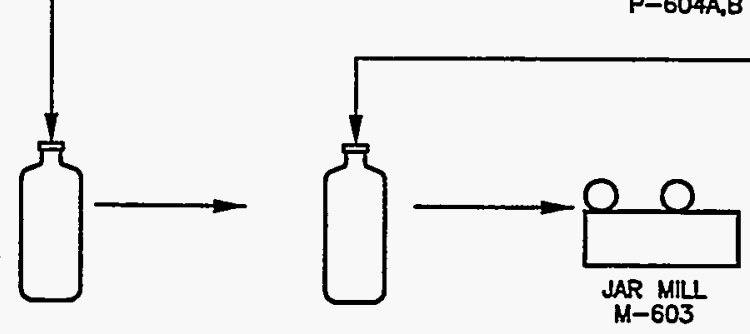

GLOVE-BOX ENCLOSURE 


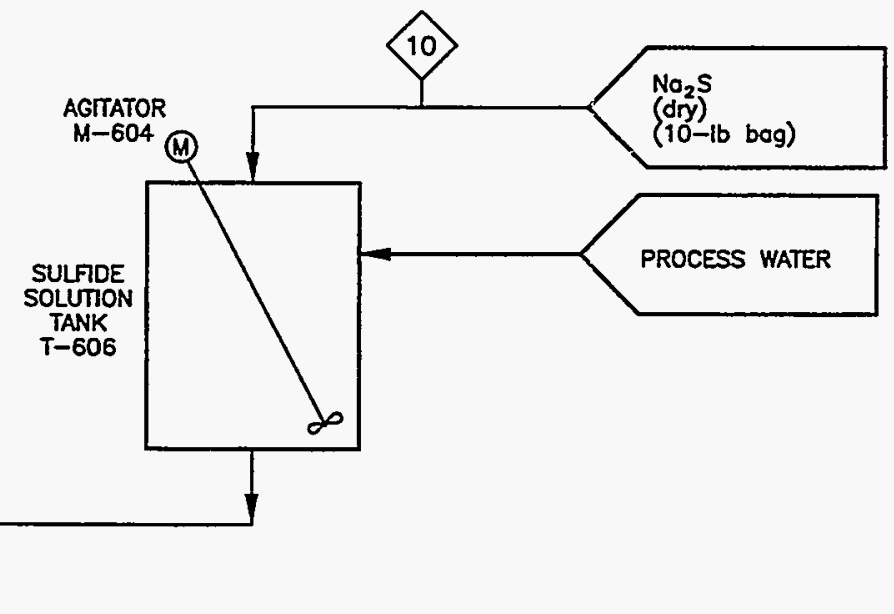

TO MERCURY INTERIM STORAGE

\begin{tabular}{|c|c|c|c|}
\hline SPConTruct ma & \multicolumn{3}{|c|}{ LOCKHEED WATTIND } \\
\hline REOESTIJ: & \multirow{5}{*}{\multicolumn{3}{|c|}{$\begin{array}{c}\text { ICPP } \\
\text { WASTE TREATMENT FACIUTIES } \\
\text { VIRIFED WASTE OPTION } \\
\text { VIRIFICATION FACILTY } \\
\text { OFF-GAS SCRUBBER BLOWDOWN STSTEM }\end{array}$}} \\
\hline Desset: & & & \\
\hline manut: & & & \\
\hline PRaECT MO & & & \\
\hline $\begin{array}{lll}\text { Ferc cooe } & \end{array}$ & & & \\
\hline $\begin{array}{l}\text { FOR REMEW/APPRONR SCAUTRES } \\
\text { GE DUR HQ }\end{array}$ & 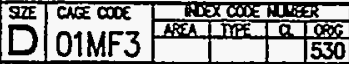 & Dine- & Pay \\
\hline DFECTRE OATE & SCHE NONE & \multicolumn{2}{|c|}{ SFen WWO-O6 } \\
\hline
\end{tabular}




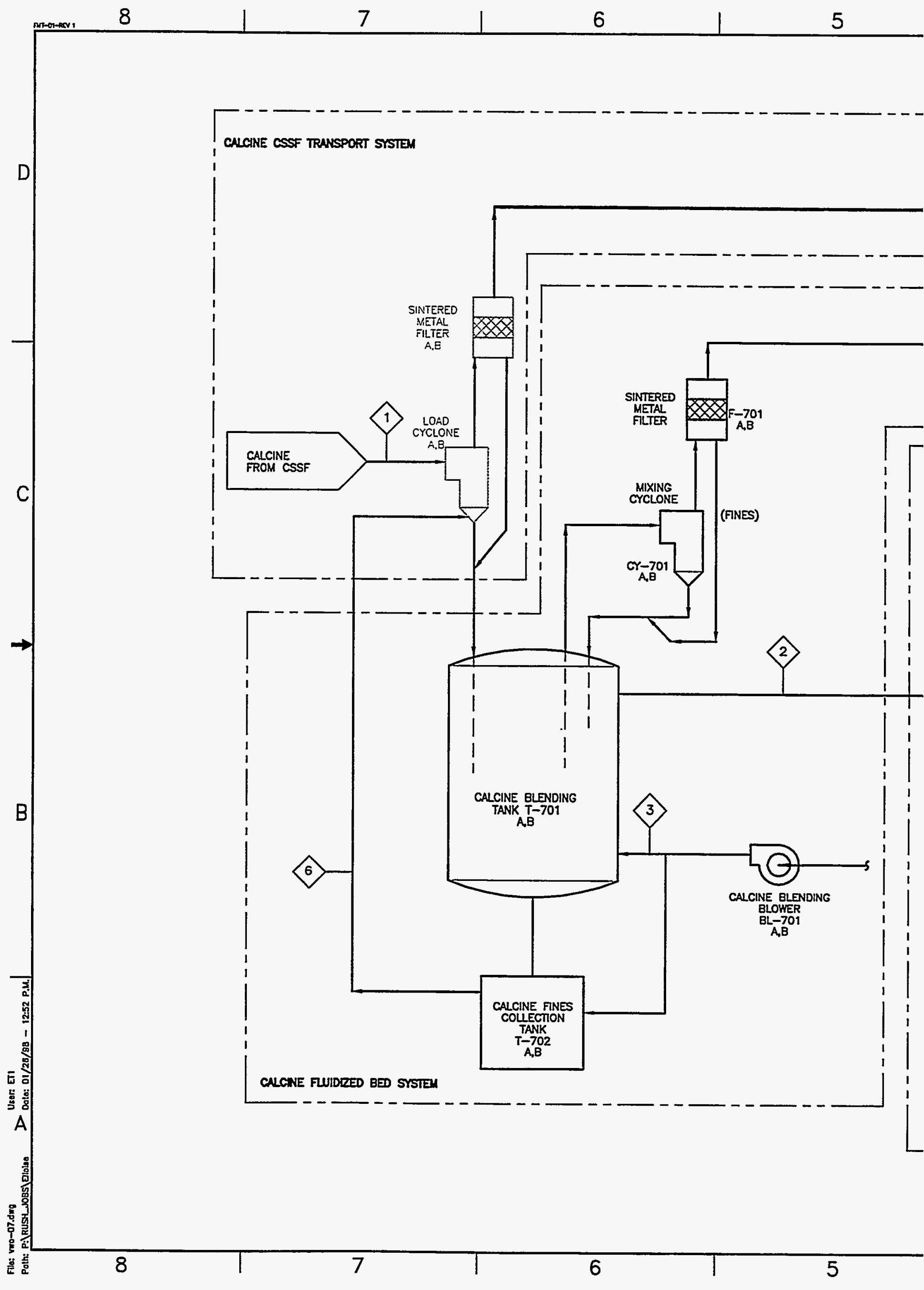




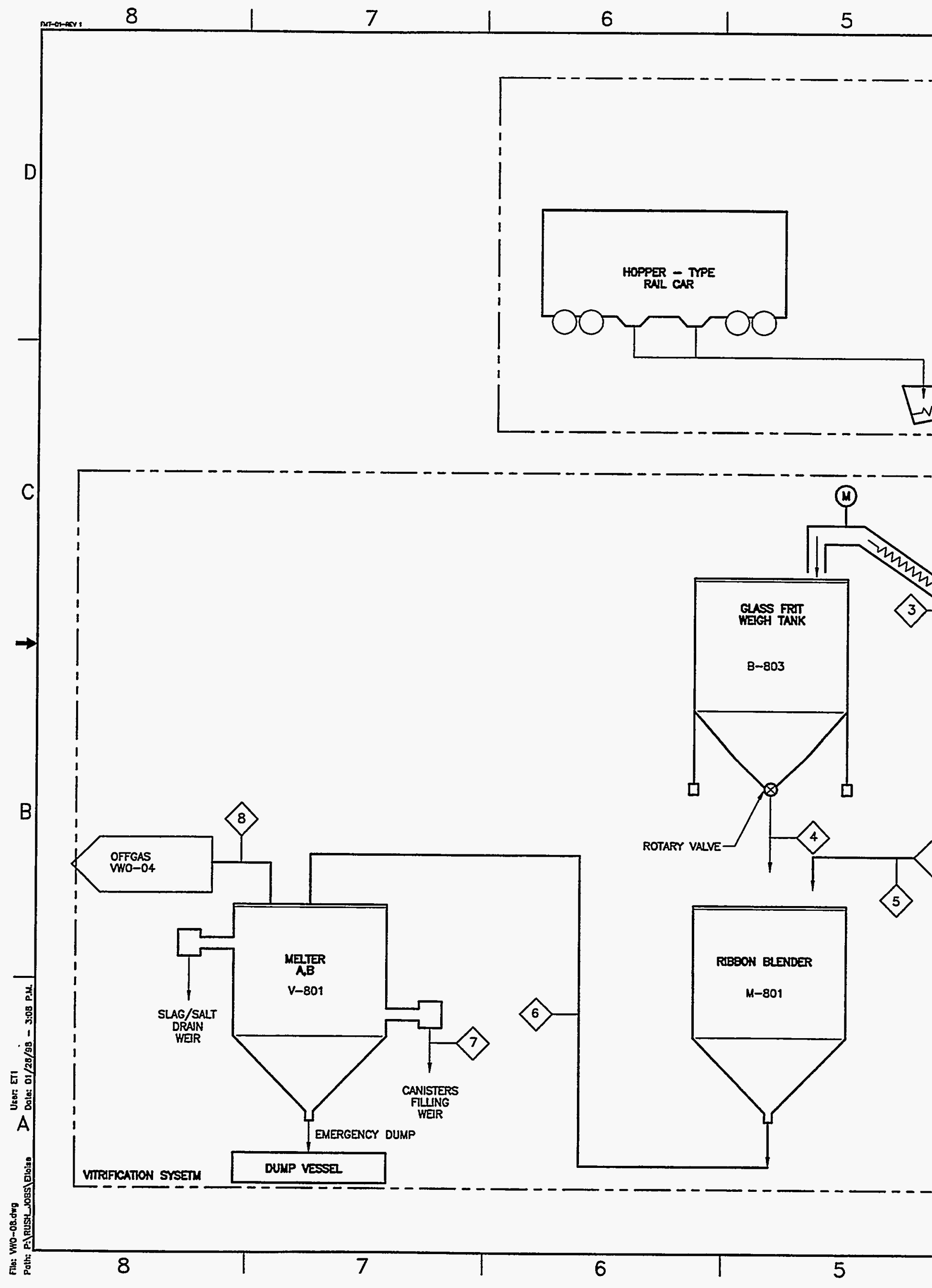




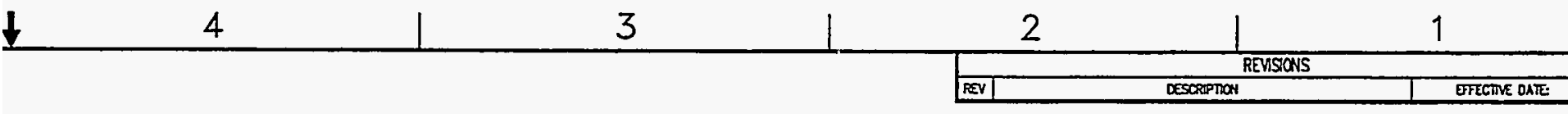

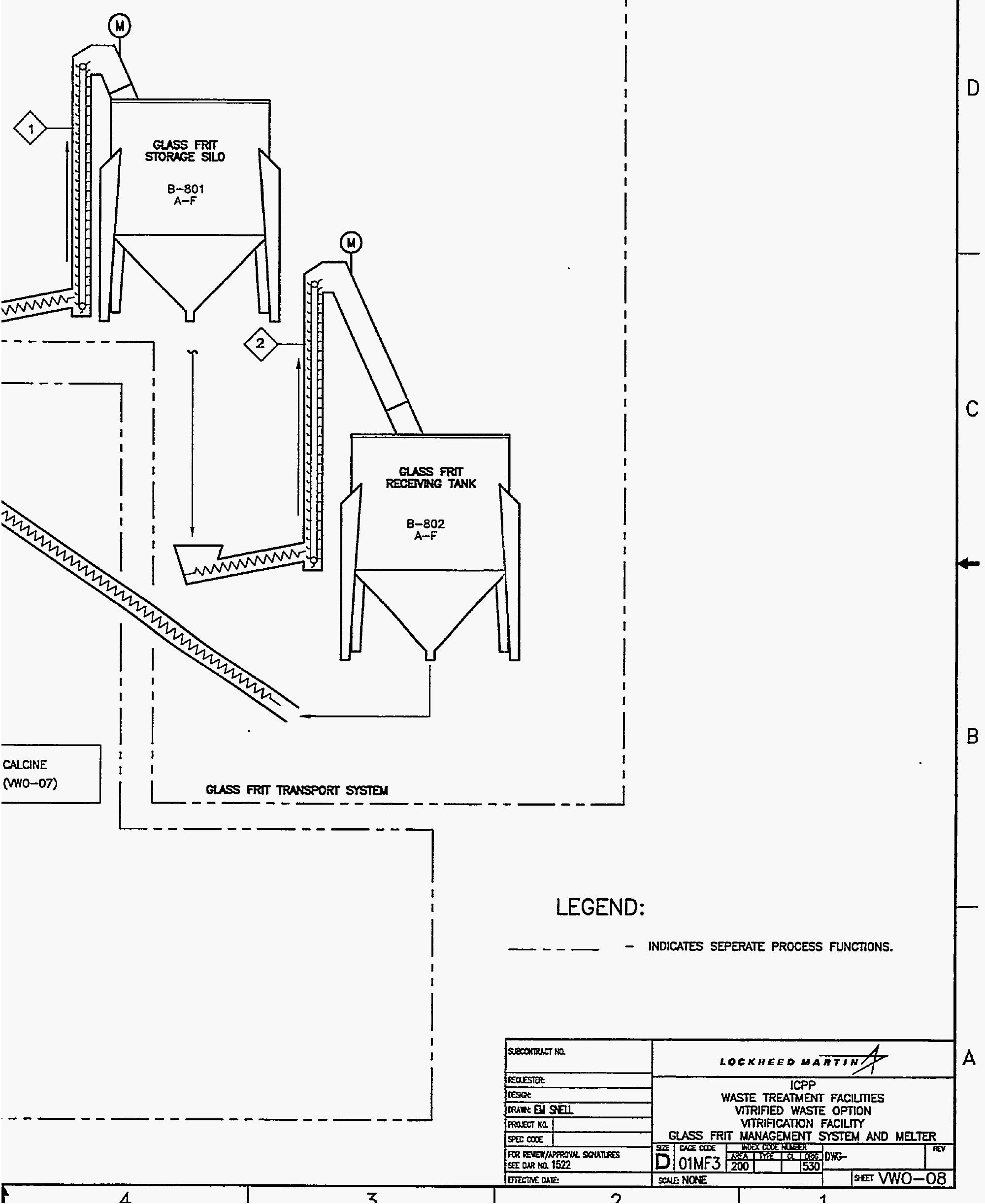




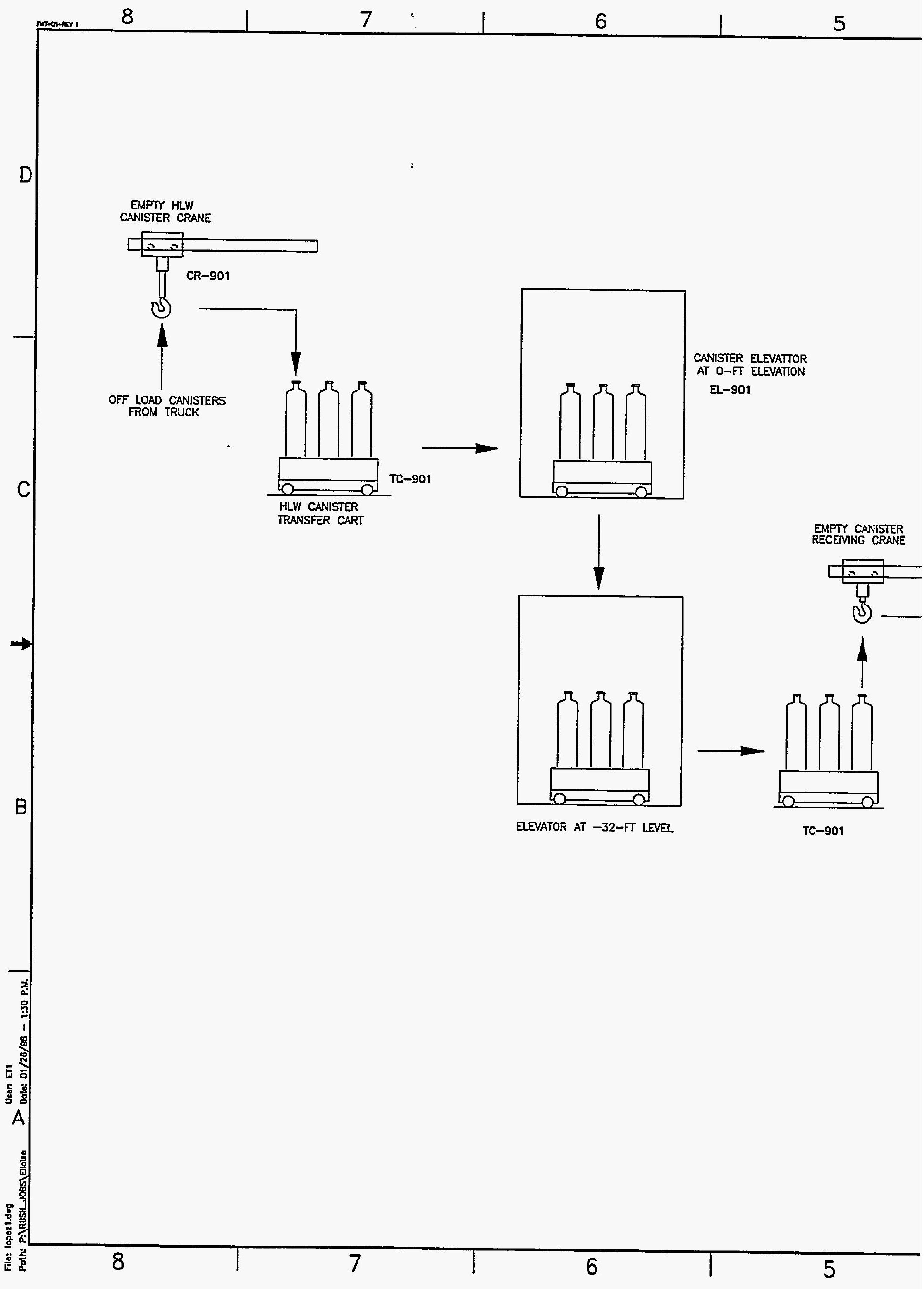




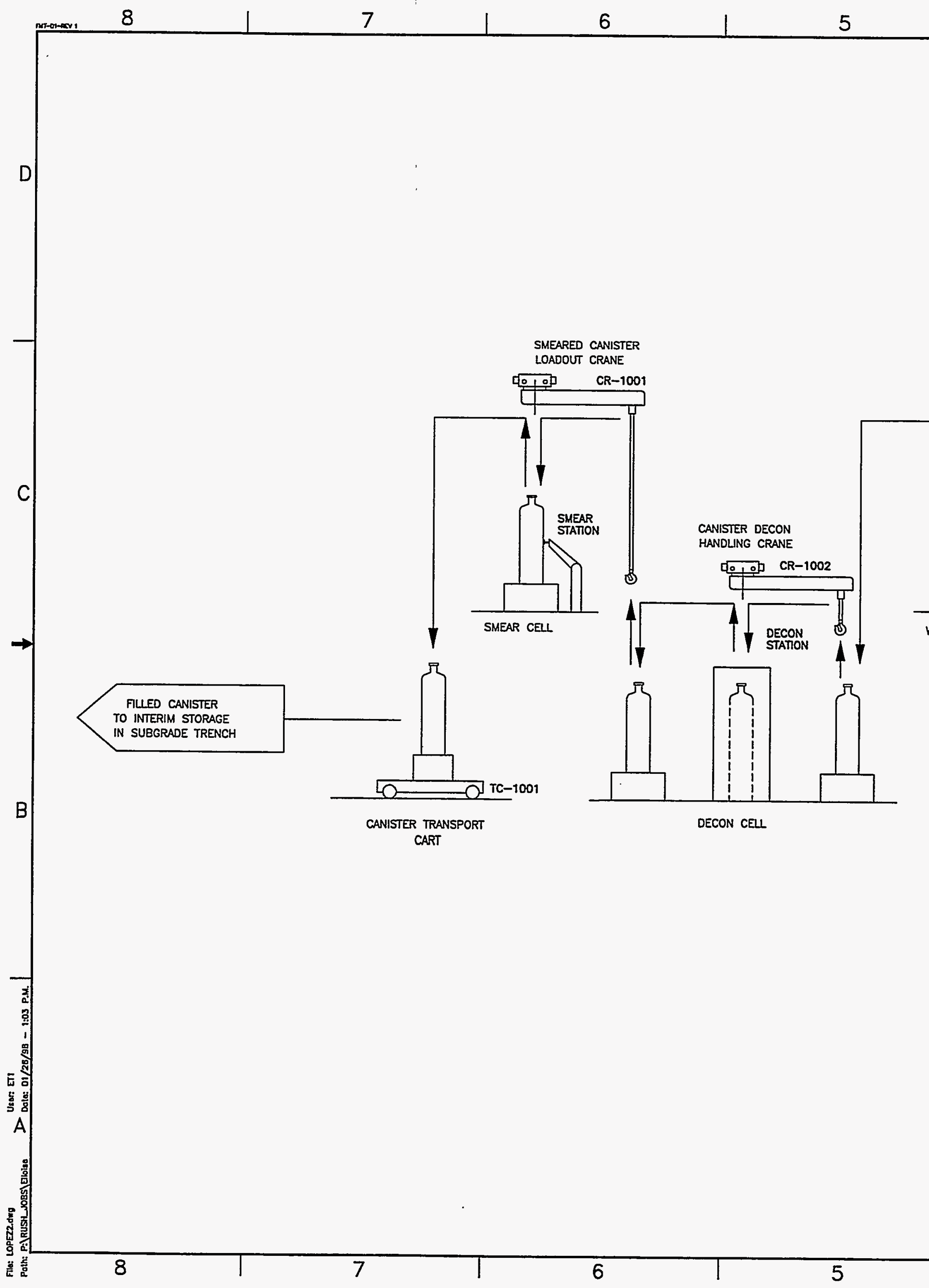


Appendix C

Key Assumptions 


\section{Key Assumptions}

\section{Vitrified Waste Option Study Report}

\begin{tabular}{|c|c|c|c|c|c|}
\hline $\begin{array}{c}\text { Number } \\
\text { Latest Rev } \\
\text { Initials }\end{array}$ & Assumption & References & Application to Volumes & $\begin{array}{c}\text { Application to } \\
\text { Alternatives }\end{array}$ & \begin{tabular}{c} 
Contact and Date \\
\hline
\end{tabular} \\
\hline
\end{tabular}

\begin{tabular}{|c|c|c|c|c|}
\hline S-1 & The VWO will be designed based on the Raytheon Waste immobiliza & on Facility Direct Vitrification option in & ume 4 of Reference 1 ( 0 & \\
\hline Basis & 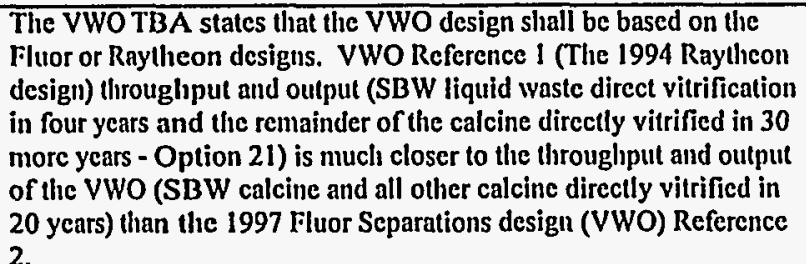 & $\begin{array}{l}\text { VWO TBA, VWO Reference 1, VWO } \\
\text { Reference } 2\end{array}$ & $\begin{array}{l}\text { Volume } 4 \text { of Reference } \\
1\end{array}$ & None \\
\hline
\end{tabular}

\begin{tabular}{|c|l|l|l|l|}
\hline $\mathrm{M}-1$ & The total potver requirement for the lid heaters is 1.5 million BTU/hr $(-440 \mathrm{~kW})$. & & \\
\hline Basis & $\begin{array}{l}\text { This is approximately the same lid heater power requirements as at } \\
\text { DWPF. }\end{array}$ & & $\begin{array}{l}\text { D. Bickford, } \\
\text { (SRS), 10/30/97 }\end{array}$ \\
\hline
\end{tabular}

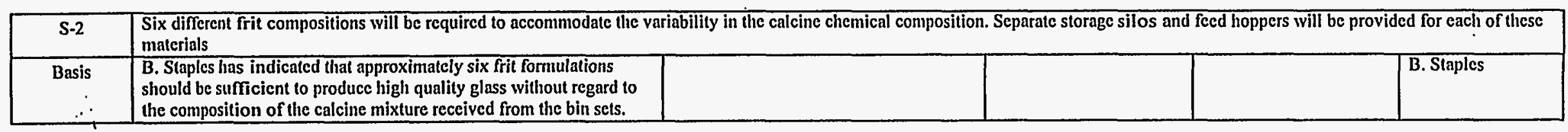

\begin{tabular}{|c|l|l|l|l|}
\hline M-2 & $\begin{array}{l}\text { Two hundred fify SCFM of ambient air will be pulled into the headspace of the melter, which will be operated under a slight vacuum. The air will cool instrument penctrations and control } \\
\text { the temperature of the cold cap. }\end{array}$ & $\begin{array}{l}\text { J. Whitehouse } \\
\text { (SRS - TVS) } \\
\text { 10/10/97; D. } \\
\text { Bickford (SRS - } \\
\text { DWPF), 10/30/97 }\end{array}$ \\
\hline Basis & $\begin{array}{l}\text { This figure lies between the off-gas flow rates for the TVS and the } \\
\text { DWPF melters }\end{array}$ & &. & \\
\hline
\end{tabular}

\begin{tabular}{|l|l|l|l|l|}
\hline WS-1 & Evaporation and solids stabilization capability will be provided by others & & \\
\hline Basis & $\begin{array}{l}\text { R. Garcia is performing an analysis of utilities capability in support } \\
\text { of the EIS process alternatives }\end{array}$ & & $\begin{array}{l}\text { R. Garcia, } \\
\text { 11/18/97 }\end{array}$ \\
\hline
\end{tabular}

\footnotetext{
M-3 $T 90 \%$ of the mercury released from the calcine will be in the form of elemental mercury. $10 \%$ will be in the form of soluble salts
} 


\section{Key Assumptions}

Basis 7 Mercury in the calcine is present in the form of $\mathrm{HgO}$, which decomposes to elemental species below the operating temperature of the melter. It is possible that some elemental mercury will be oxidized in the scrubber water system, due to the presence of nitrite and nitrate anions.

\section{\begin{tabular}{|l|l|}
\hline WS-2 & The GCs, as scoped, will meet the repository WAPS for co-disposal witl SNF \\
\hline
\end{tabular}}

\section{\begin{tabular}{|l|l|}
\hline Basis & DWPF is currently generating waste glass in this type of canister.
\end{tabular}}

\begin{tabular}{|c|c|c|c|c|c|}
\hline WS-3 & \multicolumn{5}{|c|}{$\begin{array}{l}\text { The final waste from package }-61 \mathrm{~cm} \text { outside diameter } \times 3 \mathrm{~m} \text { long canister - will meet the requirements for transportation of HAW under } 10 \mathrm{CFR} 72 \text {, and DOT } 10 \mathrm{Cr} \text {, } 71 \text {, as defined by } \\
\text { NRC and DOT. }\end{array}$} \\
\hline Basis & $\begin{array}{l}\text { An asstumption is provided in the referenced document states that the } \\
\text { DOT Research and Special Programs Adninistration will approve } \\
\text { shipment of special form HAW in NRC approved Type " } B \text { " shipping } \\
\text { containers. }\end{array}$ & $\begin{array}{l}\text { DOE/ID-10544, Regulatory Analysis and } \\
\text { Proposed Path Forvard for the Idaho } \\
\text { National Enginecring Laboratory High- } \\
\text { Level Wastc Program, U. S. Department } \\
\text { of Encrgy, Idalio Operations Office, } \\
\text { Idaho National Enginecring Laboratory, } \\
\text { Nuciear Operations Division High-Level } \\
\text { Wastc Directorate, October I996 }\end{array}$ & $\begin{array}{l}\text { This refers to EIS } \\
\text { volume numbers and } \\
\text { will be completed by } \\
\text { others }\end{array}$ & $\begin{array}{l}\text { This refers to the EIS } \\
\text { alternatives and will be } \\
\text { completed by oflers }\end{array}$ & \begin{tabular}{|l|} 
G. W. Waclis \\
(208)526-9796 \\
gww@inel.gov
\end{tabular} \\
\hline
\end{tabular}

WS-4 $\quad$ The SBW will be calcined prior to vitrification. This option will not process any waste generated after 2012.

Basis The VF will only be capable of handling calcined materials. The

SBW currently is in liquid form and must be calcined prior to commencement of vitrification.

This refers to EIS

volume numbers and

will be completed by

This refers to the EIS

alternatives and will be others.

completed by others.

S-3 $\quad$ Calcine volume is $5435 \mathrm{~m}^{3}$ with an average density of $1408 \mathrm{~kg} \mathrm{per} \mathrm{m}$.

Basis $\quad$ Best information avalable is documented in Barnes EDF-FDO-001.

This data is required to deternine the number of grout filled canisters

that will be produced.

\section{EDF-FDO-00I, Estimates of Feed and}

Waste Volumcs, Compositions and

Properties, C. M. Barnes, August 21, 1997.

\section{This refers to EIS \\ volume numbers and \\ will be completed by}

others
This refers to the EIS

alternatives and will be

completed by others

S-4 Canister loading is $0.72 \mathrm{~m}^{3}$. The number of vitrified canisters produced is approximately 14,115

Basis The capacity of the Savannah river Site HLW canister is listed at

$25.3 \mathrm{f}^{3}$ or $0.72 \mathrm{~m}^{3}$. The assumption is that the canister can and will

be filled to capacity. EDF-VWO-001 estimates the 14,115 based on

this loading

Savannal River site HLW canister

drawing, ORNL DWG 90-418.
This refers to EIS

volume numbers and

will be completed by

others
This refers to the EIS

alternatives and will be completed by others 


\section{Key Assumptions}

\begin{tabular}{|c|c|c|c|c|c|}
\hline Basis & $\begin{array}{l}\text { The requirements applicable to security systems are continuing to } \\
\text { cvolve. This assumption is primarily a result of interpretations of } \\
\text { existling regulations (10 CFR 73) and an understanding of proposed } \\
\text { NRC rules. Where questions concerning the interpretation of } 10 \mathrm{CFR} \\
73 \text { arise, guidance lias been sought from NUREG-1497. }\end{array}$ & $\begin{array}{l}10 \text { CFR } 73 \\
\text { NUREG-1497 }\end{array}$ & $\begin{array}{l}\text { This refers to EiS } \\
\text { volume numbers and } \\
\text { will be completed by } \\
\text { others. }\end{array}$ & $\begin{array}{l}\text { This refers to the EIS } \\
\text { altematives and will bc } \\
\text { completed by ollers. }\end{array}$ & $\begin{array}{l}\text { J. L. Rohrbaugi1 } \\
\text { (208) 526-0687 } \\
\text { jxr@inel.gov }\end{array}$ \\
\hline WS-5 & \multicolumn{5}{|c|}{ All Low-Level Waste (LLW) or mixed LLW produced by the VF will be class $A$, B, or C as defined in NRC 10 CFR 61.55} \\
\hline Basis & $\begin{array}{l}\text { A calculation was performed for the scrubber blowvlown water, and it } \\
\text { was shown to be a class } C \text { waste, based on estimated releases of Cs- } \\
137 \text { in the melter off-gas. All other waste secondary waste streams } \\
\text { generated at the VF are expected to be significantly below the Class } \\
\text { C level. }\end{array}$ & 10 CFR 61.55 & & & . \\
\hline
\end{tabular}

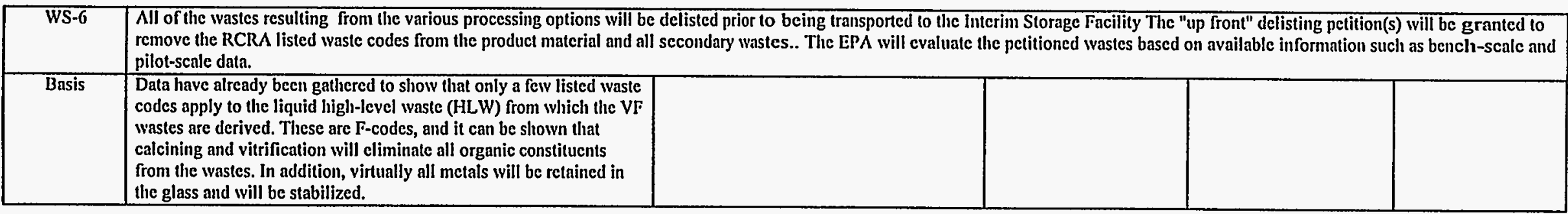

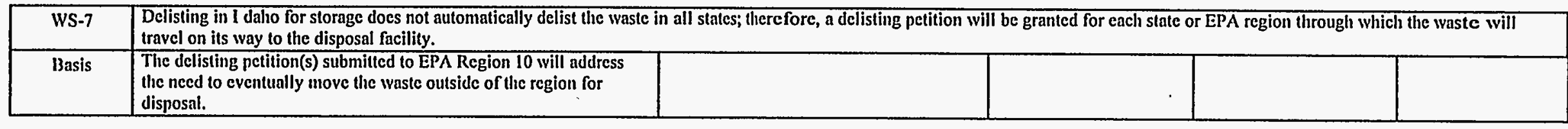

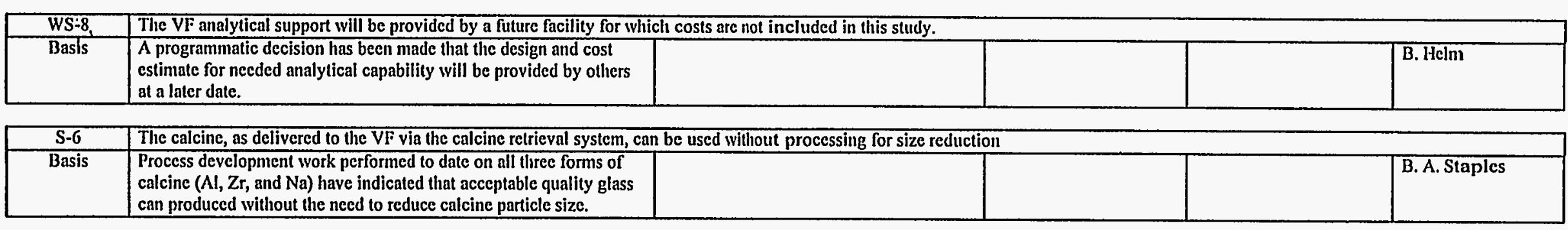

S-7 $\quad$ A shiclded probe system can be used in the VF exhaust stack instead of an isokinclic sampling system. The probe will be used to monitor the off-gas and HEPA-filtcred HVAC exhaust air.

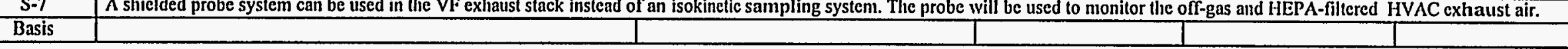

\begin{tabular}{l|l} 
S-8 & Precipitation of mercury as a sulfide salt will meet the definition of amalgamation with sulfur under $40 \mathrm{CFR} 268$, so that the solids from this scrubber blowdown treatment process will meet \\
\hline
\end{tabular} the Land Disposal Restrictions (LDR). 


\section{Key Assumptions}

\begin{tabular}{|c|c|c|}
\hline Basis & $\begin{array}{l}\text { The definition of amalgamation allows treatment with sulfur so } \\
\text { treatment of mercury ion with a sulfide salt should be acceptable. }\end{array}$ & $\begin{array}{l}\text { Based on a } \\
\text { conversation with } \\
\text { J. Boslcy. }\end{array}$ \\
\hline S-9 & \multicolumn{2}{|c|}{ No canisters will require recycling. The glass product and canister welding procedures will meet disposal site WAC. } \\
\hline Basis & $\begin{array}{l}\text { The VF processes will be operated in a manner similar to those at } \\
\text { the DWPF. At that facility, sufficient development work has been } \\
\text { done to define the ingredients and operating conditions needed to } \\
\text { produce acceptable glass. Statistical process control is used to assure } \\
\text { that the system is operated within defined parameters. Design studies } \\
\text { and drop test will have to be performed on canisters prior to their use } \\
\text { in the system. }\end{array}$ & $\begin{array}{l}\text { D. Bickford, } \\
10 / 30 / 97 \text {. }\end{array}$ \\
\hline
\end{tabular}


Appendix D

Cell Descriptions 


\section{Appendix D}

\section{Cell Descriptions}

For this section, refer to the VF building plan and elevation drawings in Appendix B. The process is arranged into several types of segregated hot cell areas with each area surrounded by the necessary support systems and access corridors. Each of the five types of cells are designed as follows:

The VF contains six separate production cells; the two melter cells, a single canister filling and capping cell (which services both melters), the welding cell, the decontamination cell, and the smear cell. These cells are shown in Facility Drawings. The vertical, staggered arrangement and relationships between the six process cells is shown in two VF building elevation views in Appendix B. The cells are all isolated, by positive ventilation barriers and shield hatches, from each other and from the rest of the facility. Positive isolation between cells and surrounding areas will be accomplished using rail mounted, horizontaily actuated shielding/confinement hatch covers over floor and wall openings. This ensures that contamination will be unlikely to occur downstream of the decontamination and smear cells, or to enter the transfer tunnel or the ISF. The hatches are located in the smear, weld, decontamination, and canister filling and capping cells. The weld, decontamination, and smear cells are examples of single purpose cells. A single module exists within each cell to perform the task. The following summarizes the operations performed in the cells

- The calcine receiving cell, holds the two large fluidized bed blenders and associated equipment, that receives calcine from the CSSF, homogenizes it, and delivers it to the melter cells. The cell occupies the north cell from the -32-ft level to the cell shield covers at the $42-$ $\mathrm{ft}$ level. The CRTS, which delivers calcine from the CSSF to the fluidized bed blenders, is discussed on the system and process section of this report. The secondary calcine delivery system, that delivers calcine from the fluidized bed blenders to the melter cell, is discussed in the vitrification process section of this report.

- The offgas system equipment canyon holds high maintenance process equipment, (primarily for offgas treatment). An operating corridor runs along two sides of the offgas system equipment canyon. Shield windows allow the operators to view remote activities, and a $\mathrm{PaR}^{2}$-type wall-mounted electro-mechanical manipulator will be used for remote maintenance.

- Calcine and glass frit will be mixed and vitrified in the melter cells. One melter cell will always be in operation while the other is on standby. The cell equipment can be separated into subcomponent sections that can be removed to the maintenance/disassembly cell above, using the master-slave manipulators and the canyon crane after removing the melter cell shield cover. The offgas systems are all directly connected to the melters.

- The canister filling and capping cell remotely receives and lifts the empty canisters to the melter pour weir where they will be preheated (preheating promotes uniform filling and eliminates voids), and filled. While pouring the glass, gases will be continuously extracted through a special ventilation circuit and routed to offgas treatment. A load cell weighs the canisters during all pouring operations to monitor the glass pour rate, and a gamma detector measures glass level. The GCs will be cooled for 24 hours in a rack, and a lid placed on the cooled GC before being moved out of the canister filling and capping cell and up into the 
welding cell. The cell equipment can be separated into subcomponent sections that can be removed to the maintenance/disassembly cell above, via the welding cell, using the canyon crane after removing the cell shield cover.

- The canister weld-handling crane and grapple remotely lift the GC from the canister filling and capping cell. The weld cell uses a gas tungsten arc welding module to remotely weld the GC lid and to test the seal weld. The cell equipment can be separated into subcomponent sections that can be removed to the maintenance/disassembly cell above using the canyon crane after removing the cell shield cover.

- Remote GC decontamination, using solid carbon dioxide pellet blasting, will decontaminate the outside surface of each canister. This process is based on commercially available decontamination processes. Decontamination occurs inside a chamber isolated from the canister-handling cell. Before the decontamination step begins, a movable lid will be remotely closed and sealed to prevent the spread of contamination. The cell equipment can be separated into subcomponent sections that can be removed to the maintenance/disassembly cell, via the welding cell, using the canyon crane after removing the cell shield cover.

- The GC smear cell tests for surface contamination using a remotely operated module to determine if the $\mathrm{GC}$ has to be returned to the decontamination cell or can be placed on the canister transport cart in the transfer tunnel and sent to the ISF. The cell equipment can be separated into subcomponent sections that can be removed to the maintenance/disassembly cell above using the canyon crane after removing the cell shield cover.

- The underground canister transfer tunnel will be used to transport GCs on a canister transport cart, approximately $100 \mathrm{ft}$ to the ISF. The transfer tunnel will be maintained by hands-on maintenance when all GCs have been removed from the tunnel.

- The maintenance/disassembly cell is located above the upper row of cells at the 45-ft level. This will be used to disassemble equipment that has been removed from service. Manipulators, widows, and other remote equipment in this area will be available for equipment maintenance, or equipment sizing. Sized equipment will be packaged in DWPF canisters and stored in the ISF along with the GCs. The maintenance/disassembly cell contains a canister welding station for making the circumferential weld around the 2-ft diameter of the canisters containing sized equipment. 


\section{Appendix E}

HVAC Requirements 


\section{Appendix E}

\section{HVAC Requirements}

The following is a list of the primary design requirements for the VF HVAC system:

- Maintain office and operational areas at temperatures recommended by the appropriate codes and standards specified to assure personnel comfort and safety and to protect instruments and equipment during normal and off-normal conditions.

- Detect and monitor ventilation flows and pressure differentials throughout the facility as required to prevent the possible spread of potential hazards. All ventilation air flows and pressure differentials will be alarmed if out of compliance.

- Assure facility airflows are from areas of less contamination potential to areas of greater contamination potential. Means should be provided to seal all containment boundaries in case of loss of ventilation or pressure differentials or both.

- Confine radioactive materials as close as practicable to the point of release.

- Maintain ALARA release of the radioactivity to the environment as required by DOE Order 5400.5.

- $\quad$ Provide redundant or backup equipment in all exhaust systems serving contaminated areas as needed to assure contamination control.

- Provide sampling ports in the individual branches of supply and exhaust ducting for testing to verify system performance, operability, and in-place filter component leakage.

- Provide air changes sufficient to remove heat, hazardous and particulate gases, and other contaminants. The system will be designed to provide proper distribution of airflow throughout the facility during normal, off-normal and maintenance activities.

- Provide an interlocked HVAC barrier system so that reversed airflow patterns cannot be established.

- Provide a stack to exhaust all contaminated or potentially contaminated air. The exhaust stack will be monitored using a shielded probe system. As a minimum, the system will monitor for Beta/Gamma particulate, Alpha particulate, and tritium. The system will allow for both local and remote readout and alarm annunciation. 


\section{Appendix F}

Cost Estimates 


\section{Lockheed Martin Idaho Technologies Company INTERDEPARTMENTAL COMMUNICATION}

Date: January 27, 1998

To:

D. A. Lopez

MS 3765

$6-9020$

From:

D. R. James

MS 3655

$6-7139$

Subject: HWO VITRIFICATION FACILITY - DRJ-01-98

As requested, Cost Estimating has completed the Planning Cost Estimates for the project referenced above. Listed below are the various types of estimates prepared and the associated estimated cost:

$$
\begin{array}{ll}
\text { Total Estimated Cost - Escalated } & \$ 600,000,000 \\
\text { Total Estimated Cost - Unescalated } & \$ 472,000,000 \\
\text { Other Project Cost - Escalated } & \$ 196,000,000 \\
\text { Other Project Cost - Unescalated } & \$ 180,314,000
\end{array}
$$

Attached please find the Estimate Summary, Support Data Recapitulation and Detail Sheets for your reference. These documents should adequately describe the scope of work, assumptions and unit cost associated with the project.

If you have any questions or comments, please do not hesitate to contact me at 526-7139 or Office Vision-ID NIE.

DRJ

Attachments

cc: Estimate File \#2418

D. R. James Files

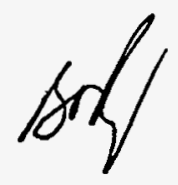




\section{COST ESTIMATE SUPPORT DATA RECAPITULATION}

Project Title: VWO VITRIFICATION FACILITY Type of Estimate: Planning File No: 2418
Estimator: D. R. James Approved By:

I. SCOPE OF WORK: Brief description of the proposed project. Construct a Vitrification (VIT) Facility to accept, process and transport calcined waste. The facility will be complete with all internal utilities and process equipment necessary to accomplish the vitrification process.

II. BASIS OF THE ESTIMATE: Drawings, Design Report, Engineers notes, and/or other documentation upon which the estimate is originated.

1. Sketches, equipment lists and descriptions from cognizant project personnel.

2. Discussions with the individuals responsible for the various components of the facility.

3. Historical data on waste processing facilities.

4. Raytheon Engineers and Constructors, Inc., Cost Estimate dated Nov. 7, 1994.

III. ASSUMPTIONS: Condition statements accepted or supposed true without proof or demonstration. An assumption has a direct impact on total estimated cost.

1. The current Vitrification Facility will be similar in design to the previous Direct Vitrification facility designed by Raytheon.

2. The soil containing low level radioactivity, encountered during excavation, will be stockpiled and used as backfill or processed at a later date.

3. Open cut excavation with a $11 / 2 / 1$ slope will be used.

4. Costs for utilities to the facility will be evaluated in a different study.

5. Modifications to the existing facilities that will support the VIT Facility will be evaluated in separate studies.

6. A concrete batch plant will be mobilized at the INEEL for construction of this facility.

7. The exhaust stack will be fabricated from carbon steel material.

8. Excess clean soil will be spread outside the facility within 1 mile. 
Lockheed Martin Idaho Technologies Co.

\section{COST ESTIMATE SUPPORT DATA RECAPITULATION (CONTINUATION)}

File No: 2418

Page 2 of 2

III. ASSUMPTIONS: (Continued)

9. The current facility will not have the liquid waste processing capabilities that were present in the previous facility designed by Raytheon.

10. Construction will begin in January, 2006 and complete in December, 2011.

11. Costs for the Transfer Tunnel from the VIT Facility to the Interim Storage Facility (ISF) will be included in the ISF Cost Estimate.

12. It is assumed that the process will work as designed. Costs have not been estimated to compensate for the incorporation of an alternative process in the event the current process does not work.

IV. CONTINGENCY GUIDELINE IMPLEMENTATION: The percentage used for contingency as determined by the contingency allowance guidelines can be altered to reflect the type of construction and conditions that may impact the total estimated cost.

The estimate was prepared from limited information. In some instances the details are based on the estimator's best judgement of the requirements to construct this facility. Areas of major risk are the process equipment, mechanical systems and electrical systems. Therefore the contingency for these areas has been increased accordingly.

The estimated contingency for this project of $43.89 \%$ is within the guidelines for a project at this stage of design. Please refer to the Contingency Analysis sheet for the breakdown of contingency.

\section{OTHER COMMENTS/CONCERNS SPECIFIC TO THE ESTIMATE:}

1. G\&A and PIF have been applied to the estimate in accordance with current guidelines.

2. Considering the magnitude of the project, a $1 \%$ Procurement Fee was applied rather than the standard $3 \%$. 
Lockheed Martin Idaho Technologies Co.

PROIECT NAME: HWO VITRIFICATION FACILITY

LOCATION

TOTAL ESTIMATED COST - ESCALAT

ICPP, INEEL

REOUESTOR:

D. A. Lopez
COST ESTIMATE SUMMARY

OFESTIMATE: PLANNING

PROSECTNO: 2418

PREPARED BY: D. R. James

REPORT NAME: Cost Estimate Summary

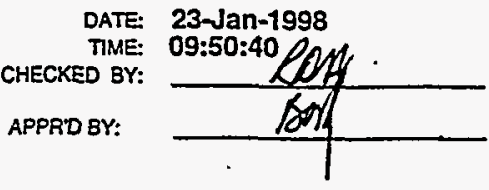

\begin{tabular}{|c|c|c|c|c|}
\hline $\begin{array}{l}\text { WBS } \\
\text { Element }\end{array}$ & Cost Estimate Element & $\begin{array}{c}\text { Total } \\
\text { Unescalated }\end{array}$ & Escalation & $\begin{array}{l}\text { Total } \\
\text { Incl Escalation }\end{array}$ \\
\hline $\begin{array}{l}\frac{1.1}{1.1 .1} \\
1.1 .2 \\
1.2 \\
1.2 .1 \\
1.2 .2 \\
1.3 \\
1.3 .1 \\
1.3 .2 \\
1.3 .3 \\
1.3 .4 \\
1.3 .5 \\
1.3 .6 \\
1.3 .7 \\
1.3 .8 \\
1.3 .9 \\
1.3 .10 \\
1.3 .11 \\
1.3 .12 \\
1.3 .13 \\
1.3 .14 \\
1.3 .15 \\
1.3 .16 \\
1.4 \\
1.4 .1 \\
1.5 \\
1.5 .1 \\
1.5 .2\end{array}$ & $\begin{array}{l}\text { ENGINEERING, DESIGN AND INSPECTION } \\
\text { DESIGN ENGINEERING TITLE I \& II } \\
\text { TITLEIII INSPECTION } \\
\text { MANAGEMENT COSTS } \\
\text { PROJECT MANAGEMENT } \\
\text { CONSTRUCTION MANAGEMENT } \\
\text { CONSTRUCTION } \\
\text { GENERAL CONDITIONS } \\
\text { SITEWORK } \\
\text { CONCRETE } \\
\text { MASONRY } \\
\text { METALS } \\
\text { WOOD \& PLASTICS } \\
\text { THERMAL \& MOISTURE PROTECTION } \\
\text { DOORS \& WINDOWS } \\
\text { FINISHES } \\
\text { SPECIALTIES } \\
\text { EQUIPMENT } \\
\text { FURNISHINGS } \\
\text { SPECIAL CONSTRUCTION } \\
\text { CONVEYING SYSTEMS } \\
\text { MECHANICAL } \\
\text { ELECTRICAL } \\
\text { GOVERNMENT FURNISHED EQUIP. } \\
\text { GOVERNMENT FURNISHED EQUIP. } \\
\text { G\&AIPIF } \\
\text { G\&APIF ADDER } \\
\text { PROCUREMENT FEES } \\
.\end{array}$ & $\begin{array}{r}29,344,000 \\
21,000,000 \\
4,941,905 \\
2,429,941 \\
22,888,800 \\
0 \\
8,400,751 \\
0 \\
5,764,140 \\
2,446,236 \\
2,966,400 \\
23,150,409 \\
83,531,926 \\
2,152,136 \\
0 \\
163,440 \\
32,158,828 \\
18,604,676\end{array}$ & $\begin{array}{c}8,509,760 \\
6,090,000 \\
\\
1,433,153 \\
704,683 \\
6,637,752 \\
0 \\
2,436,218 \\
0 \\
1,671,601 \\
709,409 \\
860,256 \\
6,713,619 \\
24,224,259 \\
624,120 \\
0 \\
47,398 \\
9,326,060 \\
5,395,356 \\
\end{array}$ & 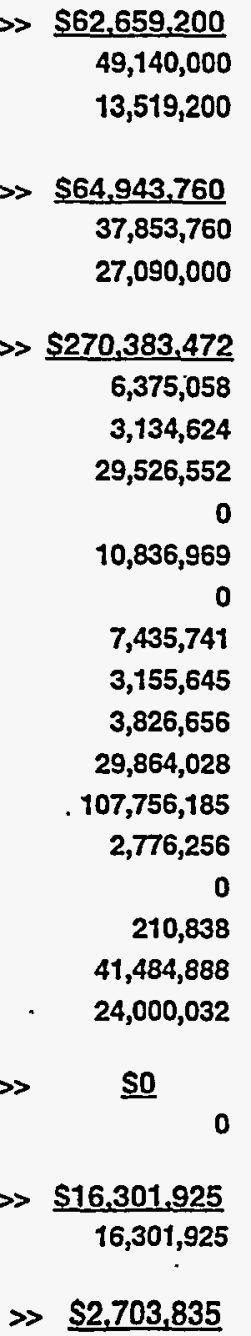 \\
\hline & $\begin{array}{l}\text { SUBTOTAL INCLUDING ESCALATION } \\
\text { PROJECT CONTINGENCY }\end{array}$ & $327,156,735$ & $89,835,457$ & $\gg \$ 416,992,192$ \\
\hline & MANAGEMENT RESERVE & & & $\$ 28,938,923$ \\
\hline & CONTINGENCY & & & $\gg \$ 154,068,885$ \\
\hline & TOTAL ESTIMATED COST & & : & \\
\hline
\end{tabular}

PROJECT COST PARAMETERS

EDI AS A \% OF CONST. + GFE $=23.00 \%$

CONTINGENCY $=43.89 \%$ 
Lockheed Martin Idaho Technologies Co.

PRONECT NAME: HWO VITRIFICATION FACILITY

LOCATION 1: TOTAL ESTIMATED COST - UNESC. ICPP, INEEL

REQUESTOR:
COST ESTIMATE SUMMARY

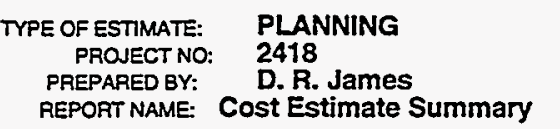

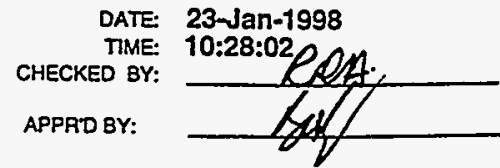

DATE: 23-Jan-1998
Total Incl Escalation

$>\$ 52,480,000$

$42,000,000$

$10,480,000$

\begin{tabular}{l|l}
1.1 .2 & TITLE III INSPECTION
\end{tabular}

1.2 MANAGEMENT COSTS

1.2.1 PROJECT MANAGEMENT

1.2.2 CONSTRUCTION MANAGEMENT.

1.3 CONSTRUCTION

1.3.1 GENERAL CONDITIONS

1.3.2 SITEWORK

1.3.3 CONCRETE

1.3.4 MASONRY

1.3.5

1.3.6

1.3.7

1.3 .8

1.3 .9

1.3.10

1.3.11

1.3 .12

1.3 .13

1.3.14

1.3.15

METALS

WOOD \& PLASTICS

THERMAL \& MOISTURE PROTECTION

DOORS \& WINDOWS

FINISHES

SPECIALTIES

EQUIPMENT

FURNISHINGS

SPECIAL CONSTRUCTION

CONVEYING SYSTEMS

MECHANICAL

1.3.16

ELECTRICAL

1.4 GOVERNMENT FURNISHED EQUIP.

1.4.1 GOVERNMENT FURNISHED EQUIP.

1.5 G\&A/PIF

1.5.1 G\&AVIF ADDER

1.5.2 PROCUREMENT FEES

SUBTOTAL INCLUDING ESCALATION

PROJECT CONTINGENCY

MANAGEMENT RESERVE

CONTINGENCY

TOTAL ESTIMATED COST

Total Unescalated

\section{$42,000,000$}

$10,480,000$

.

$29,344,000$

$21,000,000$

$4,941,905$

$2,429,941$

$22,888,800$

0

$8,400,751$

$5,764,140$

$2,446,236$

$2,966,400$

$23,150,409$

$83,531,926$

2,152,136

163,440

$32,158,828$

$18,604,676$

\begin{tabular}{|}
\hline \\
\hline \\
\hline
\end{tabular}

\section{PROJECT COST PARAMETERS}

EDI AS A \% OF CONST. + GFE $=25.00 \%$ 
Lockheed Martin Idaho Technologles Co. PROJECT NAME: HWO VITRIFICATION FACILITY

TOTAL ESTIMATED COST - ESCALATED

LOCATION I: ICPP, INEEL

REQUESTOR: D. A. LOPEZ
DETAILED COST ESTIMATE SHEET

TYPE OF ESTMATE: PLANNING

PROJECT NO: 2418

PREPARED 8Y: D. R. James
PAGE $i$

DATE 23-Jan-1998

TIME: 09:50:53

REPORT Name: Detall Cost Estlmate Sheet

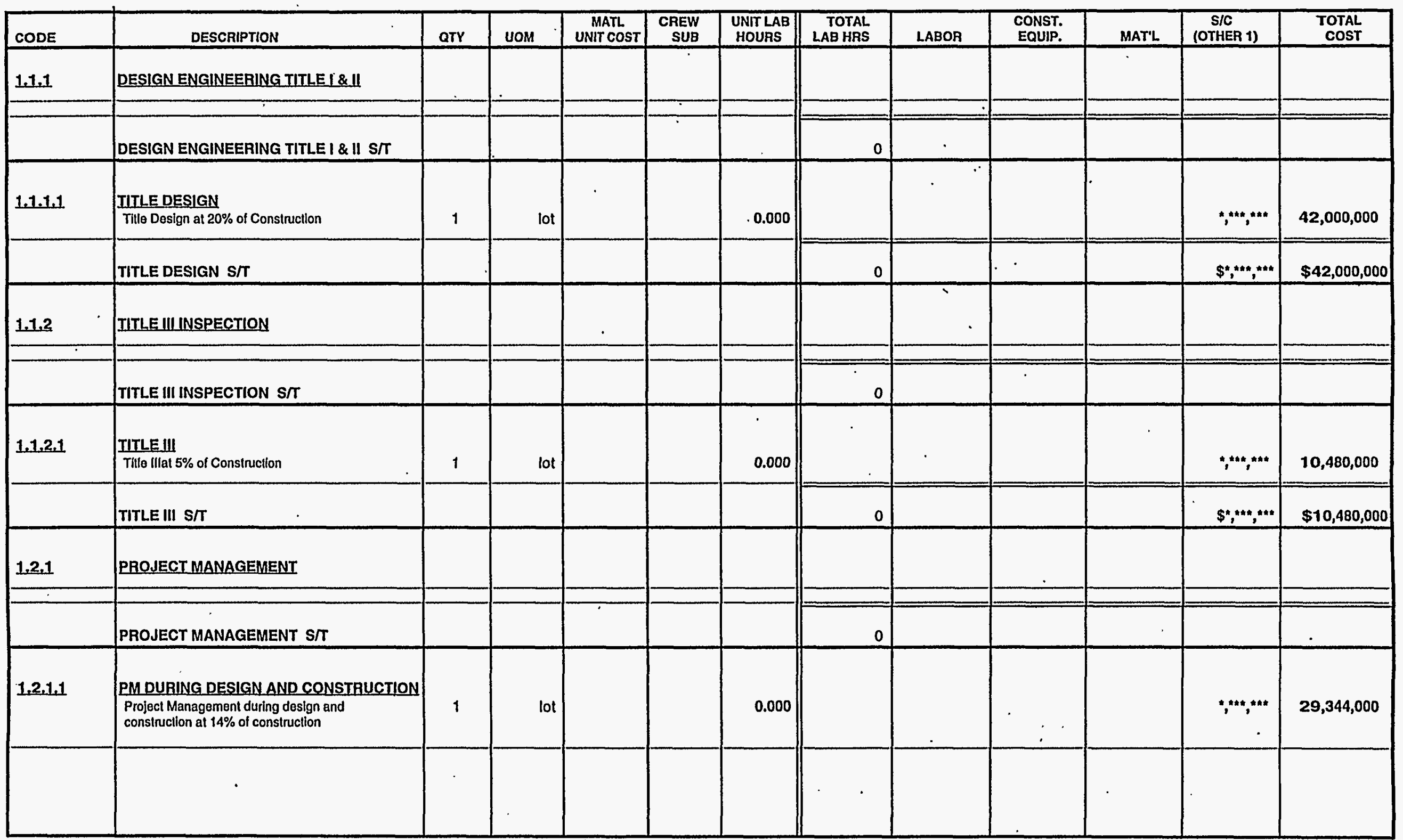




\begin{tabular}{|c|c|c|c|c|c|c|c|c|c|c|c|c|}
\hline $\begin{array}{l}\text { Lockheed } \\
\text { Rov B.96 } \\
\text { PROJECT NAME: } \\
\text { LOCATION 1: } \\
\text { REQUESTOR: }\end{array}$ & $\begin{array}{l}\text { Martin Idaho Technologies Co. } \\
\text { HWO VITRIFICATION FACILITY } \\
\text { TOTAL ESTIMATED COST - ESCALATED } \\
\text { ICPP, INEEL } \\
\text { D. A. LOpEZ }\end{array}$ & & \multicolumn{5}{|c|}{$\begin{array}{l}\text { DETAILED COST ESTIMATE SHEET } \\
\text { TYPE OF ESTIMATE: PLANNING } \\
\text { PROJECT NO: } 2418 \\
\text { PAEPARED BY: D. R. James }\end{array}$} & \multicolumn{2}{|c|}{$\begin{array}{r}\text { PAGE \# } \\
\text { DATE } \\
\text { TIME: } \\
\text { REPOAT NAME: }\end{array}$} & $\begin{array}{l}2 \\
\text { 23-Jan-199 } \\
\text { 09:50:53 } \\
\text { Detail Cos }\end{array}$ & 8 & \multirow[b]{2}{*}{$\begin{array}{l}\text { TOTAL } \\
\text { COST } \\
\end{array}$} \\
\hline CODE & DESCAIPTION & aTY & vom & $\begin{array}{c}\text { MATL } \\
\text { UNIT COST } \\
\end{array}$ & $\begin{array}{r}\text { CAEW } \\
\text { SUB } \\
\end{array}$ & $\begin{array}{l}\text { UNIT LAB } \\
\text { HOURS } \\
\end{array}$ & $\begin{array}{l}\text { TOTAL } \\
\text { LAB HAS } \\
\end{array}$ & LABOR & $\begin{array}{l}\text { CONST. } \\
\text { EQUIP. }\end{array}$ & MATL & $\begin{array}{c}\text { S/C } \\
\text { (OTHER 1) } \\
\end{array}$ & \\
\hline 1.2 .1 .1 & PM DURING DESIGN AND CONSTRUCTION & & & & & & & & & & & \\
\hline & PM DURING DESIGN AND CONSTRUCTION & $\mathbf{S} / \mathbf{T}$ & & & & & 0 & & & & 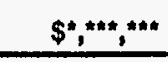 & $\$ 28,344,000$ \\
\hline 1.2 .2 & CONSTRUCTION MANAGEMENT. & & & & & & & & & & & \\
\hline & & & & & & & & & & & & $\bar{L}$ \\
\hline & CONSTRUCTION MANAGEMENT S/T & & & & & & 0 & & & & & \\
\hline 1.2 .2 .1 & $\begin{array}{l}\text { CONSTRUCTION MANAGEMENT AND SUPP } \\
\text { Construction Management @ } 10 \% \text { of } \\
\text { Construction }\end{array}$ & ORT & 10t & & & 0.000 & & & & & $\because \because *, ", * *$ & $21,000,000$ \\
\hline & CONSTRUCTION MANAGEMENT AND SUPP & ORT S/T & & & & & 0 & & & & $\$ *, \ldots *, * * *$ & $\$ 21,000,000$ \\
\hline 1.3 .1 & GENERAL CONDITIONS & & & . & & & & & & & & \\
\hline & & & & & & & & & & & & $=$ \\
\hline & GENERAL CONDITIONS S/T & & & & & & 0 & & & & & \\
\hline 1.3 .1 .1 & $\begin{array}{l}\text { IRAINING AND SUPERVISION } \\
\text { Training } 2 \%\end{array}$ & 1 & allow. & & $\begin{array}{l}\text { PIPE } \\
M E C H\end{array}$ & 20000.0 & 20,000 & 735,800 & & & & 735,800 \\
\hline & Supervision - 5 men 4 years & 1 & allow & & $\begin{array}{l}\text { PIPE } \\
\text { MEQE }\end{array}$ & 41600.0 & 41,600 & $1,530,464$ & & & & $1,530,464$ \\
\hline & TRAINING AND SUPERVISION S/T & & & & & & 61,600 & $\$ 2,266,264$ & & & & $\$ 2,266,264$ \\
\hline $1.3 .1,2$ & $\begin{array}{l}\text { EQUIPMENT SUPPORT } \\
\text { Crane Support }\end{array}$ & 1 & allow & . & $\underset{G E N}{E Q H V}$ & 4160.00 & 4,160 & 131,248 & $1,000,000$ & & & $1,131,248$ \\
\hline & & & & & & & & & & & & \\
\hline
\end{tabular}


Lockheed Martin Idaho Technologies Co. Rov 6-96 PROJECT NAME: HWO VITRIFICATION FACILITY TOTAL ESTIMATED COST - ESCALATED LOCATION 1: ICPP, INEEL REQUESTOR: D. A. LOpez
DETAILED COST ESTIMATE SHEET

TYPE OF ESTIMATE: PLANNING

PROJECT NO: 2418

PREPARED BY: D. R. Jamés
PAGE * 3

DATE 23-Jan-1998

TIME: 09:50:53

RePort Name. Detall Cost Estimate Sheet

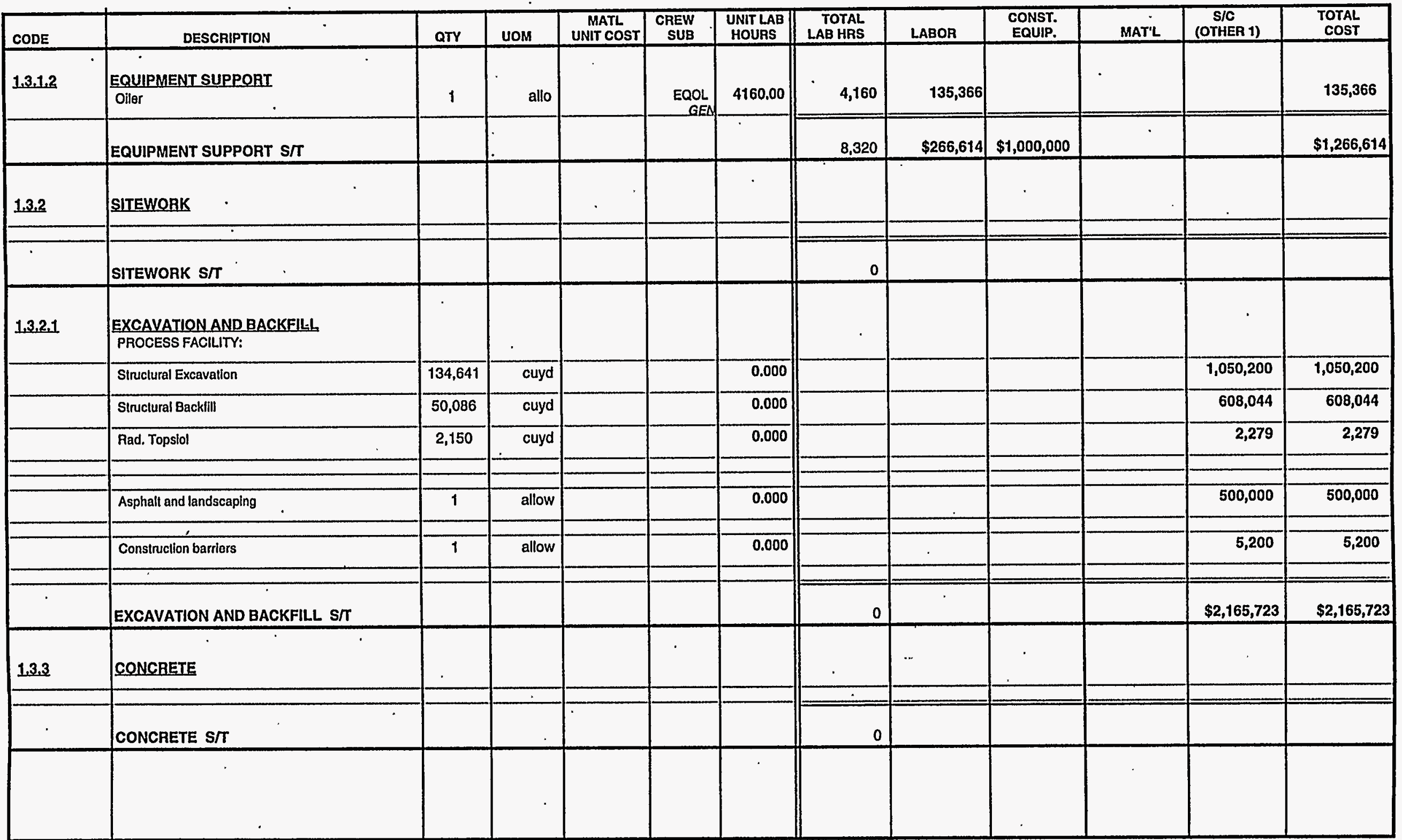


Lockheed Martin Idaho Technologles Co. Rov 6.98 PROJECT NAME: HWO VITRIFICATION FACILITY TOTAL ESTIMATED COST - ESCALATED OCATION 1: ICPP, INEEL REQUESTOR: D. A. LOPOZ

\section{DETAILED COST ESTIMATE SHEET}

TYPE OF estimate: PLANNING

PROJECT NO.: 2418

PREPAREO 8Y: D. R. James
PAgE " 4

DATE 23-Jan-1998

TIME: 09:50:53

REPORT NAME: Detall Cost Estimate Sheot

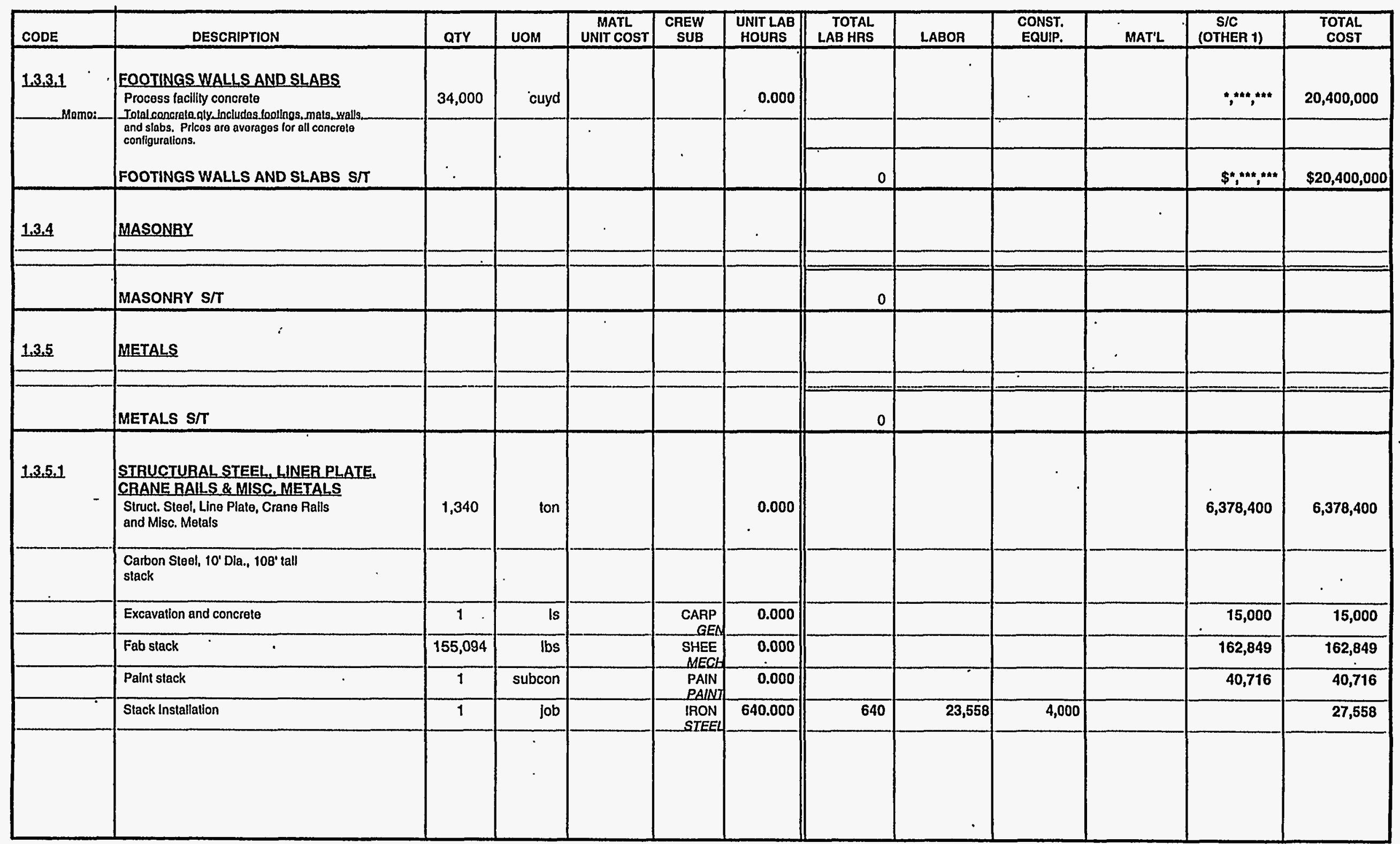


Lockheed Martin Idaho Technologles Co. PROIECT NAME: HWO VITRIFICATION FACILITY

PROAECT NAME: HWTAL ESTIMATED COST - ESCALATED

LOCATION 1: ICPP, INEEL

REQUESTOR: D. A. LOpez

\section{DETAILED COST ESTIMATE SHEET}

TYPE OF ESTIMATE: PLANNING

PROJECT NO: 2418

PREPARED BY: D. R. James
PAGE * 5

DATE 23-Jan-1998

TIME: 09:50:53

REPORT NAME: Detail Cost Estimate Sheet

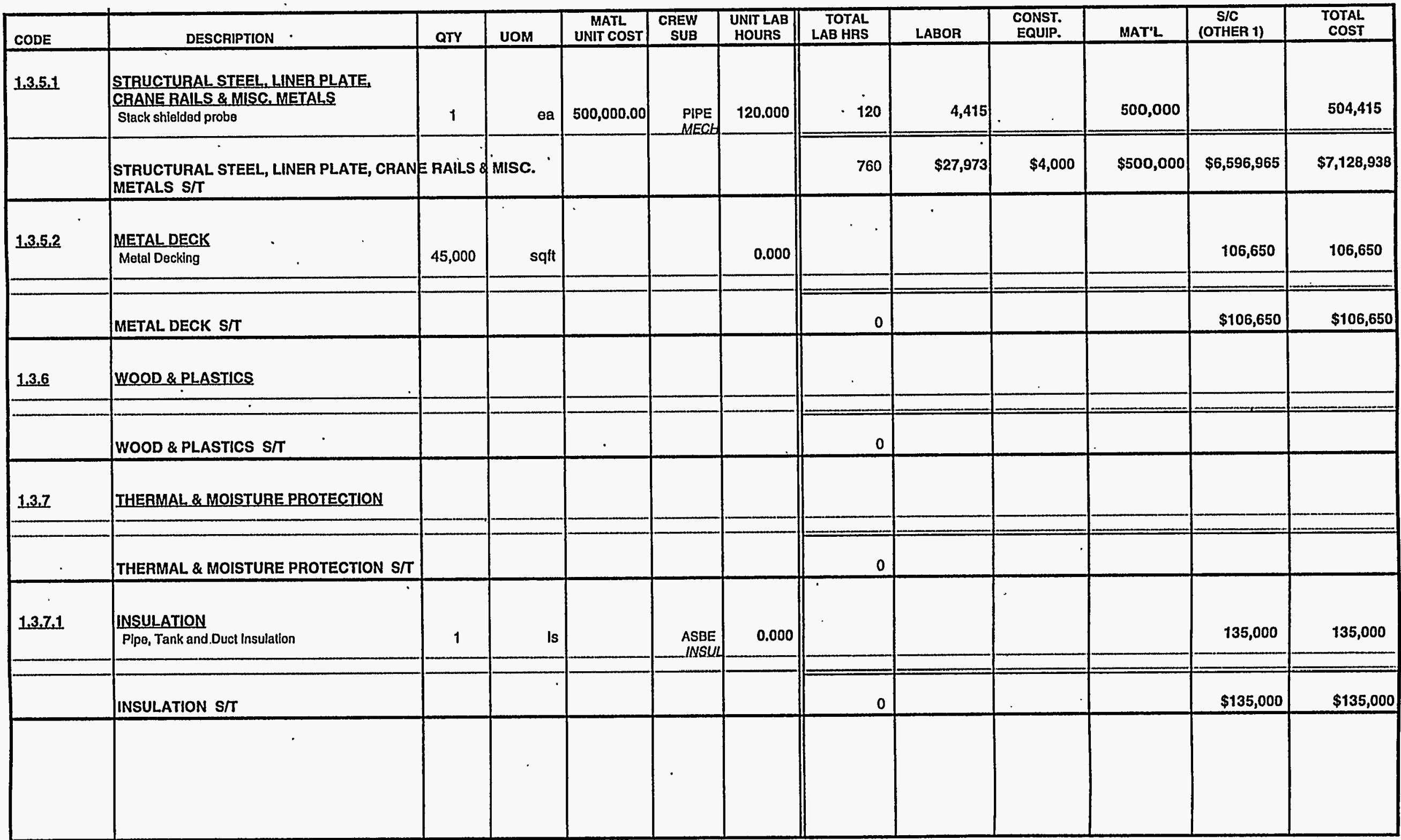


Lockheed Martin Idaho Technologles Co.

$$
\text { Rev 6.96 }
$$

PROJECT NAME: HWO VITRIFICATION FACILITY

TOTAL ESTIMATED COST - ESCALATED

LOCATION I:

ICPP, INEEL.

AEQUESTOR: D. A. Lopez

\section{DETAILED COST ESTIMATE SHEET}

TYPE OF ESTIMATE: PLANNING

PROJECTNO: 2418

PREPARED BY: D. R. James
PAGE $\quad 6$

DATE 23-Jan-1998

TIME: 09:50:53

REPORT NAME: Detall Cost Estimate Sheet

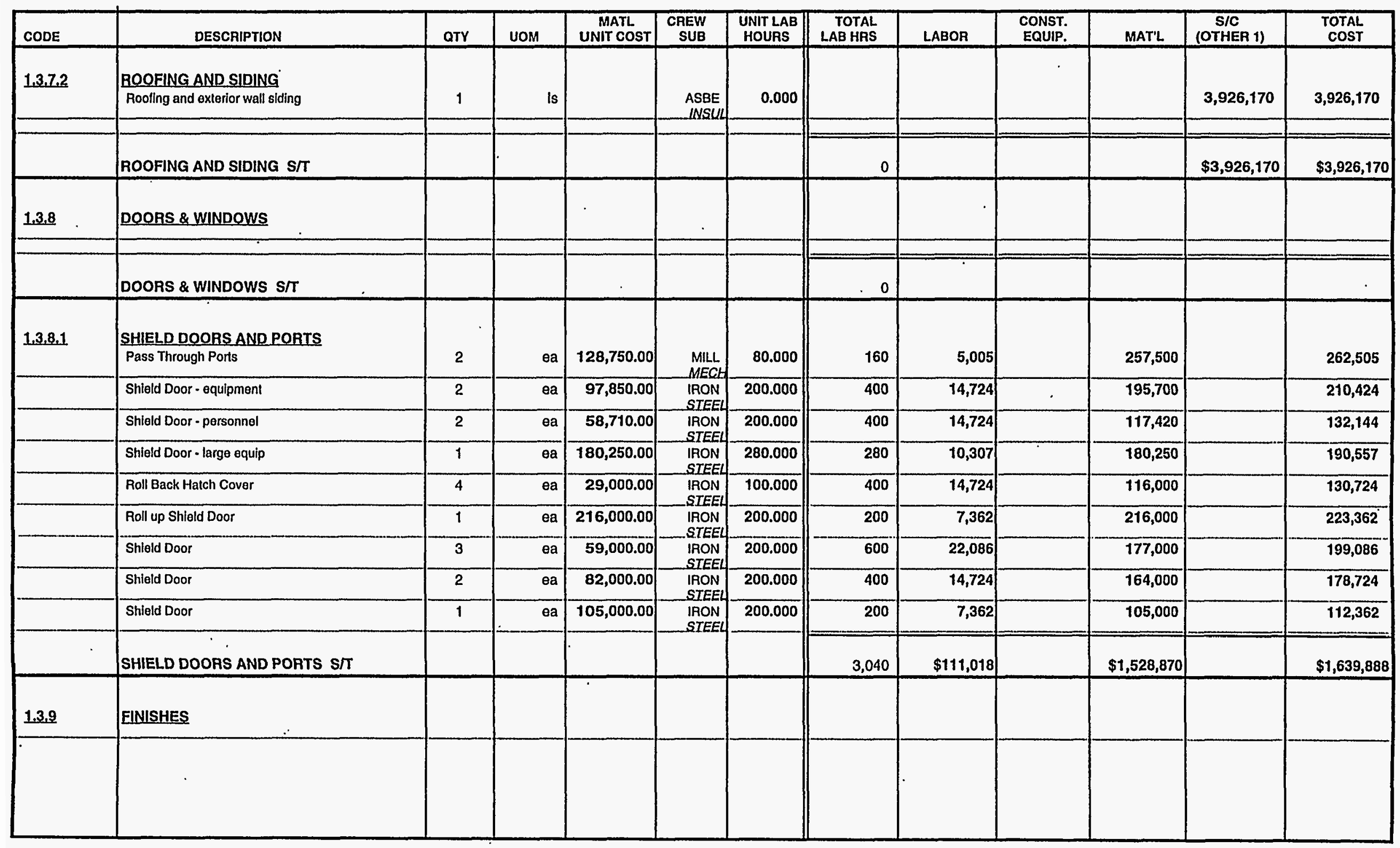


Lockheed Martin Idaho Technologies Co. Rev 6.95

PROSECT NAME: HWO VITRIFICATION FACILITY TOTAL ESTIMATED COST - ESCALATED

LOCATION 1:

ICPP, INEEL

REQUESTOR: D. A. Lopez

\section{DETAILED COST ESTIMATE SHEET}

TYPE OF ESTIMATE: PLANNING

PROJECTNO:: 2418

PREPARED BY: D. R. James
PAGE 7

DATE 23-Jan-1998

TIME: 09:50:53

REPORT NAME: Detall Cost Estlmate Sheet

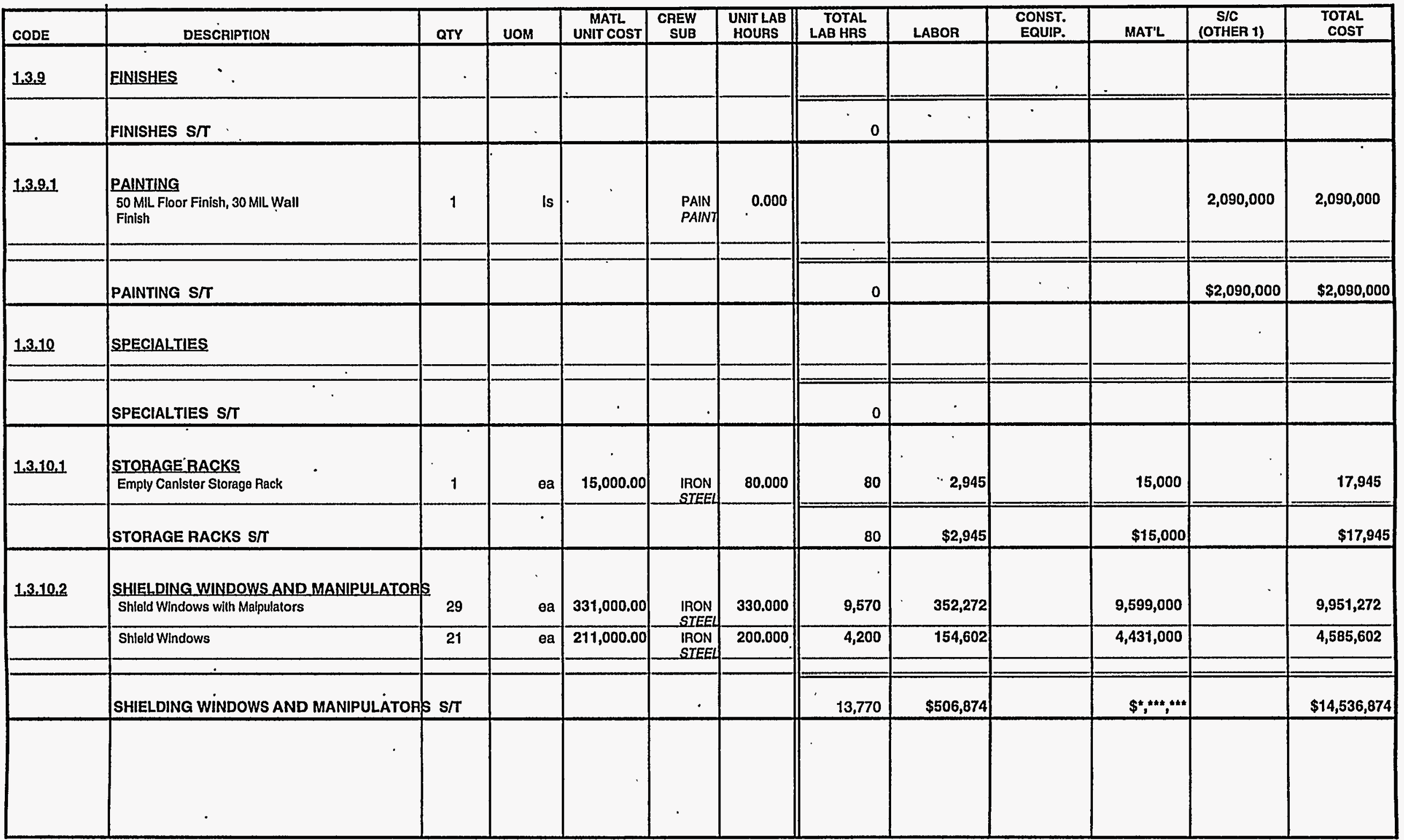




\begin{tabular}{|c|c|c|c|c|c|c|c|c|c|c|c|c|}
\hline Zos' $\varepsilon \varepsilon$ & & $000^{\prime} L \varepsilon$ & & $z o g^{\prime} z$ & 08 & 000.06 & FIOW & $00^{\circ} 00 s^{\prime} s t$ & EQ & $z$ & 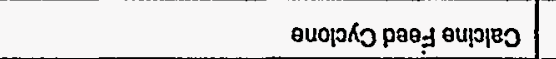 & \\
\hline $2 \varepsilon \theta^{\prime} 9 L$ & & $000 ' 9 L$ & & Zह8 & $\forall z$ & $000 \mathrm{ZL}$ & $\begin{array}{l}70 \exists W \\
\exists \exists H S\end{array}$ & $00^{\circ} 000^{\prime} 8 \varepsilon$ & eө & 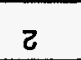 & 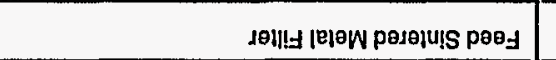 & \\
\hline$\angle S 6^{\prime} 9$ & & $\$ 10^{\circ} \mathrm{t}$ & & Et6'z & 08 & 000.06 & $\begin{array}{l}\text { HDEW } \\
\text { Gdld }\end{array}$ & $00^{\circ} \angle 00^{\prime} Z$ & Eө & $\boldsymbol{z}$ & YUQ $\perp$ L & \\
\hline $2 \varepsilon \theta^{\prime} 9 L$ & & $000^{\prime} 92$ & & z६в & $b z$ & $000 \mathrm{ZL}$ & HOJW & $00^{\circ} 000^{\prime} 8 \varepsilon$ & eө & $z$ & 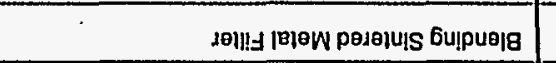 & \\
\hline zos' $\varepsilon \varepsilon$ & & $000^{\prime} 1 \varepsilon$ & & $20 \operatorname{s}^{\prime} z$ & 08 & $000^{\circ} 0 t$ & 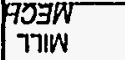 & oo.0os'si & вө & $z$ & 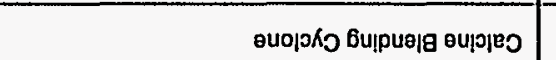 & \\
\hline oBg'ets & & $000^{\circ} 0 \angle 0$ & & $0 B g^{\prime} \varepsilon L$ & $000^{\circ} z$ & 00.0001 & Fald & $00^{\circ} 000^{\prime} s \varepsilon z$ & вө. & 2 & 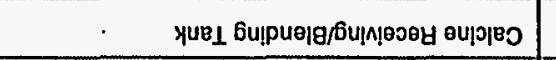 & \\
\hline $068^{\prime} \varepsilon 6 s^{\prime} z z$ & & **n'*n*: & & O०8'86 & $000^{\prime} \varepsilon$ & $00^{\circ} 0001$ & Biw & 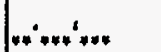 & $8 \theta$ & $\varepsilon$ & גө\||øW SSE|O & \\
\hline SOO'S91 & & $000^{\prime} 091$ & & $500 ' s$ & 091 & 00008 & 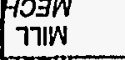 & $00^{\circ} 000^{\prime} 08$ & вө & $z$ & sepueje uoqq!y & \\
\hline LSZ'LSL & & $000^{\prime} 091$ & & LszZ't & ob & 00000 & (7DSW & $00^{\circ} 000^{\prime} 0 \mathrm{St}$ & eө & 1 & LaddoH P807!بs & \\
\hline $2 Z s^{\prime} 0 \angle 9$ & & $000^{\prime} 869$ & & $z z s^{\prime} z z$ & $0 Z 2$ & 000.021 & $\begin{array}{l}103 \mathrm{~W} \\
\mathrm{H} 7 \mathrm{~W}\end{array}$ & $00^{\circ} 000^{\prime} 801$ & eo & 9 & 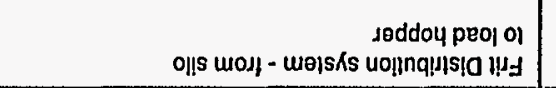 & \\
\hline $000^{\prime} t 01$ & $000^{\circ} b 01$ & & & & & $000^{\circ} 0$ & & & ee & 9 & 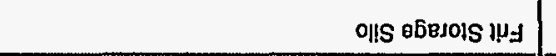 & \\
\hline \multirow[t]{5}{*}{$\angle 08^{\prime} \varepsilon 6$} & & $00 \varepsilon^{\prime} 98$ & & $\angle O S^{\prime} L$ & $0 b z$ & 000000 & $\begin{array}{ll}403 W \\
771 W\end{array}$ & $00.00 \varepsilon^{\prime} 98$ & eө & 1 & 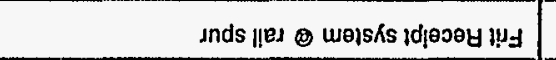 & \\
\hline & & & & & & & & & & & 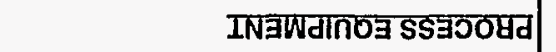 & गमान' \\
\hline & & & & & 0 & & & & & & L/S INGWdInOG & \\
\hline & & & & & & & & & & & & \\
\hline & & & & & & & & & & & INजWDInO司 & TLET \\
\hline $880^{\prime} 60 l^{\prime} 1 \$$ & & $000^{\prime} 006 \$$ & & $880^{\prime} 602 \$$ & $00 z^{\prime} L$ & & & & . & & L/S sפกา $d-\not|r|$ & \\
\hline $880^{\prime} 60 L^{\prime} \mathrm{L}$ & & $000^{\prime} 006$ & & $880^{\prime} 602$ & $00 z^{\prime} L$ & 000.06 & 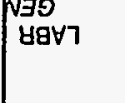 & $00^{\circ} 000^{\prime} \mathrm{s}$ & eө & 081 & $\begin{array}{c}\text { s6n/d-x } \\
\text { S5nTd }\end{array}$ & EगT'E' \\
\hline $\begin{array}{l}1500 \\
7 \forall 101\end{array}$ & $\begin{array}{c}(1 \mathrm{8gH10}) \\
0 / \mathrm{S}\end{array}$ & $7,1 \forall W$ & $\begin{array}{l}\text { dinOJ } \\
\text {-1SNOO }\end{array}$ & $808 \forall 7$ & $\begin{array}{l}\text { SHH 8V7 } \\
7 \forall 101\end{array}$ & 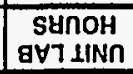 & $\begin{array}{l}\text { ans } \\
\text { Mayo }\end{array}$ & $\begin{array}{c}1 \text { ISOJ IINn } \\
\text { THWW }\end{array}$ & won & 110 & NOILditos & 3000 \\
\hline & 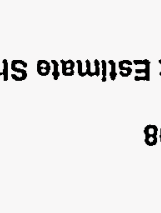 & 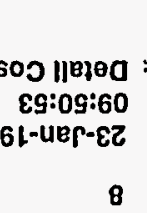 & $\begin{array}{l}\text { N18Oday } \\
\mathrm{L}\end{array}$ & & $\perp \exists \exists \mid$ & S $\exists \perp \forall W$ & $\begin{array}{l}\text { ues 'y } 0 \\
816 z \\
\text { VINNY7d }\end{array}$ & 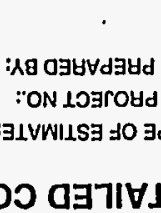 & & & 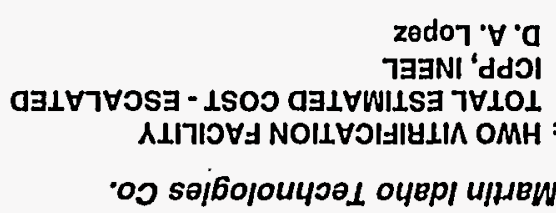 & 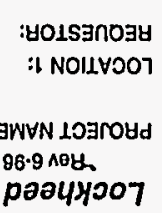 \\
\hline
\end{tabular}


Lockheed Martin Idaho Technologies Co.

Rev6-96

PAOJECT NAME: HWO VITRIFICATION FACILITY

TOTAL ESTIMATED COST - ESCALATED

LOCATION 1: ICPP, INEEL

REQUESTOR: D. A. Lopez
DETAILED COST ESTIMATE SHEET

TYPE OF ESTIMATE: PLANNING

PROJECTNO: 2418

PREPARED BY: D. R. James
PAGE: 9

DATE 23-Jan-1998

TIME: 09:50:53

REPORT NAME: Detall Cost Estlmate Sheet

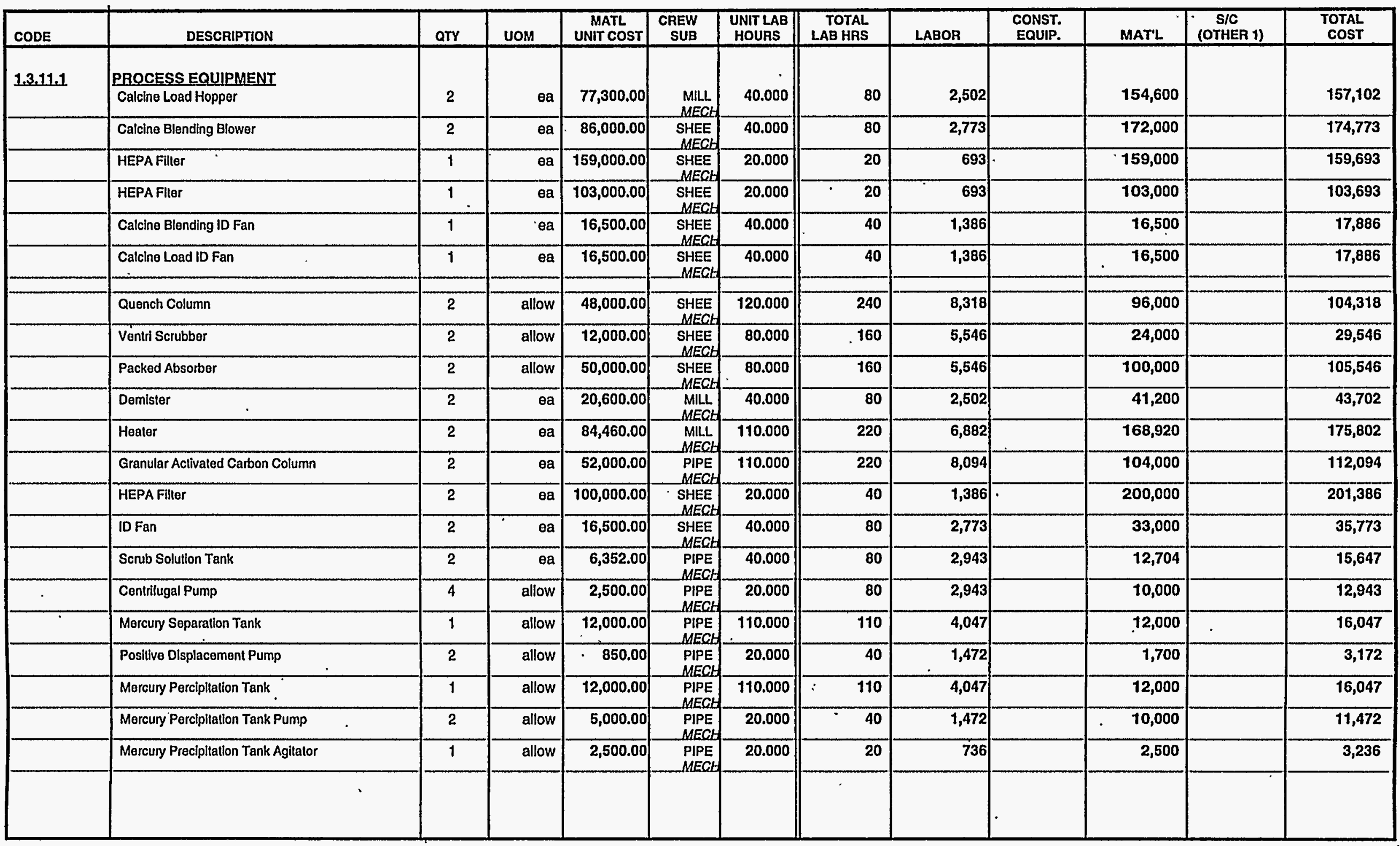


Lockheed Martin Idaho Technologles Co. AQV 6.96 : HWO VITRIFICATION FACILITY PROJECT NAME: HWO VITRIFICATION FACILITY
TOTAL ESTIMATED COST - ESCALATED LOCATION I: ICPP, INEEL REQUESTOR: D. A. Lopez

\section{DETAILED COST ESTIMATE SHEET}

TYPE OF ESTIMATE: PLANNING

PROJECT NO.: 2418

PREPARED BY: D. R. James
PAGE \| 10

DATE 23-Jan-1998

TIME: 09:50:53

REPORT NAME: Detall Cost Estimate Sheet

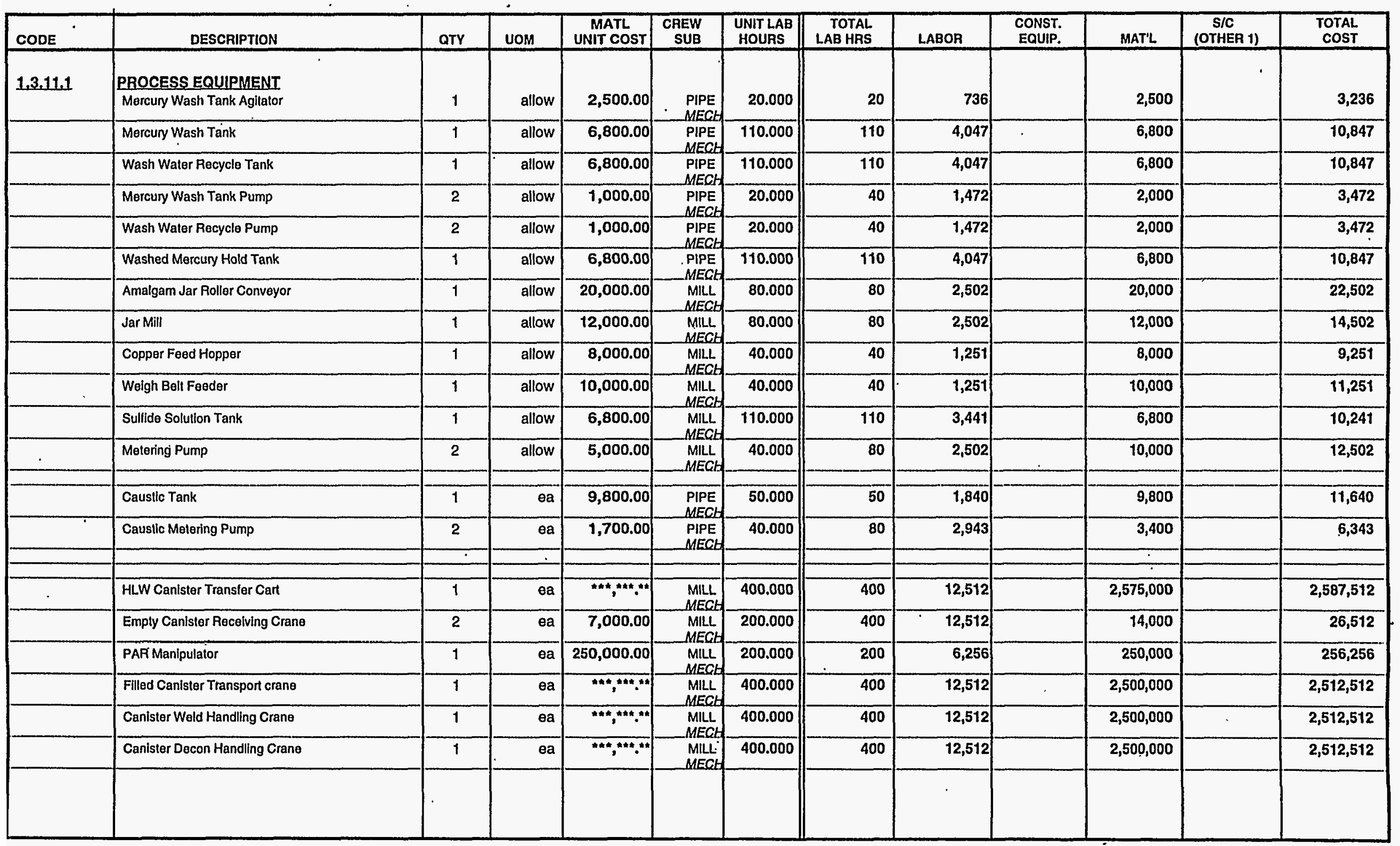


Lockheed Martin Idaho Technologies Co.

Rev 6.96

PROJECT NAME: HWO VITRIFICATION FACILITY TOTAL ESTIMATED COST - ESCALATED

LOCATION 1: ICPP, INEEL

REQUESTOR: D. A. LopeZ

\section{DETAILED COST ESTIMATE SHEET}

TYPE OF ESTIMATE: PLANNING

PROJECT NO: 2418

PAEPARED BY: D. R. James
PAgE" 11

DATE 23-Jan-1998

TIME: 09:50:53 REPORT NAME: Detall Cost Estimate Sheet

\begin{tabular}{|c|c|c|c|c|c|c|c|c|c|c|c|c|}
\hline CODE & DESCRIPTION & aTY & UOM & $\begin{array}{c}\text { MATL } \\
\text { UNIT COST }\end{array}$ & $\begin{array}{l}\text { CREW } \\
\text { SUB }\end{array}$ & $\begin{array}{l}\text { UNIT LAB } \\
\text { HOURS }\end{array}$ & $\begin{array}{l}\text { TOTAL } \\
\text { LAB HAS }\end{array}$ & LABOR & $\begin{array}{l}\text { CONST. } \\
\text { EQUIP. }\end{array}$ & MAT'L & $\begin{array}{l}\text { S/C } \\
\text { (OTHER 1) }\end{array}$ & $\begin{array}{l}\text { TOTAL } \\
\text { COST }\end{array}$ \\
\hline 1.3 .11 .1 & $\begin{array}{l}\text { PRQCESS EQUIPMENT } \\
\text { Smeared Canister Loadout Crane }\end{array}$ & 1 & ea & $* * * * \ldots * \ldots * *$ & MILL & 400.000 & .400 & 12,512 & & $2,500,000$ & & $2,512,512$ \\
\hline & $\begin{array}{l}\text { Canister Storage Crane - clean } \\
\text { environment operation }\end{array}$ & 1 & ea & $250,000.00$ & MILL & 400.000 & 400 & 12,512 & & 250,000 & & 262,512 \\
\hline & Canister Heater & 2 & ea & $103,000.00$ & $\begin{array}{l}\text { ELEC } \\
\text { ELEO }\end{array}$ & 100.000 & 200 & 6,662 & & 206,000 & & 212,662 \\
\hline & CO2 System & 1 & allow & $175,000.00$ & PIPE & 100.000 & 100 & 3,679 & & 175,000 & & 178,679 \\
\hline & Canister Transportation Cant & 1 & ea & $25,000.00$ & MILL & 100.000 & 100 & 3,128 & & 25,000 & & 28,128 \\
\hline & Canister Lifting Mechanism & 2 & ea & $257,500.00$ & $\begin{array}{c}\text { MILL } \\
\text { MECLE }\end{array}$ & 120.000 & 240 & 7,507 & & 515,000 & & 522,507 \\
\hline & Canister Sealing Manipulator & 1 & ea & $120,000.00$ & $\begin{array}{c}\text { MILL } \\
M E Q G \mathrm{~L}\end{array}$ & 80.000 & 80 & 2,502 & & 120,000 & & 122,502 \\
\hline & $\begin{array}{l}\text { Blending Room Equipment for Decon } \\
\text { Process }\end{array}$ & 1 & allow & $150,000.00$ & $\begin{array}{c}\text { MILL } \\
\text { MECH }\end{array}$ & 120.000 & 120 & 3,754 & & 150,000 & & 153,754 \\
\hline & Decon Solulton Pumping Stalion & 1 & allow & $50,000.00$ & $\begin{array}{l}\text { PIPE } \\
\text { MECh }\end{array}$ & 120.000 & 120 & 4,415 & & 50,000 & & 54,415 \\
\hline & Decon Cell Equipment & 1 & ea & $515,000.00$ & $\begin{array}{l}\text { MILL } \\
\text { MECL }\end{array}$ & 240.000 & 240 & 7,507 & & 515,000 & & 522,507 \\
\hline & $\begin{array}{l}\text { Decon/Dlssassembly Equipment - } \\
\text { Turntable, manipulator tools w/rack, } \\
\text { etc. }\end{array}$ & 1 & allow & $500,000.00$ & $\begin{array}{l}\text { MILLL } \\
\text { MECH }\end{array}$ & 240.000 & 240 & 7,507 & & 600,000 & & 507,507 \\
\hline & Smear Monitor & 1 & ea & $515,000.00$ & MILL & 100.000 & 100 & 3,128 & & 515,000 & & 518,128 \\
\hline & Smear Station Module & 1 & sub & . & sue & 0.000 & & & & & 42,000 & 42,000 \\
\hline & Shutlle Cart & 1 & ea & $150,000.00$ & MELL & 80.000 & 80 & 2,502 & & 150,000 & & 152,502 \\
\hline & Glove Box $\cdot$ & 1 & ea & $41,200.00$ & SHEE & 40.000 & 40 & 1,386 & & 41,200 & & 42,586 \\
\hline & Cameras & 30 & ea & $3,000.00$ & ELEC & 24.000 & 720 & 23,983 & & 90,000 & & 113,983 \\
\hline & Filter Change out Unit & 1 & ea & $1,500.00$ & $\begin{array}{l}\text { SHEE } \\
\text { MECH }\end{array}$ & 40.000 & 40 & 1,386 & & 1,500 & & 2,886 \\
\hline & Weid Station Modulo & 1 & ea & $103,000.00$ & $\begin{array}{c}\text { MILL } \\
\text { MECLE }\end{array}$ & 200.000 & 200 & 6,256 & & 103,000 & & 109,256 \\
\hline & & & & & & & & & & & & \\
\hline & & & & & & & & & & & & \\
\hline
\end{tabular}


Lockheed Martin Idaho Technologies Co. PROJECT NAME: HWO VITRIFICATION FACILITY

TOTAL ESTIMATED COST - ESCALATED

ICPP, INEEL

REQUESTOR: D. A. Lopez

\section{DETAILED COST ESTIMATE SHEET}

TYPE OF ESTIMATE: PLANNING

PROJECT NO:: 2418

PREPARED BY: D. R. James
PAGE H 12

DATE 23-Jan-1998

TIME: 09:50:53

REPORT NAME: Detall Cost Estimate Sheet

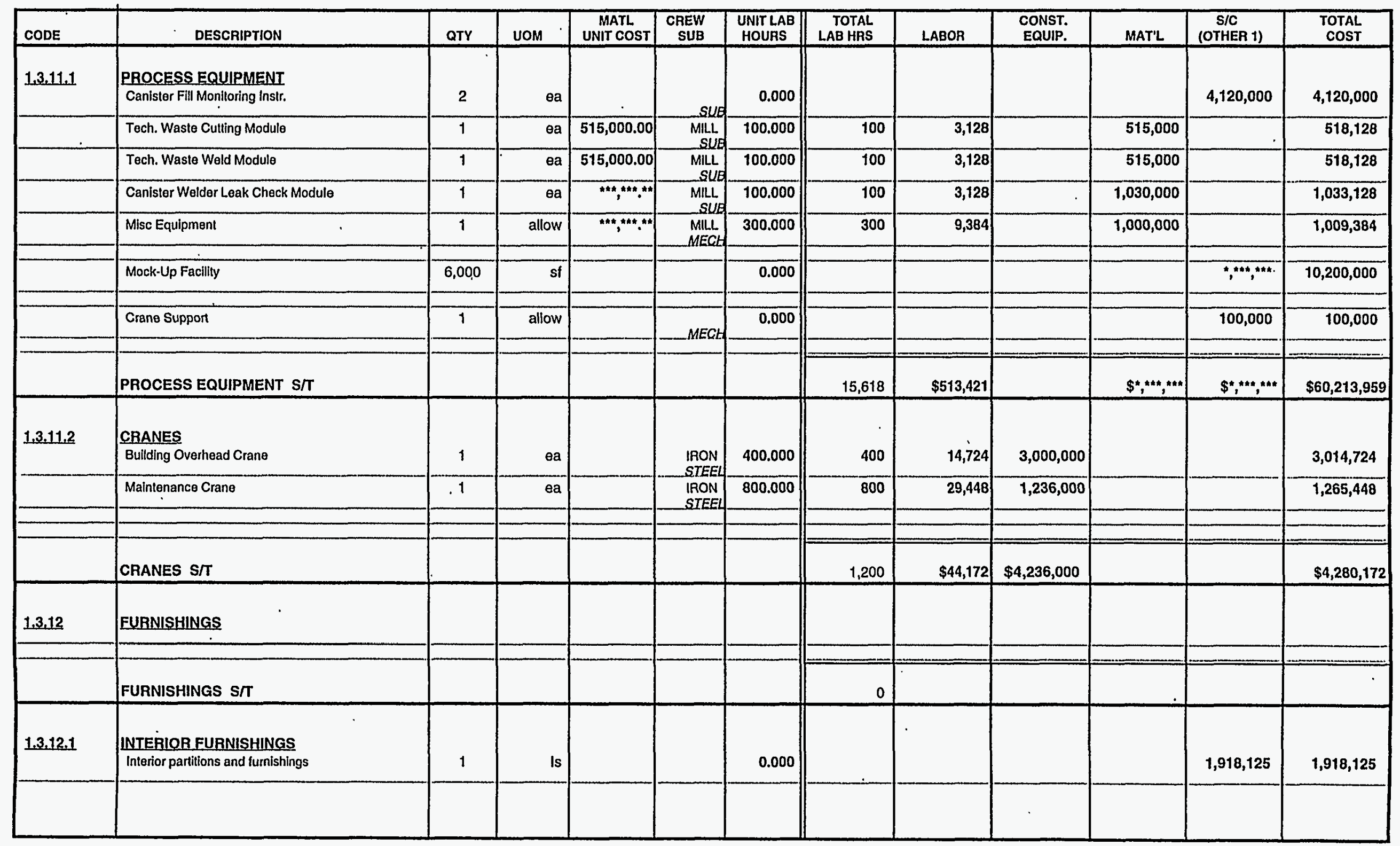




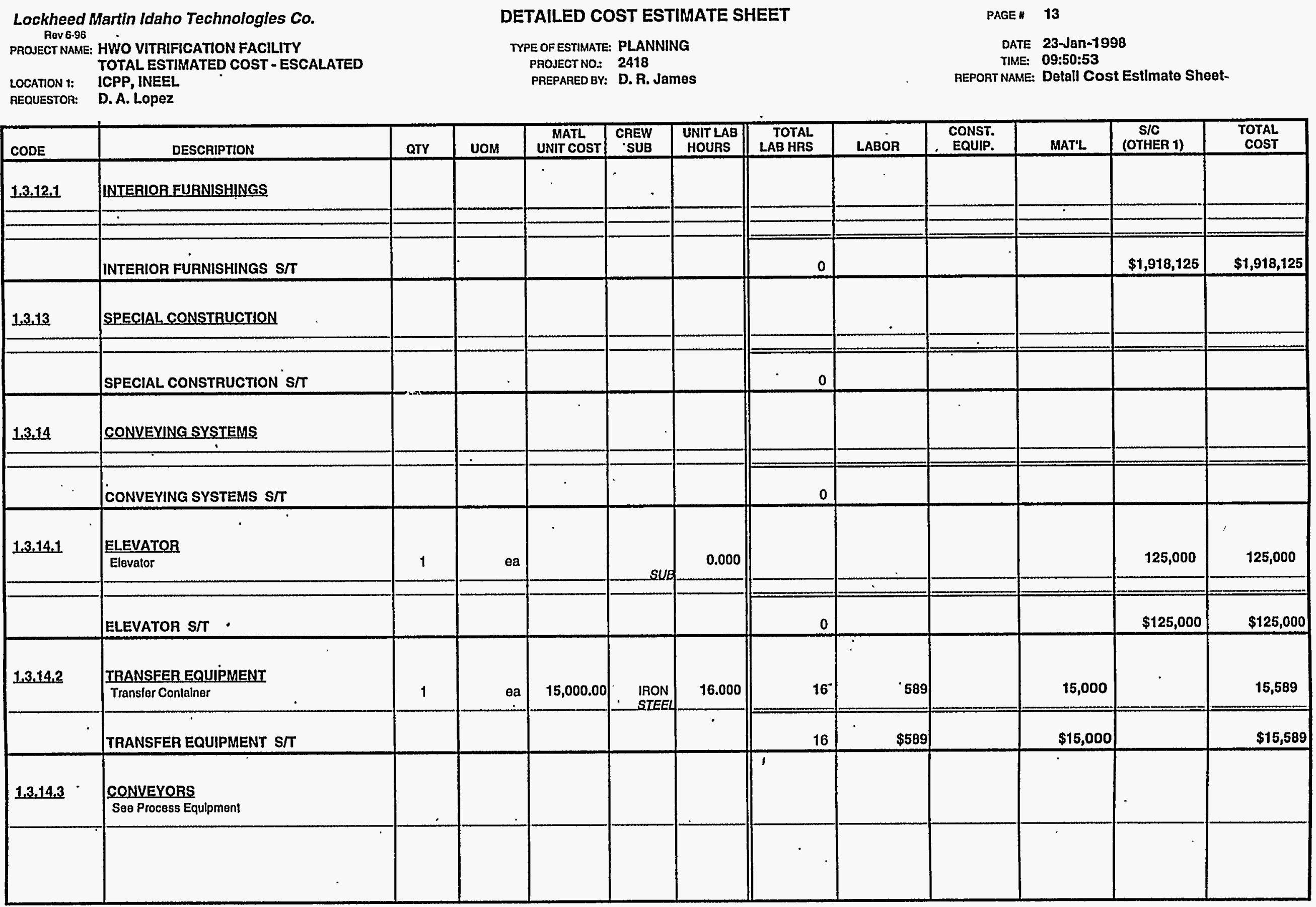


Lockheed Martin Idaho Technologles Co.

Rov 8.98

PROJECT NAME: HWO VITRIFICATION FACILITY

TOTAL ESTIMATED COST - ESCALATED

LOCATION 1:

ICPP, INEEL

REQUESTOR: D. A. LopeZ
DETAILED COST ESTIMATE SHEET

TYPE OF ESTIMATE: PLANNING

PROJECT NO.: 2418

PREPAPED BY. D. R. James
PAGE H 14

DATE 23-Jan-1998

TIME: 09:50:53

RePort nAME: Detail Cost Estlmate Sheet

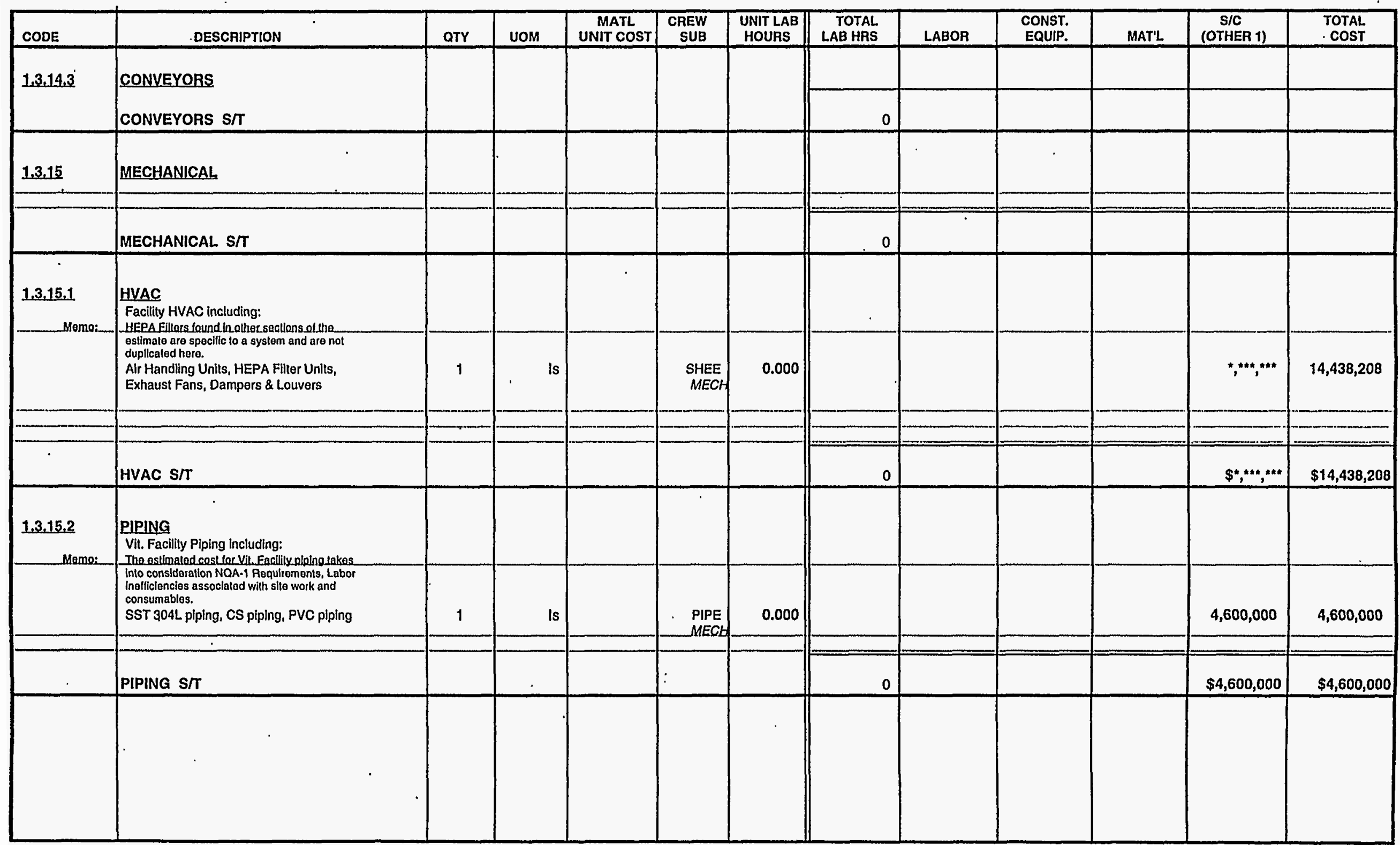


Lockheed Martin Idaho Technologies Co. PROJECT NAME: HWO VITRIFICATION FACILITY

TOTAL ESTIMATED COST - ESCALATED

LOCATION 1: ICPP, INEEL

REQUESTOR: D. A. LOPOZ

\section{DETAILED COST ESTIMATE SHEET}

TYPE OF ESTIMATE: PLANNING

PROJECT NO: 2418

PREPARED BY: D. R. James
PAgE \# 15

DATE 23-Jan-1998

TIME: 09:50:53

REPORT NAME: Detail Cost Estimate Sheet

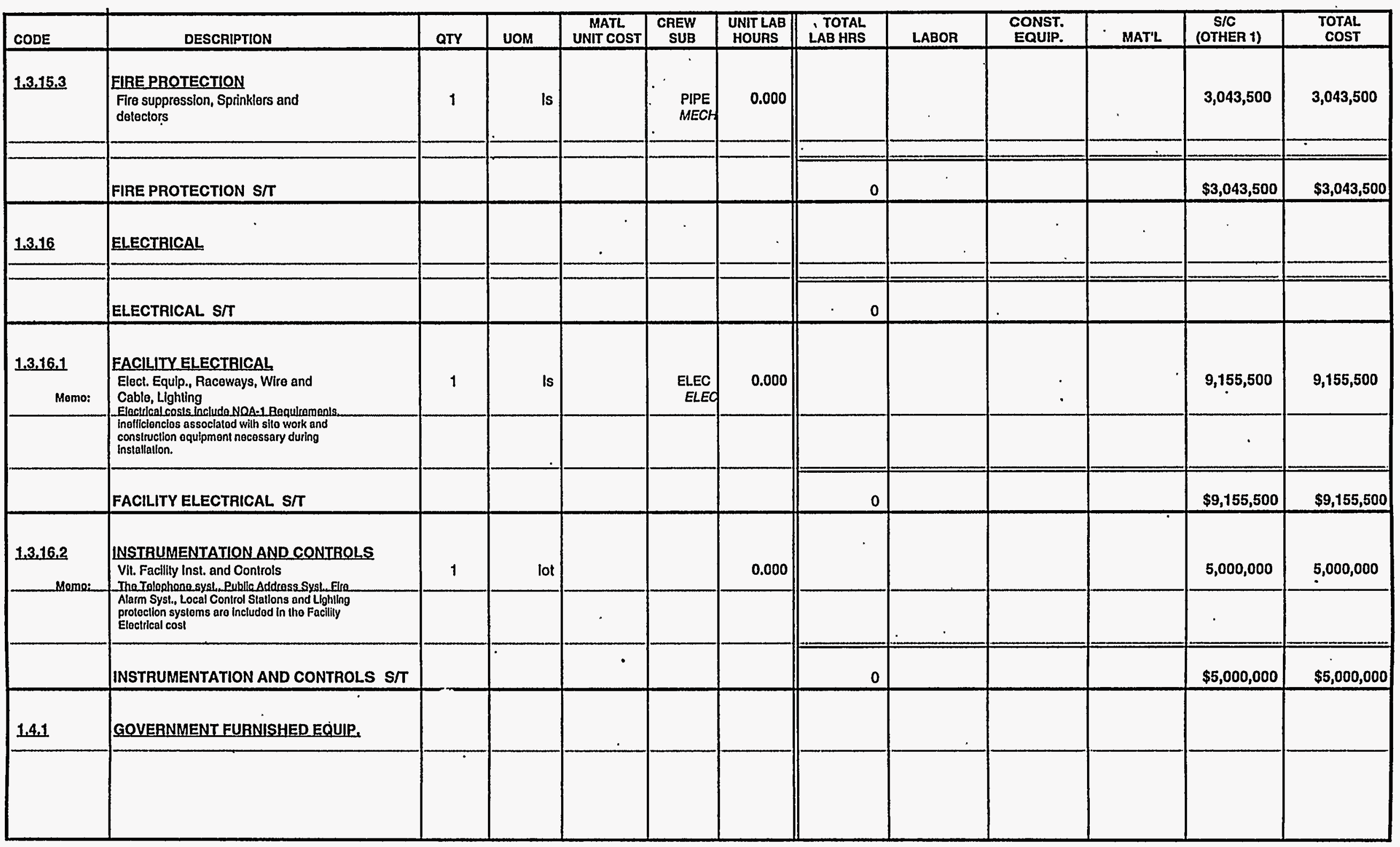


Lockheed Martin Idaho Technologies Co. PROJECT NAME: HWO VITRIFICATION FACILITY

LOCATION : TOTAL ESTIMATED COST - UNESC. LOCATION : REOUESTOR:
D. A. Lopez
CONTINGENCY ANALYSIS

$\begin{array}{cl}\text { TPE OF ESTIMATE: } & \text { PLANNING } \\ \text { PROJECT NO: } & 2418 \\ \text { PREPAREO BY: } & \text { D. R. James }\end{array}$

DATE: 23-Jan-1998

TIME: 10:27:43

REPORT NAME: Contingency Analysis

\begin{tabular}{|c|c|c|c|c|c|c|c|c|c|c|c|}
\hline & PROBA & BLE \% VARIAT & ON & & & & & & $\begin{array}{r}\text { PRO } \\
\text { CONTI }\end{array}$ & $\begin{array}{l}\text { ECT } \\
\text { IGENCY }\end{array}$ & SUMMARY \\
\hline $\begin{array}{l}\text { WBS } \\
\text { Element }\end{array}$ & Cost Estimate Element & Total Cost w/o & $\begin{array}{l}\text { \% Total } \\
\text { Cost }\end{array}$ & & $\begin{array}{l}\% \text { Var. } \\
\text { m Est. }\end{array}$ & Wt. \% & Prob. & Contingency & $\%$ & Cost & \\
\hline & & Contingency & & - & + & - & + & & & & by Element \\
\hline 1.1 .1 & DESIGN ENGINEERING TITLE I \&\| & $42,000,000$ & 12.84 & 15 & 30 & 1.93 & 3.85 & $3.274 \%$ & $7.39 \%$ & $10,701,143$ & $52,701,143$ \\
\hline 1.1 .2 & TITLE III INSPECTION & $10,480,000$ & 3.20 & 15 & 30 & 0.48 & 0.96 & $0.817 \%$ & $1.84 \%$ & $2,670,190$ & $13,150,190$ \\
\hline 1.2 .1 & PROJECT MANAGEMENT & $29,344,000$ & 8.97 & 15 & 30 & 1.35 & 2.69 & $2.287 \%$ & $5.16 \%$ & $7,476,532$ & $36,820,532$ \\
\hline 1.2 .2 & CONSTRUCTION MANAGEMENT & $21,000,000$ & 6.42 & 15 & 30 & 0.96 & 1.93 & $1.637 \%$ & $3.69 \%$ & $5,350,571$ & $26,350,571$ \\
\hline 1.3 .1 & GENERAL CONDITIONS & $4,941,905$ & 1.51 & 10 & 45 & 0.15 & 0.68 & $0.597 \%$ & $1.35 \%$ & $1,950,438$ & $6,892,343$ \\
\hline 1.3 .2 & SITEWORK & $2,429,941$ & 0.74 & 5 & 60 & 0.04 & 0.45 & $0.397 \%$ & $0.90 \%$ & $1,298,943$ & $3,728,884$ \\
\hline 1.3 .3 & CONCRETE & $22,888,800$ & 7.00 & 5 & 60 & 0.35 & 4.20 & $3.743 \%$ & $8.45 \%$ & $12,235,381$ & $35,124,181$ \\
\hline 1.3 .4 & MASONRY & 0 & 0.00 & 5 & 45 & 0.00 & 0.00 & $0.000 \%$ & $0.00 \%$ & 0 & 0 \\
\hline 1.3 .5 & METALS & $8,400,751$ & 2.57 & 5 & 60 & 0.13 & 1.54 & $1.374 \%$ & $3.10 \%$ & $4,490,685$ & $12,891,436$ \\
\hline 1.3 .6 & WOOD \& PLASTICS & 0 & 0.00 & 5 & 30 & 0.00 & 0.00 & $0.000 \%$ & $0.00 \%$ & 0 & 0 \\
\hline 1.3 .7 & THERMAL \& MOISTURE PROTECTION & $5,764,140$ & 1.76 & 5 & 60 & 0.09 & 1.06 & $0.943 \%$ & $2.13 \%$ & $3,081,265$ & $8,845,405$ \\
\hline 1.3 .8 & DOORS \& WINDOWS & $2,446,236$ & 0.75 & 5 & 65 & 0.04 & 0.49 & $0.434 \%$ & $0.98 \%$ & $1,417,644$ & $3,863,880$ \\
\hline 1.3 .9 & FINISHES & $2,966,400$ & 0.91 & 5 & 50 & 0.05 & 0.45 & $0.403 \%$ & $0.91 \%$ & $1,318,956$ & $4,285,356$ \\
\hline 1.3 .10 & SPECIALTIES & $23,150,409$ & 7.08 & 5 & 40 & 0.35 & 2.83 & $2.512 \%$ & $5.67 \%$ & $8,211,599$ & $31,362,008$ \\
\hline 1.3.11 & EQUIPMENT & $83,531,926$ & 25.53 & 5 & 65 & 1.28 & 16.60 & $14.809 \%$ & $33.42 \%$ & $48,408,450$ & $131,940,376$ \\
\hline 1.3 .12 & FURNISHINGS & $2,152,136$ & 0.66 & 5 & 45 & 0.03 & 0.30 & $0.263 \%$ & $0.59 \%$ & 860,142 & $3,012,278$ \\
\hline 1.3 .13 & SPECIAL CONSTRUCTION & 0 & 0.00 & 5 & 45 & 0.00 & 0.00 & $0.000 \%$ & $0.00 \%$ & 0 & 0 \\
\hline 1.3 .14 & CONVEYING SYSTEMS & 163,440 & 0.05 & 5 & 45 & 0.00 & 0.02 & $0.020 \%$ & $0.05 \%$ & 65,322 & 228,762 \\
\hline 1.3.15 & MECHANICAL & $32,158,828$ & 9.83 & 5 & 65 & 0.49 & 6.39 & $5.701 \%$ & $12.87 \%$ & $18,636,695$ & $50,795,523$ \\
\hline 1.3 .16 & ELECTRICAL & $18,604,676$ & 5.69 & 5 & 65 & 0.28 & 3.70 & $3.298 \%$ & $7.44 \%$ & $10,781,788$ & $29,386,464$ \\
\hline 1.4 .1 & GOVERNMENT FURNISHED EQUIP. & 0 & 0.00 & 5 & 45 & 0.00 & 0.00 & $0.000 \%$ & $0.00 \%$ & 0 & 0 \\
\hline 1.5 .1 & G\&ANPIF ADDER & $12,637,151$ & 3.86 & 5 & 45 & 0.19 & 1.74 & $1.545 \%$ & $3.49 \%$ & $5,050,680$ & $17,687,831$ \\
\hline 1.5 .2 & PROCUREMENT FEES & $2,095,996$ & 0.64 & 5 & 45 & 0.03 & 0.29 & $0.256 \%$ & $0.58 \%$ & 837,705 & $2,933,701$ \\
\hline & ESCALATION & 0 & 0.00 & 0 & 0 & 0.00 & 0.00 & $0.000 \%$ & $0.00 \%$ & (864) & (864) \\
\hline & SUBTOTAL & $327,156,735$ & 100.00 & & & & & $44.310 \%$ & & & \\
\hline & CALCULATED CONTINGENCY & $144,964,014$ & & & & & & & & & \\
\hline & RESULTANT TEC & $472,120,749$ & & & & & & & & & \\
\hline & ROUNDED TEC & $472,000,000$ & & & & & & & & & \\
\hline & PROJECT CONTINGENCY & $144,843,265$ & & & & & & $44.27 \%$ & & & \\
\hline & MANAGEMENT RESERVE & $22,433,274$ & & & & & & & & & \\
\hline & CONTINGENCY & $-122,409,991$ & & & & & & & & & \\
\hline & TOTAL ESTIMATED COST & $472,000,000$ & & & & & & & & $\therefore 144,843,265$ & $472,000,000$ \\
\hline
\end{tabular}

CONFIDENCE LEVEL AND ASSUMED RISKS:

The Lockheed Idaho Technologies Co. Cost Estimate Contingency Analysis Model is based on the applied contingency and the assumptions upon which

the estimate was predicated. The model is applied with a suggested risk level of $18 \%$ and a level of confidence of $90 \%$ the estimate will fall within the bid range. The Contingency Analysis is based on a weighted average to provide a

$90 \%$ probability of underrun and a $10 \%$ probability of overrun.
CONTINGENCY ANALYSIS GUIDE BY TYPE OF ESTIMATE

Guidelines established by DOE/FM 50, Cost Estimating Guide, Vol. 6, Cost Guide, and as presented in the INEL Cost Estimating Guide. PLANNING $20 \%-30 \%$ Experimental/Special Conditions...........Up to 50\% Conceptual $15 \%-25 \%$ Experimental/Special Conditions............Up to 40\% TITLE I

TITLE II TITLE II/AFC
$10 \%-20 \%$

$5 \%-15 \%$ Market Conditions 

Lockheed Martin Idaho Technologies Co.

PROJECT NAME: HWO VITRIFICATION FACILITY TOTAL ESTIMATED COST - ESCALAT PROJECT NO

LOCATION 1: REQUESTOR:
ICPP, INEEL

D. A. Lopez
CONTINGENCY ANALYSIS
PLANNING

2418

D. R. James
DATE: $23-$ Jan-1998

TIME: $09: 49: 41$
REPORT NAME: Contingency Analysis

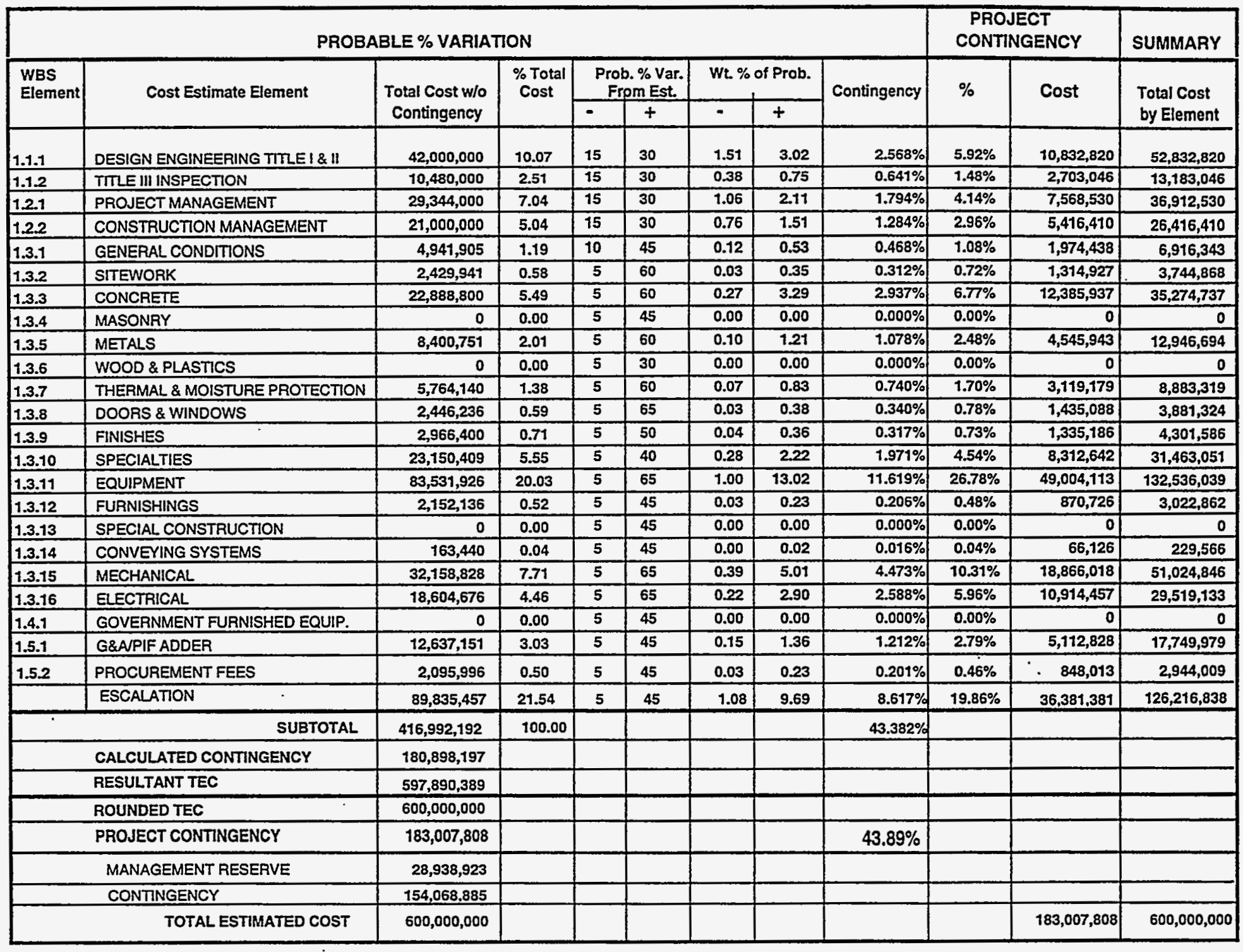

CONFIDENCE LEVEL AND ASSUMED RISKS:

The Lockheed ldaho Technologies Co. Cost Estimate Contingency Analysis

Model is based on the applied contingency and the assumptions upon which

the estimate was predicated. The model is applied with a suggested risk level

of $18 \%$ and a level of confidence of $90 \%$ the estimate will fall within the bid range.

The Contingency Analysis is based on a weighted average to provide a

$90 \%$ probability of underrun and a $10 \%$ probability of overrun.
CONTINGENCY ANALYSIS GUIDE BY TYPE OF ESTIMATE

Guidelines established by DOE/FM 50 , Cost Estimating Guide, Vol. 6 ,

Cost Guide, and as presented in the INEL Cost Estimating Guide.

PLANNING 20\%-30\%

Experimental/Special Conditions............Up to $50 \%$ Conceptual $15 \%-25 \%$

Experimental/Special Conditions.............Up to $40 \%$

TITLE ! $10 \%-20 \%$

TITLE II $5 \%-15 \%$

TITLE II/AFC Market Conditions 


\section{G\&A/PIF ADDER CALCULATION SHEET}

PROCUREMENT FEE:

CONSTRUCTION $=$ GFE =

FEE (9) $1 \%=$
$\$ 209,599,589$

Subtotal $\$ 209,599,589$

$\$ 209,599,589 * 0.01=\$ 2,095,995.89$

G\&A@ $23 \%$ (with a ceiling of $\$ 500,000$ imposed per year

CONSTRUCTION OR

CEILING • \# OF YEARS $=$

GFE =

PROCUREMENT FEE $=$.

Subtotal

FEE @ $23 \%=$
$\$ 2,000,000$.

$\$ 0$

$\$ 2,095,996$

$\$ 4,095,996$

$\$ 4,095,996 * 0.23=$

$\$ 942,079$

PIF @ 5.5\%

CONSTRUCTION =

GFE =

PROCUREMENT FEE $=$

$G \& A=$

FEE @ $5.5 \%=$
$\$ 209,599,589$

$\$ 0$

$\$ 2,095,996$

$\$ 942,079$

$\$ 212,637,664$

$\$ 212,637,664 \cdot 0.055=$

TOTAL PROCUREMENT FEE:

$\$ 2,095,996$

TOTAL G\&A FEE:

$\$ 942,079$

TOTAL PIF:

$\$ 11,695,072$ 
Lockheed Martin Idaho Technologies Co. Rav, 6-96 PROUECT NAME: HWO VITRIFICATION FACILITY LOCATION 1: OTHER PROJ. COSTS - ESC. INEELICPP REQUESTOR: D. A. LOPEZ
COST ESTIMATE SUMMARY

TYPE OF ESTIMATE: PLANNING
PROJECT NO: 24180
PREPARED BY: D.R. James
REPORT NAME: Cost Estimate Summary

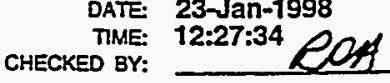

APPRO BY:

\begin{tabular}{|c|c|c|c|c|}
\hline $\begin{array}{l}\text { WBS } \\
\text { Element }\end{array}$ & Cost Estimate Element & $\begin{array}{c}\text { Total } \\
\text { Unescalated }\end{array}$ & Escalation & $\begin{array}{c}\text { Total } \\
\text { Incl Escalation }\end{array}$ \\
\hline $\begin{array}{l}\frac{1.1}{1.1 .1} \\
\frac{1.2}{1.2 .1} \\
\frac{1.3 .}{1.3 .1} \\
\frac{1.4}{1.4 .1} \\
1.5 .2\end{array}$ & $\begin{array}{l}\text { CONCEPTUAL } \\
\text { CONCEPTUAL DESIGN } \\
\text { MANAGEMENT } \\
\text { PM FOR PROJECT DEVELOPMENT } \\
\text { PERMITTING } \\
\text { PERMITTING \& DOCUMENTATION } \\
\text { SO TEST \& STARTUP } \\
\text { SO TEST \& START-UP } \\
\text { PROCUREMENT FEES }\end{array}$ & $\begin{array}{r}85,720,000 \\
12,980,000 \\
2,904,000 \\
36,040,000 \\
0\end{array}$ & $\begin{array}{r}3,764,200 \\
842,160 \\
2,162,400 \\
0\end{array}$ & $\begin{array}{l}\gg \frac{\$ 90,863,200}{90,863,200} \\
\gg \frac{\$ 16,744,200}{16,744,200} \\
\gg \frac{\$ 3,746,160}{3,746,160} \\
\gg \frac{\$ 38,202,400}{38,202,400} \\
\gg \quad \underline{\text { S0 }}\end{array}$ \\
\hline & $\begin{array}{l}\text { SUBTOTAL INCLUDING ESCALATION } \\
\text { PROJECT CONTINGENCY }\end{array}$ & $137,644,000$ & $11,911,960$ & $>\$ 149,555,960$ \\
\hline & MANAGEMENT RESERVE- & & & $\gg$ \\
\hline & CONTINGENCY - & & & $>\$ 46,444,040$ \\
\hline & TOTAL ESTIMATED COST & & & \\
\hline
\end{tabular}

PROJECT COST PARAMETERS

EDI AS A \% OF CONST. + GFE $=$ 
Lockheed Martin Idaho Technologies Co. Rev. 6-96 PROIECT NAME: HWO VITRIFICATION FACILITY OTHER PROJ. COSTS - UNESC. INEEL ACPP

LOCATION 1: REQUESTOR:

D. A. Lopez
COST ESTIMATE SUMMARY

$\begin{array}{cl}\text { TYPE OF ESTIMATE: } & \text { PLANNING } \\ \text { PROJECT NO: } & 24180 \\ \text { PREPARED BY: } & \text { D. R. James } \\ \text { REPORT NAME: } & \text { Cost Estimate Summary }\end{array}$

DATE: 23-Jan-1998

CHECKED BY:

APPR'D BY:

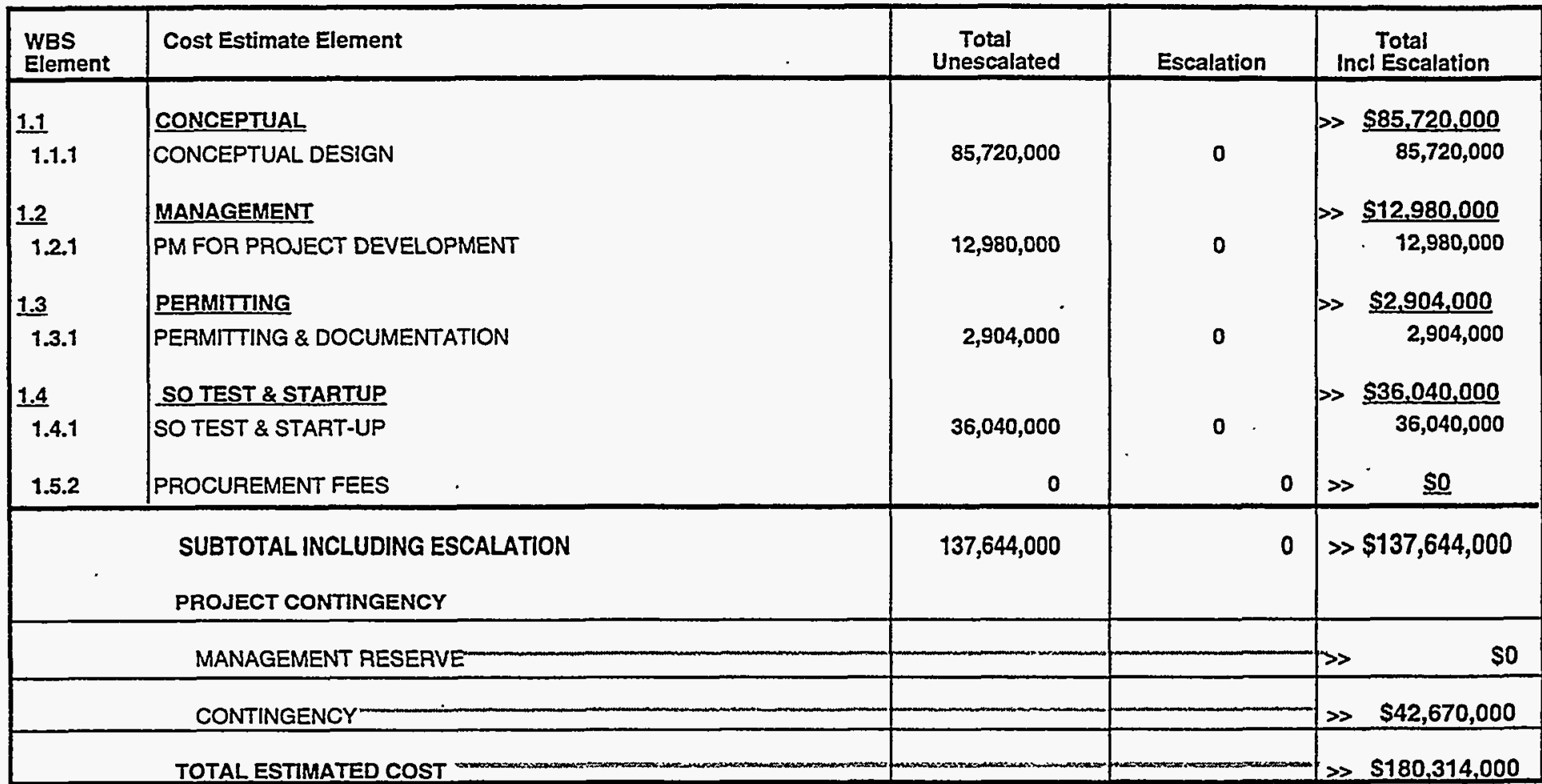




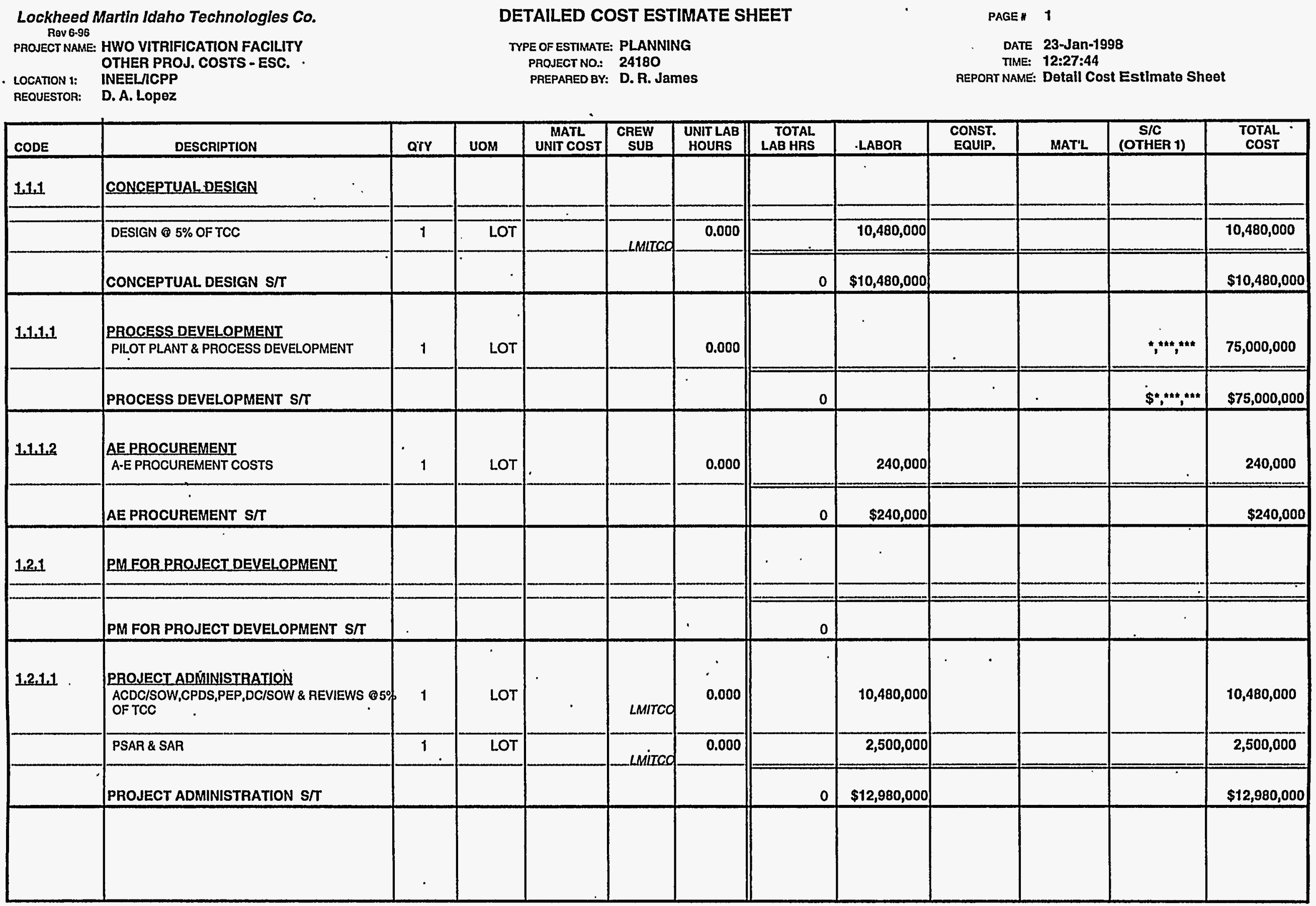


Lockheed Martin Idaho Technologles Co. Rov 6.90 PROJECT NAME: HWO VITRIFICATION FACILITY OTHER PROJ. COSTS - ESC.

LOCATION 1: INEEL/ICPP REOUESTOR: D. A. Lopez

\section{DETAILED COST ESTIMATE SHEET}

TYPE OF ESTIMATE: PLANNING

PROJECT NO.: 24180

PREPARED BY: D. R. James
PAGE 2

DATE - 23-Jan-1998

TIME: 12:27:44

REPORT NAME: Detall Cost Estimate Sheet

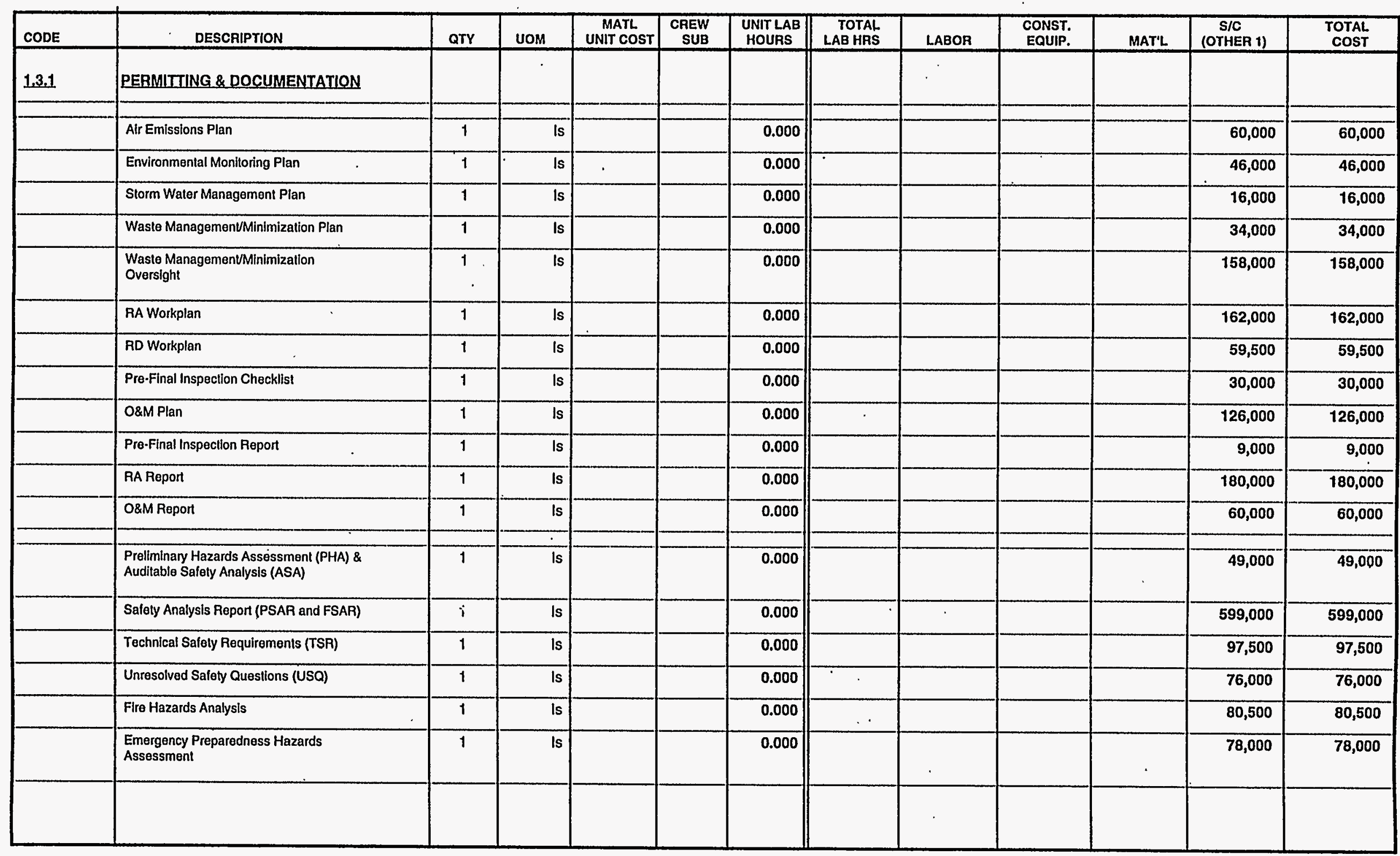


Lockheed Martin Idaho Technologles Co. Rev 6-96 PROJECT NAME: HWO VITRIFICATION FACILITY OTHER PROJ. COSTS - ESC.

LOCATION I: INEELIICPP

REQUESTOR: D. A. LopeZ
DETAILED COST ESTIMATE SHEET

TYPE OF ESTIMATE: PLANNING

PROJECT NO.: 24180

PREPARED BY: D. R. James
PAGE 3

DATE 23-Jan-1998

TIME: 12:27:44

REPORT NAME: Detall Cost Estimate Sheet

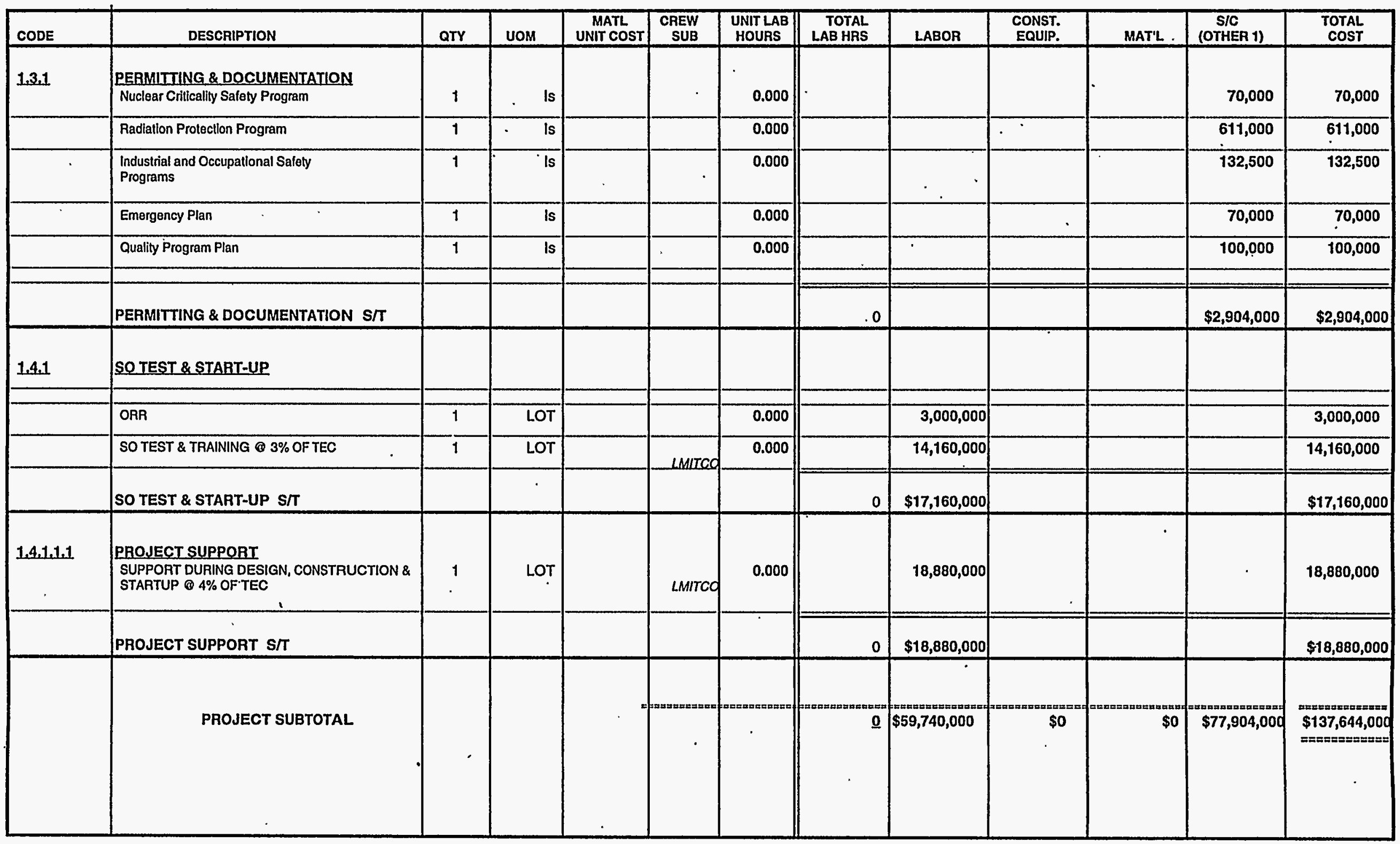


Lockheed Martin Idaho Technologies Co.

PROECT NAME: HWO VITRIFICATION FACILITY OTHER PROJ. COSTS - UNESC.

LOCATION 1:

REQUESTOR:
INEEL CPP

CONTINGENCY ANALYSIS

TYPE OF ESTIMATE:

PROJECT NO:

PAEPARED BY:
PLANNING

24180

D. R. James
DATE: 23-Jan-1998

TME: 12:31:42

REPORT NAME: Contingency Analysis

\begin{tabular}{|c|c|c|c|c|c|c|c|c|c|c|c|}
\hline \multicolumn{9}{|c|}{ PROBABLE \% VARIATION } & \multicolumn{2}{|c|}{$\begin{array}{l}\text { PROJECT } \\
\text { CONTINGENCY }\end{array}$} & \multirow{3}{*}{$\begin{array}{l}\text { SUMMARY } \\
\begin{array}{l}\text { Total Cost } \\
\text { by Element }\end{array}\end{array}$} \\
\hline \multirow[t]{2}{*}{$\begin{array}{l}\text { WBS } \\
\text { Element }\end{array}$} & \multirow[t]{2}{*}{ Cost Estimate Element } & \multirow{2}{*}{$\begin{array}{c}\text { Total Cost w/o } \\
\text { Contingency }\end{array}$} & \multirow[t]{2}{*}{$\begin{array}{l}\text { \% Total } \\
\text { Cost }\end{array}$} & \multicolumn{2}{|c|}{$\begin{array}{c}\text { Prob. \% Var. } \\
\text { From Est. } \\
\end{array}$} & \multicolumn{2}{|c|}{ Wt. \% of Prob. } & \multirow[t]{2}{*}{ Contingency } & \multirow[t]{2}{*}{$\%$} & \multirow[t]{2}{*}{ Cost } & \\
\hline & & & & - & + & - & + & & & & \\
\hline 1.1 .1 & CONCEPTUAL DESIGN & $85,720,000$ & 62.28 & 5 & 35 & 3.11 & 21.80 & $19.306 \%$ & $62.28 \%$ & $26,573,424$ & $112,293,424$ \\
\hline 1.2 .1 & PM FOR PROJECT DEVELOPMENT - & $12,980,000$ & 9.43 & 5 & 35 & 0.47 & 3.30 & $2.923 \%$ & $9.43 \%$ & $4,023,834$ & $17,003,834$ \\
\hline 1.3 .1 & PERMITTING \& DOCUMENTATION & $2,904,000$ & 2.11 & 5 & 35 & 0.11 & 0.74 & $0.654 \%$ & $2.11 \%$ & 900,248 & $3,804,248$ \\
\hline 1.4 .1 & SO TEST \& START-UP & $36,040,000$ & 26.18 & 5 & 35 & 1.31 & 9.16 & $8.117 \%$ & $26.18 \%$ & $11,172,494$ & $47,212,494$ \\
\hline \multirow[t]{2}{*}{1.5 .2} & PROCUREMENT FEES & 0 & 0.00 & 5 & 35 & 0.00 & 0.00 & $0.000 \%$ & $0.00 \%$ & 0 & 0 \\
\hline & ESCALATION & 0 & 0.00 & 5 & 35 & 0.00 & 0.00 & $0.000 \%$ & $0.00 \%$ & 0 & 0 \\
\hline \multicolumn{2}{|r|}{ SUBTOTAL } & $137,644,000$ & 100.00 & & & & & $31.000 \%$ & & & \\
\hline \multicolumn{2}{|r|}{ CALCULATED CONTINGENCY } & $42,669,640$ & & & & & & & & & \\
\hline \multicolumn{2}{|r|}{ RESULTANT TEC } & $180,313,640$ & & & & & & & & & $\cdot$ \\
\hline \multicolumn{2}{|r|}{ ROUNDED TEC } & $180,314,000$ & & & & & & & & & \\
\hline \multicolumn{2}{|r|}{ PROJECT CONTINGENCY } & $42,670,000$ & & & & & & $31.00 \%$ & & & \\
\hline \multicolumn{2}{|r|}{ MANAGEMENT RESERVE } & 0 & & & & & & & & & \\
\hline \multicolumn{2}{|r|}{ CONTINGENCY } & $42,670,000$ & & & & & & & & & \\
\hline \multicolumn{2}{|r|}{ TOTAL ESTIMATED COST } & $180,314,000$ & & & & & & & & $42,670,000$ & $180,314,000$ \\
\hline
\end{tabular}

\section{CONFIDENCE LEVEL AND ASSUMED RISKS:}

The Lockheed Idaho Technologies Co. Cost Estimate Contingency Analysis Model is based on the applied contingency and the assumptions upon which

the estimate was predicated. The model is applied with a suggested risk level of $18 \%$ and a level of confidence of $90 \%$ the estimate will fall within the bid range. The Contingency Analysis is based on a weighted average to provide a $90 \%$ probability of underrun and a $10 \%$ probability of overrun.
CONTINGENCY.ANALYSIS GUIDE BY TYPE OF ESTIMATE

Guidelines established by DOE/FM 50, Cost Estimating Guide, Vol. 6,

Cost Guide, and as presented in the INEL Cost Estimating Guide. PLANNING Conceptual $15 \%-25 \%$

TITLE !

TITLE IIIAFC ....Up to $50 \%$ $10 \%-20 \%$ $5 \%-15 \%$ Market Conditions 
Lockheed Martin Idaho Technologies Co. PROIECT NAME: HWO VITRIFICATION FACILITY OTHER PROJ. COSTS - ESC.

LOCATION :: INEELICPP

REQUESTOR:

\section{CONTINGENCY ANALYSIS}

TYPE OF ESTIMATE:

PROJECTNO: 24180

PREPARED BY: D. R. James
DATE: 23-Jan-1998

TIME: 12:27:21.

REPORT NAME: Contingency Analysis

\begin{tabular}{|c|c|c|c|c|c|c|c|c|c|c|c|}
\hline \multicolumn{9}{|c|}{ PROBABLE \% VARIATION } & \multicolumn{2}{|c|}{$\begin{array}{l}\text { PROJECT } \\
\text { CONTINGENCY }\end{array}$} & \multirow{3}{*}{$\begin{array}{l}\text { SUMMARY } \\
\begin{array}{l}\text { Total Cost } \\
\text { by Element }\end{array}\end{array}$} \\
\hline \multirow[t]{2}{*}{$\begin{array}{l}\text { WBS } \\
\text { Element }\end{array}$} & \multirow[t]{2}{*}{ Cost Estimate Element } & \multirow{2}{*}{$\begin{array}{c}\text { Total Cost w/o } \\
\text { Contingency }\end{array}$} & \multirow[t]{2}{*}{$\begin{array}{l}\text { \% Total } \\
\text { Cost }\end{array}$} & \multicolumn{2}{|c|}{$\begin{array}{c}\text { Prob. \% Var. } \\
\text { From Est. }\end{array}$} & \multicolumn{2}{|c|}{ Wt. \% of Prob. } & \multirow[t]{2}{*}{ Contingency } & \multirow[t]{2}{*}{$\%$} & \multirow[t]{2}{*}{ Cost } & \\
\hline & & & & - & + & - & \pm & & & & \\
\hline 1.1 .1 & CONCEPTUAL DESIGN & $85,720,000$ & 57.32 & 5 & 35 & 2.87 & 20.06 & $17.768 \%$ & $57.32 \%$ & $26,620,023$ & $112,340,023$ \\
\hline 1.2 .1 & PM FOR PROJECT DEVELOPMENT & $12,980,000$ & 8.68 & 5 & 35 & 0.43 & 3.04 & $2.690 \%$ & $8.68 \%$ & $4,030,890$ & $17,010,890$ \\
\hline 1.3 .1 & PERMITTING \& DOCUMENTATION & $2,904,000$ & 1.94 & 5 & 35 & 0.10 & 0.68 & $0.602 \%$ & $1.94 \%$ & 901,826 & $3,805,826$ \\
\hline 1.4 .1 & SO TEST \& START-UP & $36,040,000$ & 24.10 & 5 & 35 & 120 & 8.43 & $7.470 \%$ & $24.10 \%$ & $11,192,086$ & $47,232,086$ \\
\hline \multirow[t]{2}{*}{1.5 .2} & PROCUREMENT FEES & 0 & 0.00 & 5 & 35 & 0.00 & 0.00 & $0.000 \%$ & $0.00 \%$ & 0 & 0 \\
\hline & ESCALATION & $11,911,960$ & 7.96 & 5 & 35 & 0.40 & 2.79 & $2.469 \%$ & $7.96 \%$ & $3,699,215$ & $15,611,175$ \\
\hline \multicolumn{2}{|r|}{ SUBTOTAL } & $149,555,960$ & 100.00 & & & & & $31.000 \%$ & & & \\
\hline \multicolumn{2}{|r|}{ CALCULATED CONTINGENCY } & $46,362,348$ & & & & & & & & & \\
\hline \multicolumn{2}{|r|}{ RESULTANT TEC } & $195,918,308$ & & & & & & & & & \\
\hline \multicolumn{2}{|r|}{ ROUNDED TEC } & $196,000,000$ & & & & & & & & & \\
\hline \multicolumn{2}{|r|}{ PROJECT CONTINGENCY } & $46,444,040$ & & & & & & $31.05 \%$ & & & \\
\hline \multicolumn{2}{|r|}{ MANAGEMENT RESERVE } & 0 & & & & & & & & & \\
\hline \multicolumn{2}{|r|}{ CONTINGENCY } & $46,444,040$ & & & & & & & & & \\
\hline \multicolumn{2}{|r|}{ TOTAL ESTIMATED COST } & $196,000,000$ & & & & & & & & $46,444,040$ & $196,000,000$ \\
\hline
\end{tabular}

CONFIDENCE LEVEL AND ASSUMED RISKS:

The Lockheed Idaho Technologies Co. Cost Estimate Contingency Analysis Model is based on the applied contingency and the assumptions upon which the estimate was predicated. The model is applied with a suggested risk level of $18 \%$ and a level of confidence of $90 \%$ the estimate will fall within the bid range. The Contingency Analysis is based on a weighted average to provide a $90 \%$ probability of underun and a $10 \%$ probability of ovemun.
CONTINGENCY ANALYSIS GUIDE BY TYPE OF ESTIMATE

Guidelines established by DOE/FM 50, Cost Estimating Guide, Vol. 6 , Cost Guide, and as presented in the INEL Cost Estimating Guide. PLANNING $20 \%-30 \%$ Experimental/Special Conditions..........Up to 50\% Conceptual Experimental/Special Conditions.............Up to $40 \%$ TITLE I

TITLE U TITLE II/AFC
$10 \% \quad \ldots 20 \%$

$5 \% \quad-.15 \%$ Market Conditions 
Date: January 28, 1998

To: $\quad$ D. A. Lopez $\quad$ MS $3765 \quad 6-9020$

From:

R. J. Turk RDfuch MS 3875

6-3611

Subject: $\quad$ ECONOMIC AND LIFE CYCLE ANALYSIS CONDUCTED VITRIFIED WASTE OPTION - VITRIFICATION WASTE FACILITY-RJT-9-97 Rev.3

\section{Purpose:}

As requested an Economic and Life-Cycle Cost (LCC) has been conducted to evaluate the VITRIFIED WASTE FACILITY. This facility will accept all raw calcined waste, including SWB calcined waste form ICPP Bin Sets, vitrify and cast it into a SRSDWPF-Type Glass Canisters (GC). The GC's will be sent to an Interim Storage Facility (ISF) until transport to final disposition.

This economic analysis is based on information provided by S. E. Gifford, S. L. Alstad, R. R. Kimmitt and other team members. D. R. James and R. D. Adams provided cost estimates. W. J. Prendergast provided process personnel modeling.

\section{Methodology:}

The Economic Evaluation assumed a 38-year period, (2001-2038) since this is the estimated time required to complete all of the anticipated remediation activities. The LCC identifies evaluated the initial development, construction, operation and post-operating costs over the life-cycle. A discounted LCC analysis assumes a constant-dollar basis, discounted at $6.30 \%$ annually per the Office of Management and Budget (OMB) Circular A-94. All costs are conservatively discounted assuming the end-of-year convention.

\section{Assumptions:}

The scope of work and requirements of all related activities are vague at this time. Facility and processing costs were developed from historical experience associated with DD\&D work at the INEEL. The LCC analysis was generated to match cost estimating cost structure. These costs include Permitting, Direct and Indirect Construction, G\&A, Procurement Fee, Engineering, 
Inspection, Project Management, Construction Management, Escalation and Contingency costs.

The design period is assumed to be accomplished in seven years with construction completed in four years. Labor rates were assumed as follows: Managers, $\$ 125 / \mathrm{hr}$; Engineers, $\$ 108 \$ / \mathrm{hr}$; Other Technicians \$ 85/hr; Administration/support staff $\$ 65 / \mathrm{hr}$; Operators and Maintenance personnel $\$ 65 / \mathrm{hr}$. The operational period for this facility was assumed to be twenty years, followed by five years of post-operations activities. Due to this project's lack of complexity and relative cleanliness this analysis assumed a decommissioning cost equal to $20 \%$ of the engineering design cost, decontamination costs equal to $5 \%$ of total pre-operation cost, and demolition costs equal to $8 \%$ of total pre-operation cost. These DD\&D costs were allocated over the remaining 5 years available to the project schedule. Utility costs were calculated assuming a $\$ 4.07$ per square foot cost. Per your direction, procurement costs for GS's Canisters at $\$ 10,000$ each, Materials for blending costs (borosilica glass frit) $\$ 4.40 / \mathrm{kg}$. Cost of glass frit for $\mathrm{S} \mathrm{O}$ Testing was calculated to take place during 2010-2011 at a cost of \$2.7 million per year. Estimated disposal cost for Murcury was obtained from Larbi Bonni of Handford.

\section{Results:}

The Vitrified Waste Option-Vitrification Facility has a Discounted LCC of $\$ 1.3$ billion.

Attachments:

cc: R. J. Turk File 


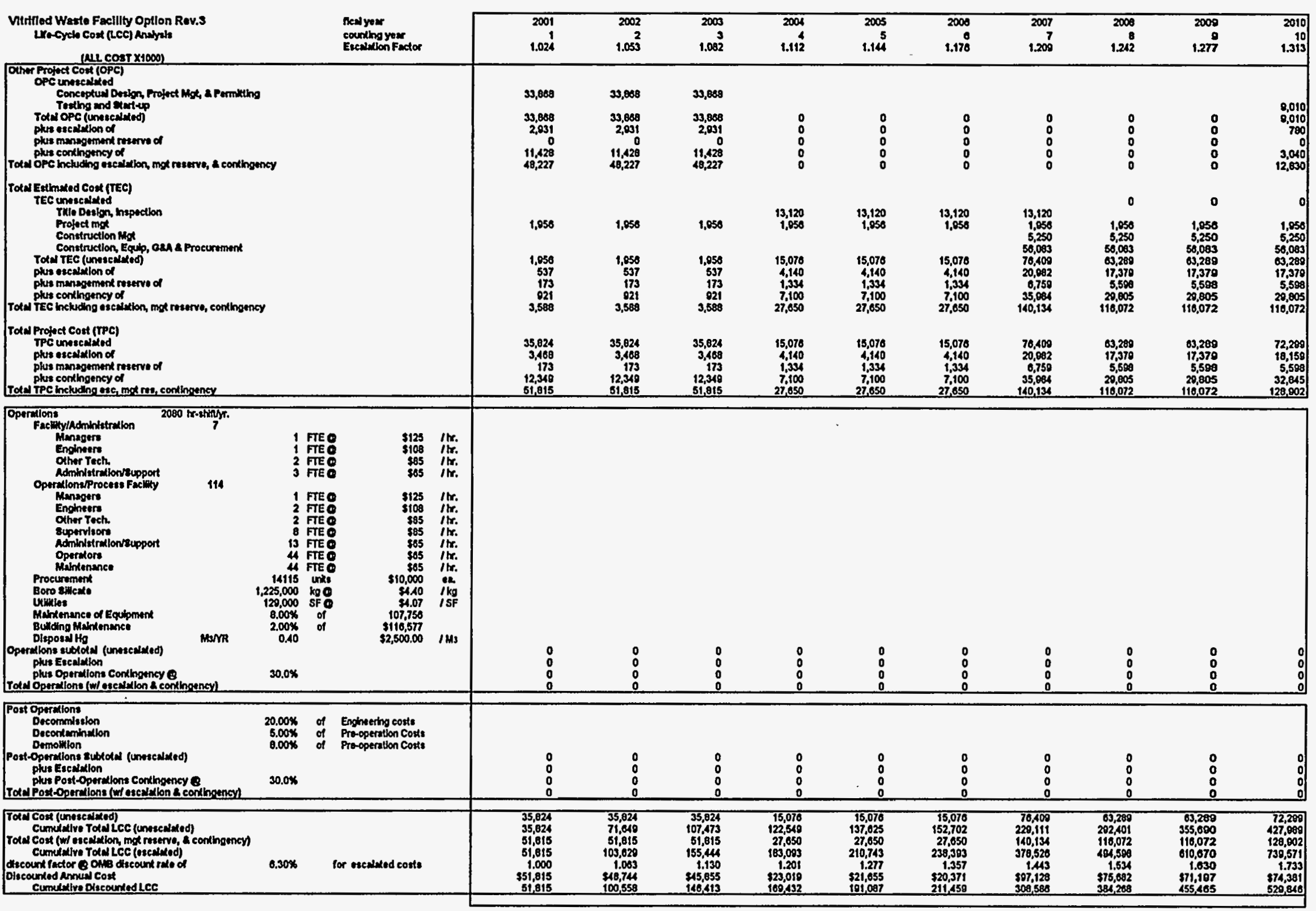




\begin{tabular}{|c|c|c|c|c|c|c|c|c|c|c|c|c|c|}
\hline \multicolumn{2}{|l|}{ 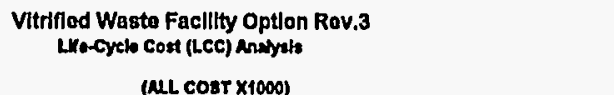 } & \multicolumn{2}{|l|}{ 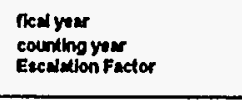 } & $\begin{array}{l}2011 \\
11 \\
1.350\end{array}$ & $\begin{array}{r}2012 \\
12 \\
1.387\end{array}$ & $\begin{array}{r}2013 \\
13 \\
1.226\end{array}$ & $\begin{array}{l}2014 \\
14 \\
1.468\end{array}$ & $\begin{array}{l}2015 \\
15 \\
1.507\end{array}$ & $\begin{array}{l}2018 \\
16 \\
1.550\end{array}$ & $\begin{array}{l}2017 \\
17 \\
1.593\end{array}$ & $\begin{array}{r}2010 \\
18 \\
1.038\end{array}$ & $\begin{array}{r}2019 \\
10 \\
1.080\end{array}$ & $\begin{array}{r}2020 \\
20 \\
1.730\end{array}$ \\
\hline \multicolumn{4}{|c|}{ 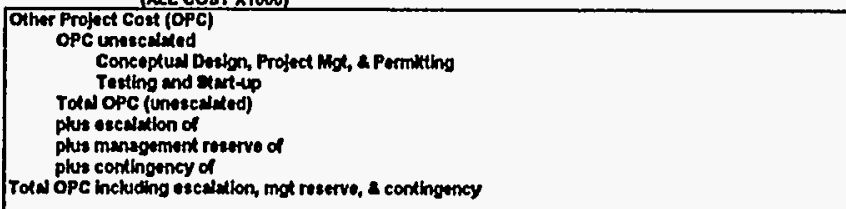 } & $\begin{array}{r}9,010 \\
9,010 \\
700 \\
0 \\
0.010 \\
32,030 \\
12,030\end{array}$ & $\begin{array}{r}9,010 \\
9,010 \\
700 \\
0 \\
0,040 \\
12,030\end{array}$ & $\begin{array}{r}9,010 \\
0,010 \\
780 \\
0 \\
0,010 \\
32,040 \\
12,830\end{array}$ & $\begin{array}{l}0 \\
0 \\
0 \\
0 \\
0\end{array}$ & $\begin{array}{l}0 \\
0 \\
0 \\
0 \\
0\end{array}$ & $\begin{array}{l}0 \\
0 \\
0 \\
0 \\
0\end{array}$ & $\begin{array}{l}0 \\
0 \\
0 \\
0 \\
0\end{array}$ & $\begin{array}{l}0 \\
0 \\
0 \\
0 \\
0\end{array}$ & $\begin{array}{l}0 \\
0 \\
0 \\
0 \\
0\end{array}$ & $\begin{array}{l}0 \\
0 \\
0 \\
0 \\
0\end{array}$ \\
\hline \multirow{2}{*}{\multicolumn{4}{|c|}{ 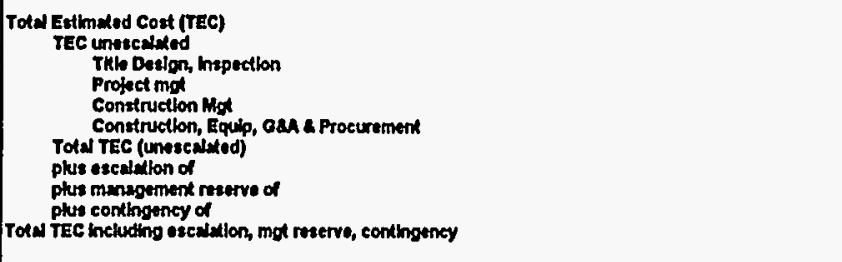 }} & 1,058 & 1,058 & 1,850 & 1.958 & 1.050 & & & & & \\
\hline & & & & $\begin{array}{r}1,050 \\
537 \\
173 \\
921 \\
3,580\end{array}$ & $\begin{array}{r}1,056 \\
537 \\
173 \\
021 \\
3,608\end{array}$ & $\begin{array}{r}1,050 \\
537 \\
173 \\
921 \\
3,588\end{array}$ & $\begin{array}{r}1,050 \\
537 \\
173 \\
921 \\
9,588\end{array}$ & $\begin{array}{r}1,050 \\
537 \\
173 \\
921 \\
3,588\end{array}$ & $\begin{array}{l}0 \\
0 \\
0 \\
0 \\
0\end{array}$ & $\begin{array}{l}0 \\
0 \\
0 \\
0 \\
0\end{array}$ & $\begin{array}{l}0 \\
0 \\
0 \\
0 \\
0\end{array}$ & $\begin{array}{l}0 \\
0 \\
0 \\
0 \\
0\end{array}$ & $\begin{array}{l}0 \\
0 \\
0 \\
0 \\
0\end{array}$ \\
\hline \multicolumn{4}{|l|}{ 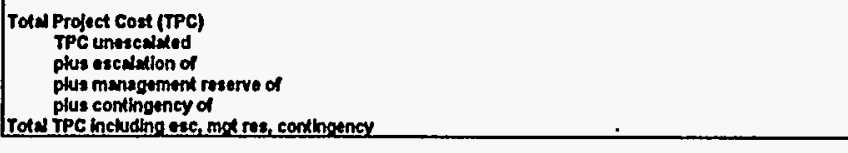 } & $\begin{array}{r}10,960 \\
1,317 \\
173 \\
3,891 \\
16,418 \\
\end{array}$ & $\begin{array}{r}10,060 \\
1,317 \\
173 \\
3,981 \\
18,418 \\
\end{array}$ & $\begin{array}{r}10,060 \\
1,317 \\
173 \\
3,061 \\
10,418 \\
\end{array}$ & $\begin{array}{r}1,058 \\
537 \\
173 \\
921 \\
3,589 \\
\end{array}$ & $\begin{array}{r}1,056 \\
537 \\
173 \\
021 \\
3,588 \\
\end{array}$ & $\begin{array}{l}0 \\
0 \\
0 \\
0 \\
0\end{array}$ & $\begin{array}{l}0 \\
0 \\
0 \\
0 \\
0\end{array}$ & $\begin{array}{l}0 \\
0 \\
0 \\
0\end{array}$ & $\begin{array}{l}0 \\
0 \\
0 \\
0 \\
0\end{array}$ & $\begin{array}{l}0 \\
0 \\
0 \\
0 \\
0\end{array}$ \\
\hline 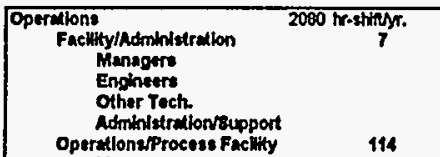 & $\begin{array}{l}1 \text { FTE } \\
1 \\
2 \text { TTE } \\
3 \text { FTE } \\
3 \text { FTE }\end{array}$ & $\begin{array}{l}\$ 125 \\
\$ 108 \\
\$ 85 \\
\$ 65\end{array}$ & 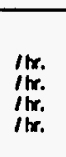 & $\begin{array}{l}130 \\
112 \\
177 \\
203\end{array}$ & $\begin{array}{l}130 \\
112 \\
177 \\
203\end{array}$ & $\begin{array}{l}280 \\
225 \\
354 \\
406\end{array}$ & $\begin{array}{l}280 \\
225 \\
354 \\
406\end{array}$ & $\begin{array}{l}200 \\
225 \\
344 \\
400\end{array}$ & $\begin{array}{l}230 \\
225 \\
334 \\
406\end{array}$ & $\begin{array}{l}200 \\
225 \\
354 \\
406\end{array}$ & $\begin{array}{l}200 \\
225 \\
354 \\
406\end{array}$ & $\begin{array}{l}200 \\
225 \\
354 \\
400\end{array}$ & $\begin{array}{l}260 \\
225 \\
354 \\
406\end{array}$ \\
\hline 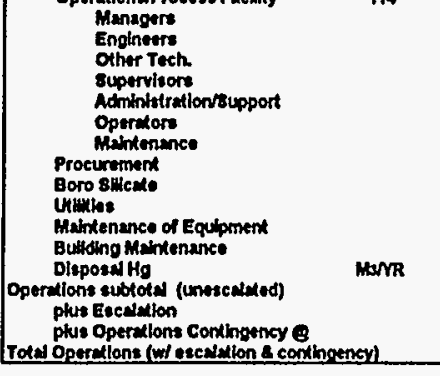 & $\begin{array}{rr}1 & \text { FTE } \\
2 & \text { FTE } \\
2 & \text { TTE } \\
8 & \text { TTE } \\
13 & \text { TTE } \\
4 & \text { FTE } \\
44 & \text { FTE } \\
14115 & \text { wilk } \\
1,25,000 & \text { kg } \\
128,000 & \text { SF } \\
8.00 \% & \text { of } \\
2.00 \% & \text { of } \\
0.40 & \\
& \\
30.0 \% & \end{array}$ & $\begin{array}{r}\$ 125 \\
\$ 108 \\
\$ 05 \\
\$ 85 \\
\$ 85 \\
\$ 85 \\
\$ 85 \\
\$ 10,000 \\
\$ 1.40 \\
\$ 4.07 \\
107,756 \\
\$ 18,517 \\
\$ 2,500.00\end{array}$ & 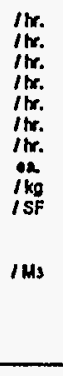 & $\begin{array}{r}822 \\
217 \\
252 \\
1.091 \\
\end{array}$ & $\begin{array}{r}622 \\
241 \\
250 \\
1,122 \\
\end{array}$ & 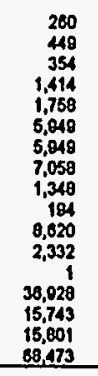 & 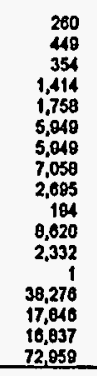 & 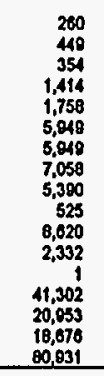 & 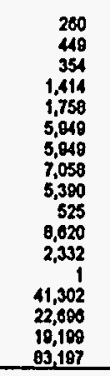 & 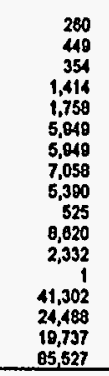 & 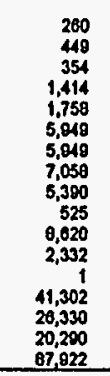 & 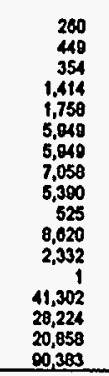 & 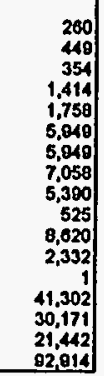 \\
\hline 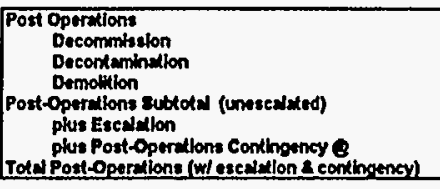 & 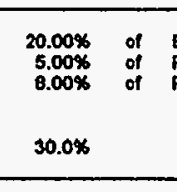 & $\begin{array}{l}\text { Enghneeting costs } \\
\text { Pro-operntion Corts } \\
\text { Pro-opertition Costs }\end{array}$ & & $\begin{array}{l}0 \\
0 \\
0 \\
0\end{array}$ & $\begin{array}{l}0 \\
0 \\
0 \\
0\end{array}$ & $\begin{array}{l}0 \\
0 \\
0 \\
0 \\
\end{array}$ & $\begin{array}{l}0 \\
0 \\
0 \\
0 \\
\end{array}$ & $\begin{array}{l}0 \\
0 \\
0 \\
0\end{array}$ & $\begin{array}{l}0 \\
0 \\
0 \\
0\end{array}$ & $\begin{array}{l}0 \\
0 \\
0 \\
0\end{array}$ & $\begin{array}{l}0 \\
0 \\
0 \\
0\end{array}$ & $\begin{array}{l}0 \\
0 \\
0 \\
0\end{array}$ & $\begin{array}{l}0 \\
0 \\
0 \\
0\end{array}$ \\
\hline 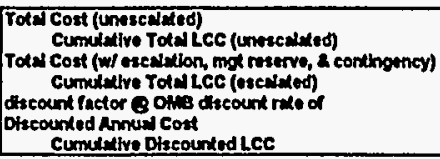 & $0.30 \%$ & for esedseded costs & & 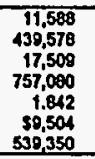 & 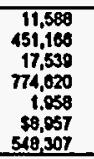 & 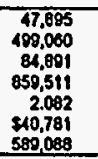 & 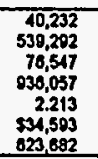 & $\begin{array}{r}43,239 \\
582,551 \\
84,510 \\
1,020,570 \\
2.252 \\
\$ 35,039 \\
859.014 \\
\end{array}$ & 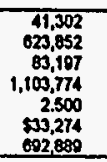 & $\begin{array}{r}41,302 \\
685,154 \\
85,527 \\
1,189,301 \\
2.658 \\
\$ 32,179 \\
725,008\end{array}$ & $\begin{array}{r}41.302 \\
700.450 \\
87,922 \\
1,227,222 \\
2.825 \\
\$ 031.119 \\
750,187\end{array}$ & 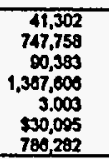 & 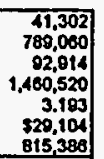 \\
\hline
\end{tabular}




\begin{tabular}{|c|c|c|c|c|c|c|c|c|c|c|c|c|c|}
\hline \multicolumn{2}{|l|}{$\begin{array}{l}\text { Vitrifled Waste Facllity Option Rev.3 } \\
\text { Lre-ges Cost LCC) Andyats }\end{array}$} & \multicolumn{2}{|l|}{$\begin{array}{l}\text { neal yerr } \\
\text { counthoyer } \\
\text { Eecultion Fetor }\end{array}$} & $\begin{array}{l}2021 \\
21 \\
8.77\end{array}$ & $\begin{array}{r}2022 \\
22 \\
1.828\end{array}$ & $\begin{array}{l}2023 \\
23 \\
1.800\end{array}$ & $\begin{array}{r}2024 \\
24 \\
1.233\end{array}$ & $\begin{array}{r}2025 \\
25 \\
1.087\end{array}$ & $\begin{array}{l}2028 \\
28 \\
2.012\end{array}$ & $\begin{array}{r}2027 \\
27 \\
2.100\end{array}$ & $\begin{array}{r}2028 \\
29 \\
2.159\end{array}$ & $\begin{array}{r}2029 \\
29 \\
22210\end{array}$ & $\begin{array}{r}2030 \\
2.201 \\
2.201\end{array}$ \\
\hline \multicolumn{4}{|l|}{ 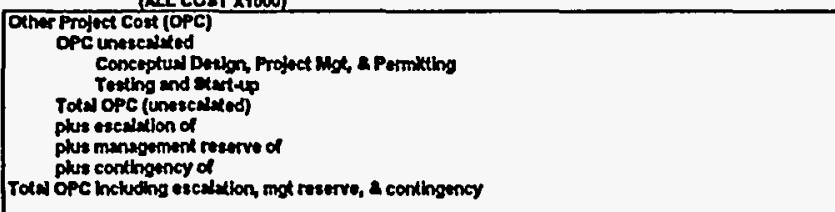 } & $\begin{array}{l}0 \\
0 \\
0 \\
0 \\
0\end{array}$ & $\begin{array}{l}0 \\
: \\
: \\
0\end{array}$ & $\begin{array}{l}0 \\
0 \\
0 \\
0 \\
0\end{array}$ & $\begin{array}{l}0 \\
0 \\
0 \\
0 \\
0\end{array}$ & $\begin{array}{l}0 \\
0 \\
0 \\
0 \\
0\end{array}$ & $\begin{array}{l}0 \\
0 \\
0 \\
0\end{array}$ & $\begin{array}{l}0 \\
0 \\
0 \\
0 \\
0\end{array}$ & $\begin{array}{l}0 \\
0 \\
0 \\
0 \\
0\end{array}$ & $\begin{array}{l}0 \\
0 \\
0 \\
0 \\
0\end{array}$ & $\begin{array}{l}0 \\
: 0 \\
0 \\
0\end{array}$ \\
\hline \multicolumn{4}{|l|}{ 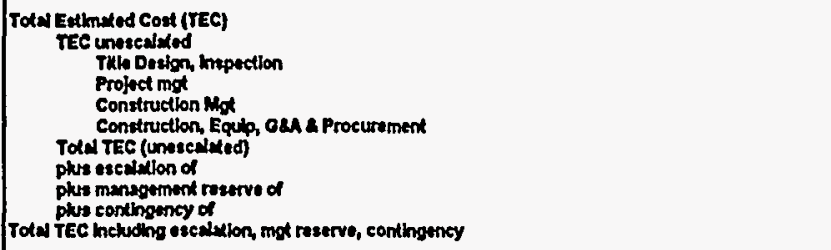 } & $\begin{array}{l}0 \\
: \\
: \\
0\end{array}$ & $\begin{array}{l}0 \\
: \\
0 \\
0\end{array}$ & $\begin{array}{l}0 \\
0 \\
0 \\
0 \\
0\end{array}$ & $\begin{array}{l}0 \\
0 \\
0 \\
0\end{array}$ & $\begin{array}{l}0 \\
0 \\
0 \\
0 \\
0\end{array}$ & $\begin{array}{l}0 \\
0 \\
0 \\
0\end{array}$ & $\begin{array}{l}0 \\
: \\
0 \\
0\end{array}$ & $\begin{array}{l}0 \\
: \\
0 \\
0\end{array}$ & $\begin{array}{l}0 \\
0 \\
0 \\
0 \\
0\end{array}$ & $\begin{array}{l}0 \\
0 \\
0 \\
0\end{array}$ \\
\hline \multicolumn{4}{|l|}{ 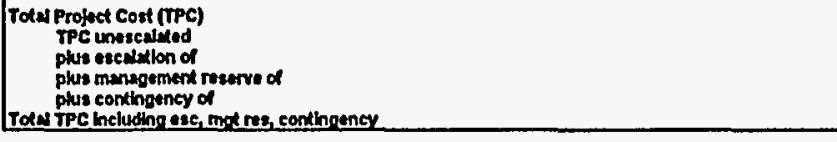 } & $\begin{array}{l}0 \\
0 \\
0 \\
0 \\
0\end{array}$ & $\begin{array}{l}0 \\
0 \\
0 \\
0 \\
\end{array}$ & $\begin{array}{l}0 \\
0 \\
0 \\
0 \\
0\end{array}$ & $\begin{array}{l}0 \\
0 \\
0 \\
0 \\
0 \\
\end{array}$ & $\begin{array}{l}0 \\
0 \\
0 \\
0 \\
0 \\
\end{array}$ & $\begin{array}{l}0 \\
0 \\
0 \\
0 \\
\end{array}$ & $\begin{array}{l}0 \\
\vdots \\
0 \\
0\end{array}$ & $\begin{array}{l}0 \\
\vdots \\
0 \\
0\end{array}$ & $\begin{array}{l}0 \\
: \\
0 \\
0 \\
0\end{array}$ & $\begin{array}{l}0 \\
0 \\
0 \\
0 \\
0\end{array}$ \\
\hline 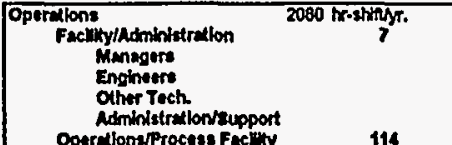 & $\begin{array}{l}1 \text { FIE } \\
1 \text { FIE } \\
2 \text { FEg } \\
3 \text { FTE }\end{array}$ & $\begin{array}{l}\$ 125 \\
\$ 109 \\
\$ 05 \\
\$ 05\end{array}$ & $\begin{array}{l}\text { fhr. } \\
\text { thr. } \\
\text { thr. } \\
\text { thr. }\end{array}$ & $\begin{array}{l}200 \\
225 \\
354 \\
406\end{array}$ & $\begin{array}{l}200 \\
225 \\
354 \\
400\end{array}$ & $\begin{array}{l}260 \\
225 \\
354 \\
400\end{array}$ & $\begin{array}{l}260 \\
225 \\
354 \\
400\end{array}$ & $\begin{array}{l}250 \\
225 \\
354 \\
408\end{array}$ & $\begin{array}{l}200 \\
225 \\
354 \\
400\end{array}$ & $\begin{array}{l}250 \\
225 \\
.354 \\
400\end{array}$ & $\begin{array}{l}220 \\
225 \\
354 \\
406\end{array}$ & $\begin{array}{l}200 \\
225 \\
354 \\
400\end{array}$ & $\begin{array}{l}280 \\
225 \\
335 \\
400\end{array}$ \\
\hline 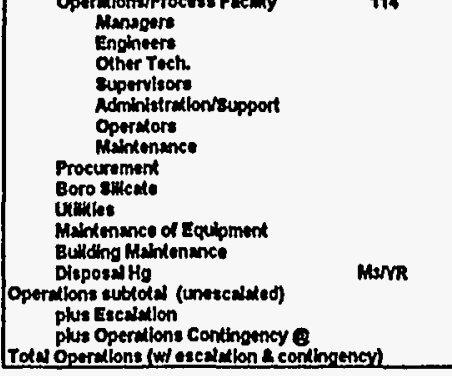 & 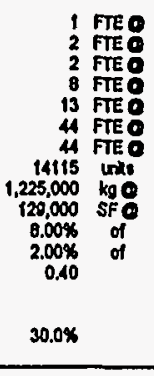 & 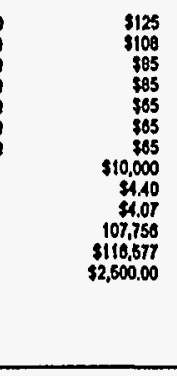 & 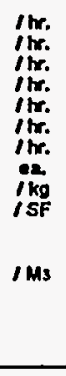 & $\begin{array}{r}200 \\
449 \\
354 \\
1,144 \\
1,758 \\
5,490 \\
5,909 \\
7,050 \\
5,390 \\
525 \\
8,020 \\
2,332 \\
11,302 \\
132,172 \\
22,042 \\
05,516 \\
\end{array}$ & $\begin{array}{r}200 \\
140 \\
354 \\
1,144 \\
1,758 \\
5,040 \\
5,40 \\
7,050 \\
5,390 \\
525 \\
0,620 \\
2,332 \\
1 \\
11,302 \\
13,220 \\
22,650 \\
00,100 \\
\end{array}$ & 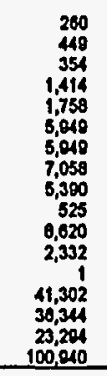 & 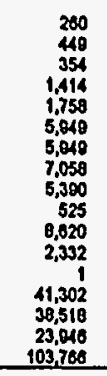 & 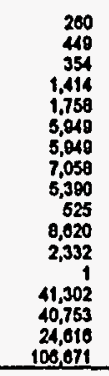 & $\begin{array}{r}200 \\
449 \\
354 \\
1,414 \\
1,756 \\
5,909 \\
3,099 \\
7,050 \\
5,390 \\
625 \\
8,020 \\
2,3032 \\
41,302 \\
43,051 \\
25,306 \\
102,058 \\
\end{array}$ & 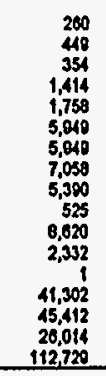 & 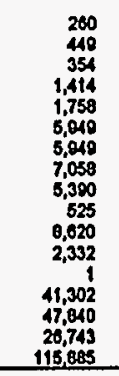 & 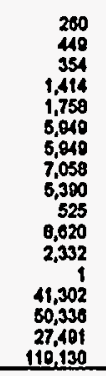 & 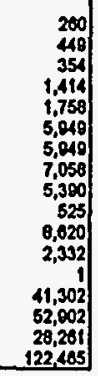 \\
\hline 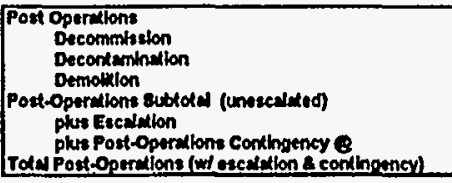 & $\begin{array}{ll}20.00 \% & \text { of } \\
5.00 \% & \text { of } \\
8.00 \% & \text { of } \\
& \\
30.0 \% & \end{array}$ & $\begin{array}{l}\text { Enghoering corts } \\
\text { Pro-opertiton Costs } \\
\text { Pro-operation Costs }\end{array}$ & & $\begin{array}{l}0 \\
0 \\
0 \\
0 \\
\end{array}$ & $\begin{array}{l}0 \\
0 \\
0 \\
0\end{array}$ & $\begin{array}{l}0 \\
0 \\
0 \\
0\end{array}$ & $\begin{array}{l}0 \\
0 \\
0 \\
0\end{array}$ & $\begin{array}{l}0 \\
0 \\
0 \\
0\end{array}$ & $\begin{array}{l}0 \\
0 \\
0 \\
0\end{array}$ & $\begin{array}{l}0 \\
0 \\
0 \\
0\end{array}$ & $\begin{array}{l}0 \\
0 \\
0 \\
0\end{array}$ & $\begin{array}{l}0 \\
0 \\
0 \\
0 \\
\end{array}$ & $\begin{array}{l}0 \\
0 \\
0 \\
0\end{array}$ \\
\hline 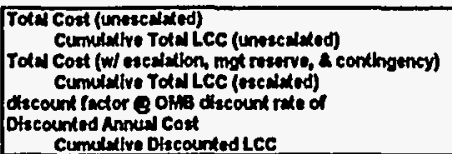 & $0.30 \%$ & for ereaded costs & & 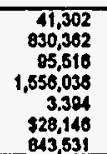 & 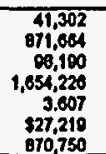 & 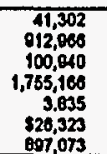 & $\begin{array}{r}41,302 \\
054,207 \\
103,760 \\
1,050,632 \\
4,070 \\
\$ 25,450 \\
922,529\end{array}$ & 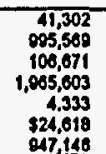 & 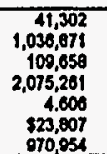 & 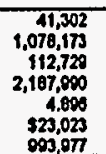 & $\begin{array}{r}11,302 \\
1.119,475 \\
115,605 \\
2,303,675 \\
5,205 \\
332,205 \\
1,010,262\end{array}$ & 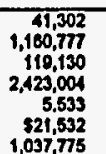 & 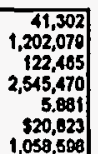 \\
\hline
\end{tabular}




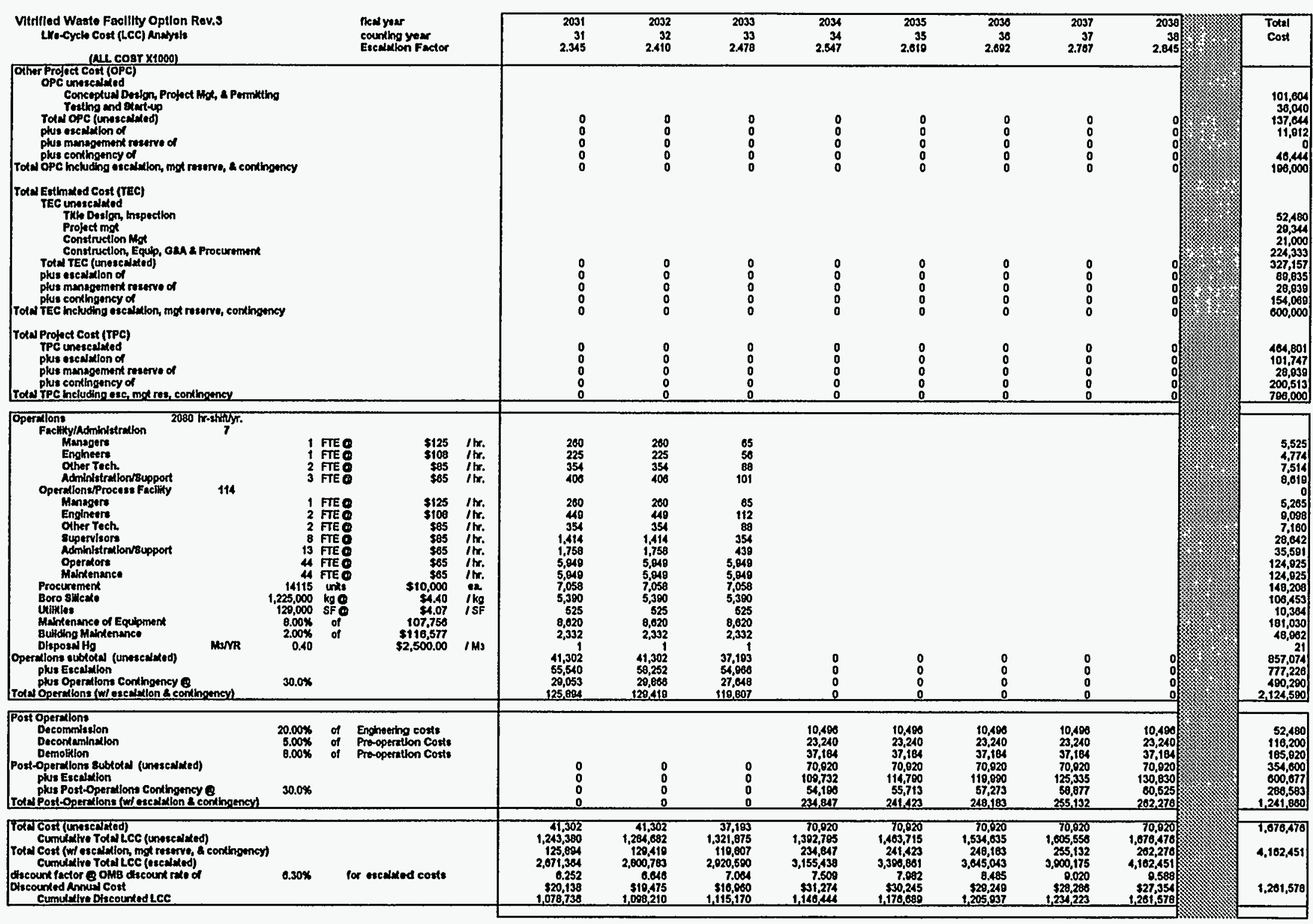




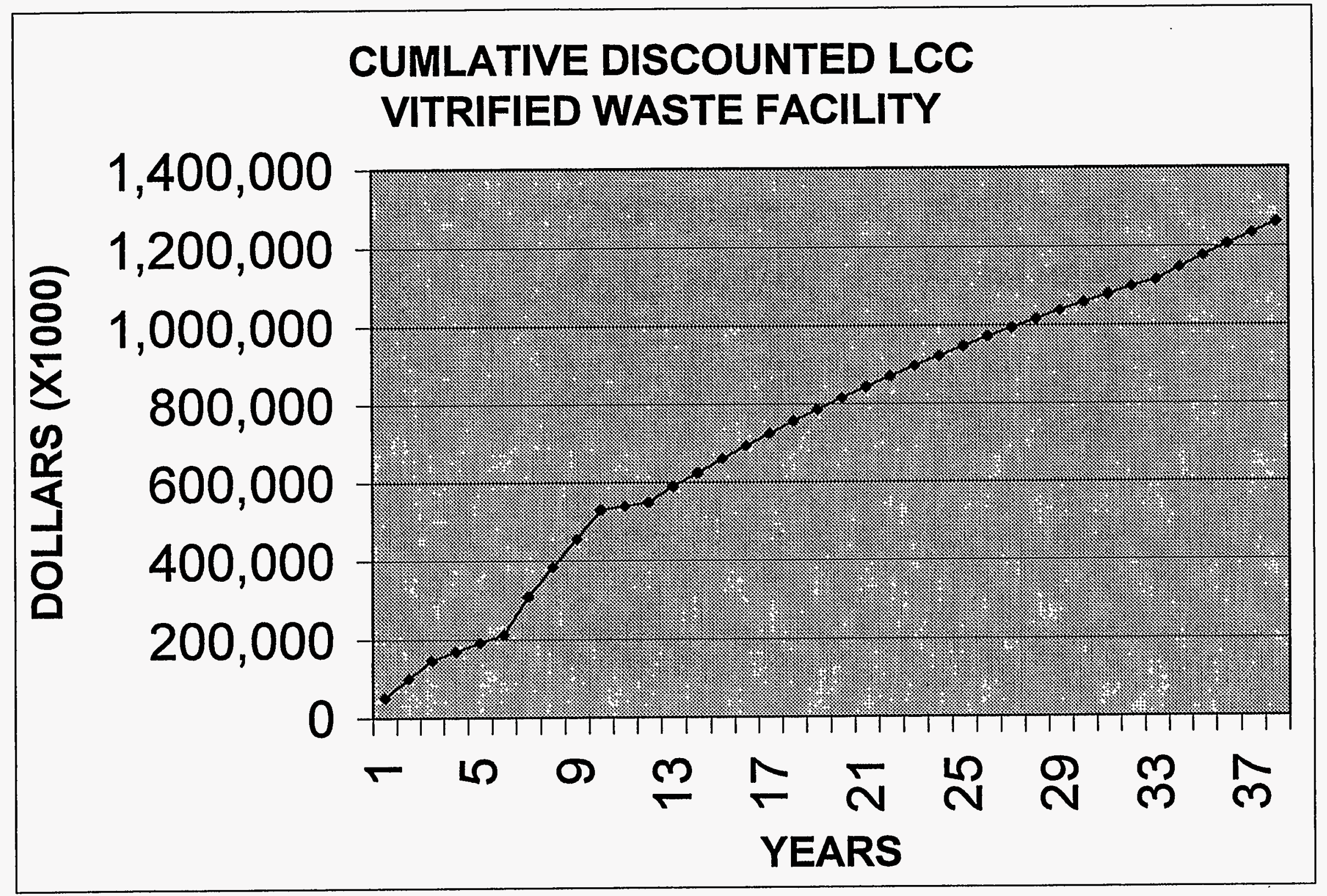




\section{TOTAL ANNUAL COST (escalated) VITRIFIED WASTE FACILTY}

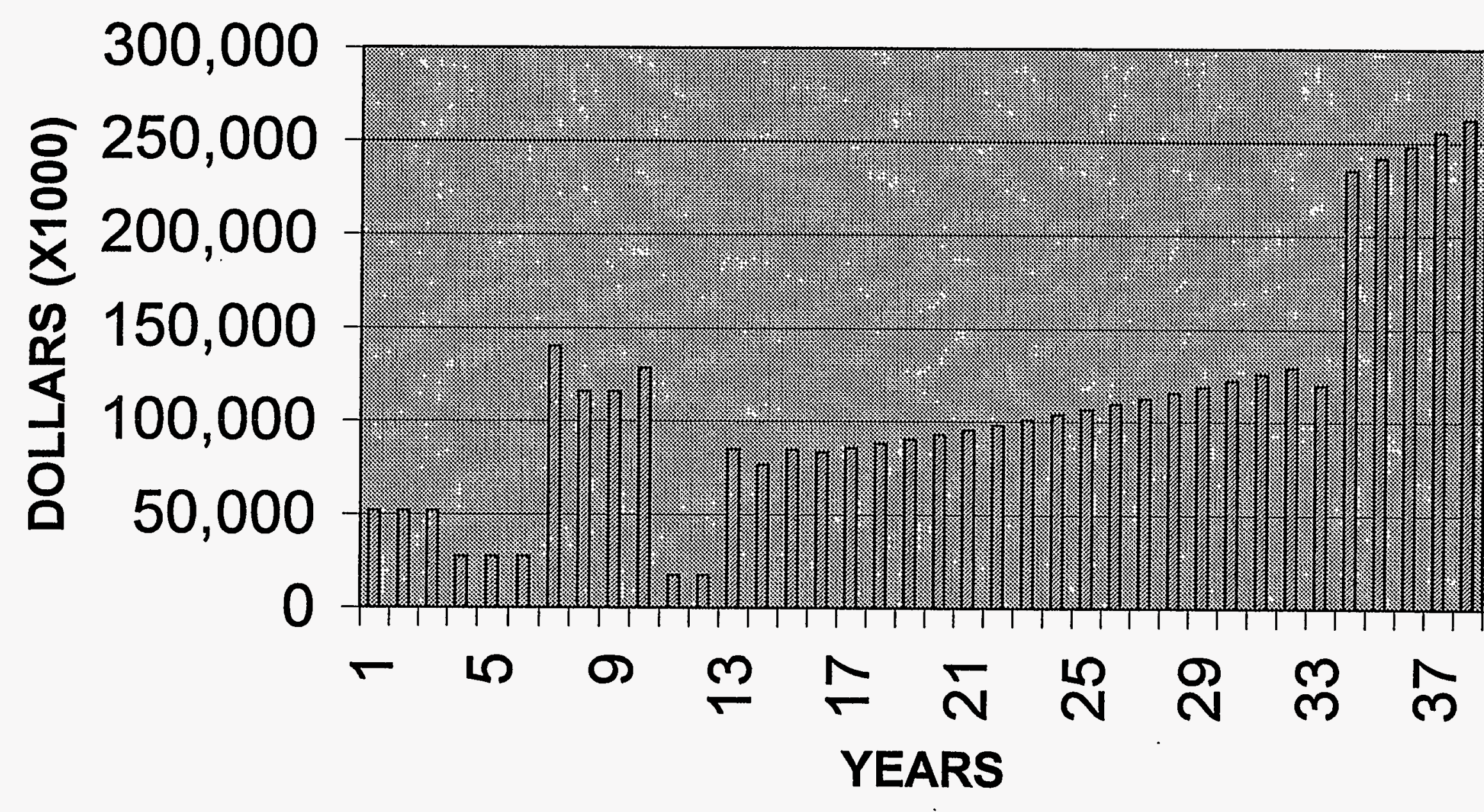




\begin{tabular}{|c|c|c|c|c|c|c|c|c|c|}
\hline & & & & & & & & \multicolumn{2}{|c|}{ VWO VITRIFIC } \\
\hline ID & Task Name & 1997 & 1998 & 1999 & 2000 & 2001 & 2002 & 2003 & 2004 \\
\hline 1 & VWO VITRIFICATION FACILITY & & & & & & & & \\
\hline 2 & CONCEPTUAL DESIGN & & & & & $6 / 4-$ & SII & $11 / 29$ & \\
\hline 3 & ADVANCED CONCEPTUAL DESIGN & & & & & & & & SIDण \\
\hline 4 & PM FOR PROJECT DEVELOPMENT & & & & & $6 / 4 \times 5$ & & & 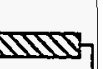 \\
\hline 5 & PERMITTING & & & & & & बISTI & & 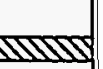 \\
\hline 6 & PROJECT MANAGEMENT & & & & & & & & $5 / 31$ \\
\hline 7 & TITLE DESIGN & & & & & & & & $5 / 31$ \\
\hline 8 & CONSTRUCTION & & & & & & & & \\
\hline 9 & SO TEST \& STARTUP & & & & & & & & \\
\hline 10 & START PROCESSING & & 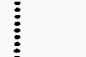 & & & & & & \\
\hline 11 & OPERATIONS & & & & & & & & \\
\hline 12 & D\&D & & & & & & & & \\
\hline
\end{tabular}




\section{ON FACILITY}

\begin{tabular}{|l|l|l|l|l|l|l|l|l|l|l|l|}
2005 & 2006 & 2007 & 2008 & 2009 & 2010 & 2011 & 2012 & 2013 & 2014 & 2015 \\
\hline
\end{tabular}

$12 / 2$

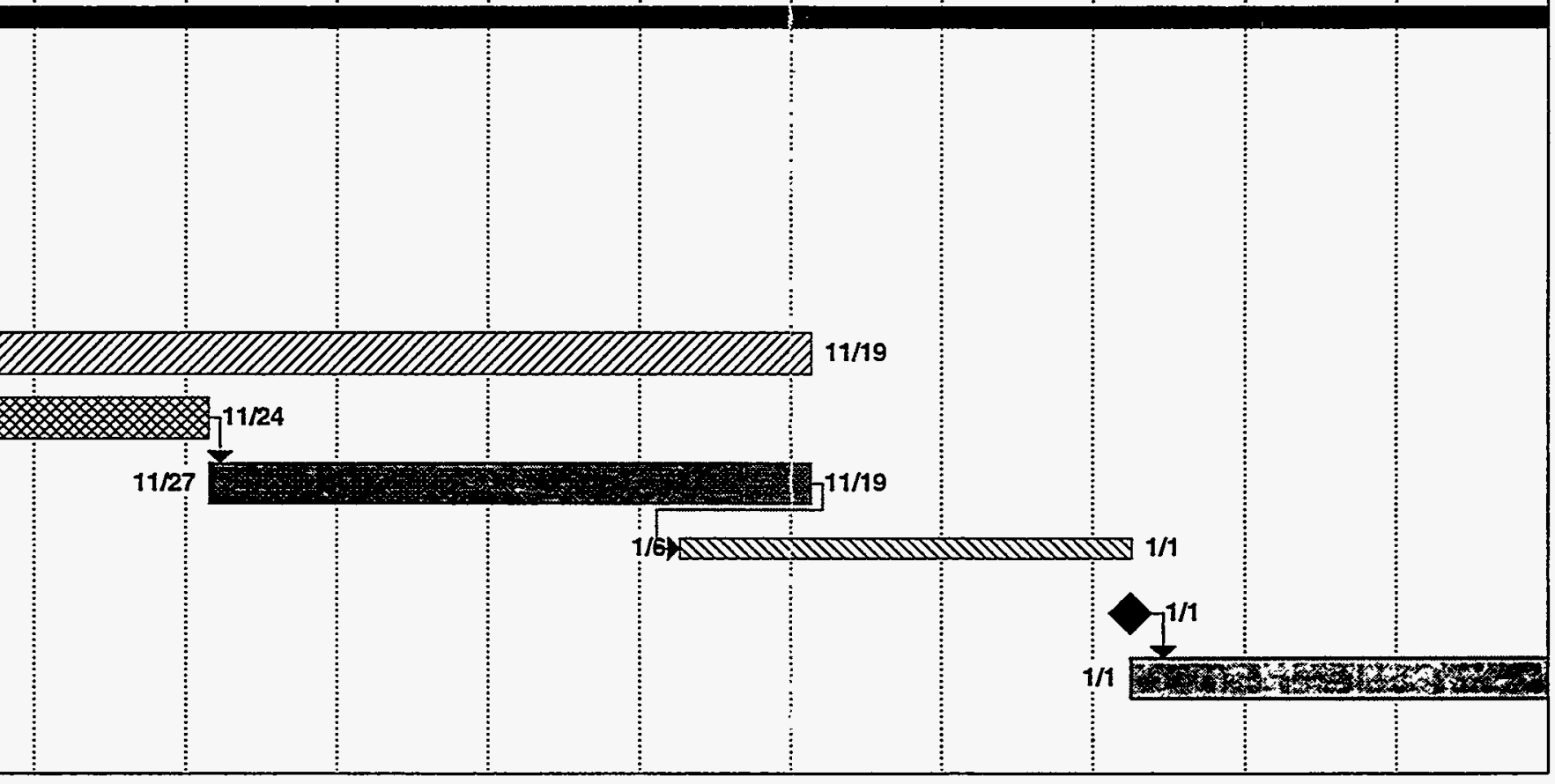




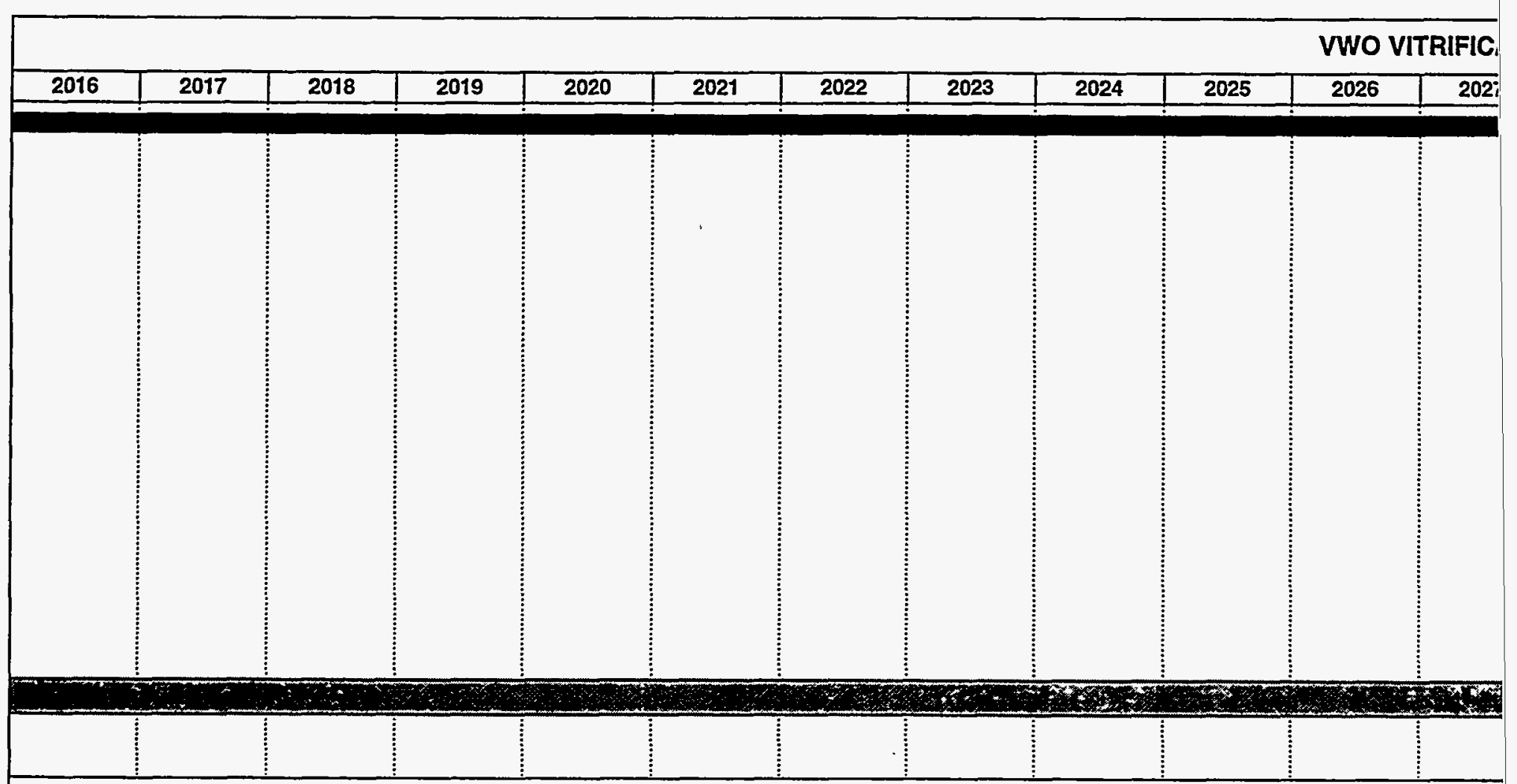




\section{ON FACILITY}

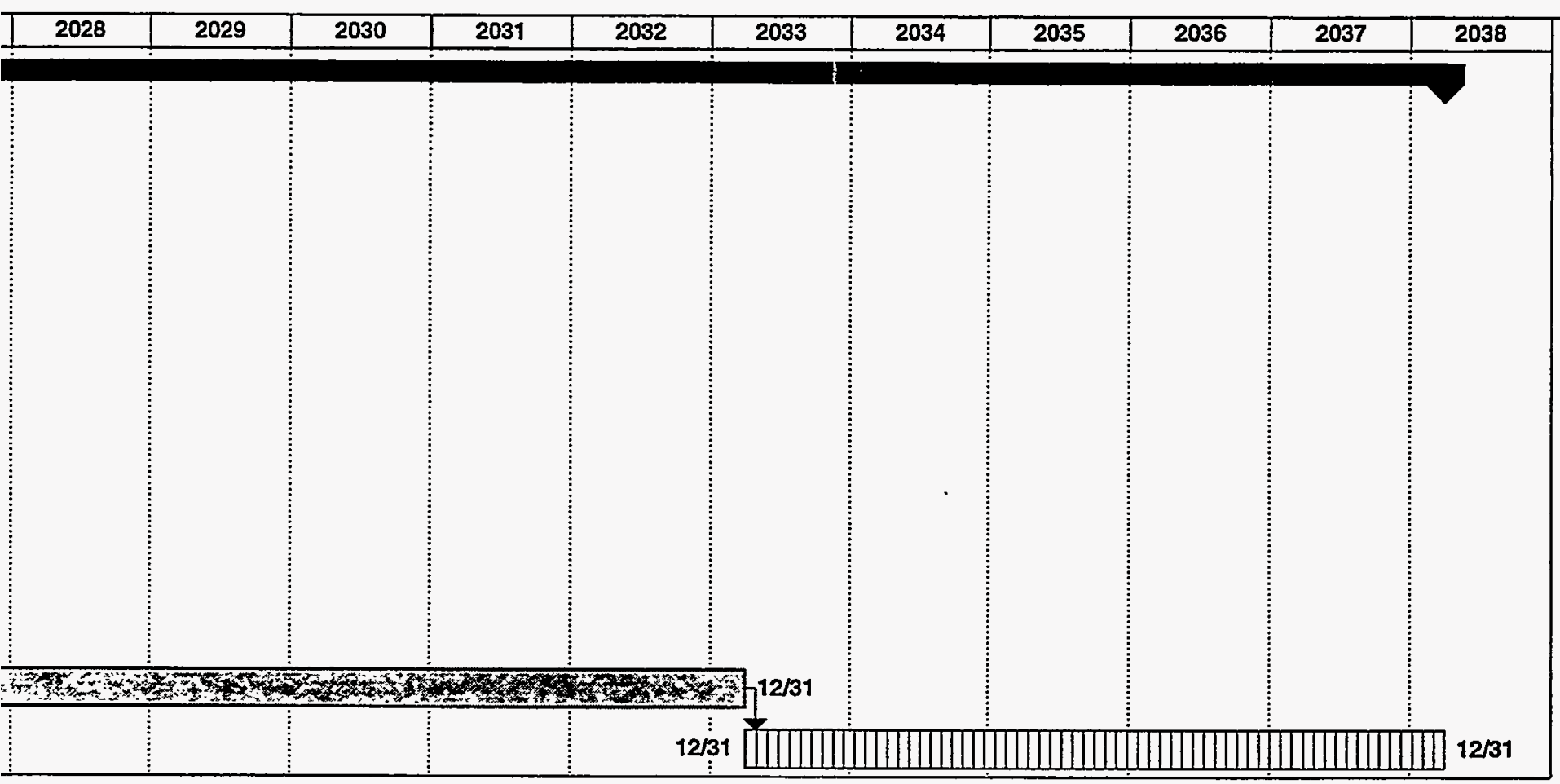




\section{Appendix G}

Risk Assessment Data Sheets 


\section{Risk Assessment - Data Sheet}

\section{Risk Type ๑ Project OTechnical OESH}

RISK:

It may not be possible to fill canisters with 0.72 cubic meters of product glass. (See assumption S-4).
PREVENTIVE PLANS:

None

\section{PROBABLE CAUSE(S):}

Shutoff of the glass pour is not as immediate as shutting off a flow of tap water. With changing glass compositions, the viscosity of the poured glass is likely to vary, meaning that it may not be possible for achieve a repeatable pour volume. In addition, the glass wil contract slightl on cooling.

\section{CONSEQUENCES IF RISK NOT RESOLVED:}

More than the design basis 14,115 canisters of glass will be produced. This implies that more storage space will have to be built.

\section{PROBABILITY}

\begin{tabular}{|ll|}
\hline$\bigcirc$ & High (3) \\
$\bigcirc$ & Medium (2) \\
$\bigcirc$ & Low (1) \\
\hline
\end{tabular}

\section{IMPACT:}

\begin{tabular}{ll}
$\bigcirc$ & High (3) \\
$\odot$ & Medium (2) \\
$\bigcirc$ & Low (1) \\
\hline
\end{tabular}

\section{Risk $=4$}

Risk $=$ Probability $\times$ Impact

\section{Probability Definition}

High - Likely to occur during the project.

Medium - Has the potential to occur during the project.

Low - Has little potential to occur during the project.

Impact Definition

High - Likely to cause significant disruption of schedule, increase in cost, or degradation of performance.

Medium - Has the potential to cause some disrutpion to schedule, increase in cost, or degradation of performance.

Low - Has little potential to cause disruption to schedule, increase in cost, or degradation of performance.

\section{CONTINGENCY PLAN(S) IF RISK IS REALIZED:}

The design of the interim storage facility is modular, so that additional capacity could be added, if necessary.

\section{TRIGGER POINT(S) FOR EARLY RISK IDENTIFICATION:}

It should be possible to conduct pouring tests with surrogate material and a melter of similar design, so that the performance of the pouring operation can be evaluated. This work should be done before the end of conceptual design. 


\section{Risk Assessment - Data Sheet}

Risk Type ๑ Project OTechnical OESH

\section{RISK:}

Canisters do not meet EPANRC/DOT requirements for transportation and disposal at MGDS and must be recycled. (See assumption S-9)

\section{PREVENTIVE PLANS:}

Verify applicability of delisting petitions in the States involved. Also, design studies will be needed to provide assurance that the canister welding techniques are suitable.

\section{PROBABLE CAUSE(S):}

Delisting petitions are now reviewed and approved by EPA at the regional level. It is possible that States outside of Region 10 may not recognize the validity of a delisting petition granted by EPA in Region 10 . In addition to the regulatory status of the waste, another cause could be the failure of the canister welds to meet drop test requirements

\section{PROBABILITY}

$\bigcirc$ High (3)

$\bigcirc$ Medium (2)

- Low (1)
IMPACT:

$\begin{array}{ll}\bigcirc & \text { High (3) } \\ \bigcirc & \text { Medium (2) } \\ \bigcirc & \text { Low (1) }\end{array}$

\section{CONSEQUENCES IF RISK NOT RESOLVED:}

Waste cannot be shipped out of Idaho as required under the Settlement Agreement.

\section{Risk $=3$}

Risk $=$ Probability $\times$ Impact

\section{Probability Definition}

High - Likely to occur during the project.

Medium - Has the potential to occur during the project.

Low - Has little potential to occur during the project.

Impact Definition

High - Likely to cause significant disruption of schedule, increase in cost, or degradation of performance.

Medium - Has the potential to cause some disrutpion to schedule, increase in cost, or degradation of performance.

Low - Has little potential to cause disruption to schedule, increase in cost, or degradation of performance.

\section{CONTINGENCY PLAN(S) IF RISK IS REALIZED:}

Additional delisting activities will be undertaken, if necessary. The aacceptability of $10^{\prime} \times 2^{\prime}$ canisters will be verified prior to use.

\section{TRIGGER POINT(S) FOR EARLY RISK IDENTIFICATION:}

The delisting petition process will be undertaken well before conceptual design. At the time the process is begun, discussions will take place with regulators in Nevada and other States outside EPA Region 10 through which the waste might travel. Also, design studies and drop test programs will be undertaken to verify compliance of full canisters with DOT and NRC requirements. 
Risk Assessment - Data Sheet

Risk Type

○ Project

Technical

OESH

RISK:

Physical security requirements cannot be met with typical access controls used at the ICPP (card readers, alarmed doors, etc.). (See assumption S-5)

\section{PREVENTIVE PLANS:}

Review of DOE orders and NRC regulations related to safeguards and security.

\section{PROBABLE CAUSE(S):}

Changes in regulation

\section{CONSEQUENCES IF RISK NOT RESOLVED:}

Startup of the facility would be delayed.

\section{PROBABILITY}

High (3)

Medium (2)

(-) Low (1)
IMPACT:

\begin{tabular}{ll}
$\bigcirc$ & High (3) \\
$\odot$ & Medium (2) \\
$\bigcirc$ & Low (1) \\
\hline
\end{tabular}

\section{Risk $=2$}

Risk $=$ Probability $\times$ Impact

\section{Probability Definition}

High - Likely to occur during the project.

Medium - Has the potential to occur during the project.

Low - Has little potential to occur during the project.

\section{Impact Definition}

High - Likely to cause significant disruption of schedule, increase in cost, or degradation of performance.

Medium - Has the potential to cause some disrutpion to schedule, increase in cost, or degradation of performance.

Low - Has little potential to cause disruption to schedule, increase in cost, or degradation of performance.

\section{CONTINGENCY PLAN(S) IF RISK IS REALIZED:}

Security requirements for the project will be changed to meet any new regulations

\section{TRIGGER POINT(S) FOR EARLY RISK IDENTIFICATION:}

Security requirements will be reviewed at the start of each phase of design and will be included in the systems requirements document. 


\section{Risk Assessment - Data Sheet}
Risk Type
(-) Project
OTechnical
OESH

\section{RISK:}

The VF Exhaust stack shielded probe system may not be an acceptable substitute for an isokinetic sampling system. (See assumption S-7)

\section{PREVENTIVE PLANS:}

Stay in contact with NWCF operations personnel and environmental compliance personnel so that any change in availability of existing systems and/or changes in regulatory requirements can be accommodated during project planning.

\section{PROBABLE CAUSE(S):}

MACT or other regulatory requirements require isokinetic. sampling.

\section{CONSEQUENCES IF RISK NOT RESOLVED:}

Some new off-gas monitoring equipment will have to be added to the project scope.

\section{PROBABILITY}

High (3)

$\bigcirc$ Medium (2)

(-) Low (1)

\section{IMPACT:}

High (3)

Medium (2)

Low (1)

\section{CONTINGENCY PLAN(S) IF RISK IS REALIZED:}

Project scope and estimate will be modified to inciude a new stack and appropriate monitoring equipment.

\section{Risk $=1$}

Risk = Probability $\times$ Impact

\section{Probability Definition}

High - Likely to occur during the project

Medium - Has the potential to occur during the project.

Low - Has little potential to occur during the project.

Impact Definition

High - Likely to cause significant disruption of schedule, increase in cost, or degradation of performance.

Medium - Has the potential to cause some disrutpion to schedule, increase in cost, or degradation of performance.

Low - Has little potential to cause disruption to schedule, increase in cost, or degradation of performance.

\section{TRIGGER POINT(S) FOR EARLY RISK} IDENTIFICATION:

This issue should be resolved before conceptual design is complete. 


\section{Risk Assessment - Data Sheet}

Risk Type O Project OTechnical OESH

RISK:

Amount of calcine to be treated is significantly different from current estimates. (See assumption S-3)

\section{PREVENTIVE PLANS:}

None

\section{PROBABLE CAUSE(S):}

Poor initial estimates

\section{CONSEQUENCES IF RISK NOT RESOLVED:}

System will not have appropriate capacity.

\section{PROBABILITY}

High (3)

Medium (2)

(C) Low (1)
IMPACT:

$\begin{array}{ll}\bigcirc & \text { High (3) } \\ \bigcirc & \text { Medium (2) } \\ \odot & \text { Low (1) }\end{array}$

CONTINGENCY PLAN(S) IF RISK IS REALIZED:

Current proposed operating scheme has $50 \%$ down time. If the amount of calcine is larger than expected, it will likely be possible to operate more than 180 days per year. If the amount of calcine to be processed is lower than current estimates, the feed rate to the melter can be reduced without significant impact.

\section{Risk $=1$}

Risk $=$ Probability $x$ Impact

Probability Definition

High - Likely to occur during the project.

Medium - Has the potential to occur during the project.

Low - Has little potential to occur during the project.

Impact Definition

High - Likely to cause significant disruption of schedule, increase in cost, or degradation of performance.

Medium - Has the potential to cause some disrutpion to schedule, increase in cost, or degradation of performance.

Low - Has little potential to cause disruption to schedule, increase in cost, or degradation of performance.

\section{TRIGGER POINT(S) FOR EARLY RISK} IDENTIFICATION:

Update calcine quantity estimates prior to the start of Title 1 design. 


\title{
Risk Assessment - Data Sheet
}

\author{
Risk Type \\ (Project \\ Technical \\ ESH
}

\section{RISK:}

Precipitation of soluble mercury (in scrubber blowdown) with suifide salt does not meet the LDR Requirement for amalgamation. (See assumption S-8)

\section{PREVENTIVE PLANS:}

Discussions will be held with regulatory authorities prior to conceptual design. If the proposed treatment is unacceptable, alternative processing can be included in the design.

\section{PROBABLE CAUSE(S):}

The chemical form of the precipitated mercury sulfide is not considered equivalent to an amalgam of elemental mercury with sulfur.

\section{CONSEQUENCES IF RISK NOT RESOLVED:}

A waste will be generated that cannot be stored for more than 1 year without further processing by others.

\section{PROBABILITY}

High (3)

$\bigcirc$ Medium (2)

(C) Low (1)

\section{IMPACT:}

\begin{tabular}{|ll|}
$\bigcirc$ & High (3) \\
$\odot$ & Medium (2) \\
$\bigcirc$ & Low (1) \\
\hline
\end{tabular}

\section{Risk $=2$}

Risk $=$ Probability $x$ Impact

Probability Definition

High - Likely to occur during the project.

Medium - Has the potential to occur during the project.

Low - Has little potential to occur during the project.

Impact Definition

High - Likely to cause significant disruption of schedule, increase in cost, or degradation of performance.

Medium - Has the potential to cause some disrutpion to schedule, increase in cost, or degradation of performance.

Low - Has little potential to cause disruption to schedule, increase in cost, or degradation of performance.

\section{CONTINGENCY PLAN(S) IF RISK IS REALIZED:}

Approval of an LDR variance can be requested from the regulatory authorities.

\section{TRIGGER POINT(S) FOR EARLY RISK IDENTIFICATION:}

This issue will be addressed during the next design phase. 


\section{Risk Assessment - Data Sheet}

Risk Type OProject OTechnical OESH

\section{RISK:}

Six frit compositions are not adequate to meet the requirements of all calcine mixtures as received. (See assumption S-2)

\section{PREVENTIVE PLANS:}

Facility design includes the capbility of adding raw glass forming ingredients (e.g., silicon dioxide, boron oxide, sodium carbonate) in any combination needed to produce acceptable glass

\section{PROBABLE CAUSE(S):}

Compositions of the calcine might vary significantly from currentiy available information.

\section{CONSEQUENCES IF RISK NOT RESOLVED:}

Some quantitiy of product glass does not meet disposal site WAC.

\section{PROBABILITY}
High (3)
$\bigcirc$ Medium (2)
(-) Low (1)

\section{IMPACT:}
High (3)
Medium (2)
- Low (1)

\section{Risk $=1$}

Risk $=$ Probability $x$ Impact

\section{Probability Definition}

High - Likely to occur during the project.

Medium - Has the potential to occur during the project.

Low - Has little potential to occur during the project.

\section{Impact Definition}

High - Likely to cause significant disruption of schedule, increase in cost, or degradation of performance.

Medium - Has the potential to cause some disrutpion to schedule, increase in cost, or degradation of performance.

Low - Has little potential to cause disruption to schedule, increase in cost, or degradation of performance.

\section{CONTINGENCY PLAN(S) IF RISK IS REALIZED:}

Design of the facility accommodates custom glass formulations, if the need arises.

\section{TRIGGER POINT(S) FOR EARLY RISK} IDENTIFICATION:

Development work and additional calcine characterization should be undertaken before conceptual design begins. 


\section{Risk Assessment - Data Sheet}
Risk Type
Project
() Technical
$\mathrm{OESH}$

\section{RISK:}

Production of acceptable product glass requires the grinding of calcine to reduce its particle size range prior to addition to the melter. (See assumption S-6)

\section{PREVENTIVE PLANS:}

A development program adequate to resolve this question will be completed prior to the start of conceptual design.

\section{CONSEQUENCES IF RISK NOT RESOLVED:}

\section{PROBABLE CAUSE(S):}

The calcine is a complex mixture of minerals, some of which may not adequately melt or dissolve under planned melter operating conditions. The likelyhood of such a situation is enhanced if calcine particles are large.

If this issue is not resolved, it is possible that the melter will produce glass that does not meet disposal site waste acceptance criteria.

\section{CONTINGENCY PLAN(S) IF RISK IS REALIZED:}

\section{PROBABILITY}

$\begin{array}{ll}\bigcirc & \text { High (3) } \\ \bigcirc & \text { Medium (2) } \\ \odot & \text { Low (1) }\end{array}$

Risk $=3$

Risk $=$ Probability $\times$ Impact

Probability Definition

High - Likely to occur during the project.

Medium - Has the potential to occur during the project.

Low - Has littie potential to occur during the project.

\section{Impact Definition}

High - Likely to cause significant disruption of schedule, increase in cost, or degradation of performance.

Medium - Has the potential to cause some disrutpion to schedule, increase in cost, or degradation of performance.

Low - Has little potential to cause disruption to schedule, increase in cost, or degradation of performance.

\section{TRIGGER POINT(S) FOR EARLY RISK} IDENTIFICATION:

Process development work should be initiated early enough so that this issue can be resolved prior to the start of conceptual design. 
Appendix $\mathrm{H}$

VF Project Data Sheet Supporting Data 


\section{Appendix $\mathrm{H}$ \\ VF Project Data Sheet Supporting Data}

This Appendix provides the backup information for the project data sheet in Section 8 of this report. The information is divided into five parts:

1. Construction estimates and assumptions

2. Operations estimates and assumptions

3. D\&D labor estimates

4. Other D\&D estimates and assumptions

5. Diesel emission estimates for construction, operations, and D\&D

6. Memo of conversation with S. Aitken by W. Landman, November 24, 1997

Cost information presented in the data sheet comes directly from the VF cost estimates in Appendix F. 


\begin{tabular}{|c|c|c|c|c|c|c|c|}
\hline Construction duration = & & years & & & & & \\
\hline SO testing = & & years & & & & & \\
\hline Total years $=$ & 7 & & & & & & \\
\hline Labor - use a total of & 100 & new workers/yr & & & & & \\
\hline from Dan James & & & & & & & \\
\hline & & & & & & & \\
\hline Sanitary Wastewater = & 562,500 & gal/yr $=$ & $14,903,438$ & liters (total & & & \\
\hline (based on 25 gallperson-day an & dd 225 days/yea & ar of construction & & & & & \\
\hline $\begin{array}{l}\text { (Benefield, LD and C.W. Randal } \\
\text { wastewater generation }=15-30\end{array}$ & $\begin{array}{l}\text { all, Biological Pr } \\
\text { gal/day-person }\end{array}$ & $\begin{array}{l}\text { rocess Design for } \\
\text { n) }\end{array}$ & Wastewater Treat & tment, InPrint, In & nc., 1987, p. & $104-$ & \\
\hline & & & & & & & \\
\hline Water used for dust control = & 2000 & gallwk = & 605,600 & liters (total) & & & \\
\hline (assumes dust control required 2 & 20 weeks/yT...F & R. Kimmitt) & & & & & \\
\hline & & & & & & & \\
\hline Electrical usage assumed to be & $3,000 \mathrm{kWh}$ (frc & om John Duggan & & & & & \\
\hline $\begin{array}{r}156 \\
\end{array}$ & MWh/yr & & & & & & \\
\hline $\begin{array}{l}\text { Assume } 3 \text { gallons of lubricating } \\
\text { hours of operation of heavy equi }\end{array}$ & $\begin{array}{l}\text { oil and hydrauli } \\
\text { ipment }=\end{array}$ & lic fiuid generated & I for every 60 & 1,417 & liters (total) & & \\
\hline Square footage $=$ & 175,878 & sg.ft $=$ & 16,340 & $\mathrm{~m}^{2}$ & & & \\
\hline (Stephanie Austed, 1/12/98) & & & & & & & \\
\hline & & & & & & & \\
\hline Acres disturbed = & 115,560 & sq.ft $=$ & 10,736 & $m^{2}=$ & 2.7 & acres (prev & jous) \\
\hline (Stephanie Austed, 1/12/98) & & & & & & & \\
\hline & & & & & & & \\
\hline Heavy equipment $=$ & 3 vehicles@6 & $624 \mathrm{hrs} / \mathrm{yr}$ during & construction = & 7,488 & hrs total & & \\
\hline Equipment fuel usage (see http: & :/lwww/deere.cc & om/ind $=$ & & 6 & gal/hr & & \\
\hline Total heavy equipment fuel usag & $g e=$ & 44928 & gal $=$ & 170,052 & liters (total) & & \\
\hline & & & & & & & \\
\hline Dust during construction $=1.2^{\prime} t$ & tons/month-acr & $\mathrm{re}=$ & 153 & tons (total) & & & \\
\hline (from USEPA Office of Ar Qualit & Ty Planning and & d Standards) & & & & & \\
\hline & & & & & & & \\
\hline Construction costs are from cap & oital cost estime & ate (D. James) & & & & & \\
\hline Air emissions from fuel usage ar & re based on the & e diesel emission & is soreadsheet & & & & \\
\hline Aur emisslons from tuel usage ar & re Dased on une & e olesel emission & is spreaasneet. & & & & \\
\hline Air emissions during SO \& start- & up testing are & based on non-ra & dioactive operation & is for 3 years: & & & \\
\hline Flow rate $=$ & $5,234,540$ & $\mid \mathrm{bs} / \mathrm{yr}=$ & 7,852 & tons (total) & & & \\
\hline (based on 250 scfm, 24 hours/d & day for 180 day & s/yr) & & & & & \\
\hline & & & & & & & \\
\hline Construction trash $=$ & 6,200 & yd3 (total) = & & 4,742 & $\mathrm{~m}^{3}$ (total) & & \\
\hline (Use 15.5 yd3/yr per capita. This & is is twice the $\mathrm{g}$ & jeneration rate of & trash from site ope & erations) & & & \\
\hline Hazardous waste generation $=$ & 275 & gal/week = & & 217 & $m^{3}$ (total) & & \\
\hline (based on an assumed generat & ion rate of 555 & -gallon drums of & waste per week) & & & & \\
\hline & & & & & & & \\
\hline Hazardous waste storage $=$ & 3300 & gal = & 13 & $\mathrm{~m}^{3}$ & & & \\
\hline (Assume waste is accumulated & for 12 weeks [ & [ 84 days] in a 90 & day accumulation a & area, then pickec & d up & & \\
\hline & & & & & & & \\
\hline 1 man-year of labor $=$ & 1800 & manhours & & & & & \\
\hline & & & & & & & \\
\hline \begin{tabular}{|l|} 
SO testing liquid effluent $=$ \\
\end{tabular} & $2,514,240$ & Ibs. total $=$ & & $1,142,425$ & liters (total) & & \\
\hline (based on scrubber blowdown ra & ate of $194 \mathrm{lbs} . \Omega$ & hr. for 24 hours/c & day and 180 days $p$ & per year) & & & \\
\hline & & & & & & & \\
\hline Hazardous waste (SO testing) = & & 4.2 & $\mathrm{~m}^{3}$ (total) & & & & \\
\hline (based on an assumed 50 cu.ft. & of spent activa & ated carbon/yr) & & & & & \\
\hline
\end{tabular}




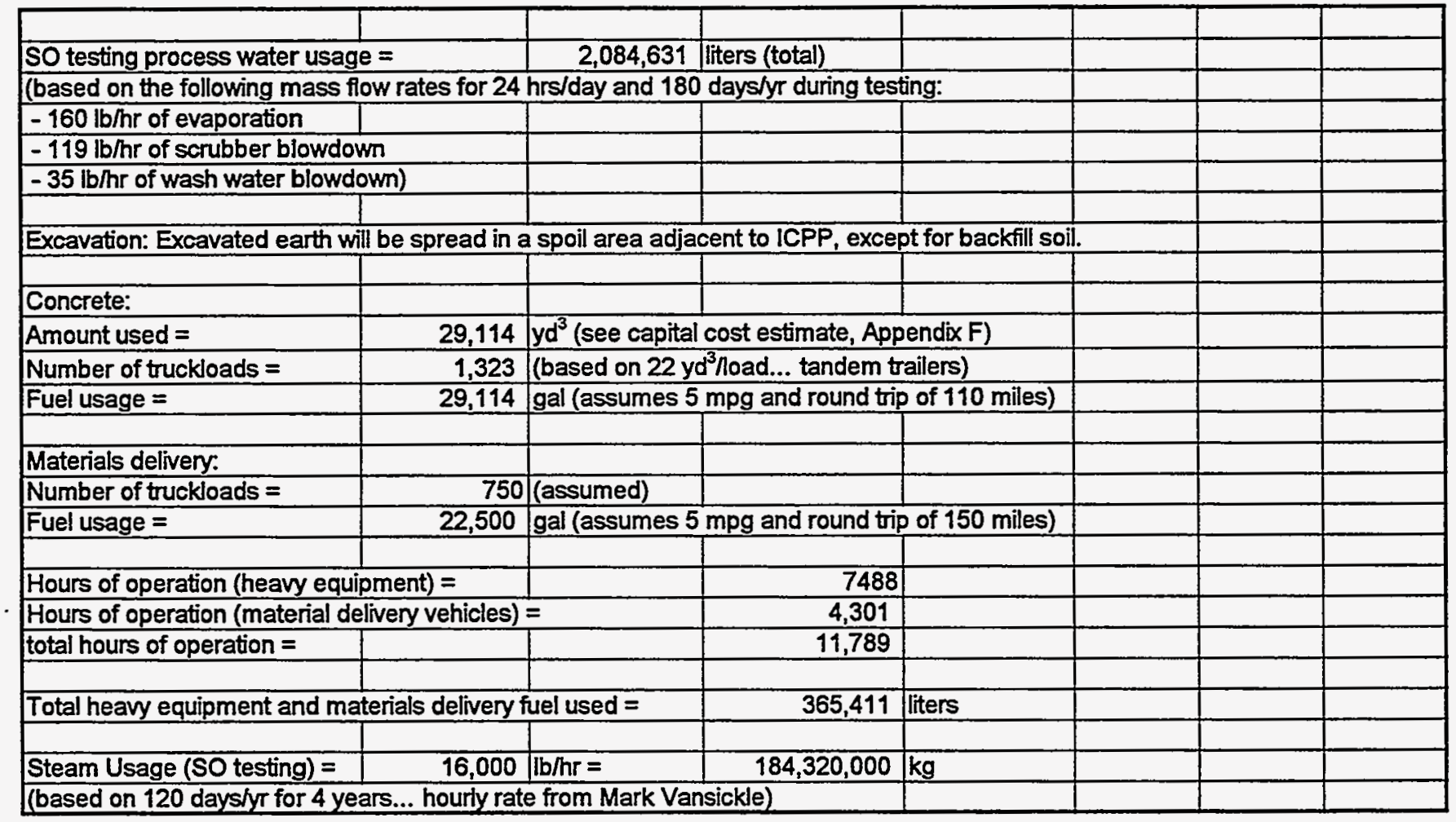




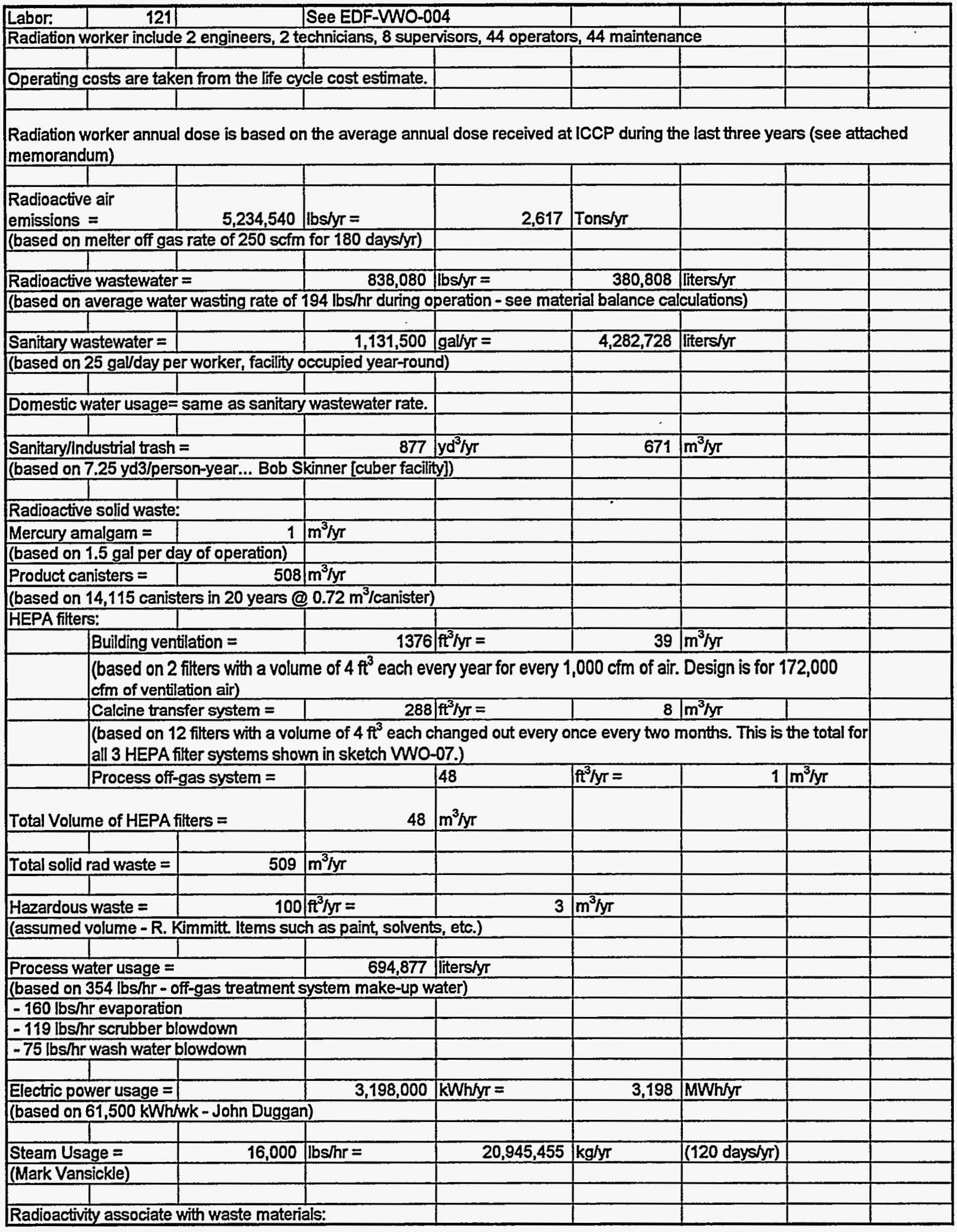




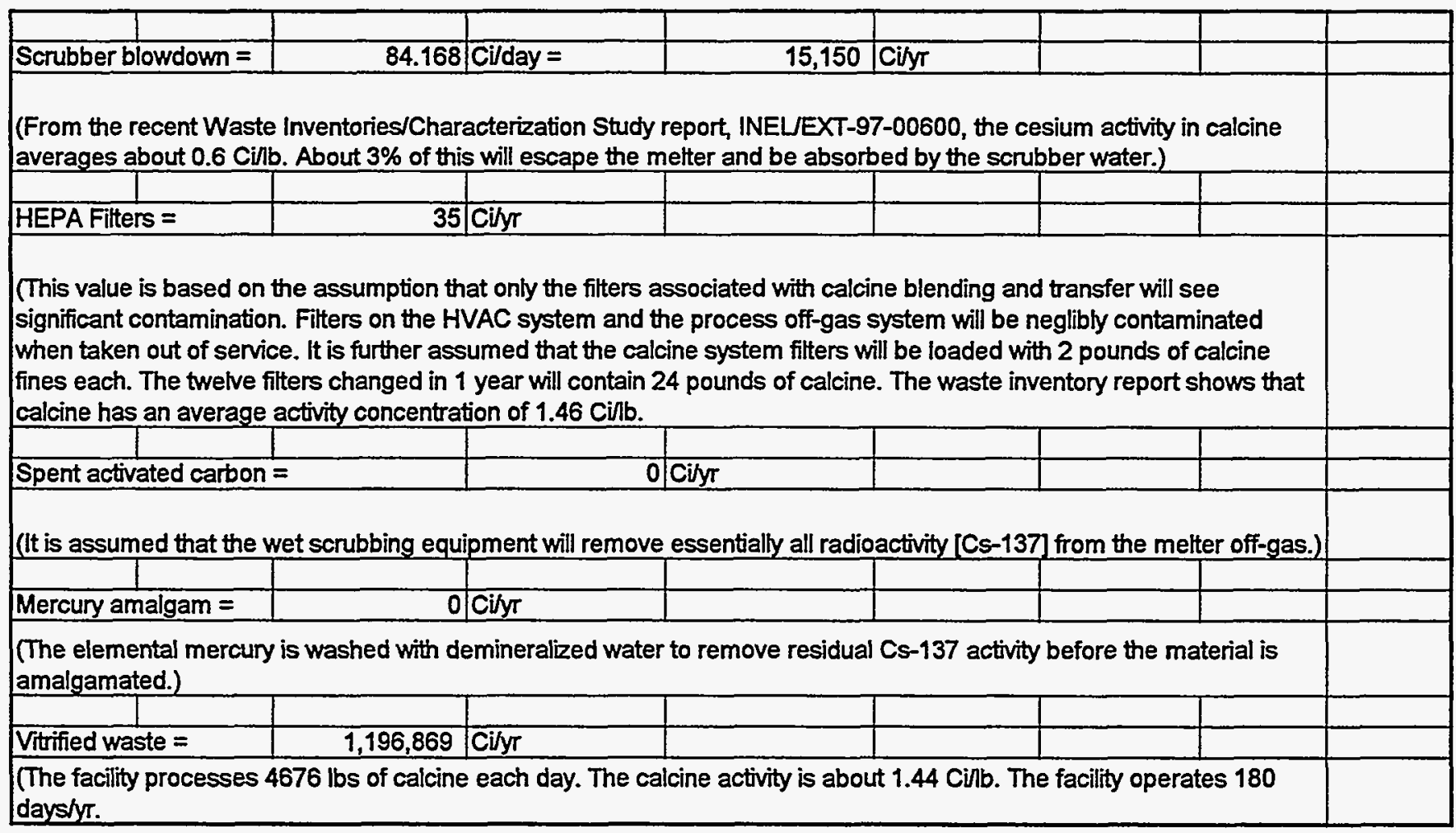


D\&D Labor

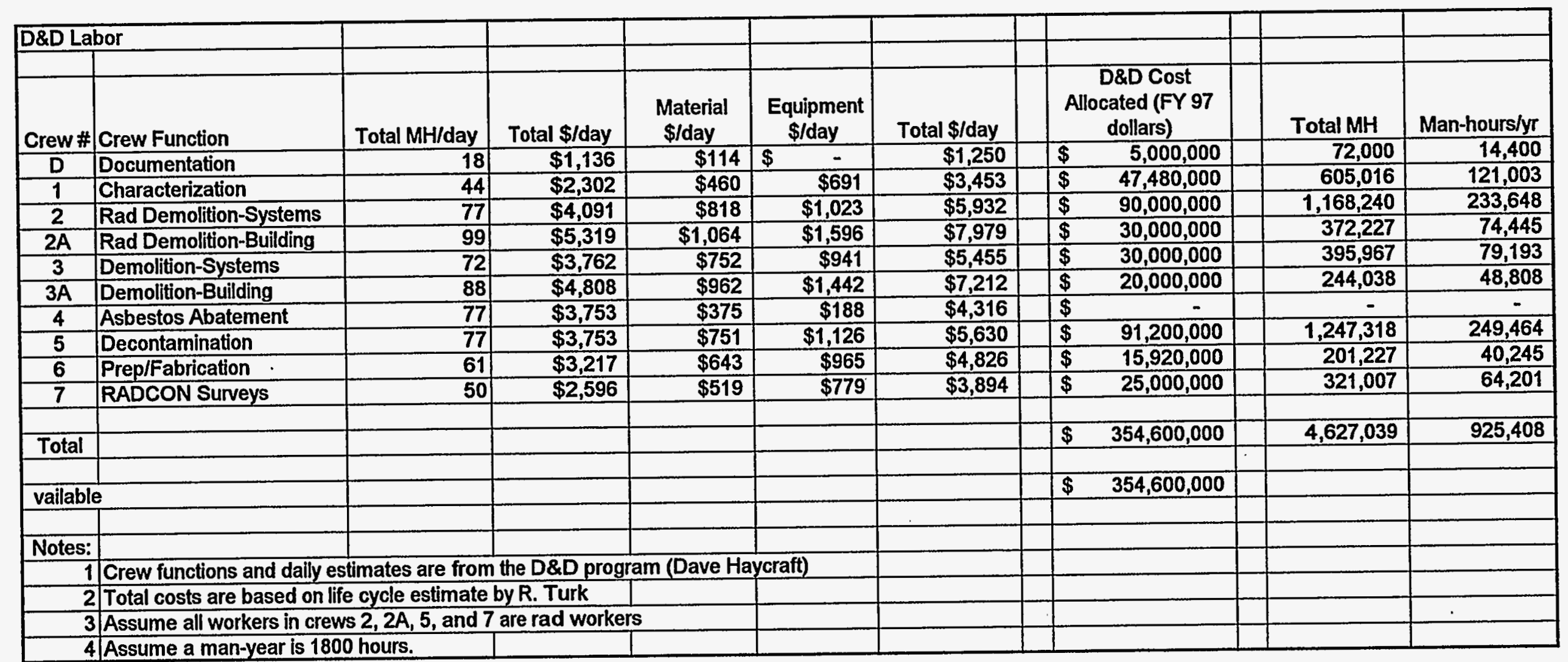




\begin{tabular}{|c|c|c|c|c|c|c|}
\hline Duration of $\mathrm{D} \& \mathrm{D}=$ & & years & & & & \\
\hline Heavy Equipment & & \#Uced & Hours/dav & Davshuk & Whatur & Hourstur \\
\hline & Mobile Crane & II & Thencos & 4 & Ponsen & 540 \\
\hline & Roll-Off Truck & 5 & 8 & 5 & 45 & 9,000 \\
\hline & Dozer & 2 & 5 & 5 & 45 & 2,250 \\
\hline & Loader & 5 & 8 & 5 & 45 & 9,000 \\
\hline & $\begin{array}{l}\text { Scabbler (w/ } \\
\text { Vacuum } \\
\text { System) }\end{array}$ & 3 & 8 & 5 & 45 & 5,400 \\
\hline & $\begin{array}{l}\text { Pneumatic } \\
\text { Ram }\end{array}$ & 1 & 4 & 4 & 45 & 720 \\
\hline & $\begin{array}{l}\text { Demolition } \\
\text { Machine } \\
\text { (Remote } \\
\text { Control) } \\
\end{array}$ & 2 & 4 & 3 & 45 & 1,080 \\
\hline & & & & & & \\
\hline Total hoursfyr & & & & & & 27,990 \\
\hline Total heavy equipment hol & urs $=$ & & & & & 139,950 \\
\hline $\begin{array}{l}\text { Assume each piece of eq } \\
\text { (Construction Equipment - }\end{array}$ & $\begin{array}{l}\text { juipment uses } 6 \\
\text { - hittp://unw.dee }\end{array}$ & $\begin{array}{l}\text { gallon of diesel fu } \\
\text { re.com/ind/produc }\end{array}$ & $\begin{array}{l}\text { Jel per hour. Co } \\
\text { t/product.html) }\end{array}$ & nsumption ra & ate from John De & ere Web Site \\
\hline No. of gallons of fuel used & 1 during $D$ \& $D=$ & & 839,700 & gal $=$ & $3,178,265$ & liters (total) \\
\hline Acreage disturbed is the s & ame as for cons & struction $=$ & 2.7 & acres & & \\
\hline & & & & & & \\
\hline D \& D labor requirements & are taken from & D\& D labor and $e$ & quipment spree & idsheet. & & \\
\hline & & & & & & \\
\hline$D \& D$ costs come from th & e life cycle cost & estimate. & & & & \\
\hline & & & & & & \\
\hline Assume each roll-off truck & makes 3 trips & per day to RWMC & & & & \\
\hline No. of trips $=$ & & & 15 & & & \\
\hline Miles traveled @ 12 miles & round trip= & & 180 & miles/day & & \\
\hline Decontamination solution & stored $=$ & & 2,000 & gallons & 205 & $\mathrm{~m}^{3}$ \\
\hline & & & & & & \\
\hline Daily process water usage & & & 3000 & gal/day $=$ & $11,424,375$ & liters (total) \\
\hline (washing, decon, etc.; bas & sed on 225 days & (yr) & & & & \\
\hline & & & & & & \\
\hline Domestic water usage $=$ & & $54,729,197$ & liters (total) & & & \\
\hline Sanitary wastewater = san & ne as domestic & water usage & & & & \\
\hline & & & & & & \\
\hline Assume portable HEPA s & ystems off-gas : & rate $=$ & 2000 & scfm $=$ & 130,864 & Tons (total) \\
\hline (assumes 225 days $/ y r)$ & & & & & & \\
\hline Assume daily spent decon & 7. solution $=$ & & 2000 & gal/day & $8,516,250$ & liters (total) \\
\hline (assumes 225 days/yr tota & & & & & & \\
\hline & & & & & & \\
\hline Solid Waste Generation & (factors from D & ave Kenoyer - D8 & Drogram) & & & \\
\hline Waste Type & $\begin{array}{c}\text { Factor } \\
\text { (cu.ft/sq.ft.) }\end{array}$ & Sq.Ft. in Facility & $\begin{array}{l}\text { Cu.Ft. of } \\
\text { Waste }\end{array}$ & Cu. Meters & & \\
\hline $\begin{array}{l}\text { WERF-LLW Combustible } \\
\text { PPEs }\end{array}$ & 0.167 & 175,878 & 29,372 & 832 & & \\
\hline $\begin{array}{l}\text { WERF-LLW Combustible } \\
\text { Building Debris }\end{array}$ & 0.128 & 475,878 & 22,512 & 638 & & \\
\hline $\begin{array}{l}\text { WERF-LLW } \\
\text { Compactable Building } \\
\text { Debris }\end{array}$ & 0.195 & 175,878 & 34,296 & 972 & & \\
\hline
\end{tabular}




\begin{tabular}{|c|c|c|c|c|c|}
\hline $\begin{array}{l}\text { RWMC-LLW Non- } \\
\text { Compactable Equipment }\end{array}$ & 0.513 & 175,878 & 90,225 & 2,556 & \\
\hline $\begin{array}{l}\text { RWMC-LLW Non-Compt } \\
\text { Building Debris }\end{array}$ & 0.684 & 175,878 & 120,301 & 3,408 & \\
\hline $\begin{array}{l}\text { RWMC-LLW Non-Compt } \\
\text { Concrete Rubble }\end{array}$ & 3.44 & 175,878 & 605,020 & 17.139 & $\begin{array}{l}\text { This factor is twice as large } \\
\text { as that recommended by the } \\
\text { D\&D program to account for } \\
\text { the fact that large amounts } \\
\text { of concrete are used in } \\
\text { construction of the facility. }\end{array}$ \\
\hline $\begin{array}{l}\text { RWMC-LLW Non-Compt } \\
\text { Scrap Metal }\end{array}$ & 0.778 & 175,878 & 136,833 & 3,876 & \\
\hline $\begin{array}{l}\text { RWMC-LLW } \\
\text { Asbestos/ACM Covered } \\
\text { Pipe }\end{array}$ & O & 175,878 & - & - & \\
\hline $\begin{array}{l}\text { CFA Landfill Non-Compt } \\
\text { Building Debris }\end{array}$ & 1.99 & 175,878 & 349,997 & $\mathbf{9 , 9 1 5}$ & \\
\hline $\begin{array}{l}\text { CFA Landfill Non-Compt } \\
\text { Concrete Rubble }\end{array}$ & 2.45 & 175,878 & 430,901 & 12,207 & $\begin{array}{l}\text { This factor is twice as large } \\
\text { as that recommended by the } \\
\text { D\&D program to account for } \\
\text { the fact that large amounts } \\
\text { of concrete are used in } \\
\text { construction of the facility. }\end{array}$ \\
\hline CFA Landfill Asbestos & 0 & 175,878 & - & - & \\
\hline $\begin{array}{l}\text { HWSF Hazardous Mtrls } \\
\text { (Hg/PCBs/etc) }\end{array}$ & 0.002 & 175,878 & 352 & 10 & \\
\hline Metal Recycle & 0.022 & 175,878 & 3,869 & 110 & \\
\hline$L L W=$ & & & $1,038,560$ & 29,421 & \\
\hline Non-Rad $=$ & & & 780,898 & 22,122 & \\
\hline Hazardous $=$ & & & 352 & 10 & \\
\hline Metal $=$ & & & 3,869 & 110 & \\
\hline Electric power usage = & 156,000 & kWh/yr & 156 & MWh/yr & \\
\hline \multicolumn{6}{|c|}{ (based on 3,000 kWhWwk - John Duggan) } \\
\hline \multicolumn{6}{|c|}{ Air emissions from fuel are based on the diesel emissions spreadsheet. } \\
\hline & & & & & \\
\hline 1 manyear of labor $=$ & 1800 & manhours & & & \\
\hline & & & & & \\
\hline Lube oil $=$ & 26,486 & liters (total) & & & \\
\hline \multicolumn{6}{|c|}{ (based on 3 gal for every 60 hours of operation) } \\
\hline & & & & & \\
\hline Mixed waste $=$ & 61,875 & gal (total) $=$ & 234 & m3 (total) & \\
\hline \multicolumn{6}{|c|}{ (based on an assumed 5 55-gallon drums generated per week... work only 45 weeks/yr) } \\
\hline & & & & & \\
\hline \multicolumn{6}{|c|}{ Radioactivity associated with waste materials: } \\
\hline & & & & & \\
\hline Spent decontamination sol & lution $=$ & 8,516 & $\mathrm{Ci}$ & & \\
\hline \multicolumn{6}{|c|}{ (based on an assumed average activity concentration of $1 \mathrm{uCi} / \mathrm{ml}$ ) } \\
\hline & & & & & \\
\hline Radioactive solid waste $=$ & & 294 & $\mathrm{Ci}$ & & \\
\hline \multicolumn{6}{|c|}{ (based on an assumed activity concentration of $0.01 \mathrm{uCi} / \mathrm{cc}\left[0.01 \mathrm{Ci} / \mathrm{m}^{3}\right]$ ) } \\
\hline & & & & & \\
\hline Mixed waste $=$ & & 2 & $\mathrm{Ci}$ & & \\
\hline (based on an assumed act & tivity concentrat & tion of $0.01 \mathrm{uCi} / \mathrm{cc}$ & {$\left[0.01 \mathrm{cl} / \mathrm{m}^{3} \mathrm{l}\right)$} & & \\
\hline
\end{tabular}




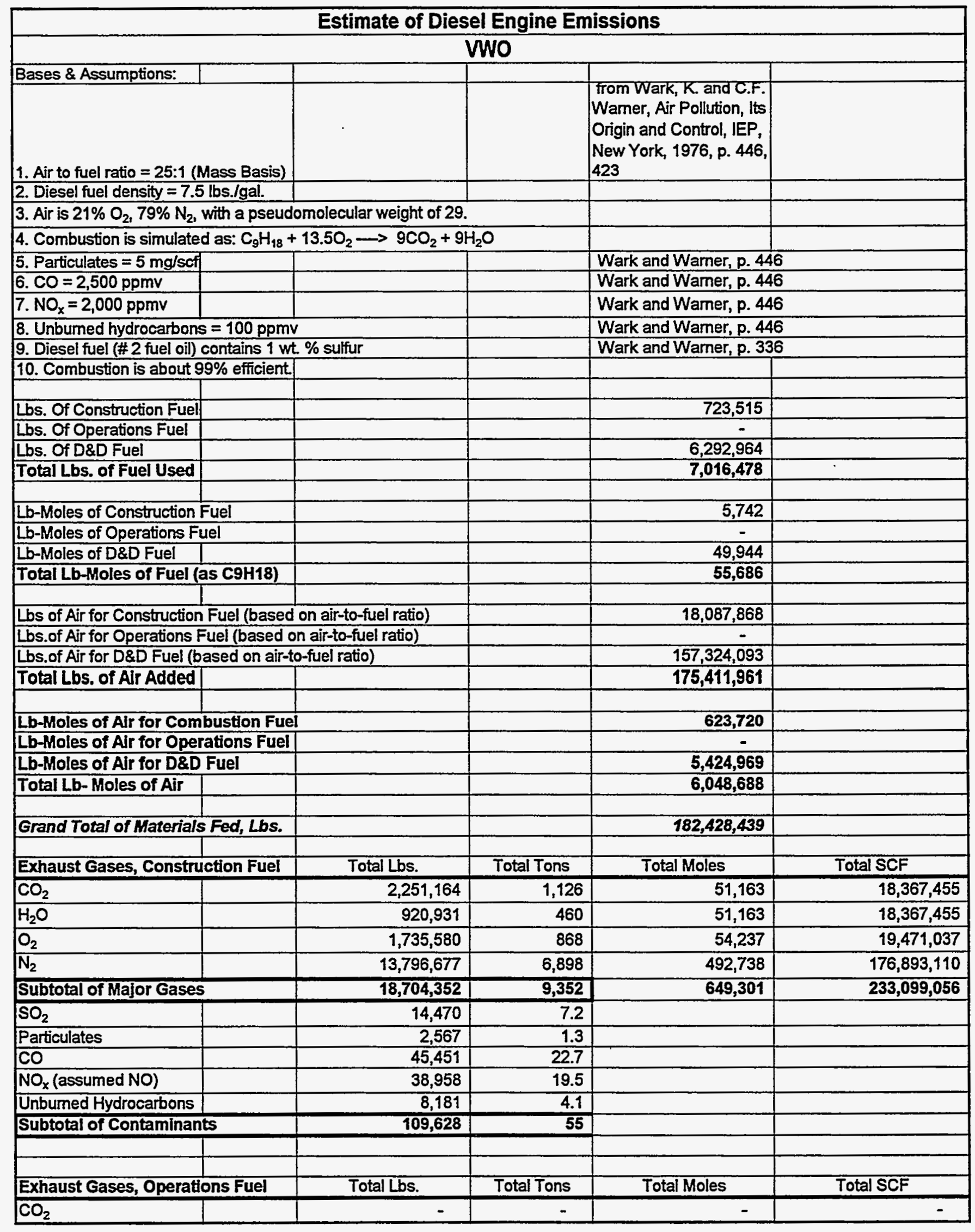




\begin{tabular}{|c|c|c|c|c|}
\hline $\mathrm{H}_{2} \mathrm{O}$ & - & - & - & - \\
\hline $\mathrm{O}_{2}$ & - & - & - & - \\
\hline$\overline{N_{2}}$ & - & - & - & - \\
\hline Subtotal of Major Gases & - & - & - & - \\
\hline $\mathrm{SO}_{2}$ & - & - & & \\
\hline Particulates & - & - & & \\
\hline $\mathrm{CO}$ & - & - & & \\
\hline $\mathrm{NO}_{\mathrm{x}}$ (assumed $\mathrm{NO}$ ) & - & - & & \\
\hline Unbumed Hydrocarbons & - & - & & \\
\hline \multirow[t]{2}{*}{ Subtotal of Contaminants } & - & - & & \\
\hline & & & 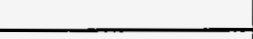 & \\
\hline Exhaust Gases, D\&D Fuel & Total Lbs. & Total Tons & Total Moles & Total SCF \\
\hline \begin{tabular}{|l|l}
$\mathrm{CO}_{2}$ & \\
\end{tabular} & $19,580,107$ & 9,790 & 445,002 & $159,755,874$ \\
\hline $\mathrm{H}_{2} \mathrm{O}$ & $8,010,044$ & 4,005 & 445,002 & $159,755,874$ \\
\hline $\mathrm{O}_{2}$ & $15,095,673$ & 7,548 & 471,740 & $169,354,581$ \\
\hline $\mathrm{N}_{2}$ & $120,000,307.99$ & 60,000 & $4,285,725$ & $1,538,575,377$ \\
\hline Subtotal of Major Gases & $162,686,132$ & 81,343 & $5,647,470$ & $2,027,441,706$ \\
\hline \begin{tabular}{|l|l}
$\mathrm{SO}_{2}$ \\
\end{tabular} & 121,926 & 61.0 & & \\
\hline Particulates & 22,329 & 11.2 & & \\
\hline $\mathrm{CO}$ & 395,323 & 197.7 & & \\
\hline $\mathrm{NO}_{x}$ (assumed NO) & 338,848 & 169.4 & & \\
\hline \begin{tabular}{|l|} 
Unburned Hydrocarbons \\
\end{tabular} & 71,158 & 35.6 & & \\
\hline Subtotal of Contaminants & 949,584 & 475 & & \\
\hline
\end{tabular}




\section{Memo of Telephone Conversation}

Name

Organization

LMITCO S\&H ICPP ALARA Coordinator

Bill Landman

Chemical and Environmental Eng'g
Phone

$6-3174$

$6-5279$

Date: November 24, 1997 Time: $\quad$ 4:15 pm

Subject: $\quad$ Average Worker Dose Rate at ICPP

Discussion:

Steve was contacted for information to support development of the Project Data Sheet for the Separations Options. He provided the following information for the ICPP site:

Average dose (per worker) for $1996 \quad 180 \mathrm{mR} / \mathrm{hr}$

Average dose (per worker) for $1995 \quad 252 \mathrm{mR} / \mathrm{hr}$

Average dose (per worker) for $1994 \quad 143 \mathrm{mR} / \mathrm{hr}$

The 1995 year average was higher due to extensive work on the tank farm. 
Appendix I

Remote Handling 


\section{Appendix I}

\section{Remote Handling}

Because of the radioactive nature of the materials processed in the VF, remote systems must be used extensively to achieve operational, maintenance, environmental and ALARA requirements. Shield walls, operating corridors, or other cell areas surround the canyon, cells, and the overhead remote maintenance/disassembly cell. Equipment items requiring maintenance will be constructed in modules that will be remotely removable. All process equipment items that will last the lifetime of the facility and require minimal maintenance will be permanently located. Items having a mixture of the two attributes above will be partially removable and partially fixed. The maintenance designation of a piece of equipment, and its use in the process determines its placement within the facility; therefore, VF process equipment will be located as follows. The smaller modules, pumps, valves, filters, and other high maintenance items will be in the offgas and scrubber blowdown system equipment canyon, and the unique and single purpose mechanical canister handling modules and the melter will be in isolated but remotely accessible cells. The calcine transport equipment will also be serviced by the overhead canyon crane. These different areas are described separately below.

The canyon approach uses of the 75-ton bridge crane almost exclusively, to detach, remove, reinstall, and reattachment process equipment. The melter cell, sized waste canister welding area, disassembly cell, and remote decontamination cell, however, use master-slave manipulators in conjunction with the bridge crane. The process piping, and instrument and electrical connections to removable equipment items will be made using jumpers with Hanford type connectors.

The cell approach minimizes contamination spread and simplifies remote maintenance because no more than one module will be located within each process. The two melter cells will be isolated from each other, and each will also be isolated from the canister filling and capping cell by a slide gate valve when no canister is present, or by a double bellows seal between the canister and the melter during the canister filling process.

- Offgas system equipment canyon

High-maintenance process equipment items will be located within the offgas system equipment canyon. Items will be serviced remotely by disconnecting, removing, replacing, and reconnecting the modular unit. Examples are (1) centrifugal pumps, (2) condensers, (3) superheaters, (4) scrubbers, (5) blowers, (6) offgas HEPA filters, and (7) charcoal filters. This shielded area will be covered by removable steel roof panels and concrete cell shield covers, which form a ventilation barrier between the canyon and the maintenance/disassembly cell area above the canyon. The canyon has its own drainage trench and sumps.

Two sides of the offgas system equipment canyon are bounded by an operating corridor, which allows visibility via shield windows to the operators to facilitate remote activities. A $\mathrm{PaR}^{\otimes}$-type wall-mounted electro-mechanical manipulator will be used for remote maintenance. Modules can be moved in and out of the cells using the 75-ton maintenance/disassembly cell bridge crane. The canyon crane will be equipped with hoists as well as CCTV cameras that allow it to be remotely operated. 
The weld, decontamination, and smear cells will be remotely-operated single-purpose cells. A single module exists within each cell to perform one or more tasks. The modules can be disconnected, removed, replaced, and reconnected for maintenance. The old unit can then be repaired in the remote maintenance cell offline, allowing the process to continue. Facility length will be reduced by vertically alternating (staggering) the process cells. Alternating vertical cells allow the use of small horizontal hatches, instead of large vertical shield doors, for transferring equipment and canisters. The weld, decontamination, and smear cells each perform a single basic task.

A light-duty polar crane will be located in each of the following cells: The decontamination cell, welding cell, smear cell, and canister filling and capping cell, for remote maintenance and canister handling. Each crane will be equipped with a SRS DWPF canister grapple to lift and transfer empty or filled canisters. Each crane can enter a crane maintenance area that will be shielded from the rest of the cell, and will be located between two adjacent cells. The polar cranes consist of a linearly traversing trolley containing an underhung pivoting jib crane. The Jib can pivot 360 degrees about its vertical axis. The jib can reach nearly to the walls of a cell by pivoting 90 degrees to the direction of the trolley rails. Rotating the jib parallel to the trolley rails and retracting the hoist allows the crane to pass through the relatively narrow shield door opening and into the crane maintenance area. In this orientation, the crane presents a narrow projected frontal area because the trolley rails will be closely spaced. It will also be possible to remove the cranes from the trolley rails using the maintenance/disassembly cell bridge crane. Access rooms adjacent to the cells allow personnel to enter each a cell. Horizontally-actuated vertical shield doors separate and isolate the access rooms from the cells. A polar crane maintenance area will be located above each access room. Personnel pass through an airlock to enter the access room from the operating corridors. Horizontal-plane hatches in the cell floor or ceiling, or both, allow equipment transfer into the overhead maintenance/disassembly cell for maintenance, disassembly, or size reduction.

The canister filling and capping cell will be used to lift, preheat, and fill empty canisters, and lower, cool, and cap the GCs in preparation for transfer to the welding cell. Empty canisters will be brought into the cell through an airlock, which separates the empty canister staging area from the canister filling and capping cell. The filled canister transport crane and grapple place the canister in a lift mechanism under the filling weir nozzle of the operating melter. The drive for the canister lift mechanism will be located outside of the cell shield wall and will be available for hands-on maintenance. The lifting mechanism incorporates a heater to preheat the canister to eliminate thermal shock and glass voids inside the canister. When the lift mechanism is at its top (filling) position, the lip of the canister engages a metal bellows seal that surrounds the melter weir nozzle. The air-actuated bellows contains a knife valve that isolates the canister filling and capping cell from the melter cell above. This system minimizes exterior canister and cell contamination during the canister filling. The knife valve can only be opened when the bellows is sealed to the canister lip. Glass starts to pour when the level in the melter exceeds the level of the weir and glass overflows into the canister. Glass frit and calcine will be continuously added to the melter. The glass pours inside the bellows conduit from above the open knife valve. Offgas will be extracted from the inside the bellows by the offgas system negative pressure. Several levels of instrumentation surround the fill station to monitor the fill process, including temperature monitoring, negative pressure (effectiveness of canister lip seal integrity), gamma, neutron or X-ray detection (fill level), weight (contents), infra red CCTV (fill level), CCTV for 
canister presence and position, with redundant systems on critical instruments. The instrumentation features remote replacement, verification, calibration, and testing.

While an empty canister is being staged on the canister shuttle cart, the newly filled GC will be lowered by the canister lift mechanism, removed by the filled canister transport crane and grapple, and placed in the GC cooling station. After a 24-hr cooling period, a lid will be placed on the $\mathrm{GC}$ by a remotely replaceable capping module. The module's pick-and-place mechanism will be remotely operated and will be supplied with lids by a canister sealing manipulator. After cooling, the polar crane and grapple place the $\mathrm{GC}$ at a position below the floor hatch in the welding cell. The hatch will then be opened and the canister weld handling crane and grapple lift the GC into the welding cell and place it into the welding module.

Each item in the canister filling and capping cell requiring maintenance will be remotely replaceable by removing it with the filled canister transport crane, staging it below the welding cell floor hatch, and removing it with the canister weld handling crane. The item can then be lifted through the welding cell shield cover by the 75-ton maintenance/disassembly cell bridge crane.

The welding cell contains a module that rotates the CG for automatic lid welding. The module also installs testing apparatus that externally pressurizes the lid to detect $\mathrm{GC}$ inleakage resulting from a defective weld. Following a successful leak test, the $\mathrm{GC}$ will be lowered through the welding cell floor hatch into the decontamination cell using the canister weld handling crane and grapple. The welding module can be remotely disassembled and removed through the welding-cell shield cover.

Remote GC decontamination using a carbon dioxide pellet blast will be performed in the decontamination module inside the decontamination cell. This decontamination technique was selected because it aggressively cleans the canister and creates no residual liquid or solid waste stream. The decontamination medium must remove the oxide layer that forms on the $\mathrm{GC}$ exterior when it is heated by the molten glass. $\mathrm{CO}_{2}$ pellets sprayed on the $\mathrm{GC}$ at short range and high velocity will remove the oxide layer. Before decontamination, a movable decontamination module lid will be remotely closed and sealed to prevent spread or overspray of $\mathrm{CO}_{2}$ and contamination. The $\mathrm{CO}_{2}$ gas will be removed by the decontamination cell HVAC exhaust system.

The decontaminated $\mathrm{GC}$ will be removed from the decontamination module by the canister decontamination handling crane and grapple, and staged for transfer up and into the smear cell. Components inside the decontamination cell will be remotely replaceable using the canister decontamination handling crane. Items to be removed from the decontamination cell will be staged below the welding cell floor hatch for transfer up to the welding cell by the canister weld handling crane. They will then be staged beneath the welding-cell shield cover for removal by the maintenance/disassembly cell bridge crane.

Canister smear testing will be performed in the smear cell. The GC will be lifted through the floor hatch into the smear cell using the smeared canister loadout crane and grapple. GCs that do not meet smear test acceptance criteria will be lowered back into the decontamination cell and will again be subjected to the decontamination process. Following successful smear testing, the smeared canister loadout crane and grapple lower the $\mathrm{GC}$ through the floor hatch and onto the canister transport cart within the canister transfer tunnel. The smear module 
will be capable of being disassembled remotely and transferred through the cell shield cover into the maintenance/disassembly cell using the maintenance/disassembly cell bridge crane.

The melter cells and melters will be serviced by the 75-ton maintenance/disassembly cell bridge crane operating through the cell shield covers. Maintenance personnel use airlocks to enter the crane maintenance area from operating areas. The 75-ton crane has its own shielded maintenance area at one end of the building. A vertical shielding door at the crane maintenance area shields maintenance personnel from radiation sources located in the rest of the maintenance/disassembly cell. Remotely actuated 'drawbridge' crane rail sections allow the crane to pass between the maintenance/disassembly cell, past the shield door opening, and into the crane maintenance area.

- Maintenance/disassembly cell

The maintenance/disassembly cell occupies the space $45-\mathrm{ft}$ above grade. This will be above the cell shield covers of the upper level cells. Component disassembly and maintenance can be done in this cell. The maintenance/disassembly cell also extends above the offgas system cell. Cell shield covers in the smear, weld, and melter cells open into the canyon maintenance/disassembly cell. All items removed from any of the cells will be lifted into the maintenance/disassembly cell using the maintenance/disassembly cell bridge crane. The maintenance/disassembly cell allows size reduction of "technological waste" and remote maintenance on equipment removed from vitrification handling equipment and offgas canyon equipment. One end of the maintenance canyon provides access to a decontamination cell, remote maintenance cell (with several windows and master-slave manipulators), a hands-on maintenance cell, crane maintenance/disassembly cell and loadout area. Contaminated equipment that has reached the end of its useful life can be sized remotely and placed into DWPF type canisters. This equipment canister will be sealed with a circumferential weld made by a canister-welding module located in the maintenance/disassembly cell. A (small diameter) glass fill port lid will be placed on the canister after the integrity of the circumferential weld is checked, by lowering the canister into the welding cell for verification.

Following the weld leak check, this canister will be handled and stored in the same manner as the GCs. These equipment canisters will hold used melter parts, worn out or plugged melter offgas equipment, etc., which cannot be restored by remote maintenance.

- Canister transfer tunnel

GCs will be transported to the ISF on a rail-mounted battery-powered canister transport cart. The cart runs in the underground canister transfer tunnel. The tunnel will be approximately 100 -ft long from end wall to end wall. GCs will be unloaded from the cart in the ISF, and the empty cart returns to the VF.

The cart has at least two backup means of mobility. Besides using its own battery packs, it can be hauled by a cable system (with external drive), or can be retrieved using grade-level ports built into the roof of the tunnel. The tunnel has one set of tracks allowing traffic in one direction only. The canister transport cart hauls one GC per trip, and at the vitrification rate of up to $5 \mathrm{GCs}$ per day. Every week up to 35 round trips through the tunnel will be made. 
The canister transport cart will be maintainable using hands-on techniques in the ISF, where the tunnel can be entered via an entry vestibule. A tunnel entry point also exists at the VF end. The reinforced concrete tunnel has no comers, (tracks will be straight), but will be sloped to the drainage trench and will be equipped with sumps. Because GCs carried on the cart will be shipped only after decontamination, the assumption will be that no contamination will be present in the tunnel and the tunnel can be entered following removal of the radiation sources, which consist only of the GCs.

The rationale for selection of the tunnel is that it was determined to be less expensive than a shielded transfer cask and cask transporter. The transporter with cask, hoist, and positioning system, would be a very heavy vehicle, and must operate during year-round weather conditions at the site. If the relationship for the site were such that there was a longer distance from the VF to the storage facility, or a route with several turns was necessary, a transporter such as that featured in the SRS DWPF Vitrification Plant could be considered.

- Mercury bottling glovebox

Mercury removed from offgas treatment will be amalgamated, packaged in a glovebox, and disposed of. The glovebox provides contamination control by preventing heavy metal exposure to the operators. 


\section{Appendix J}

Conveying Systems 


\section{Appendix $\mathrm{J}$}

\section{Conveying Systems}

The following handling equipment will be required to support the VF. This equipment has been selected to establish an efficient handling system, while maintaining a safe working environment.

- Maintenance/disassembly cell overhead bridge crane-75-ton

The 75-ton overhead bridge crane has a span of approximately $60 \mathrm{ft}$ and will be used to convey equipment in and out of the canyons, laydown area, smear cell, welding cell, decontamination cell, hands-on maintenance cell, remote maintenance cell, and melter cells. A crane maintenance area will be located at the south end of the cell.

The crane will be remotely controlled. A conveniently located remote panel will be mounted in clear view of the crane and hook. A festooned cable system will supply crane power because busbar or panel systems will have a high potential for corrosion.

- Load-out cell and truck loading area monorail-15 Ton

A 15-ton monorail will be used to load equipment in the load-out area and the truck airlock at the south end of the VF. This monorail will be split at the shield door between the truck loading and the load-out area. The section in the truck area will be a common stationary rail, mounted overhead. The section in the Load-out area will have the rail mounted onto an overhead bridge and trolley to allow the monorail to swing out of the way to permit equipment loading from above by the maintenance/disassembly cell 75-ton bridge crane.

The monorail will be controlled by both local and remote methods. A conveniently located local panel will be mounted in clear view of the crane and hook from the shield window and remotely operated from an operators console and viewed by CCTV.

The monorail, trolley, and hoist will be supplied with both a remote panel and a pendant control. The power to the crane will be via a festooned cable system.

- Canister weld handling crane-3 Ton

This remotely controlled polar crane and its grapple will be used to convey GCs from the canister filling and capping cell to the welding cell, and from the welding cell to the decontamination cell. It will also move equipment inside the welding cell and assist with maintenance on the welding equipment. Welding cell equipment and equipment retrieved from the adjoining cells can be staged, using the canister weld handling crane, for pickup through the welding cell shield cover by the 75-ton overhead crane. Hands-on crane maintenance will be done in the crane maintenance area south of the welding cell. The power to the crane will be via a festooned cable system. 
This remotely controlled polar crane and its grapple will be used to convey decontaminated GCs from the decontamination cell to the smear cell, and from the smear cell to the canister transport cart in the transfer tunnel. It will also move equipment inside the smear cell and assist with maintenance. Decontamination cell equipment, and equipment retrieved from the decontamination cell below can be staged, using the canister decontamination handling crane, for pickup through the decontamination cell cover by the maintenance/disassembly cell 75-ton bridge crane. Hands-on crane maintenance will be done in the crane maintenance area north of the smear cell. The power to the crane will be via a festooned cable system.

- Wall-mounted PaR ${ }^{\circledR}$

One remotely controlled $\mathrm{PaR}^{\circledast}$-type wall-mounted electro-mechanical manipulator traveling north and south, and vertically in the offgas system cell, will move materials and equipment. It will be specifically used for remote removal and replacement of equipment. The $\mathrm{PaR}^{\circledR}$ manipulator will be remotely operated and viewed by CCTV at an operators console and can be viewed from shield windows in the operating gallery.

- Filled canister transport crane-3 Ton

This remotely controlled polar crane and its grapple will be used to move empty canisters from the empty canister transfer airlock to the operating melter pour station, and GCs from the pour stations to the cooling and capping station module. It will also be used to move equipment inside the canister filling and capping cell and assist with maintenance. Cell equipment will be staged below the welding cell floor hatch for retrieval by the canister weld-handling crane. Hands-on maintenance will be done in the crane maintenance area located to the south of the canister filling and capping cell. The power to the crane will be via a festooned cable system.

- Canister decontamination handling crane-3 Ton

This remotely controlled polar crane and its grapple will be used to move equipment and GCs inside the canister decontamination cell and assist with maintenance. Cell equipment will be staged below the smear cell floor hatch for retrieval by the smeared canister loadout crane. Hands-on maintenance will be done in the crane maintenance area located to the north of the canister decontamination cell. The power to the crane will be via a festooned cable system

- Empty canister storage overhead bridge crane-1 Ton

A one-ton overhead bridge crane and its grapple will be used for loading canisters from the HLW canister transfer cart to the storage rack, and from the storage rack to canister filling and capping cell canister shuttle cart located inside the empty canister transfer airlock. Hands-on maintenance will be performed in this area.

The crane will be controlled locally using a local panel mounted in view of the crane and hook. The crane, trolley, and hoist will be supplied with pendant control. The power to the crane will be via a festooned cable system. 
- Canister shuttle cart

The canister shuttle cart will be used to convey an empty canister from the empty canister storage area airlock to the canister filling and capping cell. The cart will be remotely operated from a console and viewed by CCTV. The cart will be electrically driven by a power cable and cable reel.

The cart will run on anchored tracks with its wheels totally retained by the track to eliminate the possibility of derailing. Shock absorbers will be located on each end of the track to ensure safe stopping. Hands-on maintenance will be performed in the empty canister storage area.

- Glass frit bucket conveyors

These conveyors transport glass frit in the glass frit delivery systems. Hands-on maintenance will be performed as required

- Glass frit auger conveyors

These conveyors transport grit in the glass frit delivery systems. Hands-on maintenance will be performed as required.

- Canister lift mechanism

The canister lift mechanism will be used to raise an empty canister from the canister filling and capping cell floor level up to the melter fill weir (in the ceiling of the canister filling and capping cell), and lower the filled GC back down to floor level. One of two canister filling stations will be operating at a time. Canister Lift Mechanism maintenance within the cell will be performed remotely, however, the mechanism drive is located in an adjacent shielded room for hands-on drive maintenance. The mechanism will be a "SERAPID" type chain system.

- Transfer port

The transfer port has a shielded sample-can carrier for remote insertion of consumables and removal of samples from the sample cell.

- Tool drops

Tools and sample bottles will be transferred from the operating gallery into each hot cell, decontamination cell, and sample cell, using a standard hot cell tool drop cell penetration design.

- Canister transport cart

The canister transport cart will be used to convey decontaminated and welded GCs from the VF through the underground transfer tunnel, to the ISF. The cart will be located $20 \mathrm{ft}$ below grade. 
The cart will be remotely operated from a console and viewed by CCTV. It will be battery powered and have two backup transport methods. Besides using its own battery pack, it can be hauled via cable system (with external drive), or retrieved via grade-level ports built into the roof of the tunnel. The cart will run on a single set of anchored tracks with its wheels totally retained by the track to eliminate the possibility of derailing. Shock absorbers will be located on each end of the track to ensure safe stopping. Hands on maintenance will be performed at the ISF maintenance area. 